Universidad

Politécnica de Cartagena

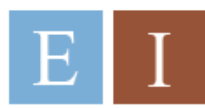

$\mathrm{C} M \mathrm{M}$ yo
E.T.S. de Ingenievía de Caminos, Canales y Puepros y @e Ingeniería de Minas

\title{
El puente arco espacial como una evolución tipológica
}

\section{Tesis doctoral}

\author{
Director: \\ Juan José Jorquera Lucerga \\ Dr. Ingeniero de Caminos, Canales y Puertos
}

Cartagena, 2018 



\section{Universidad \\ Politécnica \\ de Cartagena}

DT-16

\section{CONFORMIDAD DE SOLICITUD DEAUTORIZACIÓN DE DEPÓSITO DE}

\section{TESIS DOCTORAL POR EL/LA DIRECTOR/A DE LA TESIS}

D/D ${ }^{\mathrm{a}}$. Juan José Jorquera Lucerga, Director/a de la Tesis doctoral: El puente arco espacial como una evolución tipológica.

\section{INFORMA:}

Que la referida Tesis Doctoral, ha sido realizada por D/Da. Juan Manuel García Guerrero, dentro del Programa de Doctorado Tecnología y Modelización en Ingeniería Civil, Minera y Ambiental, dando mi conformidad para que sea presentada ante el Comité de Dirección de la Escuela Internacional de Doctorado para ser autorizado su depósito.

La rama de conocimiento en la que esta tesis ha sido desarrollada es:

Ciencias

Ciencias Sociales y Jurídicas

\ Ingeniería y Arquitectura

En Cartagena, a 15 de mayo de 2018

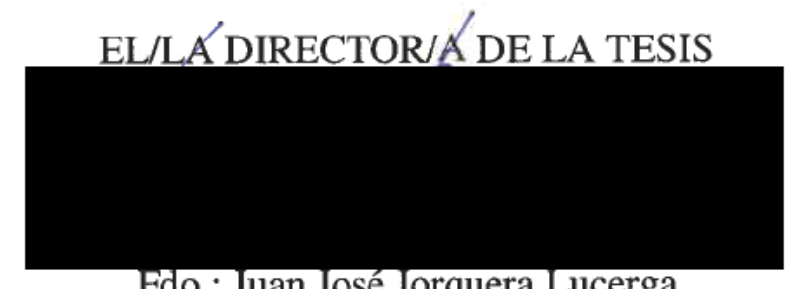

Fdo.: Juan José Jorquera Lucerga

\section{COMITÉ DE DIRECCIÓN ESCUELA INTERNACIONAL DE DOCTORADO}



Universidad

Politécnica

de Cartagena

DT-17

\section{CONFORMIDAD DE DEPÓSITO DE TESIS DOCTORAL POR LA COMISIÓN ACADÉMICA DEL PROGRAMA}

D/D ${ }^{a}$. Ángel Faz Cano, Presidente/a de la Comisión Académica del Programa Tecnología y Modelización en Ingeniería Civil, Minera y Ambiental.

\section{INFORMA:}

Que la Tesis Doctoral titulada, "El puente arco espacial como una evolución tipológica" ha sido realizada, dentro del mencionado Programa de Doctorado", por D/D ${ }^{\mathbf{a}}$. Juan Manuel García Guerrero, bajo la dirección y supervisión del Dr./ Dra. Juan José Jorquera Lucerga.

En reunión de la Comisión Académica, visto que en la misma se acreditan los indicios de calidad correspondientes y la autorización del Director/a de la misma, se acordó dar la conformidad, con la finalidad de que sea autorizado su depósito por el Comité de Dirección de la Escuela Internacional de Doctorado.

La Rama de conocimiento por la que esta tesis ha sido desarrollada es:

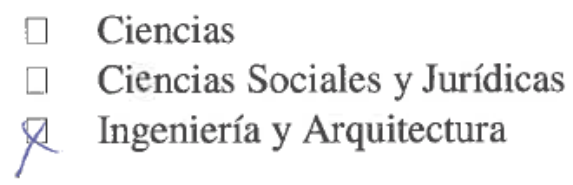

En Cartagena, a 16 de mayo de 2018

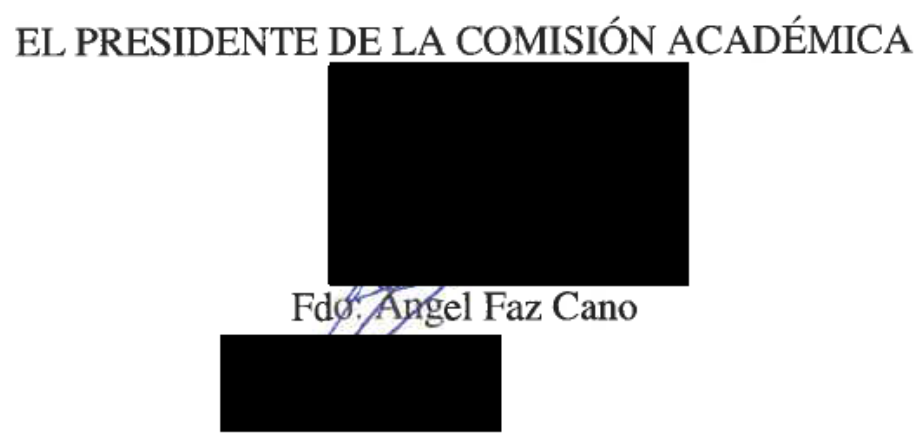

COMITÉ DE DIRECCIÓN ESCUELA INTERNACIONAL DE DOCTORADO 



\section{Resumen}

El puente arco espacial aparece en un contexto de nuevas demandas formales para los puentes, principalmente en entornos urbanos, donde la innovación estética es siempre deseada, e incluso se convierte en el objetivo primordial. También aparecen como el resultado de un proceso de diseño "ortodoxo", para satisfacer requisitos funcionales poco habituales, como el puente de Schwandbach, diseñado por Robert Maillart, donde un arco soporta un tablero de planta curva.

El objetivo fundamental de esta tesis es demostrar cómo el puente arco espacial simétrico supone una evolución tipológica del puente arco plano clásico. Esta estrategia de diseño permite verificar los condicionantes en tensiones y en deformaciones que determinan la validez de la estructura, es decir, en rotura y servicio. Según esta aproximación, los elementos propios del puente arco espacial simétrico, como las péndolas rigidizadas transversalmente, los atirantamientos al borde del tablero, la duplicación de arcos o los arcos inclinados convergentes, tienen una justificación que va más allá de razones estéticas, pues su aparición sería la consecuencia de la decisión de un diseñador que pretende resolver un problema de índole puramente estructural.

Dado que, merced a la simetría longitudinal, los comportamientos estructurales dentro y fuera del plano del arco pueden considerarse desacoplados, el estudio del puente arco espacial simétrico analiza independientemente su comportamiento longitudinal y transversal (es decir, contenido en el plano del arco y perpendicular a éste).

Entre los estudios llevados a cabo en esta tesis, se ha estudiado el diseño preliminar de secciones de arco y tablero cuando viene gobernado por sus esfuerzos y deformaciones en el plano del arco; el efecto de la rigidización longitudinal (y transversal) de péndolas sobre el comportamiento en el plano (y fuera de éste); el efecto de las distribuciones de secciones transversales del arco sobre el pandeo dentro y fuera del plano; el efecto de la posición de las articulaciones en las péndolas en sentido longitudinal y transversal; el estudio de configuraciones de péndolas tridimensionales formadas por cables aunque con capacidad a flexión; la flexión transversal del arco frente a cargas de viento y la efectividad de configuraciones de péndolas inclinadas, como las Nielsen-Löhse y Network.

Esto permite además al diseñador elegir una amplia variedad de formas novedosas que resultan al mismo tiempo estéticamente agradables y altamente eficientes desde el punto de vista estructural. 



\section{Abstract}

Spatial arch bridges (SAB) arise in a context of new architectural requirements for bridges, mainly in urban environments, where aesthetic innovation may be a desired, or even the primary, objective. They also appear, as a result of a "classic-engineering" design process, to meet unusual functional requirements, such as the Schwandbach Bridge, designed by Robert Maillart, where an arch supports a horizontally curved deck.

The main objective of this thesis is to show how the longitudinally symmetrical SAB can be understood as a typological evolution of classical planar arch bridge. This design strategy opens the way for designers to verify stress and deflections requirements, both in ULS and SLS. Following this approach, the distinctive structural elements of longitudinally symmetrical SAB, such as transversally stiffened hangers, hangers attached at the edges of the deck, doubled arches or convergent arches are justified beyond their aesthetic value, since they emerge as the consequence of the decision of a designer who intends to solve a problem of a purely structural nature.

Since, due to the longitudinal symmetry, the in-plane an out-of-plane structural behavior are uncoupled, the study of the longitudinally symmetrical SAB is carried out separately for the longitudinal and the transversal behavior, i.e. respectively, contained within the plane of the arch or a perpendicular one.

Among the most relevant studies carried out in this thesis, it is worth mentioning: the preliminary design of the cross-sections of the arch and the deck when their size is governed by their in-plane internal forces and deflections; the effect of the longitudinal (and transversal) stiffening of hangers on the in-plane (and out-of-plane) structural behavior; the effect of the distribution of cross-sections of the arch on its sensitivity to in and outof plane buckling; the effect of the location of longitudinal (and transversal) hinges at the hangers on the in-plane (and out-of-plane) structural behavior; the study of threedimensional arrangements of hangers composed of cables, yet with bending capacity; the out-of-plane bending moment of the arch under wind loads, or the efficiency of cable arrangements with inclined hangers, such as Nielsen-Löhse and Network.

This allows the designer to choose from a wide variety of novel forms that are both aesthetically pleasing and highly efficient from the structural point of view. 



\section{Agradecimientos}

Una tesis doctoral no es nunca trabajo de una sola persona, y aunque sea mi nombre el que figura como autor, este documento y el trabajo que ha llevado aparejado no hubieran podido realizarse, ni siquiera imaginarse, sin la aportación de numerosas personas a las que quiero expresar mi agradecimiento con estas líneas.

En primer lugar quisiera agradecer a mi familia el apoyo y el cariño recibido durante todos estos años. Quisiera dar las gracias a mis padres, Juan y María, por animarme siempre a conseguir lo que me he propuesto, y por aconsejarme, siempre tan acertadamente, en las diferentes vicisitudes que han ido apareciendo a lo largo de los años. También quisiera agradecer a mis abuelos, Andrés, Juana, Manuel y María, hacerme ver, desde siempre, la necesidad de estudiar. Aunque algunos ya no puedan leer estas líneas quisiera expresarles mi profundo agradecimiento.

Sin lugar a dudas, esta tesis no sería la misma sin el contrato FPI que me brindó la Fundación Séneca, Agencia de Ciencia y Tecnología de la Región de Murcia, el cual me ha permitido dedicarme estos años a investigar algo que me apasiona. Me gustaría agradecer el trato recibido por todos los integrantes de la fundación, especialmente por Viviane Barelli, que tan amablemente ha atendido mis mil y una preguntas durante estos años de doctorado.

Durante estos años también han sido muy recurrentes las muestras de ánimo por parte de los amigos que hice en la Residencia de Estudiantes de la UPCT, especialmente de Pedro, Carpena, Bermúdez, Antonio Vera, Alejandro, Antonio Romera y Jesús. También quisiera agradecer el apoyo de mis compañeros estudiantes del Grado de Ing. Civil y del Máster de Caminos, especialmente a Jesús Aguilar y Andrés Márquez, con quienes realicé un inolvidable viaje por Europa viendo puentes y otras estructuras. Tampoco quisiera olvidarme de los muchos amigos con los que compartí Colegio e Instituto en mi Lorca natal, y con los que aún comparto almuerzos y salidas en bici. A todos ellos muchas gracias por preguntarme siempre "qué tal iba la tesis".

Quisiera agradecer también el apoyo recibido por parte del Departamento de Ingeniería Civil de la UPCT, y especialmente a Luis Castillo, Juan García Bermejo y José María Carrillo. Sin lugar a dudas los consejos y la ayuda recibida han ayudado a terminar esta tesis.

También quisiera expresar mi agradecimiento a todos los integrantes del grupo de investigación New Structural Typologies (Nest), así como a todas las personas que han pasado por nuestra mitad del I+D de Construcción (más conocida, cariñosamente, como "el ponedero"). Especialmente quisiera agradecer a José Manuel, Enrique, Lola y Nicole los buenos 
ratos que hemos pasado.

Por supuesto quisiera agradecer también el apoyo recibido por parte del Director de la Escuela de Ingeniería de Caminos, Canales y Puertos y de Ingeniería de Minas, Manuel Alcaraz, con quien tuve la oportunidad de disfrutar de mis primeras becas, y quien me permitió descubrir y trabajar, durante mis años de estudiante, con los sistemas de información geográfica. Para mí fue todo un privilegio poder colaborar en el proyecto de microzonificación sísmica de mi ciudad.

Por último quisiera dar las gracias con estas líneas, aunque por muchas que escriba nunca podré agradecérselo lo suficiente, a Juan José Jorquera Lucerga, director de esta tesis doctoral. Esta vez intentaré no ser rácano con el elogio, pues para mí ha sido todo un honor poder trabajar con él durante estos años, y sin duda alguna sus consejos acerca de Matlab, los idiomas, sus acertadas sugerencias a la hora de trabajar en el día a día, o sus enseñanzas en el ámbito personal, me acompañarán siempre a donde vaya.

Muchas gracias a todos.

Juan Manuel García Guerrero

Cartagena, 2018 
A mis padres y a mis abuelos 

"La complejidad aventura formas diferentes y sólo las revela a los que buscan significados en profundidad."

Javier Manterola La forma de lo resistente (2008) 



\section{Índice general}

I Generalidades $\quad 1$

1. Introducción 3

1.1. Razón de ser de la tesis doctoral . . . . . . . . . . . . . . . . 3

1.2. Objetivos del estudio . . . . . . . . . . . . . . . 5

1.3. Contenido de la tesis . . . . . . . . . . . . . . . 8

1.4. Metodología de trabajo . . . . . . . . . . . . . 8

2. Estado del arte $\quad 11$

2.1. Concepto de puente arco espacial . . . . . . . . . . . . . . . . 11

2.2. Estudios teóricos . . . . . . . . . . . . . . . . 12

2.3. Clasificación . . . . . . . . . . . . . . . . . 13

2.4. Generación de puentes arco espaciales por combinación de elementos estructurales . . . . . . . . . . . . . . . . 15

2.4.1. Puentes arco espaciales con simetría longitudinal . . . . . . . . 15

2.4.2. Puentes arco espaciales con asimetría longitudinal . . . . . . . . . 16

2.5. Desarrollo del puente arco espacial . . . . . . . . . . . . . . . 18

2.6. Realizaciones con asimetría longitudinal . . . . . . . . . . . 26

2.6.1. Arco vertical excéntrico . . . . . . . . . . . . . 26

2.6.2. Arco inclinado excéntrico con tablero recto . . . . . . . . . . 28

2.6.3. Arco plano con tablero curvo . . . . . . . . . . . . . 38

2.6.4. Arco girado con respecto de un eje vertical . . . . . . . . . . . . 52

2.6.5. Arco de directriz espacial . . . . . . . . . . . . . . . 57

2.7. Realizaciones con simetría longitudinal . . . . . . . . . . . . . 62

2.7.1. Arco girado perpendicularmente al eje de tablero . . . . . . . . . 62

2.7.2. Arco único de ancho o cordones variables . . . . . . . . . . . . 65

2.7.3. Arco y tablero únicos unidos por péndolas/montantes dobles . . . . 70

2.7.4. Arco único con dos tableros . . . . . . . . . . . . . . . . 71 
2.7.5. Arcos convergentes . . . . . . . . . . . . . 73

2.7.6. Arcos divergentes . . . . . . . . . . . . . . . 77

3. Modelos de cálculo $\quad 81$

3.1. Introducción . . . . . . . . . . . . . . . . . . . . 81

3.2. Programas de cálculo . . . . . . . . . . . . . . . . . 81

3.3. Modelos de cálculo . . . . . . . . . . . . . . . . . . . . . . 84

3.3.1. Parámetros geométricos . . . . . . . . . . . . 85

3.4. Valores de las acciones . . . . . . . . . . . . . . . . . 88

3.4.1. Cargas permanentes . . . . . . . . . . . . . 89

3.4.2. Sobrecargas verticales de uso . . . . . . . . . . . . . . 89

3.4.3. Acción del viento . . . . . . . . . . . . . . . . . . . . 89

3.4.4. Acción térmica . . . . . . . . . . . . . . . . . . 90

3.5. Hipótesis simples de carga y combinaciones . . . . . . . . . . . . . . . 90

3.5.1. Hipótesis simples . . . . . . . . . . . . . . . . . . . . . . 90

3.5.2. Combinaciones de hipótesis simples . . . . . . . . . . . . 91

3.6. Criterio de signos de los esfuerzos . . . . . . . . . . . . . . . . 92

3.7. Materiales . . . . . . . . . . . . . . . . . 94

3.8. Secciones . . . . . . . . . . . . . . . . . . . . . 94

3.8.1. Notación de las secciones . . . . . . . . . . . . . . . . 94

3.8.2. Dimensiones de las secciones . . . . . . . . . . . . . . 95

3.8.3. Criterios de dimensionamiento de las secciones . . . . . . . . . . 95

$\begin{array}{lll}\text { II Diseño en el plano } & 99\end{array}$

4. Dimensionamiento de secciones en el plano 101

4.1. Introducción . . . . . . . . . . . . . . . . . . . 102

4.1.1. Estrategia de diseño preliminar en el plano . . . . . . . . . . . 103

4.1.2. Aplicación práctica del método . . . . . . . . . . . . 105

4.1.3. Ámbito de aplicación del método . . . . . . . . . . . . . . . . . 106

4.2. Propiedades mecánicas simplificadas para las secciones transversales . . . . 108

4.2.1. Módulo elástico máximo . . . . . . . . . . . . . . . . . . 110

4.2.2. Inercia máxima . . . . . . . . . . . . . . . . 110

4.2.3. Propiedades mecánicas simplificadas _. . . . . . . . . . 111

4.3. Formulación simplificada para flechas verticales . . . . . . . . . . 113 


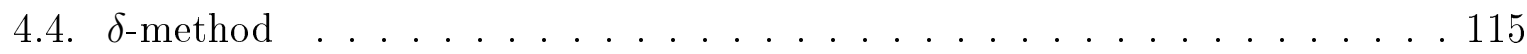

4.4.1. Justificación del método . . . . . . . . . . . . . 115

4.4.2. Diagrama de flujo y proceso iterativo . . . . . . . . . . . 117

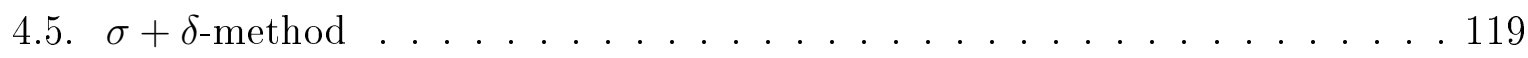

4.6. Ejemplos de aplicación . . . . . . . . . . . . . . 127

4.6.1. Arco atirantado . . . . . . . . . . . . . . . 127

4.6.2. Puente arco de tablero superior . . . . . . . . . . . . . 129

4.6.3. Puente arco con atirantamiento tipo Nielsen-Löhse . . . . . . . . 131

4.7. Efecto de los parámetros de diseño en el diseño preliminar . . . . . . . . . 133

4.8. Consideraciones generales sobre los métodos propuestos . . . . . . . . 133

5. Péndolas rigidizadas longitudinalmente 135

5.1. Introducción . . . . . . . . . . . . . . . . . 135

5.2. Modelo de referencia y cargas usadas en el estudio . . . . . . . . . . 137

5.3. Péndolas rígidas longitudinalmente . . . . . . . . . . . . 139

5.3.1. Comparación de péndolas articuladas y rígidas . . . . . . . . . . 141

5.3.2. Efecto de la rigidez de las péndolas . . . . . . . . . . . . . . . 143

5.3.3. Efecto de la rigidez de las péndolas y del tablero . . . . . . . . . . . 144

5.4. Combinación de péndolas rígidas y articuladas . . . . . . . . . . . . 145

5.5. Consideraciones generales sobre las péndolas rígidas y articuladas longitu-

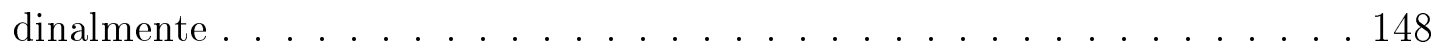

6. Pandeo en el plano 151

6.1. Introducción . . . . . . . . . . . . . . . . . . 151

6.2. Pandeo en el plano de arcos vinculados al tablero con péndolas . . . . . . . 151

6.3. Estudio de pandeo en el plano con arcos de sección variable . . . . . . . . . 153

$\begin{array}{ll}\text { III Diseño fuera del plano } & 157\end{array}$

7. Esfuerzos fuera del plano $\quad 159$

7.1. Flexión transversal . . . . . . . . . . . . . . . . . 159

7.1.1. Flexión negativa en los arranques del arco . . . . . . . . . . 159

7.1.2. Flexión positiva en la clave del arco . . . . . . . . . . . . . 160

7.2. Pandeo fuera del plano . . . . . . . . . . . . . . . . 162

7.2.1. Introducción . . . . . . . . . . . . . . . 162 
7.3. Pandeo fuera del plano en arcos vinculados al tablero con péndolas articuladas 163

7.4. Estudio de pandeo fuera del plano con arcos de sección variable . . . . . 163

8. Péndolas rigidizadas transversalmente $\quad 167$

8.1. Introducción . . . . . . . . . . . . . . . . . . . . 167

8.1.1. Modelo de referencia y acciones usadas en el estudio . . . . . . . . 174

8.1.2. Desacoplamiento de los sistemas estructurales dentro y fuera del plano175

8.2. Comportamiento en el plano: péndolas rígidas y articuladas longitudinal-

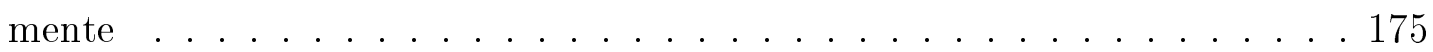

8.2.1. Estudio de la posición de la articulación (flexion longitudinal) . . . 176

8.3. Comportamiento fuera del plano: péndolas rigidizadas transversalmente . . 178

8.3.1. Efecto de la posición de las articulaciones . . . . . . . . . . 178

8.3.2. Sistemas estructurales . . . . . . . . . . . . . 179

8.3.3. Efectos de la rigidez transversal del arco y la péndola . . . . . . . . 181

8.3.4. Comparación de péndolas rígidas frente a péndolas con una articu-

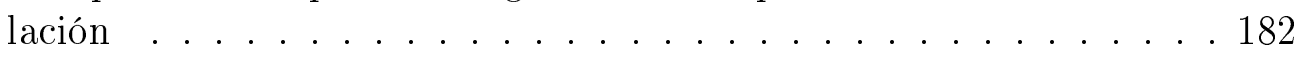

8.3.5. Pandeo fuera del plano . . . . . . . . . . . . . . 186

8.3.6. Péndolas rígidas de sección variable frente a constante . . . . . . . 186

8.4. Configuraciones de cables con rigidez a flexión . . . . . . . . . . . 187

8.5. Consideraciones acerca de las péndolas rigidizadas transversalmente . . . . 190

\section{La espacialidad como evolución del diseño conceptual en puentes arco simétricos}

9. Atirantamiento a ambos bordes

9.1. Modelo de referencia y acciones consideradas . . . . . . . . . . . 193

9.2. Puentes arco con atirantamiento simple . . . . . . . . . . . 195

9.3. Puentes arco con atirantamiento doble . . . . . . . . . . . . . 199

9.4. Comportamiento resistente de puentes arco con atirantamiento doble . . . 206

9.4.1. Trabajo de la celosía en alzado . . . . . . . . . . . . 209

9.4.2. Trabajo de la celosía en planta . . . . . . . . . . . . 209

9.4.3. Arco bifurcado en arranques . . . . . . . . . . . . . . . 212

9.4.4. Pandeo . . . . . . . . . . . . . . . . . . . 212

9.5. Consideraciones funcionales . . . . . . . . . . . . . . . 214 
V Conclusiones y futuras líneas de estudio

10. Conclusiones y futuras líneas de estudio

10.1. Conclusiones . . . . . . . . . . . . . . . . . . . . . . . . . 219

10.1.1. Diseño en el plano . . . . . . . . . . . . . . . . . . . . 219

10.1.2. Diseño fuera del plano . . . . . . . . . . . . . . . . . 221

10.1.3. La espacialidad como estrategia de diseño . . . . . . . . . . 222

10.2. Futuras líneas de estudio . . . . . . . . . . . . . . . . . . . . 224

10.2.1. Posibilidades formales de los puentes arco espaciales . . . . . . . . 224

10.2.2. Asimetría longitudinal . . . . . . . . . . . . . 226 



\section{Índice de figuras}

1.1. Pabellón puente de la Expo 2008 de Zaragoza . . . . . . . . . . . . . . . 4

1.2. Puente de Euskalduna (Bilbao) . . . . . . . . . . . . . 5 5

1.3. Vista en alzado y planta del proyecto fin de carrera del autor. . . . . . . 6

2.1. Obtención de puentes arco espaciales simétricos por combinación de arcos

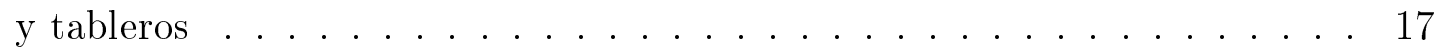

2.2. Obtención de puentes arco espaciales asimétricos por combinación de arcos y tableros ............................. 18

2.3. Puente de Fehmarnsund . . . . . . . . . . . . . . . . . . . 19

2.4. Viaducto de Landwasser . . . . . . . . . . . . . . . . 20

2.5. Arcos espaciales de Robert Maillart . . . . . . . . . . . . . . . 21

2.6. Puente de Fehmarnsund . . . . . . . . . . . . . . . . . 22

2.7. Pont Gentil . . . . . . . . . . . . . . . . . . 23

2.8. Puente de la Barqueta y puente del Tercer Milenio . . . . . . . . . . 23

2.9. Pasarela del museo Miho y Pont Citadelle . . . . . . . . . . . . . . 24

2.10. Puente del Milenio de Gateshead . . . . . . . . . . . . . . . . 24

2.11. Pasarela de Ripshorst . . . . . . . . . . . . . . . 25

2.12. Puente de Galindo y Puente de Endarlatsa . . . . . . . . . . . . 25

2.13. Puente sobre el río Vinalopó . . . . . . . . . . . . . . . . 26

2.14. Puente del puerto de Ondarroa . . . . . . . . . . . . 27

2.15. Destructor Bridge . . . . . . . . . . . . . . . . . 28

2.16. Propuesta para el Pont Gentil . . . . . . . . . . . . . . . 28

2.17. Puente de Europa (Orleans) . . . . . . . . . . . . . . . . 29

2.18. Pasarela de La Devesa . . . . . . . . . . . . . . . . . 30

2.19. Puente de la Alameda . . . . . . . . . . . . . . . . . 31

2.20. York Millennium Footbridge . . . . . . . . . . . . . 32

2.21. Cittadella Bridge . . . . . . . . . . . . . . . . 33 
2.22. Puente sobre el río Vltava . . . . . . . . . . . . . . . . . 34

2.23. Main Street Bridge, Columbus (Ohio) _ . . . . . . . . . . 35

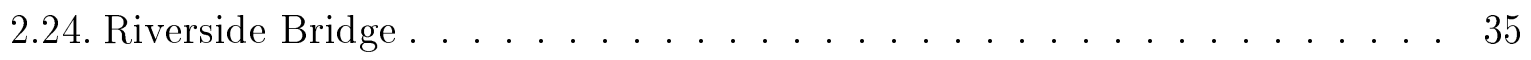

2.25. Mimico Creek Bridge . . . . . . . . . . . . . . . 35

2.26. Mardyke Walk Bridge $\ldots \ldots \ldots \ldots \ldots \ldots$

2.27. Puentes del Hospital General . . . . . . . . . . . . . . . . . 37

2.28. Via Asconio Pediano Footbridge . . . . . . . . . . . . . . . 37

2.29. Rari Nantes Footbridge . . . . . . . . . . . . . . 38

2.30. Roundabout Ovotonde . . . . . . . . . . . . . . . . 39

2.31. Gateshead Millennium Bridge . . . . . . . . . . . . . 40

2.32. Pasarela del Campo Volantín _. . . . . . . . . . . . . . . 41

2.33. Puente del observatorio . . . . . . . . . . . . . . . 42

2.34. Pasarela de acceso a Chimisay Alto . . . . . . . . . . . . 42

2.35. Merchants Bridge . . . . . . . . . . . . . 43

2.36. Ågade Bridge . . . . . . . . . . . . . . . . 44

2.37. Pasarela peatonal del Malecón del Salado . . . . . . . . . . . . 44

2.38. Pasarela sobre el río Nervión . . . . . . . . . . . . . . . . . 45

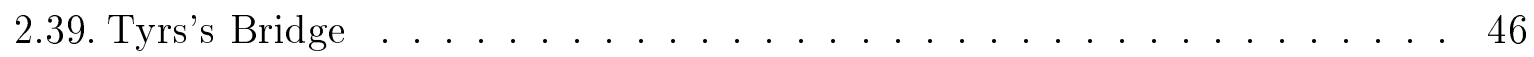

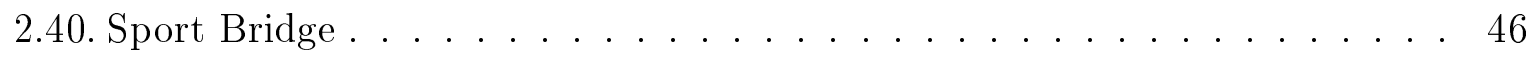

2.41. Elizabeth Quay Bridge . . . . . . . . . . . . . . 47

2.42. Fort York Pedestrian and Cycle Bridge . . . . . . . . . . . . 48

2.43. Weinberg Bridge . . . . . . . . . . . . . . . . . 49

2.44. Whitehall Riverside Bridge . . . . . . . . . . . . . 50

2.45. Jiak Kim Bridge . . . . . . . . . . . . . . . 50

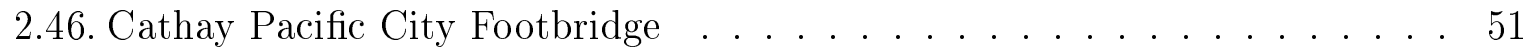

2.47. Puente de Schwandbach _. . . . . . . . . . . . . . 52

2.48. Nordsternpark Double Arch Bridge . . . . . . . . . . . . . 53

2.49. Lehrhovebruch Footbridge . . . . . . . . . . . . . . . . 54

2.50. Nordsternpark Arch Bridge _. . . . . . . . . . . . . 54

2.51. Hulme Arch Bridge . . . . . . . . . . . . . . . 55

2.52. Puente Juscelino Kubitschek . . . . . . . . . . . . . . . . . 56

2.53. Pont Citadelle . . . . . . . . . . . . . . . . . 57

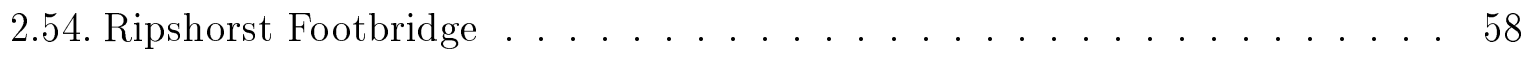

2.55. Puente sobre el río Galindo . . . . . . . . . . . . . . . 59 
2.56. Puente de Endarlatsa . . . . . . . . . . . . . . . . 60

2.57. Glasgow Bridge . . . . . . . . . . . . . . . . 60

2.58. Pasarela ciclo-peatonal sobre el río Amstel en Amsterdam . . . . . . . . . 61

2.59. Diseño de puente en Deizisau . . . . . . . . . . . . . . . 61

2.60. Puente de acceso al Museo Miho . . . . . . . . . . . . . . 63

2.61. Ponte Laterale Sud, Reggio Emilia . . . . . . . . . . . . . 63

2.62. Pasarela olímpica de Turín . . . . . . . . . . . . . . . . . . 64

2.63. Margaret Hunt Hill Bridge . . . . . . . . . . . . . . . . . 65

2.64. Puente de la Barqueta . . . . . . . . . . . . . . . . 65

2.65. Puente del Tercer Milenio . . . . . . . . . . . . . 66

2.66. IV puente de Logroño sobre el Ebro . . . . . . . . . . . . . . . . 67

2.67. Arco del hangar 6 de Iberia (Aeropuerto Madrid-Barajas) . . . . . . . . 68

2.68. Montigny-lès-Cormeilles Footbridge . . . . . . . . . . . . . 68

2.69. Arthur von Weinberg Footbridge . . . . . . . . . . . . 69

2.70. De Oversteek . . . . . . . . . . . . . . . . . 69

2.71. Pasarela Jorge Manrique (Murcia, España) . . . . . . . . . . . . 70

2.72. Rajhrad Bridge, R52 Expressway _. . . . . . . . . . . . . 71

2.73. Pasarela Miguel Navarro Molina, Lorca (España) . . . . . . . . . . . 72

2.74. Puente sobre el río Vinalopó en Elche (España) . . . . . . . . . . . . 72

2.75. Father Ojca Bernatka Bridge . . . . . . . . . . . . . . . . . . 73

2.76. Fehmarnsund Bridge . . . . . . . . . . . . . . . . . 74

2.77. Pasarela de Plentzia . . . . . . . . . . . . . . . 75

2.78. Puente arco sobre el río Guadalquivir en Palma del Río (España) . . . . . 76

2.79. Puente sobre el río Deba . . . . . . . . . . . . . . 76

2.80. Desdoblamiento del puente de la Peraleda en Toledo (España) . . . . . . . 77

2.81. Puentes en Hoznayo - Villaverde . . . . . . . . . . . . . . . 78

2.82. Butterfly Bridge . . . . . . . . . . . . . . . 78

2.83. Minto Island Bridge en Salem, Oregón (EEUU) ～. . . . . . . . . . . 79

2.84. Pasarela sobre la Ronda de la Hispanidad . . . . . . . . . . . . . . . 80

2.85. Rotherhithe Tunnel Bridge . . . . . . . . . . . . . . . . 80

3.1. Esquema de funcionamiento del código escrito. . . . . . . . . . . . . 84

3.2. Modelo de referencia . . . . . . . . . . . . . . 86

3.3. Modelos secundarios para estudios específicos . . . . . . . . . 87

3.4. Zonas de carga para cada sobrecarga de uso . . . . . . . . . . . . . . 91 
3.5. Fuerzas y momentos resultantes según las zonas cargadas con SCU . . . . . 92

3.6. Criterio de signos empleado en la tesis . . . . . . . . . . . . . 93

3.7. Notación usada para las secciones . . . . . . . . . . . . . . . 95

3.8. Deformación vertical máxima del tablero . . . . . . . . . . . . . 97

3.9. Efecto cortina para diferentes valores de diámetro de las péndolas . . . . . 98

4.1. Ejemplos de criterios de carga simplificados y de criterios de dimensionamiento para un diseño preliminar . . . . . . . . . . . . . . 102

4.2. Ejemplos de $C_{A}$ (ecuación 4.1) para diferentes rigideces relativas arco-tablero104

4.3. Ejemplos de tipologías de puente donde el método descrito ha sido aplicado satisfactoriamente . . . . . . . . . . . . . 106

4.4. Ejemplos de secciones transversales donde el método puede ser aplicado. Secciones macizas rectangulares, así como secciones circulares huecas y macizas, pueden ser usadas también para el arco y el tablero . . . . . . . . . . 107

4.5. Ejemplos de distribuciones del área del arco que se encuentran dentro del rango de aplicación del método. a) ancho constante, b) ancho variable. . . 108

4.6. Secciones transversales equivalentes con respecto al diseño simplificado en el plano . . . . . . . . . . . . . . . . . . . 109

4.7. $I(z)$ y $W(z)$ para diferentes valores de $\beta$, dada un área $\Omega \ldots \ldots$. . . . 111

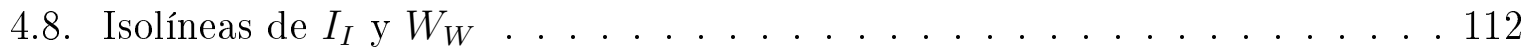

4.9. Error de la formulación simplificada para ejemplos de secciones clase 1 y $3 \quad 113$

4.10. Flechas debidas a: a) acortamiento de la directriz, b) alargamiento del tablero, c) deformación por flexión . . . . . . . . . . . . 113

4.11. Diagrama de flujo del $\delta$-method . . . . . . . . . . . . . . 118

4.12. Definición del puente analizado en el ejemplo . . . . . . . . . . . . . . 119

4.13. Ejemplo de aplicación $\left(C_{A}=0.30\right)$ del $\delta$-method para el puente definido en

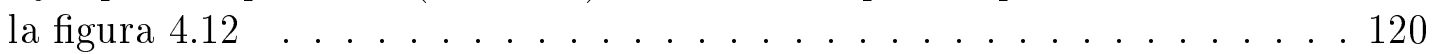

4.14. $I$ (ecuación 4.4), $W$ (ecuación 4.5) y $\sigma$ (ecuación 4.35) en función de $z$,

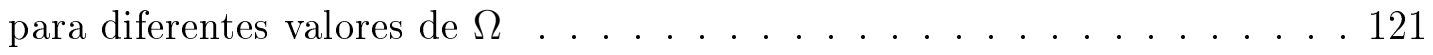

4.15. Redefinición de una sección transversal para verificar el límite de flechas y tensiones . . . . . . . . . . . . . . . . . . . 122

4.16. Diagrama de flujo para el $\sigma+\delta$-method. . . . . . . . . . . . 125

4.17. Ejemplo de aplicación del $\sigma+\delta$-method, para el puente definido en las figuras 4.12 y $4.13 \ldots \ldots \ldots . \ldots \ldots . \ldots \ldots$

4.18. Ejemplo de aplicación para el puente definido en la figura 4.12 . . . . . 128

4.19. Definición del puente arco de tablero superior usado para el ejemplo . . . . 129

4.20. Ejemplo de aplicación para el puente definido en la figura 4.19 . . . . . 130 
4.21. Definición del puente arco con atirantamiento tipo Nielsen-Löhse usado para el ejemplo . . . . . . . . . . . . . . . . . . . 131

4.22. Ejemplo de aplicación para el puente definido en la figura 4.21 . . . . . 132

4.23. Efecto de la esbeltez del alma y de la tensión longitudinal admisible en el

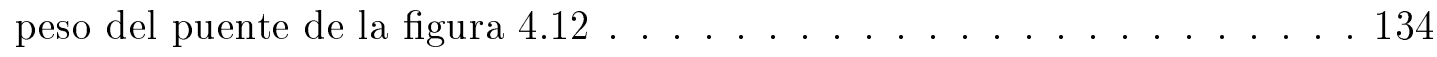

5.1. Puente de la Autobahn A 42 sobre el Canal Rhine-Herne . . . . . . . . 136

5.2. Definición geométrica del puente arco de referencia usado en el capítulo 5 . 138

5.3. Puente de La Devesa . . . . . . . . . . . . . . . . . . 139

5.4. Puente de La Alameda . . . . . . . . . . . . . . . . . . 140

5.5. Town Centre Link Bridge en Stratford (Reino Unido) . . . . . . . . . . 140

5.6. Diagramas de momentos flectores para péndolas rígidas $(800 \times 800 \times 20$ mm) y articuladas . . . . . . . . . . . . . . . . . 141

5.7. Comparación de péndolas rígidas y articuladas: momentos flectores en el arco y el tablero . . . . . . . . . . . . . . . . . . . 142

5.8. Flechas para péndolas rígidas . . . . . . . . . . . . . 143

5.9. Efecto de la rigidez de la péndola en la distribución del momento flector del arco y del tablero . . . . . . . . . . . . . . . . . . . 144

5.10. Comparación de péndolas rígidas y articuladas: distribución de momento flector en una péndola . . . . . . . . . . . . . . . . . 145

5.11. Efecto de una péndola rígida con una sección rectangular hueca de $800 \mathrm{x}$ 800 x $20 \mathrm{~mm}$, para un $C_{A}=0.20,0.33$ (puente de referencia) y $0.50 \ldots 146$

5.12. Momentos flectores para una distribución de péndolas rígidas y articuladas 147

5.13. Efecto de la configuración mixta de péndolas rígidas y articuladas en la reducción de los momentos flectores para una carga $q_{3}$. . . . . . . . . 148

6.1. Coeficientes de pandeo en el plano para arcos parabólicos exentos . . . . 152

6.2. Coeficientes de pandeo en el plano para arco parabólico vinculado al tablero con péndolas . . . . . . . . . . . . . . . . . . . . . 154

6.3. Coeficientes de pandeo dentro del plano del arco estimados para diferentes secciones . . . . . . . . . . . . . . . . . . 155

7.1. Flexión del arco para una carga transversal . . . . . . . . . . . . 160

7.2. Coeficiente $\xi$ para el cálculo de los momentos transversales en los arranques

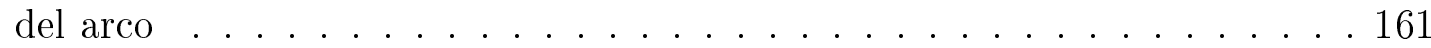

7.3. Error en tanto por 1 del momento teórico respecto al momento experimental 162

7.4. Coeficientes de pandeo $C_{2}$ fuera del plano de Godden . . . . . . . . . . 164

7.5. Coeficientes de pandeo fuera del plano del arco estimados para diferentes secciones . . . . . . . . . . . . . . . . . . 166 
8.1. Ejemplo de péndolas articuladas. Chanxe Bridge . . . . . . . . . . . 167

8.2. Puente de Castelmoron sobre el río Lot, Francia . . . . . . . . . . . 168

8.3. Puente de Fehmarnsund . . . . . . . . . . . . . . . . . 169

8.4. Comparación de momentos flectores para diferentes configuraciones de atirantamiento, dibujadas a la misma escala, para una carga uniforme en un

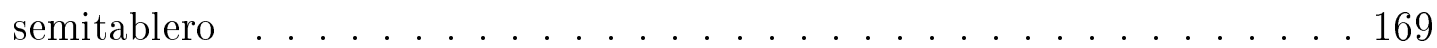

8.5. Pasarela de La Devesa . . . . . . . . . . . . . . . . . . . . 170

8.6. Merchants Bridge . . . . . . . . . . . . . . . . 170

8.7. Ejemplo de péndolas rígidas. Puente de La Alameda (Valencia) . . . . . . . 171

8.8. Destructor Bridge, Bath (Reino Unido) . . . . . . . . . . . . . . 171

8.9. Puente de Ondarroa . . . . . . . . . . . . . . . . . 172

8.10. Puente sobre el río Galindo . . . . . . . . . . . . . . . 172

8.11. Alternativas no construidas para el río Galindo . . . . . . . . . . . . 173

8.12. Puente de Endarlatsa . . . . . . . . . . . . . . . . 173

8.13. Momentos flectores para el puente de referencia (a, b), péndolas rígidas SHB 400x400x20mm (c, d) y SHB 800x800x20mm (e, f), bajo cargas $q_{3}$ (a,

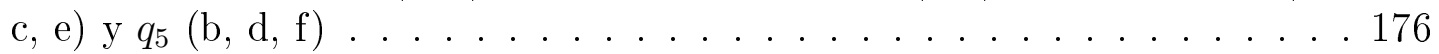

8.14. Diagramas longitudinales de momentos flectores en arco y tablero vs. rigidez de péndolas y localización de las articulaciones . . . . . . . . . . . 177

8.15. Flexión longitudinal vs. rigidez. Rigideces en el plano del arco y del tablero ponderadas, respectivamente, por $k_{A}$ y $k_{D}$. a) $k_{A}=1, k_{D}=10$, b) $k_{A}=10$,

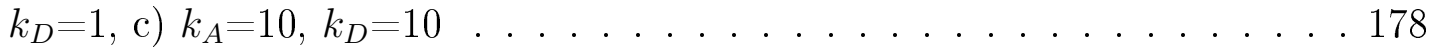

8.16. a) deformada del puente para $q_{2}$. b) deformada de la sección transversal del tablero . . . . . . . . . . . . . . . . 179

8.17. Momento transversal del arco (a) y del tablero (b) para una carga $q_{2}$ en función de la altura de la articulación . . . . . . . . . . . . . . . 180

8.18. Torsión para $q_{2}$ en el arco (a) y el tablero (b) vs. posición de la articulación. c) detalle de resultados en arranques y estribos . . . . . . . . . . . . . . 181

8.19. a) Deformación transversal en la clave para $q_{2}$. b) Deformación vertical en el borde del tablero para $q_{2}$. c) Detalle de resultados en el centro de la luz . 182

8.20. Transferencia de cargas de un tablero cargado asimétricamente hacia el mecanismo resistente compuesto por un arco y una péndola con una articulación 183

8.21. Eficacia $e_{H}=M_{i} / M_{t}$ vs rigidez. Rigidez transversal de péndolas ponderada por $k_{H}$, rigidez transversal y torsional del arco ponderada por $k_{A}$. (a) $k_{H}=k_{A}=1$, (b) $k_{H}=100, k_{A}=1$, (c) $k_{H}=1, k_{A}=100$, (d) $k_{H}=k_{A}=100 \ldots 184$

8.22. Mecanismos resistentes en péndolas con y sin articulaciones. . . . . . . 185

8.23. $M_{s} / M_{i}$ para $q_{2}$. Puente de referencia . . . . . . . . . . . 185 
8.24. Puente de referencia: Coeficiente $\lambda_{u}$ para diferentes configuraciones de péndolas, para la hipótesis de carga $1,35 \cdot(P P+C M)+0,6 \cdot 1,5 \cdot V T O+\lambda \cdot q_{5} 186$

8.25. Extremo articulado conseguido mediante una sección de muy baja rigidez en el extremo. Merchants Bridge, Manchester . . . . . . . . . . . 187

8.26. Deformación del borde del tablero para $q_{2}$, (a) Puente de referencia, (b) rigidez torsional del puente de referencia ponderada por 0.02 . . . . . 187

8.27. Configuraciones de cables contenidas en el plano del arco . . . . . . . . 188

8.28. Configuraciones de cables contenidas en el plano perpendicular al del arco . 188

8.29. Tablero para $q_{3}$. a) flectores, b) deformaciones verticales en el eje . . . . . 189

8.30. Tablero para $q_{2}$. a) torsores, b) deformaciones verticales en el borde . . . . 189

8.31. Configuración tridimensional de cables obtenida por combinación de configuraciones planas . . . . . . . . . . . . . . . . 189

9.1. Puente de Wittenberg sobre el río Elba . . . . . . . . . . . . . . . 194

9.2. Secciones transversales de los puentes estudiados en el capítulo 9 . . . . . 194

9.3. Definición de los modelos con un juego de (a) cables verticales (V1) y (b) tipo Nielsen (N1), anclados al eje del tablero . . . . . . . . . . 196

9.4. Flechas del eje del tablero para modelos con un solo juego de péndolas verticales (V1) o Nielsen (N1) ancladas al eje del tablero . . . . . . . . 196

9.5. Flechas del eje y del borde del tablero para modelos con un solo juego de péndolas verticales (V1) o Nielsen (N1) ancladas al eje del tablero . . . . 197

9.6. Cargas equivalentes para modelos con un solo juego de péndolas verticales (V1) o Nielsen (N1) ancladas al eje del tablero . . . . . . . . . . . 198

9.7. Flexión longitudinal del arco para modelos con un solo juego de péndolas verticales (V1) o Nielsen (N1) ancladas al eje del tablero . . . . . . . 198

9.8. Flexión longitudinal del tablero para modelos con un solo juego de péndolas verticales (V1) o Nielsen (N1) ancladas al eje del tablero . . . . . . . . 199

9.9. Definición de los modelos con dos juegos de cables, (a) verticales (V2) y (b) tipo Nielsen (N2), anclados a ambos bordes del tablero . . . . . . 200

9.10. Flechas del eje del tablero para modelos con un solo juego de péndolas verticales (V1) o Nielsen (N1), y para modelos con dos juegos de péndolas

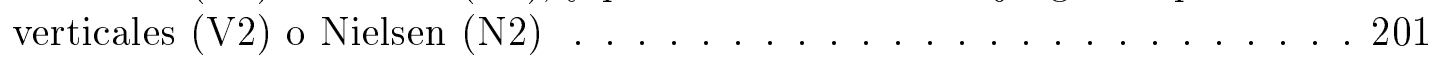

9.11. Flechas del eje y del borde del tablero para modelos con un solo juego de péndolas verticales (V1) o Nielsen (N1), y para modelos con dos juegos de

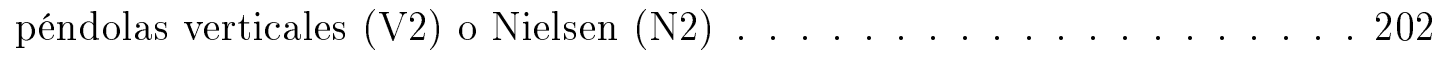

9.12. Flexión transversal del arco para modelos con un solo juego de péndolas verticales (V1) o Nielsen (N1) ancladas al eje del tablero, y para modelos con dos juegos de péndolas verticales (V2) o Nielsen (N2), para la carga de viento . . . . . . . . . . . . . . . . . . 202 
9.13. Flexión transversal del tablero para modelos con un solo juego de péndolas verticales (V1) o Nielsen (N1) ancladas al eje del tablero, y para modelos con dos juegos de péndolas verticales (V2) o Nielsen (N2), para la carga de

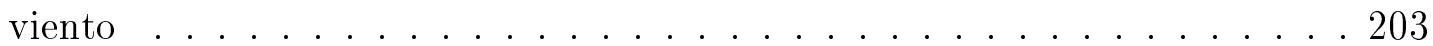

9.14. Flexión longitudinal del arco para modelos con un solo juego de péndolas verticales (V1) o Nielsen (N1) ancladas al eje del tablero, y para modelos con dos juegos de péndolas verticales (V2) o Nielsen (N2) . . . . . . . . 203

9.15. Flexión longitudinal del tablero para modelos con un solo juego de péndolas verticales (V1) o Nielsen (N1) ancladas al eje del tablero, y para modelos con dos juegos de péndolas verticales (V2) o Nielsen (N2) . . . . . . . . . 204

9.16. Flexión transversal del arco para modelos con un solo juego de péndolas verticales (V1) o Nielsen (N1) ancladas al eje del tablero, y para modelos con dos juegos de péndolas verticales (V2) o Nielsen (N2) . . . . . . . . . 204

9.17. Flexión transversal del tablero para modelos con un solo juego de péndolas verticales (V1) o Nielsen (N1) ancladas al eje del tablero, y para modelos con dos juegos de péndolas verticales (V2) o Nielsen (N2) . . . . . . . 205

9.18. Torsión del arco para modelos con un solo juego de péndolas verticales (V1) o Nielsen (N1) ancladas al eje del tablero, y para modelos con dos juegos de péndolas verticales (V2) o Nielsen (N2) . . . . . . . . . . 205

9.19. Torsión del tablero para modelos con un solo juego de péndolas verticales (V1) o Nielsen (N1) ancladas al eje del tablero, y para modelos con dos juegos de péndolas verticales (V2) o Nielsen (N2) . . . . . . . . . 206

9.20. Proyección de los elementos del puente que conforman las celosía vertical y en planta, para un arco con doble atirantamiento vertical (a) y tipo Nielsen (b) . . . . . . . . . . . . . . . . . . 207

9.21. Descomposición de fuerzas actuantes en la sección transversal del puente arco con doble atirantamiento . . . . . . . . . . . . . 208

9.22. Descomposición de fuerzas actuantes en la sección transversal del puente arco con doble atirantamiento, supuesta $N_{H, 1}>N_{H, 2}$. . . . . . . . 208

9.23. Comportamiento de la sección transversal del puente para una carga de borde (flecha hueca). a) arco con inercia transversal igual a 0 . b) arco con inercia transversal infinita. c) arco con su inercia transversal. . . . . . . . 209

9.24. Esquemas para el cálculo de una sección equivalente de péndolas. . . . . . 210

9.25. Axiles en las péndolas (fig. superior/inferior: péndolas del semitablero descargado/cargado) para los modelos V2 y N2 bajo una carga $q_{2} \ldots \ldots$. . . . 211

9.26. Bifurcación del arco en los arranques. a) arco con doble atirantamiento vertical. b) arco con doble atirantamiento tipo Nielsen . . . . . . . . . . . 212

9.27. Gálibo para puentes arco con un solo juego de cables anclados al eje del tablero . . . . . . . . . . . . . . . . . . . . . 214

9.28. Gálibo para puentes arco con dos juegos de cables anclados a ambos bordes del tablero . . . . . . . . . . . . . . . . . . . 215 
9.29. Vista en planta de los sobreanchos necesarios para mantener el gálibo . . . 215

10.1. Resumen de estrategias a seguir para el diseño en el plano . . . . . . . . 223

10.2. Resumen de estrategias a seguir para el diseño fuera del plano . . . . . . . 225

10.3. Obtención de puentes arco espaciales simétricos por combinación de arcos y tableros . . . . . . . . . . . . . . . . . 227

10.4. Obtención de puentes arco espaciales asimétricos por combinación de arcos

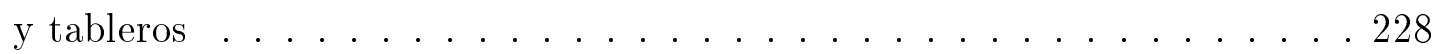





\section{Índice de tablas}

3.1. Variaciones de temperatura. . . . . . . . . . . . . . . 90

5.1. Materiales y dimensiones de las secciones del puente usado en el estudio del capítulo 5. . . . . . . . . . . . . . . . . . . . . . 139

7.1. Coeficientes $\xi$ para estimar los momentos transversales en los arranques del

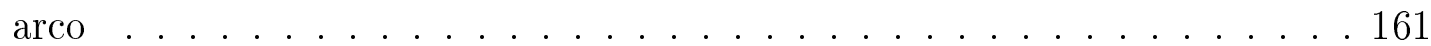

7.2. Coeficientes de pandeo $C_{2}$ fuera del plano de Shukla-Ojalvo . . . . . . . . 164

8.1. Materiales y dimensiones de las secciones del puente usado en el estudio del capítulo 8. . . . . . . . . . . . . . . . . . 175

9.1. Materiales y dimensiones de las secciones del puente usado en el estudio del capítulo 9. . . . . . . . . . . . . . . . . . . 195

9.2. Coeficientes de pandeo fuera del plano para arcos con atirantamiento simple al eje del tablero, y para modelos con doble atirantamiento a los bordes del tablero. . . . . . . . . . . . . . . . . . 213 



\section{Notación}

En las siguientes líneas se detalla la notación usada con mayor frecuencia en los diferentes textos de la tesis, con el fin de que los diferentes escritos de esta tesis queden lo más claros posibles:

\section{Minúsculas latinas}

$b \quad$ Ancho cargado del tablero.

$b_{A} \quad$ Ancho de la sección transversal de arco.

$b_{D} \quad$ Ancho de la sección transversal de tablero.

$e_{H} \quad$ Eficiencia de las péndolas.

$f \quad$ Flecha vertical del arco.

$g_{A} \quad$ Peso propio del arco.

$g_{D} \quad$ Peso propio del tablero.

$h \quad$ Longitud de la péndola.

$h_{A} \quad$ Canto de la sección transversal de arco.

$h_{D} \quad$ Canto de la sección transversal de tablero.

$k_{A} \quad$ Factor de ponderación de la rigidez del arco.

$k_{D} \quad$ Factor de ponderación de la rigidez del tablero.

$k_{H} \quad$ Factor de ponderación de la rigidez de las péndolas.

$m_{t} \quad$ Momento torsor exterior por unidad de longitud del tablero.

$p \quad$ Carga vertical exterior por unidad de longitud del tablero.

$q \quad$ Carga vertical exterior por unidad de superficie del tablero.

$q_{y} \quad$ Carga transversal exterior por unidad de longitud.

$s \quad$ Distancia entre péndolas medida sobre el eje X.

$t_{f, A} \quad$ Espesor de las alas de la sección transversal de arco.

$t_{f, D} \quad$ Espesor de las alas de la sección transversal de tablero.

$t_{w, A} \quad$ Espesor de las almas de la sección transversal de arco.

$t_{w, D} \quad$ Espesor de las almas de la sección transversal de tablero.

$t_{A} l_{A}$ Tolerancia predefinida para la sección transversal de arco.

$t_{D} l_{D}$ Tolerancia predefinida para la sección transversal de tablero.

$z \quad$ Altura del alma de la sección transversal.

$z_{A} \quad$ Altura del alma de la sección transversal de arco.

$z_{D} \quad$ Altura del alma de la sección transversal de tablero.

$z_{I} \quad$ Altura del alma del área que maximiza la inercia.

$z_{W} \quad$ Altura del alma del área que maximiza el módulo elástico. 


\section{Mayúsculas latinas}

$C_{A} \quad$ Contribución del arco a la rigidez a flexión global del puente.

$C M \quad$ Carga muerta.

$E \quad$ Módulo de Young.

$E_{A} \quad$ Módulo de Young del material del arco.

$E_{D} \quad$ Módulo de Young del material del tablero.

$G_{A} \quad$ Peso del arco.

$G_{D} \quad$ Peso del tablero.

$G \quad$ Módulo de elasticidad transversal (en el capítulo 4 hace referencia al peso total del puente).

I Inercia.

$I_{A} \quad$ Inercia longitudinal de la sección transversal de arco.

$I_{A, z} \quad$ Inercia transversal de la sección de arco.

$I_{D} \quad$ Inercia longitudinal de la sección transversal de tablero.

$I_{D, z} \quad$ Inercia transversal de la sección de tablero.

$I_{I} \quad$ Inercia del área que maximiza la inercia.

$I_{W} \quad$ Inercia del área que maximiza el módulo elástico.

$I^{\delta} \quad$ Inercia obtenida con $\delta$-method.

$I^{\sigma \delta} \quad$ Inercia obtenida con $\sigma+\delta$-method.

$J \quad$ Inercia torsional.

$L \quad$ Luz del puente.

$L_{A} \quad$ Longitud del arco.

$L_{\text {parab }}$ Longitud desarrollada de la directriz parabólica del arco.

$M_{A} \quad$ Momento flector en el arco.

$M_{A, z} \quad$ Momento flector transversal en el arco.

$M_{D} \quad$ Momento flector en el tablero.

$M_{D, z} \quad$ Momento flector transversal en el tablero.

$M_{i} \quad$ Momento flector transversal soportado en la base de la péndola.

$M_{s} \quad$ Momento flector transversal soportado en la cabeza de la péndola.

$M_{t} \quad$ Momento torsor tributario de una péndola.

$N_{A} \quad$ Axil en el arco.

$N_{c r} \quad$ Axil crítico de pandeo.

$N_{D} \quad$ Axil en el tablero.

$N_{H} \quad$ Axil en las péndolas del puente.

$N_{H, 1}$ Axil de las péndolas derechas en puentes con atirantamiento doble.

$N_{H, 2} \quad$ Axil de las péndolas izquierdas en puentes con atirantamiento doble.

N1 Puente arco con un solo juego de péndolas tipo Nielsen ancladas al eje del tablero.

N2 Puente arco con dos juegos de péndolas tipo Nielsen ancladas a los bordes del tablero.

$P \quad$ Carga vertical tributaria de una péndola.

$P P \quad$ Carga de peso propio.

$S C U$ Sobrecarga de uso.

$T_{A} \quad$ Torsión en el arco.

$T_{D} \quad$ Torsión en el tablero. 
VTO Carga de viento.

$V 1$ Puente arco con un solo juego de péndolas verticales ancladas al eje del tablero.

$V 2$ Puente arco con dos juegos de péndolas verticales ancladas a los bordes del tablero.

$W \quad$ Módulo elástico.

$W_{I} \quad$ Módulo elástico del área que maximiza la inercia.

$W_{W} \quad$ Módulo elástico del área que maximiza el módulo elástico.

\section{Minúsculas griegas}

$\alpha \quad$ Coeficiente de posición relativa de la articulación en péndolas rígidas.

$\beta \quad$ Esbeltez geométrica del alma de la sección transversal.

$\beta_{A} \quad$ Esbeltez geométrica del alma de la sección transversal de arco.

$\beta_{D} \quad$ Esbeltez geométrica del alma de la sección transversal de tablero.

$\delta_{1} \quad$ Flecha (ELS) debida al acortamiento axial de la directriz del arco.

$\delta_{2} \quad$ Flecha (ELS) debida a la elongación axial de la directriz del tablero.

$\delta_{3} \quad$ Flecha (ELS) debida a una sobrecarga uniforme $q$ que actúa sobre la mitad dorsal o frontal del tablero.

$\delta_{D} \quad$ Flecha total $\left(\delta_{1}+\delta_{2}+\delta_{3}\right)$ en la sección de control del tablero.

$\delta_{C, A} \quad$ Flecha transversal del arco.

$\delta_{D, l i m}$ Flecha máxima permitida en el tablero.

$\delta_{E} \quad$ Flecha del borde de tablero.

$\lambda_{u} \quad$ Factor de ponderación de la sobrecarga de uso al pandear.

$\mu \quad$ Relación entre la rigidez a flexión del tablero y del arco.

$\xi \quad$ Coeficiente para el cálculo de los momentos transversales en los arranques del arco.

$\sigma_{A} \quad$ Tensión longitudinal máxima en el arco.

$\sigma_{A, \text { lim }}$ Tensión longitudinal admisible en el arco.

$\sigma_{D} \quad$ Tensión longitudinal máxima en el tablero.

$\sigma_{D, l i m}$ Tensión longitudinal admisible en el tablero.

$\phi_{H} \quad$ Diámetro de péndola.

$\omega \quad$ Inclinación del plano del arco.

\section{Mayúsculas griegas}

$\Omega \quad$ Área.

$\Omega_{A} \quad$ Área de la sección transversal de arco.

$\Omega_{D} \quad$ Área de la sección transversal de tablero.

$\Omega_{f} \quad$ Área del ala de la sección transversal.

$\Omega_{H} \quad$ Área de la sección de péndola.

$\Omega_{H}^{\prime} \quad$ Área equivalente de la sección de péndola.

$\Omega^{\delta} \quad$ Área de la sección transversal obtenida con $\delta$-method. 
$\Omega^{\sigma \delta} \quad$ Área de la sección transversal obtenida con $\sigma+\delta$-method.

\section{Subíndices y superíndices}

$i, j, k$ Genérico, como $\mu^{k}$.

A Relativo al arco, como $N_{A}, M_{A}$.

$D \quad$ Relativo al tablero, como $N_{D}, M_{D}$.

$H \quad$ Relativo a las péndolas, como $\phi_{H}$.

I Relativo a la inercia, como $W_{I}$.

lim Valor límite de una magnitud, como $\delta_{D, l i m}$ o $\sigma_{A, l i m}$.

$W \quad$ Relativo al módulo elástico, como $I_{W}$.

$\delta \quad$ Valor de una variable obtenida con $\delta$-method, como $\Omega^{\delta}$ o $I^{\delta}$.

$\sigma \delta \quad$ Valor de una variable obtenida con $\sigma+\delta$-method, como $\Omega^{\sigma \delta}$ o $I^{\sigma \delta}$. 


\section{Parte I}

\section{Generalidades}





\section{Capítulo 1}

\section{Introducción}

\subsection{Razón de ser de la tesis doctoral}

La aparición de nuevas tipologías estructurales es fruto de la mejora de los métodos de ejecución, el progreso en el conocimiento científico, la introducción generalizada de la informática, y la aparición y conocimiento de nuevos materiales. Esta tesis surge en este contexto, donde existe una clara desproporción de los fines respecto de los medios, sobre todo en puentes de luces cortas y medias.

A esta situación hay que añadir que, sobre todo en obras de ámbito urbano, los equipos de diseño tienen un carácter cada vez más multidisciplinar, e incorporan además de ingenieros, a arquitectos o incluso escultores.

Por lo tanto, no es de extrañar que la estética se haya convertido en un factor cada vez más relevante en el proyecto de estructuras. Hoy en día, ya no sólo es necesario que la estructura cumpla unos requerimientos funcionales, sino que además, en obras urbanas, es muy frecuente que se pretenda convertir a los puentes en referentes arquitectónicos, señas de identidad para la población, o incluso elementos icónicos del paisaje urbano ${ }^{1}$.

Este afán por la estética ha relegado incluso, en algunas ocasiones, a los mecanismos estructurales a un mero papel de "sostenimiento", sin darles la importancia que les corresponde $^{2}$. Como siempre hay excepciones, en las que el ingeniero ha hecho que esos mecanismos resistentes sean algo estético y funcional, evitando que queden ocultos bajo una piel de acero u hormigón.

Como ejemplo de este tipo de estructuras, el puente arco espacial ${ }^{3}$, estudiado en esta tesis, es una tipología con numerosas realizaciones en diversas ciudades de todo el mundo, al presentar una estética muy llamativa. Basta mencionar a Santiago Calatrava, que ha repetido en numerosas ocasiones su diseño propuesto para París en 1988, con un arco

\footnotetext{
${ }^{1}$ Ejemplos de hitos arquitectónicos los hay a cientos, pero puede tomarse como uno de los ejemplos más famosos la Torre Eiffel, hito arquitectónico que cualquier persona no dudará en relacionar con la ciudad de París.

${ }^{2}$ La estatua de la libertad, inaugurada en 1886 en Nueva York, es una clara muestra donde la estructura original que sostiene la obra, proyectada por Gustave Eiffel, queda oculta.

${ }^{3}$ El término puente arco espacial fue usado por primera vez en la tesis defendida por Juan José Jorquera Lucerga en 2007 (véase [46]).
} 
inclinado sujeto al borde del tablero. Hay quien afirma que no es casualidad que estas estructuras sean de arco superior, pues resultan mucho más perceptibles y notorias en el ámbito urbano que si la estructura portante se sitúa bajo el tablero.

Ante esta situación, caben fundamentalmente dos estrategias de diseño. La primera, que podríamos llamar formal, en la que prima la estética por encima de cualquier consideración resistente, y que suele ser propia de profesionales no vinculados directamente a la ingeniería estructural, o que, por lo menos, no se consideran concernidos por sus criterios. Este sería el caso del pabellón puente de Zaragoza, proyecto de Zaha Hadid, en el que, a pesar de su luz, las consideraciones estructurales quedaron postergadas frente a las consideraciones de índole formal (véase la figura 1.1).

La segunda, que podríamos llamar ortodoxa, se centra en explotar los recursos formales y visuales que todavía ofrecen las estructuras que podríamos llamar "canónicas", es decir estructuras esencialmente correctas desde el punto de vista de la ingeniería estructural. En esta categoría podríamos incluir el puente de Euskalduna, en Bilbao, proyecto de Javier Manterola, que explota de modo novedoso y magistral la capacidad de las secciones en $\mathrm{Z}$ para resistir la torsión producida por su planta curva (véase la figura 1.2).

Además, existiría una tercera vía, en la que las estructuras presentan una fuerte originalidad que, sin embargo, no es buscada de antemano, y aparece de modo natural como consecuencia a posteriori del proceso de diseño. Es en esta categoría donde podríamos clasificar a las tipologías de puente arco que han surgido, obligadas por las necesidades funcionales, para sostener un tablero curvo, como los puentes arcos espaciales asimétricos de Ripshorst, Galindo o Endarlatsa (véase Manterola et al. [61]), descritos en el capítulo 2 .

Es decir, el puente arco espacial no sólo es una opción estética, sino que en determinados casos, constituye una evolución tipológica no forzada del diseño de los puentes arco clásicos. A este respecto es muy importante si el puente es simétrico longitudinalmente o no. Como puede verse en la clasificación de los puentes arco espaciales del capítulo 2, desde el punto de vista de la simetría longitudinal, los puentes pueden ser simétricos o asimétricos. El puente arco clásico, es decir, el formado por un arco vertical, un tablero recto y un conjunto de péndolas, articuladas o no, que los unen, también es simétrico.
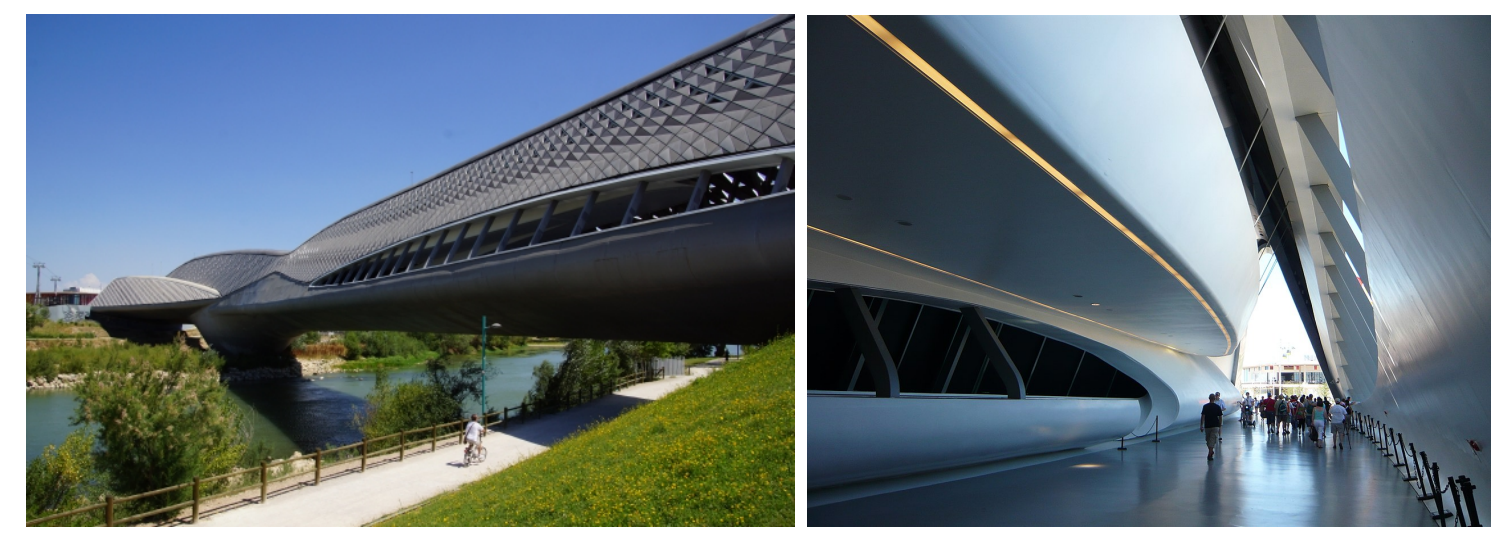

Figura 1.1: Pabellón puente de la Expo 2008 de Zaragoza. Fotografía: Nicolas Janberg (structurae.net) y Oikema 0 (Wikimedia Commons). 


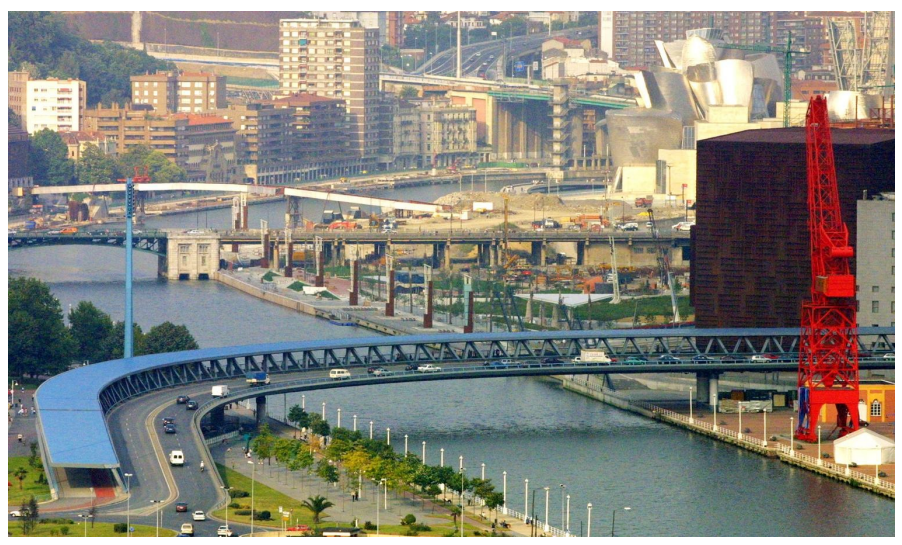

Figura 1.2: Puente de Euskalduna (Bilbao). Fotografía: El Correo (elcorreo.com).

Resulta por tanto difícil, que, partiendo de un puente arco clásico se acabe en un puente arco espacial asimétrico, salvo que las restricciones funcionales sean muy exigentes, como en los casos que hemos visto de los puentes de Ripshorst o Galindo.

Sin embargo, es mucho más fácil que un puente arco clásico acabe derivando, durante el proceso de diseño, en un puente arco espacial simétrico. Los elementos propios del puente arco espacial simétrico, como las péndolas rigidizadas transversalmente o el atirantamiento a ambos bordes del tablero, no sólo suponen una elección visual, sino que permiten satisfacer determinados condicionantes tensodeformacionales, que determinan la validez o no de la estructura.

Esta es, en esencia, la motivación de esta tesis: comprender cómo los mecanismos resistentes propios del puente arco espacial simétrico longitudinalmente, pueden ser movilizados deliberadamente, en la fase de diseño conceptual, como parte de una estrategia de proyecto de puentes arco.

Además de las motivaciones ya expuestas, el interés por los puentes arco espaciales viene de lejos para el autor, cuando en 2014 el director de esta tesis le propone al autor realizar un estudio sobre arcos inclinados con vinculación tipo Nielsen en la asignatura "Tipología estructural y constructiva". Posteriormente el interés por el tema se vería reforzado por el trabajo de fin de máster que el autor realizó bajo la supervisión del director de la tesis. En él se proyectó un puente arco inclinado sujeto al borde del tablero (véase la figura 1.3).

\subsection{Objetivos del estudio}

El objetivo fundamental de esta tesis es demostrar cómo el puente arco espacial simétrico supone una evolución tipológica del puente arco plano clásico, que permite verificar los condicionantes tensodeformacionales que determinan la validez de la estructura, en rotura y servicio.

Es decir, el puente arco espacial simétrico tendría un origen que podríamos llamar ortodoxo desde el punto de vista de la ingeniería estructural. Según esta aproximación, los elementos propios del puente arco espacial simétrico, como las péndolas rigidizadas transversalmente, los atirantamientos al borde del tablero, la duplicación de arcos o los arcos 


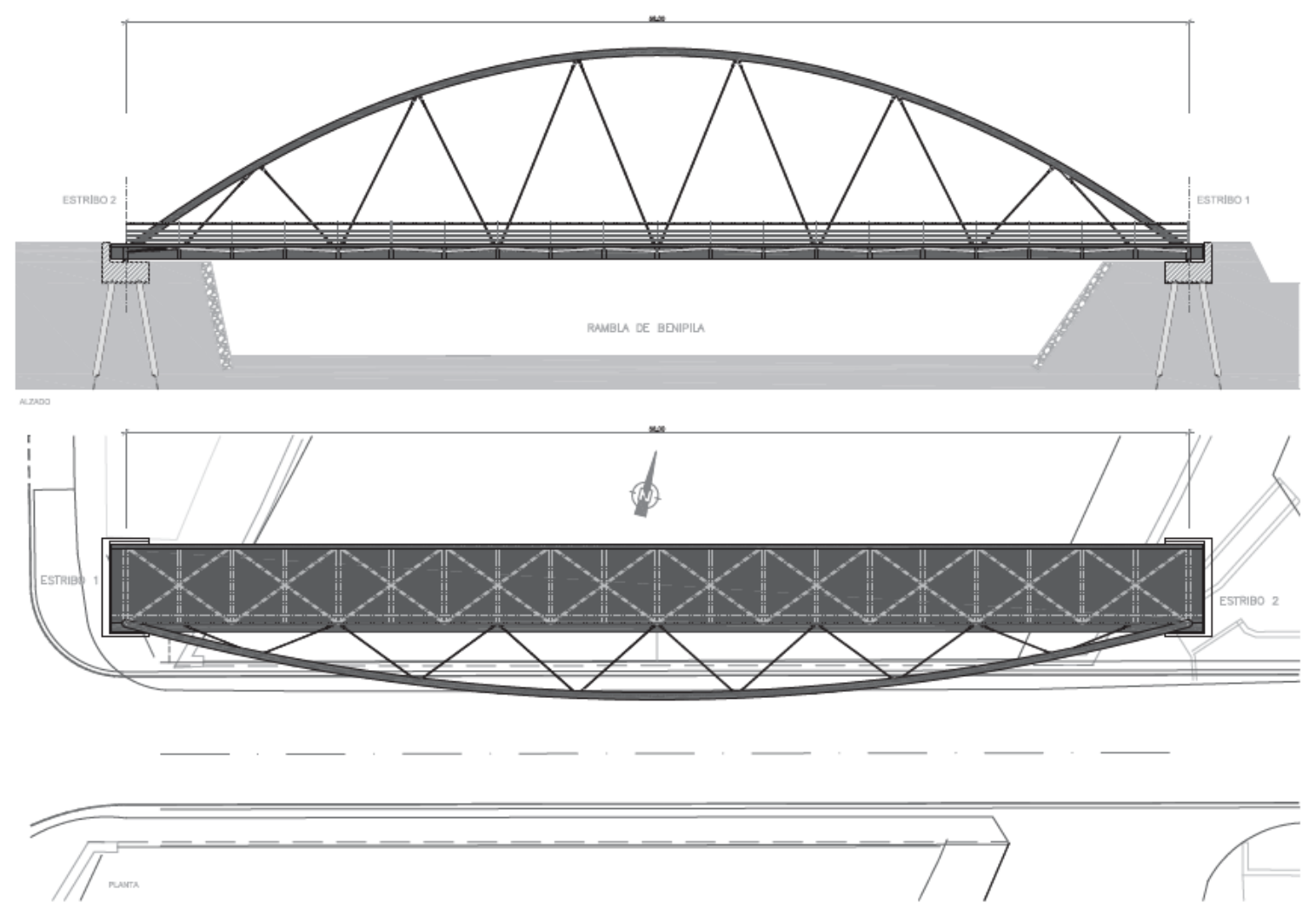

Figura 1.3: Vista en alzado y planta del proyecto fin de carrera del autor.

inclinados convergentes, tienen una justificación que va más allá de razones estéticas, pues su aparición sería la consecuencia de la decisión de un diseñador que pretende resolver un problema de índole puramente estructural.

Dado que, merced a la asimetría longitudinal, los comportamientos estructurales dentro y fuera del plano del arco pueden considerarse desacoplados, un estudio del puente arco espacial simétrico puede estudiar independientemente el comportamiento longitudinal (es decir, contenido en el plano del arco) y el comportamiento transversal (es decir, en el plano perpendicular al arco).

En lo que se refiere al comportamiento en el plano, en esta tesis se procederá a desarrollar los siguientes estudios:

- El diseño preliminar de secciones transversales tanto de arco como de tablero, suponiendo que dicho diseño viene gobernado por sus esfuerzos y deformaciones contenidos en el plano del arco.

- El efecto que la rigidización longitudinal de las péndolas tiene sobre el comportamiento estructural en el plano del puente.

- Aunque el pandeo en el plano es un modo muy infrecuente de colapso, se estudiará brevemente el efecto de las distribuciones longitudinales de material en el arco sobre la carga de pandeo. 
- La constatación de la efectividad de configuraciones de péndolas inclinadas en el plano, como las Nielsen-Löhse y Network.

De modo similar, en el comportamiento fuera del plano, se realizarán los siguientes estudios:

- Un estudio paramétrico que permita estimar, simplificadamente, los esfuerzos correspondientes a la flexión transversal del arco frente a cargas como el viento, recogiendo factores como el rebajamiento y la relación entre las rigideces a flexión y torsional.

- La comprobación de que existen distribuciones de secciones transversalmente variables, que, conservando invariable la cantidad de material empleado en el arco, reducen significativamente la sensibilidad de éste a pandeo transversal.

- El estudio del efecto que la rigidización transversal tiene sobre el comportamiento estructural fuera del plano del puente.

- El estudio de configuraciones de péndolas con capacidad a flexión formadas por cables.

- El estudio de la posición de articulaciones a lo largo de la longitud de la péndola, para determinar la variación en su eficacia con respecto a las péndolas empotradas.

- El estudio de los mecanismos resistentes que se movilizan tanto en arco como en tablero cuando el atirantamiento se duplica y las péndolas se anclan en los bordes del tablero.

- La constatación de la efectividad de configuraciones de péndolas inclinadas en el plano, como las Nielsen-Löhse ancladas en los bordes del tablero.

Por lo tanto, los estudios relacionados pretenden establecer una serie de estrategias de diseño, de carácter netamente espacial, que permite al diseñador satisfacer los condicionantes tensodeformacionales de la estructura.

Además de los objetivos específicos anteriores, todo el trabajo comparte en su desarrollo las siguientes características:

- Las cargas consideradas para el estudio de los puentes son de carácter estático, pues se considera que las cargas dinámicas podrían complicar en exceso los análisis y podrían enmascarar el problema a resolver.

- Dependiendo del estudio que se haya realizado, las hipótesis de carga actúan con sus valores característicos, combinadas en estados límites de servicio o en estados límite últimos.

- Con el fin de simplificar el problema, todos los cálculos han sido realizados considerando un comportamiento elástico lineal del material, si bien se considera el efecto de la no linealidad para el estudio del pandeo en los capítulos necesarios. 
- Los materiales usados tienen unas características mecánicas similares a los comerciales, con el fin de aproximarse lo más posible a la realidad del problema resistente. En la medida de lo posible, se han usado elementos resistentes como cables o aparatos de apoyo provenientes de catálogos de marcas comerciales.

- No se ha realizado ninguna campaña de experimentación, pues los estudios realizados son de carácter teórico, lo que reduce con mucho los gastos, y la necesidad de infraestructuras y personal asociado a la tesis.

- Por último, dado el elevado número de modelos, la complejidad geométrica de las estructuras y los algoritmos a emplear, se ha usado de forma metódica la programación informática para la gestión de modelos y el análisis de los resultados obtenidos con los programas de cálculo de estructuras a emplear en la tesis.

\subsection{Contenido de la tesis}

En el capítulo 2 se matizan las definiciones que hasta la fecha existen del concepto de puente arco espacial, se repasa el estado actual de los puentes arco espaciales, se propone una clasificación y se muestran configuraciones obtenidas por combinaciones de arcos y tableros, lo que ilustra las posibilidades formales de la tipología.

En el capítulo 3 se describe la metodología empleada en los estudios realizados en esta tesis, definiéndose los modelos estructurales empleados, así como las diferentes variables geométricas y acciones consideradas.

Los capítulos 4 al 6 están dedicados al estudio del comportamiento en el plano del puente arco. En el capítulo 4 se estudia el dimensionamiento de secciones transversales de arco y tablero. El capítulo 5 se centra en evaluar el efecto de las péndolas rigidizadas longitudinalmente sobre el comportamiento estructural del puente. El capítulo 6 analiza brevemente el pandeo del plano en el arco.

Los capítulos 7 y 8 están dedicados al comportamiento fuera del plano. En el capítulo 7 se analiza la flexión transversal y el pandeo fuera del plano, mientras que en el capítulo 8 se estudia el efecto de la rigidización transversal de péndolas.

El capítulo 9 está dedicado al efecto que tiene sobre el comportamiento transversal del puente el atirantamiento a ambos bordes del tablero. En el capítulo 10 se recogen las conclusiones de la tesis.

\subsection{Metodología de trabajo}

La tesis busca fundamentalmente introducir una referencia al diseño y cálculo de los puentes arco espaciales, pues la falta de homogeneidad en la evolución tipológica de este tipo de estructuras ha provocado también la ausencia de una serie de estudios de investigación que arrojen luz acerca de las características propias del tipo estructural.

Se puede dividir la tesis doctoral desarrollada en cuatro grandes bloques de trabajo, que pretenden paliar parcialmente las carencias descubiertas en las referencias técnicas y en 
la documentación relativa a las obras analizadas:

1. Recopilación y análisis crítico de las referencias técnicas a análisis teóricos y a obras realizadas o proyectadas, relacionadas con el tipo estructural objeto de la tesis propuesta. Es notable, pese al número de grupos de trabajo, la escasez de estudios teóricos en relación con las referencias que describen obras concretas.

2. Programación e implementación informática de códigos de pre y postproceso sobre el programa de elementos finitos SAP2000 para la generación automática de todos los modelos necesarios durante la redacción de la tesis. Toda la programación, se desarrolla en lenguaje MATLAB, y se basa en el código SABRINA (Spatial Arch Bridges Iterative Non-linear Analysis), desarrollado por el Dr. Jorquera Lucerga, director de esta tesis. Los criterios de generalidad y de flexibilidad son primordiales en el desarrollo de los programas, ya que, a priori, se desconocen las características de las estructuras que se han de analizar.

El programa SABRINA es un código abierto que permite sin modificaciones la incorporación de funciones y módulos adicionales. Los archivos de datos de entrada son en sí mismos archivos programables que permiten definir tipologías estructurales mucho más variadas que las necesarias en esta tesis. De hecho, SABRINA se ha utilizado recientemente para estudios paramétricos de puentes atirantados altamente asimétricos (véase Jorquera Lucerga et al. [48]). En concreto, el programa permite definir procesos iterativos, considerando o no la linealidad geométrica, de estructuras definibles por el usuario, con total control de varios centenares de variables a los que se accede con notación matricial muy compacta. En el programa principal existen módulos que permiten por ejemplo: la resolución iterativa no lineal, mediante modelos auxiliares, de sistemas de ecuaciones definibles por el usuario que ajusten tesados de péndolas y cargas de aperturas en clave o estribos para imponer movimientos o esfuerzos arbitrarios en la estructura; obtención de directrices antifuniculares; obtención de contraflechas de ejecución; o algoritmos de dimensionamiento de áreas de péndolas, todo ello, si se desea, simultáneamente y en la misma estructura.

SABRINA cuenta, además, con una completa serie auxiliar de programas, también en MATLAB, de pre y postproceso, incluyendo el postproceso gráfico, de SAP2000.

3. Estudio, con ayuda de las citadas herramientas informáticas descritas anteriormente, y basados tanto en la literatura técnica como en las realizaciones, de los parámetros ya mencionados que gobiernan la respuesta en servicio del puente arco espacial y su influencia relativa.

4. Redacción de la tesis, difusión y presentación. 



\section{Capítulo 2}

\section{Estado del arte}

\subsection{Concepto de puente arco espacial}

A priori puede resultar complejo definir los puentes que quedan englobados por el término puente arco espacial, pues las creaciones llamadas así son numerosas, y el carácter único y distinto de cada una de ellas puede ocultar las semejanzas que comparten.

Antes de definir un puente arco espacial, convendría aclarar el concepto de puente arco plano, por ser el puente del que evolucionan inicialmente los puentes arco espaciales. Se entiende por estructura plana, aquella en la que todas sus barras son coplanarias. Luego un puente arco plano será aquel en el que el arco y la directriz del tablero quedan englobados en el mismo plano vertical. Atendiendo a esta definición, un puente arco asimétrico es siempre un puente arco espacial, pues el arco y el tablero no pueden estar en el mismo plano.

Diversos autores han definido el puente arco espacial, pero siempre las definiciones han compartido una característica esencial, que es el trabajo transversal al que se somete el arco bajo diferentes cargas.

Según Jorquera Lucerga en [46], el puente arco espacial es aquél cuyo comportamiento no es asimilable al de un puente arco plano clásico, vertical, con tablero recto de directriz coplanaria a la del arco y atirantamiento centrado al eje. Además especifica que el puente arco espacial está muy vinculado a la excitación de los mecanismos resistentes transversales para cargas permanentes o sobrecargas exclusivamente verticales.

Por otro lado, Sarmiento Comesías define en [93] y [94] los puentes arco espaciales, como puentes en los que las cargas verticales sobre el tablero producen momentos flectores y esfuerzos cortantes no contenidos en el plano del arco debido a su configuración estructural y geométrica, considerando también los puentes sustentados por láminas como puentes arco espaciales.

Sarmiento Comesías distingue además entre puentes arco espaciales verdaderos y falsos. Los primeros serían aquellos en los que una carga vertical centrada produce esfuerzos fuera del plano del arco debido a su configuración geométrica y estructural. Los falsos serían puentes arco simétricos longitudinalmente en planta con más de un tablero, más de un arco, o más de un juego de péndolas, en los que el comportamiento espacial es activado 
por la excentricidad de las cargas verticales o del peso propio de los arcos inclinados.

En esta tesis se ha definido el puente arco espacial como aquel que bajo cargas verticales cuya resultante no está contenida en el plano del arco, está sometido a esfuerzos que no están contenidos en el plano del arco.

Esta definición excluye al viento como sobrecarga que puede determinar la espacialidad de un puente, pues su resultante se considera transversal al plano del arco. Si se considera el viento, cualquier estructura plana se convertiría automáticamente en espacial, pues es una carga que induce esfuerzos fuera del plano.

Se consideran como puentes arco espaciales por esta definición, aquellos puentes arco simétricos en los que el arco está sometido a esfuerzos transversales por aplicación de cargas excéntricas. Un ejemplo serían los puentes formados por un arco centrado sobre un tablero recto, que tienen una vinculación mediante péndolas rígidas, pues estas son capaces de transmitir esfuerzos del tablero al arco fuera de su plano ${ }^{1}$. También se considerarían espaciales los puentes formados por un arco único centrado sobre el tablero, y anclado a éste con péndolas a ambos bordes, o un puente arco formado por un único arco y dos tableros curvos sujetos al borde. Todos estos puentes, aunque simétricos, tienen una clara función espacial, como por ejemplo la pasarela sobre el río Guadalentín a su paso por Lorca (véase Manterola [60]).

No se consideran puentes arco espaciales aquellos que se sustentan con láminas de doble curvatura, por ser un elemento estructural distinto del arco. Si se deben considerar sin embargo, aquellos puentes arco espaciales formados por arcos laminares, pues estas láminas tienen curvatura nula en uno de sus ejes ${ }^{2}$.

La asimetría es otro de los conceptos clave para definir un puente arco espacial, pues todo puente con asimetría es un puente arco espacial, bien sea porque la asimetría provenga del arco (arcos girados o diagonales) o del tablero (tableros curvos o en forma de S).

\subsection{Estudios teóricos}

El puente arco espacial nace como respuesta a una serie de demandas formales. Las estructuras construidas se materializan en forma de realizaciones aisladas, inconexas entre sí, pudiendo ser esto una de las causas de que no exista un cuerpo articulado de conocimientos, o una serie de estudios de investigación dedicada a este tipo estructural.

También es causa el hecho de que las realizaciones modernas no necesitan ir acompañadas de teorías analíticas tan laboriosas como en épocas anteriores, pues se dispone de medios informáticos que facilitan la labor del ingeniero. Aquí también pudiera radicar la causa de que en la bibliografía técnica reciente abunden las descripciones de estructuras y escaseen los estudios de su comportamiento.

El trabajo que se realizará está basado en los trabajos anteriores de diferentes grupos de

\footnotetext{
${ }^{1}$ Este efecto se estudia con más detalle en los capítulos 5 y 8 sobre rigidización de péndolas.

${ }^{2}$ Un ejemplo de puente arco espacial formado por un arco laminar es el puente de las Oblatas en Pamplona, proyectado por Juan José Arenas de Pablo. En este puente la espacialidad vendría motivada por el doble juego de péndolas que vinculan el arco y el tablero, las cuales introducen esfuerzos transverales al arco.
} 
investigación que, en mayor o menor grado, han estudiado el puente arco espacial:

1. Jörg Schlaich, que desde la empresa Schlaich, Bergermann und Partner, han estudiado las directrices antifuniculares espaciales, como figuras invertidas de cables. Fruto de este estudio es la pasarela de Ripshorst (1998) [97].

2. Jorquera Lucerga y Manterola Armisén (UPM), que realizan un trabajo pionero desde el año 2004 en el estudio de los puentes arco espaciales, originado en el proyecto por parte de éste último de los viaductos de Endarlatza y del Río Galindo en España (véase Manterola et al. [61]). Como aportación a destacar se menciona la tesis "Estudio del comportamiento resistente de los puentes arco espaciales" (UPM, 2007) [46].

3. Aparicio (UPC) y Diaz Terán (Imperial College), que dirigieron la tesis de Sarmiento Comesías (2015) [93].

4. Philippe Block y su equipo, en el Block Research Group de la ETH de Zurich, especialmente en los trabajos realizados en colaboración con Lachauer [52].

5. El equipo de William F. Baker, compuesto por miembros de Skidmore, Owings and Merrill, y por componentes del Department of Civil and Environmental Engineering, University of Illinois at Urbana-Champaign, que realiza un enfoque de form-finding de arcos mediante la aplicación del teorema de Rankine [15].

6. Martin Hudecek con su tesis "Structural Behaviour of Spatial Arch Bridges", defendida en la Universidad de Calgary en 2017 [39].

\subsection{Clasificación}

Dada la gran cantidad de puentes arco espaciales y la variabilidad de estos, se hace preciso establecer un clasificación que ayude a entender mejor su conocimiento, y que permita ordenar las diferentes tipologías. Una clasificación muy completa es la que establece Jorquera Lucerga en [46], estableciendo como criterios de clasificación el número, la forma y la disposición del arco y el tablero, así como la vinculación entre ambos. Esta clasificación se ha completado en la medida de lo posible, proponiéndose la siguiente:

- Arco

- Número de arcos

- Arco único

- Arco doble

- Más de dos arcos

- Número de cordones de cada arco

- Cordón único

- Más de un cordón 
- Número variable según la directriz

- Posición relativa de los cordones del arco

- Posición relativa constante según la directriz del arco

- Posición relativa variable

- Giro longitudinal del arco

- Arco vertical

- Arco girado respecto de la cuerda que une sus arranques

- Giro vertical del arco

- Arranques alineados con el eje longitudinal del puente

- Arco girado respecto a un eje vertical

- Posición del arco respecto a la sección transversal del tablero

- Arco centrado en la sección

- Arco excéntrico situado entre el centro y el borde

- Arco excéntrico en borde de sección transversal

- Arco excéntrico situado fuera de la sección transversal

- Planeidad de la directriz del arco

- Arco de directriz plana

- Arco de directriz alabeada

- Tablero

- Número de tableros

○ Un tablero

- Dos o más tableros

- Planta del tablero

- Planta recta

- Planta curva

- Planta en S

- Combinación de plantas rectas y curvas

- Posición del tablero respecto al arco

- Tablero inferior al arco

- Tablero superior al arco

- Tablero intermedio

- Vinculación $\operatorname{arco}(\mathrm{s})$-tablero(s)

- Posición relativa arco-tablero

- Arranques del arco coincidentes con estribos del tablero

- Arranques del arco y estribos del tablero no coincidentes

- Número de familias de péndolas en cada arco 
- Una familia de péndolas

- Dos o más familias de péndolas

- Posición de los anclajes de péndolas en la sección transversal de tablero

- Sobre el eje de tablero

- En los bordes

$\diamond$ En ambos bordes de tablero simultáneamente con anclajes coincidentes entre sí

$\diamond$ En ambos bordes de tablero simultáneamente con anclajes no coincidentes entre sí

$\diamond$ En un borde del tablero recto

$\diamond$ En el borde interior de un tablero curvo

$\diamond$ En el borde exterior de un tablero curvo

- Posición intermedia entre el eje y los bordes del tablero

\subsection{Generación de puentes arco espaciales por combi- nación de elementos estructurales}

En general, cualquier puente arco espacial puede obtenerse combinando los distintos elementos mostrados en el punto 2.3. Se deben distinguir dos grandes grupos, los puentes arco espaciales con simetría longitudinal, y los puentes arco espaciales asimétricos.

\subsubsection{Puentes arco espaciales con simetría longitudinal}

En los puentes con simetría longitudinal, la espacialidad se alcanza solo bajo cargas excéntricas, y siempre que se dé alguna de las siguientes condiciones:

1. Péndolas o montantes rígidos: Transmiten al arco flexión transversal cuando el tablero está sometido a una carga asimétrica. Por ejemplo, un arco plano vertical centrado sobre el tablero tendrá un comportamiento plano si está vinculado al tablero con cables, y será espacial si los cables se sustituyen por péndolas rígidas.

2. Varias familias de péndolas: Al existir más de una familia de péndolas, estas deben disponerse fuera del plano del arco, lo que produce esfuerzos transversales en el arco (véase la columna A de la figura 2.1).

3. Tableros de planta curva: al existir dos tableros curvos, las péndolas que vinculan el arco y el tablero no están contenidas en el mismo plano del arco (véanse las filas III y IV de la figura 2.1).

4. Arcos inclinados: sean convergentes o divergentes, al estar los arcos inclinados el peso propio del arco actúa fuera del plano del arco (véase la columna $\mathrm{C}$ y $\mathrm{D}$ de la figura 2.1). 
5. Arco girado 90 grados: Al estar el arco girado, se necesitan dos juegos de péndolas para vincularlo con el tablero, haciendo que trabaje de manera transversal (véase la columna E de la figura 2.1).

\subsubsection{Puentes arco espaciales con asimetría longitudinal}

Los puentes arco asimétricos son forzosamente espaciales, en tanto que el peso propio por si solo hace que el arco esté sometido a esfuerzos transversales. Se pueden citar las siguientes condiciones de asimetría:

1. Arranque de arco y tablero no coincidentes: La asimetría en el conjunto es inmediata, independientemente de la forma del arco y el tablero (véase la columna A de la figura 2.2).

2. Tablero de planta curva: las péndolas que vinculan el arco y el tablero no están contenidas en el mismo plano del arco (véanse las filas II, IV y V de la figura 2.2).

3. Arco de planta curva o de directriz alabeada: El arco no está contenido es un plano, lo que hace que sea espacial independientemente de los demás elementos (véase la columna D de la figura 2.2).

4. Arco inclinado respecto de la cuerda que une sus arranques: Al inclinarse el arco, el peso propio actúa fuera de su plano, propiciando esfuerzos transversales en el arco (véase la columna B de la figura 2.2).

5. Arco girado respecto a un eje vertical: Se produce una falta de coincidencia entre los arranques, propiciando la asimetría del conjunto (véase la columna $\mathrm{C}$ de la figura 2.2). 


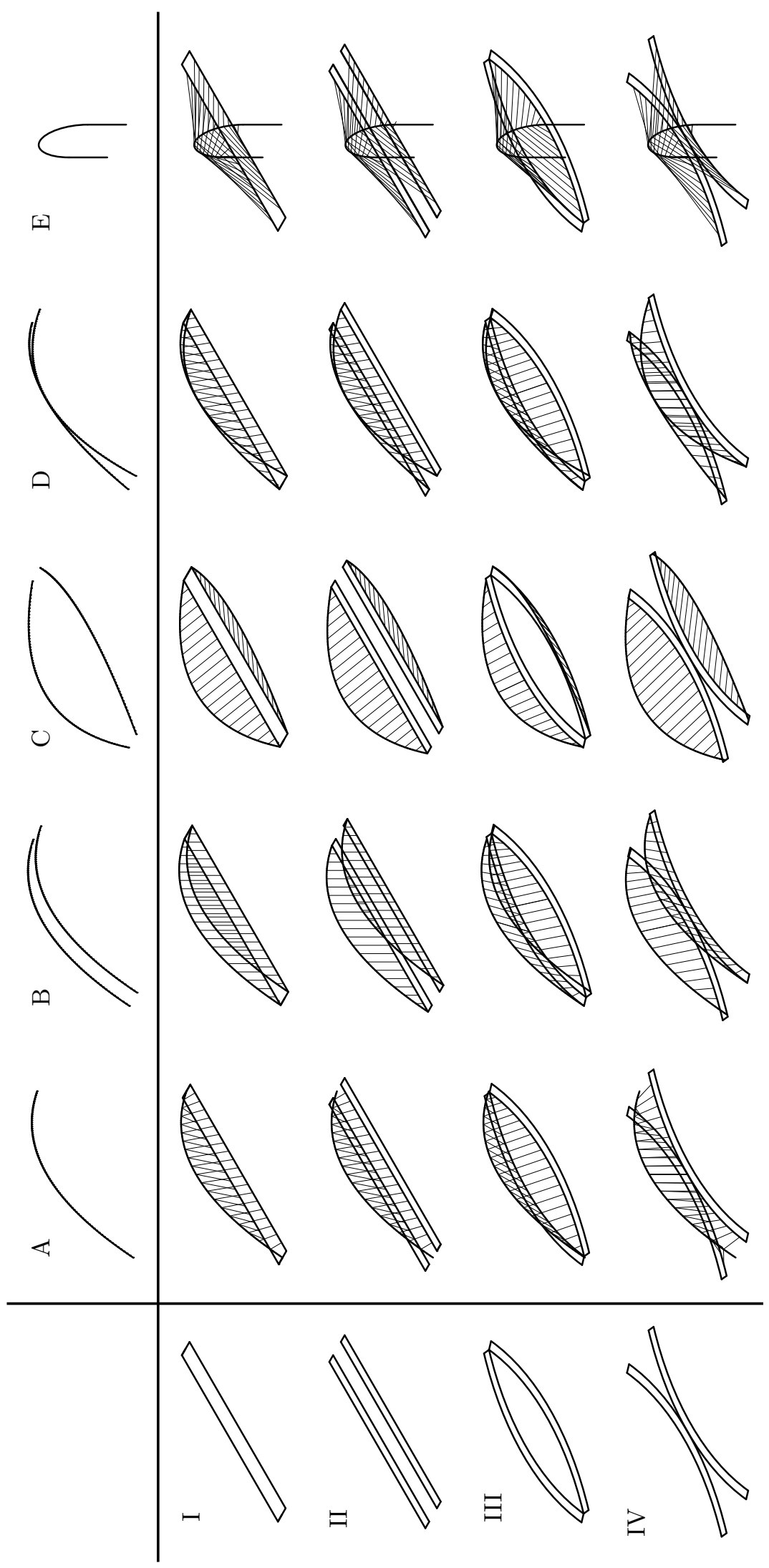

Figura 2.1: Obtención de puentes arco espaciales simétricos por combinación de arcos y tableros 


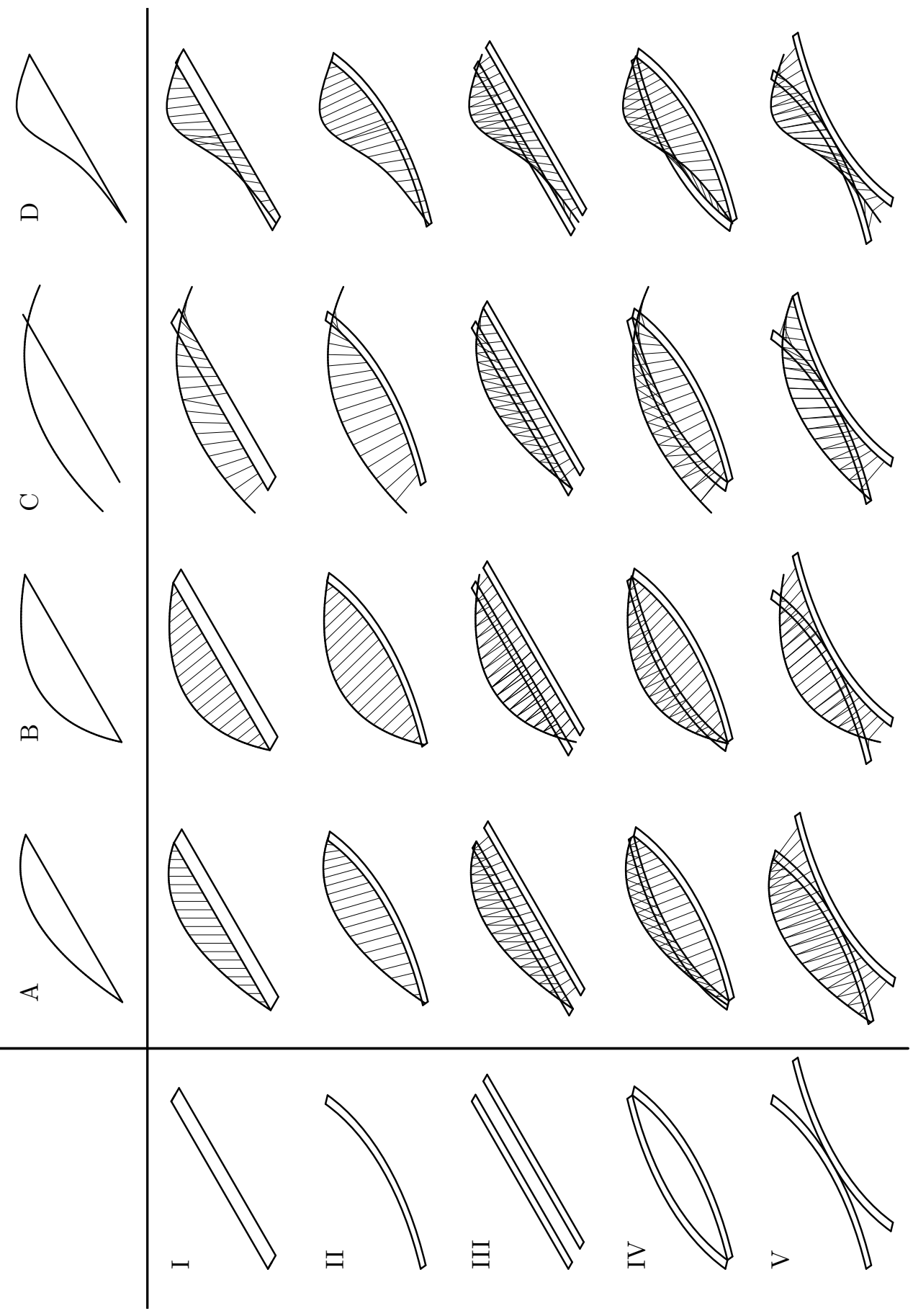

Figura 2.2: Obtención de puentes arco espaciales asimétricos por combinación de arcos y tableros

\subsection{Desarrollo del puente arco espacial}

Los arcos espaciales existen desde bastantes siglos atrás, y quizás haya que buscar sus orígenes en las bóvedas de iglesias y catedrales, donde quedan ocultos formando lo que aparenta ser una única unidad estructural. 
Usados como puentes, los primeros arcos espaciales considerados como tal podrían ser los arcos curvos y oblicuos ${ }^{3}$ de mampostería de las líneas de ferrocarril, pues es en estos puentes donde empieza a considerarse la vertiente espacial del arco, desprendiéndose de su consideración hasta el momento de estructura plana. Estos puentes surgen al mejorarse la talla de los sillares, y como respuesta a los requerimientos geométricos de las locomotoras, que hacían necesario evitar giros bruscos, no pudiéndose construir puentes que conectasen los dos puntos más cercanos, sino aquellos que permitiesen un trazado idóneo para la vía. Como dice José Serna García-Conde en [99], Ya no era el puente el que condicionaba al camino, sino el camino el que condicionaba al puente. Nacen así multitud de arcos oblicuos (véase por ejemplo la figura 2.3) como los de la primera línea de tren entre Liverpool y Manchester, y arcos de mampostería con planta curva como el Viaducto de Aix-en-Provence en la línea a Marsella, o el Viaducto de Cabanasse $^{4}$ en los Pirineos orientales (véase [99]).

Entre los puentes de mampostería de planta curva, quizá el más representativo de su clase sea el viaducto de ferrocarril de Landwasser. Este viaducto (véase la figura 2.4), proyectado por Friedrich C. S. von Hennings a principios del siglo XX, se compone de cinco arcos sucesivos dispuestos en una planta curva (véase Leonhardt [56]).

Los primeros puentes arco espaciales no construidos con mapostería se suelen atribuir a Robert Maillart en la década de los años 20 y 30, según Laffranchi y Marti en [54].

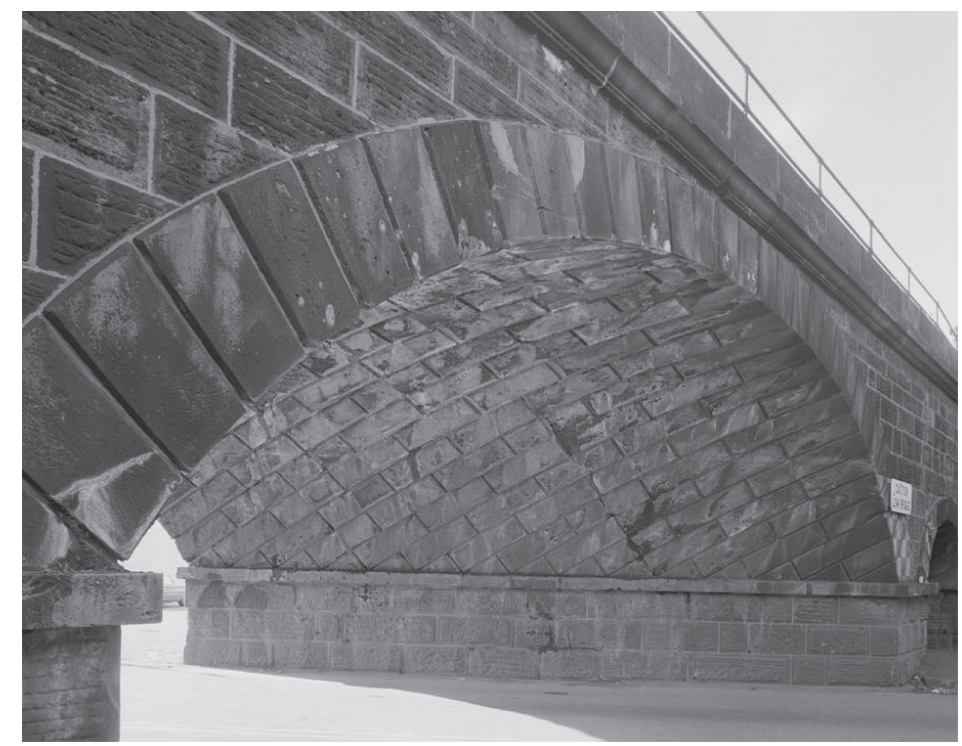

Figura 2.3: Arco oblicuo, Pensilvania, EEUU. En la fotografía se puede observar como las hiladas de sillares están inclinadas. Fotografía: William Edmund Barrett, loc.gov (Library of Congress).

\footnotetext{
${ }^{3}$ Los arcos oblicuos están sujetos a dos condicionantes: por un lado el constructivo, que implica que los sillares deben de ser iguales y situarse en hiladas horizontales, y por otro lado el estructural,pues el plano de la junta de los sillares debe mantenerse también perpendicular a la curva de presiones. Mientras que en un arco recto la línea de presiones es paralela al trazado y perpendicular a los estribos, en un arco oblicuo la línea de presiones se mantiene paralela al trazado pero no es perpendicular a los estribos.

${ }^{4} \mathrm{El}$ viaducto de Cabanasse es famoso porque es atravesado por el tren amarillo (en fránces "le train jaune"), o como se lo conoce popularmente, "el canario de los Pirineos".
} 


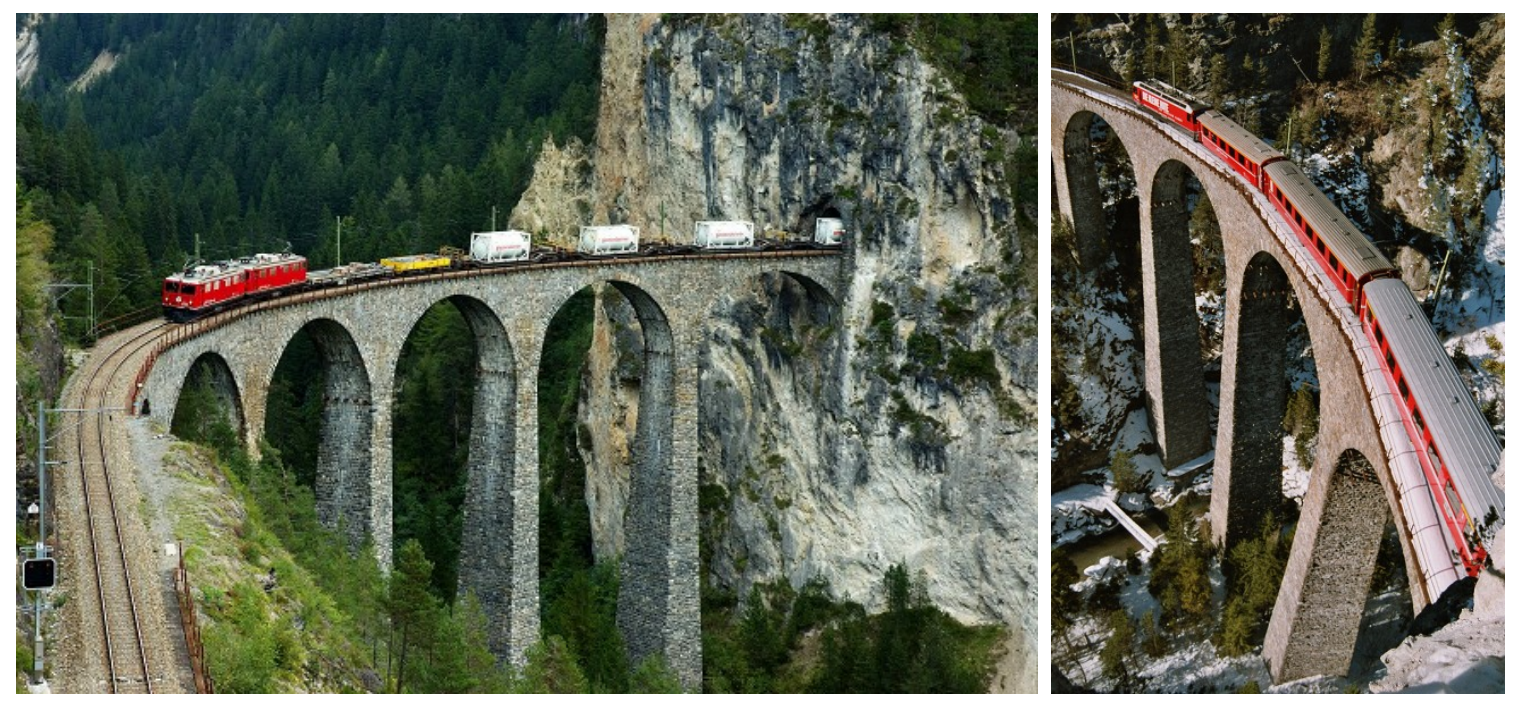

Figura 2.4: Viaducto de Landwasser. Fotografía: Ueli Meier (structurae.net).

Estos puentes son Ziggenbach (1924), Landquart $^{5}$ (1930), Bohlbach (1932) y Schwandbach (1933)(véase la figura 2.5). Estos puentes de Maillart, precursores de los arcos espaciales actuales, están compuestos por un arco único y un tablero de planta curva, siendo el arco en la mayoría de los casos de tipo laminar ${ }^{6}$. El arco es plano en los puentes de Ziggenbach y Landquart, mientras que es de planta curva para los puentes de Bohlbach y Schwandbach (véase Billington [18]).

Posteriores a los arcos de Maillart son los primeros arcos espaciales simétricos, siendo claros ejemplos los arcos gemelos arriostrados transversalmente o los arcos convergentes en clave (véase la figura 2.6), muy usados con la aparición de los nuevos sistemas de atirantamiento tipo Nielsen y Network. Estos tipos de atirantamiento dan como resultado arcos muy esbeltos que deben arriostrarse entre si para evitar el pandeo. El puente de Fehmarnsund (1963), situado en Alemania, está compuesto por dos arcos convergentes vinculados al tablero con péndolas tipo Network (véase la figura 2.6), es un claro ejemplo del desarrollo de los puentes arco espaciales simétricos de mediados del siglo XX.

Los puentes arco espaciales asimétricos, tal y como los conocemos hoy en día, han sido desarrollados e incorporados como solución sobre todo en los últimos 30 años. Mientras que en los puentes diseñados por Maillart la curvatura del tablero era una condición funcional impuesta por el trazado, en los nuevos puentes arco espaciales la asimetría es algo premeditado con lo que se pretende reforzar la estética del puente. Como apunta Marcos Pantaleón en [74], el renacimiento en el diseño y construcción de la tipología de puente arco en las últimas décadas se debe en gran parte a las numerosas posibilidades expresivas que reúne, sobre todo, en su vertiente de arco de tablero inferior. Así, el interés por los arcos espaciales surge con motivo de su singularidad estética y la libertad de sus formas.

\footnotetext{
${ }^{5}$ Este puente fue demolido en torno a 1993, con lo que en la actualidad solo se conservan los puentes de Ziggenbach, Bohlbach y Schwandbach.

${ }^{6}$ En el caso del puente de Schwandbach, el arco tiene un espesor de $20 \mathrm{~cm}$, que permite salvar una luz de $37.4 \mathrm{~m}$.
} 


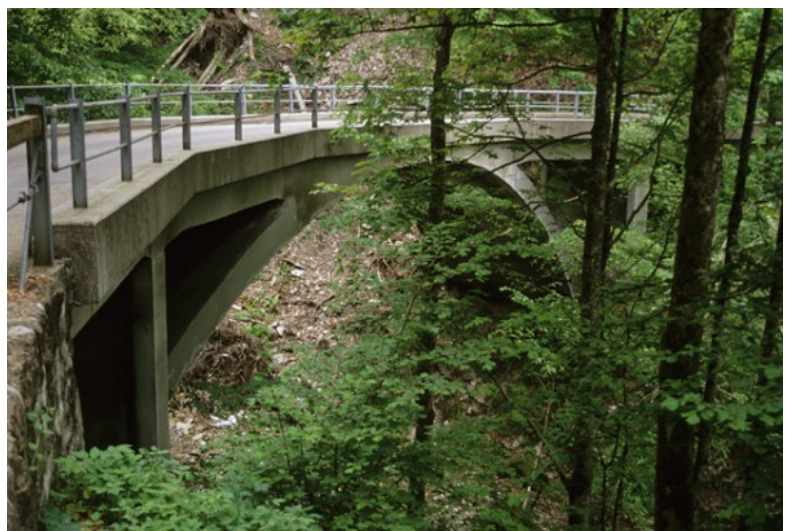

(a)

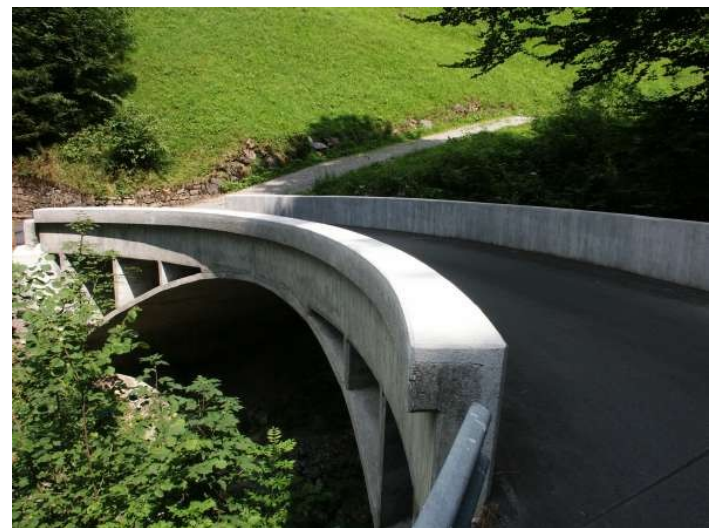

(b)

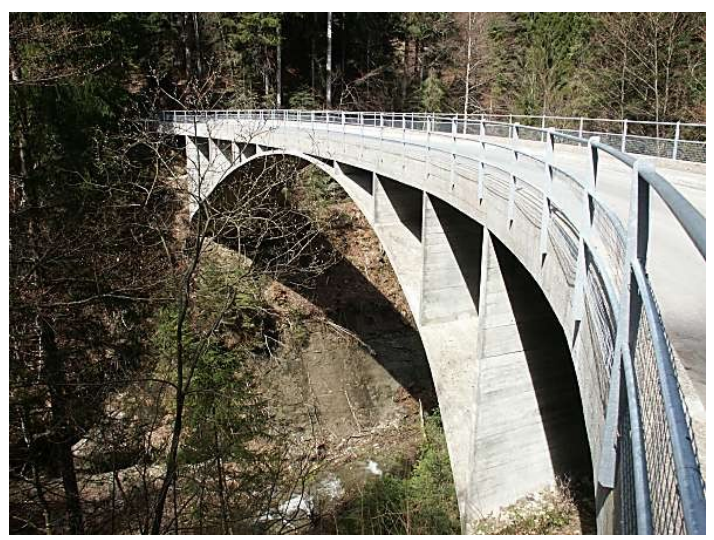

(c)

Figura 2.5: Puentes arco espaciales de Robert Maillart. (a) Puente de Ziggenbach. Fotografía: Yoshito Isono (structurae.net). (b) Puente de Bohlbach. Fotografía: Markus Widmer (structurae.net). (c) Puente de Schwandbach. Fotografía: Markus Widmer (structurae.net).

Los primeros puentes arco espaciales se caracterizan por ser obras únicas ${ }^{7}$ e inconexas, fruto del desconocimiento que se tiene todavía sobre estas estructuras. La mayoría de los arcos espaciales realizados en un principio son pasarelas, algo que obedece a las mayores libertades en el diseño, y a las menores cargas producidas por el tráfico peatonal frente al tráfico de vehículos. A pesar de lo expuesto anteriormente, cada vez más, y conforme el conocimiento de los arcos espaciales y de la técnica en general ${ }^{8}$ ha ido aumentando, se han ido incorporando a los puentes de carretera arcos espaciales. Otra de las características que comparten los primeros arcos espaciales, es la situación en entornos urbanos, algo que responde a un deseo de mejora del entorno en el que se va a situar la obra.

En lo referente a los materiales usados, dada la variabilidad en las formas de los arcos,

\footnotetext{
${ }^{7}$ Cualquier obra civil puede ser considerada única, dado que prácticamente ninguna puede ser producida en serie, pero en el caso de los arcos espaciales este carácter único hace referencia a algo nuevo y diferente de las realizaciones que se venían llevando a cabo en el contexto de la ingeniería estructural.

${ }^{8}$ La mejora de la técnica en general debe entenderse como el progresivo aumento e incorporación de las herramientas informáticas de cálculo de estructuras, así como la mejora de los materiales usados en la construcción de infraestructuras.
} 


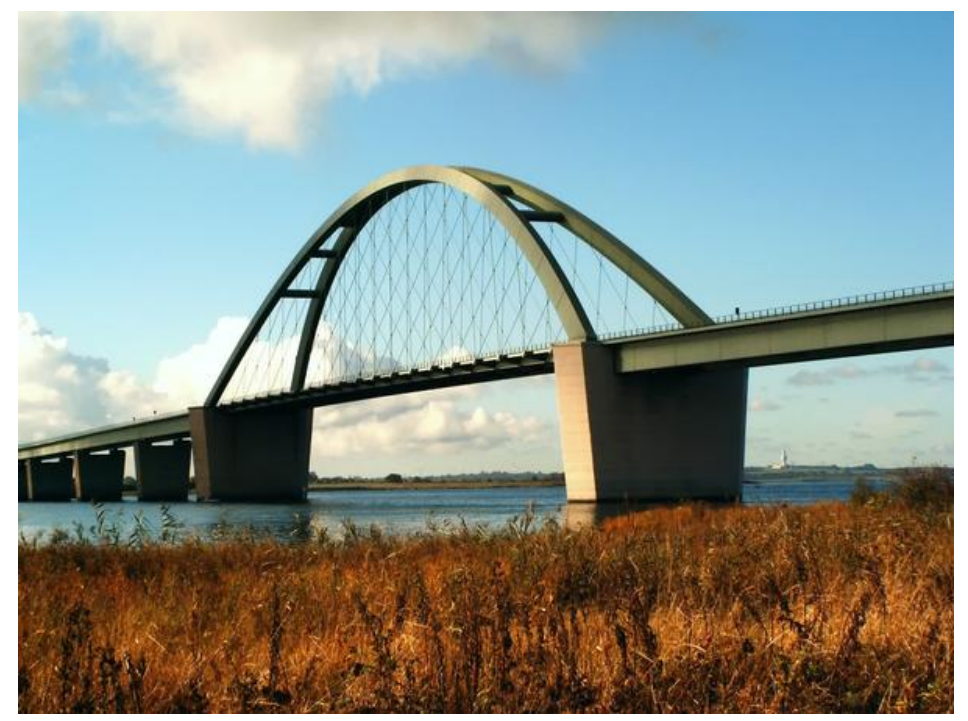

Figura 2.6: Puente de Fehmarnsund, Alemania. Fotografía: S. Möller (structurae.net).

la resistencia necesaria para soportar unos esfuerzos variables acusados, su facilidad de montaje y de manejo en taller, y el menor peso de sus secciones con respecto al hormigón, el acero es el material más usado desde los inicios y hasta la actualidad.

El desarrollo de la nueva tipología es dispar entre los distintos países. En España, por ejemplo, su desarrollo estuvo aupado por unos años de bonanza económica, junto con un plan de nuevas infraestructuras por parte del estado. La mayoría de los puentes arco espaciales responden a un afán de monumentalismo ${ }^{9}$ o creación de hitos que permitan identificar una ciudad o una determinada región. En el Reino Unido muchos arcos espaciales fueron desarrollados para festejar la llegada del nuevo milenio, acuñándose el término Millennium bridges.

El desarrollo de los arcos espaciales tiene sus orígenes en Europa, apareciendo las primeras obras en los últimos años de la década de los 80 y principios de los 90 . Un ejemplo claro es el llamado Pont Gentil propuesto por Santiago Calatrava sobre el río Sena en 1987 (véase Tzonis [118] y Jodidio [42]). Este puente compuesto por un arco inclinado vinculado al tablero con péndolas rígidas intenta asemejar el perfil de un ave volando, si bien no llegó a construirse (véase la figura 2.7). La idea de inclinar el arco en este puente es la que inspirará numerosos puentes posteriores, como el puente de Bac de Roda (Barcelona, 1987) o el de La Devesa (Ripoll, 1989) ambos obra también de Santiago Calatrava.

Otra de las ideas que surge casi al mismo tiempo que la de inclinar el arco, es la idea de bifurcarlo o dotarlo de cordones variables, siendo un claro ejemplo el puente de la Barqueta (Sevilla, 1992), diseñado por Juan José Arenas (véase la figura 2.8-a). A este le seguirían muchos otros como el puente del tercer milenio (Zaragoza, 2008), obra también de Juan José Arenas (véase la figura 2.8-b), o el más moderno puente "De Oversteek" (Nimega, Países Bajos, 2013), proyectado por el estudio Ney \& Partners.

\footnotetext{
${ }^{9}$ En España el más claro ejemplo de construcción destinada a marcar un hito que ponga una ciudad en el mapa es el Museo Guggenheim de Bilbao, al que seguirían con mayor o menor acierto otras construcciones de gran envergadura como la Ciudad de las Artes y las Ciencias de Valencia.
} 

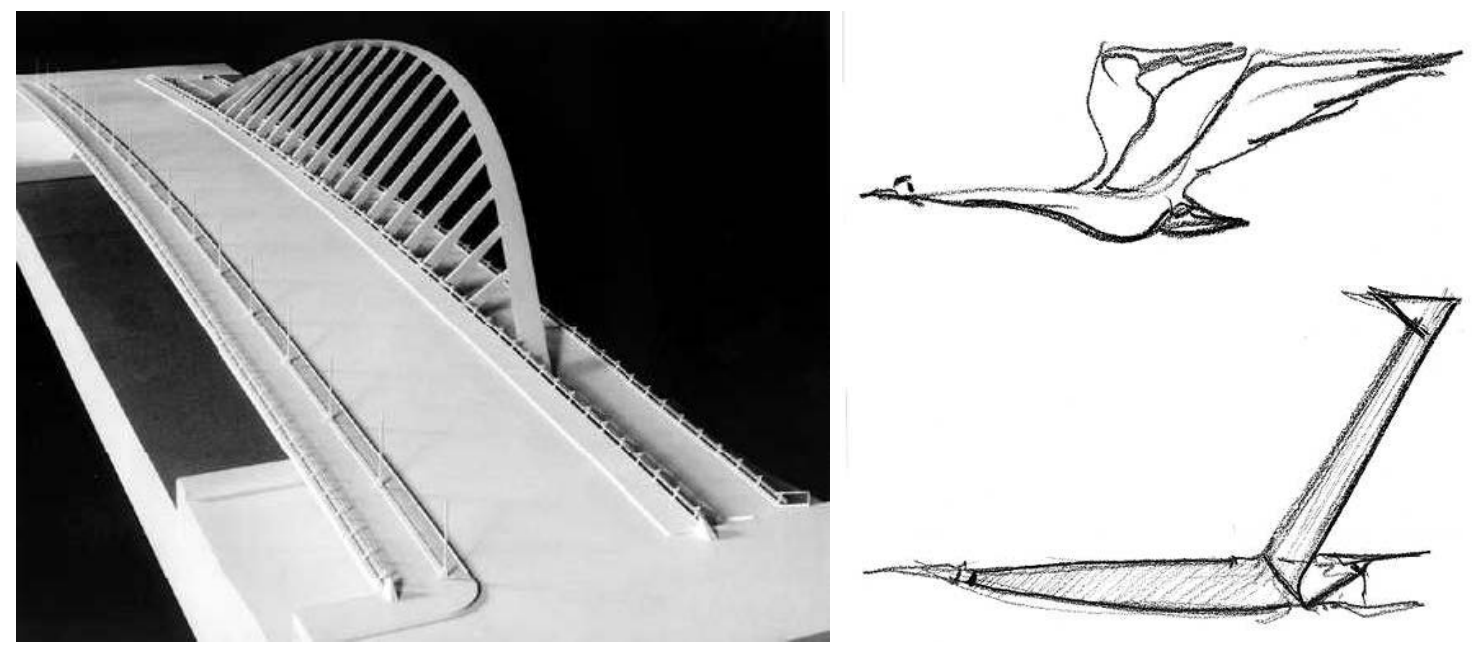

Figura 2.7: Pont Gentil, Paris, 1987. Fotografía: revista El Croquis [119].

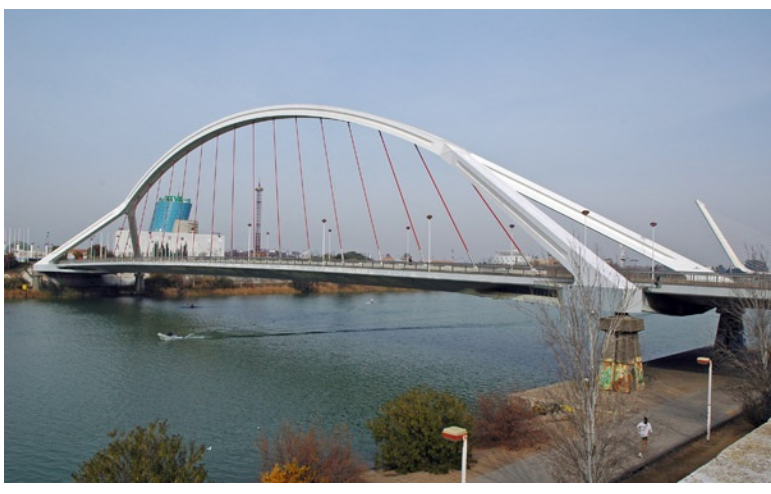

(a)

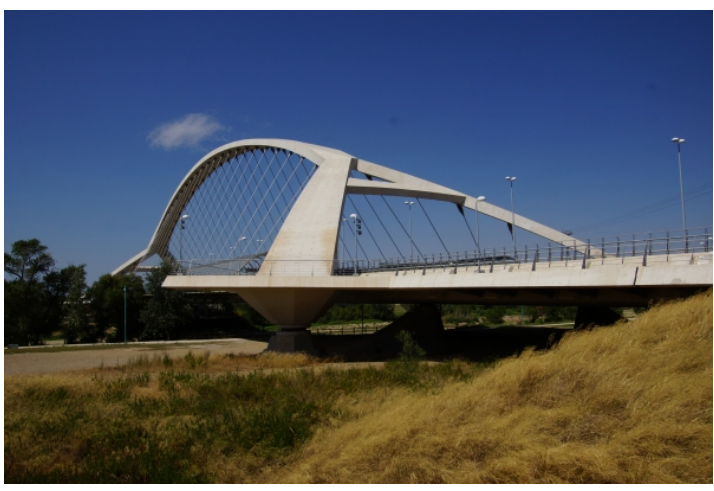

(b)

Figura 2.8: (a) Puente de la Barqueta. Fotografía: Adrien Mortini (structurae.net). (b) Puente del Tercer Milenio. Fotografía: Nicolas Janberg (structurae.net).

A mediados de los años noventa se empiezan a desarrollar arcos girados respecto a un eje vertical, lo que en la actualidad se conoce como arco diagonal (véase Jorquera Lucerga [46]). Aparecen así obras como el Arco de Hulme (Manchester, Reino Unido, 1997) o el puente Juscelino Kubitschek (Brasilia, Brasil, 2002). Un caso especial de arco diagonal es la pasarela del museo Miho (Shigaraki, Japón, 1997), donde el arco se gira 90º quedando el plano que contiene el arco perpendicular el eje del tablero (véase la figura 2.9-a). Todos los arcos diagonales anteriores tienen el tablero recto, apareciendo posteriormente los arcos diagonales de tablero curvo. Entre estos, una obra notable y de reciente construcción es el llamado Pont Citadelle (Estrasburgo, Francia, 2017) (véase la figura 2.9-b).

Contemporáneo a los arcos diagonales es también el puente del milenio de Gateshead (Newcastle, Reino Unido, 1998), construido para celebrar la llegada del nuevo milenio. Este puente (véase la figura 2.10) es el primer y único arco espacial móvil. Se trata de un arco con tablero curvo, el cual se sustenta mediante un juego de cables, haciendo que el arco se comporte como una viga balcón.

En la década de los 90, concretamente en el año 1998, se construye el puente de Ripshorst 


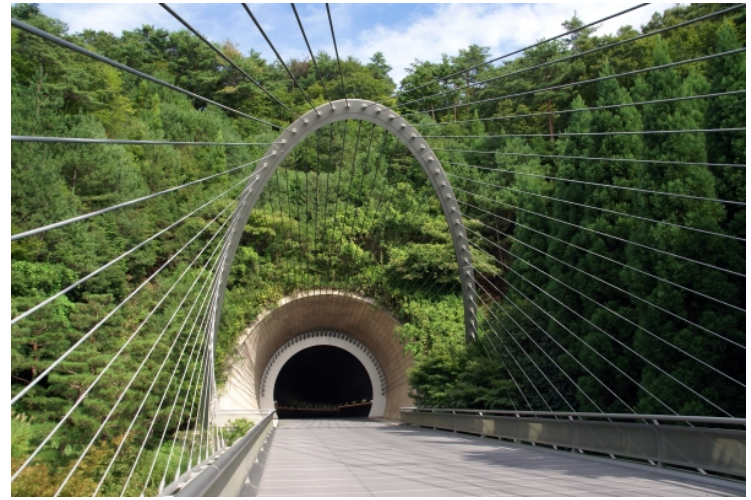

(a)

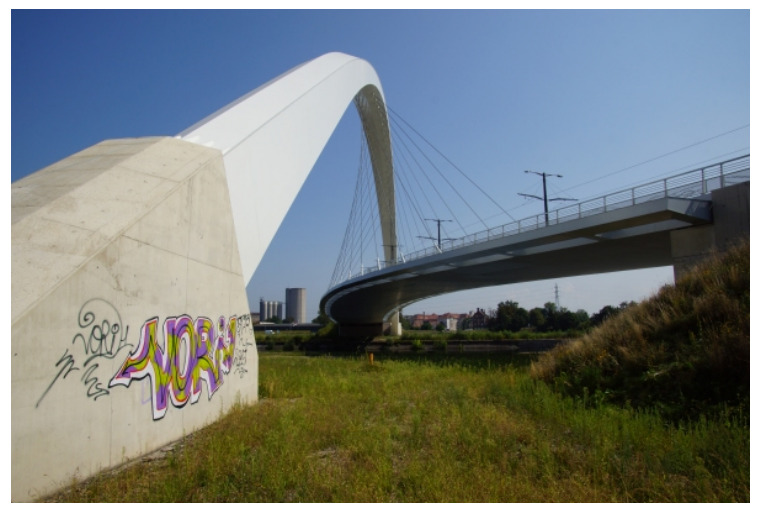

(b)

Figura 2.9: (a) Pasarela del museo Miho. Fotografía: 663highland (structurae.net). (b) Pont Citadelle. Fotografía: Nicolas Janberg (structurae.net).

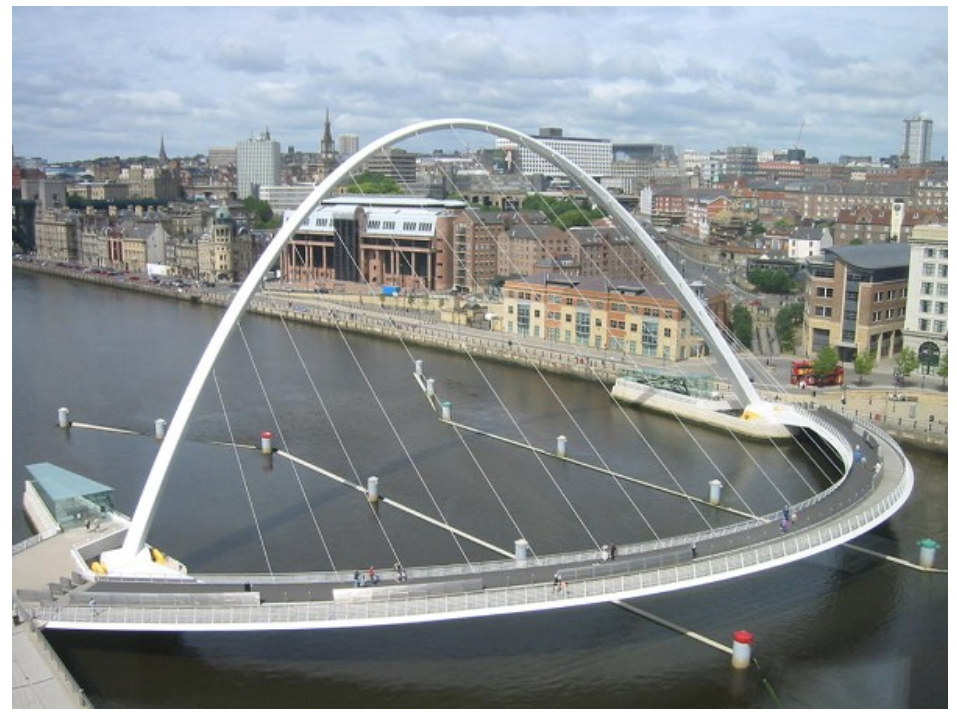

Figura 2.10: Puente del Milenio de Gateshead. Fotografía: John Welch (structurae.net).

(Oberhausen, Alemania) por parte de la oficina Schlaich, Bergermann und Partner. Este puente (véase la figura 2.11)supone un hito, al tratarse de un arco espacial de doble curvatura, en concreto se trata del primer arco antifunicular espacial. Si se compara este puente con la pasarela de Kelheim (Kelheim, Alemania, 1988), también del estudio Schlaich, Bergermann und Partner, se puede observar como Ripshorst se puede obtener si se da la vuelta a Kelheim y se cambian los cables traccionados por barras comprimidas. Así, se podría decir que Ripshorst es el puente especular de Kelheim.

No sería hasta el año 2007 cuando aparecería el puente de Galindo, el primer puente arco espacial de curvatura impuesta y tablero inferior. Es Javier Manterola Armisén quien proyecta este puente arco sobre el río Galindo (Bilbao, España, 2007). Esta obra (véase la figura 2.12-a) nace como respuesta a unos restrictivos condicionantes geométricos y constructivos, como son el trazado curvo del tablero y el hecho de no poder colocar pilas en el cauce. En 2009 sería también Javier Manterola quien diseñase el puente de 


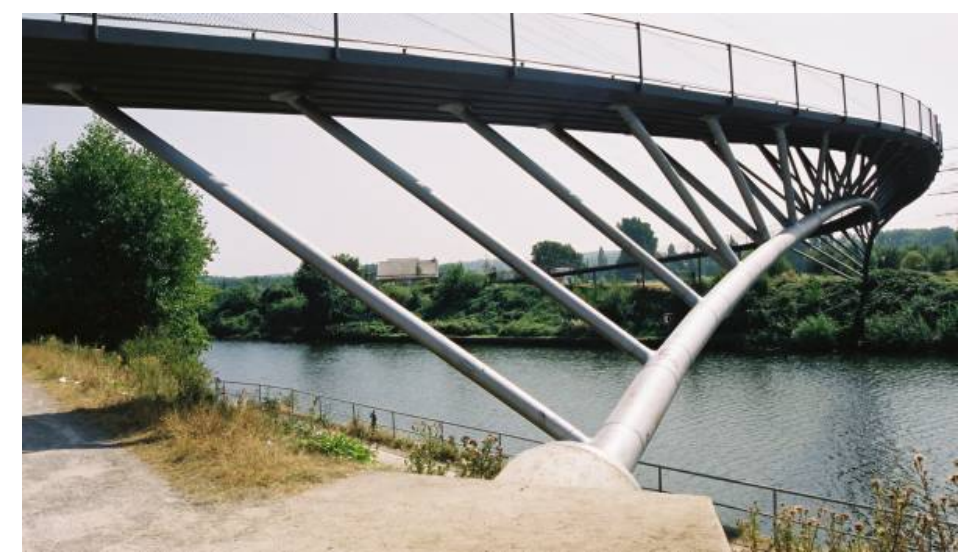

Figura 2.11: Pasarela de Ripshorst. Fotografía: Nicolas Janberg (structurae.net).

Endarlatsa (Navarra-Guipúzcoa, España, 2009), el primer arco espacial de tablero superior y curvatura impuesta (véase la figura 2.12-b) realizado desde que Robert Maillart ejecutase los primeros en los años 20 y 30 del siglo pasado.

La mayoría de los puentes que se han reseñado en este apartado (salvo los puentes arco con bifurcaciones o de cordones variables, y los arcos diagonales girados $90^{\circ}$ ) pertenecen a la categoría de arcos espaciales asimétricos. Esto no quiere decir que todos los desarrollos hasta la fecha sean asimétricos, pues existen numerosas realizaciones simétricas, entre ellas puentes arco convergentes y divergentes, y puentes compuestos por varios tableros. Dentro de estos últimos cabe destacar en España por ejemplo la pasarela Miguel Navarro Molina (Lorca, España, 2002) y el puente arco sobre el río Vinalopó (Elche, España, 2015), ambas obras de Javier Manterola Armisén (véase la figura 2.13).

Por supuesto, la evolución del puente arco espacial que en este apartado se ha expuesto, es una visión general de los logros que a día de hoy se han conseguido. El número de obras es mayor del aquí expuesto. Por otro lado, el número de realizaciones que aún están por explorar es numeroso, con un vistazo de las figuras 2.1 y 2.2 el lector se puede hacer una idea de las posibilidades formales y estructurales que permiten los puentes arco espaciales.

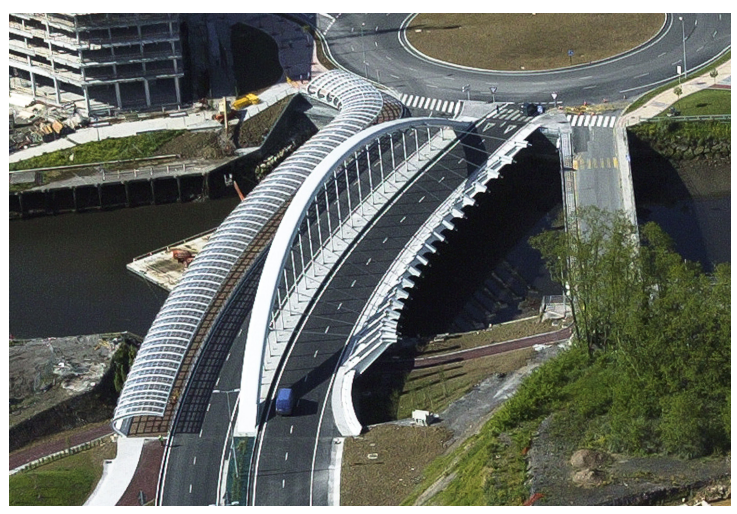

(a)

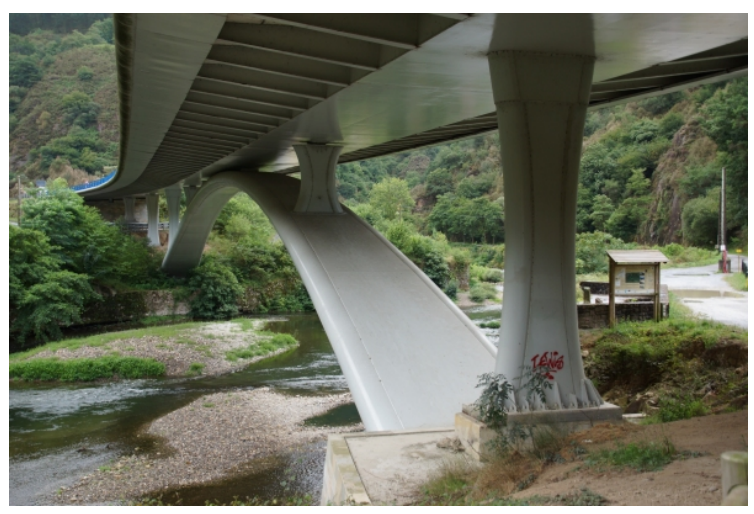

(b)

Figura 2.12: (a) Puente de Galindo. Fotografía: Javier Manterola (cfcsl.com). (b) Puente de Endarlatsa. Fotografía: Nicolas Janberg (structurae.net). 


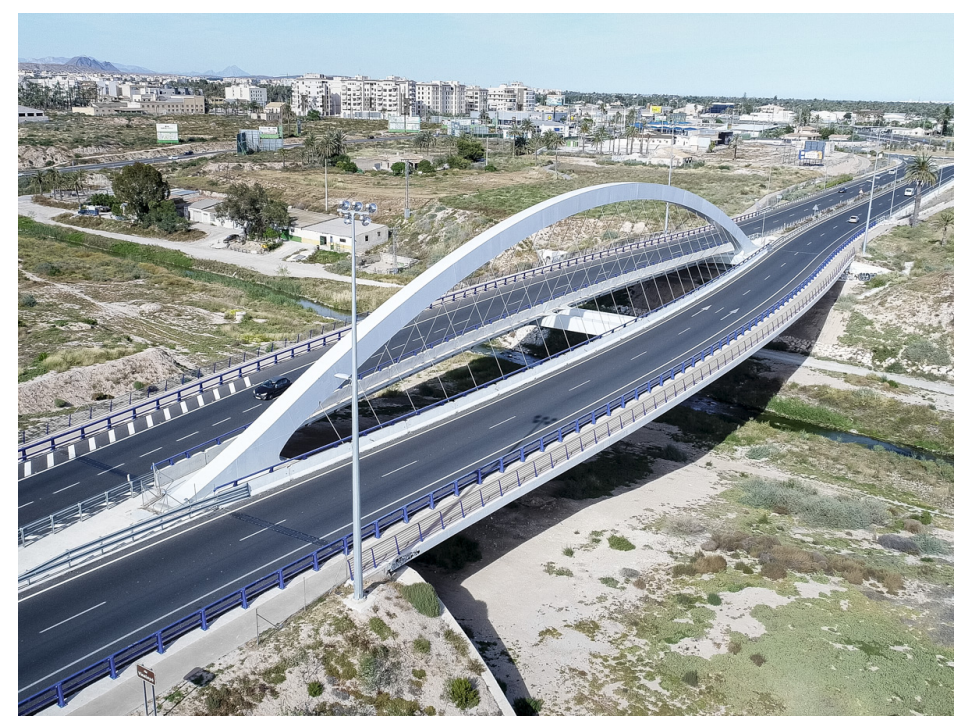

Figura 2.13: Puente sobre el río Vinalopó. Fotografía: Javier Manterola (cfcsl.com).

\subsection{Realizaciones con asimetría longitudinal}

En este punto se pretenden mostrar puentes arco espaciales con asimetría longitudinal, construidos y no construidos hasta la fecha. No se pretenden recoger todas las creaciones existentes, sino aquellas que por sus características resultan más significativas o ejemplificadoras.

\subsubsection{Arco vertical excéntrico}

\subsubsection{Puente de Ondarroa}

El puente de Ondarroa ${ }^{10}$, finalizado en 1995, supone la primera obra de Santiago Calatrava en el País Vasco (España). El puente es una de las imágenes más conocidas de la localidad de Ondarroa, situada en la desembocadura del río Artibai ${ }^{11}$, provincia de Vizcaya.

Como expone Jodidio en [42], el puente tiene una luz de $71.5 \mathrm{~m}$, con un ancho variable del tablero que va desde los $20.9 \mathrm{~m}$ en estribos, hasta los $23.7 \mathrm{~m}$ en el centro del tablero. Esto se debe a que el tablero se compone de una calzada recta de $11 \mathrm{~m}$ de ancho constante destinada a tráfico de vehículos ${ }^{12}$, y una calzada curva destinada exclusivamente a peatones (véase la figura 2.14). Al ser una zona de tablero recta y la otra curva, se crea un espacio entre ambas, que es máximo en el centro del tablero. Este espacio deja ver las costillas de acero inclinadas que sustentan el tablero curvo, las cuales están situadas en posición radial. Las costillas de acero se ven reforzadas por péndolas rígidas inclinadas cada $2.86 \mathrm{~m}$, y por cables dobles verticales que se anclan a la zona del tablero destinada a vehículos.

\footnotetext{
${ }^{10}$ También se suele llamar puente de Calatrava o puente de Itsasaurre.

${ }^{11}$ En la bibliografía se puede encontrar escrito también como Artibay.

${ }^{12}$ En el borde de la calzada recta destinada a los vehículos existe una acera, aunque con un ancho algo inferior a la zona curva de tablero destinada exclusivamente a peatones.
} 


\subsection{REALIZACIONES CON ASIMETRÍA LONGITUDINAL}
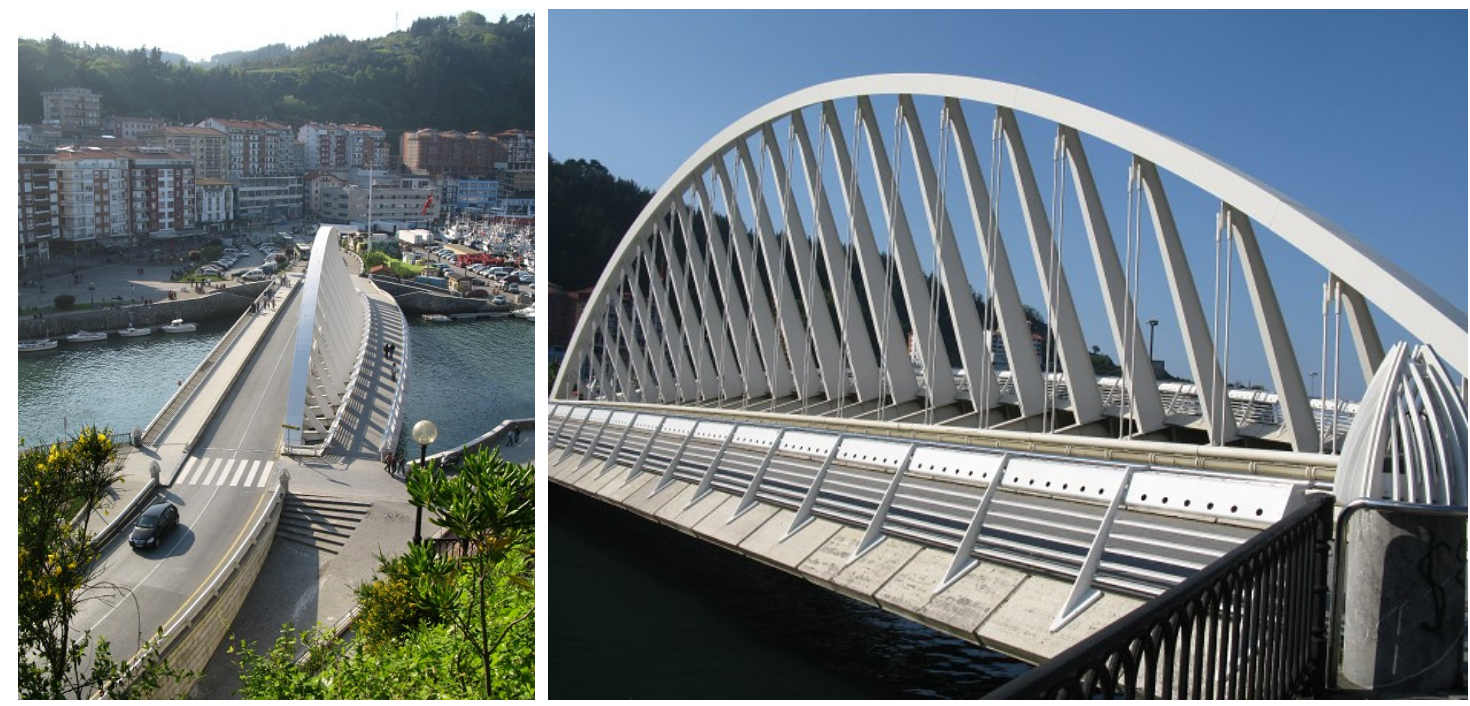

Figura 2.14: Puente del puerto de Ondarroa. Fotografía: Herrad Elisabeth Taubenheim (structurae.net).

\subsubsection{Destructor Bridge}

El Destructor ${ }^{13}$ Bridge, situado en la ciudad de Bath (Reino Unido) sustituye a otro puente homónimo que se encontraba en el mismo lugar. El puente (véase la figura 2.15) sirve para conectar el núcleo de la ciudad de Bath con la otra orilla, una zona que está experimentando un desarrollo urbano en los últimos años. El puente es obra de los estudios COWI y Knights Architects, y fue terminado en otoño del año 2012 (véase [84]).

El tablero es recto y tiene una luz de $45 \mathrm{~m}$, estando su sección dividida en tres zonas según el tipo de tráfico. La calzada central está destinada a vehículos y tiene un ancho de $6.7 \mathrm{~m}$. Esta zona central está flanqueada por dos zonas peatonales de $4 \mathrm{~m}$ (borde oeste) y $2.5 \mathrm{~m}$ (borde este). Debajo de cada borde de la sección destinada a tráfico rodado se dispone un cajón de acero, sustentándose la calzada central por medio de vigas que unen los dos cajones. La sección cajón que sustenta la zona peatonal de $4 \mathrm{~m}$ es más grande que la opuesta, y a su vez la capacidad se ve aumentada al colocar el arco sobre esta zona.

$\mathrm{El}$ arco $^{14}$ tiene una sección muy esbelta, tanto que podría considerarse laminar, y se encuentra vinculado al tablero mediante péndolas rígidas de ancho igual al del arco. La rigidez de estas péndolas se puede considerar solo en el plano transversal al eje de tablero, pues en sentido longitudinal su espesor en tan pequeño que se puede obviar su rigidez a flexión. Cabe destacar un detalle bastante ingenioso, que radica en la colocación de bancos para los transeúntes en el espacio que queda entre las péndolas rígidas.

\footnotetext{
${ }^{13} \mathrm{El}$ nombre "Destructor" hace referencia al nombre con el que se apodó el primer puente existente, pues en las inmediaciones había una incineradora.

${ }^{14}$ En los últimos años los arranques del arco han sido protegidos por vallas para evitar que los transeúntes trepen por él.
} 

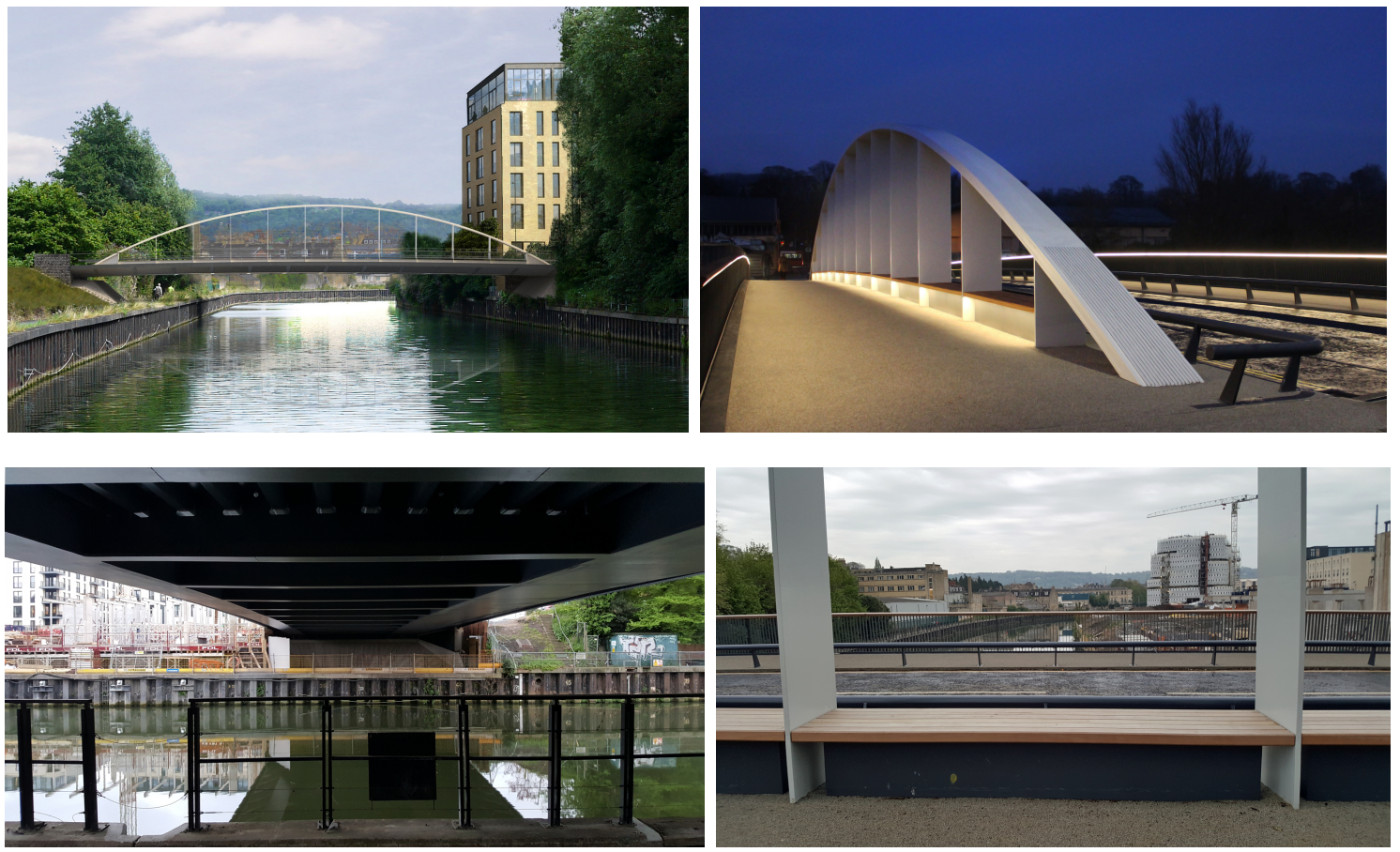

Figura 2.15: Destructor Bridge. Fotografía: Knight Architects y The Happy Pontist.

\subsubsection{Arco inclinado excéntrico con tablero recto}

\subsubsection{Pont Gentil (propuesta no construida)}

Sobre el río Sena estaba pensado este puente obra de Santiago Calatrava. La propuesta (véanse Jodidio [42] y El Croquis [119]) es de 1987 y no llego a ser construida. El puente (véanse las figuras 2.7 y 2.16) se caracteriza por un arco inclinado excéntrico que tiene una altura de 29.9 y una luz de $185.9 \mathrm{~m}$. El tablero es recto y tiene una luz total de 185.9 m. Probablemente es el primer puente en el que se inclina el arco deliberadamente, y el cual ha servido de inspiración a numerosas obras posteriores.
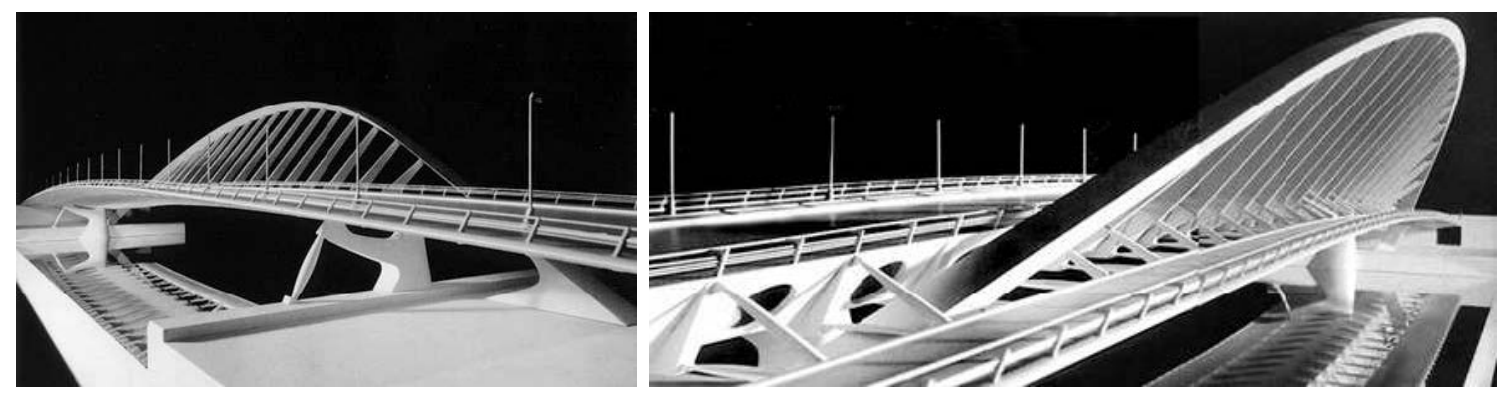

Figura 2.16: Propuesta para el Pont Gentil sobre el río Sena. Fotografía: revista El Croquis. 


\subsubsection{Puente de Europa}

El puente de Europa ${ }^{15}$ sobre el río Loira fue concluido en el año 2000 (véase la figura 2.17). El proyecto, obra de Santiago Calatrava ${ }^{16}$, une las poblaciones limítrofes a Orleans (Francia) de Saint-Jean de la Ruelle y Saint-Pryvé Saint-Mesmin, situadas al norte y al sur respectivamente (véase [83]).

El tablero es metálico, tiene un ancho de $25.74 \mathrm{~m}$, y una longitud de $378 \mathrm{~m}$, dividiéndose en tres tramos de $88.2 \mathrm{~m}, 201.6 \mathrm{~m}$ y $88.2 \mathrm{~m}$. El tramo central de tablero está sustentado por un arco inclinado y excéntrico, que divide longitudinalmente el tablero en una zona destinada a vehículos, y otra para peatones. El arco se vincula al tablero mediante una serie doble de 28 péndolas. A su vez el arco se apoya en unas pilas inclinadas de hormigón. Al tramo anterior de tablero metálico se añaden además dos secciones de tablero de hormigón pretensado en los estribos, que dotan al puente de una longitud total de $470.6 \mathrm{~m}$.
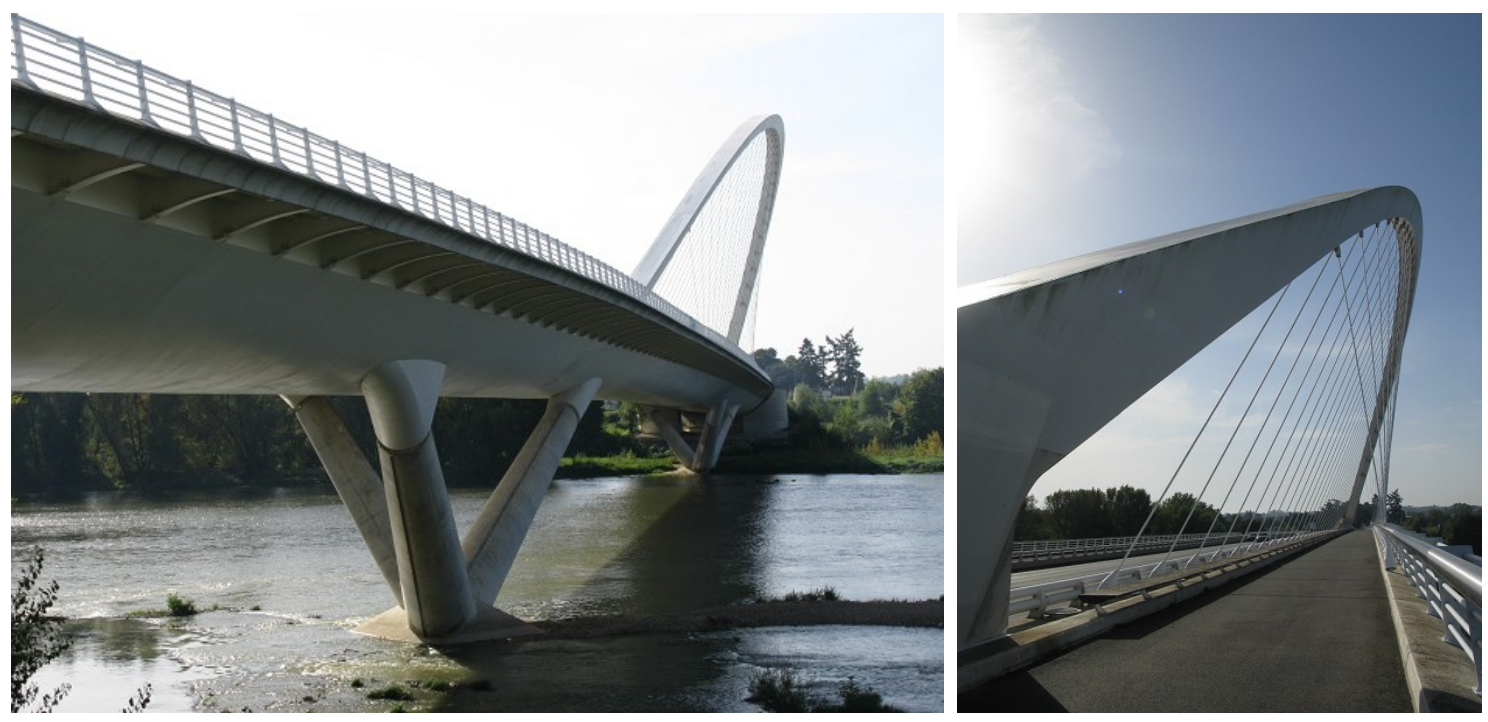

Figura 2.17: Puente de Europa (Orleans). Fotografía: Herrad Elisabeth Taubenheim (structurae.net).

\subsubsection{Pasarela de La Devesa}

Esta pasarela cruza el río Ter en la ciudad de Ripoll (España), conectando la estación del tren con una área residencial en la otra orilla. La pasarela (véase la figura 2.18) es obra de Santiago Calatrava y fue finalizada en 2001.

La pasarela tiene una luz de $64.9 \mathrm{~m}$, siendo el vano principal de $43.9 \mathrm{~m}$. El tablero es metálico y se compone de una barra de torsión de sección circular en uno de los bordes, a la que se anclan una serie de costillas transversales. El vano principal está sustentado por un arco inclinado $25^{\circ}$ con respecto a la vertical, el cual se ata al tablero mediante péndolas rígidas de sección doble $\mathrm{T}$ variable. Una descripción exhaustiva se puede encontrar en Calatrava [22], Jodidio [42], Baus y Schlaich [14] y Tzonis [118].

\footnotetext{
${ }^{15}$ También se le suele llamar puente de Orleans, al estar muy cerca de dicha ciudad.

${ }^{16}$ Según Santiago Calatrava, el puente está inspirado en el antiguo puente de la ciudad de Jorge V.
} 
En esta estructura, todas las cargas verticales que actúan sobre el tablero producen una torsión sobre el mismo. Según palabras de Calatrava, en esta obra pretende explotar el fenómeno de la torsión. Referencias imprescindibles que describen su mecanismo resistente son Jorquera Lucerga y Manterola [45] y Greenwold [36].

\subsubsection{Puente de la Alameda}

Obra de Santiago de Calatrava, el puente de la Alameda ${ }^{17}$ conecta las dos orillas del cauce seco del río Turia ${ }^{18}$ a su paso por la ciudad de Valencia (España).

El puente se finalizó en el año 1995, y se caracteriza por un arco inclinado $30^{\circ}$ con respecto a la vertical que tiene una altura de $14 \mathrm{~m}$ sobre el tablero. Por su parte, el tablero tiene un ancho de $26 \mathrm{~m}$ y una luz de $130 \mathrm{~m}$ (véanse Jodidio [42] y Tzonis [118]).

El puente se sitúa justo encima y paralelo a una estación del metro que también proyectó Calatrava. El arco y el tablero se encuentran vinculados mediante péndolas rígidas en ambas direcciones (véase la figura 2.19), al contrario de lo que pasaba en el puente de La Devesa, donde las péndola rígidas tiene mayor rigidez en el plano transversal al tablero.
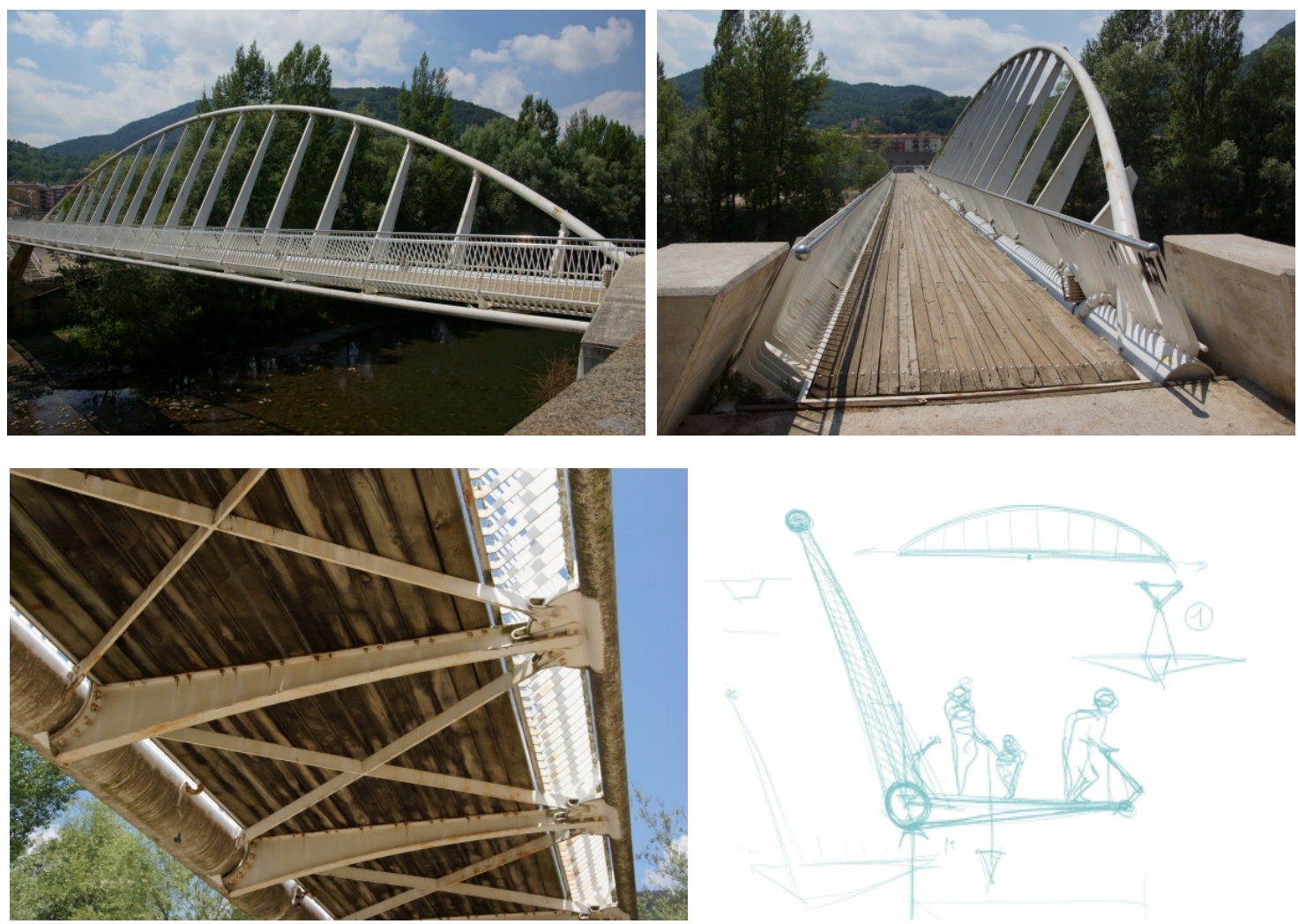

Figura 2.18: Pasarela de La Devesa. Fotografía: Nicolas Janberg (structurae.net) y Santiago Calatrava.

\footnotetext{
${ }^{17}$ También se le suele llamar puente de "la Peineta", puente de la exposición o puente de Calatrava.

${ }^{18}$ En realidad lo que cruza es el Jardín del Turia, un parque urbano de 110 hetáreas que discure unos $7 \mathrm{~km}$ por el antiguo cauce del río Turia en la ciudad de Valencia.
} 

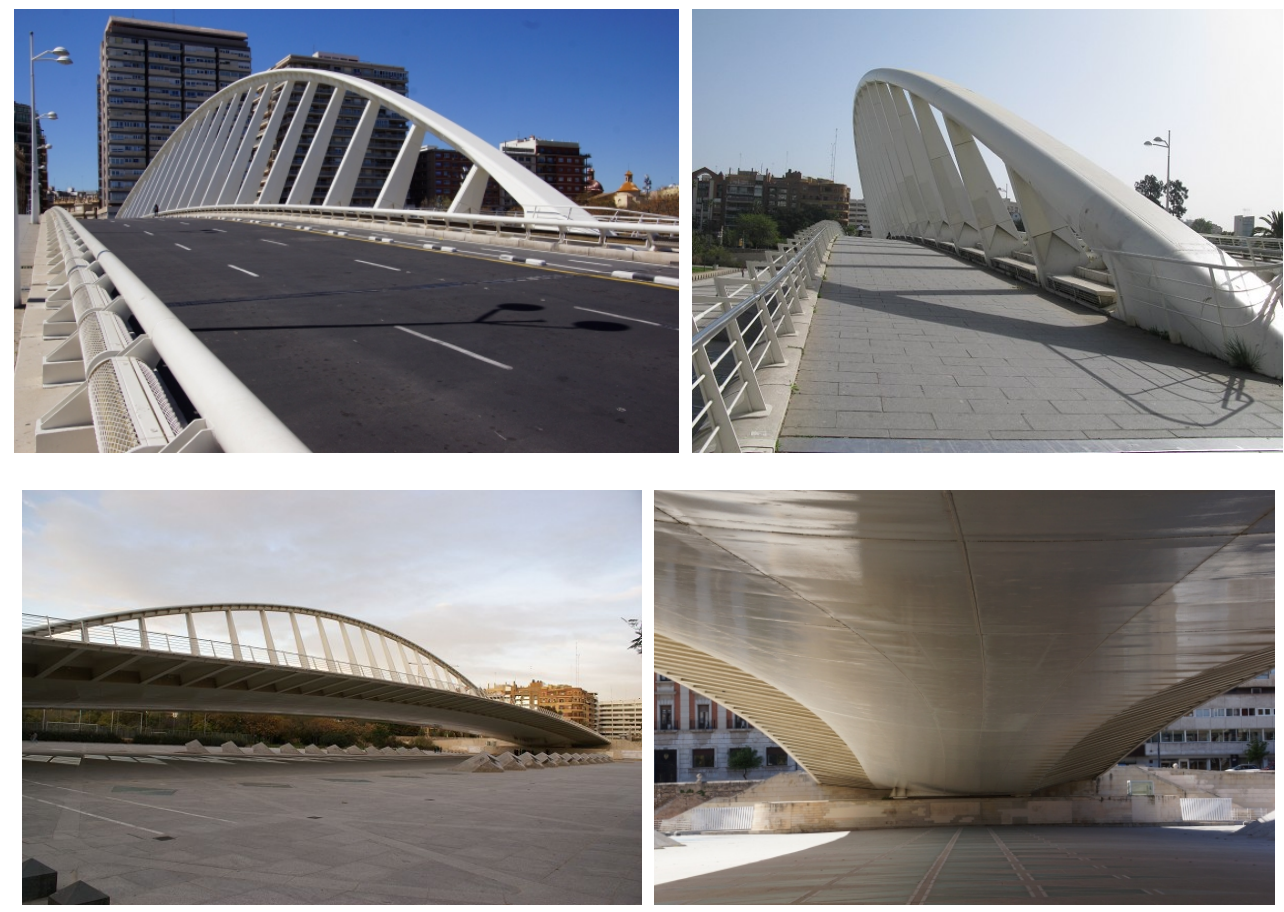

Figura 2.19: Puente de la Alameda. Fotografía: Nicolas Janberg y Herrad Elisabeth Taubenheim (structurae.net).

\subsubsection{York Millennium Footbridge}

El York Millennium Footbridge (véase la figura 2.20) fue construido para conmemorar la llegada del año 2000 en la ciudad de York (Reino Unido). La pasarela (véase Mairs [57]), que cruza el río Ouse en York (Reino Unido), es proyecto del estudio Whitbybird ${ }^{19}$, finalizándose su construcción en el año 2001.

El tablero de la pasarela tiene una longitud total de $150 \mathrm{~m}$ con un vano central de 80 $\mathrm{m}$, así como un ancho de $4 \mathrm{~m}$. La sección de tablero es trapezoidal y está dispuesta para resistir la torsión que se produce al colgar el tablero de un solo borde. El vano central queda sustentado por un arco inclinado que forma $50^{\circ}$ con la horizontal. El arco es muy esbelto, pues tiene una sección de acero hueca de 0.6 x $0.2 \mathrm{~m}$. Las péndolas que vinculan el arco y el tablero tienen un diámetro de $19 \mathrm{~mm}$, y tanto estas como el arco son de acero inoxidable.

\footnotetext{
${ }^{19}$ En la actualidad este estudio se ha integrado en Ramboll UK.
} 

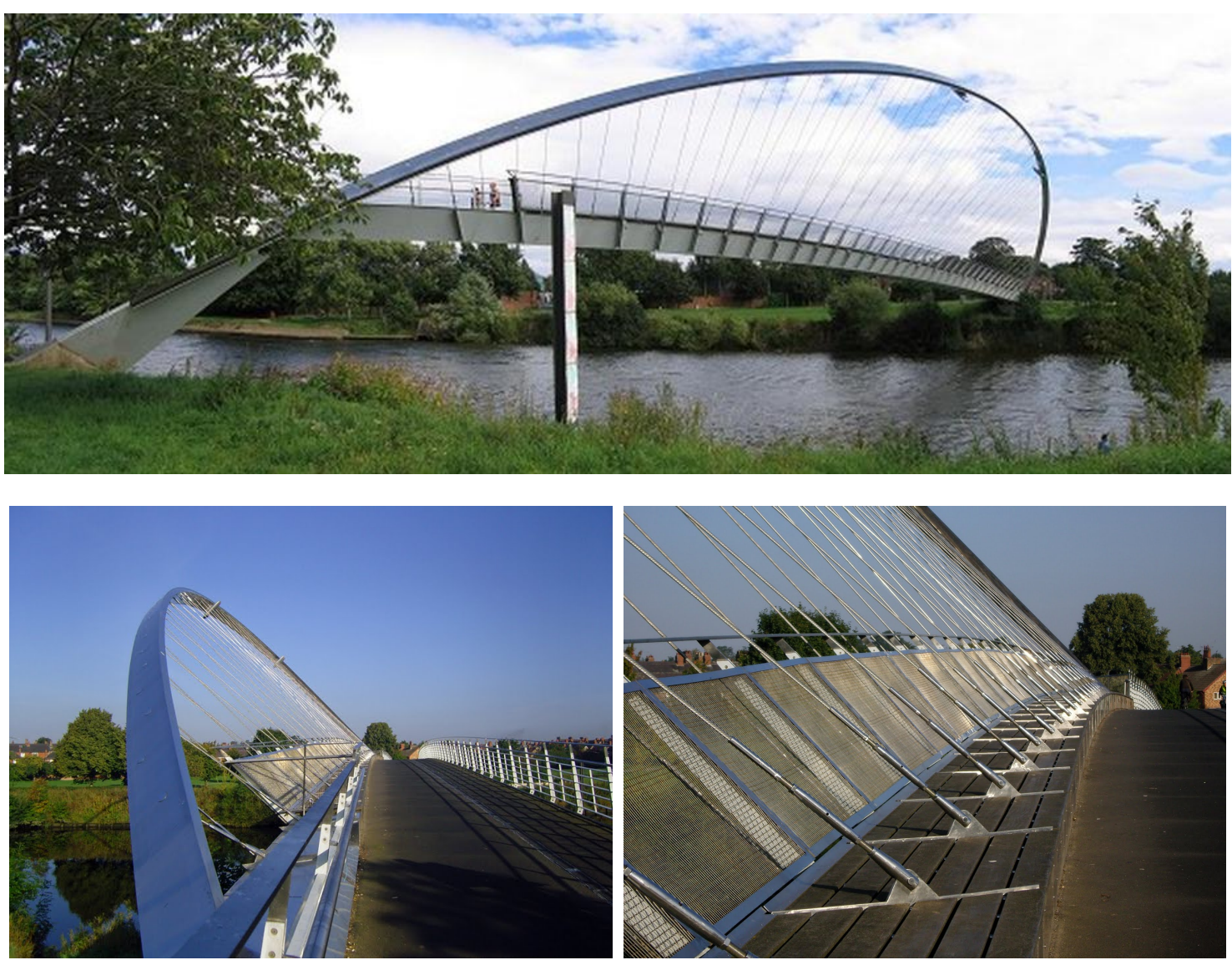

Figura 2.20: York Millennium Footbridge. Fotografía: Klaus Föhl (structurae.net) y The Happy Pontist.

\subsubsection{Cittadella Bridge}

Situado en la ciudad italiana de Alessandría, el proyecto es obra de Richard Meier (arquitectura) y Ove Arup \& Partners. Las obras del puente finalizaron en el año 2016, sustituyendo este puente al original, que databa de la época napoleónica. Las inundaciones del año 1994 en la ciudad de Alessandría hicieron que el puente original, que tenía pilas en el cauce, quedara taponado formándose una presa, por lo que se tomó la decisión de sustituir el antiguo puente por otro que no tuviera pilas en el río (véase [82]).

El nuevo puente (véase la figura 2.21) tiene una longitud de $185 \mathrm{~m}$, con un tablero peatonal y otro destinado a tráfico rodado, los cuales están unidos por costillas de acero que quedan visibles debido al espacio intermedio entre ambos. En este espacio intermedio se alza un arco tipo bow-string que se halla inclinado hacia el tablero peatonal, alcanzando una altura de $32.5 \mathrm{~m}$. Según palabras de Richard Meier, la inclinación del arco junto con el peso del tablero destinado a peatones permitiría mantener el equilibrio de la estructura. 

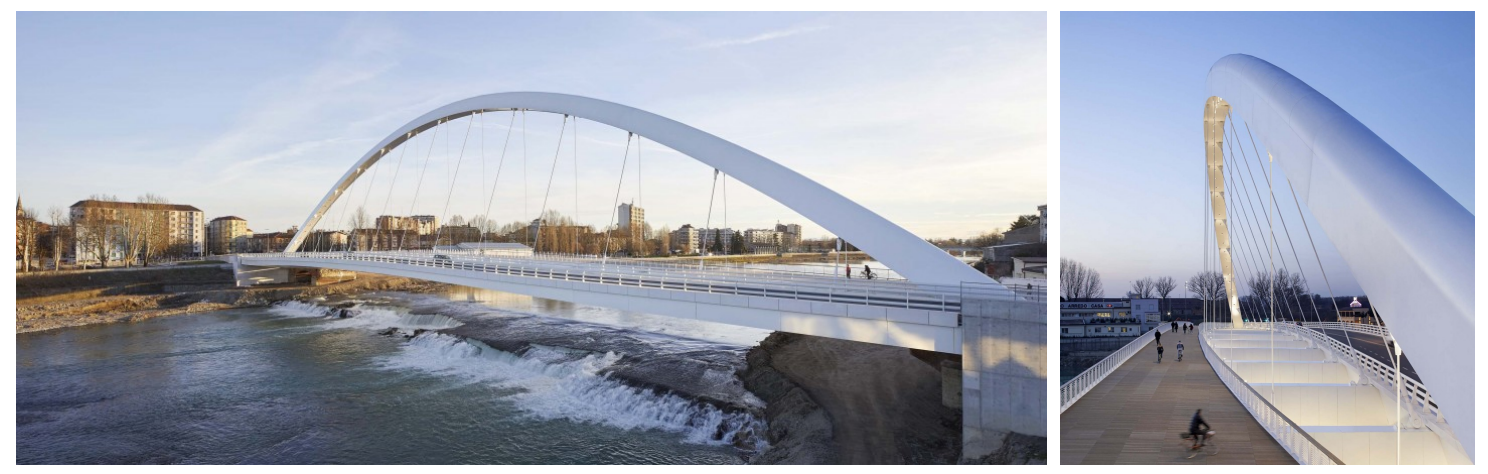

Figura 2.21: Cittadella Bridge. Fotografía: Richard Meier.

\subsubsection{Puente sobre el río Vltava}

La pasarela (véase la figura 2.22), finalizada en 2006, es obra de Jiri Strasky. Se encuentra situada en Ceske Budejovice (República Checa) y cruza el río Vltava ${ }^{20}$.

El puente dispone de un tablero mixto con una luz de $53.20 \mathrm{~m}$ y un ancho de $4.3 \mathrm{~m}$ (véanse [122] y [124]). El tablero está sujeto a un solo borde por un arco metálico inclinado con una altura máxima de $7.33 \mathrm{~m}$. La vinculación entre arco y tablero se lleva a cabo mediante péndolas rígidas. La sección del tablero está formada por dos tubos situados en ambos bordes y conectados entre sí por una celosía triangular. La losa de hormigón junto con la sección metálica antes descrita permiten al tablero resistir esfuerzos torsores debidos a cargas excéntricas. Para aumentar la rigidez del puente y eliminar roturas, la losa del tablero fue ejecutada con hormigón de alta resistencia (C55/67). En concreto, la resistencia a compresión del hormigón del tablero era de $87.6 \mathrm{MPa}$ a los 28 días.

\subsubsection{Main Street Bridge (Columbus, EEUU)}

Situado sobre el río Scioto en la ciudad de Columbus (EEUU), el Main Street Bridge, finalizado en el año 2009, es el primer arco inclinado construido en los EEUU (véase la figura 2.23). El proyecto es de Spiro N. Pollalis, profesor de diseño de puentes en la Universidad de Harvard. El puente tiene una gran similitud con el puente de Ondarroa, salvo porque en este caso el arco está inclinado, mientras que en el puente de Ondarroa son las péndolas las que están inclinadas.

El puente tiene una longitud de $215 \mathrm{~m}$, estando el tablero divido en una zona para peatones y otra para tráfico rodado (véanse Hague y Hutton [37] y Pollalis [86]). El arco, inclinado $10^{\circ}$, se encuentra entre ambas zonas del tablero. La vinculación entre el arco y el tablero se lleva a cabo mendiante péndolas rígidas y cables dobles.

\subsubsection{Riverside Bridge}

Esta pasarela (véase la figura 2.24), creada por el estudio Ramboll Whitbybird, fue finalizada en 2008 en Cambridge (Reino Unido). La pasarela tiene un esquema resistente que

\footnotetext{
${ }^{20}$ El río también es conocido como Moldava.
} 

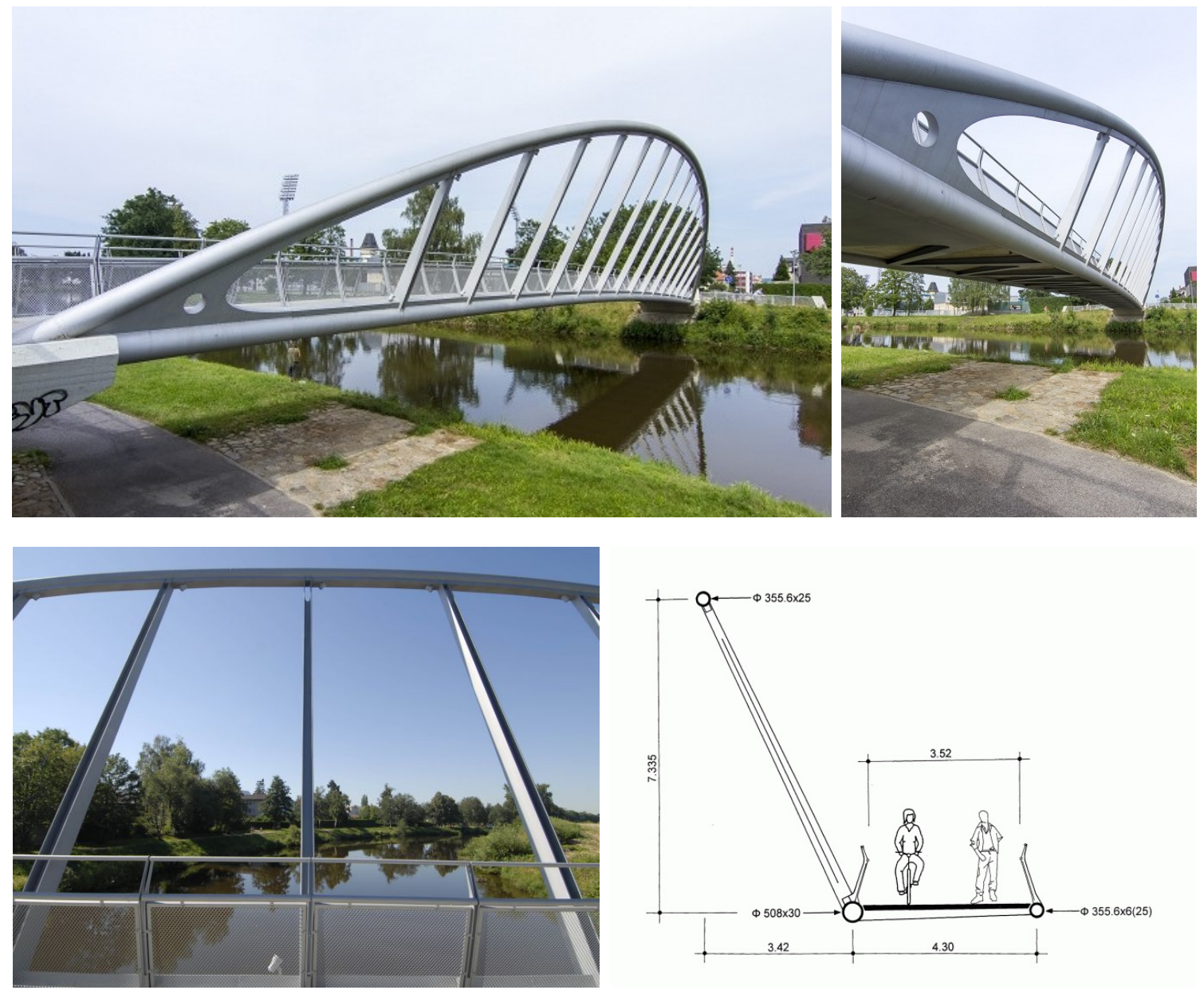

Figura 2.22: Puente sobre el río Vltava. Fotografía: Vladimír Carbol (structurae.net) y Jiri Strasky (shp.eu).

recuerda bastante al puente del puerto de Ondarroa y al Main Street Bridge, expuestos anteriormente, con la diferencia de que en este caso el tablero está pensado solamente para peatones y ciclistas (véase [81]).

\subsubsection{Mimico Creek Bridge}

Situada en Toronto (Canadá), esta pasarela (véanse Montminy [69], Anderson [3] y [123]) proyectada por Santiago Calatrava guarda muchas semejanzas con la pasarela de La Devesa, del mismo autor.

La luz del puente es de $44 \mathrm{~m}$, y al igual que en La Devesa, el tablero dispone de una barra de torsión de diámetro $762 \mathrm{~mm}$ en el borde que es sustentado por el arco inclinado. La sección de este tiene un diámetro de $273 \mathrm{~mm}$, y la vinculación con el tablero se realiza mediante péndolas rígidas con una sección doble $\mathrm{T}$ variable (véase la figura 2.25). 

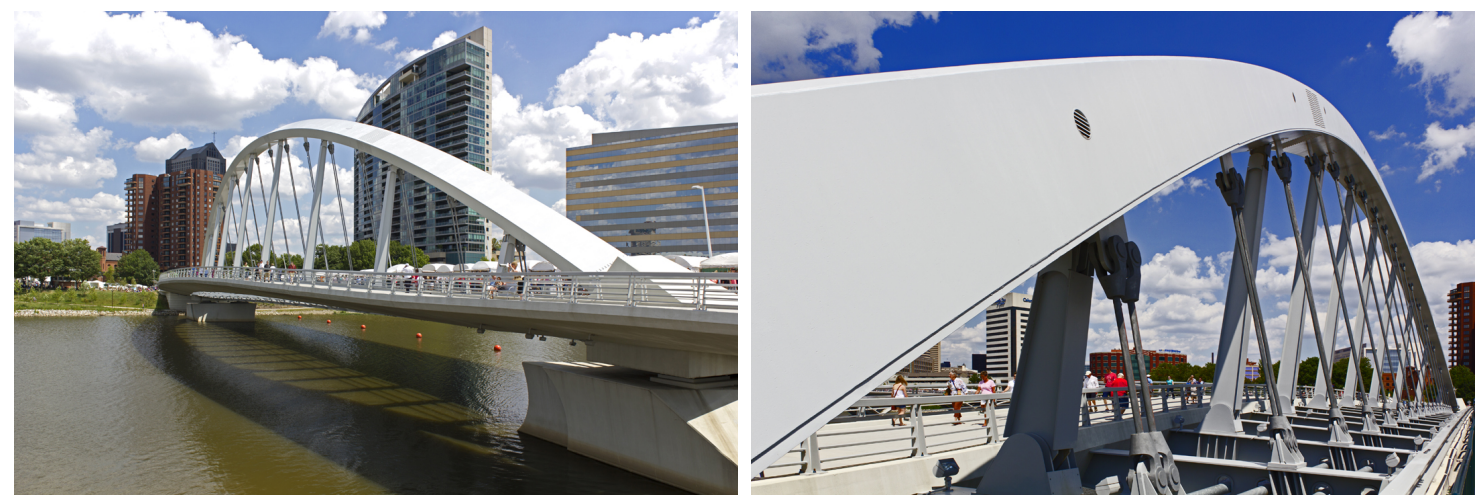

Figura 2.23: Main Street Bridge, Columbus (Ohio). Fotografía: Civic Arts Project (civicartsproject.com).
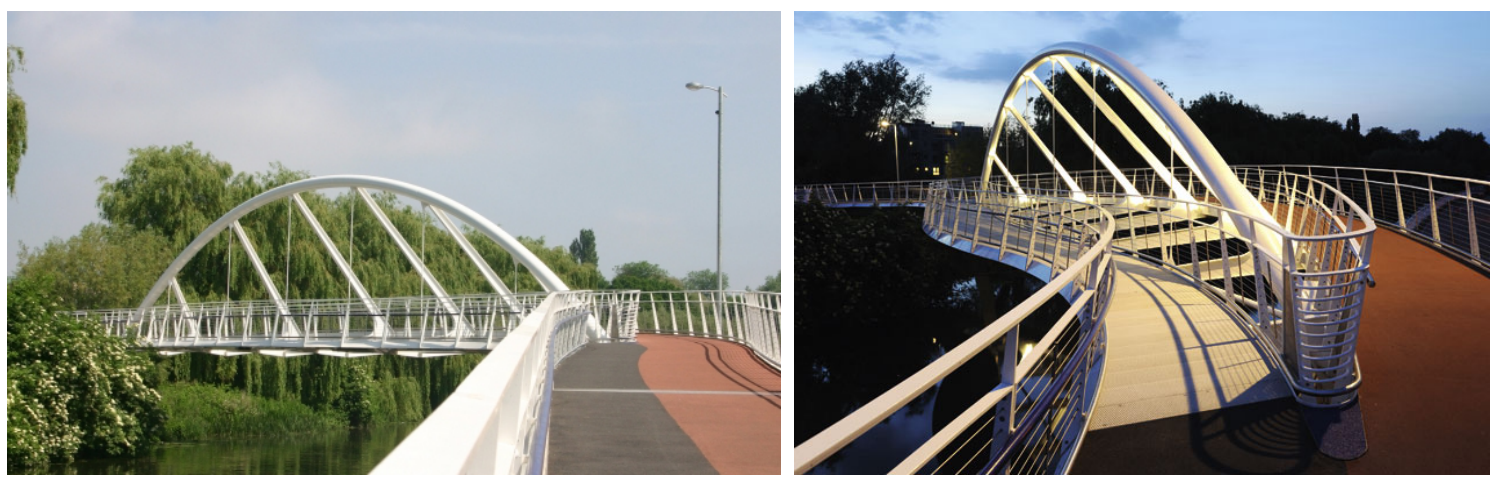

Figura 2.24: Riverside Bridge. Fotografía: Stephen Turner (structurae.net) y NSC (newsteelconstruction.com).
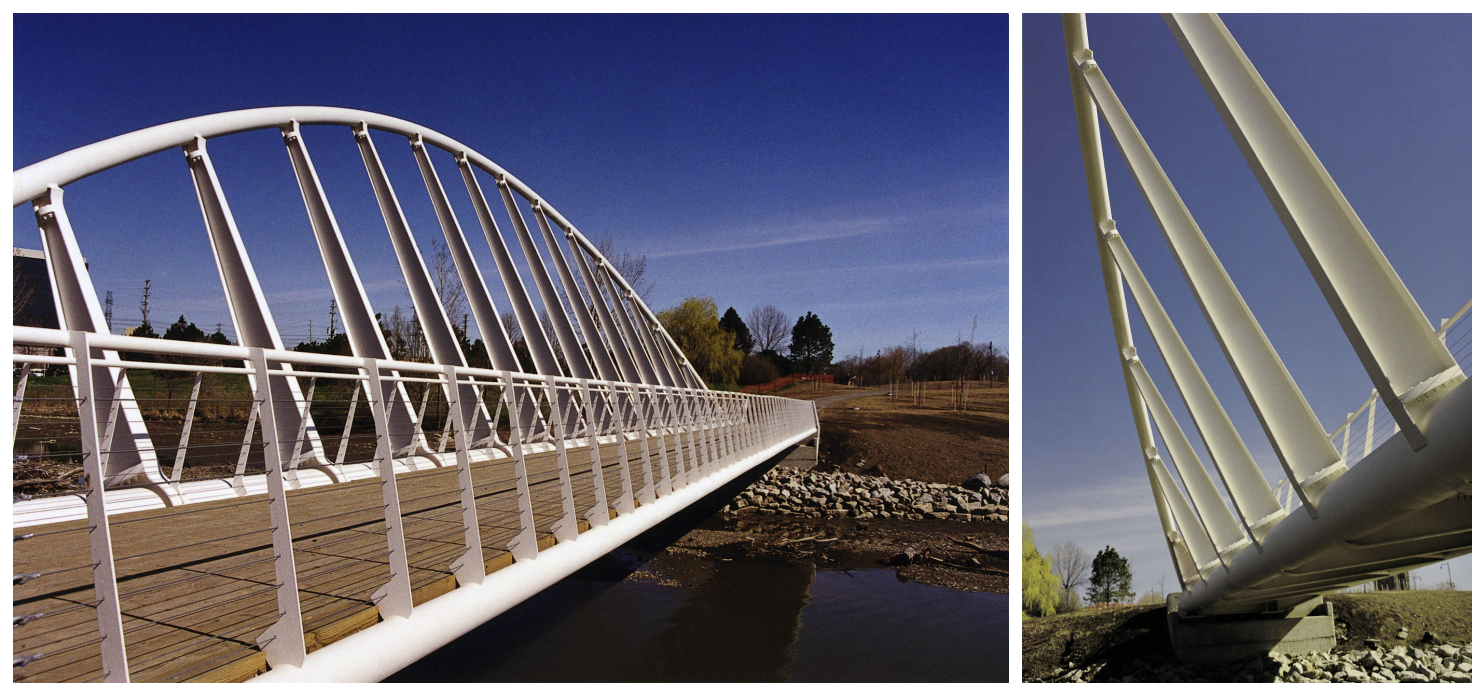

Figura 2.25: Mimico Creek Bridge. Fotografía: Santiago Calatrava (calatrava.com). 


\subsubsection{Mardyke Walk Bridge}

La ciudad de Cork fue designada Capital Europea de la Cultura en 2005, algo que motivó la construcción de esta pasarela, pues se pretendía unir ambas orillas del río Lee, que atraviesa la ciudad (véase Curran [26]). Esta pasarela también está muy influenciada por el puente de La Devesa de Santiago Calatrava, como se puede ver en la figura 2.26.

La pasarela tiene una luz de $57 \mathrm{~m}$, y está sustentada por un único arco inclinado $26^{\circ}$ con respecto a la vertical. El arco tiene una sección circular hueca, y está vinculado al tablero mediante péndolas rígidas de sección tubular, lo que hace que se consideren rígidas tanto en el plano longitudinal como en el plano transversal al eje del tablero. La sección de las péndolas rígidas es además variable, decreciendo hacia el arco. Por su parte, el tablero tiene un ancho de $3 \mathrm{~m}$ y está sujeto a un solo borde por el arco, borde en el que se encuentra el nervio principal del tablero.
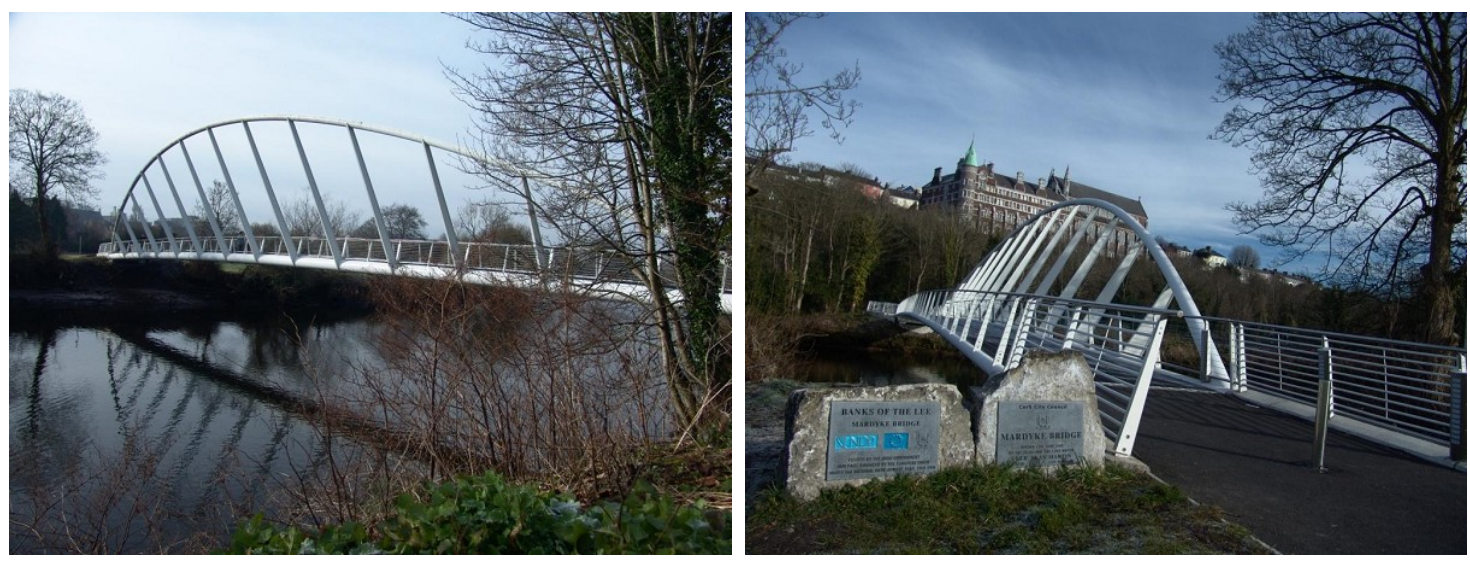

Figura 2.26: Mardyke Walk Bridge. Fotografía: Fehily Timoney Gifford (structurae.net).

\subsubsection{Puentes del Hospital General (Murcia, España)}

Los puentes del hospital general (Murcia, España) son obra de Santiago Calatrava, y fueron añadidos al puente original ${ }^{21}$ en el año 1999. Los puentes fueron planificados con el fin de desdoblar la capacidad del puente original (véase la figura 2.27).

Calatrava proyectó dos puentes gemelos (véase por ejemplo Jorquera Lucerga [47]) compuestos por un tablero recto de $54 \mathrm{~m}$ de longitud y un ancho máximo de $12.7 \mathrm{~m}$, y un arco de color blanco inclinado $52.5^{\circ}$. En ambos puentes, la vinculación entre el arco y el tablero se lleva a cabo mediante dos juegos de péndolas. Los puentes son totalmente independientes el uno del otro, incluso del puente original, que en la actualidad tiene un uso exclusivamente peatonal.

\footnotetext{
${ }^{21} \mathrm{El}$ puente original es un puente de vigas prefabricadas de hormigón armado que fue construido bajo la dirección de la Confederación Hidrográfica del Segura en el año 1973
} 


\subsection{REALIZACIONES CON ASIMETRÍA LONGITUDINAL}
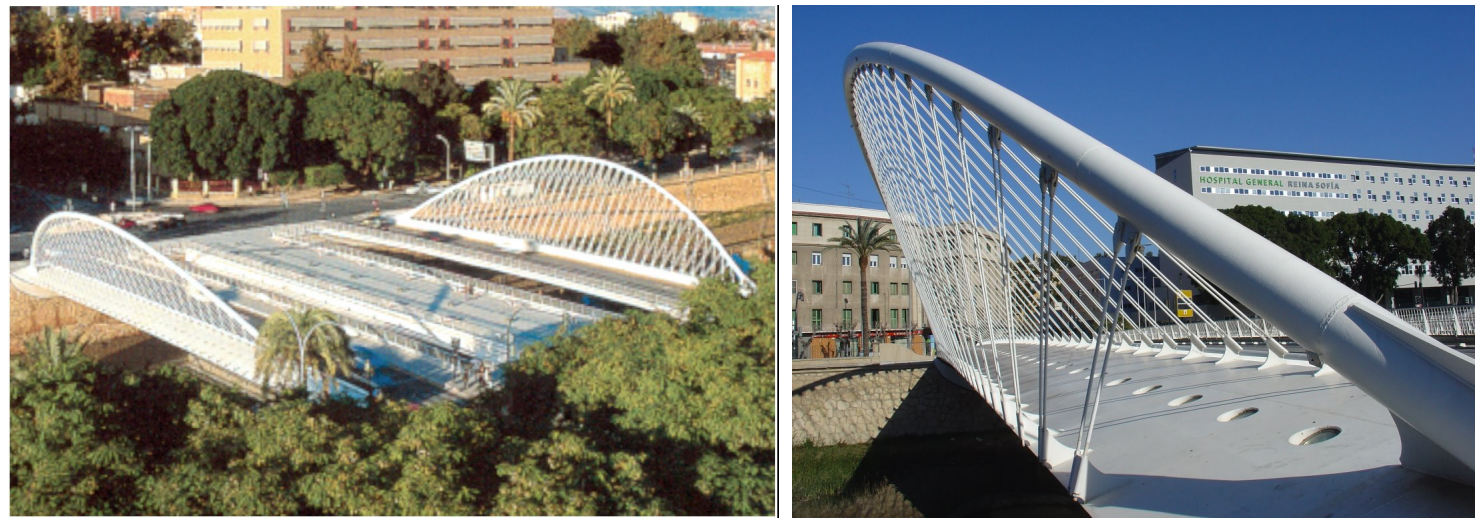

Figura 2.27: Puentes del Hospital General. Fotografía: Emilio Estrella Sevilla y Rufino Jiménez (Mapio.net).
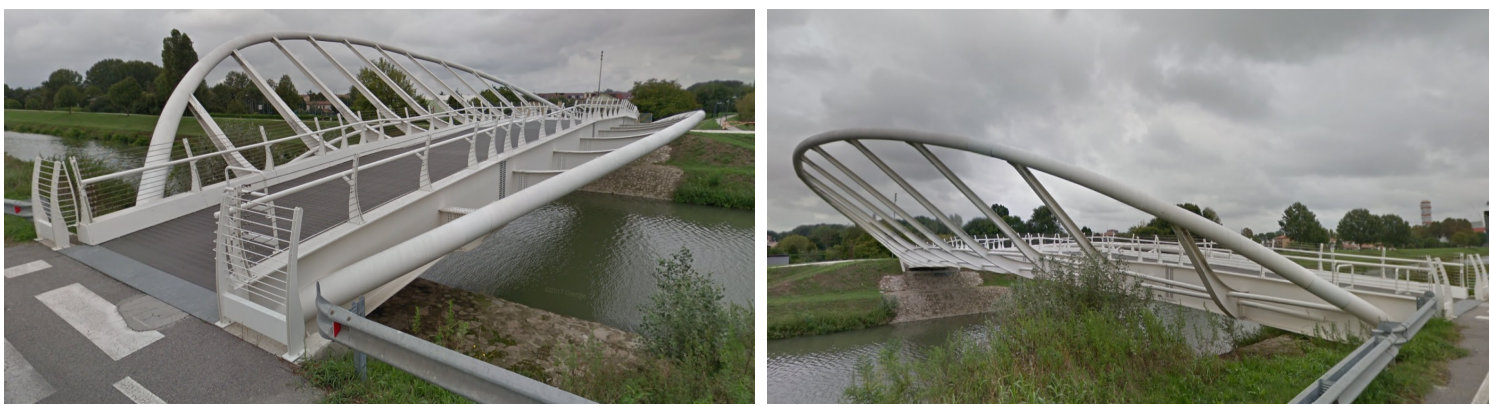

Figura 2.28: Via Asconio Pediano Footbridge. Fotografía: Google Street View.

\subsubsection{Via Asconio Pediano Footbridge}

Esta pasarela se sitúa sobre el canal de San Gregorio, en la Ciudad de Padua (Italia). La obra, que es proyecto del estudio PROGEeST srl, da acceso al parque Green Energy Park y al parque Roncajette, ambos situados en la misma ribera del canal.

El puente (véase la figura 2.28) se compone de un tablero recto con dos nervios principales en cada borde, y un arco inclinado $45^{\circ}$. El arco se vincula al tablero mediante péndolas rígidas que se sueldan al borde del tablero, teniendo estas una sección doble $\mathrm{T}$, un tanto curva en el encuentro con el borde del tablero. En el borde de tablero opuesto al del arco se dispone un cordón de sección circular muy similar al del arco, estando unido al nervio mediante costillas de acero. Más información sobre esta pasarela puede ser encontrada en Siviero y Attolico $[104]^{22}$.

\subsubsection{Rari Nantes Footbridge}

La pasarela se sitúa sobre el río Bacchiglione en Padua (Italia). El proyecto es del estudio PROGEeST srl, y se enmarca dentro del proceso de mejora del distrito central de la ciudad de Padua. Una característica del puente es que su forma está inspirada en una

\footnotetext{
${ }^{22}$ La descripción de la obra realizada por Siviero en la referencia, difiere en parte con lo realmente construido, si bien se mantienen características como el arco y su vinculación con el tablero.
} 

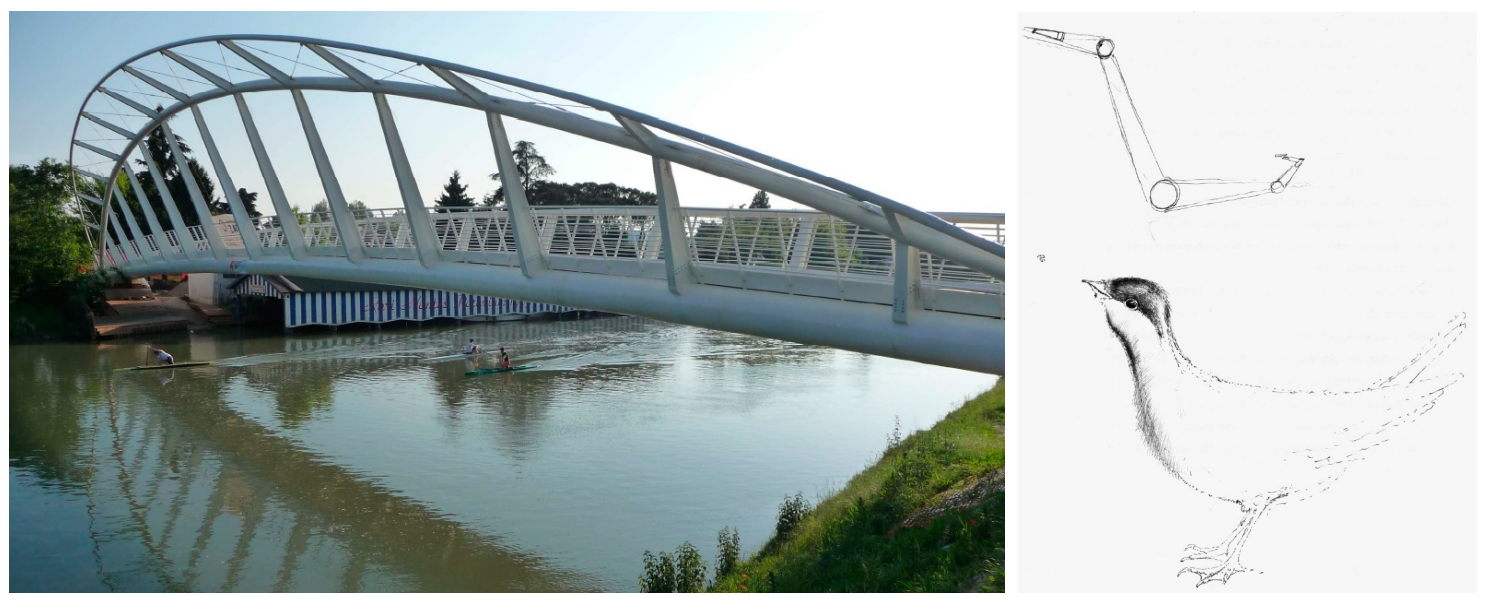

Figura 2.29: Rari Nantes Footbridge. Fotografía: Extraídas de Siviero y Attolico [103].

especie común de ave ${ }^{23}$ de la ribera del río, la gallineta común o polla de agua (Gallinula chloropus).

La luz del puente es de $60 \mathrm{~m}$, siendo el tablero recto y con un ancho de $3.8 \mathrm{~m}$, de los que $3 \mathrm{~m}$ están destinados a peatones y ciclistas, y el resto a las barandillas. El tablero es sustentado por un arco inclinado $22^{\circ}$ con respecto a la vertical. En el arco se dispone además una celosía inclinada ${ }^{24}$ de tipo Vierendeel con diagonales de cables, que lo dota de una mayor rigidez a torsión y contribuye a la estabilidad transversal del tablero (véase Siviero y Attolico [103]). La vinculación entre el arco y el tablero se materializa mediante péndolas rígidas de sección doble $\mathrm{T}$ variable. Por último, el tablero dispone de una barra de torsión de sección circular en el borde que se vincula con el arco.

\subsubsection{Roundabout Ovotonde}

El puente Roundabout Ovotonde (Nijmegen, Países Bajos), del estudio Zwarts \& Jansma Architects (véase [85]), comparte un esquema resistente muy parecido a los mencionados anteriormente, donde el arco inclinado se une al tablero recto con péndolas rígidas unidas al borde, pero con la salvedad de que en este caso son dos puentes independientes situados en la misma rotonda (véase la figura 2.30).

\subsubsection{Arco plano con tablero curvo}

\subsubsection{Gateshead Millennium Bridge}

La pasarela (véanse las figuras 2.10 y 2.31) está situada sobre el río Tyne, entre Gateshead y Newcastle (Reino Unido). Fue finalizada en el año 2001 y es obra del estudio de

\footnotetext{
${ }^{23}$ Este hecho recuerda mucho a la concepción del Pont Gentil de Calatrava, donde el puente se asemeja a un ave en vuelo.

${ }^{24}$ Según los autores de la pasarela, esta celosía inclinada representa el pico del ave en el que está inspirada la pasarela.
} 

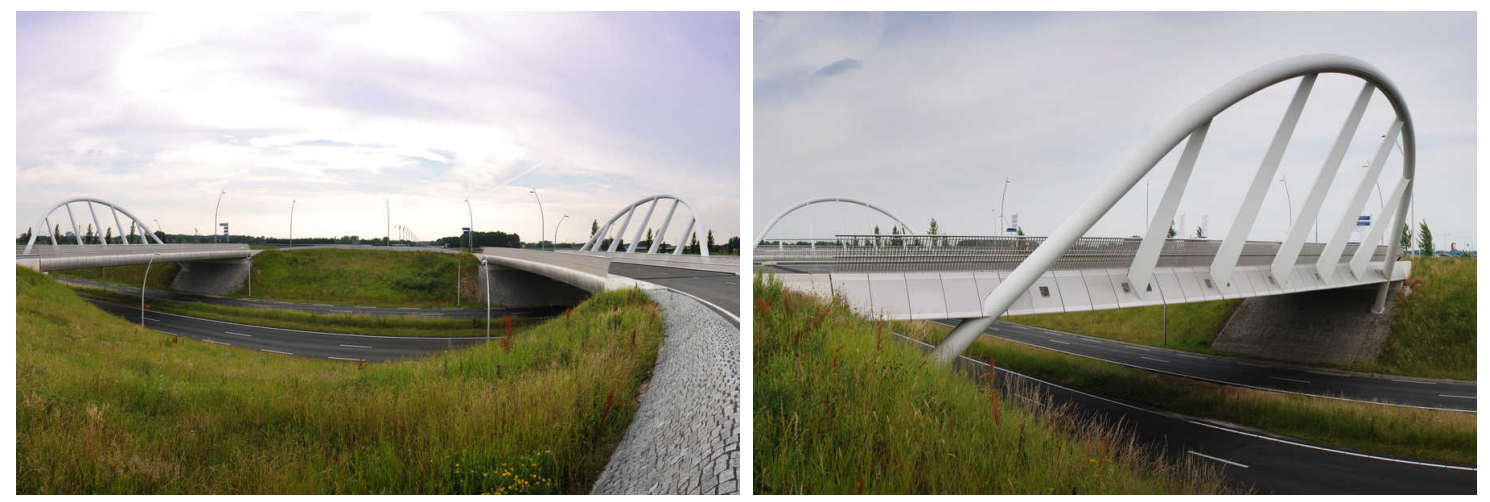

Figura 2.30: Roundabout Ovotonde. Fotografía: Zwarts \& Jansma Architects (zja.nl).

arquitectos Wilkinson Eyre y del estudio de ingenieros Gifford \& Partners ${ }^{25}$. La estructura fue construida para conmemorar la llegada del nuevo milenio, además de para revitalizar una de las orillas de la ciudad donde se encuentra. El hecho de proyectarse un arco estuvo motivado por la necesidad de armonizar la pasarela con otros puentes arco próximos situados sobre el río Tyne. La singularidad de este puente ha hecho que afloren numerosas publicaciones sobre el mismo, donde caben destacar Baus y Schlaich [14], Johnson y Curran [43], Flaga y Januszkiewicz [31] y Curran [26].

La estructura tiene una luz de $105 \mathrm{~m}$, estando compuesta por un arco parabólico de 50 m de altura y un tablero curvo. Los arranques del arco y del tablero son prácticamente coincidentes, sujetándose el tablero al arco por un solo borde mediante 18 cables espaciados cada $6 \mathrm{~m}$. El tablero se divide en dos zonas, una destinada a peatones y otra a ciclistas.

Es un puente arco espacial móvil, el único hasta la fecha. Su movimiento ${ }^{26}$ se realiza rotándose el arco y el tablero alrededor del eje que une los apoyos. Así, el conjunto estructural se gira hasta que los cables que unen el arco y el tablero quedan horizontales, permitiendo esto que barcos de hasta $25 \mathrm{~m}$ de altura puedan pasar por debajo.

\subsubsection{Pasarela del Campo Volantín}

Esta pasarela, proyecto de Santigo Calatra, está situada sobre la ría del río Nervión en Bilbao (España). La pasarela del Campo Volantín ${ }^{27}$, también conocida como Zubizurii ${ }^{28}$, fue finalizada en el año 1997, siendo su principal objetivo revitalizar la zona, muy degra-

\footnotetext{
${ }^{25}$ La construcción del puente valió a los arquitectos de Wilkinson Eyre en 2002 el Premio Stirling concedido por la Royal Institute of British Architects (RIBA). Por su parte, el estudio de ingenieros Gifford ganó en 2003, y gracias a este puente, la IStructE Supreme Award. En 2005, el puente recibió el Premio de la Estructura Excepcional otorgado por la Asociación Internacional de Puentes e Ingeniería Estructural (IABSE).

${ }^{26}$ Según Baus y Schlaich [14], el movimiento lo realizan gatos hidráulicos capaces de ejercer una compresión de $10000 \mathrm{kN}$ y una tensión de $4500 \mathrm{kN}$, algo que permite mover la estructura incluso con fuerte viento.

${ }^{27}$ El Campo de Volantín es un paseo situado en la margen derecha de la ría de Bilbao, se inicia en el ayuntamiento de Bilbao y finaliza en la confluencia de la Plaza de la Salve con la avenida de las Universidades.

${ }^{28}$ En vasco significa puente blanco.
} 

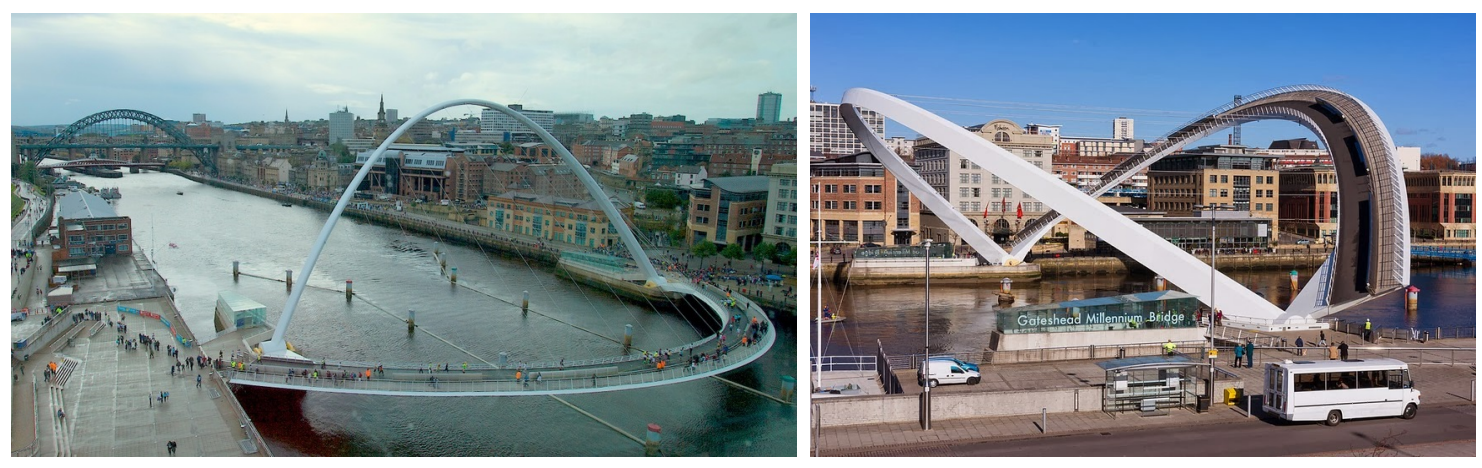

Figura 2.31: Gateshead Millennium Bridge. Fotografía: Pedro Plasencia (puentemania.com) y Ruta 33 (ruta-33.blogspot.com).

dada durante los años de pujanza industrial (véanse Torres [114], Baus y Schlaich [14], Wells [126] y Jodidio [42]). La pasarela fue inaugurada casi al mimo tiempo que el museo Guggenheim, siendo símbolos ambos del nuevo Bilbao.

La estructura, que permite salvar una luz de $75 \mathrm{~m}$ y es metálica en su totalidad, se compone de un tablero curvo y un arco parabólico inclinado $10^{\circ}$ respecto a la vertical, no siendo coincidentes los arranques del arco con los estribos del tablero. La curvatura del arco vista en planta es contraria a la del tablero. El tablero, aunque curvo en planta, dispone de un nervio central recto (véase la figura 2.32) al que se van acoplando costillas de acero que conforman la planta curva. El tablero es exclusivo de uso peatonal, teniendo un ancho variable que va desde los $6.5 \mathrm{~m}$ en los estribos, hasta los $7.5 \mathrm{~m}$ en el centro del vano (véase Smith [106]). Llama la atención el pavimento de cristal del tablero, objeto de numerosas críticas dado el tiempo húmedo de la ciudad de Bilbao y el carácter resbaladizo del vidrio, lo que motivó que fuera cubierto por una alfombra antideslizante.

El arco arranca en ambos extremos sobre el nervio del tablero, siendo este último quien recoge los esfuerzos horizontales del arco. El nervio descansa en ambos extremos sobre unos voladizos que forman parte de las rampas de acceso al puente, siendo estas las que absorben las cargas verticales del puente. La vinculación entre el tablero y el arco se realiza mediante cables de acero de $30 \mathrm{~mm}$ de diámetro a ambos bordes del tablero, existiendo un espaciamiento entre cables de $1.8 \mathrm{~m}$. La posición relativa arco-tablero hace que los cables se deban anclar a unos sobreanchos del tablero, de manera que no se interfiera en el gálibo. 

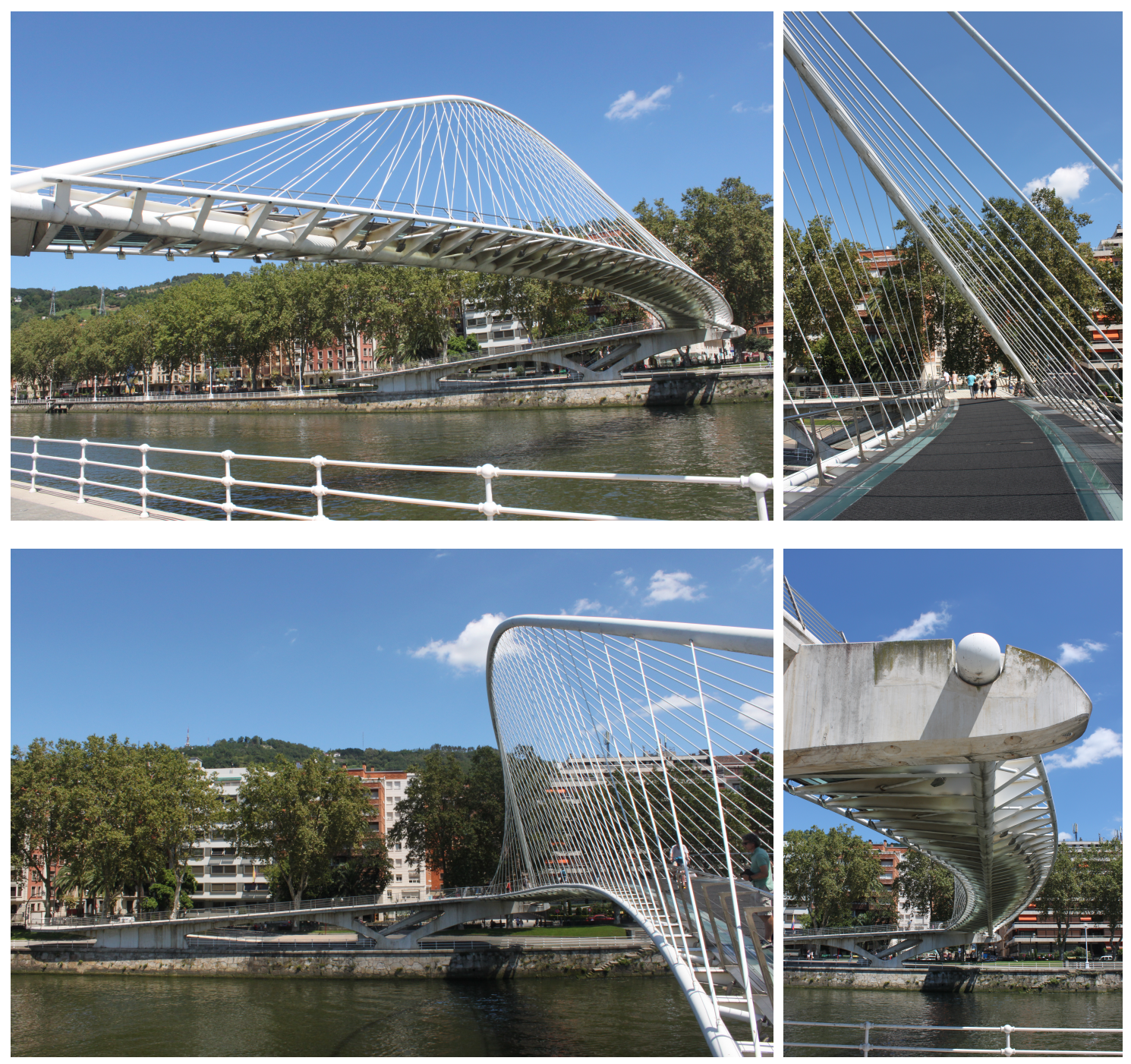

Figura 2.32: Pasarela del Campo Volantín. Fotografía del autor.

\subsubsection{Puente del observatorio (Lieja)}

El puente del observatorio, proyecto de Santiago Calatrava, fue finalizado en 2002 en la ciudad de Lieja (Bélgica). El puente forma parte de la conexión entre la estación de TGV de Guillemins con la autopista E25 (véase [120]).

Esta estructura (véase la figura 2.33), con una luz de $80 \mathrm{~m}$, se asimila mucho a la pasarela del Campo Volantín, obra también de Calatrava. El puente está constituido por un tablero curvo y un arco plano recto, que coincide en planta con el nervio recto del tablero curvo. El arco está compuesto por una sección circular de $750 \mathrm{~mm}$ de diámetro con un espesor de $80 \mathrm{~mm}$. Por su parte, el nervio recto del tablero sobre el que se asientan las costillas de acero que le confieran la curvatura en planta, también tiene una sección circular de 1420 mm de diámetro y $40 \mathrm{~mm}$ de espesor.

La vinculación entre el arco y el tablero se lleva a cabo mediante 42 cables atados a ambos bordes del tablero. 

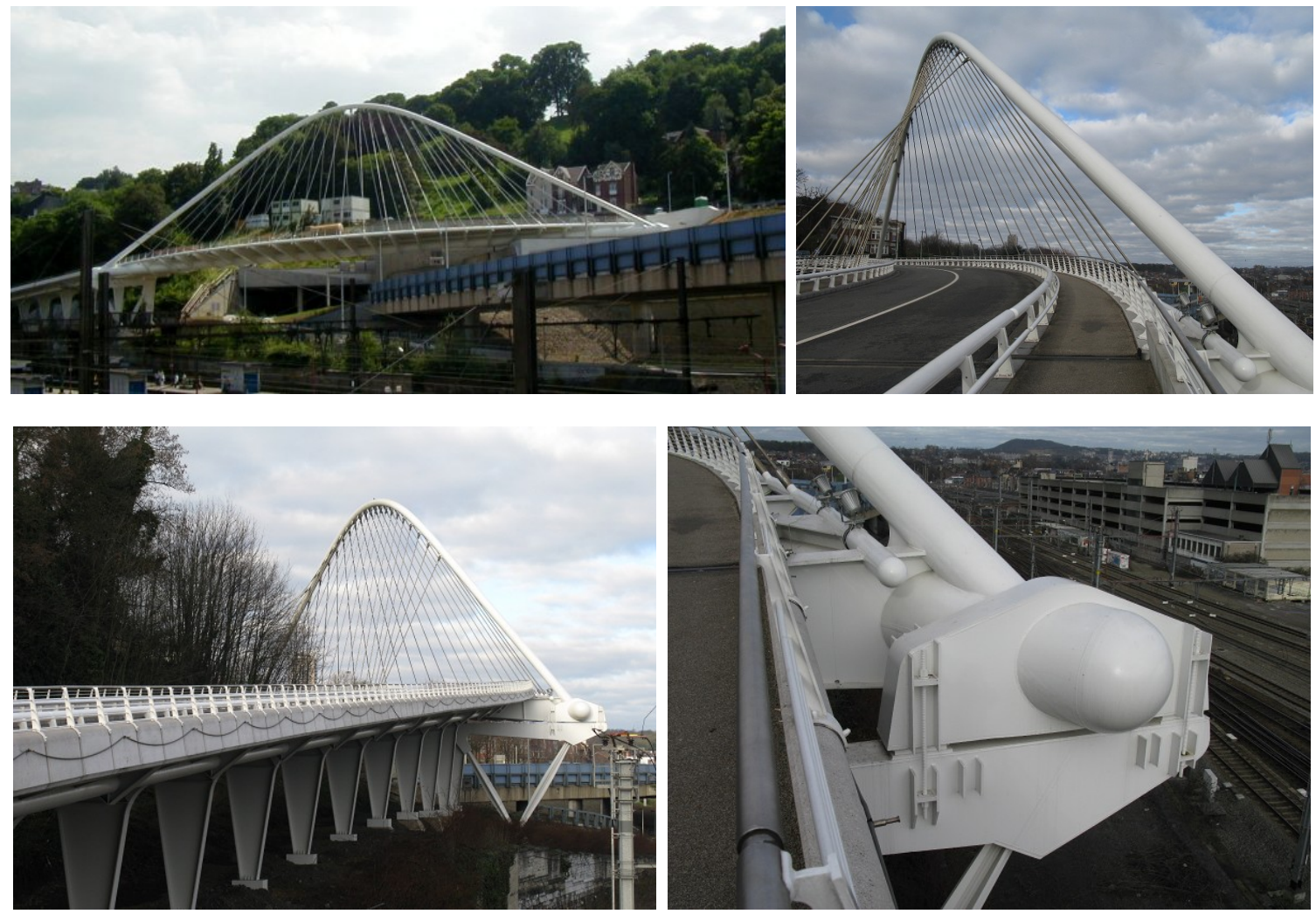

Figura 2.33: Puente del observatorio. Fotografía: Herrad Elisabeth Taubenheim (structurae.net) y Jacques Mossot (structurae.net).

\subsubsection{Pasarela de acceso a Chimisay Alto (Tenerife, España)}

Esta pasarela da acceso a los vecinos de Chimisay Alto en el barrio de Ofra (Santa Cruz de Tenerife, España). La pasarela es metálica (véase la figura 2.34) y se compone de un tablero curvo con una luz de $31 \mathrm{~m}$ y un ancho de $1.9 \mathrm{~m}$, así como de un arco plano recto con una altura de clave sobre el tablero de $6.8 \mathrm{~m}$. La vinculación entre el arco y el tablero se lleva a cabo mediante 27 cables atados a un solo borde del tablero.
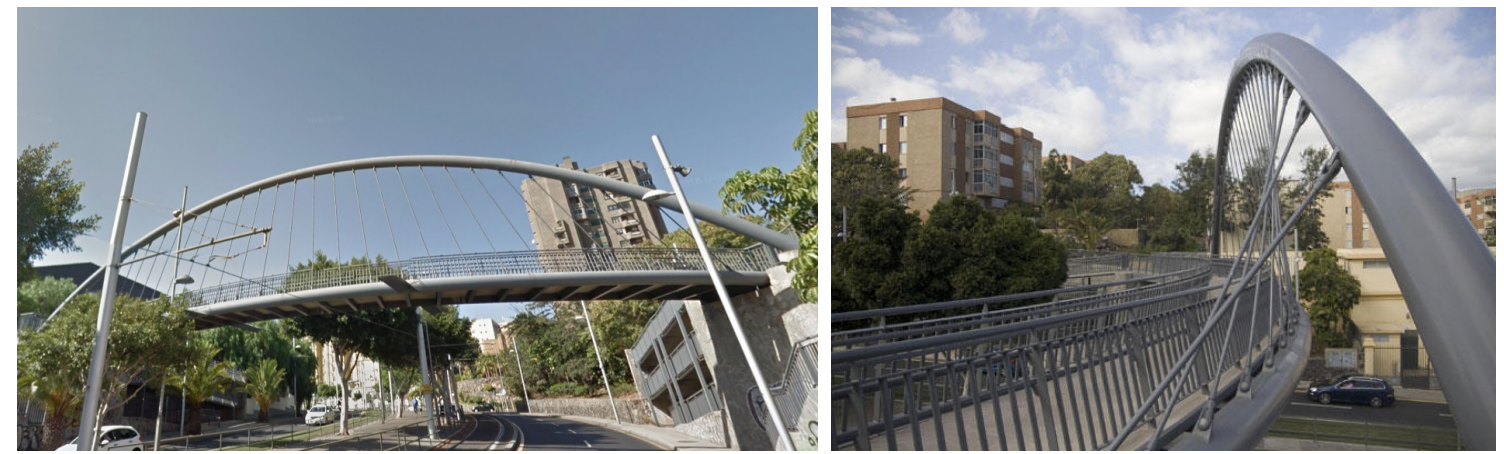

Figura 2.34: Pasarela de acceso a Chimisay Alto. Fotografía: Google Street View y Tomás García (La Opinión de Tenerife). 


\subsubsection{Merchants Bridge}

Esta pasarela fue construida para intentar revitalizar Castlefield, un área degradada de Manchester (Reino Unido). El diseño es del estudio Whitby Bird (ahora parte de Ramboll), finalizándose la construcción en el año 1995. La estructura (véanse Baus y Schlaich [14] y Torres [114]) está fuertemente influenciada por la pasarela de La Devesa de Santiago Calatrava, algo que los proyectistas no dudan en afirmar. La principal diferencia radica en el tablero, que en este caso es curvo mientras que en La Devesa es recto.

El puente (véase la figura 2.35) se compone de una tablero curvo de $68 \mathrm{~m}$ de longitud, con una vano principal de $38 \mathrm{~m}$ que está sustentado por un solo borde mediante un arco inclinado. Según Strasky [108], constituye el primer puente sujeto a un solo borde. La sección del tablero está formada por una barra de torsión en el borde que se ata al arco, a la que se unen costillas transversales de acero.

La vinculación entre el arco y el tablero se lleva a cabo mediante péndolas rígidas de sección doble T. Cabe destacar que estas se unen al arco solo soldando su alma, lo que en la práctica se podría considerar una articulación, así se reducirían los esfuerzos en el arco, como apunta Jorquera Lucerga en [47].
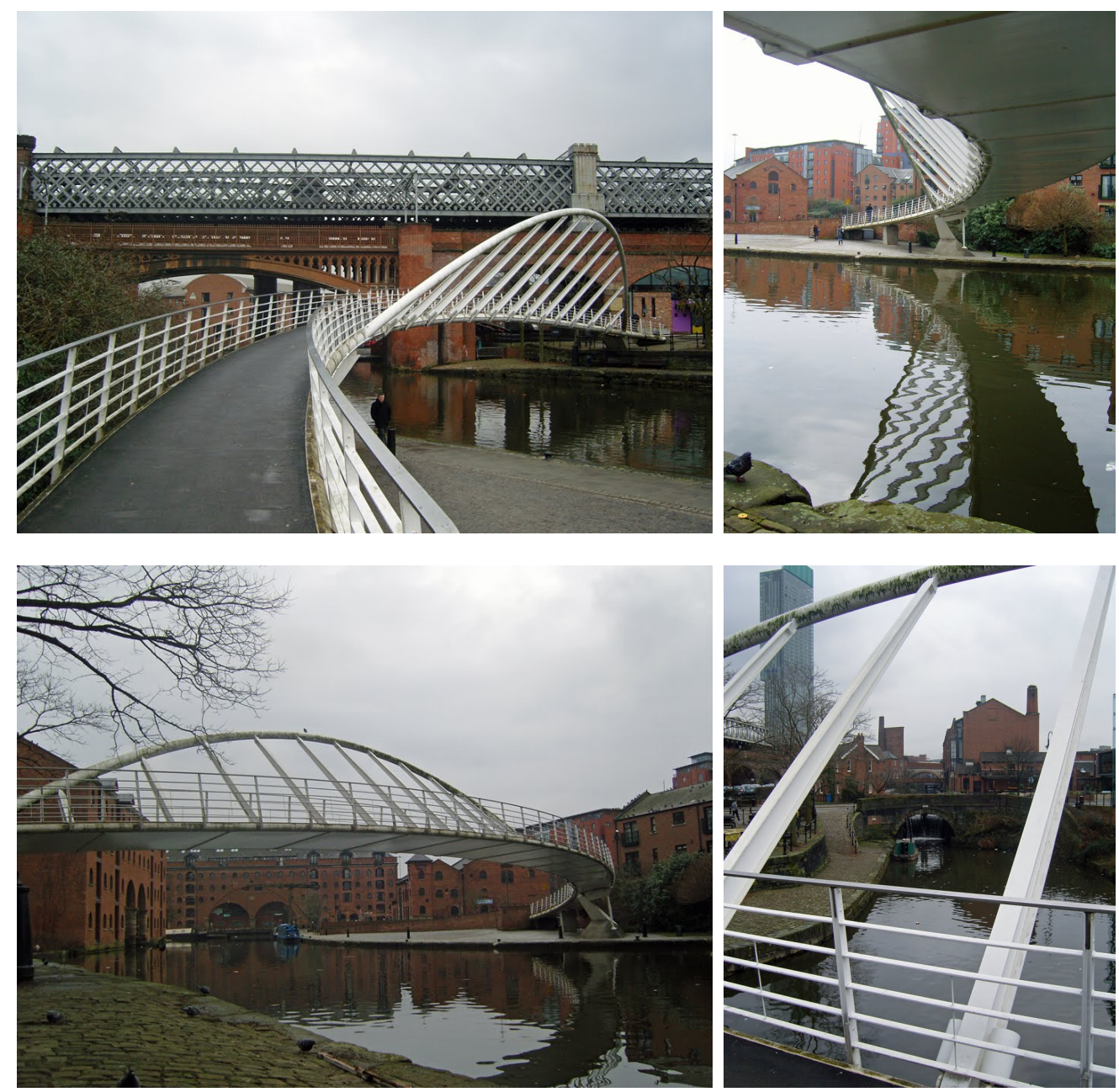

Figura 2.35: Merchants Bridge. Fotografía: The Happy Pontist. 


\subsubsection{6. Ågade Bridge}

Finalizada en Copenhague (Dinamarca) en 2008, la pasarela es obra de los estudios Dissing + Weitling (arquitectura) y NIRAS (ingeniería).

La estructura, con una luz de $65 \mathrm{~m}$, está compuesta por un tablero curvo con un ancho de $6.5 \mathrm{~m}$ sujeto a un borde por un arco inclinado $45^{\circ}$ (véase la figura 2.36). La vinculación entre arco y tablero se lleva a cabo mediante 11 cables colocados cada $4 \mathrm{~m}$ (una descripción más exhaustiva puede encontrarse en [123], Trojaborg et al. [115] y Rasmussen et al. [87]).

\subsubsection{Pasarela peatonal del Malecón del Salado (Guayaquil, Ecuador)}

La pasarela, construida en el año 2003 en Guayaquil (Ecuador), fue proyectada por la empresa Waagner-Biro.

La estructura (véase la figura 2.37) está compuesta por un tablero curvo en planta con un vano principal de $37.60 \mathrm{~m}$ sustentado por un arco plano vertical mediante cables. $\mathrm{Al}$ vano principal del tablero, cuyo ancho varía entre 4.5 y $5.20 \mathrm{~m}$, se añaden dos rampas de acceso de $8.44 \mathrm{~m}$. El tablero tiene un nervio principal de sección circular con un diámetro de 1200 mm, mientras que el arco tiene una sección también circular de $508 \mathrm{~mm}$ de diámetro. Una de las particularidades del puente radica en que este se apoya sobre dos trípodes formados por tubos de acero.
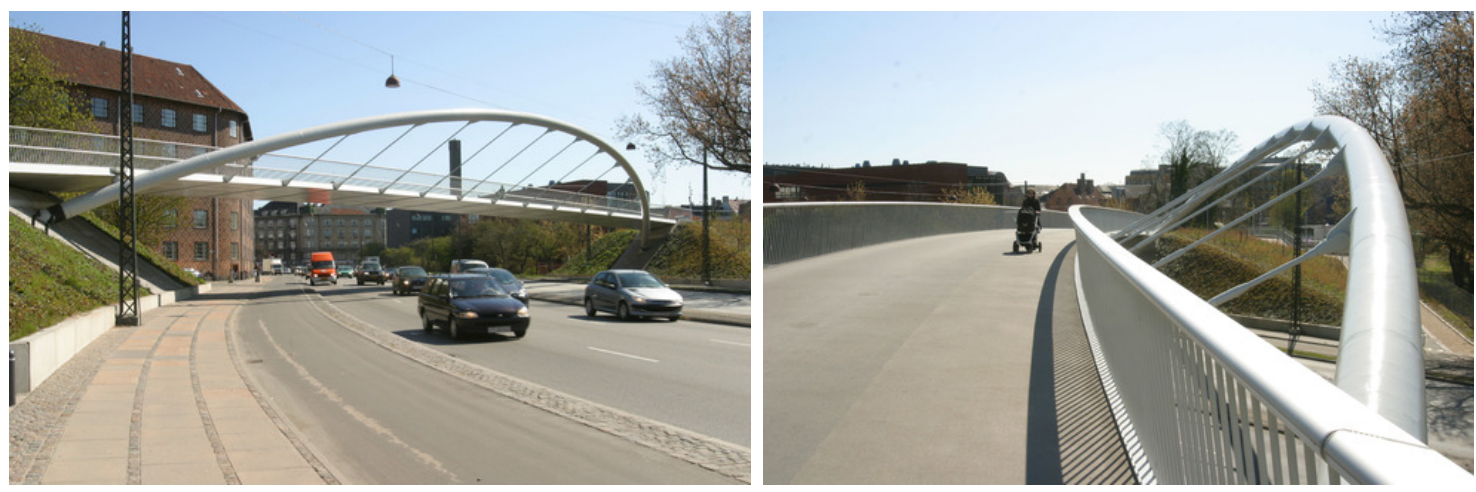

Figura 2.36: Ågade Bridge. Fotografía: Dissing+Weitling (dw.dk).
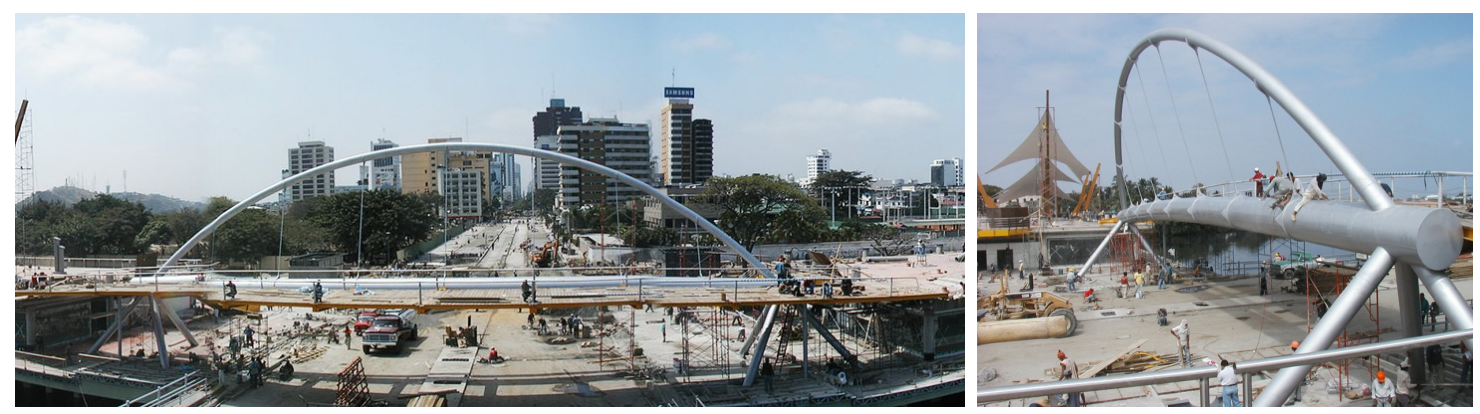

Figura 2.37: Pasarela peatonal del Malecón del Salado. Fotografía: Waagner-Biro (waagner-biro.com). 


\subsubsection{Pasarela sobre el río Nervión (Etxebarri, España)}

La pasarela sobre el río Nervión en Etxebarri, municipio próximo a Bilbao (España), es proyecto del estudio TEMHA. La pasarela fue finalizada en el año 2005, permitiendo el acceso a la nueva estación de cercanías de la ciudad (véase la figura 2.38).

La pasarela permite salvar una luz de $65.5 \mathrm{~m}$ con un tablero de $6 \mathrm{~m}$ de ancho, divido en una zona de $3 \mathrm{~m}$ destinada a ciclistas y otra zona también de $3 \mathrm{~m}$ para peatones (véase Corbal et al. [25]). El tablero dispone de un cajón central que actúa como elemento estructural principal del tablero, atirantando el arco. Unos elementos secundarios perpendiculares a modo de costillas sostienen las pasarelas. Estos elementos se disponen con una equidistancia de $3.25 \mathrm{~m}$ entre sí, siendo su sección transversal en doble T, con canto y anchura variables.

La sección del cajón es cuadrangular de lados no paralelos, con un canto que varía desde $0.70 \mathrm{~m}$ en los arranques de la pasarela hasta $1.35 \mathrm{~m}$ en el centro de vano, y un ancho que va desde los $2.55 \mathrm{~m}$ en arranques hasta los $1.88 \mathrm{~m}$ en el centro de vano.

Entre ambas zonas del tablero de alza un arco de directriz circular con una altura máxima de $7.5 \mathrm{~m}$. Este arco se encuentra inclinado $20^{\circ}$ con respecto a la vertical, siendo su inclinación hacia la zona del tablero destinada a ciclistas. La sección de arco está compuesta por un triángulo rectángulo escaleno de lados 1.50 x 1.30 x $0.70 \mathrm{~m}$.

La vinculación ente el arco y tablero se materializa a través de 19 pares de barras de acero con un diámetro de $52 \mathrm{~mm}$.
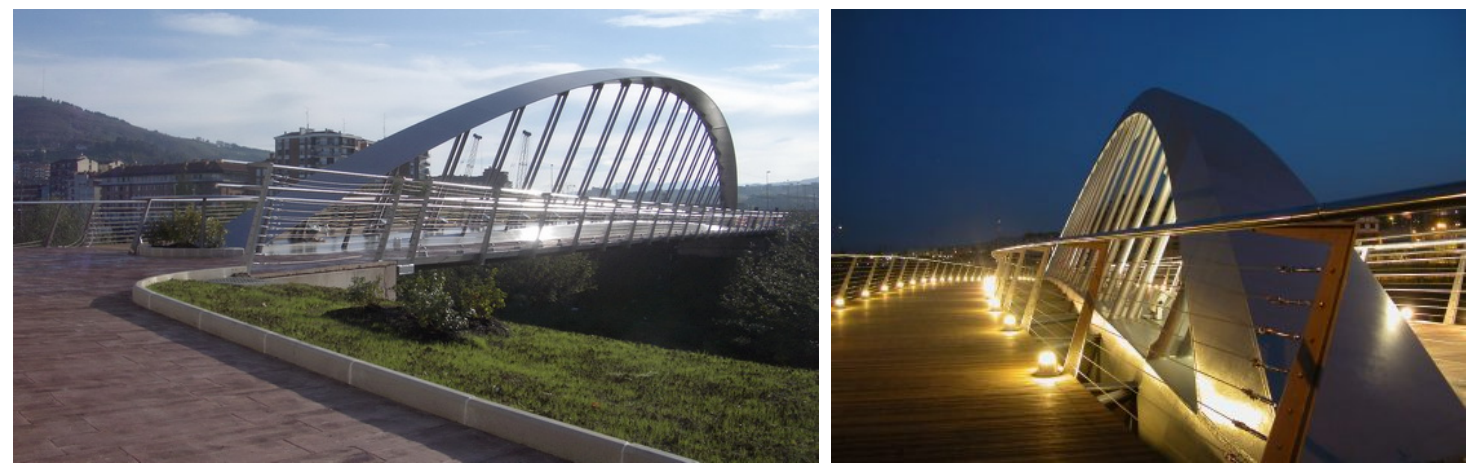

Figura 2.38: Pasarela sobre el río Nervión. Fotografía: TEMHA (temha.com).

\subsubsection{Tyrs's Bridge (Prerov, República Checa), (propuesta no construida)}

Proyectado por Strasky sobre el río Becva en la ciudad Checa de Prerov, este puente no ha llegado a construirse, según se indica en la web de Strasky, Husty and Partners, debido a que los ecologistas creen que el puente puede interferir en el paso de las aves.

El puente (véase la figura 2.39) está formado por un tablero curvo en planta con una luz de $77 \mathrm{~m}$, siendo suspendido de un borde por un arco inclinado. El tablero dispone de una sección cajón curva que actúa como tirante del arco, existiendo cables de pretensado que reducen la torsión. 

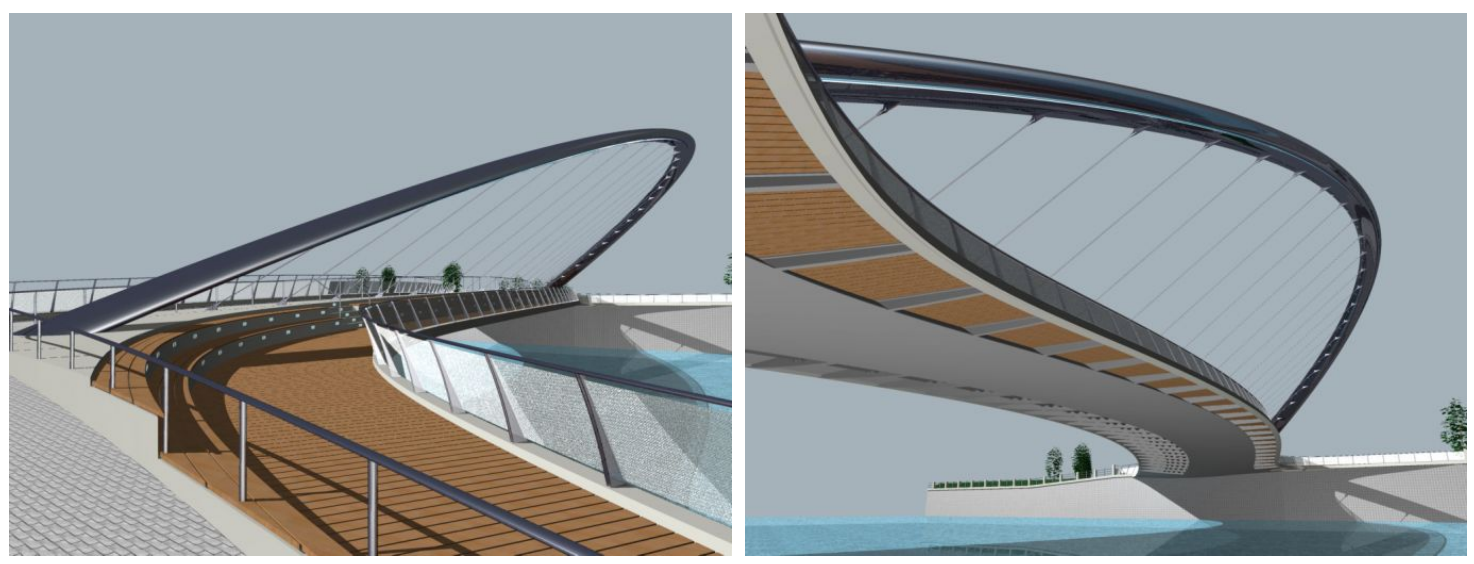

Figura 2.39: Tyrs's Bridge. Fotografía: Strasky, Husty and Partners Ltd. (SHP) (shp.eu).
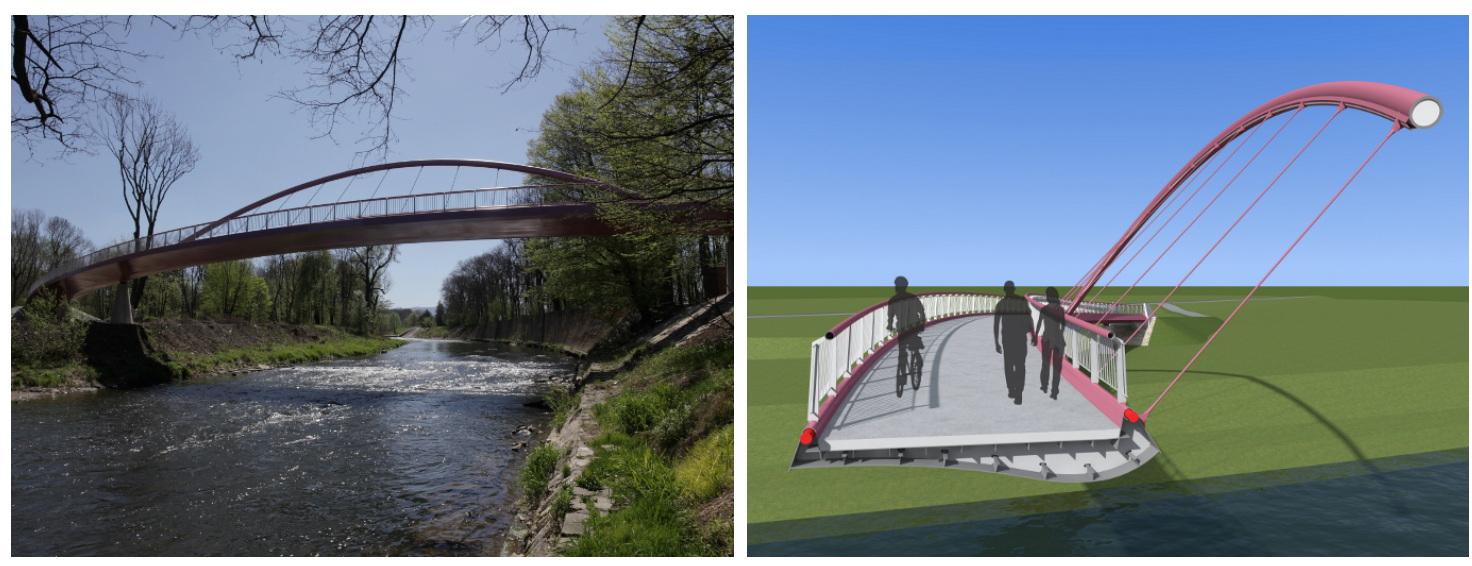

Figura 2.40: Sport Bridge. Fotografía: Strasky, Husty and Partners Ltd. (SHP) (shp.eu).

\subsubsection{Sport Bridge, Český Těšín (República Checa) - Cieszyn (Polonia)}

Esta pasarela conecta la ciudad de Český Těšín (República Checa) con Cieszyn (Polonia), ciudades situadas en orillas opuestas del río Olza. El proyecto es de Strasky, finalizándose su construcción en el año 2012 (véase [124]).

La pasarela (véase la figura 2.40) se compone de un tablero curvo de cuatro vanos $(17+$ $45+18+13 \mathrm{~m}$ ), donde el vano principal está sustentado por un arco inclinado $30^{\circ}$ hacia el lado de la curvatura del tablero. El tablero es mixto, con una losa de hormigón de $120 \mathrm{~m}$ de espesor y una sección cajón de acero, marcadamente asimétrica, con diafragmas cada $3 \mathrm{~m}$. El tablero tiene un espesor máximo de $0.903 \mathrm{~m}$ y un ancho de $4.375 \mathrm{~m}$, procurándose en todo momento que el centro de cortante esté próximo a los anclajes de los cables.

El arco tiene una directriz parabólica con una sección circular hueca de $457 \mathrm{~mm}$. El arco tiene un espesor de $40 \mathrm{~mm}$ en los arranques y de $25 \mathrm{~mm}$ en la clave, estando relleno de hormigón. La flecha del arco es de 6.75, vinculándose a un solo borde del tablero mediante cables que forman 45 grados con la horizontal ${ }^{29}$.

\footnotetext{
${ }^{29}$ Dado que el arco está inclinado $30^{\circ}$ y sujeta un tablero curvo, los cables no están dentro del plano del arco, sino que tienen una mayor inclinación, en este caso de $45^{\circ}$.
} 


\subsubsection{Elizabeth Quay Bridge}

Situada en la ciudad de Perth (Australia), esta pasarela fue proyectada por Ove Arup \& Partners, finalizándose su construcción en 2016 (véase Burnton et al. [21]).

La pasarela $^{30}$ (véase la figura 2.41) ocupa un lugar prominente del muelle Elizabeth, con lo que la estética jugó un papel importante en su diseño. Esta obra da continuidad al paseo ribereño del río Swan, por el que transitan peatones y ciclistas de la zona. Uno de los principales problemas que definieron la pasarela es el gálibo mínimo del tablero, ya que por debajo de la estructura pasan los ferris para atracar en el muelle.

La estructura dispone de un tablero en $\mathrm{S}$ con dos ondas de curvatura contraria, quedando suspendida cada onda de tablero por sendos arcos inclinados hacia la curvatura de cada onda. Según la empresa Arup \& Partners, la curvatura del tablero es la solución que permite crear las rampas requeridas impuestas por el gálibo mínimo de navegación. El tablero tiene una longitud de $110 \mathrm{~m}$ y un ancho de $5 \mathrm{~m}$, quedando sustentado de un solo borde mediante cables, por cada uno de los arcos de $22 \mathrm{~m}$ de altura y $45 \mathrm{~m}$ de luz mencionados anteriormente.

$\mathrm{El}$ arco tiene una sección metálica poligonal, variando sus dimensiones entre $2.1 \mathrm{~m}$ en apoyos y $1.2 \mathrm{~m}$ en la clave. Por su parte, el tablero se compone de una sección cajón triangular, con un canto en el centro de $650 \mathrm{~mm}$, y de $250 \mathrm{~mm}$ en cada borde.
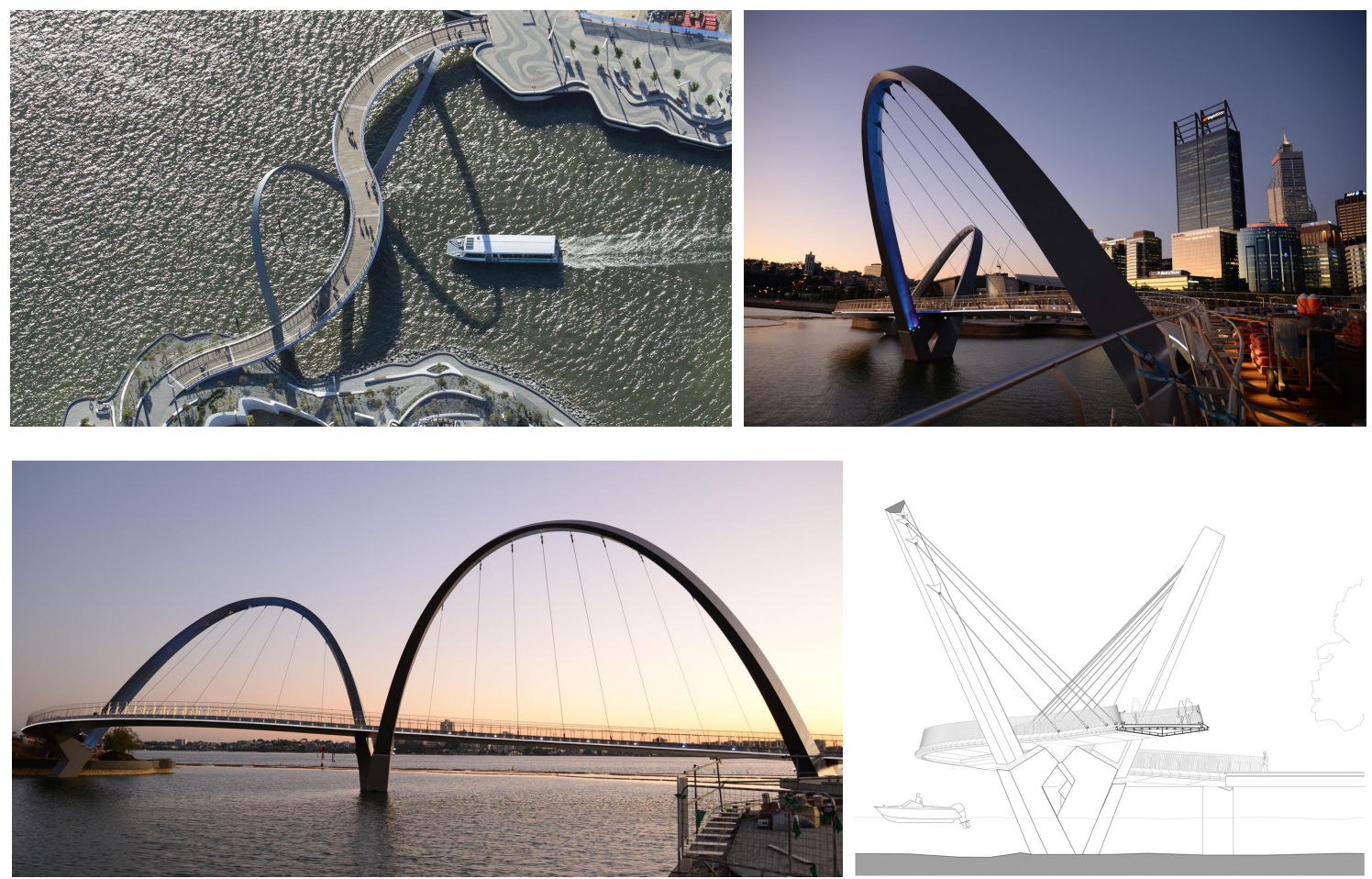

Figura 2.41: Elizabeth Quay Bridge. Fotografía: Jacaranda (archdaily.com) y Birmingham (archdaily.com).

\footnotetext{
${ }^{30}$ Esta pasarela ha recibido varios premios, como el Engineers Australia WA Excellence in Engineering 2016 o el prestigioso premio internacional IStructE Structural Award 2016 en la categoría "Pedestrian Bridges" (véase Burnton et al. [21]).
} 


\subsubsection{Fort York Pedestrian and Cycle Bridge (propuesta no construida)}

Esta pasarela, proyectada por Montgomery Sisam, se presentó a un concurso de la ciudad de Toronto (Canadá) para crear un nuevo acceso peatonal y ciclista entre el parque Stanley y el área de Fort York $^{31}$ (véase Hines et al. [38]).

La estructura (véase la figura 2.42) no ha sido construida, y constaría de un tablero en $\mathrm{S}$ y dos arcos inclinados, asemejándose bastante a la pasarela Elizabeth Quay Bridge. El tablero tendría una longitud de $300 \mathrm{~m}$, y la vinculación entre los arcos y el tablero se realizaría mediante péndolas rígidas.
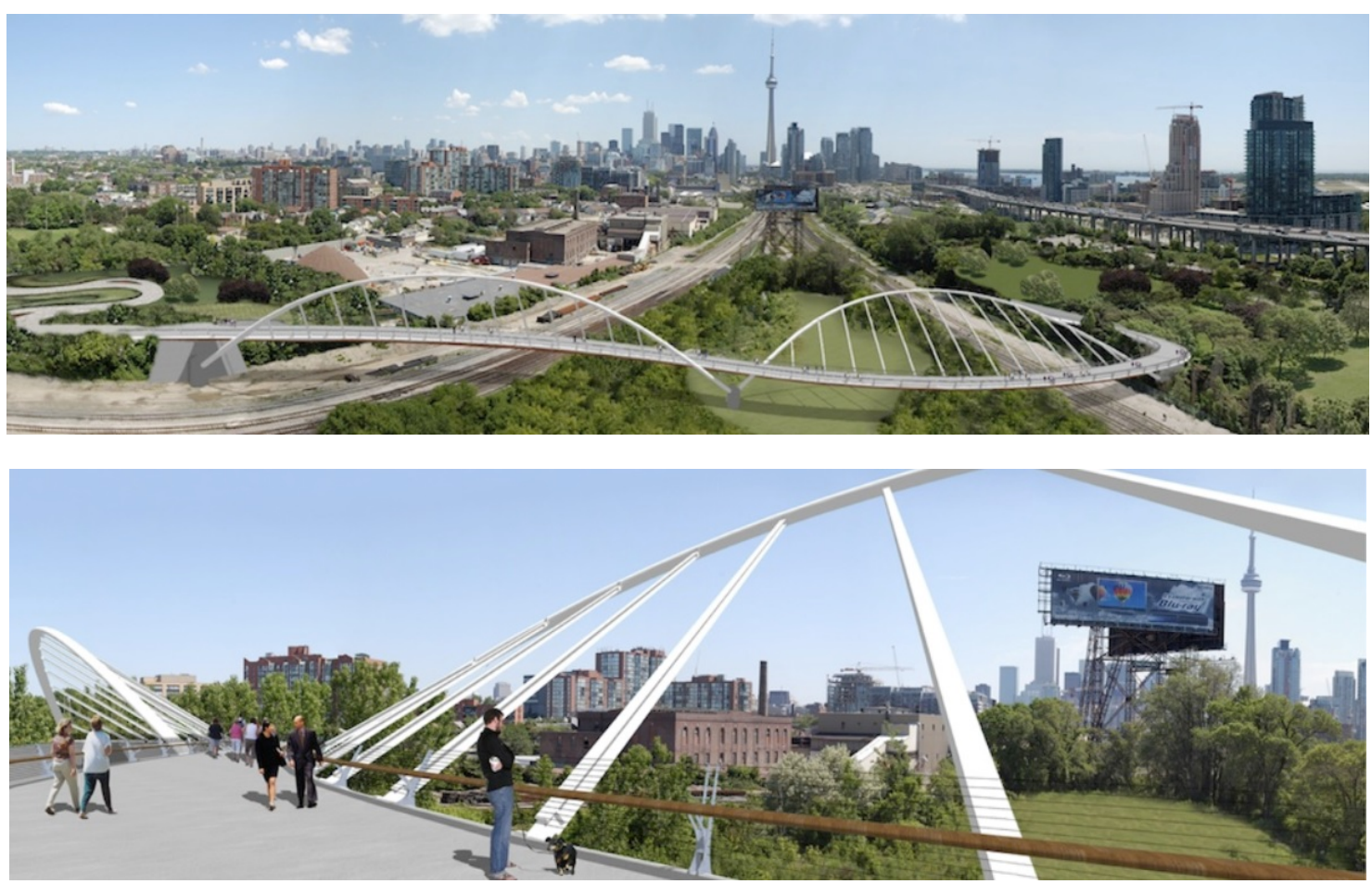

Figura 2.42: Fort York Pedestrian and Cycle Bridge. Fotografía: Urban Toronto (urbantoronto.ca).

\subsubsection{Weinberg Bridge}

El diseño original de la pasarela sobre el río Havel, en Rathenow (Alemania), fue desarrollado por cuatro estudiantes que participaban en la competición anual Schinkel para estudiantes y jóvenes profesionales, pratocinada por Architekten-und Ingenieur-Verein (AIV). La propuesta de los estudiantes consistía en un gran tablero con forma de S, el cual tenía dos vanos principales de 60 y $48 \mathrm{~m}$, estando estos sustentados por sendos arcos inclinados con arranques en el suelo (véanse Schlaich et al. [98] y Reyher [88]). La propuesta agradó a la ciudad de Rathenow, que se decidió a construirla, encargándose los trabajos al estudio Schlaich, Bergermann und Partner, finalizándose la pasarela en 2014.

\footnotetext{
${ }^{31}$ En la web urbantoronto.ca expecifican que esta pasarela no se construyó debido al coste, presentándose otra pasarelas para el concurso.
} 
La pasarela construida (véase la figura 2.43) tiene un tablero de $350 \mathrm{~m}$ de longitud y planta en S, respetándose los vanos de la propuesta inicial, de 60 y $48 \mathrm{~m}$. El tablero, con una ancho que varía entre 3 y $4 \mathrm{~m}$, tiene una sección cajón poligonal con un losa de hormigón no estructural.

Cada uno de los vanos principales se sustenta con un arco inclinado en torno a $25^{\circ}$, apoyándose los arranques de los arcos en una pila con forma de Y. Los arcos tienen una sección metálica cuadrada que se rellena con hormigón para compensar las cargas del tablero.

La vinculación entre los arcos y el tablero es bastante curiosa, pues las péndolas no se anclan al borde del tablero, sino a unas costillas de acero horizontales que salen desde el borde del tablero hacia el interior de la curvatura del mismo, lo que produce que las péndolas estén casi en el mismo plano del arco y se reduzcan notablemente los esfuerzos. Las reacciones horizontales del arco se contrarrestan atando los arranques con un cable que discurre por los anclajes entre las péndolas y las costillas de acero antes mencionadas, haciendo que en la práctica el arco sea tipo bow-string.
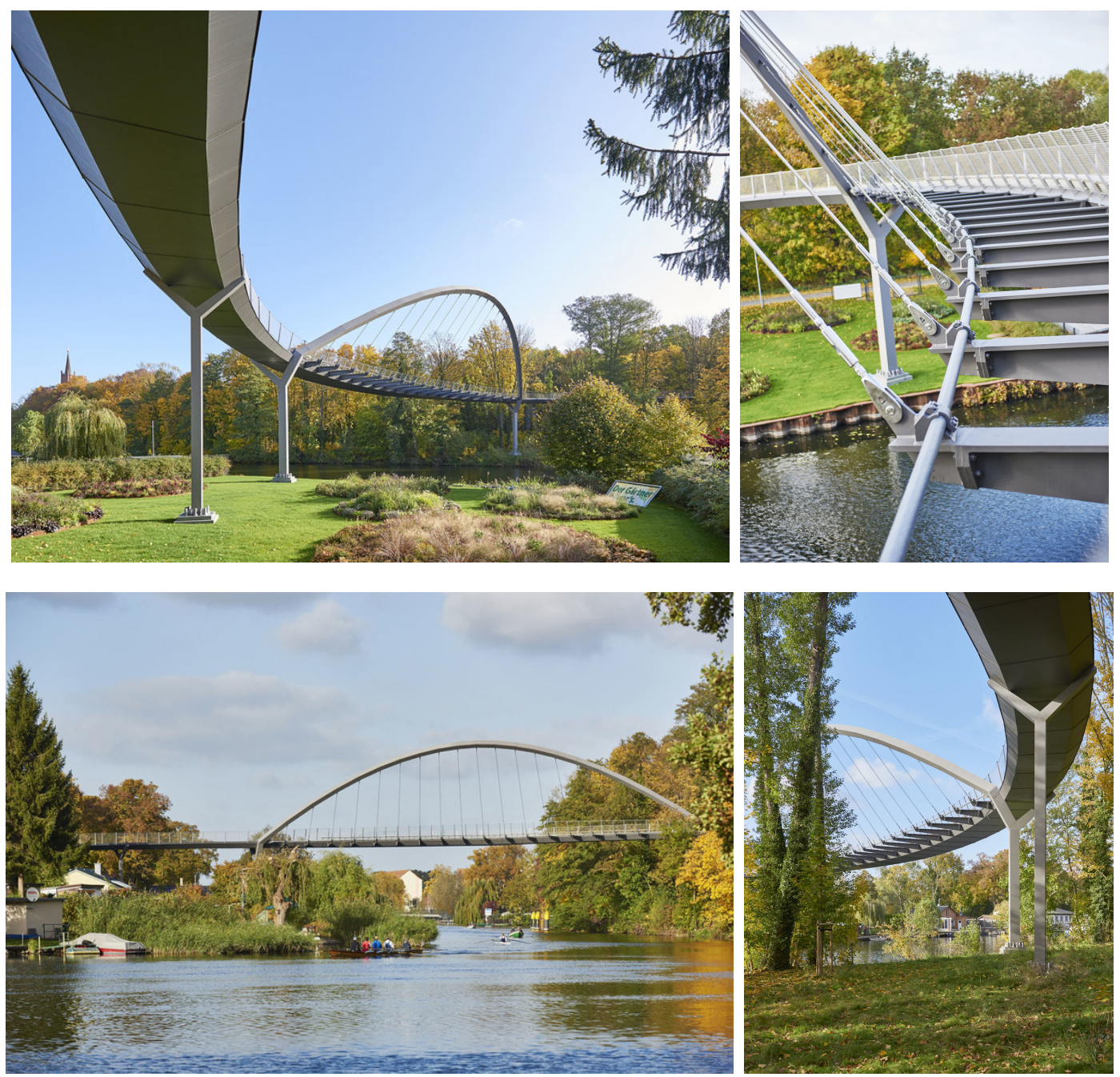

Figura 2.43: Weinberg Bridge. Fotografía: Stephan Falk (german-architects.com). 


\subsubsection{Whitehall Riverside Bridge}

Construida en el año 2008 sobre el río Aire, en Leeds (Reino Unido), la pasarela es proyecto del estudio Carey Jones Architects Ltd. La estructura pretende dar acceso y regenerar el área de Holbeck.

La pasarela (véase la figura 2.44) se compone de un tablero curvo sujeto a un borde por un arco plano inclinado. La vinculación entre el arco y el tablero se realiza mediante cables
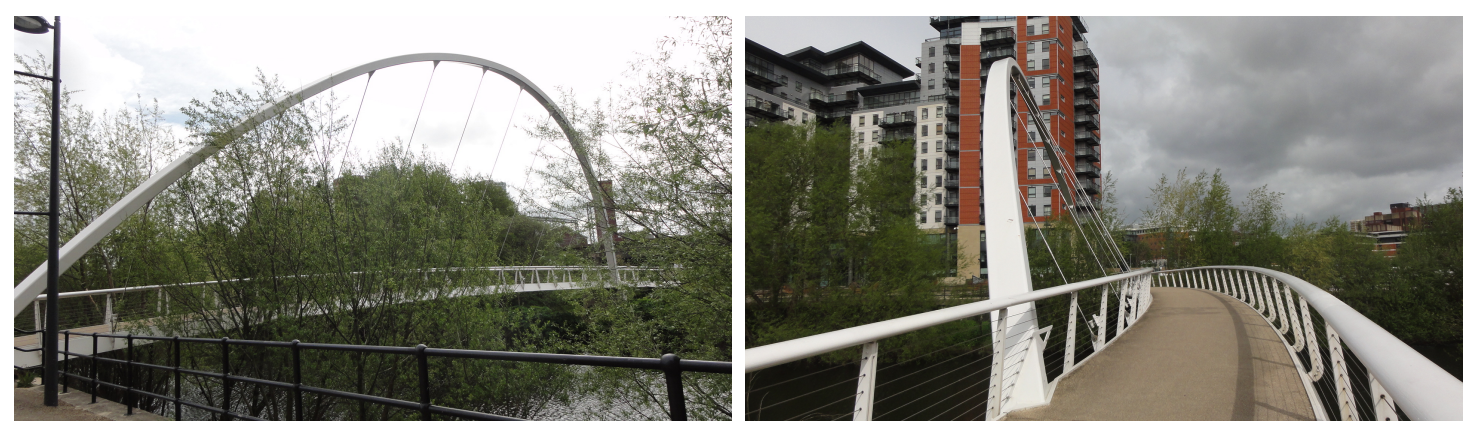

Figura 2.44: Whitehall Riverside Bridge. Fotografía: waymarking.com.

\subsubsection{Jiak Kim Bridge}

Esta pasarela, diseñada por Lim Peng Hong, se sitúa sobre el río Singapur en la ciudad homónima.

La pasarela (véase la figura 2.45) tiene un tablero curvo de $40.6 \mathrm{~m}$ de luz con un ancho de $3.5 \mathrm{~m}$, el cual está destinado exclusivamente a peatones y ciclistas. El tablero está sustentado de un solo borde mediante un arco inclinado hacia la curvatura del tablero. La altura del arco es de $8.7 \mathrm{~m}$, formando el plano que lo contiene un ángulo de $56.4^{\circ}$ con la horizontal (véase Idelberger [41]).
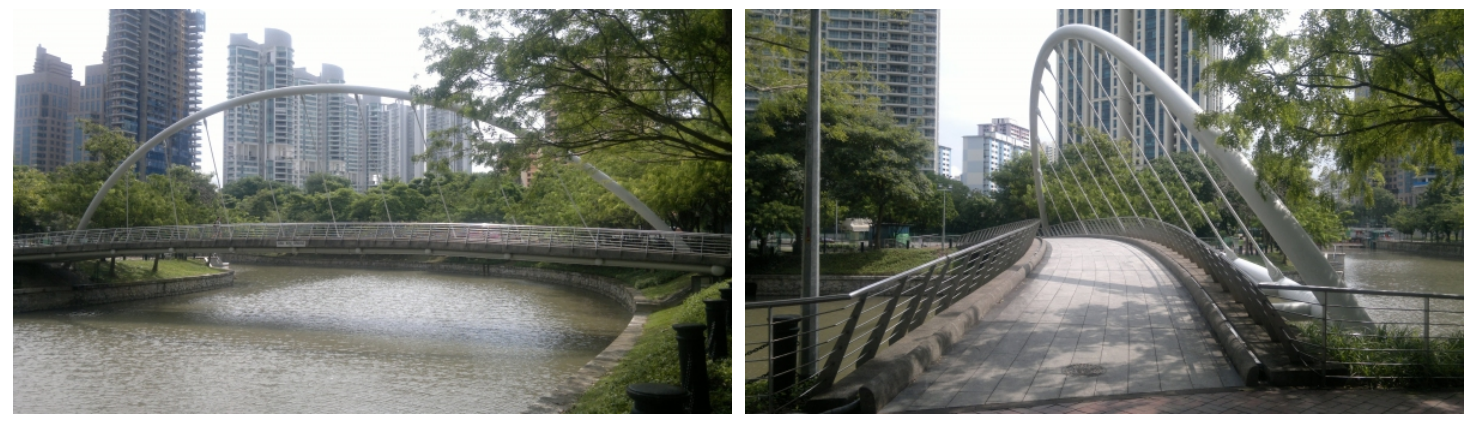

Figura 2.45: Jiak Kim Bridge. Fotografía: Prof. Peter Schaumann (structurae.net).

\subsubsection{Cathay Pacific City Footbridge}

Situada en la isla de Lantau (Hong Kong), esta pasarela se encuentra dentro del nuevo aeropuerto Check Lap Kok. El proyecto es de Harris \& Sutherland, finalizándose su 


\subsection{REALIZACIONES CON ASIMETRÍA LONGITUDINAL}
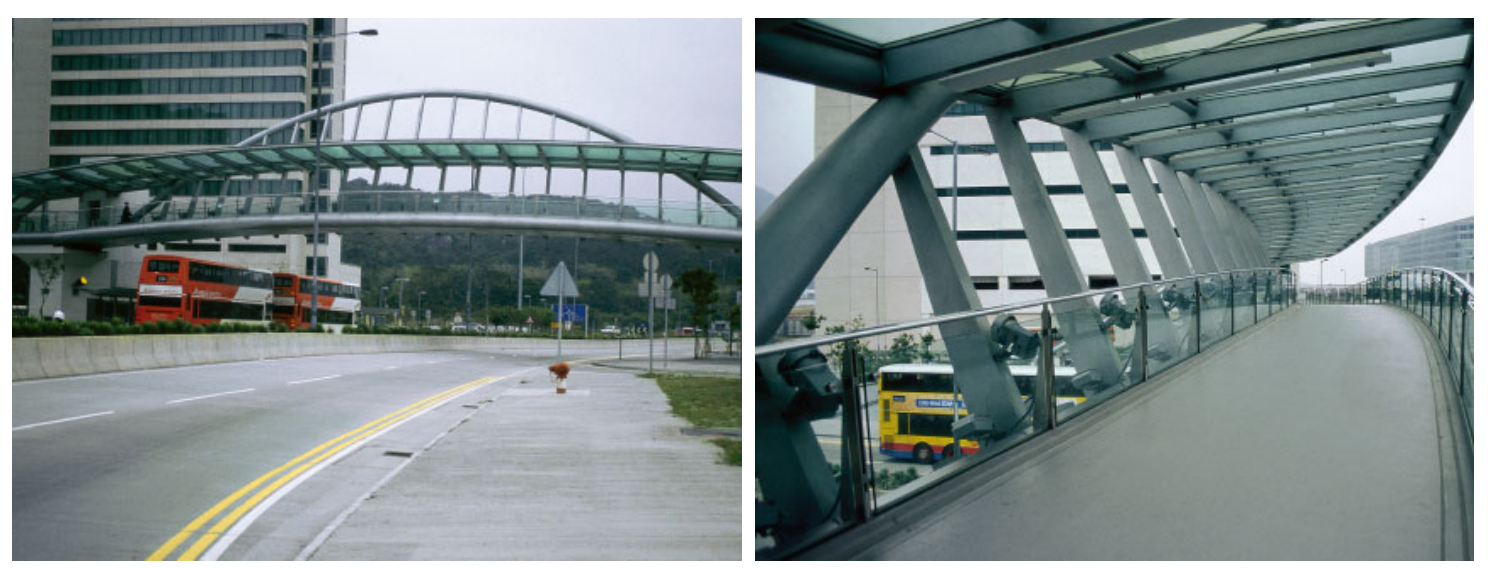

Figura 2.46: Cathay Pacific City Footbridge. Fotografía: extraídas de Idelberger [41].

construcción en 1999 (véase Idelberger [41]).

La pasarela, con una luz de $40 \mathrm{~m}$, se compone de un tablero curvo en planta de $3 \mathrm{~m}$ de ancho, sujeto a un solo borde mediante un arco inclinado $23.63^{\circ}$ respecto a la vertical (véase la figura 2.46). La vinculación entre el arco y el tablero se lleva a cabo mediante 19 péndolas rígidas de sección rectangular variable.

Con un esquema resistente muy parecido a pasarelas descritas anteriormente, la particularidad de la pasarela reside en el techo de vidrio dispuesto a mitad de altura del arco. Este techo está realizado con 19 vigas horizontales soldadas en cada una de las péndolas rígidas que vinculan el arco y el tablero.

\subsubsection{Puente de Schwandbach}

Proyecto de Robert Maillart, este puente arco de tablero superior construido en 1933 en Hinterfultigen (Suiza), es precursor del uso de arcos laminares, si bien por su tablero curvo puede ser considerado uno de los primeros puentes arco espaciales. La planta curva de este puente es resultado de un condicionante geométrico, mientras que hoy en día la mayoría de tableros curvos tienen un carácter estético ${ }^{32}$.

En el caso del puente de Schwandbach (véanse las figuras 2.5-c y 2.47), el arco tiene una directriz poligonal con un espesor de $20 \mathrm{~cm}$, permitiendo salvar una luz de $37.4 \mathrm{~m}$ (véase Billington [17] y [18]). En planta, el arco tiene una sección variable, teniendo un borde recto que coincide con la luz, y el otro borde curvo, coincidente con la planta del tablero.

El tablero es una losa de hormigón armado que queda vinculada al arco mediante unos tabiques trapeciales. Dada la mayor rigidez de este elemento con respecto al arco, el tablero es el que absorbe más flexión, estando sometido el arco solamente a compresión, lo que permite su gran esbeltez.

\footnotetext{
${ }^{32}$ Como en todo casi siempre hay excepciones, pues los puentes de Galindo y Endarlatsa, realizados a principios del nuevo milenio, tienen una planta curva impuesta por un requerimiento funcional.
} 

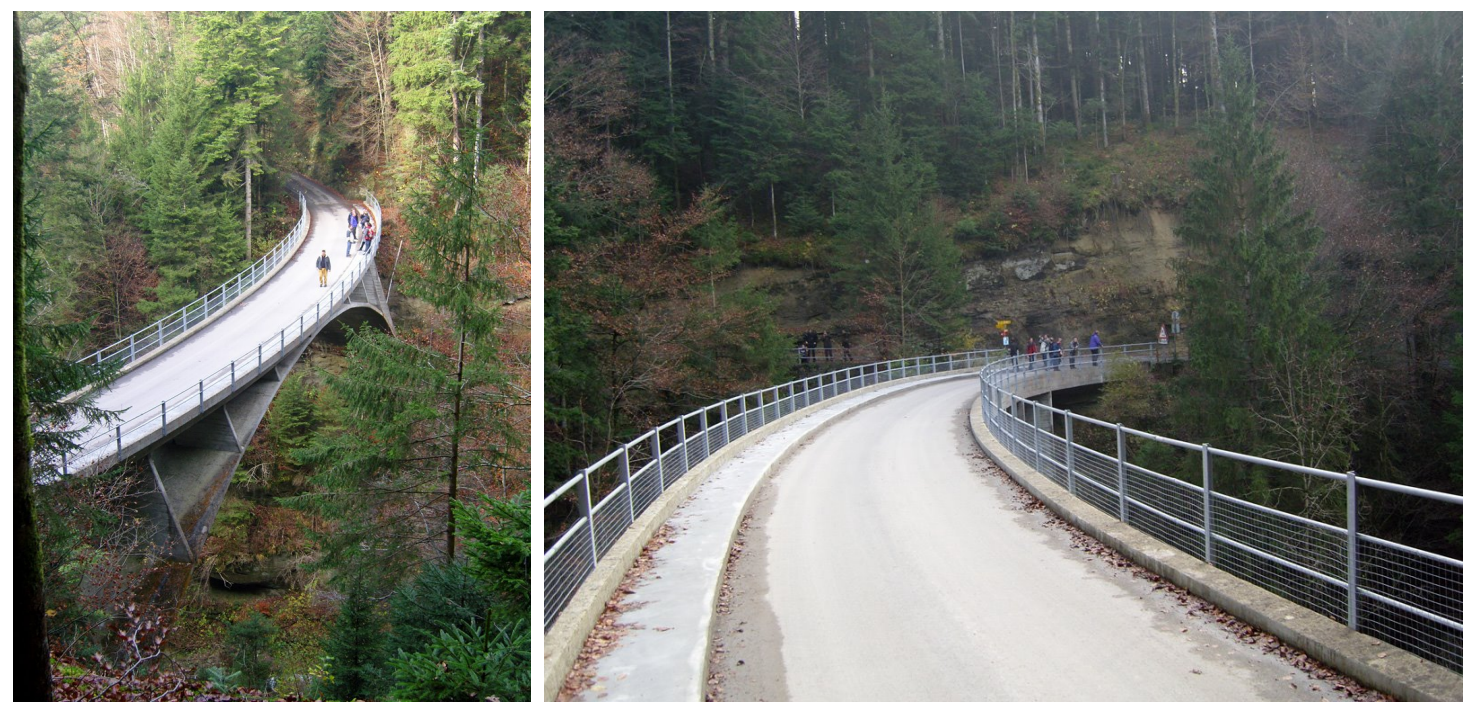

Figura 2.47: Puente de Schwandbach. Fotografía: The Happy Pontist.

\subsubsection{Arco girado con respecto de un eje vertical}

\subsubsection{Nordsternpark Double Arch Bridge}

Con una luz de arco de $79 \mathrm{~m}$ y un tablero de $109.3 \mathrm{~m}$ de longitud, esta pasarela realizada en 1996, es la mayor de las tres ${ }^{33}$ construidas para el Federal German Garden Show celebrado en la ciudad alemana de Gelsenkirchen. La tres pasarelas fueron proyectadas por Stephan Polónyi.

La estructura (véase 2.48) cruza el Rhine-Herne Canal gracias a dos arcos metálicos girados con respecto al tablero. En realidad los arcos son perpendiculares a los márgenes del canal, siendo el tablero el que cruza girado $51^{\circ}$.

La pasarela tiene un uso peatonal, si bien puede soportar el paso de un vehículo de mantenimiento de hasta $30 \mathrm{t}$ (véase Idelberger [41]). El tablero tiene un ancho de $5.5 \mathrm{~m}$, estando formado por dos perfiles HEB 600 (uno en cada borde) unidos transversalmente por $28 \mathrm{HEA} 340$ espaciados cada $2.75 \mathrm{~m}$. Encima de esta estructura se sitúa una chapa de acero de $12 \mathrm{~mm}$ de espesor rigidizada con nervios longitudinales de $6 \mathrm{~mm}$ de espesor.

Los arcos no tienen una directriz parabólica, sino que disponen de dos tramos rectos y un tramo central curvo. La directriz es asimétrica, situándose la clave del arco justo en el punto en el que el arco y el eje de tablero se cruzan. La sección de los arcos es circular hueca, con diámetro de $1200 \mathrm{~mm}$ en toda su directriz. Lo que si varía a lo largo de la directriz es su espesor, que es de $40 \mathrm{~mm}$ en los tramos rectos, y de $25 \mathrm{~mm}$ en la zona curva.

La vinculación de cada arco con el tablero se lleva a cabo mediante cables de acero de 50 mm de diámetro, anclados a ambos bordes del tablero mediante unos sobreanchos.

\footnotetext{
${ }^{33}$ Las otras dos pasarelas se mencionan en esta tesis como Lehrhovebruch Footbridge y Nordsternpark Arch Bridge.
} 

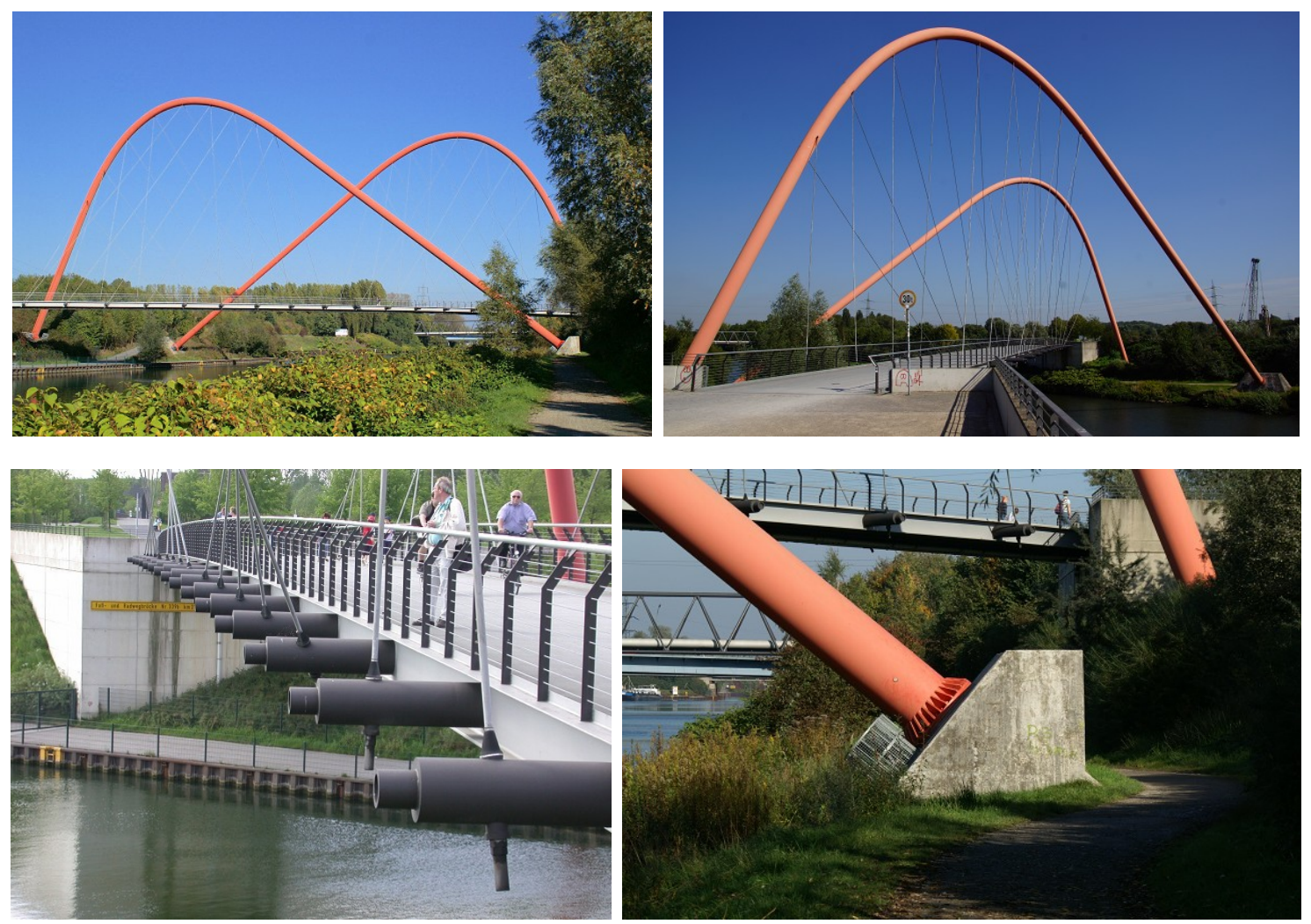

Figura 2.48: Nordsternpark Double Arch Bridge. Fotografía: Nicolas Janberg (structurae.net) y Thorsten Dahlmann (structurae.net).

\subsubsection{Lehrhovebruch Footbridge}

Es otra de las tres pasarelas proyectadas por Stephan Polónyi con motivo del Federal German Garden Show, celebrado en la ciudad alemana de Gelsenkirchen (véase Idelberger [41]). Esta pasarela constituye un icono de la entrada principal al Garden Show, permitiendo el acceso del área de Gelsenkirchen-Hessler (Alemania)

Con una estética muy similar a la pasarela Nordsternpark Double Arch Bridge, la estructura dispone en este caso de un solo arco girado $39.5^{\circ}$ con respecto al eje del tablero (véase la figura 2.49). La luz cubierta por esta estructura es de $42 \mathrm{~m}$, teniendo el tablero un ancho de $3.8 \mathrm{~m}$.

La directriz del arco es parabólica, realizándose su vinculación al tablero mediante cables a ambos bordes del tablero. El arco tiene un sección circular hueca de $20 \mathrm{~mm}$ de espesor, constante en toda la directriz. Por su parte el tablero tiene una sección muy parecida a la pasarela Nordsternpark Double Arch Bridge, con dos perfiles HEB 600 en los bordes unidos mediante 16 perfiles HEA 200 espaciados cada $2.625 \mathrm{~m}$. Encima de los perfiles anteriores se sitúa una chapa de $10 \mathrm{~mm}$ de espesor rigidizada con nervios longitudinales de $100 \mathrm{~mm}$ de canto. 


\subsubsection{Nordsternpark Arch Bridge}

Esta es la tercera y última de las tres pasarelas realizadas en Gelsenkirchen con motivo del Federal German Garden Show (véase Idelberger [41]). También proyectada por Stephan Polónyi, comparte su estética con las pasarelas antes mencionadas, algo premeditado sin lugar a dudas, y con lo que se pretende remarcar un camino o acceso común al Garden Show.

La pasarela (véase la figura 2.50) se sitúa sobre el río Emscher, teniendo el arco una luz de $40 \mathrm{~m}$ y el tablero una de $46.15 \mathrm{~m}$. El arco en planta es perpendicular al eje del río, siendo el tablero el que se gira $19^{\circ}$. Las secciones del arco y el tablero, así como el esquema resistente de la estructura, son similares a los de la pasarela Lehrhovebruch Footbridge, antes descrita.
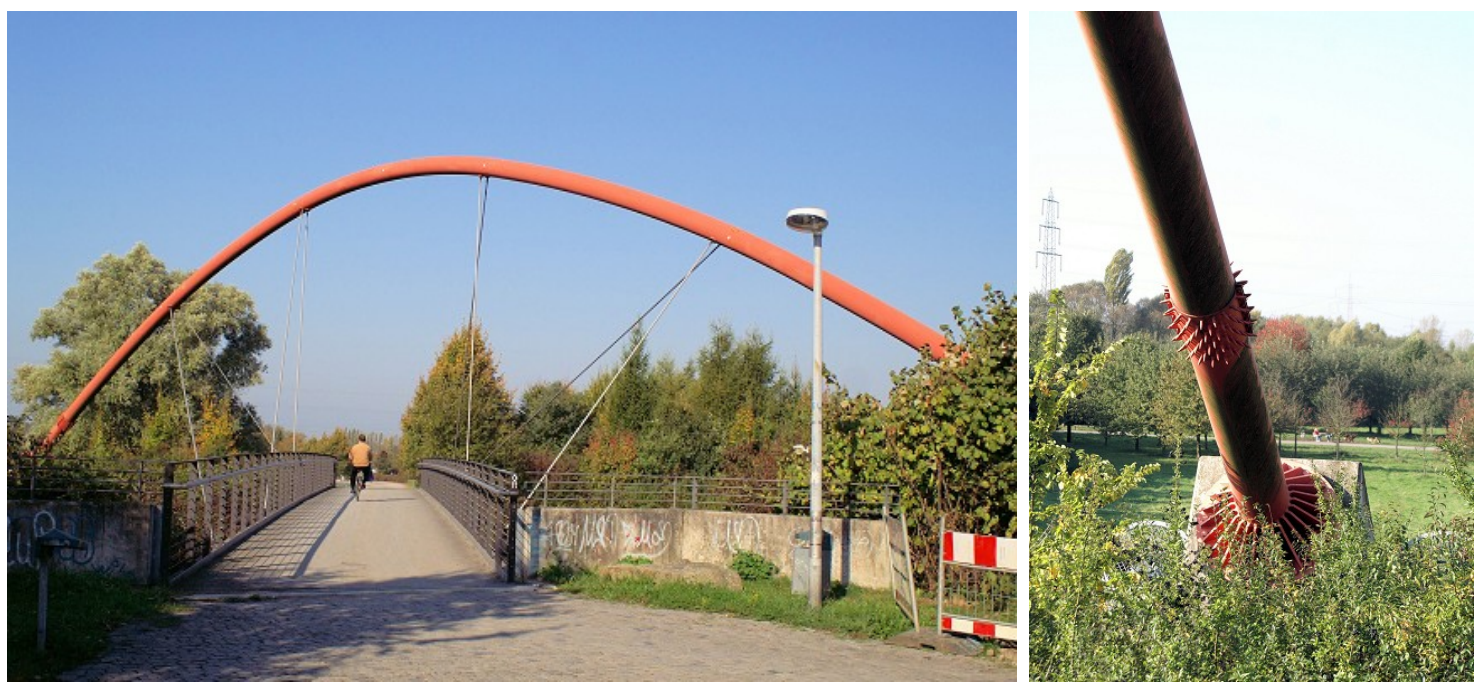

Figura 2.49: Lehrhovebruch Footbridge. Fotografía: Nicolas Janberg (structurae.net).
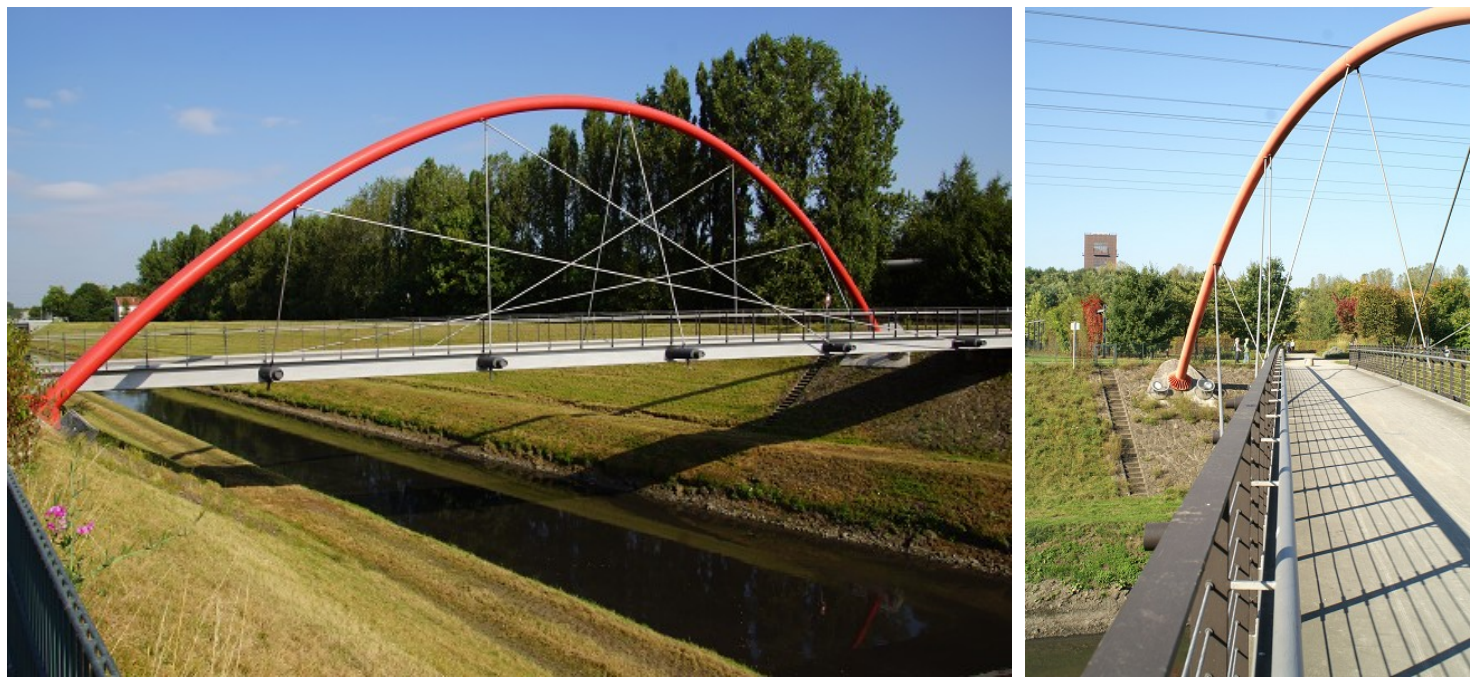

Figura 2.50: Nordsternpark Arch Bridge. Fotografía: Nicolas Janberg (structurae.net). 


\subsubsection{Hulme Arch Bridge}

Construido en el año 1997 en Manchester (Reino Unido), el proyecto fue realizado por Chris Wilkinson Architects (Arquitectura) y Arup (Ingeniería). El puente (véase la figura 2.51) se realizó con el fin de que se convirtiera en el símbolo de la regeneración del área de Hulme, en el sur de Manchester, un área asociada a viviendas de mala calidad y a oportunidades limitadas. Con esto, se decidió incrementar la accesibilidad del área, restaurando la conexión de la calle Stretford Road, la cual había quedado divida en 1969 por la calle Princess Road, una arteria de mayor capacidad.

La estructura se compone de un arco diagonal de acero que sustenta un tablero de $52 \mathrm{~m}$ de luz y un ancho aproximado de 15 m (véanse Hussain y Wilson [40] y Warren [125]). La sección del arco es trapecial, presentando este una altura máxima sobre el tablero de 25 m. Por su parte, el tablero es mixto, con dos nervios principales de acero en cada borde conectados entre si por 17 vigas transversales.

La vinculación entre el arco y el tablero se realiza mediante cables a ambos bordes del tablero, con lo que los momentos transversales en el arco son muy importantes, llegando a decir los autores en Hussain y Wilson [40], que el arco funciona más como viga balcón que como un arco convencional.
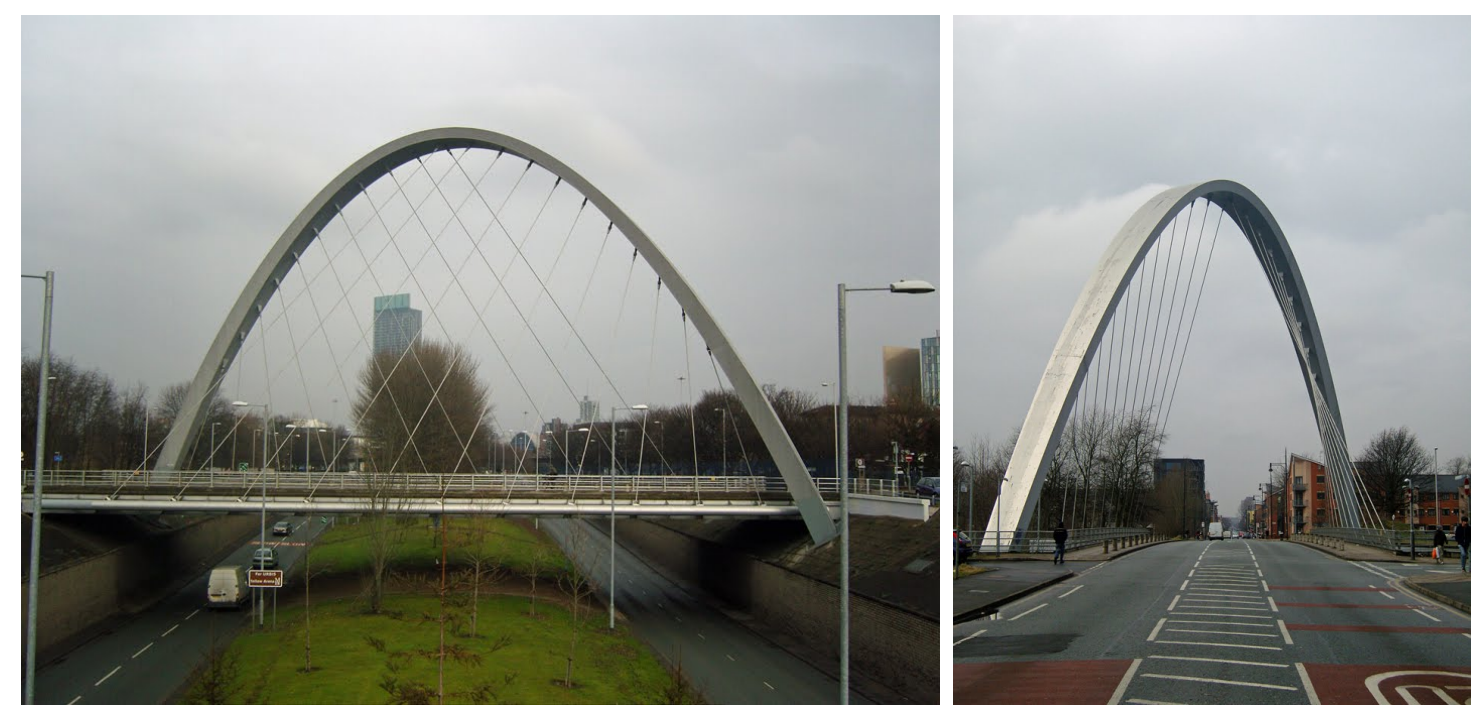

Figura 2.51: Hulme Arch Bridge. Fotografía: The Happy Pontist.

\subsubsection{Puente Juscelino Kubitschek}

El puente está situado en Brasilia (Brasil), ciudad que ha incrementado notablemente su población, pasando del medio millón de habitantes previsto a unos dos millones. La mitad de esta población reside en el distrito federal, mientras que la otra mitad lo hace en poblaciones cercanas. Este incremento de población hizo necesario aumentar las red de carreteras, con lo que se decidió construir el puente Juscelino Kubistchek sobre el lago Paranoá, conectando así el Distrito Federal con la zona sur (véase Tarquis y Hue [112]). El proyecto del puente fue realizado por un equipo multidisciplinar, donde se encontraban 
los ingenieros Mario Vila Verde, Filemon Botto de Barros y Piotr Slawinski, y el Arquitecto Alexandre Chan, pertenecientes todos ellos al estudio Projconsult. El desarrollo del proyecto fue llevado a cabo por Projconsult, junto con la empresa COWI Consultants.

La longitud total del puente es de $1200 \mathrm{~m}$, siendo el tablero en planta una curva de radio $3150 \mathrm{~m}$. En el puente destaca una zona central formada por tres vanos de 240, quedando cada vano suspendido de un arco vertical exento que cruza el vano diagonalmente (véase la figura 2.52).

El tablero es metálico en los vanos suspendidos por los arcos, y mixto en los accesos. Con un ancho de $24 \mathrm{~m}$, tiene una capacidad de 6 carriles ( 3 por sentido).

El arco es de hormigón en los arranques y hasta la altura del tablero, pasando en ese momento a tener una sección metálica. Toda la directriz del arco tiene una sección trapezoidal variable, pasando de $6.5 \mathrm{~m}$ de ancho y $5 \mathrm{~m}$ de canto en arranques, a $5 \mathrm{~m}$ de ancho y $3 \mathrm{~m}$ de canto en la clave.

La vinculación entre cada arco y el tablero se realiza mediante 16 pares de péndolas dispuestas a lo largo del tablero (se anclan ambos bordes), con una equidistancia de $20 \mathrm{~m}$ entre sus anclajes inferiores y de unos $18 \mathrm{~m}$ en los superiores. Las péndolas están inclinadas en ambos sentidos y son del tipo de cordones paralelos.

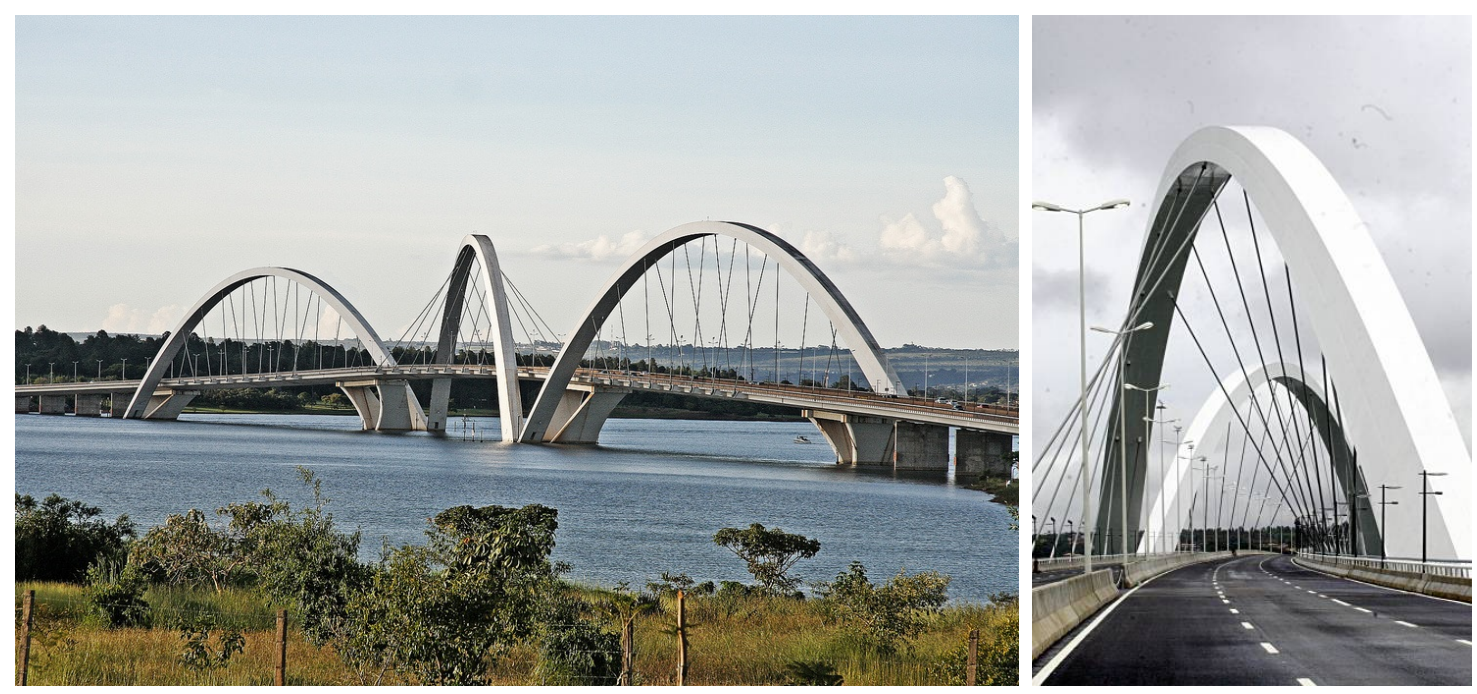

Figura 2.52: Puente Juscelino Kubitschek. Fotografía: megaconstrucciones.net y Alexandre Chan (structurae.net).

\subsubsection{Pont Citadelle}

Finalizado en el año 2017, el puente ${ }^{34}$ se construyó para dar servicio a la línea D del tranvía de la ciudad de Estrasburgo (Francia). En concreto el puente da acceso al área portuaria de Vauban, en la zona francesa de la ciudad (véase Siotor et al. [102]).

El puente, con una luz de $180 \mathrm{~m}$, tiene un tablero curvo de $16 \mathrm{~m}$ de ancho sujeto por un arco diagonal de $40 \mathrm{~m}$ de altura (véanse las figuras 2.9-b y 2.53). La vinculación entre el

\footnotetext{
${ }^{34}$ También se puede encontrar en la bibliografía con el nombre André Bord Bridge.
} 
arco y el tablero se lleva a cabo mediante cables diagonales conectados a ambos bordes del tablero.
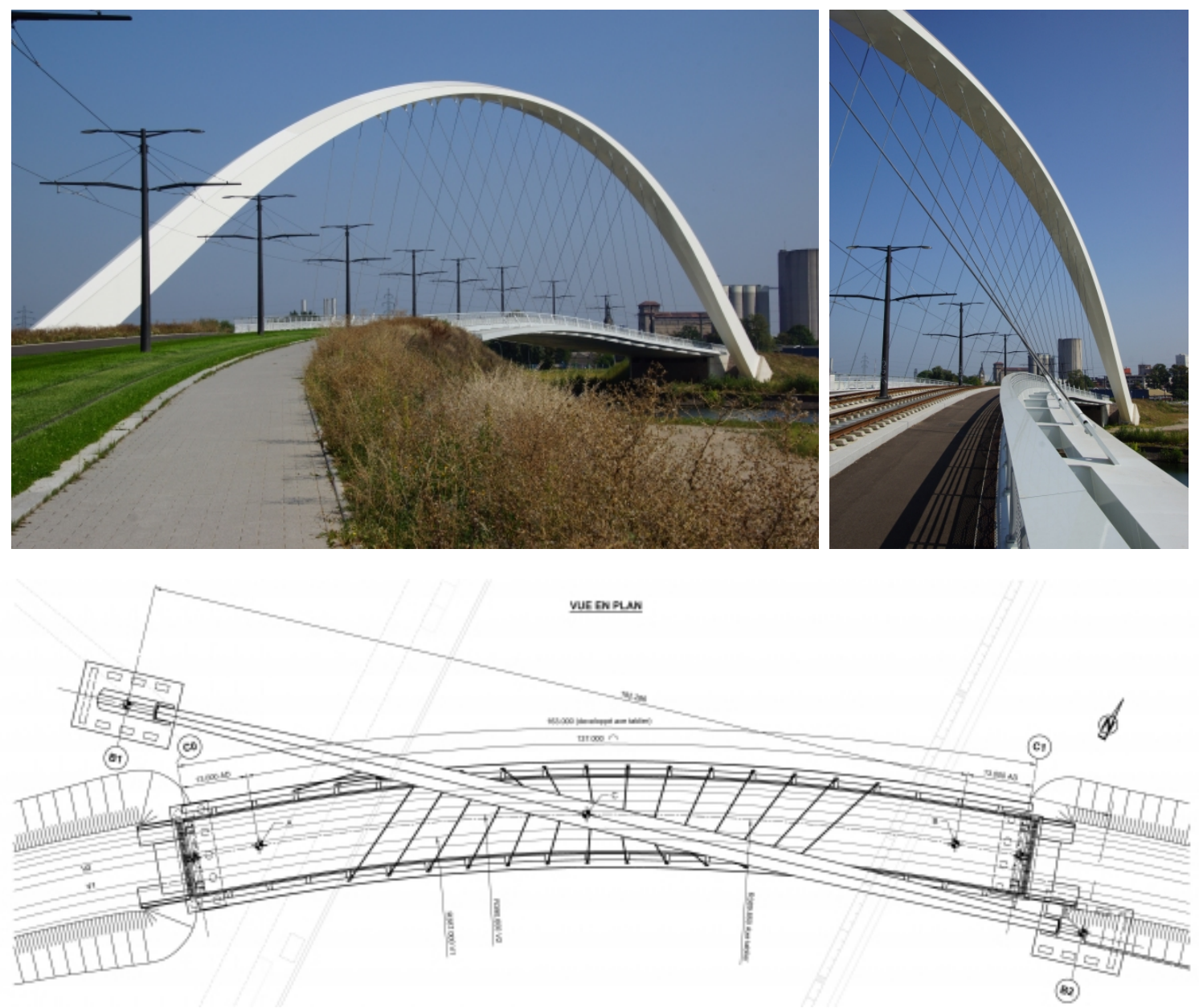

Figura 2.53: Pont Citadelle. Fotografía: Nicolas Janberg (structurae.net) y Nabil Yazbeck (structurae.net).

\subsubsection{Arco de directriz espacial}

\subsubsection{Ripshorst Footbridge}

Esta pasarela, construida en 1998, es proyecto de Jörg Schlaich (Schlaich, Bergermann und Partner). La pasarela de Ripshorst cruza el canal Rin-Herne, dando servicio a los peatones y ciclistas que quieren cruzar el mismo en la ciudad de Oberhausen (Alemania). La longitud total de la pasarela es de $130 \mathrm{~m}$, siendo la luz del arco de $78 \mathrm{~m}$ (véanse Schlaich [95] y [96], así como Bögle et al. [16]).

La mayoría de los arcos espaciales son de tablero inferior, sin embargo existen ejemplos de tablero superior, como Ripshorst, que es además el primer arco espacial de doble curvatura. Este puente (véanse las figuras 2.11 y 2.54) está muy relacionado con la pasarela de Kelheim (Kelheim, Alemania, 1988), también del estudio Schlaich, Bergermann und Partner. Si se comparan ambas estructuras, se puede observar como Ripshorst se obtiene 
si se da la vuelta a Kelheim y se cambian los cables traccionados por barras comprimidas. Se podría decir que Ripshorst es el puente especular de Kelheim.
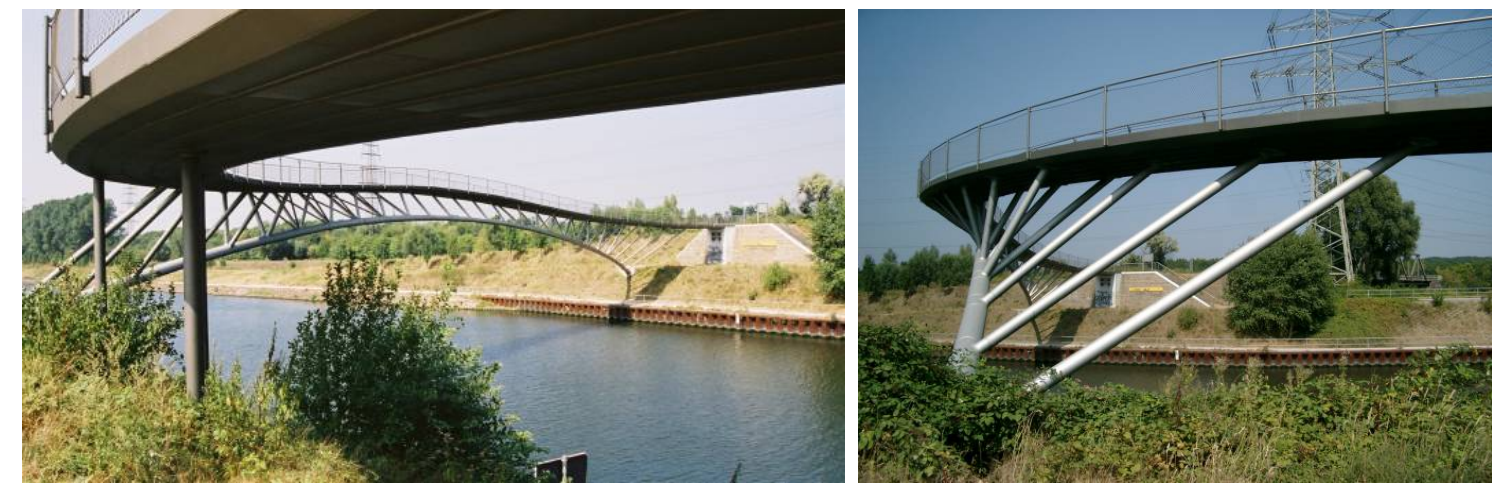

Figura 2.54: Ripshorst Footbridge. Fotografía: Nicolas Janberg (structurae.net).

\subsubsection{Puente sobre el río Galindo}

Construido en 2007 sobre el río Galindo (Bilbao, España), el puente, proyectado por Javier Manterola, es el el primer puente arco espacial de curvatura impuesta y tablero inferior.

En este caso la espacialidad del puente no es fruto de la estética, sino de unas condiciones de proyecto muy duras (véase Aguiló et al. [2]). En concreto el puente no podía tener apoyos intermedios, teniendo una luz bi-apoyada de $110 \mathrm{~m}$. Tampoco podía tener vigas de más de dos metros de canto y era de planta curva con un radio de $250 \mathrm{~m}$. Con esos condicionantes geométricos, la estructura tenía que ser colocada forzosamente encima del tablero.

El puente actual ${ }^{35}$ (véase la figura 2.55) tiene un tablero metálico curvo en planta que queda sustentado por un arco también metálico y espacial no contenido en el plano. El arco tiene un perfil parabólico de $2^{\circ}$ grado en alzado y la planta sigue la directriz curva del tablero (véanse Manterola y Gil [62], y Jorquera Lucerga y Manterola [49]).

El tablero, totalmente metálico, tiene $2 \mathrm{~m}$ de canto y un ancho de $27 \mathrm{~m}$. Junto al borde exterior del tablero curvo se dispone una acera de $6 \mathrm{~m}$ de ancho cubierta por una marquesina de acero y metracrilato no resistente. El puente soporta el trafico de cuatro carriles (dos por sentido), que quedan separados por el arco curvo en planta.

El arco está formado por dos tubos de $1219 \mathrm{~mm}$ de diámetro y $50.8 \mathrm{~mm}$ de espesor, unidos en la parte superior e inferior por chapas horizontales de $50 \mathrm{~mm}$ de espesor. La vinculación entre el arco y el tablero se lleva acabo mediante dos juegos de péndolas. El primero de ellos está compuesto por tubos de $193.7 \mathrm{~mm}$ de diámetro y $19 \mathrm{~mm}$ de espesor, atando el arco y el tablero verticalmente. El segundo juego de cables, situados casi horizontalmente, se encarga de controlar la fuerza horizontal de desvío del arco anclándolo a unas costillas de acero que se sitúan en el borde interno del tablero. Estos cables de contrarresto tienen un diámetro de $83 \mathrm{~mm}$.

\footnotetext{
${ }^{35}$ Se barajaron varias soluciones, entre las que destaca un arco de cordones variables, y otra solución con un arco curvo en planta como el actual, pero unido al tablero mediante péndolas rígidas (véanse Aguiló et al. [2], Manterola et al. [61] y el capítulo 8).
} 


\subsection{REALIZACIONES CON ASIMETRÍA LONGITUDINAL}
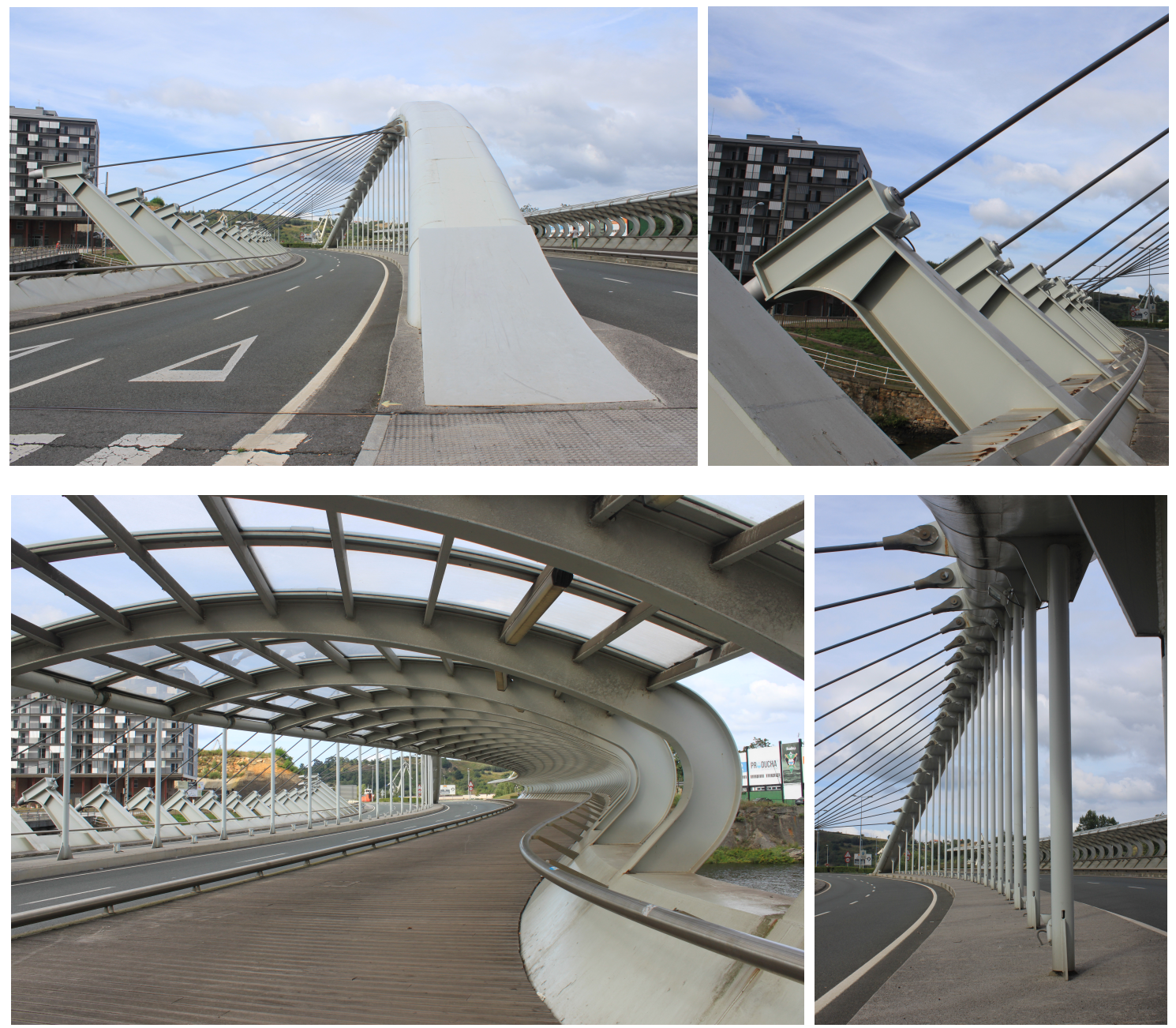

Figura 2.55: Puente sobre el río Galindo. Fotografía del autor.

\subsubsection{Puente de Endarlatsa}

El puente de Endarlatza, construido en el año 2009, cruza el río Bidasoa en la confluencia de Navarra, Guipúzcoa y Francia. El puente, proyectado por Javier Manterola, se sitúa aguas arriba del puente existente, al que pretende sustituir (véase Manterola y MuñozRojas [63]).

El puente (véase la figura 2.56) tiene una planta curva de $190 \mathrm{~m}$ de longitud, repartida en 10 luces $(15 \mathrm{~m}+8 \times 20 \mathrm{~m}+15 \mathrm{~m})$. La planta curva consiste en la unión de dos curvas (de radio $3500 \mathrm{~m}$ y $320 \mathrm{~m}$ respectivamente) mediante una clotoide de $66 \mathrm{~m}$ de longitud. Los cinco vanos centrales de $20 \mathrm{~m}$ de longitud se apoyan en un arco parabólico de $100 \mathrm{~m}$ de luz y una flecha de $10 \mathrm{~m}$. Dado que el tablero es curvo, el arco se proyectó también con planta curva, a fin de que los montantes verticales coincidieran en todo momento con la directriz del arco en planta.

El tablero está formado por una viga cajón con una sección metálica en artesa, sobre la que se disponen prelosas de hormigón que sirven de soporte a una losa armada de hormigón de $0.2 \mathrm{~m}$ de espesor. La sección de arco dispone de dos tubos de borde de 1 

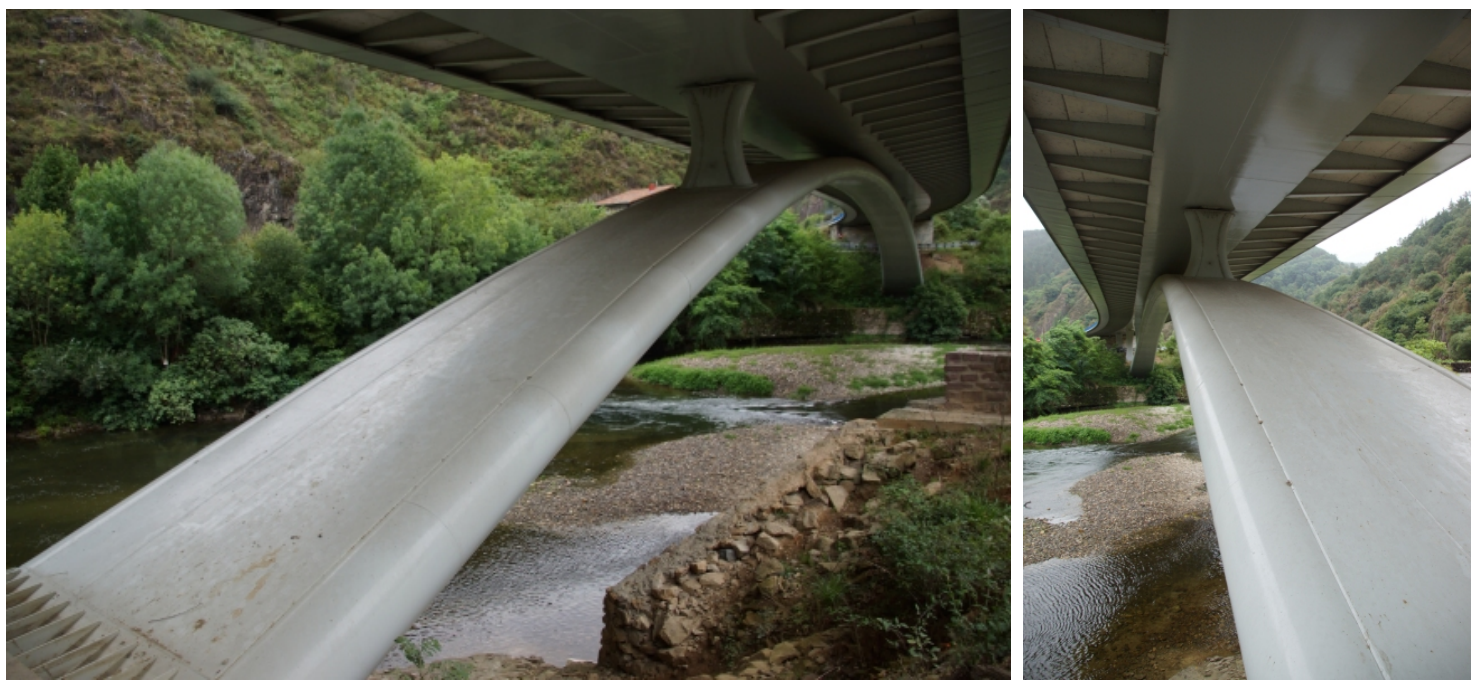

Figura 2.56: Puente de Endarlatsa. Fotografía: Nicolas Janberg (structurae.net).

m de diámetro y $25 \mathrm{~mm}$ de espesor rellenos de hormigón. Ambos arcos están unidos con chapas tangentes horizontales de $25 \mathrm{~mm}$, las cuales se encuentran rigidizadas longitudinal y transversalmente.

El tablero se apoya en el arco mediante pilares de sección pseudocilíndrica, colocándose sobre la cabeza de estos pilares apoyos tipo "pot" multidireccionales.

\subsubsection{Glasgow Bridge (propuesta no construida)}

Proyecto del estudio de arquitectura de Richard Rogers, y del estudio de ingeniería Atkins, la pasarela ganó el concurso de la ciudad de Glasgow (Reino Unido) para construir un nuevo puente sobre el río Clyde, si bien la pasarela no ha sido construida en la actulidad.

La estructura (véase la figura 2.57) se compone de un tablero curvo que es sustentado por un arco con una planta también curva, con lo que la fuerza horizontal de desvío del arco es contrarrestada por unos cables de retenida que se atan a sendos anclajes en la orilla.
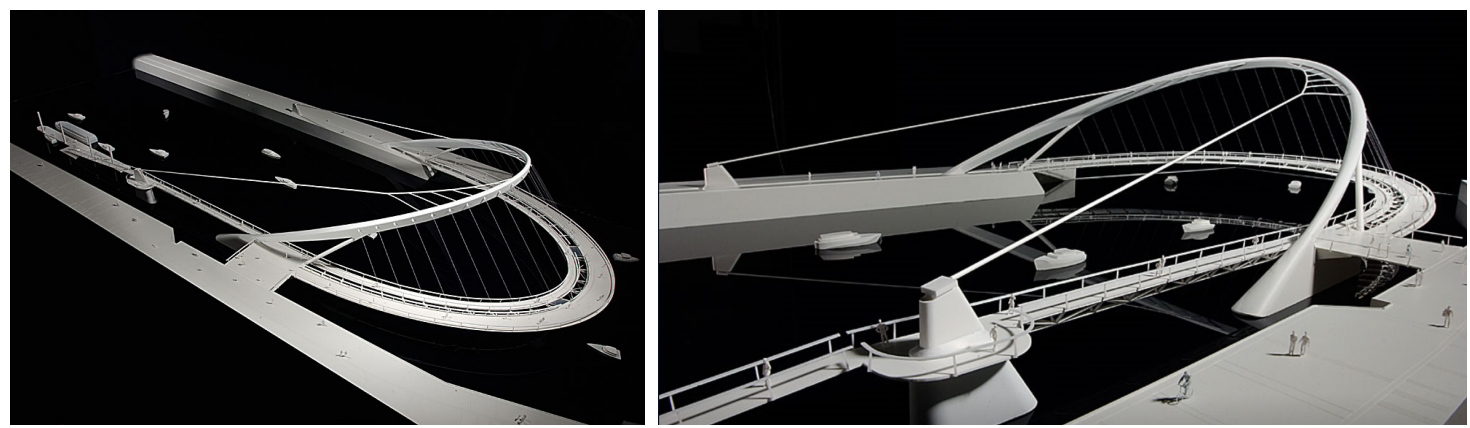

Figura 2.57: Glasgow Bridge. Fotografía: The Happy Pontist y Archello (sp.archello.com). 


\subsubsection{Pasarela ciclo-peatonal sobre el río Amstel en Amsterdam (propuesta no construida)}

Proyectada por el estudio FCK, la pasarela se presentó a un concurso de la ciudad de Amsterdam para crear un acceso al Museo Hermitage sobre el río Amstel (véase [79]). La estructura (no construida) cubre una luz de $80 \mathrm{~m}$ con un tablero en forma de $\mathrm{S}$ y un ancho variable entre 5 y $10 \mathrm{~m}$ (véase la figura 2.58). Una de las características del puente radica en que el arco tiene una planta también en forma de $\mathrm{S}$, lo que según sus autores, permite obtener una buena aproximación al antifunicular de las cargas no alineadas.

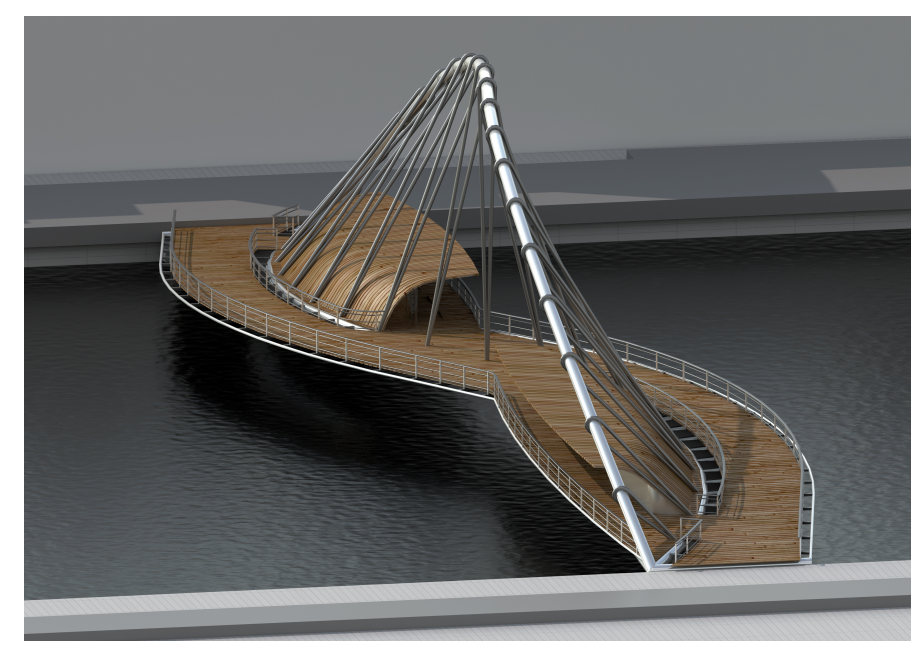

Figura 2.58: Pasarela ciclo-peatonal sobre el río Amstel en Amsterdam. Fotografía: FCK consultoría estructural.

\subsubsection{Diseño de puente en Deizisau (propuesta no construida)}

Proyectada por el estudio Schlaich, Bergermann und Partner en la ciudad alemana de Deizisau, esta pasarela dispone de un arco con una directriz espacial asimétrica (véanse Baus y Schlaich [14], y Jorquera Lucerga y Manterola [45]).

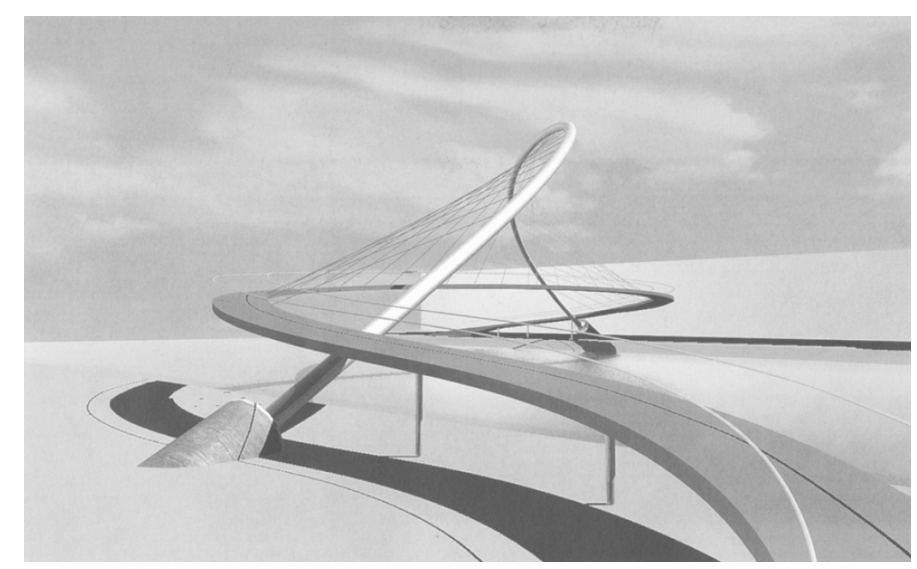

Figura 2.59: Diseño de puente en Deizisau. Fotografía: extraída de Baus y Schlaich [14]. 


\subsection{Realizaciones con simetría longitudinal}

En este apartado se pretenden mostrar puentes arco espaciales con simetría longitudinal, construidos y no construidos hasta la fecha. Al igual que ocurría en el punto 2.6, no se pretenden recoger todas las estructuras existentes, sino aquellas que por sus características resultan más significativas.

\subsubsection{Arco girado perpendicularmente al eje de tablero}

\subsubsection{Puente de acceso al Museo Miho}

Finalizado en el año 1997, el puente Miho da acceso al Museo homónimo, en Shigaraki (Japón). El proyecto es de I. M. Pei (arquitectura) y Leslie Robertson (ingeniería).

El Museo Miho se encuentra en un entorno protegido, con lo que la construcción de un acceso a este museo debía tener la mínima afección al entorno. En concreto, la estructura de acceso se proyectó como un túnel y un puente a la salida de este, puente que fue diseñado para salvar el desnivel del terreno sin necesidad de colocar pilas en el entorno, reduciendo al máximo el posible impacto (véanse Idelberger [41], Wells [126] y Robertson et al. [89]).

El puente (véanse las figuras 2.9-a y 2.60) dispone de un doble sistema de atirantamiento superior e inferior, donde el atirantamiento superior se realiza mediante un arco girado $90^{\circ}$ con respecto al eje del tablero, y a la vez inclinado. Mediante este sistema de doble atirantamiento, el canto del tablero se reduce a $2 \mathrm{~m}$ para salvar $120 \mathrm{~m}$ de longitud. El arco dispone de dos familias de cables, una de las cuales se ancla a los bordes del tablero, mientras que la otra sirve de contrarresto, anclando el arco al emboquille del túnel.

\subsubsection{Puentes de Reggio Emilia}

Un conjunto de tres puentes, proyectados por Santiago Calatrava, fue inaugurado en el 2007 en la ciudad de Reggio Emilia, cerca de Bolonia (Italia). Los tres puentes son parte de un plan más amplio, encargado por la ciudad de Reggio Emilia a Calatrava, plan que incluía una nueva estación de alta velocidad y una mejora del acceso norte de la ciudad.

Los tres puentes proyectados conectan la Autoestrada del Sole (A1) con Reggio Emilia, creando una imponente entrada desde el norte a la ciudad. De estos tres puentes, dos están girados $90^{\circ}$ con respecto al tablero, mientras que el puente restante, situado entre los otros dos, es un arco simétrico no girado (véase [83]).

Los dos puentes con arcos girados perpendicularmente al eje del tablero ${ }^{36}$, cubren cada uno una luz de $179 \mathrm{~m}$ con una tablero de $13.6 \mathrm{~m}$ de ancho. El arco en ambos casos tiene una altura de $68.8 \mathrm{~m}$, teniendo según Calatrava, forma de hipérbola. La vinculación entre cada arco girado y su correspondiente tablero, se lleva a cabo mediante dos familias de tirantes, compuestas cada una por 26 cables, que parten de la zona más alta del arco y se anclan al centro del tablero (véase la figura 2.61).

${ }^{36}$ Dependiendo de la fuente consultada, se suelen llamar Ponte Laterale Sud y Ponte Laterale Nord 

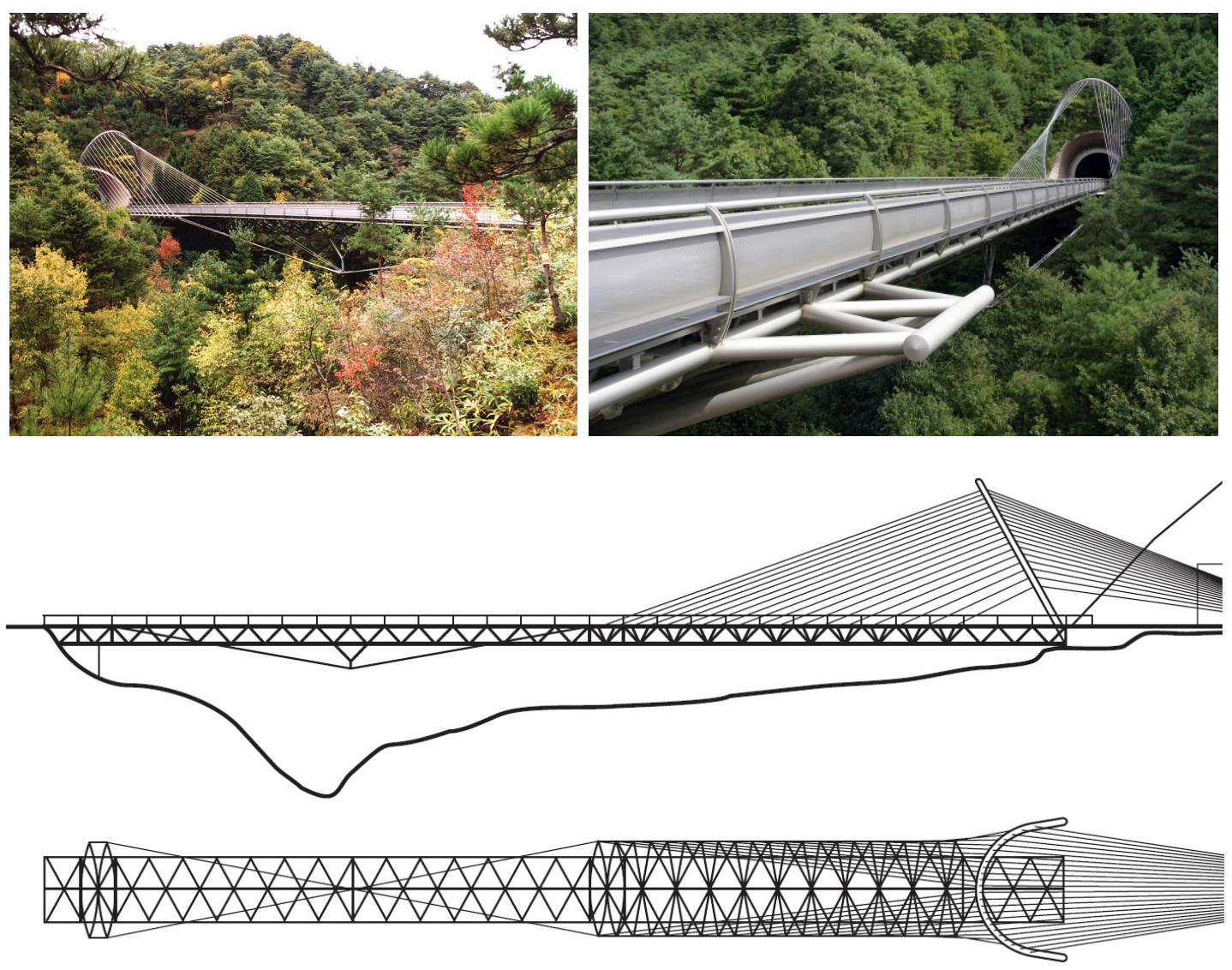

Figura 2.60: Puente de acceso al Museo Miho. Fotografía: extraídas de Idelberger [41], Leslie E. Robertson Associates (lera.com) y 663highland (structurae.net).
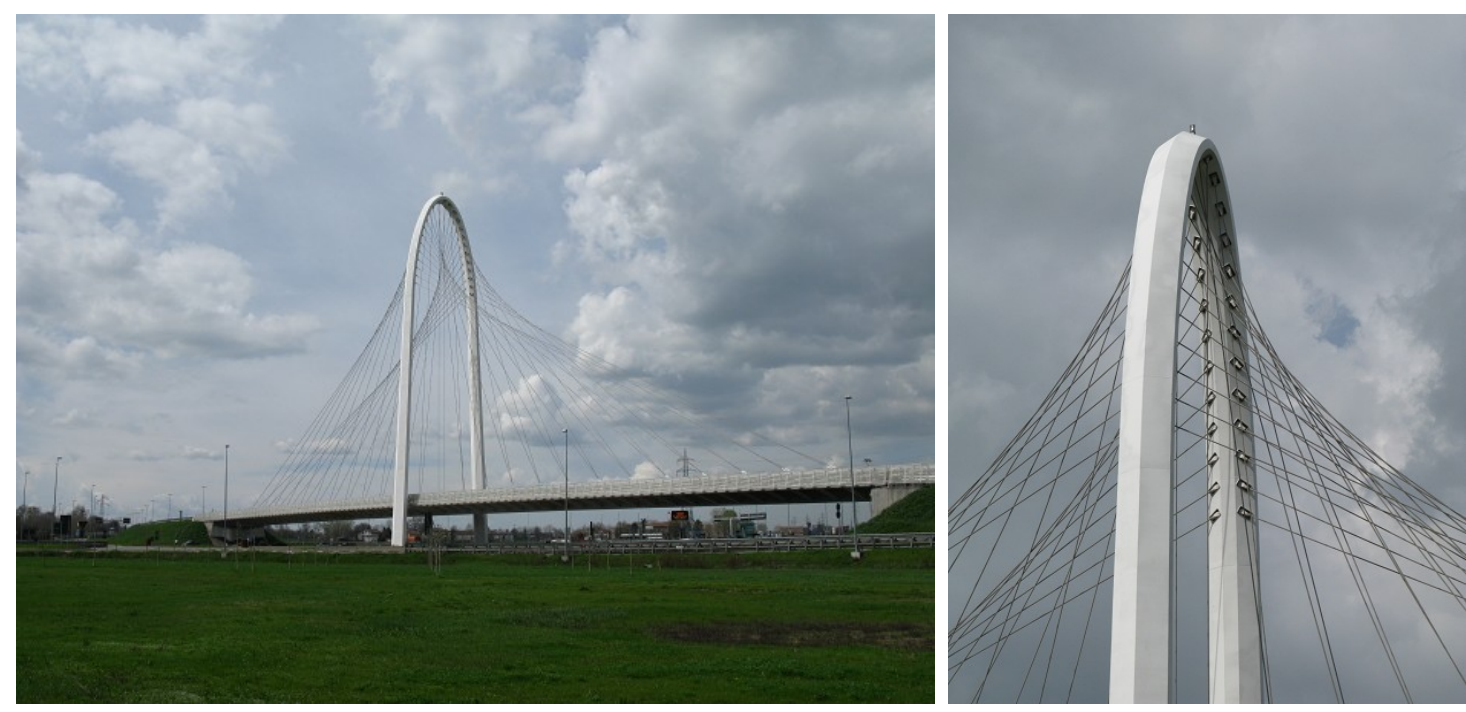

Figura 2.61: Ponte Laterale Sud, Reggio Emilia. Fotografía: Herrad Elisabeth Taubenheim (structurae.net). 


\subsubsection{Pasarela olímpica de Turín}

Construida entre los años 2003 y 2005 en Turín (Iatlia), la pasarela forma parte del programa de infraestructuras proyectadas para los juegos olímpicos de invierno de 2006. El proyecto es del estudio de arquitectura Hugh Dutton Associates (HDA). La estructura permite salvar las vías del tren, constituyendo un simbolo del nuevo Turín y un icono de las olimpiadas de invierno (véanse Dutton [28] y Dutton et al. [29]).

La pasarela (véase la figura 2.62) tiene una longitud total de $369 \mathrm{~m}$, con un tablero curvo en planta de $4 \mathrm{~m}$ de ancho, donde el vano principal de $150 \mathrm{~m}$ queda suspendido de un arco girado perpendicularmente al tablero. El arco, que tiene forma de herradura, está inclinado, formando $65^{\circ}$ con la horizontal. La distancia entre los arranques del arco es de $55 \mathrm{~m}$ y su altura total $85 \mathrm{~m}$, altura que al inclinarse se ve reducida hasta los $61 \mathrm{~m}$. El arco es metálico en su totalidad, teniendo una sección transversal con forma de triángulo equilátero de $3 \mathrm{~m}$ de lado.

El tablero se compone de dos perfiles doble $\mathrm{T}$ de $1 \mathrm{~m}$ de canto, situados en cada borde. Estos dos nervios principales quedan conectados el uno con el otro mediante perfiles transversales HEB 200 espaciados cada 4 m, y mediante diagonales hechas con perfiles HEB 160.

La vinculación entre el arco y el tablero se realiza mediante cables de $55 \mathrm{~mm}$ de diámetro atados a ambos bordes del tablero.
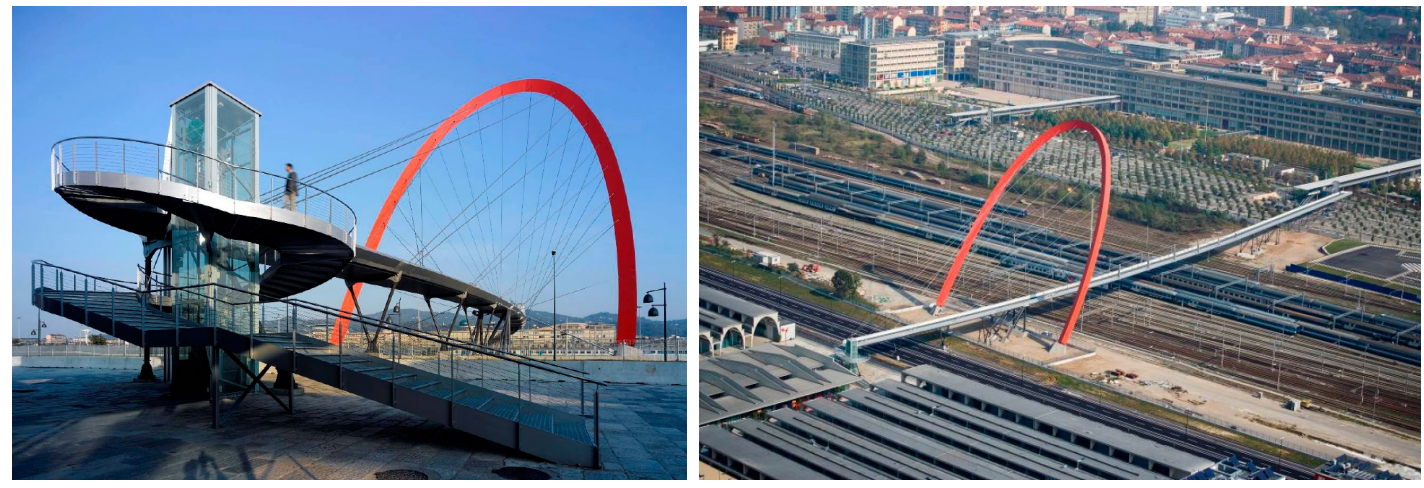

Figura 2.62: Pasarela olímpica de Turín. Fotografía: extraídas de Dutton [28].

\subsubsection{Margaret Hunt Hill Bridge}

Situado en Dallas (EEUU), su construcción se finalizó en el año 2012, siendo el proyecto obra de Santiago Calatrava ${ }^{37}$ (véase [83]).

El puente (véase la figura 2.63), similar a los puentes de Reggio Emilia, cruza el río Trinity, soportando el tráfico de 6 carriles de circulación. La estructura tiene una longitud total de $368 \mathrm{~m}$, dividida en dos vanos de $184 \mathrm{~m}$ con un ancho de $37.7 \mathrm{~m}$. El tablero se sostiene gracias a un arco girado perpendicularmente a su eje, teniendo este arco una altura de 136 m. La vinculación entre arco y tablero se lleva a cabo mediante 58 cables con diámetros de 127 a $165 \mathrm{~mm}$.

\footnotetext{
${ }^{37}$ Constituye el primer puente de carretera de Santiago Calatrava en EEUU.
} 

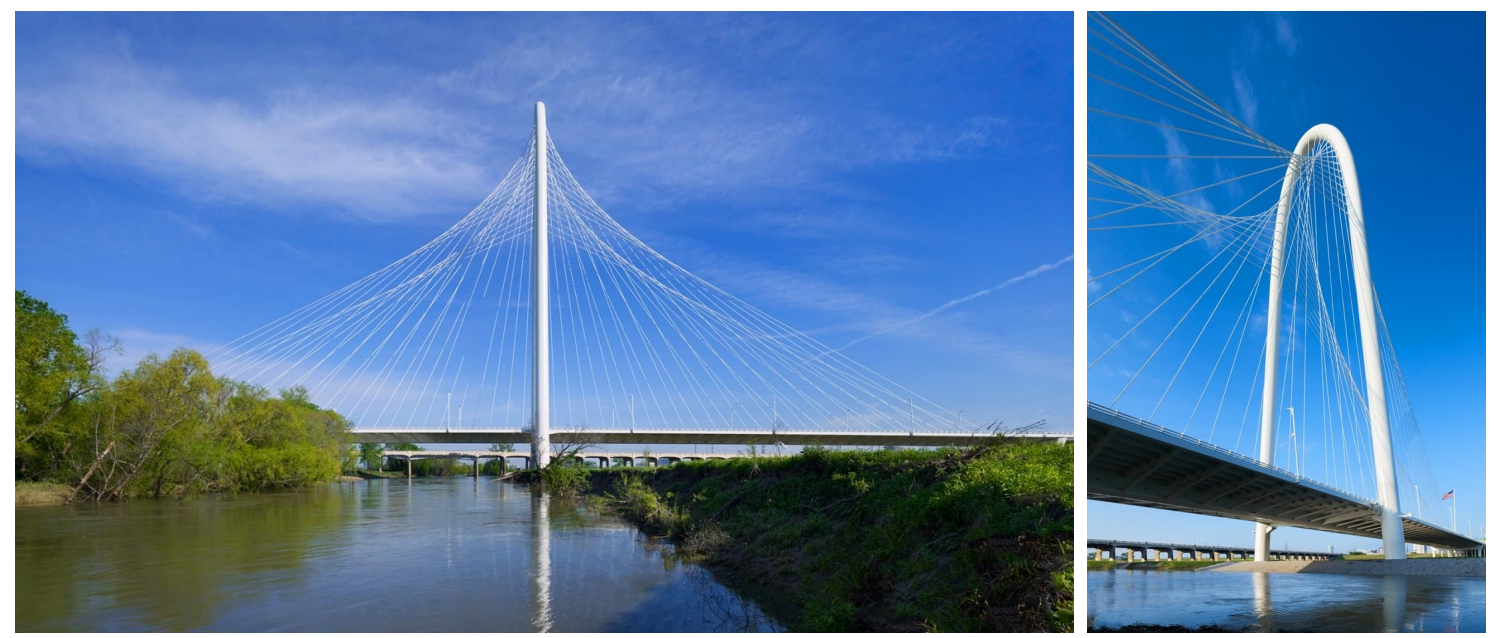

Figura 2.63: Margaret Hunt Hill Bridge. Fotografía: Alan Karchmer (archdaily.com).

\subsubsection{Arco único de ancho o cordones variables}

\subsubsection{Puente de la Barqueta}

Construido en 1992 para la Exposición Universal de Sevilla (España), el proyecto es de Juan José Arenas. El puente se sitúa sobre el río Guadalquivir, salvando una luz de 170 m (véanse Arenas y Pantaleón [8] y [7], así como [121]).

La Barqueta es un puente tipo bow-string, donde el arco se bifurca en dos para encontrarse con el tablero, formando sendos pórticos triangulares (véanse las figuras 2.8-a y 2.64). Estos pórticos triangulares se apoyan en cuatro soportes verticales distanciados transversalmente $30 \mathrm{~m}$.

El arco se vincula mediante péndolas verticales al tablero, con lo que si no se tuvieran en cuenta las bifurcaciones del arco, el arco tendría un carácter plano. La sección de las bifurcaciones y del propio arco es rectangular y metálica, con unos surcos en cada una de sus caras, que además de un fin estético tienen la misión de aportar una mayor inercia, evitando el uso de rigidizadores longitudinales internos.
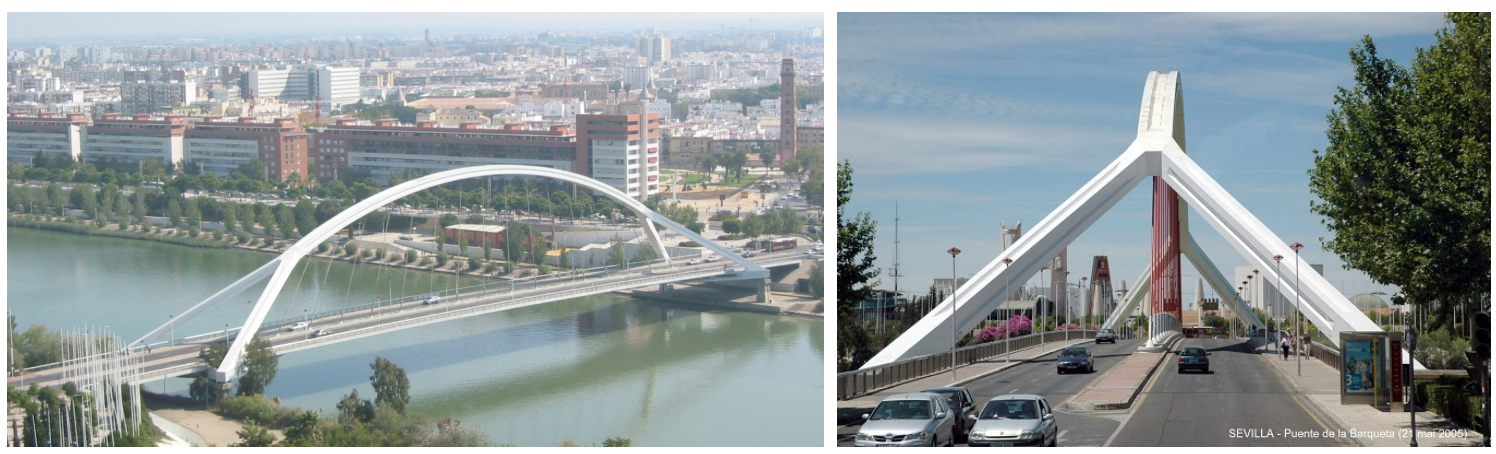

Figura 2.64: Puente de la Barqueta. Fotografía: Arenas \& Asociados (arenasing.com) y Adrien Mortini (structurae.net). 


\subsubsection{Puente del Tercer Milenio}

Proyecto de Juan José Arenas, el puente está enmarcado dentro de las obras realizadas para la Expo del agua de Zaragoza (España), finalizándose su construcción en el año 2008. La estructura cruza el río Ebro, conectando las calles Pablo Ruiz Picasso y Pablo Gargallo, lo que permite comunicar los barrios del Actur y La Almozara (véanse Arenas et al. [4], [5], [6] y Menéndez-Pidal et al. [66]).

Con un esquema resistente similar al puente de la Barqueta, la principal diferencia radica en que el tramo de arco que descansa sobre las bifurcaciones de los arranques se vincula al tablero mediante cables a ambos bordes (véanse las figuras 2.8-b y 2.65). En este caso, aunque no se considerasen las bifurcaciones, el arco seguiría siendo espacial, dados los dos juegos de péndolas que sujetan el tablero en ambos bordes.

Con sus $216 \mathrm{~m}$ de luz, y una distancia transversal entre apoyos de $48 \mathrm{~m}$, este puente constituye el mayor arco atirantado en hormigón del mundo.
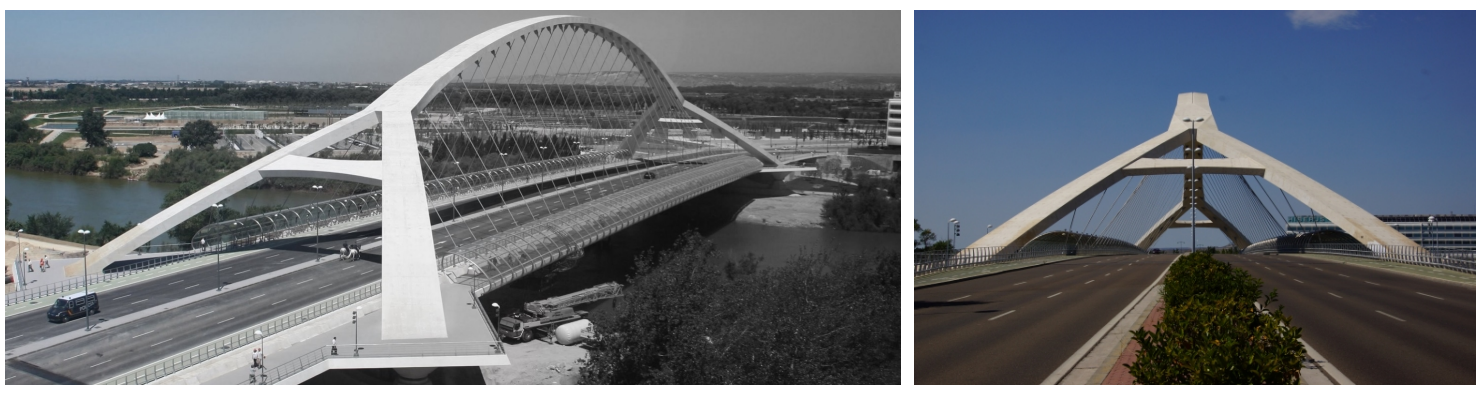

Figura 2.65: Puente del Tercer Milenio. Fotografía: Arenas \& Asociados (arenasing.com) y Nicolas Janberg (structurae.net).

\subsubsection{Cuarto puente de Logroño sobre el Ebro}

El crecimiento de la ciudad de Logroño (España) propició la construcción de esta pasarela en el año 2003. El puente, que cruza el río Ebro, es proyecto de la empresa Carlos Fernández Casado S.L. (véanse Manterola [58] y [59]).

El cuarto puente de Logroño sobre el Ebro $^{38}$ (véase la figura 2.66) es un puente arco de $140 \mathrm{~m}$ de luz que dispone de 3 tableros. El tablero central es recto y está destinado a tráfico rodado, mientras que los dos tableros restantes, curvos con un radio $260 \mathrm{~m}$, están situados a cada lado del tablero central y son peatonales. El tablero central tiene un ancho de $18 \mathrm{~m}$, soportando el tráfico de dos carriles por sentido más una mediana en el centro de $2 \mathrm{~m}$. Los dos tableros curvos destinados a tráfico peatonal tienen un ancho de $4 \mathrm{~m}$.

La sección del tablero central es un cajón mixto de $2 \mathrm{~m}$ de canto constante con forma trapecial. Por su parte, los dos tableros curvos están formados por un cajón de acero de forma trapecial con $4 \mathrm{~m}$ de ancho en la parte superior y $2 \mathrm{~m}$ en la inferior, teniendo un canto constante de $1.3 \mathrm{~m}$.

\footnotetext{
${ }^{38}$ La mayoría de la documentación relativa a este puente lo nombra como "Cuarto puente de Logroño sobre el Ebro", si bien en el callejero puede ser encontrado como "Puente de Práxedes Mateo Sagasta".
} 
El arco que sustenta los tres tableros se sitúa sobre la mediana y tiene una flecha de 28 $\mathrm{m}$, estando formada su sección por dos tubos de acero de $1200 \mathrm{~mm}$ de diámetro con un espesor variable entre 25 y $80 \mathrm{~mm}$. La unión entre los arcos se realiza mediante tubos de acero en forma de aspa.

El arco se vincula al tablero central mediante dos juegos de cables anclados al centro del tablero. Por otro lado, los tableros curvos se suspenden mediante cables atados a su borde interno. Los cables extremos de las pasarelas se anclan en el estribo del puente, sirviendo de retenida horizontal del arco y aumentado su rigidez transversal.
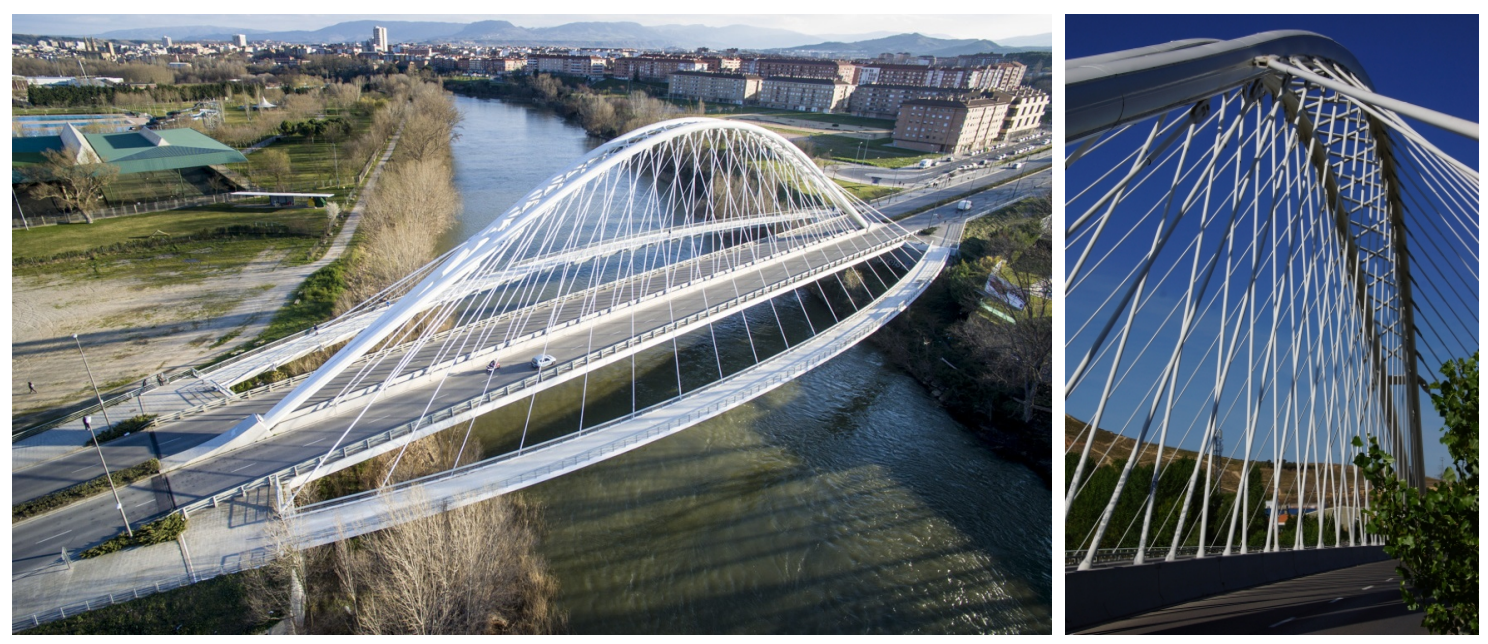

Figura 2.66: IV puente de Logroño sobre el Ebro. Fotografía: Carlos Fernández Casado S.L. (cfcsl.com) y Nicolas Janberg (structurae.net).

\subsubsection{Arco del hangar 6 de Iberia (Aeropuerto Madrid-Barajas)}

Situado al sureste del aeropuerto Madrid-Barajas (España), concretamente en La Muñoza, este arco sustenta la cubierta del hangar 6 de la compañía Iberia, espacio destinado al mantenimiento de aviones.

El arco, con una luz aproximada de $250 \mathrm{~m}$ y una directriz poligonal, se bifurca en ambos extremos. La vinculación del arco con la estructura se lleva acabo mediante dos familias de cables inclinados tipo Nielsen (véase la figura 2.67).

\subsubsection{Montigny-lès-Cormeilles Footbridge}

Construida sobre la Autorute A 15, la pasarela de Montigny-lès-Cormeilles (Francia) fue finalizada en 1999. El proyecto es de Madeleine Noeuvéglise (arquitectura) y Michel Virlogeux (ingeniería).

La pasarela, con un esquema resistente en el arco que recuerda al puente de la Barqueta de Sevilla, se compone de un arco tipo bow-string de directriz poligonal y $55 \mathrm{~m}$ de luz, el cual se bifurca en los arranques formando sendos pórticos triangulares. El tablero queda suspendido de ambos bordes mediante dos juegos de cables inclinados tipo Nielsen (véase la figura 2.68). 

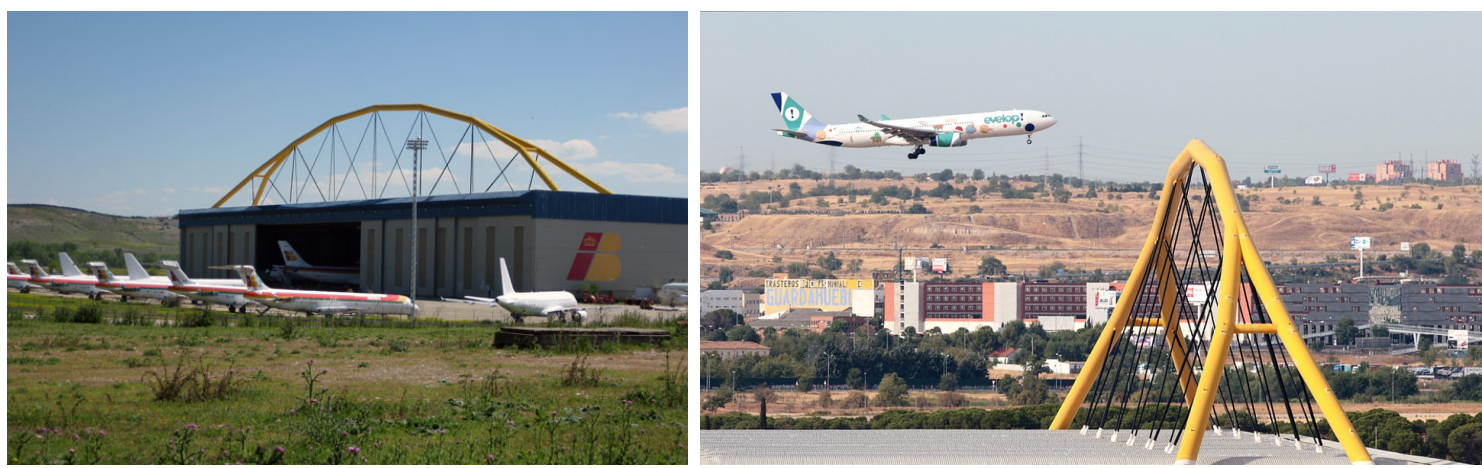

Figura 2.67: Arco del hangar 6 de Iberia (Aeropuerto Madrid-Barajas). Fotografía: Fernando Puppio (gacetaeronautica.com) y hiveminer.com.
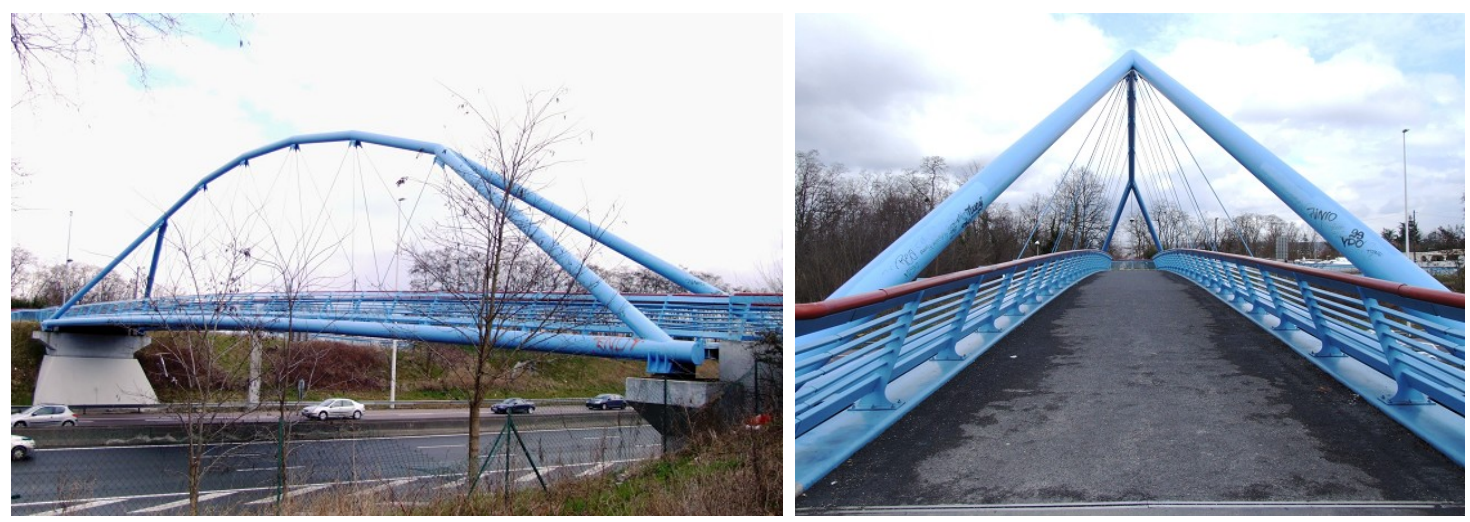

Figura 2.68: Montigny-lès-Cormeilles Footbridge. Fotografía: Jacques Mossot (structurae.net).

\subsubsection{Arthur von Weinberg Footbridge}

Situada en Fráncfort (Alemania), esta pasarela fue construida en el año 1981 para cruzar el río Meno.

La estructura se compone de un arco metálico tipo bow-string que se bifurca en los arranques, salvando una longitud de $97.5 \mathrm{~m}$ con un tablero de $3 \mathrm{~m}$ de ancho (véase la figura 2.69). El arco sostiene ambos bordes del tablero mediante dos familias de cables verticales.

\subsubsection{De Oversteek}

Proyectado por el estudio Ney \& Partners, el puente ${ }^{39}$ fue construido en el año 2013 en la ciudad de Nijmegen (Países Bajos).

El puente (véase la figura 2.70) cruza el río Waal, teniendo una longitud total de $1900 \mathrm{~m}$.

\footnotetext{
${ }^{39} \mathrm{El}$ puente ha recibido numerosos premios, entre los que se encuentran el New York Waterfront Center Award 2011 (por el plan "Ruimte voor de Waal"), el Dutch German Award for Economy (2013), el National Steel Award The Netherlands (en la categoría infraestuctura, 2014) y el Dutch Construction Award 2017 (por el proyecto Riverpark, Room for the Waal).
} 

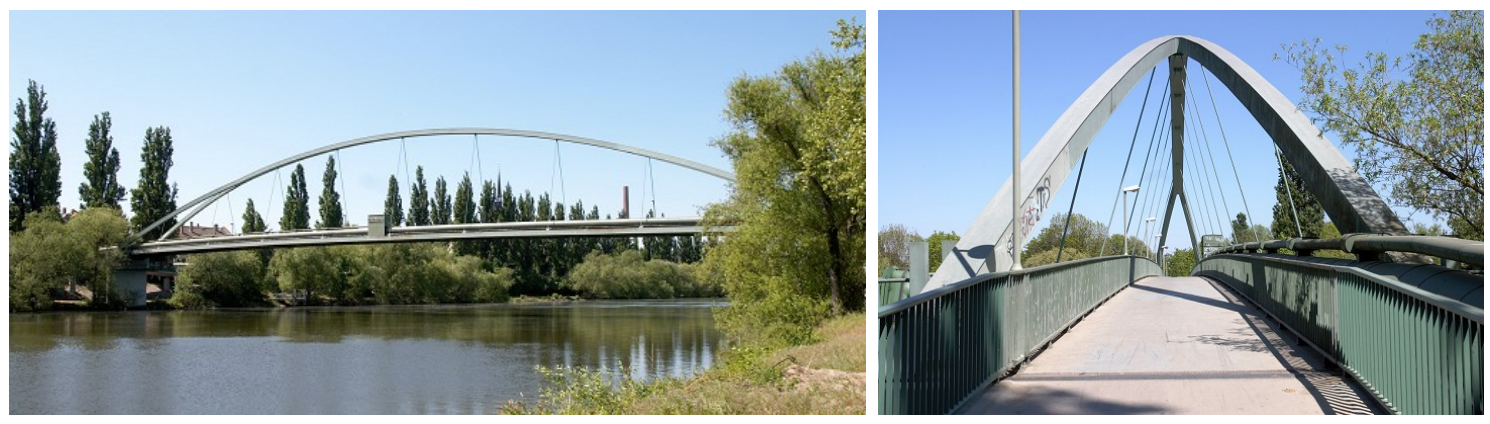

Figura 2.69: Arthur von Weinberg Footbridge. Fotografía: Jochen Kratschmer (structurae.net).
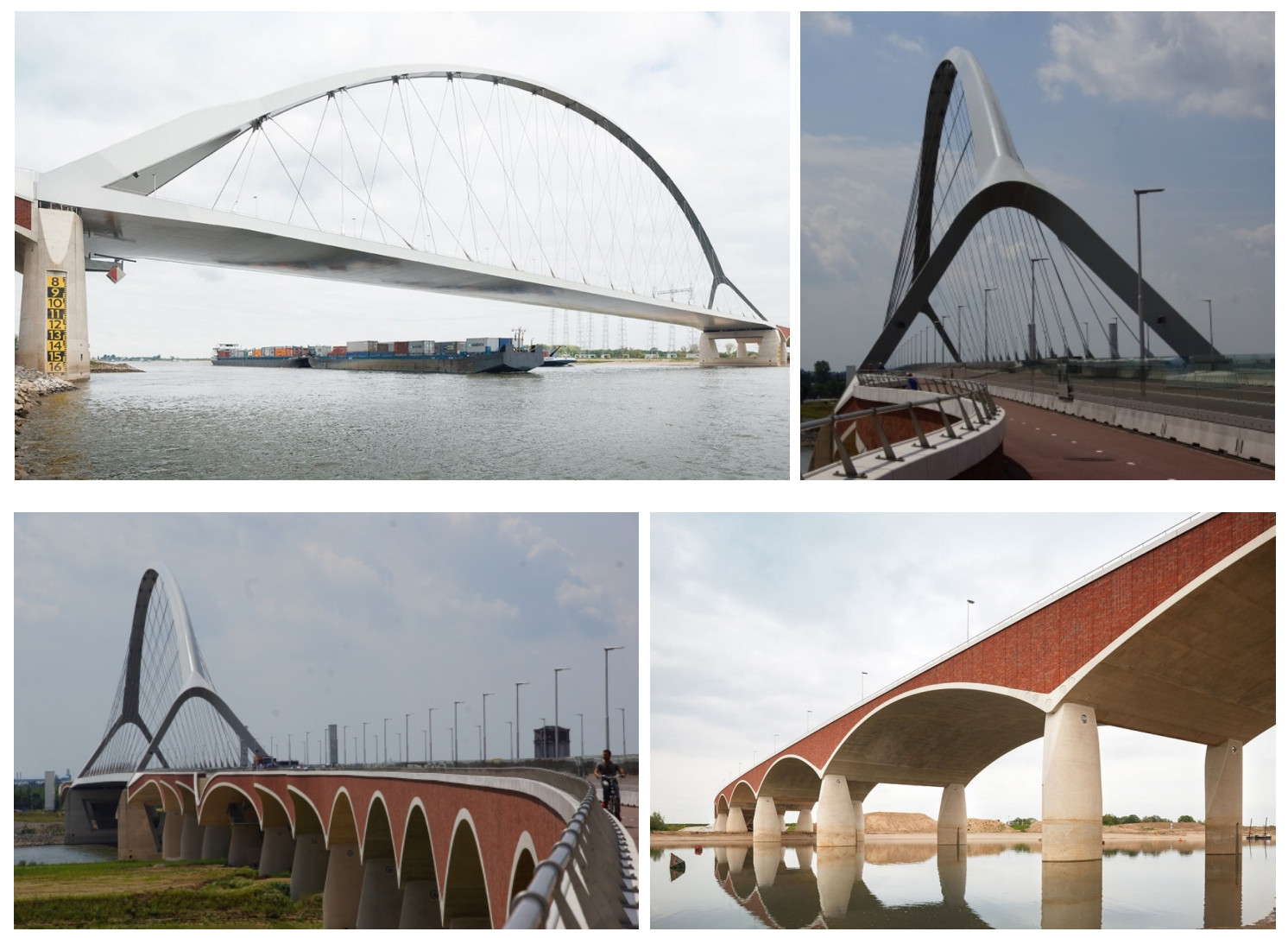

Figura 2.70: De Oversteek. Fotografía: Ney \& Partners (ney.be) y Nicolas Janberg (structurae.net).

El vano principal se sitúa justo encima del río, salvando una luz de $285 \mathrm{~m}$ con un arco metálico que se bifurca en los arranques. El tablero soporta el tráfico de cuatro carriles (dos por sentido) y un carril bici (véase [80]).

Resultan curiosos los accesos al puente, realizados con arcos de hormigón y fábrica de color rojo, según el estudio Ney \& Partners, por ser materiales y métodos de construcción típicos de la zona. 


\subsubsection{Arco y tablero únicos unidos por péndolas/montantes do- bles}

\subsubsection{Pasarela Jorge Manrique (Murcia, España)}

Situada sobre el río Segura a su paso por la ciudad de Murcia, la pasarela Jorge Manrique ${ }^{40}$ se sitúa unos 300 m aguas abajo de los puentes del Hospital General. Construida en 1998, la pasarela es proyecto de Santiago Calatrava, y responde a una necesidad de mayor conexión entre las riberas del río, densamente pobladas (véase [83]).

La estructura (véase la figura 2.71) consiste en un arco de acero de sección circular con un diámetro de $0.355 \mathrm{~m}$, que sostiene un tablero ${ }^{41}$ recto de $56.4 \mathrm{~m}$ de longitud y un ancho variable entre 6 y $10.5 \mathrm{~m}$. La directriz del arco en planta coincide con el eje del tablero, siendo la altura máxima sobre este de $9.7 \mathrm{~m}$.
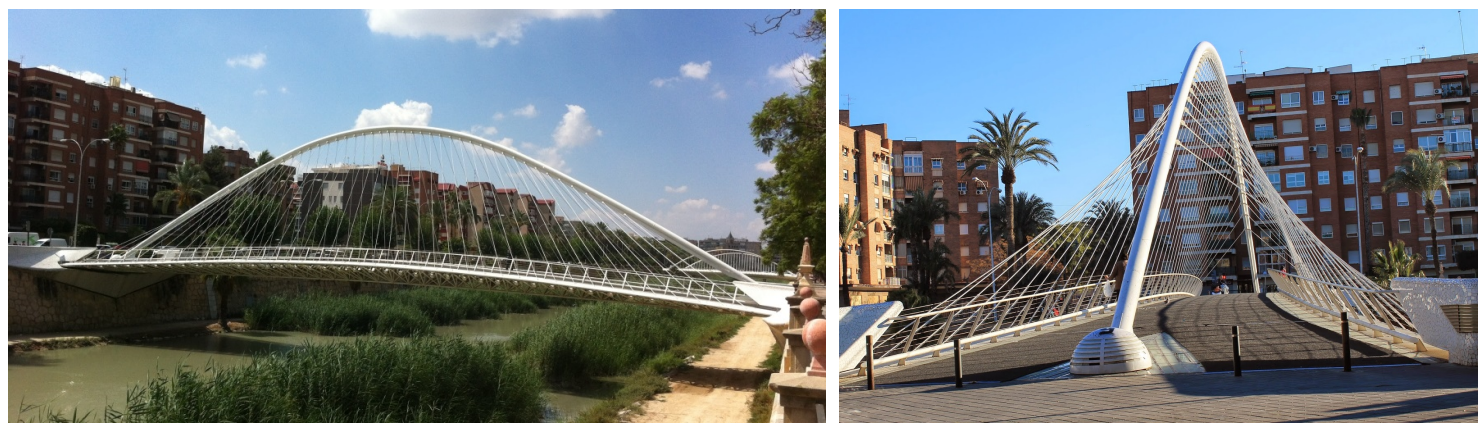

Figura 2.71: Pasarela Jorge Manrique (Murcia, España). Fotografía: abinario.com y adiezminutosdelcentro.blogspot.com.

\subsubsection{Rajhrad Bridge, R52 Expressway}

Construido cerca de la ciudad Checa de Rajhrad, este puente permite el paso de una carretera local sobre la autopista R52 entre Brno y Viena. La estructura, que cruza diagonalmente a la autopista, fue proyectada por el estudio Strasky, Husty and Partners (véanse las referencias [75] y [123]).

El puente (véase la figura 2.72) está formado por un arco que soporta un tablero de hormigón postensado. El arco tiene una sección circular con un diámtro de $900 \mathrm{~mm}$ y un espesor de $30 \mathrm{~mm}$, estando relleno de hormigón. La luz del arco es de $67.5 \mathrm{~m}$, y su flecha de $8.05 \mathrm{~m}$. El tubo del arco está rigidizado por diafragmas en forma de anillo.

El tablero descansa sobre el arco mediante montantes de acero en forma de V. La sección del tablero está formada por una losa de hormigón y dos nervios de acero con un canto constante de $1.68 \mathrm{~m}$, situados ambos en los bordes.

\footnotetext{
${ }^{40}$ La pasarela también se conoce con el nombre de "Puente de Vistabella".

${ }^{41} \mathrm{El}$ pavimento del tablero se realizó en cristal, pero dadas las numerosas roturas del vidrio, así como los resbalones que ocasionaba tal superficie, se cubrió con una alfombra antideslizante, algo que también se hizo en la pasarela del Campo Volantín, obra también de Santiago Calatrava.
} 


\subsection{REALIZACIONES CON SIMETRÍA LONGITUDINAL}
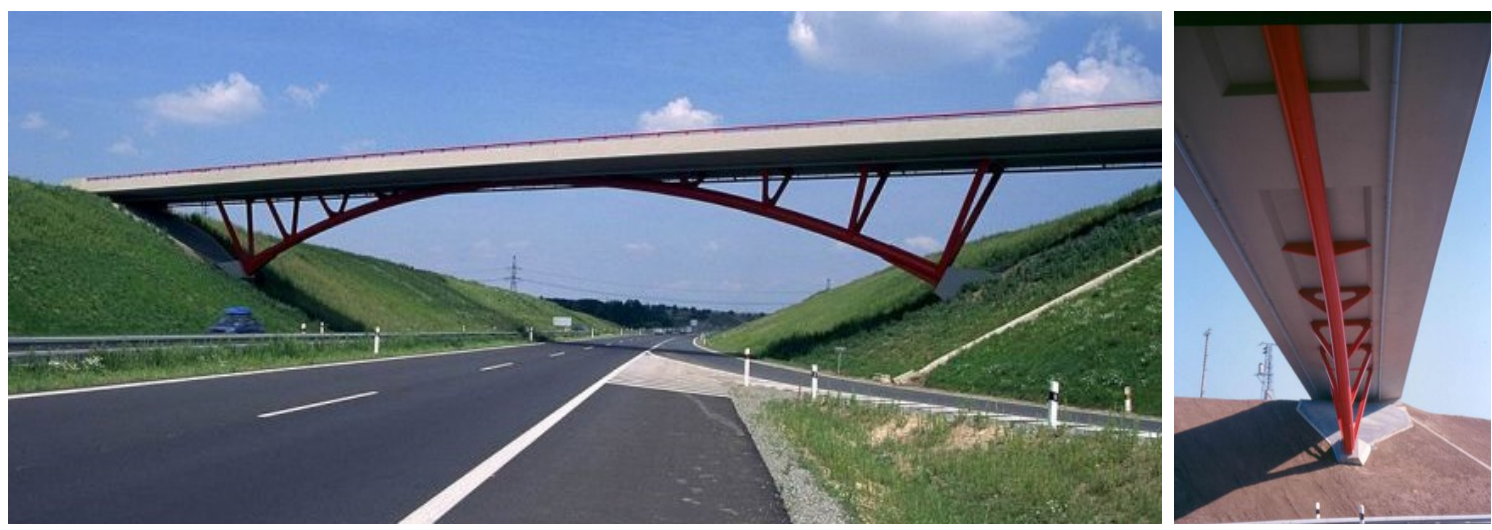

a)

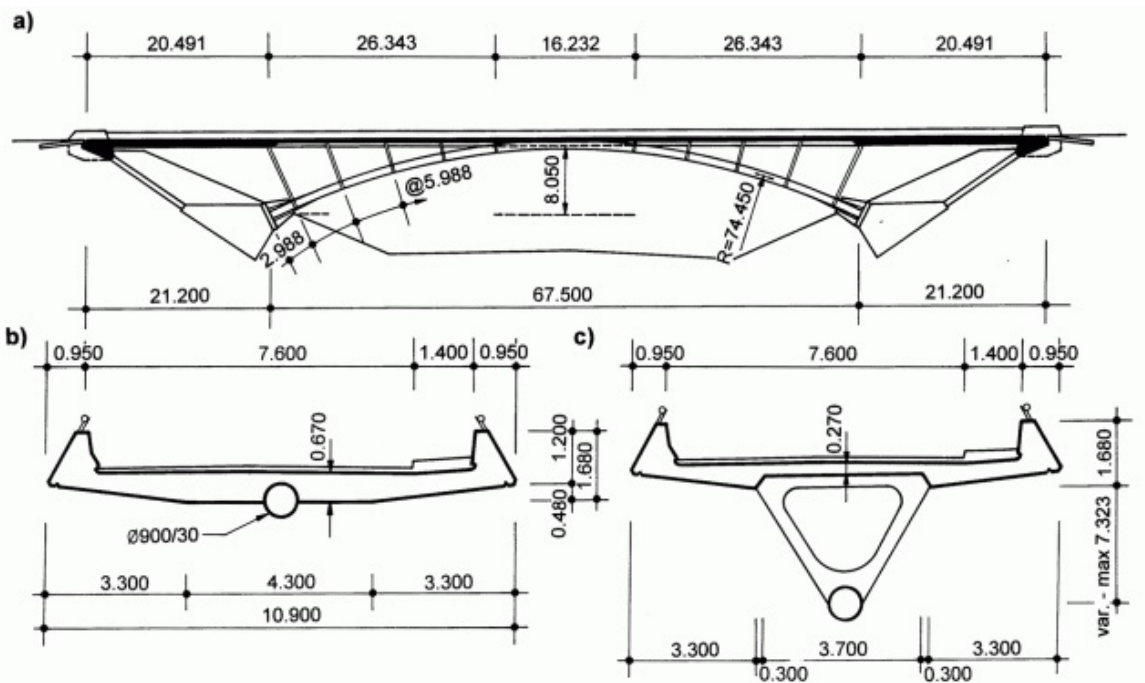

Figura 2.72: Rajhrad Bridge, R52 Expressway. Fotografía: Strasky, Husty and Partners (shp.eu).

\subsubsection{Arco único con dos tableros}

\subsubsection{Pasarela Miguel Navarro Molina, Lorca (España)}

La pasarela ${ }^{42}$ (véase la figura 2.73) se sitúa sobre el río Guadalentín a su paso por la ciudad de Lorca (España). El proyecto es del estudio Carlos Fernández Casado S.L., finalizándose su construcción en el año 2003 (véanse Manterola [58] y Manterola et al. [64]).

La estructura, que permitió regenerar las zonas aledañas a la avenida de Santa Clara y el entorno de la Casa Mata, cubre una luz de $85 \mathrm{~m}$. La pasarela es un arco superior de sección tubular con dos tableros de planta curva separados en el centro de la luz.

$\mathrm{El}$ arco, que tiene una altura de $16 \mathrm{~m}$, está formado por dos tubos de acero de $710 \mathrm{~mm}$ de diámetro unidos por chapas horizontales, teniendo así un ancho total de $1.42 \mathrm{~m}$. Los tableros laterales tienen una sección trapecial asimétrica con una anchura superior de 4

\footnotetext{
${ }^{42}$ Actualmente se la conoce como pasarela Miguel Navarro Molina, nombre del alcalde de la ciudad en cuya legislatura se inauguró, si bien en sus primeros años se le llamaba pasarela Manterola, en honor al ingeniero que la proyectó.
} 

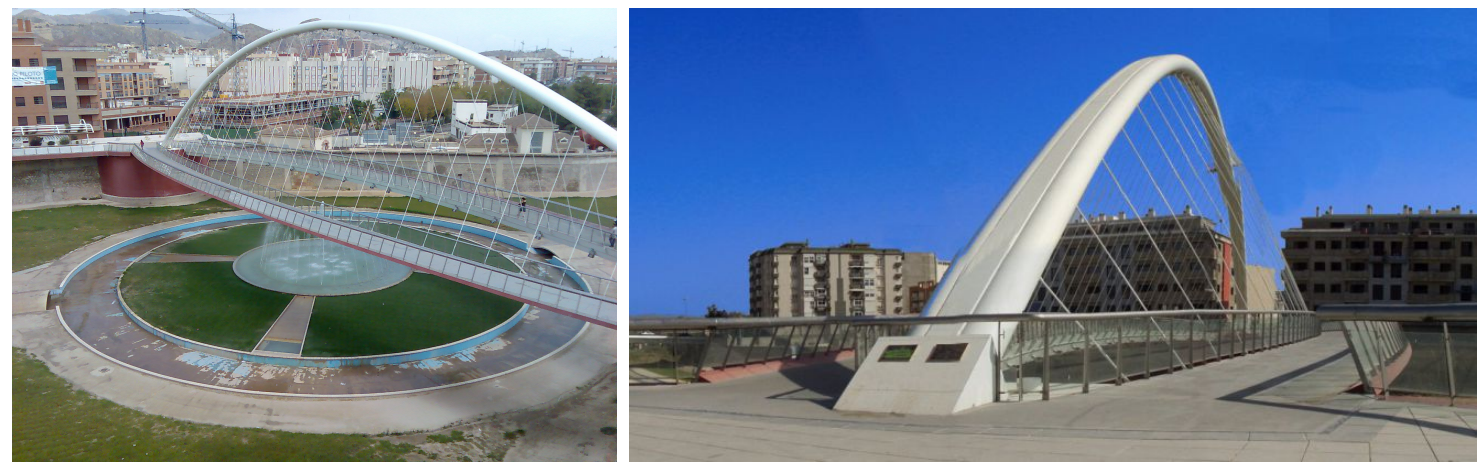

Figura 2.73: Pasarela Miguel Navarro Molina, Lorca (España). Fotografía: Mapio.net y cadenaser.com.
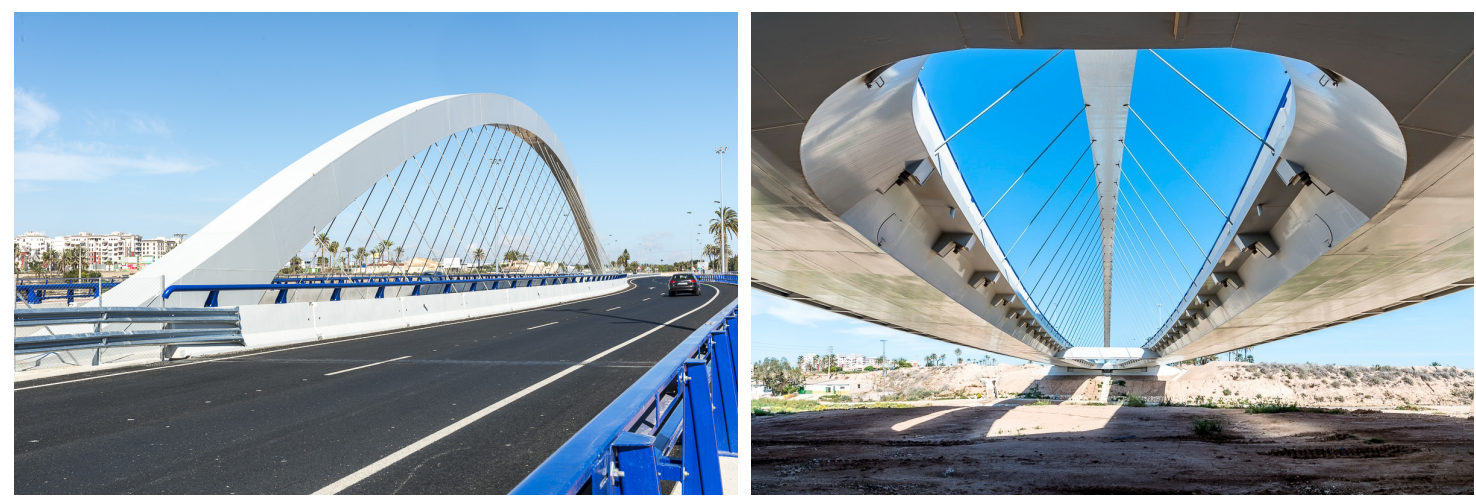

Figura 2.74: Puente sobre el río Vinalopó en Elche (España). Fotografía: Carlos Fernández Casado S.L. (cfcsl.com).

m e inferior de $1 \mathrm{~m}$, con un canto constante de $1 \mathrm{~m}$. Ambos tableros están sujetos por el borde interno por barras de acero de $28 \mathrm{~mm}$ de diámetro espaciadas cada $2.4 \mathrm{~m}$

\subsubsection{Puente sobre el río Vinalopó en Elche (España)}

Este puente, que cruza el río Vinalopó, forma parte de una vía de circunvalación por el sur de Elche (España) llamada EL-20, la cual se conecta en algunos puntos determinados con el viario urbano a través de rotondas. El puente se culminó en 2015, habiéndolo proyectado el estudio Carlos Fernández Casado S.L. (véase [58]).

El puente (véase la figura 2.74) consta de un arco superior que sustenta un tablero dividido en dos calzadas exentas, una a cada lado del arco, las cuales tienen planta curva, uniéndose en los estribos entre sí y con el arco. Son metálicos tanto el tablero como el arco, teniendo este último una luz de $120 \mathrm{~m}$ y una altura sobre la calzada de $16 \mathrm{~m}$.

Cada tablero curvo tiene un ancho de $14.4 \mathrm{~m}$, estando compuestos ambos por un cajón con un ancho superior de $9 \mathrm{~m}$ e inferior de $7.8 \mathrm{~m}$, así como un canto constante de $1.6 \mathrm{~m}$. Cada $4 \mathrm{~m}$, coincidiendo con la rigidización transversal del cajón hay una costilla que vuela $4 \mathrm{~m}$ hacia el exterior. Ambos cajones están suspendidos del borde interior por cables inclinados unidos al arco, estando los tirantes anclados en el diafragma transversal del cajón. 


\subsubsection{Father Ojca Bernatka Bridge}

Finalizado en Cracovia (Polonia) en el año 2010, la pasarela se planteó para unir las áreas de Kazimierz y Podgórze. El ayuntamiento de Cracovia celebró un concurso en el año 2006, resultando ganadora la idea de un puente inspirado en la forma de una hoja, del arquitecto Andrzej Getter ${ }^{43}$ (véanse Zóltowski y Kozakiewicz [128] y Siwowski et al. [105]).

La pasarela, con una luz de $148 \mathrm{~m}$, está compuesta por un arco atirantado que sustenta dos tableros curvos (véase la figura 2.75). El arco, con una radio de $170 \mathrm{~m}$ y una altura máxima de $15.3 \mathrm{~m}$, hace que en su conjunto la estructura sea muy esbelta. La sección del arco es circular, estando formada por dos tubos concéntricos, el exterior con un diámetro de $2020 \mathrm{~mm}$ y el interior de $1620 \mathrm{~mm}$. El espacio ente ambos tubos está relleno de hormigón autocompactante.

Los dos tableros curvos son iguales, con una longitud de $137 \mathrm{~m}$ y un ancho de $3 \mathrm{~m}$ cada uno. Los tableros curvos están formados por una losa ortótropa de acero. Los tableros se separan, alcanzándose la máxima separación en el centro del vano. Ambos tableros se encuentran unidos por vigas transversales de sección circular con un radio de $508 \mathrm{~mm}$. La vinculación entre el arco y los tableros se lleva a cabo mediante dos familias cables con una configuración tipo Network, anclándose los cables a los tubos transversales que unen los dos tableros curvos.
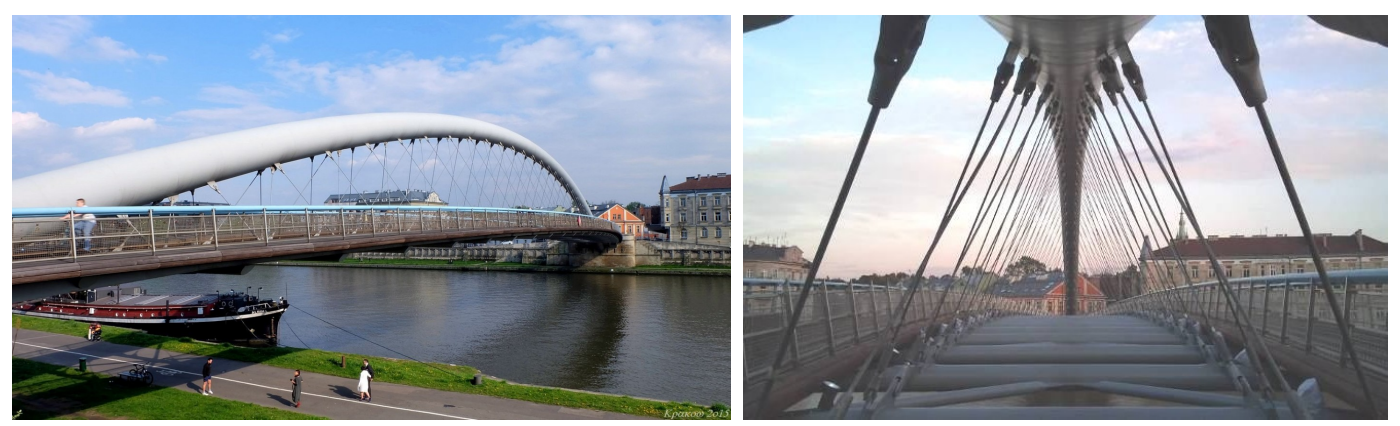

Figura 2.75: Father Ojca Bernatka Bridge. Fotografía: extraídas de Zóltowski y Kozakiewicz [128], y de Siwowski et al. [105].

\subsubsection{Arcos convergentes}

\subsubsection{Fehmarnsund Bridge}

El puente fue finalizado en el año 1963 sobre el estrecho de Fehmarn, dando así acceso a la isla de Fehmarn (Alemania). El diseño es de la firma Gutehoffnungshütte Sterkrade AG (ingeniería) y de Gerd Lohmer (Arquitectura).

La estructura $^{44}$ (véase la figura 2.76), con una longitud total de $963 \mathrm{~m}$, un vano principal de $250 \mathrm{~m}$ y un ancho de $21 \mathrm{~m}$, permite la circulación de cuatro carriles de tráfico y dos

\footnotetext{
${ }^{43}$ La propuesta del arquitecto fue revisada antes de su construcción por el estudio de ingenieros Promost Consulting.

${ }^{44}$ Una curiosidad del puente son los seis parches de asfalto en unos de los accesos, que muestran el lugar de los huecos que existían para colocar cargas explosivas en caso de invasión durante la guerra fría.
} 

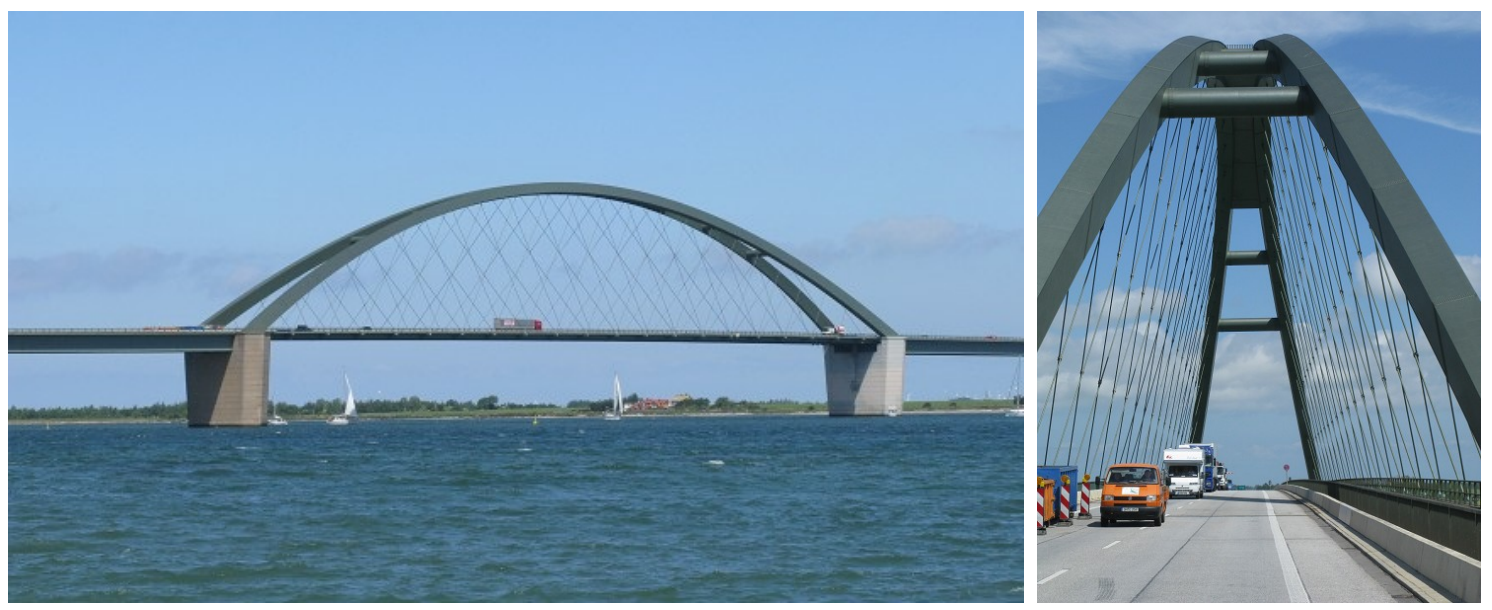

Figura 2.76: Fehmarnsund Bridge. Fotografía: Herrad Elisabeth Taubenheim (structurae.net).

vías de ferrocarril (veánse Wittfoht [127] y Fernández Troyano [30]).

El vano principal, bajo el que navegan los barcos, está suspendido mediante dos arcos gemelos inclinados hacia el interior, lo que hace que converjan en la clave. Los arcos, aparte de estar unidos en la clave, están arriostrados el uno con el otro.

La vinculación entre los arcos y el tablero se realiza mediante un plano de cables en cada arco con una configuración tipo Network.

\subsubsection{Pasarela de Plentzia}

La pasarela peatonal, construida en el año 1992 en Plentzia (España), restituye el paso entre la estación de ferrocarril y la ciudad, que había sido dañado por unas inundaciones en Vizcaya. La pasarela permite cruzar la ría de Plentzia, siendo el proyecto de Javier Manterola Armisén (véase Manterola [58]).

La estructura, con una luz de $117.6 \mathrm{~m}$, se compone de dos arcos que se inclinan hacia el interior hasta encontrarse en el centro (véase la figura 2.77).

Toda la estructura es metálica, a excepción del tablero que es mixto. Los arcos están formados por dos vigas cajón de $1.2 \mathrm{~m}$ x $0.8 \mathrm{~m}$. Las vigas de rigidez laterales que bordean el tablero tienen $50 \mathrm{~cm}$ de canto, completándose con una estructura mixta transversal para soportar los $10 \mathrm{~m}$ de anchura útil del tablero.

La pasarela fue construida sobre el antiguo puente que existía entre la estación y el pueblo, pues este permitía soportar el peso del nuevo puente. Posteriormente la estructura se ripó transversalmente a su situación definitiva, demoliéndose después el puente antiguo.

\subsubsection{Puente arco sobre el río Guadalquivir en Palma del Río (España)}

La nueva variante de Palma del Río (España) consta de una rotonda, un puente arco sobre el río Guadalquivir, y dos viaductos de acceso (uno conecta el puente arco con la rotonda, 

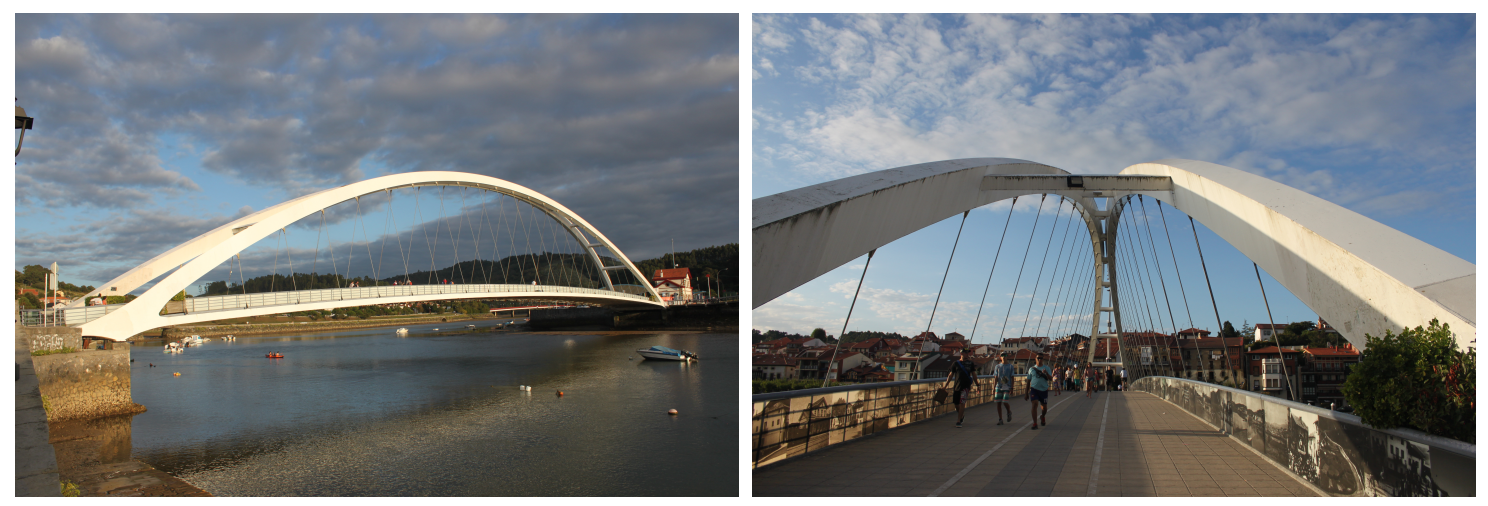

Figura 2.77: Pasarela de Plentzia. Fotografía del autor.

y el otro da acceso al puente por el lado opuesto). La variante ha sido proyectada por la empresa de ingeniería IDEAM, finalizándose las obras en el año 2007.

El puente arco de esta variante es de tipo bow-string y tiene una luz de $130 \mathrm{~m}$, estando formado por dos arcos atirantados inclinados hacia el interior que convergen en la clave. Según los autores, con esta solución se perseguía a la vez que dotar a la estructura de un especial dinamismo y originalidad, reducir la longitud de pandeo de cada uno de los arcos disponiendo el menor número de arriostramientos transversales entre ellos (véase la figura 2.78). El plano que contiene a cada arco forma $68.8^{\circ}$ respecto a la vertical (véase Millanes et al. [68]).

La sección de los arcos es un perfil tubular de $90 \mathrm{~cm}$ de diámetro, constante en toda la longitud. La directriz de los arcos es parabólica, con una flecha en clave de $25 \mathrm{~m}$. Los arcos se encuentran arriostrados el uno contra el otro mediante una celosía tipo K compuesta por perfiles tubulares, lo que permite acortar la longitud de pandeo de los arcos.

El tablero, de $16 \mathrm{~m}$ de ancho, está formado por dos nervios principales en los bordes, que hacen de tirantes para los arcos. Estos nervios tienen la misma sección que los arcos. Los nervios se unen por vigas transversales metálicas cada $5 \mathrm{~m}$, descansando sobre estas vigas transversales una losa de $0.25 \mathrm{~m}$ de espesor constante. Esta losa se ejecutó en dos partes, por un lado se colocaron prelosas sobre las vigas transversales, y posteriormente se hormigonó el espesor restante.

La vinculación entre los arcos y el tablero se lleva a cabo mediante una configuración de cables tipo Network. Los anclajes de los cables al tablero se realizan en los mismos puntos de apoyo de las vigas transversales, con el fin de que los tirantes laterales no se vean sometidos a los efectos de las cargas puntuales que actúan sobre el tablero.

\subsubsection{Puente sobre el río Deba}

En 2007 se completó un nuevo acceso al municipio de Deba (España). El acceso, proyectado por la empresa IDEAM, consta de una glorieta, un viaducto y un puente arco de $110 \mathrm{~m}$ de longitud sobre la ría del Deba (véase Millanes et al. [67]).

El puente arco tiene un esquema resistente muy parecido al puente de Palma del Río, de la misma empresa (véase la figura 2.79). La estructura, de tipo bow-string, se compone 

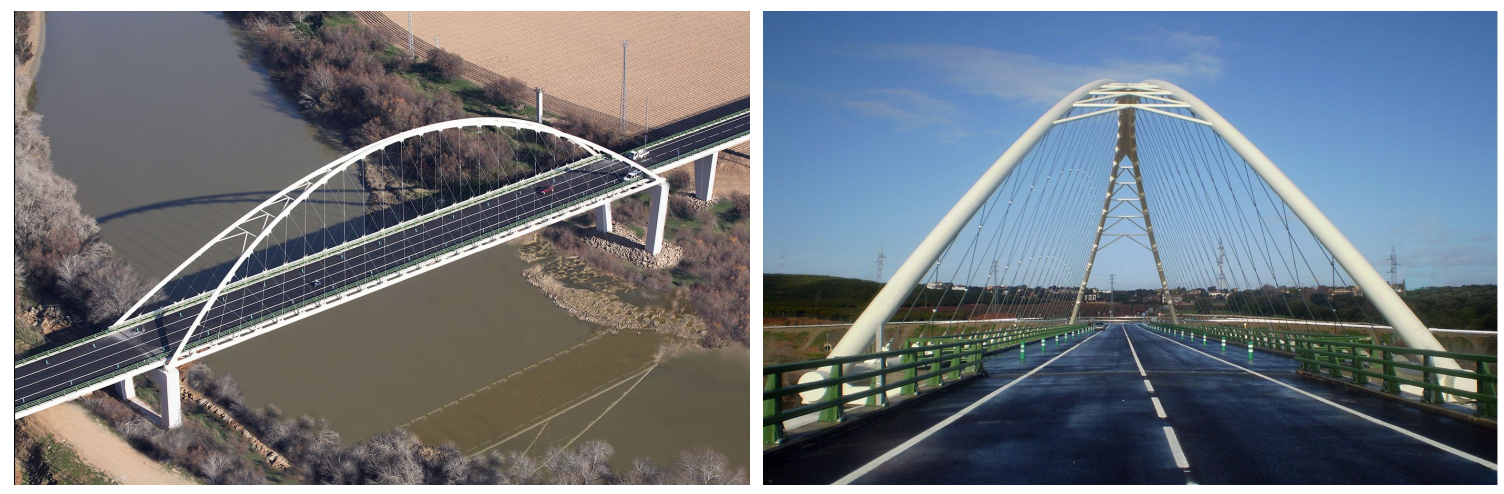

Figura 2.78: Puente arco sobre el río Guadalquivir en Palma del Río (España). Fotografía: IDEAM (ideam.es).
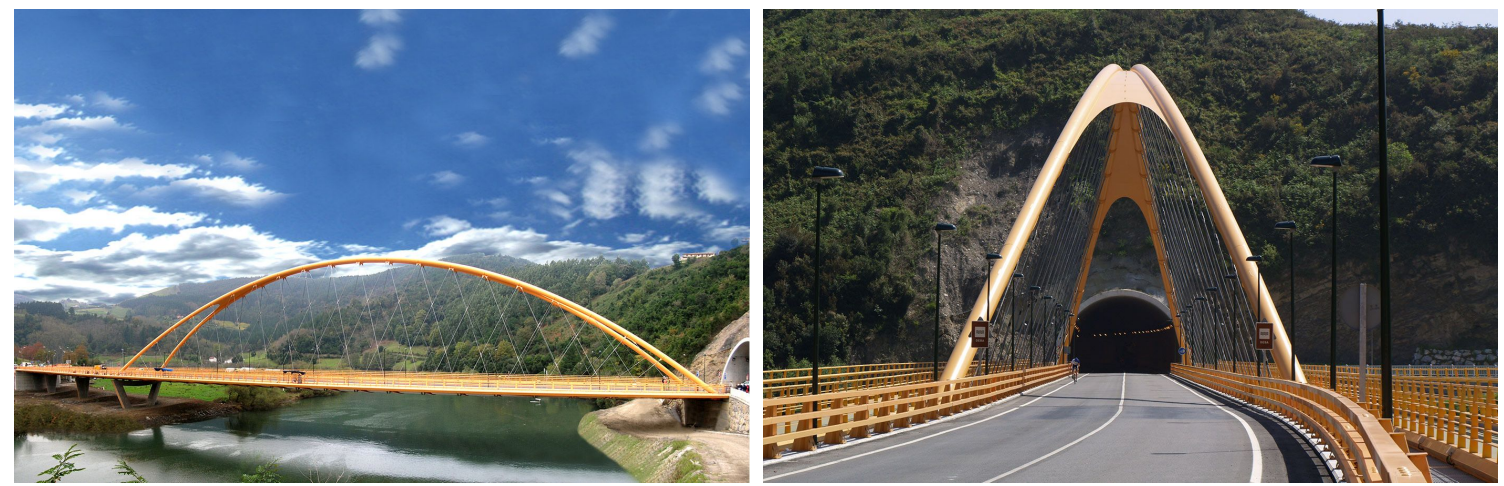

Figura 2.79: Puente sobre el río Deba. Fotografía: IDEAM (ideam.es).

de dos arcos metálicos tubulares inclinados $17.3^{\circ}$ con respecto al plano vertical, con una directriz parabólica y $20 \mathrm{~m}$ de flecha vertical en la clave. La sección tubular de los arcos tiene un diámetro de $800 \mathrm{~mm}$ y espesores de chapa comprendidos que van desde los 45 $\mathrm{mm}$ en los arranques, hasta los $25 \mathrm{~mm}$ de la clave.

El tablero, con $18.6 \mathrm{~m}$ de longitud, es mixto y soporta el tráfico de dos carriles de circulación y dos aceras peatonales. La vinculación entre el arco y el tablero se realiza mediante cables con una configuración tipo Network.

\subsubsection{Desdoblamiento del puente de la Peraleda en Toledo (España)}

Con el fin de mejorar el acceso al recinto ferial de Toledo (España) en la zona de la Peraleda, se realizó en el año 2010 el desdoblamiento del puente de vigas existente, así como la construcción a cada lado de sendas pasarelas arco tipo bow-string. El proyecto, del estudio A.I.A. (Arquitectos e Ingenieros Asociados), pretendía transformar la imagen del puente existente, una infraestructura sensiblemente degradada (véase Sánchez de León y Bernal [107]).

El puente original, con una sección formada por 6 vigas de hormigón pretensado en $\mathrm{T}$ con tramos isostáticos sobre pilas, disponía de dos carriles y dos aceras. La solución adoptada construyó un nuevo puente con vigas de sección en $\mathrm{T}$ al lado del existente, con el fin de no 

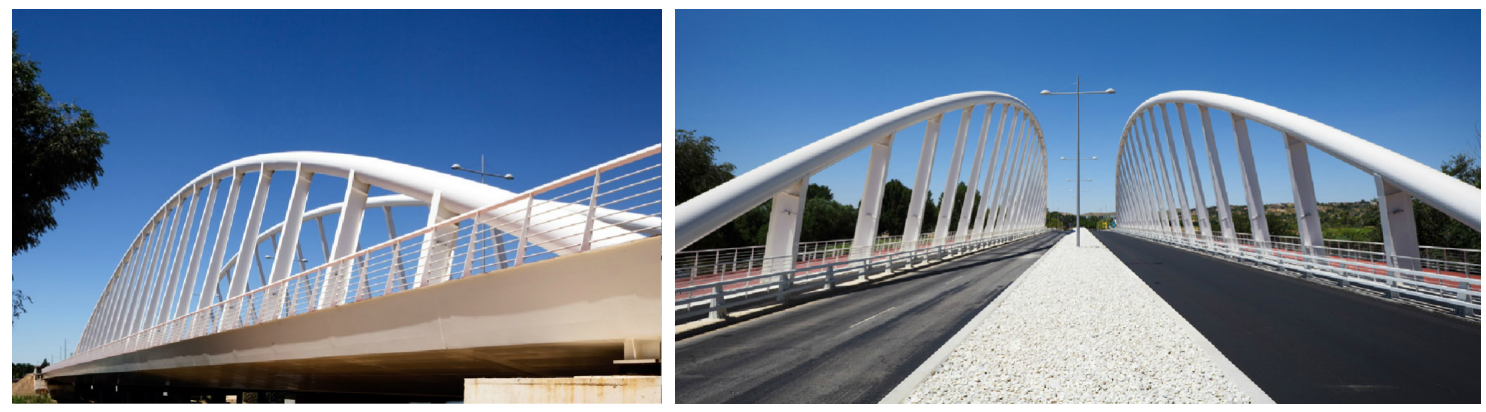

Figura 2.80: Desdoblamiento del puente de la Peraleda en Toledo (España). Fotografía: estudio A.I.A. (estudioaia.com).

desvirtuar la imagen del conjunto. La sección total resultante de sumar ambos puentes de vigas tiene $21 \mathrm{~m}$ de ancho, que se redistribuyen para alojar dos calzadas de dos carriles por sentido, arcenes, mediana para paso de instalaciones y barreras de contención laterales (véase la figura 2.80).

Las aceras existentes en el puente original se eliminaron, pues a cada lado del puente se proyectaron dos pasarelas metálicas de $127 \mathrm{~m}$ de luz con arcos inclinados hacia el centro del tablero. Estas pasarelas, que están separadas $0.5 \mathrm{~m}$ de los puentes de vigas, tienen un tablero de $6 \mathrm{~m}$ de ancho y $1.9 \mathrm{~m}$ de canto. Los arcos tienen un diámetro de $1 \mathrm{~m}$, y un espesor de $16 \mathrm{~mm}$. La vinculación entre el arco y el tablero se realiza mediante péndolas rígidas, lo que permite rigidizar transversalmente el arco.

\subsubsection{Arcos divergentes}

\subsubsection{Puentes en Hoznayo - Villaverde}

El puente, proyectado por el estudio Arenas \& Asociados, se sitúa sobre la confluencia de los ríos Aguanaz y Pontones, en Cantabria (España). El puente fue construido en el año 2005, salvando una luz de $60 \mathrm{~m}$ (véase [78]).

La estructura se compone de dos arcos tipo bow-string que se sitúan en ambos lados del tablero, usando el nervio de borde del tablero como tirante (véase la figura 2.81).

La losa del tablero, de hormigón armado, descansa sobre diafragmas metálicos transversales dispuestos cada $4 \mathrm{~m}$ según el eje del puente, sustentados mediante péndolas rígidas de los arcos inclinados hacia el exterior. Esta inclinación, según sus autores, se lleva a cabo por razones de desahogo visual para los usuarios.

\subsubsection{Butterfly Bridge}

En el año 1995 se convocó el concurso para la construcción de una pasarela de $32 \mathrm{~m}$ de luz sobre el río Ouse en la ciudad de Bedford (Reino Unido), resultando ganadores los estudios Wilkinson Eyre (arquitectura) y Jan Bobrowski \& Partners (ingeniería), de un total de 78 competidores. 

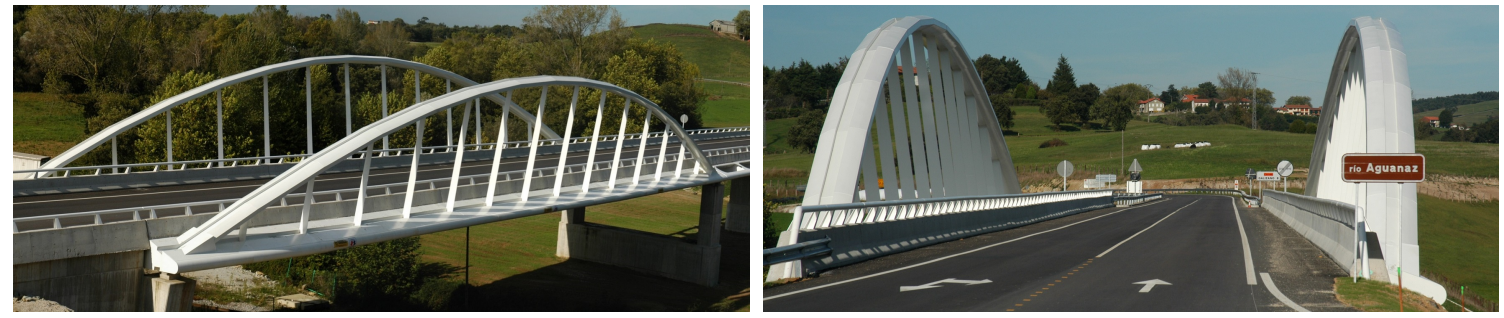

Figura 2.81: Puentes en Hoznayo - Villaverde. Fotografía: Arenas \& Asociados (arenasing.com).
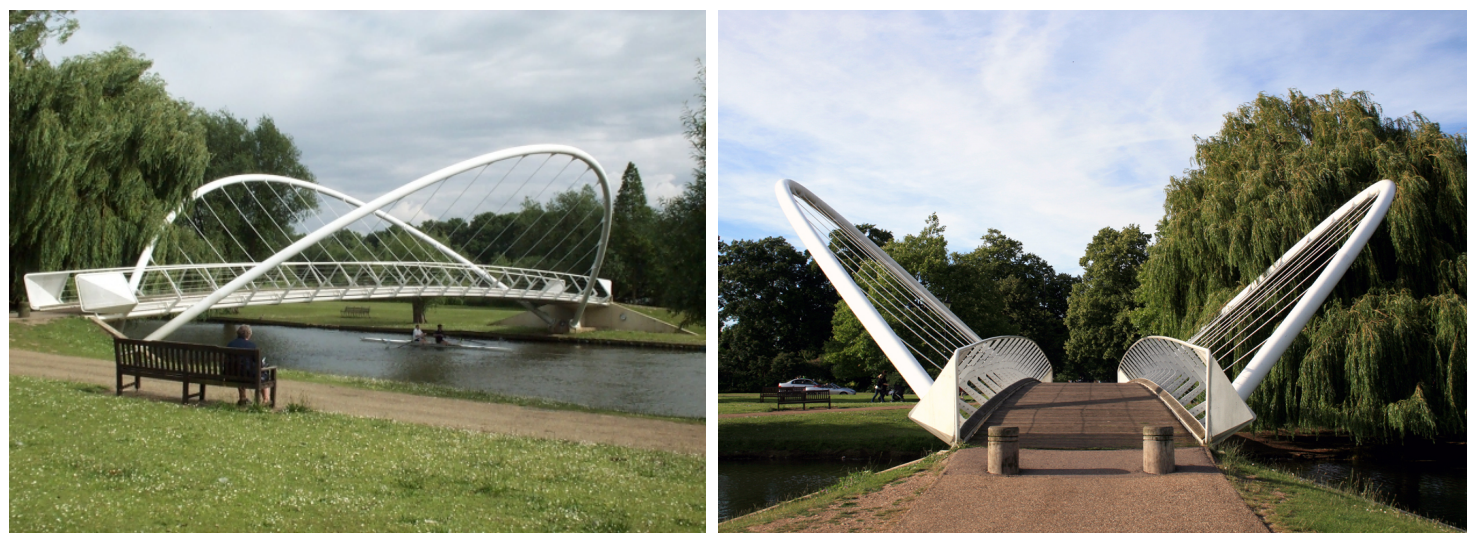

Figura 2.82: Butterfly Bridge. Fotografía: Simon Speed (structurae.net) y Philip Curnow (philipcurnow.com).

La pasarela fue finalizada en 1997, constituyendo un ejemplo de como la estética y la novedad formal no están reservadas solo para ambientes urbanos, pues la pasarela se sitúa en un entorno natural prácticamente libre de edificaciones (véase Baus y Schlaich [14]).

Los dos arcos inclinados hacia el exterior que tiene la pasarela recuerdan el perfil de una mariposa, de ahí que los habitantes la hayan bautizado como "Butterfly Bridge" 45 . Estos arcos divergentes sustentan el tablero de sus dos bordes mediante cables (véase la figura 2.82).

\subsubsection{Minto Island Bridge en Salem, Oregón (EEUU)}

Esta pasarela se sitúa sobre el río Willamette en la ciudad de Salem (EEUU). Terminada en el año 2017, el proyecto de la estructura es de los estudios Strasky, Husty and Partners y OBEC Consulting Engineers (véanse Strasky y Necas [111], y Strasky et al. [110]).

El puente está formado por un tablero continuo de 5 vanos $(15.24 \mathrm{~m}+93.88 \mathrm{~m}+3 \mathrm{x}$ $15.24 \mathrm{~m}$ ), estando el vano principal compuesto por una banda tesa suspendida por dos arcos divergentes (véase la figura 2.83). El vano principal es recto, mientras que el resto de vanos son curvos en planta. La sección de los arcos está formada por un tubo de 750 $\mathrm{mm}$ de diámetro, haciendo la banda tesa de tirante de ambos.

\footnotetext{
${ }^{45}$ Parece ser que en un principio la pasarela era nombrada "Embankment Renaissance Bridge".
} 

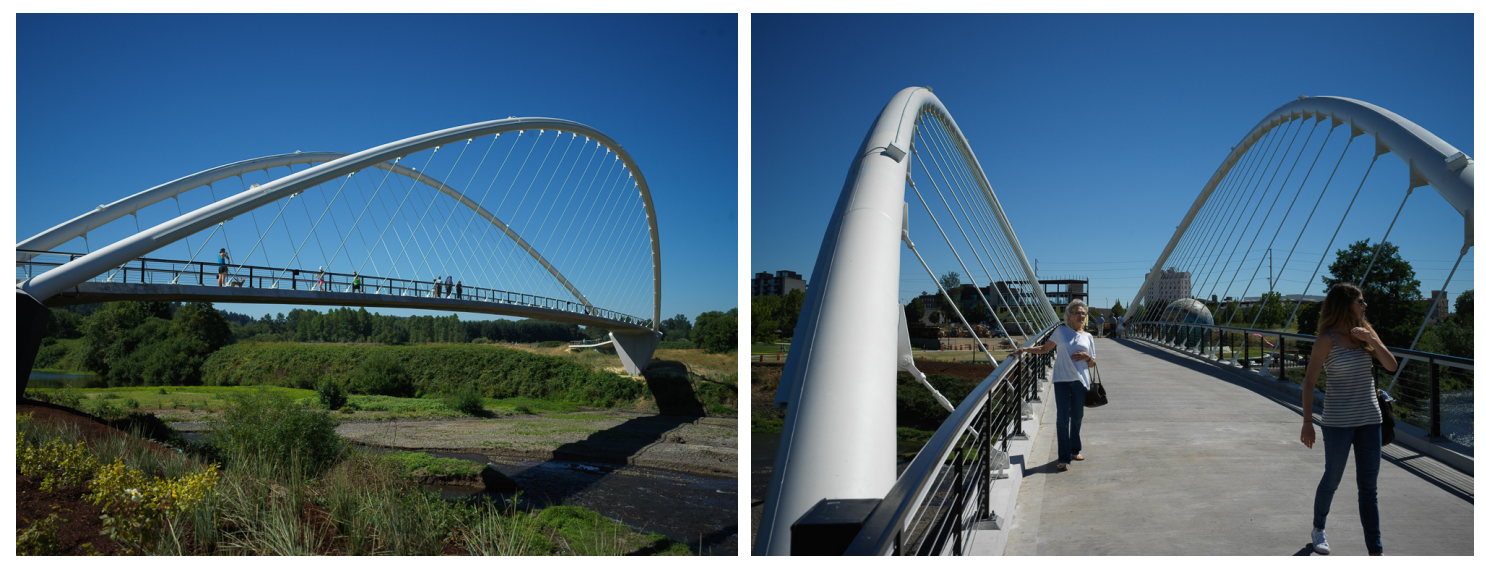

Figura 2.83: Minto Island Bridge en Salem, Oregón (EEUU). Fotografía: Mark Yashinsky (bridgeofweek.com).

El estudio Strasky, Husty and Partners está usando recientemente esta disposición de arcos divergentes para proyectar otras estructuras, como la pasarela sobre el río Nitra (Nitra, República Checa), o la pasarela sobre el río Vah en Ruzomberok (Eslovaquia).

\subsubsection{Pasarela sobre la Ronda de la Hispanidad}

La pasarela sobre la Ronda de la Hispanidad ${ }^{46}$, situada en Zaragoza (España), es un puente peatonal que cruza la circunvalación Z-30 (Ronda de la Hispanidad). La pasarela inaugurada en el año 2002, es proyecto de la empresa Carlos Fernández Casado S.L.

La estructura tiene una luz de $86 \mathrm{~m}$ repartida en tres vanos $(15.6 \mathrm{~m}+54.8 \mathrm{~m}+15.6 \mathrm{~m})$. El vano central está sustentado mediante dos arcos divergentes que se separan $10 \mathrm{~m}$ en la clave (véase la figura 2.84).

La sección del tablero tiene $3 \mathrm{~m}$ de ancho, y esta formada por un tubo central de $560 \mathrm{~mm}$ de diámetro y dos laterales de $300 \mathrm{~mm}$, unidos todos ellos mediante diafragmas situados cada $2 \mathrm{~m}$. Encima de esta estructura de tablero se dispone una chapa de $10 \mathrm{~mm}$ de espesor rigidizada. La sección de los arcos está formada por un tubo de acero de $550 \mathrm{~mm}$ de diámetro, vinculándose ambos a los bordes del tablero mediante cables.

\subsubsection{Rotherhithe Tunnel Bridge}

Construida en 1998, esta pasarela permite cruzar la carretera al túnel Rotherhithe, en el este de Londres (Reino Unido). El proyecto es de los estudios Whitbybird y Nicholas Lacey \& Partners, asesorados estructuralmente por WS Atkins \& Partners Overseas.

La pasarela es muy parecida al Butterfly Bridge de Bedford (Reino Unido), disponiendo de un tablero de unos $15 \mathrm{~m}$ de longitud, sustentado por dos arcos que se separan en la clave. Los arcos se unen al tablero mediante cables (véase la figura 2.85).

\footnotetext{
${ }^{46}$ También es llamada pasarela de los Pinares de Venecia, área de Zaragoza donde se sitúa.
} 

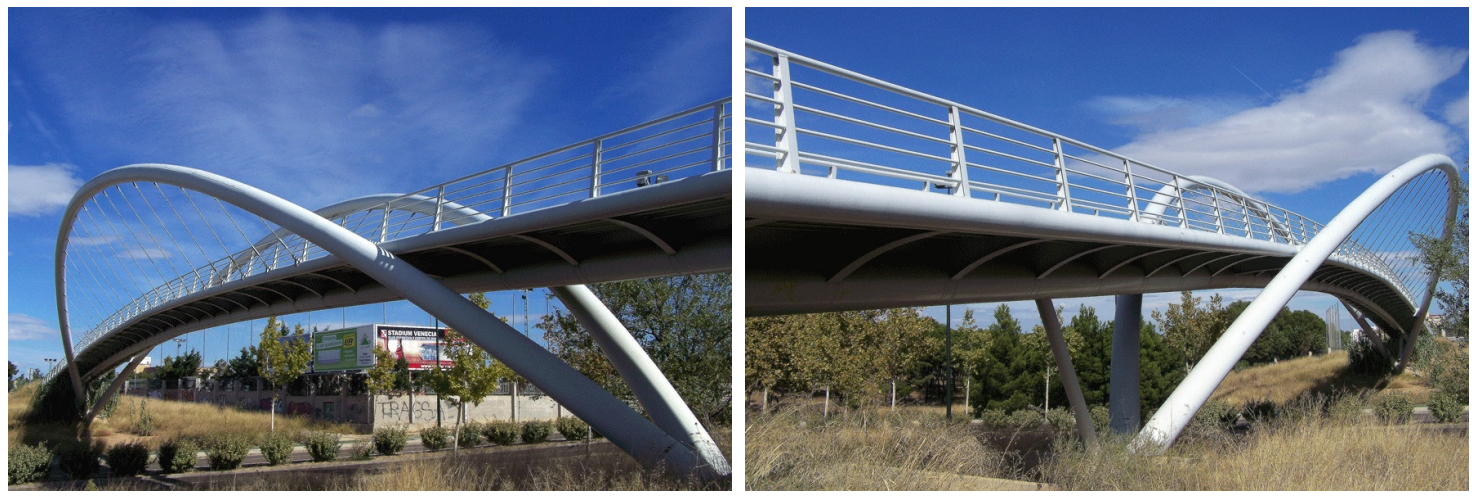

Figura 2.84: Pasarela sobre la Ronda de la Hispanidad. Fotografía: zaragozacool (zaragozacool.blogspot.com.es).
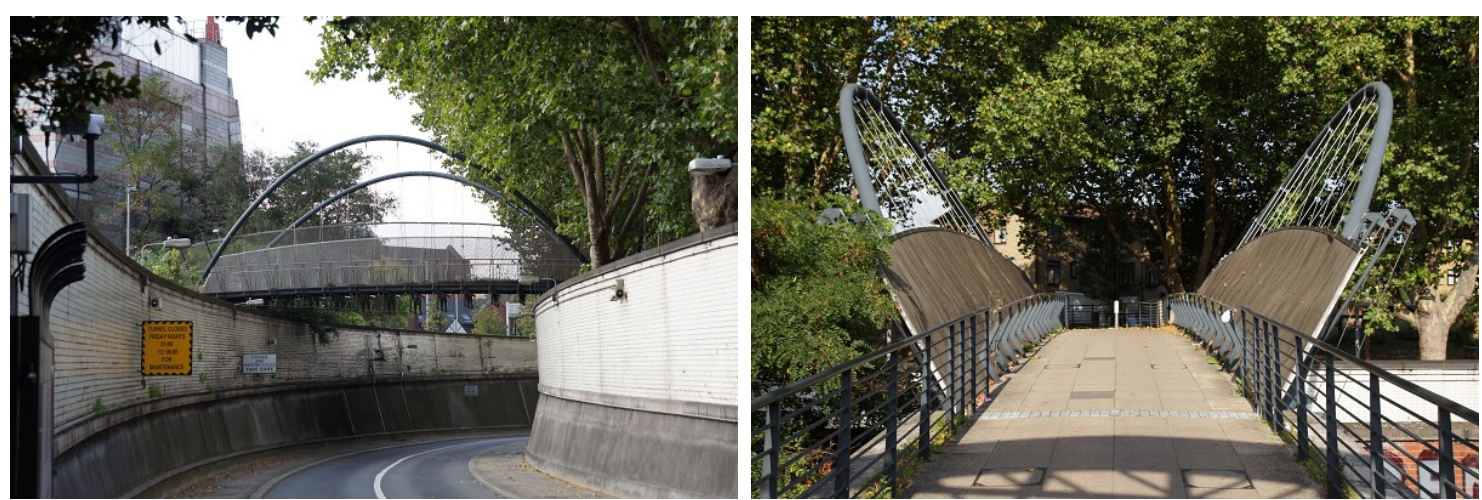

Figura 2.85: Rotherhithe Tunnel Bridge. Fotografía: Nicolas Janberg (structurae.net). 


\section{Capítulo 3}

\section{Modelos de cálculo}

\subsection{Introducción}

En esta tesis todos los cálculos estructurales se han realizado con el programa de elementos finitos SAP2000, de la empresa Computer and Structures, Inc. En concreto se ha usado la versión 16 del programa, del año 2013. Todos los modelos calculados, salvo que se especifique lo contrario, están constituidos por estructuras espaciales de barras de seis grados de libertad por nudo (véanse Computers and Structures [24] y Fu [32]).

Para el preproceso y la generación de todos los modelos estructurales, el postproceso de los resultados obtenidos, así como para los cálculos y la generación de gráficos para la puesta en valor de los resultados, se ha usado el programa Matlab (véase [113]). En ocasiones puntuales también se han usado hojas de cálculo Excel.

Todos los programas, funciones y códigos que se mencionan en las siguientes páginas, han sido realizados expresamente para esta tesis doctoral por el autor.

En este capítulo se detallan la características de los códigos informáticos, de los modelos de cálculo usados, así como las propiedades mecánicas de las barras, las acciones de cálculo consideradas, la geometría de las estructuras y sus condiciones de contorno.

\subsection{Programas de cálculo}

Para esta tesis doctoral, se han programado e implementado códigos en lenguaje MATLAB que permiten la generación, gestión y análisis de modelos de elementos finitos de SAP2000. Con estos códigos se han podido realizar de manera automática, todos los modelos necesarios para la redacción de la tesis.

El software desarrollado comparte la filosofía del programa SABRINA (Spatial Arch Bridges Iterative Non-linear Analysis), desarrollado por el Dr. Jorquera Lucerga, director de esta tesis, si bien existen algunas diferencias en el funcionamiento. Mientras que los códigos desarrollados en esta tesis interactúan directamente con el programa SAP2000 a través de MATLAB, la colección de programas de SABRINA actúa sobre los archivos de entrada (.s2k) y salida (.EKO, .OUT, .LOG) del programa SAP2000. 
La elaboración de los códigos informáticos ha consistido en los siguientes trabajos:

- Creación de una numeración única para toda la tesis, de los diferentes componentes del modelo de elementos finitos (barras, nudos, apoyos, materiales, etc.). Esto permite identificar cada elemento de manera inequívoca, pudiéndose comparar el mismo elemento en distintos modelos de cálculo.

- Establecimiento de unos criterios de notación compactos, que permitan sacar partido a la capacidad de análisis matricial de MATLAB. Esta notación se sigue en todos los programas y funciones generadas, asegurando la compatibilidad entre distintas versiones y futuros desarrollos.

- Generación de funciones específicas de preproceso y postproceso del programa SAP2000.

- Implementación de los algoritmos de cálculo de la tesis, mediante la combinación de las funciones específicas mencionadas antes.

Todo el software se escribió atendiendo a criterios de generalidad y de flexibilidad, pues a priori, se desconocían las características de las estructuras que se habían de analizar. Estos criterios han permitido analizar una gran cantidad de estructuras, algunas de ellas muy diferentes entre sí y de una complejidad elevada.

Como se ha comentado antes, la programación realizada en lenguaje MATLAB permite interactuar con SAP2000. El uso de este programa de estructuras ha estado motivado, entre otras cosas, por disponer de las siguientes características:

- SAP2000 es un programa de amplia difusión internacional, con una contrastada fiabilidad, algo que queda demostrado por su uso en gran parte de estudios profesionales, así como por su inclusión en gran parte de los programas de enseñanza de universidades técnicas.

- La OAPI ${ }^{1}$ de SAP2000 permite extender sus funcionalidades, integrando SAP2000 en aplicaciones concretas de ingeniería. La OAPI permite interactuar mediante diferentes lenguajes informáticos, entre ellos MATLAB.

- El programa SAP2000 puede ser ejecutado desde la línea de comandos de MATLAB, ejecutándose sin necesidad de entrar en el modo interactivo, es decir, SAP2000 se ejecuta en segundo plano, lo que se traduce en una mayor velocidad a la hora de realizar series paramétricas de modelos ${ }^{2}$.

En cuanto al programa MATLAB, su uso ha estado motivo por:

- Su gran disponibilidad y extendido uso en el ámbito universitario y profesional.

\footnotetext{
${ }^{1}$ Open Application Programming Interface.

${ }^{2}$ En algunos casos los análisis paramétricos han alcanzado los 1200 modelos, invirtiéndose tiempos de hasta 3 horas, que habrían sido mucho mayores al ejecutarse en primer plano, o prácticamente imposibles de realizar sin los códigos desarrollados.
} 
- El gran número de funciones, toolboxes y demás herramientas incorporadas en el programa.

- No es necesario compilar los programas.

- Su gran velocidad de cálculo si se usa notación matricial.

- La capacidad para crear funciones y programas propios.

- El Workspace de MATLAB, que da acceso directo a todos los programas y datos, lo que permite realizar cálculos complicados sin salir de su propio entorno de trabajo.

- El fácil y rápido manejo de grandes cantidades de información en formato vectorial y matricial.

- La capacidad para intercambiar información con otros programas como Excel, Adobe Illustrator y $\mathrm{HT}_{\mathrm{E} X}$.

- Facilidad para generar gráficos de alta calidad y complejidad.

En cuanto al software específico generado para la tesis, sus principales características son:

- La entrada de datos del programa es un archivo script (archivo .m de MATLAB), que se corresponde con una secuencia de comandos totalmente editable, lo que no sólo permite generar los modelos automáticamente, sino que permite generar estructuras en las que no se había pensado a la hora de escribir el programa.

- La entrada y salida de datos del programa es vectorial o matricial, lo que da como resultado una notación muy compacta, otorgando una gran potencia y sencillez a las instrucciones.

- La escritura no presenta diferencias respecto de la de MATLAB, con lo que cualquier usuario de éste puede adaptar los modelos a su interés.

- El código es abierto, lo que permite la programación de funciones y macros auxiliares que personalicen el análisis.

- Puede ser usado por usuarios que no sepan MATLAB: se puede generar un archivo sencillo de entrada de datos editable, que llame a un segundo donde esté programado el tipo estructural concreto en función de esos datos de entrada.

- El programa permite la ejecución iterativa de modelos, así como la gestión de modelos auxiliares. Es muy sencillo programar la modelización y estudios paramétricos de estructuras, ya que tiene a su disposición todas las instrucciones de control de flujo de MATLAB.

- El código se puede adaptar fácilmente a cualquier tipo de estructura, de manera que con una rápida reprogramación se pueden estudiar nuevos problemas o enfoques no contemplados en un principio. 
- El programa dispone de una biblioteca de funciones de preproceso y postproceso de SAP2000, que pueden ser usados por otras funciones de MATLAB.

- Permite ejecutar más de un análisis simultáneo, es decir, se podrían estar ejecutando a la misma vez dos análisis en dos interfaces distintas de SAP2000.

- Permite analizar modelos a partir de archivos .sdb que se hayan hecho con la propia interfaz gráfica del programa SAP2000, simplemente especificando el nombre del archivo, la numeración de barras, nudos, materiales, etc.

En cuanto al funcionamiento del software, este es muy secillo. Por lo general, se ha partido siempre desde un archivo .sdb inicial con un modelo de referencia, que posee una geometría con barras y nudos, secciones y materiales definidos, así como las cargas que actúan.

Desde MATLAB, se arranca SAP2000 con los códigos generados, y se realiza un primer preproceso del modelo de referencia .sdb, pudiéndose cambiar cargas, posiciones de nudos, así como secciones y materiales, pero siempre respetándose la topología del modelo.

Realizado el preproceso, se da la orden de análisis del modelo, y se extraen en el workspace de MATLAB los datos que se requieran. Estos datos se postprocesan, convirtiéndolos en formato vectorial y matricial, lo que permite que se puedan graficar, exportar en una tabla, o simplemente realizar una toma decisiones en base a ellos.

Todos los modelos generados durante el proceso, así como sus cambios, pueden ser abiertos y modificados posteriormente desde la interfaz gráfica de SAP2000.

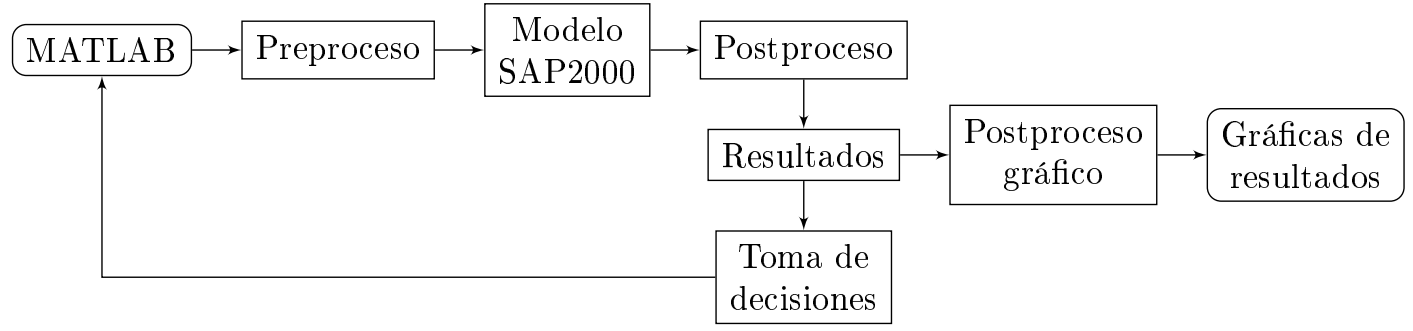

Figura 3.1: Esquema de funcionamiento del código escrito.

\subsection{Modelos de cálculo}

En general, en esta tesis todos los modelos, excepto aquellos necesarios para estudiar casos concretos, están formados por un arco y un tablero vinculados por una única familia de péndolas o montantes. Además, y salvo mención expresa, todos los modelos son puentes arco de tablero inferior. Las estructuras calculadas quedan definidas en su totalidad por una serie de parámetros mecánicos y geométricos.

Los modelos iniciales (que después son preprocesados y postprocesados), han sido generados con la interfaz gráfica de SAP2000, asegurándose siempre de la fiabilidad de los datos de partida introducidos. En las siguientes páginas se especifican los parámetros más comunes utilizados en el desarrollo de esta tesis, haciendo sobre todo hincapié en el modelo de referencia, que es el modelo usado como base para generar otros más complejos, y con el que se suelen comparar los estudios llevados a cabo en esta tesis. 


\subsubsection{Parámetros geométricos}

\subsubsection{Arco}

Como ejemplo, en este apartado se presenta el modelo de referencia con el que se suelen comparar los estudios realizados, y que sirve de partida para crear modelos más complejos.

En este modelo de referencia (véase la figura 3.2) el arco es plano y vertical con una directriz parabólica de $2^{\circ}$ grado (véase la ecuación 3.1). Por su parte el tablero es recto y se encuentra sujeto por cables en su eje.

Algunos de los parámetros que definen el arco de referencia son:

- L: luz del arco [m]. Distancia entre nudos de arranques de arco. Se ha considerado una luz $L=100 \mathrm{~m}$, un valor que está en el rango de luces de las principales realizaciones, así como de los principales estudios teóricos referentes a puentes arco espaciales.

- $f$ : flecha del arco en el plano vertical $[\mathrm{m}]$. Se impone como proyección vertical de la directriz del arco la parábola de $2^{\circ}$ grado que tiene como vértice la clave del arco y que pasa por los arranques del mismo. Se ha considerado una flecha del arco de $20 \mathrm{~m}$, lo que da un valor habitual del rebajamiento de $0.2(20 / 100)$, que no suele dar problemas por no linealidad geométrica en los puentes arco planos (véase Manterola [60]).

- $n_{A}$ : número de tramos en que se divide el arco. Define asimismo el número de vanos del tablero. Se ha tomado un número de 20 tramos.

- $n_{\text {int }}$ : número de nudos intermedios entre cada dos péndolas o entre péndolas extremas y extremos de arco o tablero. El número de nudos intermedios es 3, con lo que entre dos péndolas el número de barras es 4 . Dado que el puente se divide en 20 tramos (20 el arco y otros 20 el tablero), el número de barras que forman el arco son 80, al igual que en el tablero.

Como origen del eje de coordenadas global se coge el punto sobre el tablero que queda justo debajo de la clave del arco. Atendiendo a esta situación, las coordenadas de la clave del arco son $(0,0, f)$, y las de los arranques $(-L / 2,0,0)$ y $(L / 2,0,0)$. La ecuación de la parábola con los parámetros que definen el arco se muestra en la ecuación 3.1.

$$
z=f \cdot\left(1-\frac{4 \cdot x^{2}}{L^{2}}\right)
$$

En el caso de estudios específicos, donde intervienen modelos con arcos inclinados (véase la figura 3.3), se tiene que definir además:

- $\omega$ : ángulo que forma el plano inclinado que contiene el arco con respecto al plano vertical. 


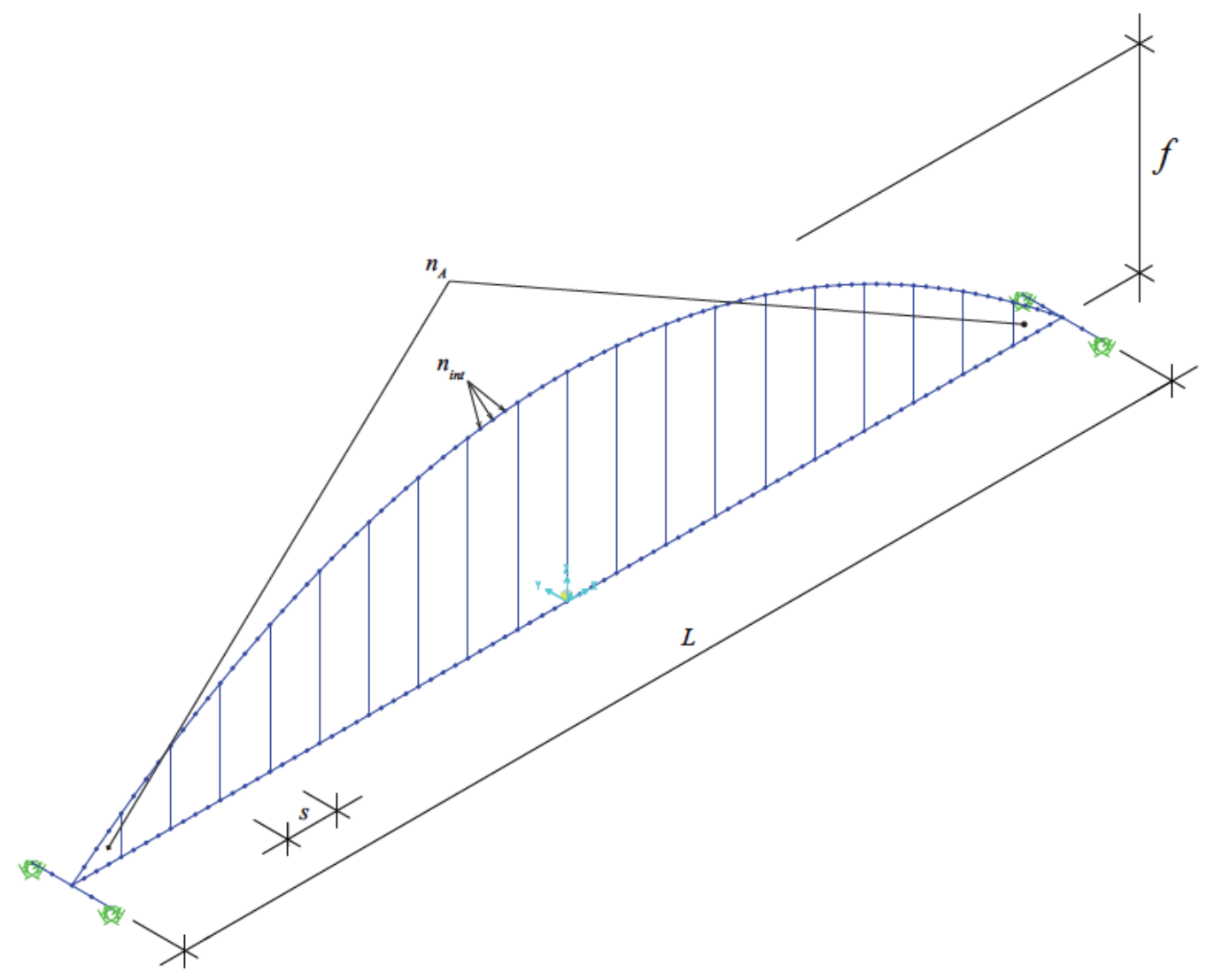

Figura 3.2: Modelo de referencia. Los parámetros geométricos se han dibujado sobre el modelo de barras y nudos de SAP2000.

Hay que tener en cuenta que en todos los modelos llevados a cabo en esta tesis, la luz del arco $L$ (medida según el eje $\mathrm{X}$ global) se ha dividido siempre en $n_{A}$ tramos iguales y que en el tablero (que puede ser un arco de circunferencia) se divide en $n_{A}$ tramos de igual desarrollo, por lo que las péndolas sólo serán perfectamente verticales cuando el tablero sea recto y si además coinciden los arranques del arco con los estribos del tablero.

\subsubsection{Péndolas}

Las péndolas o cables, han sido modeladas mediante barras. Las péndolas se han articulado en ambos extremos, y en ambas direcciones, liberándose la torsión solo en el extremo superior (unión de la péndolas con el arco). Cuando se han realizado estudios de péndolas rígidas, estas se han modelizado también como barras, pero por lo general, y salvo que se especifique lo contrario, no están articuladas en ningún extremo.

Algunos de los parámetros que definen las péndolas son:

- $n_{P}$ : número de péndolas del modelo. Se puede calcular como $n_{P}=n_{A}-1$.

- $s$ : distancia entre péndolas medida sobre el eje X. Se puede obtener como $s=L / n_{A}$.

- $h_{i}$ : longitud de la péndola i [m]. 


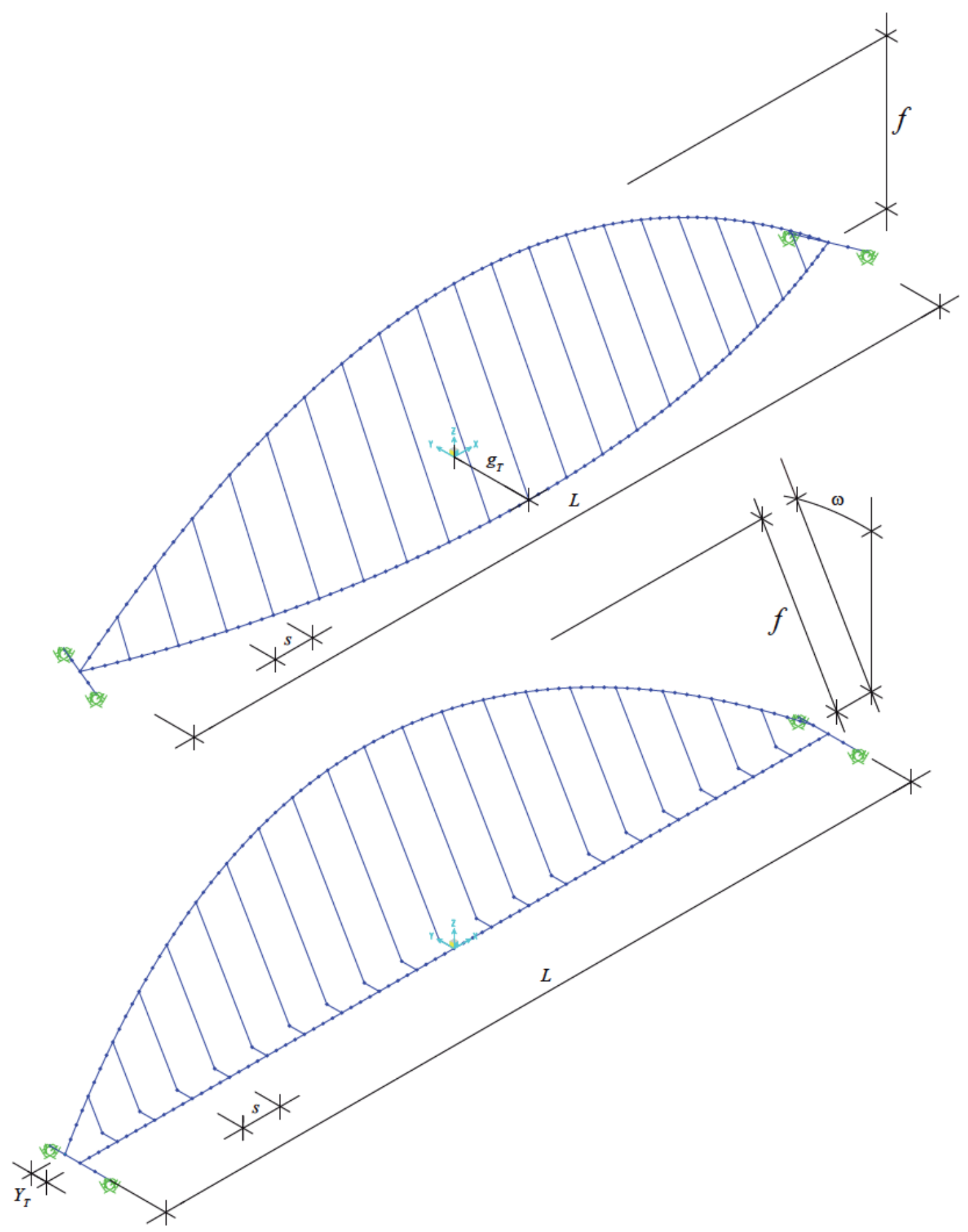

Figura 3.3: Modelos secundarios para estudios específicos. Los parámetros geométricos se han dibujado sobre el modelo de barras y nudos de SAP2000.

\subsubsection{Tablero}

El tablero del modelo de referencia es recto, quedando definido por los siguientes parámetros: 
- $Y_{T}$ : Distancia entre el inicio del tablero y el arranque del arco medida sobre el eje $\mathrm{Y}[\mathrm{m}]$. En el caso en el que el arranque del arco coincide con el inicio del tablero, $Y_{T}=0 \mathrm{~m}$.

- $Z_{T}$ : Distancia entre el arranque del arco y el inicio del tablero medida sobre el eje Z [m]. Si $Z_{T}=0 \mathrm{~m}$, el modelo es un puente arco de tablero inferior, ya que el arranque del arco coincide con el inicio del tablero. Si $0<Z_{T}<f$, entonces el puente arco es de tablero intermedio. Por último, si $f \geq Z_{T}$, entonces es un puente arco de tablero superior.

- $b_{L V}, b_{L}$ : Distancia vertical y lateral de atirantamiento [m]. Estas magnitudes definen las distancias en alzado y planta entre los nudos que modelizan las barras de tablero y los nudos que modelizan los puntos de anclaje de las péndolas. Si ambas magnitudes son nulas, el tablero se atiranta al centro de gravedad, que en esta tesis se ha supuesto coincidente con el centro de esfuerzos cortantes. En el modelo de referencia $b_{L V}$ y $b_{L}$ son nulas, pero en otros modelos como los arcos inclinados sujetos al borde de tablero, estas distancias se modelizan introduciendo una barra infinitamente rígida de peso nulo entre los nudos de tablero y de anclaje.

- $b$ : ancho cargado del tablero [m]. Por lo general el ancho en los modelos analizados es de $4 \mathrm{~m}$, salvo casos excepcionales en lo que se ha aumentado incluso a $8 \mathrm{~m}$, con el fin de estudiar e ilustrar algún efecto particular.

En el caso de estudios específicos, donde intervienen modelos con tableros curvos (véase la figura 3.3), se tiene que definir además:

- $g_{T}$ : Flecha horizontal en planta del tablero curvo [m]. La directriz del tablero queda definida por un arco de circunferencia horizontal que pasa por los arranques del tablero y cuya flecha (distancia entre la cuerda que une los arranques y el punto central del tablero) es $g_{T}$. Si $g_{T}$ es negativa, el tablero se curva hacia el eje -Y, algo que dado el origen de coordenadas considerado, suele ocurrir normalmente para que la curvatura quede del lado más fácil de visualizar.

En general, cada estribo del tablero se ha modelizado mediante dos apoyos unidos por una barra infinitamente rígida, estando el arranque del tablero justo en la mitad de esta barra (véanse las figuras 3.2 y 3.3). Los apoyos situados en la coordenada $-L / 2$ tienen una posición fija pero permiten los giros, mientras que los apoyos situados en la coordenada $L / 2$ permiten los giros y solo el desplazamiento en el eje $\mathrm{X}$, lo que significa que el tablero actúa como tirante del arco y el puente se puede considerar con un comportamiento tipo bow-string.

\subsection{Valores de las acciones}

Para determinar los valores de las diferentes acciones actuantes en el puente, se ha seguido en todo momento lo estipulado en la IAP-11, la instrucción sobre las acciones a considerar en el proyecto de puentes de carretera (véase [27]), la cual tiene unos valores muy similares al Eurocódigo 1: Acciones en estructuras, Parte 2: Cargas de tráfico en puentes (véase [10]). 


\subsubsection{Cargas permanentes}

Las cargas permanentes consideradas en todos los modelos son:

- PP: Peso Propio. Obtenido con los pesos específicos establecidos en el punto 3.7.

- CM: Carga Muerta sobre el tablero $[\mathrm{kN} / \mathrm{m}]$. Este valor, que excluye el peso propio del tablero, considera el peso de aceras, barandillas o pavimentos.

En el modelo de referencia se ha considerado un valor de $\mathrm{CM}=3.75 \mathrm{kN} / \mathrm{m}^{2}$, que multiplicado por un ancho de $4 \mathrm{~m}$ da un valor de $15 \mathrm{kN} / \mathrm{m}$. Este valor aparece al considerar para un tablero de $4 \mathrm{~m}$ de ancho las siguientes cargas muertas:

- Pavimento de $0.08 \mathrm{~m}$ de espesor y $4 \mathrm{~m}$ de ancho, con peso específico de $25 \mathrm{kN} / \mathrm{m}^{3}$.

- Losa de $1.25 \mathrm{kN} / \mathrm{m}^{2}$ y $4 \mathrm{~m}$ de ancho.

- Dos barandillas situadas en los bordes del tablero, con un peso de $1 \mathrm{kN} / \mathrm{m}$ cada una.

En lo referente al peso del pavimento, la IAP-11 establece en el punto 3.1.2 la necesidad de considerar dos valores extremos, por un lado los pesos debidos a los espesores teóricos, y por otro lado el peso debido a un incremento del $50 \%$ de los espesores teóricos. Con el fin de simplificar, solo se han considerado los espesores teóricos definidos anteriormente.

\subsubsection{Sobrecargas verticales de uso}

La IAP-11 establece en su artículo 4.1.2.2 que en las zonas de uso peatonal de los puentes (aceras, rampas y escaleras), se supondrá aplicada una sobrecarga uniforme de $5 \mathrm{kN} / \mathrm{m}^{2}$ en las zonas más desfavorables, longitudinal y transversalmente, para el efecto en estudio.

Los puentes analizados en la presente tesis son pasarelas peatonales en su totalidad, con lo que se ha considerado una sobrecarga de uso (en adelante SCU) de $5 \mathrm{kN} / \mathrm{m}^{2}$.

\subsubsection{Acción del viento}

Con ánimo de simplificar, y dado que la IAP-11 establece en su punto 4.2 la necesidad de ciertos parámetros no posibles de obtener, pues los estudios desarrollados tienen un carácter teórico, se ha considerado una valor de la carga actuante de viento de $2 \mathrm{kN} / \mathrm{m}^{2}$. Este valor es un orden de magnitud bastante razonable, muy usado en otros estudios relacionados con la temática de esta tesis.

Atendiendo al punto 4.2.3 de la IAP-11, la carga de viento se ha considerado sobre el área transversal del arco y el tablero, añadiendo a este último un área de $1.25 \mathrm{~m}$ de altura al canto del mismo. 


\subsubsection{Acción térmica}

La IAP-11 establece en su punto 4.3 la necesidad de considerar la acción térmica en puentes, donde actúa una componente uniforme de temperatura, así como la acción debida a la diferencia de temperaturas entre caras de un mismo elemento. Con el fin de simplificar las posibles combinaciones, se ha considerado en esta tesis solo el efecto de la componente uniforme.

Atendiendo a los parámetros especificados en el apartado 4.3 de la IAP-11, y considerando el modelo de referencia situado en Madrid, con una altura de unos $600 \mathrm{~m}$ sobre el nivel del mar, se han obtenido las variaciones de temperatura para arco y tablero especificadas en la tabla 3.1.

Hay que destacar que esta variaciones de temperatura toman $15{ }^{\circ} \mathrm{C}$ como la temperatura del puente en el momento de coaccionar el movimiento del puente. Por otro lado, y siempre con el fin de simplificar, no se ha tenido en cuenta la diferencia entre la temperatura del arco y el tablero especificada en el punto 4.3.3.2 de la IAP-11.

En cuanto a los tirantes del puente, se ha considerado una diferencia positiva de $+20{ }^{\circ} \mathrm{C} \mathrm{y}$ $-10{ }^{\circ} \mathrm{C}$ con respecto a los incrementos y decrementos de temperatura del arco y el tablero mostrados en la tabla 3.1.

\begin{tabular}{|c|c|c|}
\hline & \multicolumn{2}{|c|}{$\Delta \mathrm{T}$} \\
\hline Hipótesis & Arco y Tablero & Péndolas \\
\hline Incremento Térmico & $+45^{\circ} \mathrm{C}$ & $+65{ }^{\circ} \mathrm{C}$ \\
\hline Decremento Térmico & $-30{ }^{\circ} \mathrm{C}$ & $-40{ }^{\circ} \mathrm{C}$ \\
\hline
\end{tabular}

Tabla 3.1: Variaciones de temperatura.

\subsection{Hipótesis simples de carga y combinaciones}

\subsubsection{Hipótesis simples}

En los estudios llevados a cabo en esta tesis, se han considerado las siguientes hipótesis simples de carga:

- PP: peso propio de las secciones de arco, tablero y péndolas.

- CM: carga muerta sobre el tablero.

- SCU: sobrecarga de uso, dividida según las zonas cargadas del tablero en:

- $q_{1}$ : sobrecarga de uso 1 (semitablero izquierdo cargado).

- $q_{2}$ : sobrecarga de uso 2 (semitablero derecho cargado).

- $q_{3}$ : sobrecarga de uso 3 (semitablero dorsal cargado).

- $q_{4}$ : sobrecarga de uso 4 (semitablero frontal cargado). 


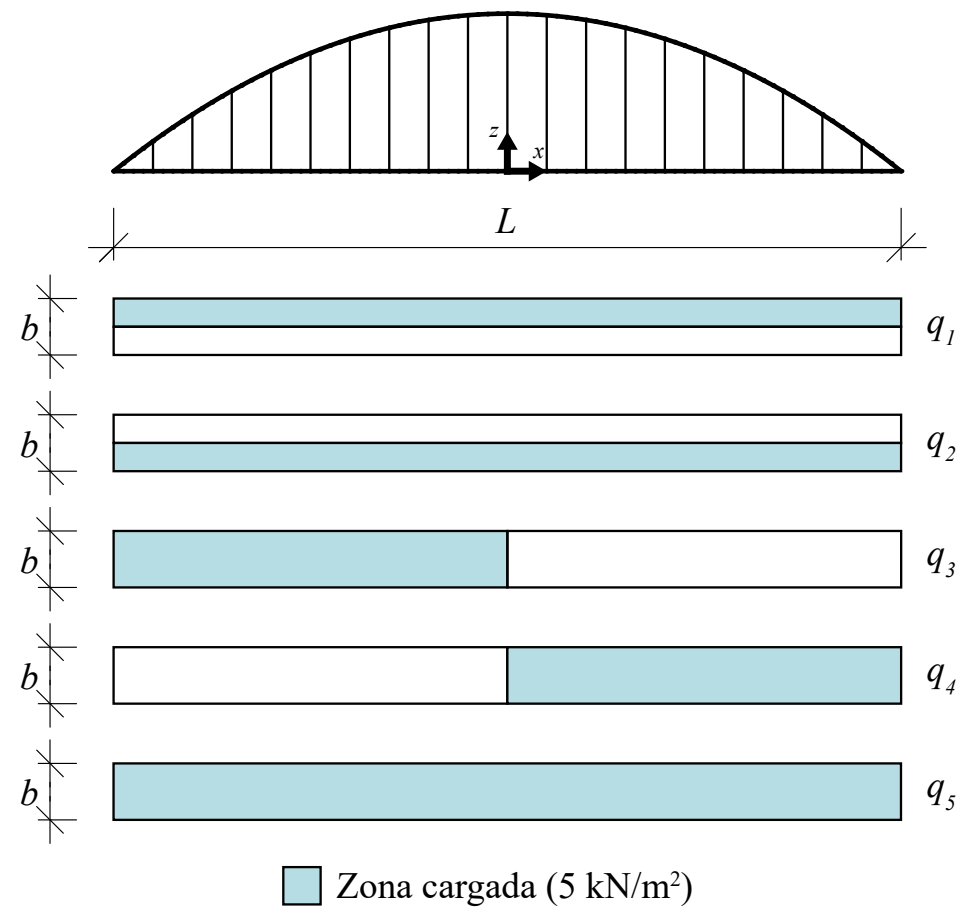

Figura 3.4: Zonas de carga para cada sobrecarga de uso.

- $q_{5}$ : sobrecarga de uso 5 (tablero cargado al completo).

- $\mathrm{T}+$ : incremento térmico.

- T- : decremento térmico.

- VTO: viento transversal sobre el arco y el tablero.

Las sobrecargas $q_{1}$ y $q_{2}$ son cargas verticales descendientes de valor SCU.b/2 y torsores concomitantes de valor SCU $\cdot \mathrm{b}^{2} / 4\left(\right.$ para $\left.q_{1}\right)$ y $-\mathrm{SCU} \cdot \mathrm{b}^{2} / 4$ (para $q_{2}$ ), que son introducidas en los modelos como cargas uniformemente repartidas (véanse las figuras 3.4 y 3.5).

Las sobrecargas $q_{3}, q_{4}$ y $q_{5}$ son cargas verticales descendientes de valor SCU.b, que son introducidas en los modelos como cargas uniformemente repartidas.

\subsubsection{Combinaciones de hipótesis simples}

En los estudios llevados a cabo en esta tesis, se han considerado las siguientes combinaciones de hipótesis simples de carga:

- COMB1: PP + CM

- COMB2: COMB1 $+q_{1}$

- COMB3: COMB1 $+q_{2}$ 
- COMB4: COMB1 + $q_{3}$

- COMB5: COMB1 $+q_{4}$

- COMB6: COMB1 + $q_{5}$
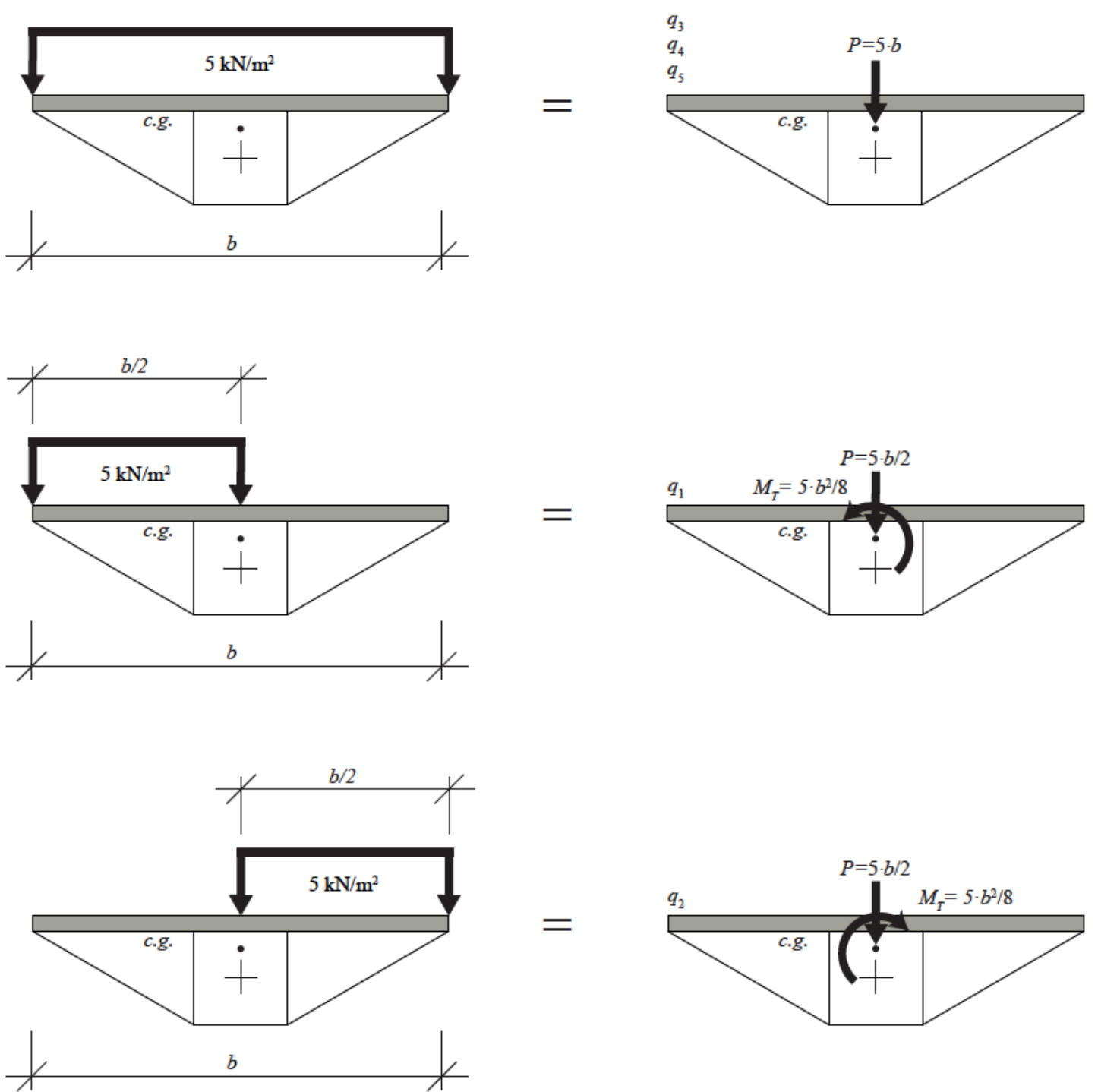

Figura 3.5: Fuerzas y momentos resultantes según las zonas cargadas con SCU.

\subsection{Criterio de signos de los esfuerzos}

En la presente tesis, se ha denominado flexión longitudinal a la que tiene como eje, el eje local horizontal de cada barra (M3 en SAP2000), es decir, que actúa según el canto de la sección. Se ha considerado la flexión transversal (M2 en SAP2000) como aquella que tiene como eje el tercer eje local, es decir, que tiene como canto el ancho de la sección. 
En la figura 3.6 se representa el criterio de signos de los esfuerzos, que coincide con el empleado por el programa SAP2000.

Axil $\mathrm{N}$ y torsor $\mathrm{T}$ positivos

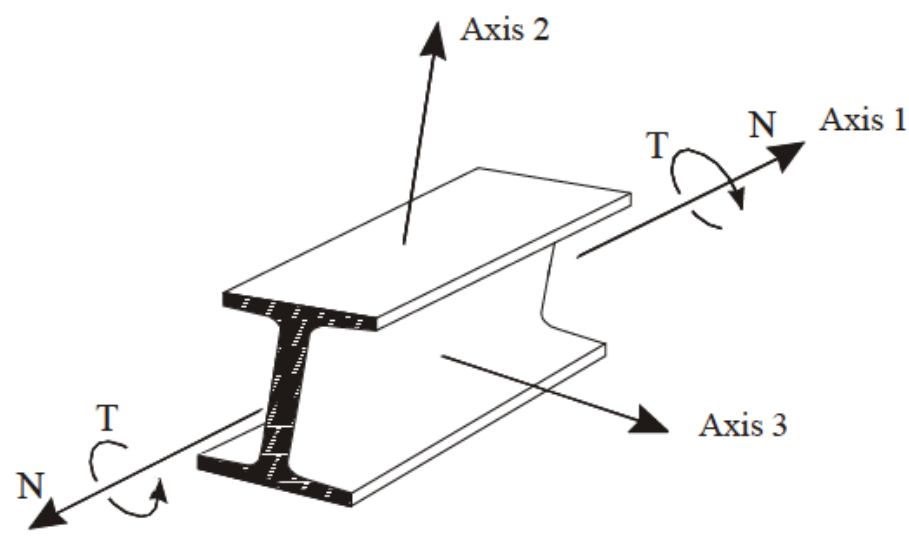

Flexión longitudinal M3 y esfuerzo cortante $\mathrm{V} 2$ positivos

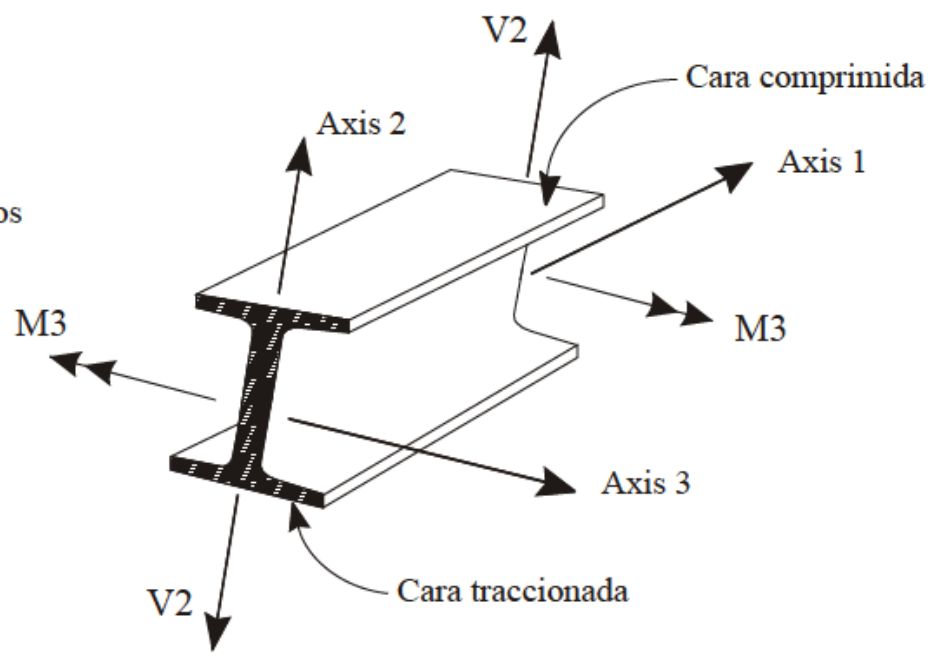

Flexión transversal M2 y esfuerzo cortante $\mathrm{V} 3$ positivos

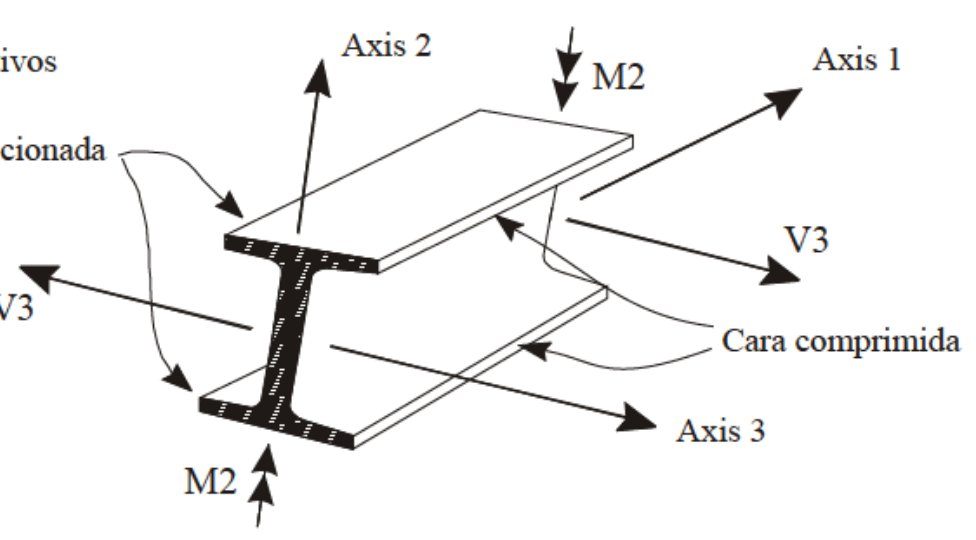

Figura 3.6: Criterio de signos empleado en la tesis. La figura a sido redibujada a partir de Computer and Structures, Inc. [24]. 


\subsection{Materiales}

Para el acero del arco y del tablero se ha considerado en todos los modelos un valor del módulo de deformación longitudinal, $E$, de $2.0 \cdot 10^{5} \mathrm{~N} / \mathrm{mm}^{2}$, así como una peso específico de $78.5 \mathrm{kN} / \mathrm{m}^{3}$. El límite elástico de este acero se ha considerado de $355 \mathrm{MPa}$.

Para las péndolas, se ha considerado un valor de $E=1.6 \cdot 10^{5} \mathrm{~N} / \mathrm{mm}^{2}$, pues se han supuesto cables del tipo Full Locked Cable del catálogo de la empresa Pfeifer (véase [77]). Los montantes, en el caso de arcos inferiores, y las péndolas rígidas, se han supuesto del mismo acero estructural del arco y del tablero.

Para el peso específico del acero de las péndolas, se ha considerado $85.24 \mathrm{kN} / \mathrm{m}^{3}$, un valor promedio para la sección formada por el acero y el conjunto inyección-protección. Este peso específico se determina con más detalle en el apartado de secciones.

\subsection{Secciones}

\subsubsection{Notación de las secciones}

Tanto en el arco como en el tablero se ha empleado una sección cajón cerrada rectangular. En algunos estudios se han empleado secciones de dimensiones variables, con secciones cajón de variación parabólica de $2^{\circ}$ grado del ancho de la sección o del canto, decreciente de arranques a clave o viceversa.

En cada estudio en particular se definen los valores concretos de las dimensiones de las secciones adoptadas.

Para las péndolas se han empleado en toda la tesis, secciones circulares macizas, excepto cuando se han empleado péndolas rígidas, las cuales se han modelizado con secciones cajón rectangulares.

La notación para las variables de las secciones anteriores está inspirada en la de SAP2000 (véase [24]):

- $h_{A}$ : canto de la sección transversal de arco.

- $b_{A}$ : ancho de la sección transversal de arco.

- $t_{w, A}$ : espesor de las almas de la sección transversal de arco.

- $t_{f, A}$ : espesor de las alas de la sección transversal de arco.

- $h_{D}$ : canto de la sección transversal de tablero.

- $b_{D}$ : ancho de la sección transversal de tablero.

- $t_{w, D}$ : espesor de las almas de la sección transversal de tablero.

- $t_{f, D}$ : espesor de las alas de la sección transversal de tablero.

- $\phi_{H}$ : diámetro de las péndolas. 


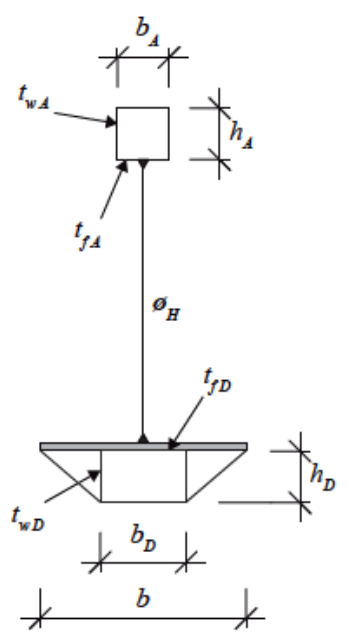

Figura 3.7: Notación usada para las secciones.

\subsubsection{Dimensiones de las secciones}

Atendiendo a la notación descrita en el punto anterior, las dimensiones para las distintas secciones del modelo de referencia en esta tesis doctoral son:

- Arco: $h_{A}=1000 \mathrm{~mm}, b_{A}=1000 \mathrm{~mm}, t_{w, A}=t_{f, A}=25 \mathrm{~mm}$.

- Tablero: $h_{D}=1000 \mathrm{~mm}, b_{D}=4000 \mathrm{~mm}, t_{w, D}=t_{f, D}=15 \mathrm{~mm}$.

- Péndolas: $\phi_{H}=60 \mathrm{~mm}$.

Las dimensiones anteriores se han obtenido siguiendo los criterios de dimensionamiento expuestos en el punto 3.8.3.

\subsubsection{Criterios de dimensionamiento de las secciones}

Para dimensionar las secciones de arco y tablero del modelo de referencia, se ha seguido en todo momento un criterio tensodeformacional. Por un lado el puente debe cumplir con un tensión máxima, pero a la vez también debe verificar una deformación límite.

\subsubsection{Combinación de dimensionamiento}

La combinación de cargas usada para el dimensionamiento es la definida como combinación característica (poco probable o rara) en el apartado 6.3.2 de la IAP-11:

$$
\sum_{j \geq 1} \gamma_{G, j} \cdot G_{k, j}+\sum_{m \geq 1} \gamma_{G, m} \cdot G_{k, m}^{*}+\gamma_{Q, 1} \cdot Q_{k, 1}+\sum_{i>1} \gamma_{Q, i} \cdot \Psi_{0, i} \cdot Q_{k, i}
$$

En todos los casos analizados, siempre ha resultado más desfavorable considerar como dominantes en la ecuación 3.2 las sobrecargas de uso, y el viento y la temperatura como concomitantes. 
En concreto, los mayores esfuerzos y deformaciones en el arco y el tablero se obtienen para la sobrecarga ${ }^{3} q_{3}$ definida en 3.5.1, algo que ya pone de manifiesto Manterola en [60] y Menn en [65]. Así, la combinación considerada para el dimensionamiento de las secciones de arco y tablero es la mostrada en la ecuación 3.3, donde se han considerado los coeficientes de las tablas 6.2-b y 6.2-c de la IAP-11.

$$
P P+C M+[0 / 1] \cdot q_{3}+[0 / 1] \cdot 0,3 \cdot[1 /-1] \cdot V T O+[0 / 1] \cdot 0,6 \cdot[T+/ T-]
$$

En la ecuación anterior, [1/-1] hace referencia a la posibilidad de que el viento actúe en uno u otro sentido. Los números entre corchetes indican los posibles coeficientes parciales para las acciones, de los que se escoge el más desfavorable en cada caso. Por último, las cargas entre corchetes son excluyentes entre sí, escogiéndose la más desfavorable.

\subsubsection{Limitación de la tensión normal}

Para predimensionar las secciones del arco y del tablero, se ha considerado que la máxima tensión normal obtenida para la combinación de la ecuación 3.3 no supere los $150 \mathrm{MPa}$, dado que las acciones se han introducido sin mayorar y el límite elástico del acero de la estructura se puede situar para espesores como los utilizados (menores de $40 \mathrm{~mm}$ ) en 355 MPa.

El límite de $150 \mathrm{MPa}$ es conservador, si bien la combinación tenida en cuenta considera los coeficientes de ponderación en servicio, que son menores que los empleados en estados límites últimos. Todos los cálculos tensionales han sido realizados sobre secciones brutas, sin considerar ningún tipo de reducción de ancho eficaz por arrastre de cortante, ni fenómenos como alabeo o distorsión, lo cual, aunque inexacto, permite simplificar sensiblemente los cálculos, y realizar comparaciones sencillas entre diferentes secciones.

Tanto en el arco como en el tablero, la sección donde se ha comprobado que el nivel de tensiones esté por debajo de $150 \mathrm{MPa}$ han sido los riñones del arco, es decir, la sección situada en $\mathrm{x}= \pm L / 4$.

\subsubsection{Limitación de la deformación máxima}

El criterio de deformación máxima asumido en esta tesis, verifica lo establecido en el punto 7.1.1 de la IAP-11. Esta instrucción establece que la flecha vertical máxima correspondiente al valor frecuente de la sobrecarga de uso no deberá superar el valor $L / 1200$ en pasarelas o en puentes peatonales, siendo $L$ la luz del vano.

La IAP-11 especifica también, que en el caso de tableros suspendidos o atirantados, arcos de tablero inferior o estructuras asimilables, se deberá tomar como $L$ la distancia entre puntos de inflexión de la deformada para la hipótesis de carga considerada.

En el caso del modelo de referencia de esta tesis, la mayor flecha del tablero se obtiene para la sobrecarga $q_{3}$, que produce la deformada de la figura 3.8. Como se puede observar

\footnotetext{
${ }^{3}$ En realidad los esfuerzos y deformaciones máximas se obtienen para las sobrecargas $q_{3}$ y $q_{4}$, pues ambas cargas son iguales pero en diferentes mitades del tablero. Atendiendo a lo anterior, y con ánimo de simplificar, se considera solo la sobrecarga $q_{3}$.
} 


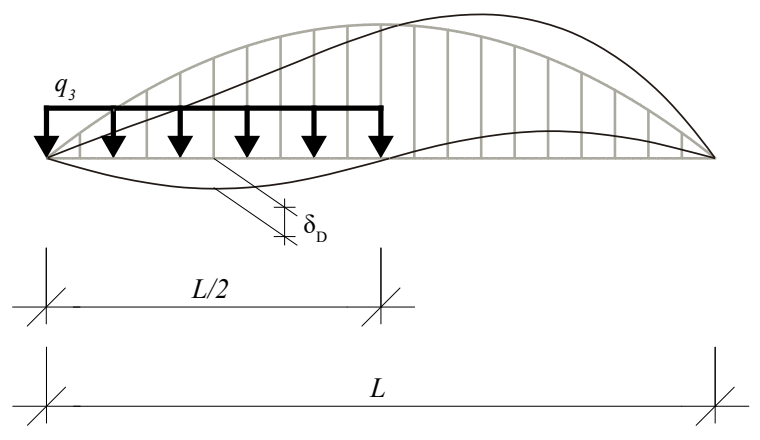

Figura 3.8: Deformación vertical máxima del tablero.

en la figura, la flecha máxima se produce en la sección de riñones $(\mathrm{x}= \pm L / 4)$, siendo la distancia entre los puntos de inflexión igual $L / 2$. Atendiendo a esto, la flecha límite será $(L / 2) / 1200=L / 2400$, y dado que $L=100$ en todo los modelos considerados en esta tesis, la flecha vertical máxima del tablero que siempre se debe cumplir es $100 / 2400=0.0416 \mathrm{~m}$, o lo que es lo mismo $41.6 \mathrm{~mm}$.

\subsubsection{Péndolas}

En cuanto al dimensionamiento de las péndolas, uno de los aspectos clave de acuerdo con Menn [65] y Siegrist [101], es que la capacidad del arco para resistir las cargas transferidas por el tablero depende de la rigidez de las péndolas.

Cuando la rigidez de una péndola vertical puede ser considerada como infinita, la flecha vertical de sus extremos es igual, y, además, la flecha del tablero es igual a la flecha del arco en la misma vertical. Esta situación ideal es llamada "efecto cortina", en la cual hay un alargamiento imperceptible de las péndolas. Este efecto puede ser alcanzado, en términos prácticos, dando a las péndolas la suficiente rigidez axial, es decir la suficiente área.

Para dimensionar la sección de las péndolas del modelo de referencia de esta tesis, se ha realizado un análisis de sensibilidad para obtener el mínimo diámetro de cable a partir del cual el "efecto cortina" ocurre, es decir, cuando el ratio entre las flechas del arco y el tablero $\delta_{A} / \delta_{D}$ puede ser considerado próximo a 1 .

Los resultados del análisis de sensibilidad, realizado para la péndola situada en $\mathrm{x}=-L / 4$ por ser el punto de máxima flecha, se muestran en la figura 3.9 para el modelo de referencia de la tesis, considerando las sobrecargas $q_{3}$ y $q_{5}$. Los valores tienden a estar muy próximos a 1 a partir de un diámetro de $60 \mathrm{~mm}$ cuando la carga considerada es $q_{3}$, sin embargo, cuando la carga considerada es $q_{5}$, el diámetro tiene que estar próximo a $250 \mathrm{~mm}$ para que el ratio valga 1. En esta tesis ha sido adoptada un péndola de diámetro igual a 60 $\mathrm{mm}$, salvo que se especifique lo contrario, pues la flecha absoluta producida por la carga $q_{3}$ es mucho mayor que la producida por $q_{5}$.

Esa péndola de $60 \mathrm{~mm}$ se corresponde con la péndola PV420 "Full Locked Cable" del catálogo de la casa comercial Pfeifer [77].

Además del efecto cortina, los otros parámetros a tener en cuenta en el dimensionamiento 
de las péndolas son la carga de rotura (viene especificada en el catálogo antes mencionado) y la fatiga.

La fatiga en péndolas se evita teniendo en cuenta una carrera máxima de tensión en los cables, la cual está recogida en el Eurocódigo 3: Proyecto de estructuras de acero, Parte 1-11: Cables y tirantes (véase [13]). Para esta tesis se ha considerado en concreto un valor de carrera de tensión de $150 \mathrm{MPa}$, valor especificado en el Eurocódigo antes mencionado.

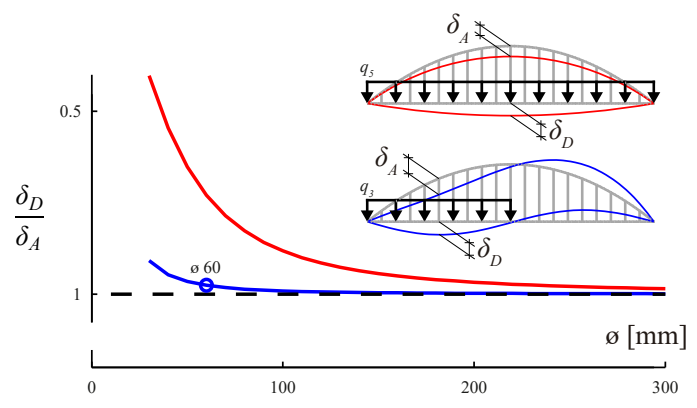

Figura 3.9: Efecto cortina para diferentes valores de diámetro de las péndolas. 


\section{Parte II}

\section{Diseño en el plano}





\section{Capítulo 4}

\section{Dimensionamiento de secciones en el plano}

Este capítulo describe un método iterativo que permite llevar a cabo un diseño preliminar de secciones en el plano para puentes arco cuyo comportamiento se pueda considerar contenido en el plano vertical.

El método permite obtener las dimensiones de las secciones transversales del arco y el tablero que dan como resultado una configuración del puente con el menor peso. Los autores del método han aplicado satisfactoriamente éste a varias tipologías de arco distintas, como arcos laminares, arcos atirantados, así como arcos con configuraciones de péndolas tipo Nielsen-Löhse o Network.

El método soluciona los casos en los que la deflexión del tablero o la tensión longitudinal de las secciones, para casos de carga en condiciones de servicio o rotura, gobiernan el dimensionamiento preliminar del puente. El método está basado en una formulación simplificada, precisa y compacta para obtener las propiedades mecánicas de las secciones, lo que permite reducir notablemente el número de parámetros de diseño.

En comparación con los métodos de diseño basados en algoritmos de optimización, este método está basado en consideraciones puramente estructurales, siendo el diseñador libre de añadir, durante la fase de diseño, cualquier otro criterio constructivo o de diseño. La formulación detallada, los diagramas de flujo, así como ejemplos de aplicación completos, son mostrados en este capítulo.

Una de las conclusiones más importantes derivadas de este método, es cómo, con el fin de obtener la distribución de secciones de peso mínimo, el criterio de diseño (fallo por tensiones o fallo por rigidez) puede ser diferente en el arco y el tablero simultáneamente. Además de todo lo anterior, este capítulo resalta la relevancia del buen criterio ingenieril en las etapas tempranas del diseño. 


\subsection{Introducción}

En la fase de diseño preliminar de un puente arco, es generalmente asumido que su respuesta estructural puede ser descompuesta en dos comportamientos estructurales (dentro del plano y fuera del plano) que se encuentran desacoplados, pudiendo ser por lo tanto analizados por separado. En este proceso, el diseño preliminar en el plano es normalmente el paso que más tiempo requiere, y es usualmente llevado a cabo por diseñadores con experiencia, ya que un dimensionamiento preliminar simplificado y preciso, puede acelerar significativamente el proceso completo de diseño.

Un predimensionamiento está normalmente basado en el estudio de puentes de la misma tipología o similar, estando las dimensiones principales del puente, como el canto de las secciones transversales, frecuentemente definidas por reglas de diseño aproximadas (véanse por ejemplo Lebet y Hirt [55], Manterola [60] o Menn [65], o los estudios de Leonhardt [56] y Salonga y Gavreau [92] para puentes arco de hormigón). Estudios paramétricos o de sensibilidad son llevados a cabo normalmente también para puentes de grandes luces.

Para un diseño preliminar, es normal considerar que la solución es válida cuando algunos criterios simplificados respecto a estados límite de servicio (ELS) o estados límite últimos (ELU), normalmente limitaciones de tensiones o flechas, son verificados bajo ciertas combinaciones de carga simplificadas.

Estos casos de carga consisten en versiones simplificadas de las combinaciones de cargas definidas en diferentes normativas o códigos, como los Eurocódigos (véanse [10] y [11]), en las cuales solo las acciones más relevantes son consideradas, como se puede ver en el ejemplo de la figura 4.1.

El puente típico considerado en este capítulo, está compuesto por un arco plano vertical y un tablero recto de luz $L$, sustentado por un arco de flecha $f$, cuyo comportamiento puede considerarse contenido dentro del plano vertical. Con respecto a las cargas, la densidad del material del arco y el tablero $\left(g_{A}\right.$ y $\left.g_{D}\right)$, las cargas muertas $(\mathrm{CM})$ y las sobrecargas
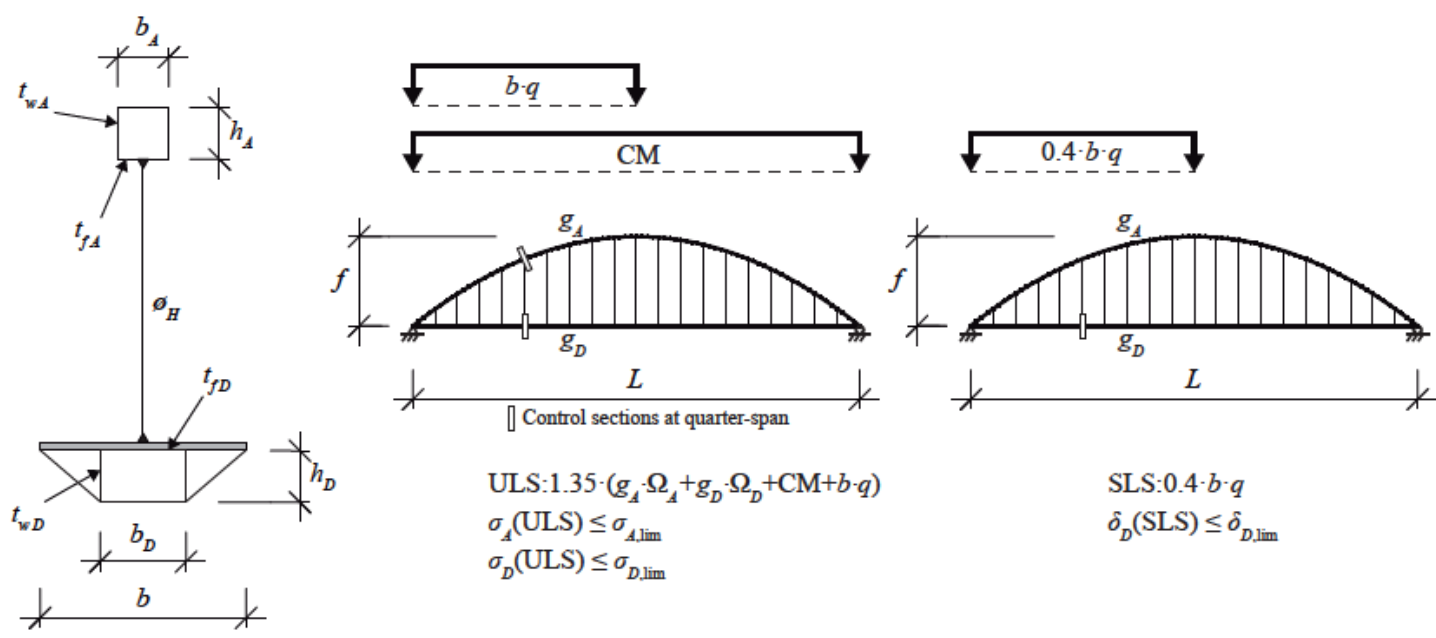

SLS: $0.4 \cdot b \cdot q$

$\delta_{D}(\mathrm{SLS}) \leq \delta_{D \text {,im }}$

Figura 4.1: Ejemplos de criterios de carga simplificados y de criterios de dimensionamiento para un diseño preliminar. 
$(q)$, han sido consideradas en los diferentes estudios llevados a cabo.

Así, el diseño preliminar se convierte en un proceso iterativo: de acuerdo con la salida de los cálculos simplificados, el diseñador debe especificar todas las dimensiones de la sección transversal del arco y del tablero, o, alternativamente, ajustar las dimensiones para la siguiente iteración. Esto no es de ninguna manera un proceso sencillo, ya que las secciones metálicas más simples, como una sección rectangular hueca o una sección doble $\mathrm{T}$ simétrica, están definidas por cuatro magnitudes $\left(b_{A}, h_{A}, t_{w A}, \mathrm{y} t_{f, A}\right.$, véase la figura 4.1). La dificultad incluso incrementa cuando se considera la interacción arco-tablero, ya que el proyectista debe trabajar con al menos ocho variables dependientes mutuamente al mismo tiempo, en un proceso donde los esfuerzos internos y las dimensiones del tablero pueden verse fuertemente afectadas cuando las dimensiones del arco cambian, y viceversa.

Es en este contexto, y con el ánimo de hacer la fase de diseño tan simple como sea posible, donde aparece la necesidad de los métodos descritos en este capítulo. A grandes rasgos, la metodología descrita en las siguientes páginas tiene la misma estructura de bucle que el proceso de predimensionamiento. En primer lugar, un modelo de elementos finitos es creado y calculado (véase por ejemplo [24]), y en segundo lugar, el método indica al proyectista cómo las secciones transversales de la estructura deben de ser redefinidas para logar, iterativamente, los objetivos del predimensionamiento. Es muy importante destacar que la metodología presentada en este capítulo obtiene no solo una solución valida que verifica los criterios de predimensionamiento, sino que adicionalmente permite obtener las dimensiones en el plano de las secciones transversales del arco y del tablero, lo que permite lograr la configuración global de mínimo peso del puente.

Además de optimizar el peso de la estructura, el método propuesto no hace uso de ninguna metodología de optimización, como algoritmos genéticos o metaheurísticos. En su lugar, el método usa un aproximación clásica desde el punto de vista estructural, lo que permite una intuitiva interacción con el proyectista durante el proceso, resultando así extremadamente adaptable.

\subsubsection{Estrategia de diseño preliminar en el plano}

Muchas de las características del método están tomadas de la experiencia en el diseño de puentes, siendo compartidas por diversos procedimientos de predimensionamiento. Solo por mencionar brevemente, hay que tener en cuenta que los esfuerzos internos y las deformaciones de la estructura están obtenidas para un análisis elástico bajo combinaciones de carga simplificadas (véase la figura 4.1).

Como se mencionó previamente, un diseño preliminar del puente completo es considerado válido, cuando una doble condición, que considera ELU y ELS, se verifica, como se muestra en la figura 4.1. En primer lugar, la tensiones longitudinales máximas $\sigma_{A}$ y $\sigma_{D}$, calculadas en las secciones de control del arco y el tablero respectivamente, deben ser inferiores a los valores de tensión máxima permitidos $\sigma_{A, l i m}$ y $\sigma_{D, l i m}$. En segundo lugar, la máxima deflexión en la sección de control del tablero, $\delta_{D}$, debe ser menor que la flecha máxima permitida, $\delta_{D, l i m}$. Como en cualquier proceso de predimensionamiento, el papel del criterio ingenieril es crucial, ya que el proyectista define las localizaciones de las secciones de control, los valores de $\sigma_{A, l i m}, \sigma_{D, \text { lim }}$ y $\delta_{D, l i m}$, y los factores de carga incluidos en las 


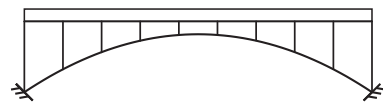

a) Deck Stiffened-Arch

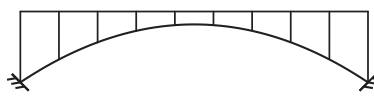

b)

$$
C_{A} \approx 0
$$

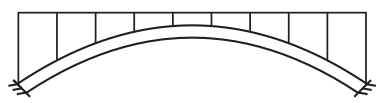

c) Arch-Stiffened deck $C_{A} \approx 1$

Figura 4.2: Ejemplos de $C_{A}$ (ecuación 4.1) para diferentes rigideces relativas arco-tablero.

combinaciones de cargas simplificadas.

Llegados a este punto se propone una clasificación, donde dos tipos de puentes son considerados, tipos que dependen de los parámetros más relevantes que gobiernan el diseño preliminar.

El primer tipo son los puentes $\delta$-controlled, donde el diseño está condicionado exclusivamente por el límite de flecha máxima para ELS. Por lo tanto, en estos puentes las secciones del arco y del tablero están dimensionadas para verificar estrictamente $\delta_{D}=\delta_{D, \mathrm{lim}}$, mientras que las limitaciones de tensiones $\sigma_{A} \leq \sigma_{A, \text { lim }}$ y $\sigma_{D} \leq \sigma_{D, \text { lim }}$ se verifican automáticamente y no resultan relevantes. En el punto 4.3 se mostrará como la flecha vertical $\delta_{D}$ no depende solo de $\Omega_{A}$ y $\Omega_{D}$, sino principalmente de la contribución combinada de sus momentos de inercia a flexión longitudinal $I_{A}$ e $I_{D}$. En consecuencia, en puentes del tipo $\delta$-controlled, y para unos valores dados de $\Omega_{A}$ y $\Omega_{D}$, la distribución del material de las secciones debe estar orientada a maximizar $I_{A}$ e $I_{D}$.

Es importante remarcar que, como señala Menn en [65], la interacción arco-tablero es crucial en un puente arco cuando se determina su respuesta estructural. En el método propuesto en este capítulo, la interacción arco-tablero puede ser globalmente implementada definiendo un único parámetro, $C_{A}$, el cual representa la contribución del arco a la rigidez a flexión global del puente (véase la ecuación 4.1).

$$
C_{A} \equiv \frac{E_{A} \cdot I_{A}}{E_{A} \cdot I_{A}+E_{D} \cdot I_{D}}
$$

En la ecuación anterior, $E_{A}$ y $E_{D}$ son los módulos de Young de los materiales del arco y del tablero respectivamente. $C_{A}$ varía en un rango que va desde valores muy bajos próximos a cero, para puentes arco laminares, como los proyectados por Maillart (véase Billington [18]), hasta un valor de 1.0 cuando la rigidez a flexión del tablero es despreciable con respecto a la del arco (véase la figura 4.2).

El segundo tipo de puentes son los llamados $\sigma+\delta$-controlled. En este tipo, se asume que el puente es inicialmente $\delta$-controlled, y el dimensionamiento se lleva a cabo con el fin de verificar $\delta_{D}=\delta_{D, l i m}$. Sin embargo, al final del proceso no se verifica el límite de tensión del arco o del tablero, o incluso de ambos en las secciones de control establecidas. Por lo tanto, el proceso de diseño debe ser reorientado a verificar las limitaciones de tensiones, 
pero simultáneamente se debe asegurar que la rigidez global de la estructura es todavía suficiente para cumplir con la limitación de flecha máxima impuesta. En la sección 4.5 se verá que en los puentes $\sigma+\delta$-controlled, y para valores dados de $\Omega_{A}$ y $\Omega_{D}$, la distribución del material de las secciones transversales no puede ser definida de antemano. En algunos casos, la distribución del material debe maximizar su inercia $I$, mientras que en otros casos debe maximizar su módulo resistente $W$. Incluso, en otros casos, la distribución de material en la sección transversal debe ser específicamente estudiada para minimizar su peso.

\subsubsection{Aplicación práctica del método}

Es importante añadir que el diseñador no conoce previamente si el puente es $\delta$-controlled o $\sigma+\delta$-controlled, ya que esto no depende solo de la tipología del puente, sino también de los valores de $\sigma_{A, l i m}, \sigma_{D, l i m}$ y $\delta_{D, l i m}$, los cuales son establecidos por el diseñador. Por consiguiente, la validez de estos métodos puede ser comprobada solo después de su aplicación. Por lo tanto, la manera más práctica de realizar un diseño preliminar es seguir una estrategia de prueba y error, usando los métodos alternativos en un orden preestablecido, de acuerdo a su grado de complejidad:

1. Inicialmente, el puente es considerado del tipo $\delta$-controlled, y es diseñado de acuerdo al procedimiento $\delta$-method, detallado en el punto 4.4. Es interesante remarcar que el $\delta$-method obtiene el mínimo peso para un solo valor de $C_{A}$, es decir, para una distribución predefinida de rigidez a flexión entre el arco y el tablero. Sin embargo, la configuración de mínimo peso y el valor de $C_{A}$ que minimiza ese peso, pueden ser fácilmente obtenidos solo comparando el peso de los puentes determinados por diferentes valores de $C_{A}$. Una búsqueda sistemática del diseño de peso óptimo es posible porque los valores de $C_{A}$ siempre oscilan entre 0 y 1 . Los valores de peso obtenidos para un valor dado de $C_{A}$ son válidos sólo cuando ambas limitaciones tensionales $\left(\sigma_{A} \leq \sigma_{A, \text { lim }}\right.$ y $\left.\sigma_{D} \leq \sigma_{D, \text { lim }}\right)$ se verifican. Así, después de aplicar el $\delta$ method, es posible que algunos diseños no sean válidos para algunos, o incluso para todos los valores de $C_{A}$.

2. Entonces, para estas soluciones no válidas (es decir, aquellos valores de $C_{A}$ que hacen que los diseños cumplan el criterio de flechas máximas, pero no cumplan uno o los dos límites de tensión), el $\sigma+\delta$-method descrito en la sección 4.5 obtiene las dimensiones del arco y del tablero que verifican tanto el criterio de flechas como el de tensiones. En general, los diseños obtenidos con el $\sigma+\delta$-method son más pesados que el diseño correspondiente que se hubiera obtenido con el $\delta$-method.

Una contribución de este capítulo resulta muy útil cuando se obtienen las propiedades mecánicas de las secciones, ya que el método saca provecho del hecho de que, para un diseño preliminar en el plano de una sección dada, solo su área $\Omega, I$ y $W$ son relevantes. Esto es posible debido a que el comportamiento estructural del puente dentro del plano vertical está desacoplado con respecto a su comportamiento fuera del plano, como se describe por ejemplo en Jorquera Lucerga [46] y [47]. En el punto 4.2 se muestra como la complejidad asociada a controlar simultáneamente todas las dimensiones puede ser 
reducida notablemente, manteniendo la suficiente precisión, mediante el uso de sólo dos parámetros para definir la sección.

\subsection{3. Ámbito de aplicación del método}

En esta tesis, el método antes descrito ha sido aplicado a diferentes tipologías de puentes arco (véase Manterola [60], Menn [65] y Park [75]). Algunos de estos puentes se muestran en la figura 4.3, como arcos con o sin rótulas, arcos tipo bow-string, arcos de tablero superior, Nielsen-Löhse, o arcos tipo Network (véase Tveit [116]).

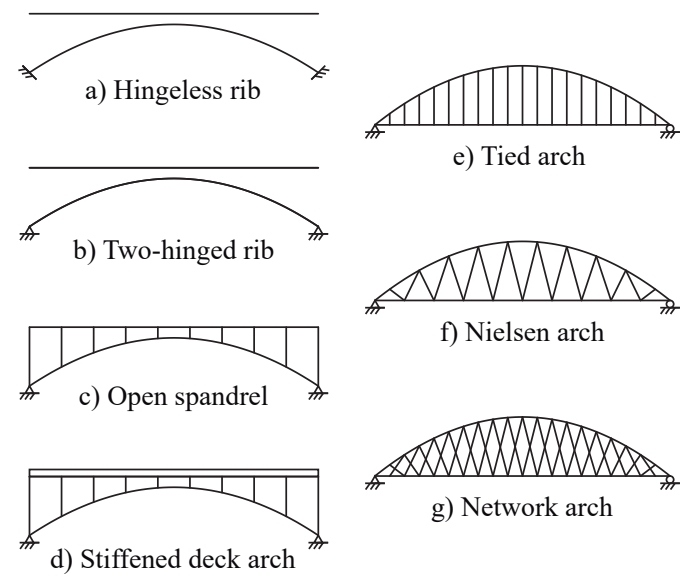

Figura 4.3: Ejemplos de tipologías de puente donde el método descrito ha sido aplicado satisfactoriamente.

Ya que todos los cálculos están "condensados" dentro del plano vertical, el método puede ser aplicado a secciones que sean simétricas con respecto al plano vertical (es decir, cuando uno de los ejes principales de la sección es horizontal).

Las secciones transversales pueden ser combinadas libremente siempre que mantengan la simetría, como los puentes mostrados en la figura 4.4. El método puede ser también aplicado a puentes con arcos simétricos inclinados, indicados con asteriscos en la figura 4.4, sin embargo en este caso, se recomienda introducir en el modelo de elementos finitos un valor realista del momento transversal de inercia, debido a su influencia en las flechas verticales.

Toda la formulación presentada en este capítulo ha sido desarrollada para secciones doblemente simétricas, es decir, aquellas que son simétricas respecto al eje neutro horizontal de la sección. Esta simplificación proporciona una formulación, inspirada en el trabajo de Argüelles [9], muy simple y compacta, como se puede ver en el punto 4.2, que ilustra perfectamente las capacidades del método. Esta decisión ha sido tomada puesto que, en puentes arco, las secciones doblemente simétricas son muy comunes para el arco, y la sección transversal del tablero puede ser a menudo asimilada a una sección doblemente simétrica para un predimensionamiento. Cuando esta suposición no es lo suficientemente precisa para un diseño preliminar, como ocurre en tableros mixtos, la formulación puede ser mejorada para incluir secciones no simétricas, aunque esto tiende a generar una 

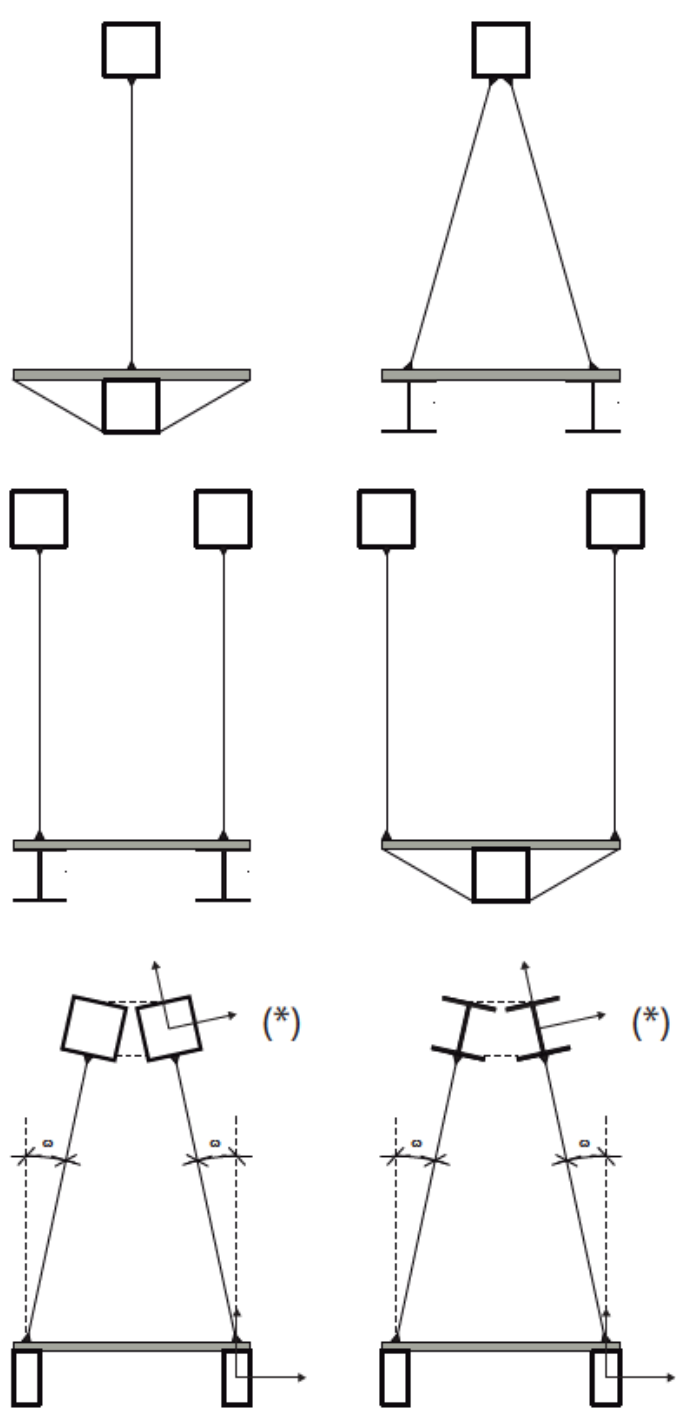

Figura 4.4: Ejemplos de secciones transversales donde el método puede ser aplicado. Secciones macizas rectangulares, así como secciones circulares huecas y macizas, pueden ser usadas también para el arco y el tablero.

formulación bastante más complicada. Usar secciones simétricas es algo extremadamente ventajoso, cuando se redefine el modelo de elementos finitos en cada iteración, ya que las coordenadas de las directrices del arco y del tablero permanecen invariables entre las distintas iteraciones.

En este capítulo, se han considerado secciones huecas tipo cajón y doble T, todas ellas de acero y doblemente simétricas (véase el punto 4.2). Para secciones rectangulares macizas (muy usuales en luces cortas y medias de arcos de hormigón) y para secciones tubulares huecas, la formulación podría ser más simple, ya que solo se necesitan dos parámetros (ancho y alto o diámetro y espesor, respectivamente) para definir completamente estos tipos de secciones.

El ámbito de aplicación del método es más amplio de lo que puede parecer a simple vista, 
ya que puede ser aplicado sin ninguna modificación a arcos o tableros con secciones variables, siempre que el arco y el tablero queden totalmente definidos cuando las dimensiones de la sección de control sean conocidas. La figura 4.5 muestra algunas distribuciones de áreas en las cuales el método puede ser aplicado.

Una característica del método con un gran potencial es que, en cualquier paso del proceso, el diseñador puede actualizar la tipología del puente a voluntad. Esto es algo tan fácil como actualizar el modelo de elementos finitos de acuerdo al criterio de diseño deseado. Por ejemplo, el arco puede ser dividido en dos ramas si el ancho de la sección transversal es mayor que un valor límite establecido. De manera similar, las cargas consideradas pueden variar durante el proceso iterativo, y, por ejemplo, la carga debida al peso de los rigidizadores puede considerarse sólo cuando la altura del alma es más alta que un valor límite definido.

El método descrito no considera todos los posibles modos de fallo de la estructura, como el pandeo dentro del plano del arco. Esta decisión se ha tomado puesto que, en general, el fallo de estos puentes se debe raramente al pandeo dentro del plano, algo que describen por ejemplo Lebet y Hirt [55] y Romeijn y Bouras [91]. Sin embargo, este fenómeno puede ser introducido posteriormente al proceso como una fase de diseño adicional. Además, es importante destacar que el método propuesto no facilita un diseño preliminar completo del puente, porque no considera ningún comportamiento fuera del plano, como la flexión transversal debida a la carga de viento transversal, o el pandeo fuera del plano. Por lo tanto, los resultados obtenidos mediante este método pueden necesitar correcciones después de las comprobaciones fuera del plano. El método solo aborda una etapa del diseño, sin embargo, esta es usualmente la que mayor tiempo requiere y la más relevante de todas.

\subsection{Propiedades mecánicas simplificadas para las sec- ciones transversales}

Como se mencionó en el punto 4.1, durante el proceso de diseño, y dada un área $\Omega$, el material de la sección transversal debe ser distribuido, en unos casos, para maximizar su inercia a flexión, $I$, mientras que en otros casos, debe maximizar su módulo elástico, $W$.

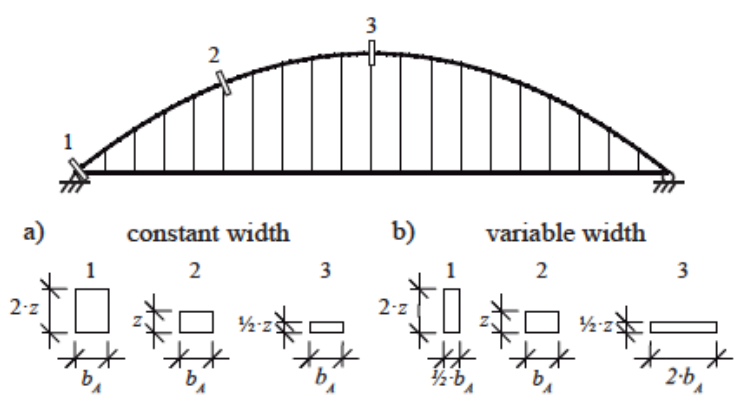

Figura 4.5: Ejemplos de distribuciones del área del arco que se encuentran dentro del rango de aplicación del método. a) Ancho constante, b) Ancho variable. 
Para determinar las propiedades mecánicas fácilmente, el número de variables de diseño (es decir, aquellas magnitudes que se necesitan para definir la sección transversal) deberían ser reducidas. Con este propósito, por un lado, se ha definido el coeficiente auxiliar $\beta$ (véase la ecuación 4.2), el cual corresponde a la esbeltez geométrica del alma, y permite usar la misma formulación independientemente del número de almas de la sección:

$$
\beta \equiv \frac{\sum_{i} t_{w, i}}{h_{w}}
$$

Por otro lado, el área de cada ala, $\Omega_{f}$, se supone que está concentrada en cada extremo del alma, es decir, $h_{f} \approx z$. Como resultado, las secciones transversales mostradas en la figura 4.6 son equivalentes desde el punto de vista del diseño en el plano.

Ya que

$$
\Omega_{f}=\frac{\Omega-\beta \cdot z^{2}}{2}
$$

para un valor dado de $\Omega, I$ y $W$ pueden ser expresados como una función que depende solo de $\beta$ y $z$ :

$$
\begin{gathered}
I \approx \frac{1}{12} \cdot \beta \cdot z^{4}+2 \cdot \Omega_{f} \cdot\left(\frac{z}{2}\right)^{2}=\frac{z^{2}}{2} \cdot\left(\frac{\beta \cdot z^{2}}{6}+\Omega_{f}\right)=\Omega \cdot \frac{z^{2}}{4}-\beta \cdot \frac{z^{4}}{6} \\
W=\frac{I}{z / 2}=z \cdot\left(\beta \cdot \frac{z^{2}}{6}+\frac{\Omega-\beta \cdot z^{2}}{2}\right)=\Omega \cdot \frac{z}{2}-\beta \cdot \frac{z^{3}}{3}
\end{gathered}
$$

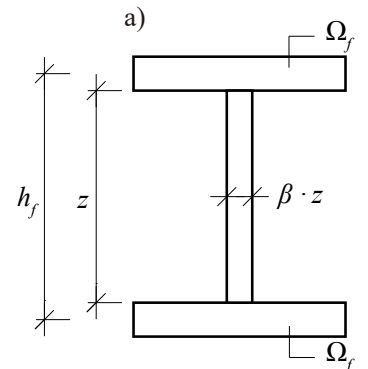

c)

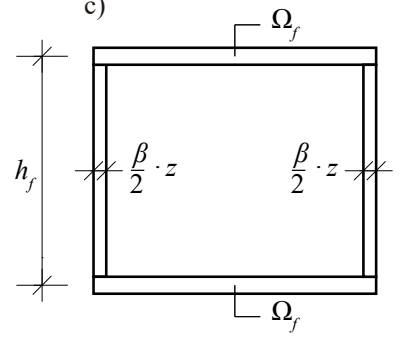

b)

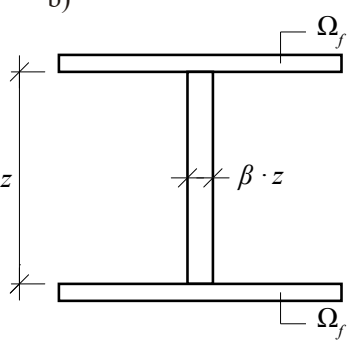

d)

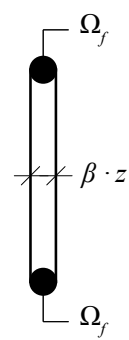

Figura 4.6: Secciones transversales equivalentes con respecto al diseño simplificado en el plano. 


\subsubsection{Módulo elástico máximo}

En este capítulo, y a partir de este punto, el subíndice $W$ será usado para identificar las propiedades mecánicas correspondientes a una distribución de área que maximiza el módulo elástico de la sección. Así, el valor máximo, $W_{W}$, se obtendrá para una altura del alma igual a $z_{W}$. La inercia correspondiente a la misma sección transversal es $I_{W}$. Estos valores son necesarios para el diseño de puentes tipo $\sigma+\delta$-controlled, obteniéndose el valor de $z_{W}$ como:

$$
\begin{aligned}
& \frac{d(W(z))}{d z}=0 \\
& z_{W}=\sqrt{\frac{\Omega}{2 \cdot \beta}}
\end{aligned}
$$

un valor que depende solo del valor de dos magnitudes escogidas por el proyectista. Una vez que $z_{W}$ es conocida, los valores de $I_{W}$ y $W_{W}$ pueden ser fácilmente escritos como:

$$
\begin{gathered}
I_{W}=\frac{\Omega^{2}}{12 \cdot \beta} \\
W_{W}=\frac{\Omega^{3 / 2}}{3 \sqrt{2 \cdot \beta}}
\end{gathered}
$$

\subsubsection{Inercia máxima}

De manera similar a lo que ocurría con el módulo resistente, de aquí en adelante el subíndice $I$ será usado para identificar las propiedades mecánicas correspondientes a una distribución de área que maximice el momento de inercia, $I$. Su valor máximo, $I_{I}$, se obtendrá para una altura del alma igual a $z_{I}$. El módulo elástico correspondiente a la misma sección es $W_{I}$. El valor de $z_{I}$ se obtiene como:

$$
\begin{aligned}
& \frac{d(I(z))}{d z}=0 \\
& z_{I}=\sqrt{\frac{3 \cdot \Omega}{4 \cdot \beta}}
\end{aligned}
$$

Una vez que $z_{I}$ es conocida, los valores de $I_{I} \mathrm{Y} W_{I}$ pueden ser fácilmente escritos como:

$$
\begin{gathered}
I_{I}=\frac{3 \cdot \Omega^{2}}{32 \cdot \beta} \\
W_{I}=\frac{\sqrt{3}}{8} \cdot \frac{\Omega^{3 / 2}}{\sqrt{\beta}}
\end{gathered}
$$




\subsubsection{Propiedades mecánicas simplificadas}

La figura 4.7 es útil para aclarar el criterio de notación adoptado. Esta figura muestra $I$ y $W$ como una función de $z$, para diferentes valores de $\beta$. Todos los resultados se muestran para el mismo valor de $\Omega$, lo que ilustra cómo de significativo es el efecto de $\beta$ en las propiedades mecánicas de la sección transversal. Se puede observar como $z_{I}>z_{W}$. A partir de las ecuaciones 4.7 y 4.11 se puede deducir que:

$$
z_{I}=\sqrt{\frac{3}{2}} \cdot z_{W} \cong 1,225 \cdot z_{W}
$$

Es interesante destacar que el valor máximo de z se corresponde con un valor $\Omega_{f}=0$, lo que lleva a:

$$
0<z<\sqrt{\frac{\Omega}{\beta}}
$$

Del mismo modo, las siguientes relaciones son de gran utilidad:

$$
\begin{gathered}
I_{I}=\frac{36}{32} \cdot I_{W}=1,125 \cdot I_{W} \\
W_{W}=\frac{8}{3 \sqrt{6}} \cdot W_{I} \cong 1,089 \cdot W_{I}
\end{gathered}
$$

Una consecuencia importante es que, para un valor dado de $\Omega, I$ y $W$ aumentan cuando $\beta$ disminuye, ya que el área del alma o almas permanece inalterada, pero el brazo mecánico de las alas aumenta.

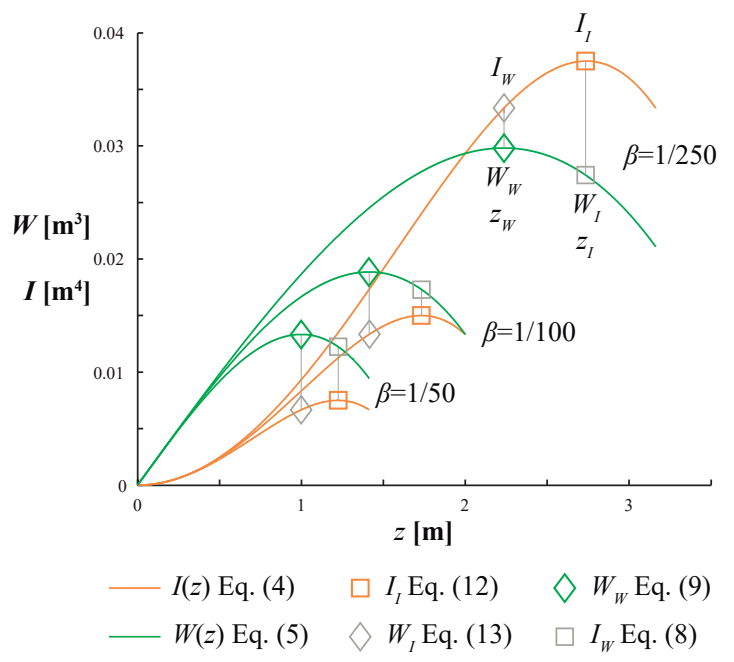

Figura 4.7: $I(z)$ y $W(z)$ para diferentes valores de $\beta$, dada un área $\Omega$. 
La figura 4.8 muestra las isolíneas de $I_{I}$ y $W_{W}$, respectivamente, para diferentes valores de $\beta$, dado una valor de $\Omega$. Los valores más altos de $I$ y $W$ se obtienen siempre para las almas más esbeltas.

Para ilustrar la validez de la formulación simplificada, los valores de $I_{I}$ y $W_{W}$ mostrados respectivamente en las ecuaciones 4.12 y 4.9 , han sido graficados y comparados con los obtenidos con una formulación estricta sin ninguna simplificación. Para ilustrar la precisión de las fórmulas, se ha asumido que el área $\Omega_{f}$ ha sido distribuida de dos formas diferentes. La primera es asumiendo un ala con un ratio ancho/espesor $b / t_{f}=15$, y la segunda es considerando una sección cajón hueca con un ala sometida a compresión de ratio $b / t_{f}=42$.

El primer caso es un limite conservador entre la Clase 1 y 2 para un ala exenta en una sección soldada, $b \approx t_{w}+2 \cdot 9 \cdot \varepsilon \cdot t_{f} \approx 15 \cdot t_{f}$, para $f_{y}=355$ MPa y $\varepsilon=0,81$, de acuerdo al Eurocódigo 3 (véase [11]).

El segundo caso es un límite conservador de la Clase 3 para un ala interna, $b \approx 42 \cdot \varepsilon \cdot t_{f}$ para $f_{y}=235 \mathrm{MPa}$ y $\varepsilon=1,00$. Los resultados se muestran en la figura 4.9.

Una conclusión práctica es que el error depende solo de $\beta$. Para un valor dado de $\Omega_{f}$, la precisión de la formulación aumenta cuando $t_{f}$ disminuye. Sin embargo, el error permanece por debajo del $3 \%$ para $I_{I}$ incluso en los casos más restrictivos, siendo necesario diseñar un alma con una esbeltez tan baja como $1 / 30$ para encontrar una sección con un error del $5 \%$ en $W_{W}$. Esta precisión se considera suficiente para un diseño preliminar, aunque de cualquier modo, tal error puede ser fácilmente contrarrestado asignando unos valores ligeramente más conservadores de $\delta_{D, \text { lim }}, \sigma_{A, l i m}$ o $\sigma_{D, l i m}$.
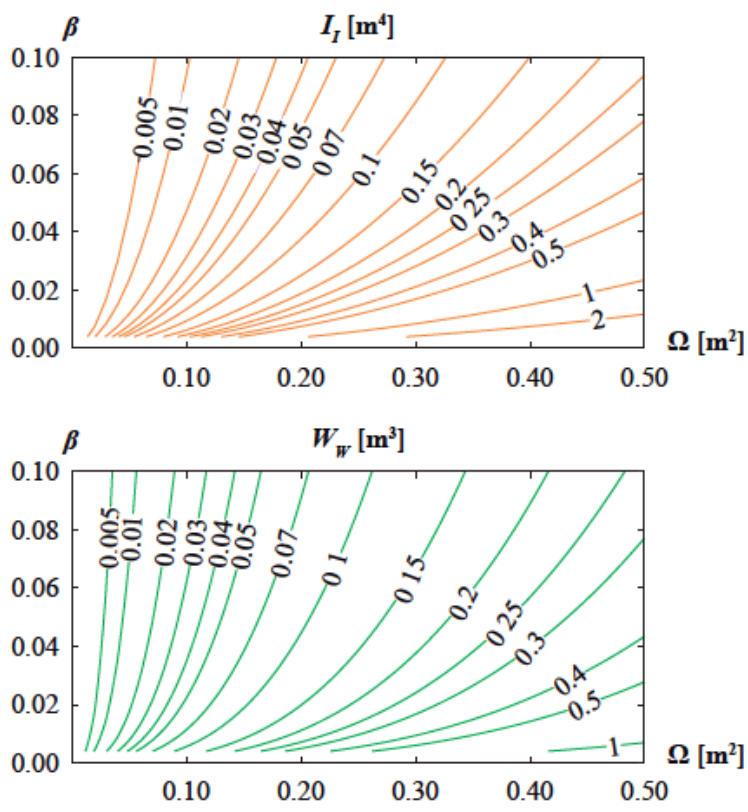

Figura 4.8: Isolíneas de $I_{I}$ y $W_{W}$. 


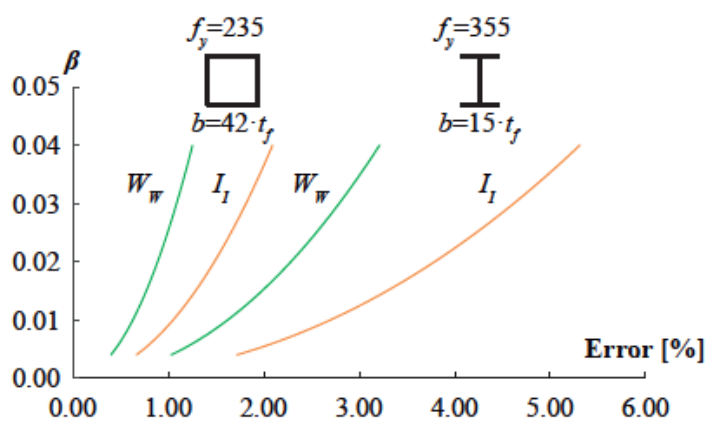

Figura 4.9: Error de la formulación simplificada para ejemplos de secciones clase 1 y 3.

\subsection{Formulación simplificada para flechas verticales}

Con el objetivo de abordar un diseño preliminar, se ha desarrollado una formulación simplificada para estimar las flechas del puente bajo una carga asimétrica ${ }^{1}$. Esta formulación lleva a unos cálculos simples a mano que permiten al proyectista centrarse en los parámetros relevantes del diseño. A pesar de que puede ser usada en otro contexto, la consecuencia más relevante de esta formulación, es que establece la base del llamado $\delta$-method, descrito en el punto 4.4.

La formulación se ha obtenido para una configuración estructural típica, como la del arco atirantado de la figura 4.10, que se vincula al tablero mediante un juego de cables verticales articulados en ambos extremos. El axil de pretensado de las péndolas contrarresta la flecha del tablero para cargas permanentes (véase Jorquera Lucerga [46] o Strasky [109]). La flecha se determina para una carga uniformemente distribuida $q$ que actúa sobre medio tablero. Este caso de carga puede transformarse en la suma de otros dos casos de carga: el primero es simétrico, con una carga $q / 2$ actuando hacia abajo sobre el tablero completo, mientras que el segundo caso es antisimétrico, donde dos cargas opuestas, hacia arriba y hacia abajo, iguales a $-q / 2$ y $q / 2$ respectivamente, actúan sobre ambas mitades del tablero.

Siempre que la abcisa $\mathrm{x}=0$ corresponde a la clave del arco, la sección de control se localiza en el cuarto de la luz, $\mathrm{x}=-L / 4$, donde las flechas son máximas bajo cargas longitudinales asimétricas (véanse Manterola [60] o Menn [65]). La fórmula propuesta descompone la
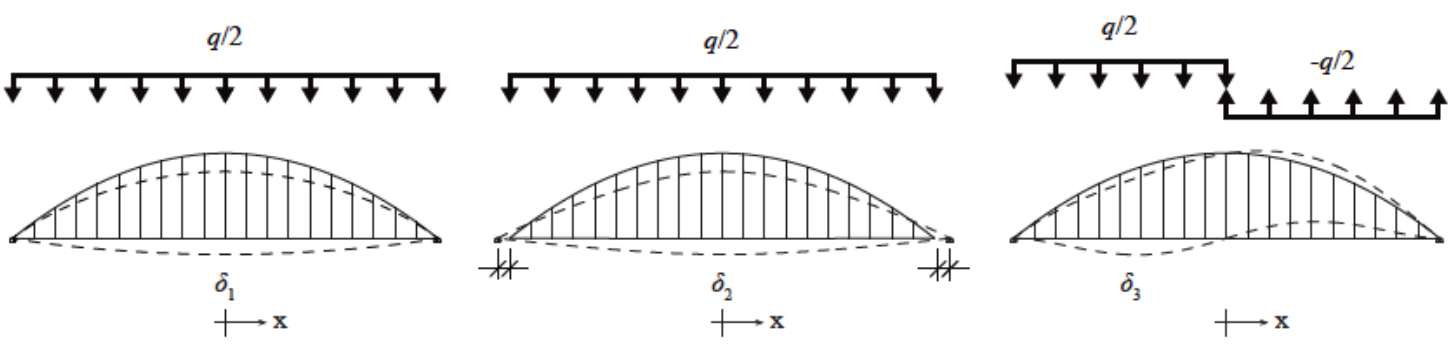

Figura 4.10: Flechas debidas a: a) acortamiento de la directriz, b) alargamiento del tablero, c) deformación por flexión.

\footnotetext{
${ }^{1}$ Esta carga asimétrica es la definida en el capítulo 3 como $q_{3}$.
} 
flecha total $\delta$ en tres sumandos, $\delta_{1}, \delta_{2}$ y $\delta_{3}$. Estos sumandos se corresponden (véase la figura 4.10), respectivamente, con las flechas verticales de la sección de control del tablero debidas al acortamiento de la directriz del arco, el alargamiento del tablero que actúa de tirante entre los apoyos y, finalmente, el efecto de los momentos flectores en el arco y el tablero.

$$
\delta_{x=-L / 4}=\delta_{1, x=-L / 4}+\delta_{2, x=-L / 4}+\delta_{3, x=-L / 4}
$$

De acuerdo con Nettleton [70], $\delta_{1}$ puede ser estimada en la clave del arco, localizada en $\mathrm{x}=0$, como:

$$
\delta_{1, x=0}=\frac{N_{A, x=0}}{E_{A} \cdot \Omega_{A}} \cdot\left(\frac{L^{2}}{5 \cdot f}+f\right)
$$

donde $f$ es la flecha del arco. Para estimar $\delta_{2}$ la ecuación 4.20, adaptada de Buchholdt [20], originalmente desarrollada para $\mathrm{x}=0$ para un cable funicular sujeto con soportes flexibles, arroja buenos resultados.

$$
\delta_{2, x=0}=\frac{120 \cdot L^{4}-320 \cdot f^{2} \cdot L^{2}+2304 \cdot f^{4}}{640 \cdot f \cdot L^{3}-3072 \cdot f^{3} \cdot L} \cdot \frac{N_{D} \cdot L}{E_{D} \cdot \Omega_{D}}
$$

La flecha para la carga antisimétrica en el cuarto de la luz puede ser calculada usando las expresión clásica:

$$
\delta_{3, x=-L / 4}=\frac{\frac{q}{2} \cdot\left(\frac{L}{2}\right)^{4}}{384 \cdot\left(E_{A} \cdot I_{A}+E_{D} \cdot I_{D}\right)}=\frac{q \cdot L^{4}}{12288 \cdot\left(E_{A} \cdot I_{A}+E_{D} \cdot I_{D}\right)}
$$

Incluso combinadas, $\delta_{1}$ y $\delta_{2}$ son normalmente mucho más pequeñas que $\delta_{3}$, y por lo tanto, su precisión no es crucial en un diseño preliminar. Para calcularlas en $\mathrm{x}= \pm L / 4$, los valores de $\delta_{1, x=0}$ y $\delta_{2, x=0}$ pueden ser multiplicados por 0.75 . Este coeficiente se obtiene asumiendo que la forma del tablero deformado es parabólica, ya que es el valor de la ordenada para $\mathrm{x}= \pm L / 4$ en una parábola de flecha unitaria. Por lo tanto, considerando la formulación previa, la flecha total en el cuarto de la luz es:

$$
\delta_{x=-L / 4} \simeq 0,75 \cdot\left(\delta_{1, x=0}+\delta_{2, x=0}\right)+\delta_{3, x=-L / 4}
$$

El rango de aplicación de la formulación puede ser ampliado para puentes con apoyos empotrados. En este caso $\delta_{2}=0$, mientras que $\delta_{1}$ puede ser evaluado en la clave del arco mediante la siguiente fórmula, obtenida de Menn [65]:

$$
\delta_{1, x=0}=\frac{N_{A, x=0}}{E_{A} \cdot \Omega_{A}} \cdot \frac{L \cdot\left(1+3 \cdot(f / L)^{2}\right)}{4 \cdot f / L}
$$

La formulación presentada anteriormente permite al proyectista estimar las flechas verticales de una manera precisa, para la mayoría de las configuraciones usuales de puentes. 
Sin embargo, la consecuencia más importante es que la formulación hace visible el hecho de que las flechas verticales debidas a las cargas simétricas dependen solo del área de las secciones transversales, mientras que la flecha vertical debida a las cargas antisimétricas depende de la inercia a flexión de las secciones. Estas son las bases del método mostrado en el punto 4.4.

\section{4. $\delta$-method}

En este punto se describe el $\delta$-method, incluyéndose un diagrama de flujo y un ejemplo de aplicación. El método propuesto minimiza las áreas del arco y del tablero (es decir, el peso del puente) para puentes $\delta$-controlled (véase el punto 4.1). Es de destacar, que el método obtiene el peso mínimo para un solo valor de $C_{A}$, es decir, para un valor predefinido de distribución de rigidez a flexión entre el arco y el tablero. Sin embargo, esto no debería ser considerado como una desventaja, ya que se puede llevar a cabo fácilmente una búsqueda sistemática del peso mínimo, comparando solo los pesos de los puentes determinados para un conjunto de valores de $C_{A}$ comprendidos en un rango entre 0 y 1 . En consecuencia, el proyectista puede estrechar el rango de valores de $C_{A}$ para el cual son obtenidas las soluciones, y así, puede disfrutar de un mayor control de la solución.

Se asume que el estado límite de servicio se verifica limitando $\delta_{D}$ en la sección de control del tablero, la cual puede no coincidir con la sección de control previamente definida para la tensión longitudinal. De igual forma, la localización de la sección de control es escogida por el diseñador, y se sitúa normalmente en el cuarto de la luz, donde las flechas son máximas para una carga longitudinal asimétrica (véanse Manterola [60] y Menn [65]).

La sección de control no necesita ser el punto exacto donde la flecha máxima tiene lugar, sino que es solo un punto donde se comprueba el predimensionamiento. La flecha máxima permitida, $\delta_{D, l i m}$, es definida también por el proyectista, y dependerá de lo aproximadas que sean las combinaciones de cargas simplificadas a las cargas exactas definidas en las diferentes normativas, como los Eurocódigos. En este estudio, el caso de carga es más simple que para estados límite últimos, ya que se supone que solo actúan sobrecargas verticales.

Como ejemplo, la normativa española IAP-11 [27], muy similar al Eurocódigo 1 [10], considera valores iguales a $\delta_{D, l i m} \approx L / 2400$, cuando se carga la mitad del tablero de los puentes arco con la parte frecuente (es decir, factorizada por $\psi=0.4$ ) de $5 \mathrm{kN} / \mathrm{m}^{2}$, siendo este el modelo de carga LM4 definido en el Eurocódigo 1. Así, la parte frecuente de la carga se puede considerar como $0.4 \cdot 5=2.0 \mathrm{kN} / \mathrm{m}^{2}$.

\subsubsection{Justificación del método}

La estrategia para lograr una solución se basa en la validez de las conclusiones del punto 4.3: en primer lugar, que la flecha debida a las cargas simétricas depende solo de la rigidez axial del arco y del tablero, y en segundo lugar, que la flecha debida a las cargas antisimétricas depende solo de la rigidez a flexión del puente. La flecha total $\delta$, puede calcularse como se vio en el punto 4.3, considerándose la suma de tres términos: $\delta_{1}$ y $\delta_{2}$, 
que dependen de $E_{A} \cdot \Omega_{A}$ y $E_{D} \cdot \Omega_{D}$ respectivamente, y $\delta_{3}$, que depende de $E_{A} \cdot I_{A}+E_{D} \cdot I_{D}$. Por lo tanto, las tres flechas mostradas en las ecuaciones 4.19, 4.20 y 4.21 pueden ser reescritas de la siguiente forma, donde $k_{1}^{\prime}, k_{2}^{\prime}$ y $k_{3}^{\prime}$ reúnen en una constante el resto de los términos de cada ecuación:

$$
\delta_{1}=\frac{k_{1}^{\prime}}{\Omega_{A}} ; \quad \delta_{2}=\frac{k_{2}^{\prime}}{\Omega_{D}} ; \quad \delta_{3}=\frac{k_{3}^{\prime}}{E_{A} \cdot I_{A}+E_{D} \cdot I_{D}}
$$

La ecuación 4.24 demuestra que, para unos valores dados de $\Omega_{A}$ y $\Omega_{D}$ (es decir, para valores dados de $\delta_{1}$ y $\delta_{2}$ ), la flecha mínima se obtiene minimizando $\delta_{3}$, es decir, maximizando la rigidez a flexión global del puente. En consecuencia, $\Omega_{A}$ y $\Omega_{D}$ deben ser distribuidas de manera que las inercias, $I_{A}$ y $I_{D}$, sean maximizadas. De acuerdo al punto 4.2 , la inercia máxima $I_{I, A}$, para un valor dado de $\Omega_{A}$, se obtiene con la siguiente expresión:

$$
I_{I, A}=\frac{3 \cdot \Omega_{A}^{2}}{32 \cdot \beta_{A}}
$$

y de forma similar, para el tablero:

$$
I_{I, D}=\frac{3 \cdot \Omega_{D}^{2}}{32 \cdot \beta_{D}}
$$

Teniendo en cuenta las ecuaciones 4.25 y 4.26 , la ecuación 4.24 puede ser expresada de tal manera que $\Omega_{A}$ sea la única variable desconocida para un valor dado de $C_{A}$. El coeficiente auxiliar $\mu$ hace que la formulación sea más fácil:

$$
\mu \equiv \frac{E_{D} \cdot I_{D}}{E_{A} \cdot I_{A}}=\frac{1}{C_{A}}-1
$$

Sustituyendo las ecuaciones 4.25 y 4.26 en la ecuación 4.27

$$
\mu \equiv \frac{E_{D} \cdot \frac{3 \cdot \Omega_{D}^{2}}{32 \cdot \beta_{D}}}{E_{A} \cdot \frac{3 \cdot \Omega_{A}^{2}}{32 \cdot \beta_{A}}}
$$

pudiéndose expresar $\Omega_{D}$ como una función de $\Omega_{A}$

$$
\Omega_{D}=\Omega_{A} \cdot \sqrt{\mu \cdot \frac{E_{A}}{E_{D}} \cdot \frac{\beta_{D}}{\beta_{A}}}
$$

De forma similar,

$$
E_{A} \cdot I_{A}+E_{D} \cdot I_{D}=E_{A} \cdot I_{I, A} \cdot(1+\mu)=E_{A} \cdot \frac{3 \cdot \Omega_{A}^{2}}{32 \cdot \beta_{A}} \cdot(1+\mu)
$$

Así, la ecuación 4.24 puede ser reescrita como: 


$$
\delta_{1}=\frac{k_{1}}{\Omega_{A}} ; \quad \delta_{2}=\frac{k_{2}}{\Omega_{A}} ; \quad \delta_{3}=\frac{k_{3}}{\Omega_{A}^{2}}
$$

de tal forma que la única variable no conocida es $\Omega_{A}$. Asociando $\delta_{1}$ y $\delta_{2}$ en el mismo termino, la ecuación 4.22 puede ser escrita como:

$$
\delta=\delta_{1}+\delta_{2}+\delta_{3}=\frac{k_{12}}{\Omega_{A}}+\frac{k_{3}}{\Omega_{A}^{2}}
$$

Por lo tanto, una vez que se conocen $\delta_{1}+\delta_{2}+\delta_{3}$ para un área dada $\Omega_{A}$ (por ejemplo, como resultado del cálculo de un modelo de elementos finitos) el valor de la flecha total para un valor diferente de área del arco, por ejemplo, $\Omega_{A}^{\prime}$, puede ser expresado como:

$$
\delta\left(\Omega_{A}^{\prime}\right)=\delta_{1}+\delta_{2}+\delta_{3}=\Omega_{A}^{\prime} \cdot \frac{\delta_{1}+\delta_{2}}{\Omega_{A}}+\left(\Omega_{A}^{\prime}\right)^{2} \cdot \frac{\delta_{3}}{\Omega_{A}^{2}}
$$

Esta ecuación es la esencia del $\delta$-method, y puede ser resuelta iterativamente, como se muestra en el diagrama de flujo de la figura 4.11.

\subsubsection{Diagrama de flujo y proceso iterativo}

El diagrama de flujo para el $\delta$-method se muestra en la figura 4.11. Ya que éste sólo calcula para un valor dado de $C_{A}$, el proceso empieza eligiendo $C_{A}^{k}$ (paso a), el elemento $k$-ésimo de un conjunto de valores de $C_{A}$ sobre los que se va a aplicar el método. El coeficiente $\mu^{k}$ se define de acuerdo a la ecuación 4.27 (paso b).

Entonces, se define un modelo inicial (pasos c a f). El proyectista solo necesita establecer el valor inicial ( $\mathrm{i}=0)$ del área del arco, $\Omega_{A}^{i}$, ya que $\Omega_{D}^{i}, I_{A}^{i}$ e $I_{D}^{i}$ se calculan con las ecuaciones $4.29,4.25$ y 4.26 (pasos d a f). El modelo de elementos finitos con las propiedades mecánicas de las secciones del arco y del tablero se calcula (paso g), y las flechas $\delta_{1}+\delta_{2}$ y $\delta_{3}$ se obtienen separadamente (pasos h e i) para el caso de carga en estado límite de servicio.

El valor actualizado del área del arco, $\Omega_{A}^{i+1}$, se obtiene resolviendo la ecuación 4.33 (paso j). De manera similar, el área actualizada del arco y las nuevas propiedades mecánicas $\Omega_{D}^{i+1}, I_{A}^{i+1}$ y $I_{D}^{i+1}$ son calculadas (pasos 1 a n). Entonces, el proceso se repite hasta que la diferencia para los valores $\Omega_{A}$ y $\Omega_{D}$ sea más pequeña que el valor de las tolerancias predefinidas, $t_{0} l_{A}$ y $t_{0} l_{D}$, entre dos iteraciones sucesivas (paso o). En este capítulo, tolerancias entre $1 \mathrm{y} 10 \mathrm{~cm}^{2}$ han proporcionado un valor equilibrado entre la precisión y el tiempo de cálculo. Las tolerancias demasiado pequeñas no conducen a soluciones más precisas, sino a un exceso del tiempo de cálculo.

Se recomienda comprobar que, después de que el proceso haya logrado la convergencia, la diferencia entre $\delta_{D, \text { lim }}$ y $\delta_{1}+\delta_{2}+\delta_{3}$ (obtenidas del paso $\mathrm{j}$ al k) es aceptable, es decir, $\delta_{1}+\delta_{2}+\delta_{3} \approx \delta_{D, \text { lim }}$ (paso $\mathrm{p}$ ). Esto puede ser muy importante por dos razones. En primer lugar, porque puede indicar un error en la aplicación del método, ya que el valor final de $\Omega_{A}$ se calcula precisamente para verificar $\delta_{D, l i m}=\delta_{1}+\delta_{2}+\delta_{3}$. Y en segundo lugar, siempre que el método se aplique sin errores, porque puede establecer si el método es 


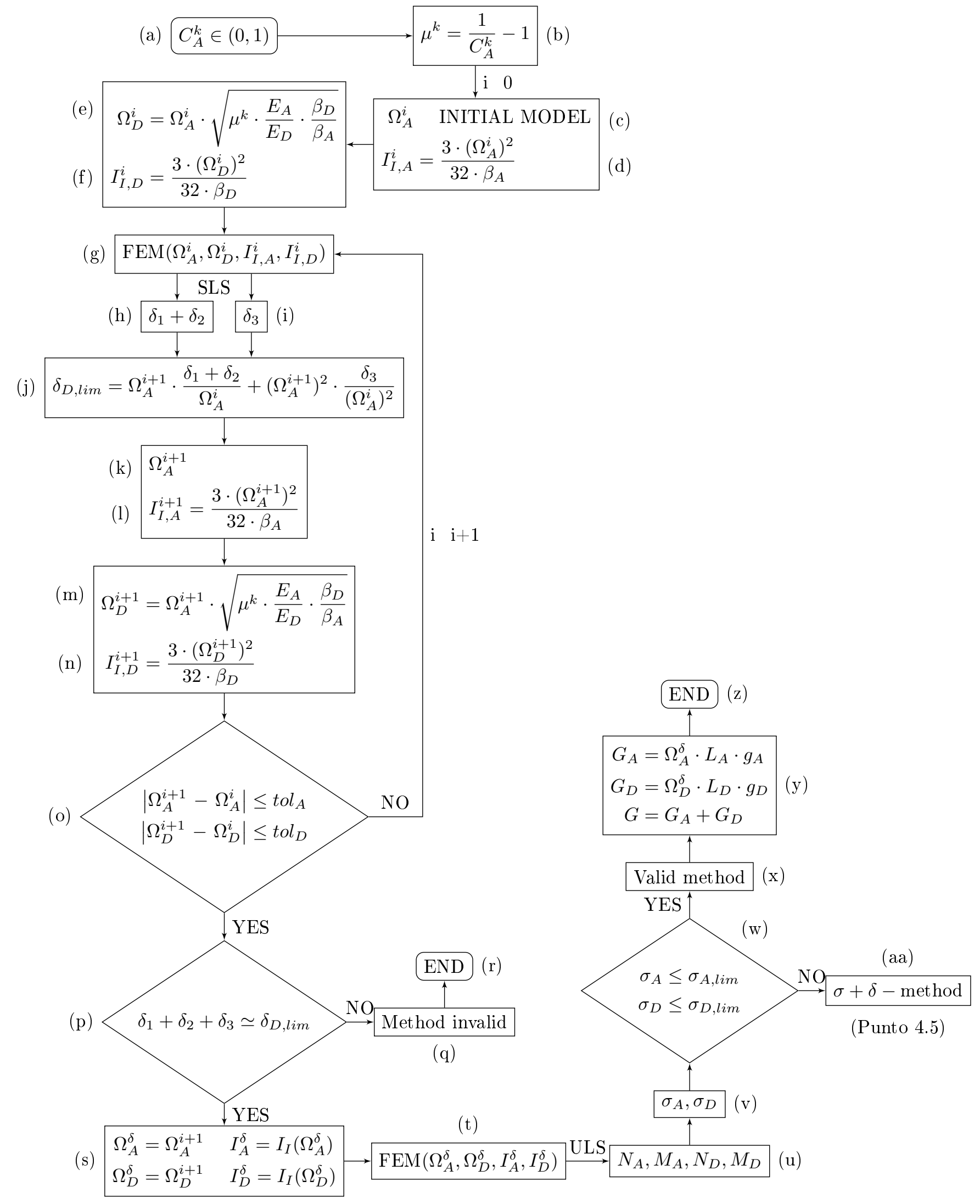

Figura 4.11: Diagrama de flujo del $\delta$-method. 
aplicable o no para un tipología concreta. En otras palabras, lo más cerca que el valor de $\delta_{D, \text { lim }}-\left(\delta_{1}+\delta_{2}+\delta_{3}\right)$ esté de 0 , más válidas serán las hipótesis descritas en el punto 4.3, y, en consecuencia, el mismo $\delta$-method. Se ha usado satisfactoriamente esta comprobación, como criterio para identificar tipologías de puentes donde el método es aplicable, como los puentes Nielsen-Löhse or Network (véase la figura 4.3).

Una vez que se ha alcanzado la convergencia (paso s), la última verificación es comprobar si la suposición inicial (es decir, si el puente es $\delta$-controlled) es cierta. Con este objetivo, se define un modelo de elementos finitos (paso t) con las propiedades mecánicas que se han obtenido para el arco y el tablero. Los esfuerzos axiles y los momento flectores se obtienen (paso u) para el estado límite último, y se calculan y comprueban las tensiones longitudinales (pasos v y w). El peso del puente puede calcularse entonces (paso y). Si el puente no verifica tensiones, el método no se considera válido y el puente óptimo debería ser calculado mediante el $\sigma+\delta$-method definido en el punto 4.5.

La figura 4.13 muestra un ejemplo completo de aplicación para una valor de $C_{A}=0.30$, del puente definido en la figura 4.12 .

\section{5. $\sigma+\delta$-method}

En este apartado, se presenta el $\sigma+\delta$-method, incluyéndose un diagrama de flujo y un ejemplo de aplicación. El método minimiza las áreas del arco y el tablero (es decir, el peso del puente) para puentes del tipo $\sigma+\delta$-controlled. Como se ha visto en el punto 4.4 , en el $\delta$ method se asume que el puente es $\delta$-controlled y se dimensiona para cumplir estrictamente $\delta_{D}=\delta_{D, l i m}$. Sin embargo, en el caso en el que las tensiones en estado límite último fallan al final del proceso, el $\sigma+\delta$-method rediseña las secciones transversales haciendo que cumplan la limitación a tensiones, y además, se mantenga la rigidez global del puente por encima de un valor límite, ya que el puente debe ser siempre lo suficientemente rígido para verificar el estado límite de servicio de flechas. Es interesante resaltar, que de manera similar al $\delta$-method y con las mismas ventajas y desventajas, el $\sigma+\delta$-method obtiene el mínimo peso para un solo valor de $C_{A}$.

En términos prácticos, la estrategia de diseño del $\sigma+\delta$-method permanece sin cambios

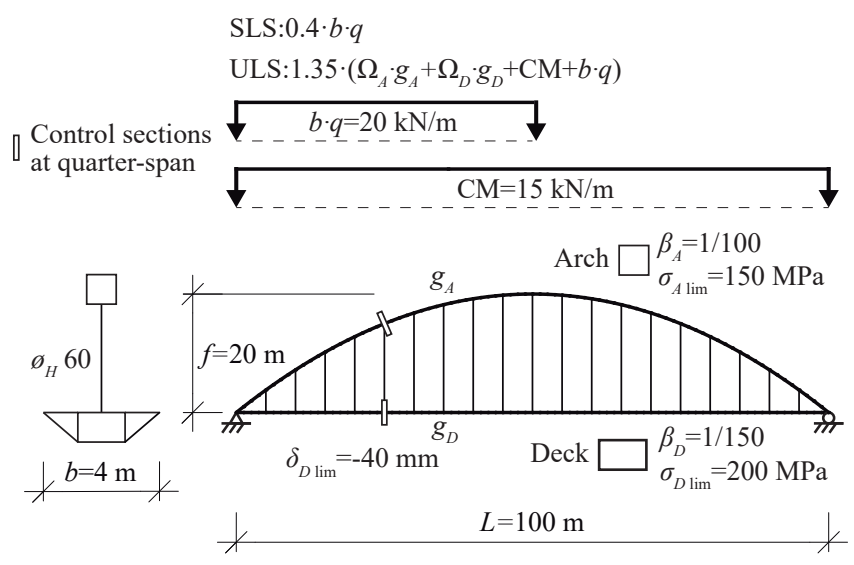

Figura 4.12: Definición del puente analizado en el ejemplo. 


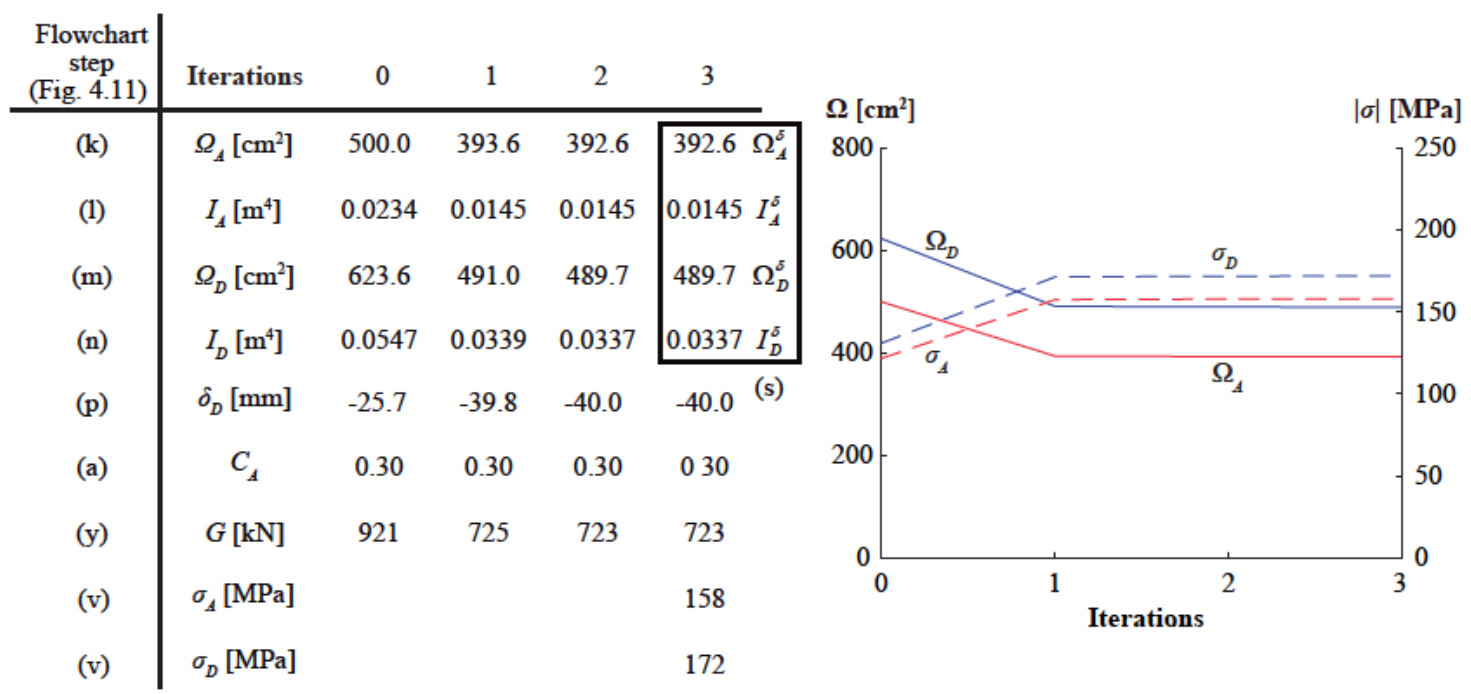

Figura 4.13: Ejemplo de aplicación $\left(C_{A}=0.30\right)$ del $\delta$-method para el puente definido en la figura 4.12 .

independientemente de si el fallo en tensiones se produce en el arco, el tablero o simultáneamente en ambos. Cuando un elemento estructural, como por ejemplo el arco, falla en tensiones, su sección transversal se redimensiona para cumplir estrictamente la verificación a tensiones, un proceso que modificará su área y, en algunos casos, también su inercia. Sin embargo, cuando la inercia del arco se modifica, la inercia del tablero debe cambiarse en consecuencia, ya que la distribución relativa arco-tablero de rigidez a flexión está impuesta previamente por el coeficiente $C_{A}$, es decir, $I_{D}=\mu \cdot I_{A}$.

Para ilustrar el proceso de diseño de una sección que verifique las limitaciones tensionales, la figura 4.14 representa la relación entre la tensión longitudinal debida a $N$ y $M, \mathrm{y}$ los valores de $I(\Omega, \beta)$ y $W(\Omega, \beta)$ definidos en las ecuaciones 4.4 y 4.5 . Las curvas se han dibujado considerando $N=1000 \mathrm{kN}, M=500 \mathrm{kN} \cdot \mathrm{m}, \sigma_{\text {lim }}=250 \mathrm{MPa}$ y $\beta=1 / 100$, para un conjunto de áreas crecientes, $\Omega_{2}<\Omega_{12}<\Omega_{1}<\Omega_{0}$. Para que quede más claro, la notación y los valores anteriores coinciden con los usados en la figura 4.15. El eje horizontal corresponde a la altura del alma, $z$. La parte válida de cada curva, es decir, el rango de $z$ que evita que la sección falle a tensiones, se ha dibujado con una línea más gruesa. Los extremos de la zona de validez están representados por marcadores circulares, los cuales se corresponden con los puntos de las curvas $\Omega-W$ y $\Omega-I$ dibujadas e la figura 4.15.

El mínimo valor de $\Omega$ que verifica estrictamente el límite de tensión es $\Omega_{2}$. Esta es la razón por la que la parte válida de $z-\sigma\left(\Omega_{2}\right)$, dibujada en una línea más gruesa, se convierte en un punto único, que se corresponde con un único valor de $z$. Por lo tanto (véase el punto $4.2)$, su área se distribuye de manera que se maximice $W$, es decir, $W\left(\Omega_{1}\right)=W_{W}\left(\Omega_{1}\right)$ e $I\left(\Omega_{1}\right)=I_{W}\left(\Omega_{1}\right)$, variables definidas en las ecuaciones 4.9 y 4.8 . Cuando $\Omega<\Omega_{2}$, la sección transversal no cumple el criterio de tensiones, independientemente de la distribución del material.

Cuando $\Omega=\Omega_{1}$, la sección transversal no falla a tensiones incluso cuando su área está distribuida maximizando $I$. $\Omega_{1}$ es el área mínima que verifica tensiones para $I=I_{I}\left(\Omega_{1}\right)$, de hecho, se puede observar como el valor de $z$ donde $I=I_{I}\left(\Omega_{1}\right)$ coincide con el extremo 


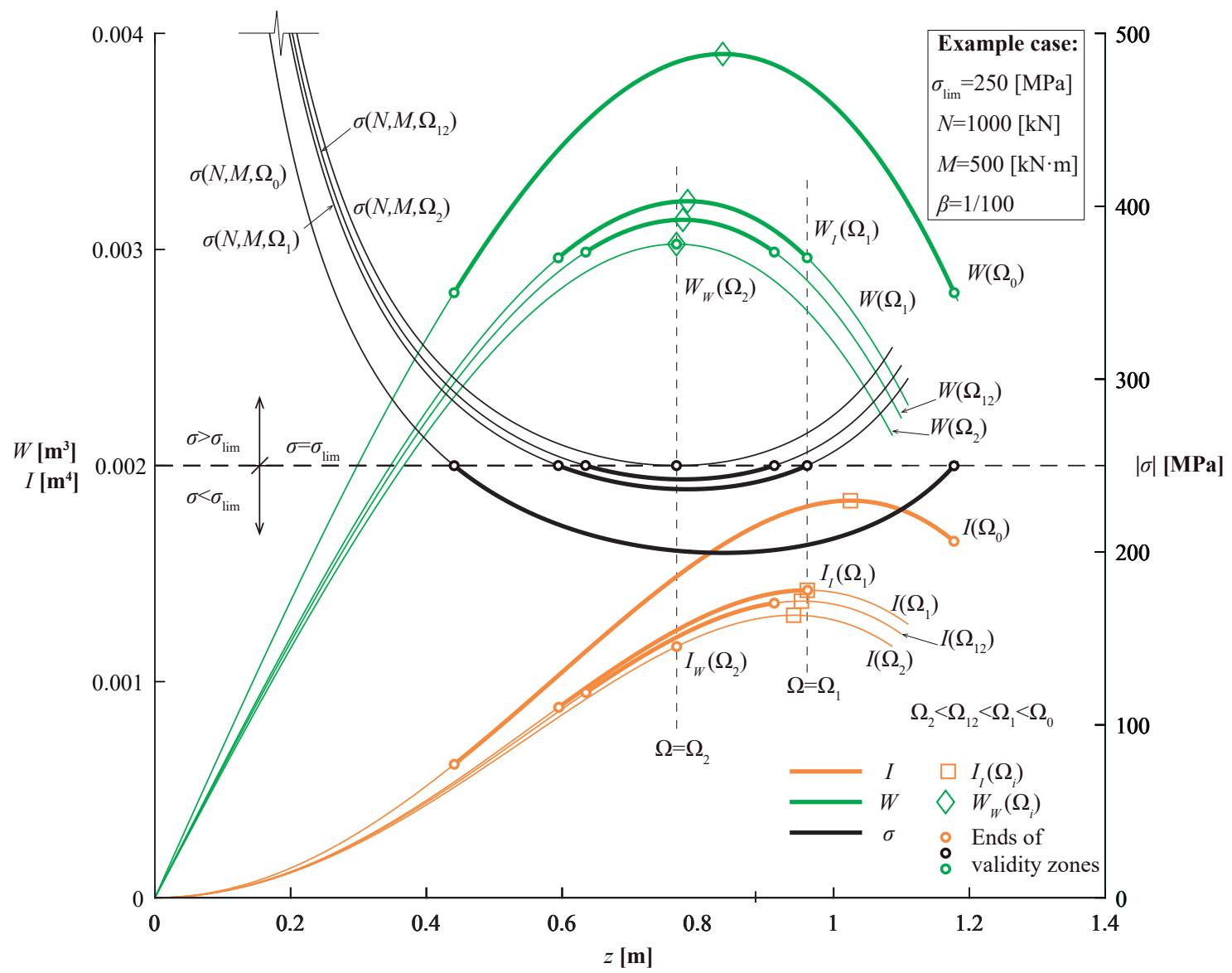

Figura 4.14: $I$ (ecuación 4.4), $W$ (ecuación 4.5) y $\sigma$ (ecuación 4.35) en función de $z$, para diferentes valores de $\Omega$.

derecho de la zona de validez. Por consiguiente, cuando, como resultado del $\delta$-method, la inercia $I^{\delta}$ de una sección debe ser $I^{\delta} \geq I_{I}$, el peso mínimo de la sección transversal se alcanza maximizando su inercia, ya que no fallará a tensiones si $\Omega>\Omega_{1}$.

Para verificar las limitaciones de tensiones, áreas intermedias entre $\Omega_{2}$ y $\Omega_{1}$, como $\Omega_{12}$, no maximizan ni $W_{W}$ ni $I_{I}$. En su lugar, estas áreas son minimizadas distribuyendo su material de una forma diferente. En la figura 4.15 se puede ver como $\Omega_{12}$ se corresponde con cualquier punto que pertenezca al arco 1-2.

Es interesante remarcar que el extremo izquierdo de cada zona de validez corresponde a una sección transversal que verifica estrictamente la limitación de tensión mientras dispone de la mínima inercia posible. Esto significa que, a pesar de que estas secciones tienen la $z$ mínima posible (es decir, la altura), son más deformables. Estas secciones son especialmente útiles, cuando la inercia de una sección debe mantenerse tan baja como sea posible por cualquier motivo.

A la luz de la figura 4.14, el procedimiento de redefinir, cuando es necesario, la sección transversal, por ejemplo del arco, puede ser fácilmente entendido gracias a la figura 4.15. Ya que ambas secciones se analizan simultáneamente, una figura similar debería ser dibujada también para el tablero. El área del $\operatorname{arco} \Omega_{A}^{\delta}$ (y la del tablero $\Omega_{D}^{\delta}$ ) han sido obtenidas 


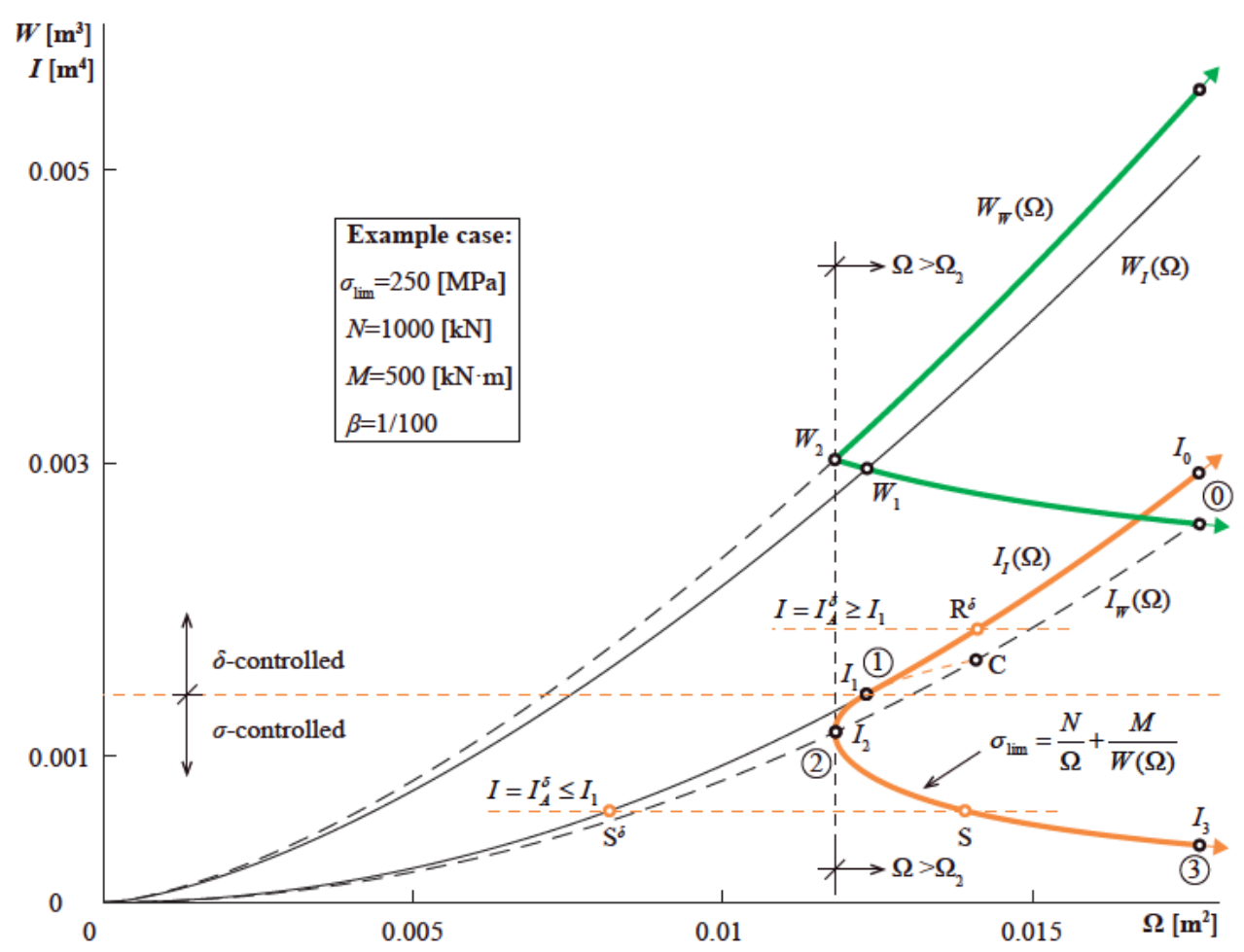

Figura 4.15: Redefinición de una sección transversal para verificar el límite de flechas y tensiones.

como resultado del $\delta$-method (figura 4.11, paso s), y han sido distribuidas maximizando $I$, es decir, $I_{A}=I_{A}^{\delta}=I_{I}\left(\Omega_{A}^{\delta}\right), I_{D}=I_{D}^{\delta}=I_{I}\left(\Omega_{D}^{\delta}\right)$. Por consiguiente, una vez que el $\delta$-method ha sido aplicado, el punto $\left(\Omega_{A}^{\delta}, I_{A}^{\delta}\right)$ pertenecerá a la curva $I=I_{I}(\Omega)$, definida por la ecuación 4.12. Los puntos $R^{\delta}$ y $S^{\delta}$ son dos ejemplos de posibles resultados del $\delta$-method.

Si la sección transversal del arco (y su inercia) tienen que ser redefinida por el $\sigma+\delta$ method, debe verificarse:

$$
I_{A} \geq I_{A}^{\delta}
$$

ya que $I_{A}^{\delta}$ se corresponde con el mínimo valor de $I_{A}$ que verifica la limitación de flechas para un valor dado de $C_{A}$. Simultáneamente, se debe verificar la siguiente expresión referente a la tensión:

$$
\sigma_{A, l i m} \geq \frac{N_{A}}{\Omega_{A}}+\frac{M_{A}}{W\left(\Omega_{A}\right)}
$$

donde $N_{A}$ y $M_{A}$ son el esfuerzo axil y el momento flector en la sección de control del arco, respectivamente, y $W\left(\Omega_{A}\right)$ es el valor del módulo resistente (ecuación 4.5) para $\Omega=\Omega_{A}$ y $\beta=\beta_{A}$.

Los límites de las zonas donde la ecuación 4.35 se verifica están dibujados en la figura 4.15 , y dependen de los valores de $N_{A}$ y $M_{A}$. Para un valor dado de $\Omega_{A}$, la ecuación 4.35 se cumplirá para un rango de valores de $W$ correspondiente a un rango de valores de 
$z$ (véase la ecuación 4.5 y la figura 4.14). Los valores máximos y mínimos del rango de valores válidos de $W$, y los correspondientes valores de $I$, han sido representados para cada valor de $\Omega$, resultando dos curvas. Estos valores se corresponden con los extremos de las zonas de validez dibujadas en la figura 4.14. La curva $\Omega-I$, representada en color naranja, pasa por los puntos $0,1,2$ y 3 , y es ilimitada más allá de los puntos 0 y 3 . Por encima del punto 1, la curva que verifica la ecuación 4.35 coincide con la curva $I=I_{I}(\Omega)$. En el punto 2, el valor de $\Omega_{A}$ es mínimo y el rango de valores de $W$ que verifica la ecuación 4.35 se reduce a un único punto que corresponde a $W_{W}$ (véase la ecuación 4.9), como se mencionó previamente. Por lo tanto, el punto 1 pertenece a la curva $I=I_{W}(\Omega)$, definido en la ecuación 4.8, siendo la tangente a este punto vertical. La parte de la curva entre los puntos 1 y 2 muestra como el material puede ser gradualmente distribuido de una forma menos efectiva para cumplir con las limitaciones de tensiones cuando $\Omega$ aumenta.

Así, el punto redefinido $\left(\Omega_{A}, I_{A}\right)$ debe pertenecer a la curva $\Omega-I$ (con el fin de verificar la ecuación 4.35 y minimizar $\Omega_{A}$ ) y, específicamente, a la parte de la curva donde $I_{A} \geq I_{A}^{\delta}$, para cumplir así la ecuación 4.34. Hay dos posibles casos. En el primer caso, representado por el punto $R^{\delta}$, que se encuentra localizado por encima del punto 1 de la curva $\Omega-I$, es decir $I\left(R^{\delta}\right)>I_{1}$, la sección transversal del arco cumple la limitación de tensiones sin necesidad de modificarla, y, por lo tanto, no necesita ser redefinida. En el segundo caso, representado con el punto $S^{\delta}$, el cual está a la izquierda de la curva $\Omega-I$, y fuera de la zona de validez donde $I\left(S^{\delta}\right)<I_{1}$, el área debe ser gradualmente incrementada manteniendo constante $I$, hasta que intersecte con la curva $\Omega-I$ en el punto $\mathrm{S}$.

En este caso, es importante distinguir si $S$ pertenece al arco 1-2 o al arco 2-3. En el primer caso, $I$ se incrementa cuando $\Omega$ incrementa a lo largo del arco S-1. Esto significa que el resto de los puntos del arco S-1 son soluciones menos efectivas que el punto $\mathrm{S}$, ya que no solo el área del arco aumenta (lo que implica un arco más pesado), sino que también su inercia es mayor que $I_{A}^{\delta}$, lo que significa que la sección transversal del tablero tendrá que ser aumentada para cumplir el ratio impuesto $I_{D}=\mu \cdot I_{A}$.

Sin embargo, si S pertenece a la curva 2-3 (cuyos puntos se corresponden con los extremos derechos de las zonas de validez definidas en la figura 4.14), cuando $I$ se incrementa a lo largo del arco S-2, $\Omega$ decrece. Esto significa que la sección transversal del arco es más ligera, pero, debido al ratio impuesto $I_{D}=\mu \cdot I_{A}$, la sección transversal del tablero debe ser aumentada. Por consiguiente, en el arco S-2, el peso mínimo global no puede ser determinado de antemano, ya que aligerar el arco implica aumentar el tablero. En consecuencia, cada punto del rango S-2 (y su correspondiente sección transversal para el arco) debe ser considerado para obtener el peso mínimo.

Para estructuras con una única sección de control, como el caso de una viga, se puede dibujar una figura similar a la de la figura 4.15, a pesar de que el arco 2-3 es necesario solo cuando se quieren buscar las soluciones de menor canto, ya que el punto 2 siempre proporciona una solución más efectiva, es decir, menos pesada y con más rigidez que cualquier otro punto del arco 2-3. El arco 2-3 resulta especialmente útil en casos con dos o más secciones de control, como el caso de un puente arco, ya que se pueden obtener configuraciones con menor peso global a expensas del diseño de secciones menos efectivas para el arco o el tablero.

Una figura similar se debe representar para el tablero con el fin de redimensionar su 
sección transversal, cuando sea necesario. Puede ocurrir que la sección transversal del arco esté condicionada por el criterio de tensiones, mientras que la sección del tablero está gobernada por el criterio de rigidez mínima, o viceversa.

Desde el punto de vista de la literatura técnica, es la primera vez que se prueba que, para una distribución de rigidez a flexión arco-tablero impuesta, las secciones transversales del arco y del tablero están condicionadas por criterios diferentes, como la tensión longitudinal o la limitación de flechas.

El proceso es iterativo, y las curvas $\Omega-I$ para el arco y el tablero cambian con $N$ y $M$ en cada iteración, como se detalla en el diagrama de flujo de la figura 4.16, donde los datos iniciales son leídos de la salida de datos del $\delta$-method (pasos a y b) o calculados al final de la iteración previa. Entonces, un modelo de elementos finitos se lleva a cabo (paso c) y se actualizan los esfuerzos internos (paso d). Las secciones transversales del arco (pasos e, f e i) y del tablero (pasos g, h e i) se redefinen de acuerdo al método descrito anteriormente, verificando las ecuaciones 4.34 y 4.35 y, simultáneamente, respetando el valor impuesto de $C_{A}$. En caso de que la solución no sea única, es decir, cuando la solución del arco o del tablero pertenece al arco 2-3, el arco completo debe ser estudiado para obtener la combinación más ligera. Finalmente, el proceso se repite hasta que se alcance la convergencia (paso l).

En la figura 4.17 se muestra un ejemplo de aplicación del método. Este ejemplo continúa el ejemplo definido en las figuras 4.12 y 4.13. Solo se necesitan dos iteraciones, ya que la solución final está muy cerca de los resultados obtenidos con el $\delta$-method. La sección transversal del arco y del tablero se ha redefinido para logar una tensión longitudinal máxima de $150 \mathrm{MPa}$, mientras que la sección transversal del tablero no necesita ninguna redefinición adicional con respecto a los resultados del $\delta$-method. Este es un ejemplo, en el que la sección transversal del arco se redimensiona de acuerdo al límite tensional, mientras que el tablero está condicionado por el criterio de rigidez. 


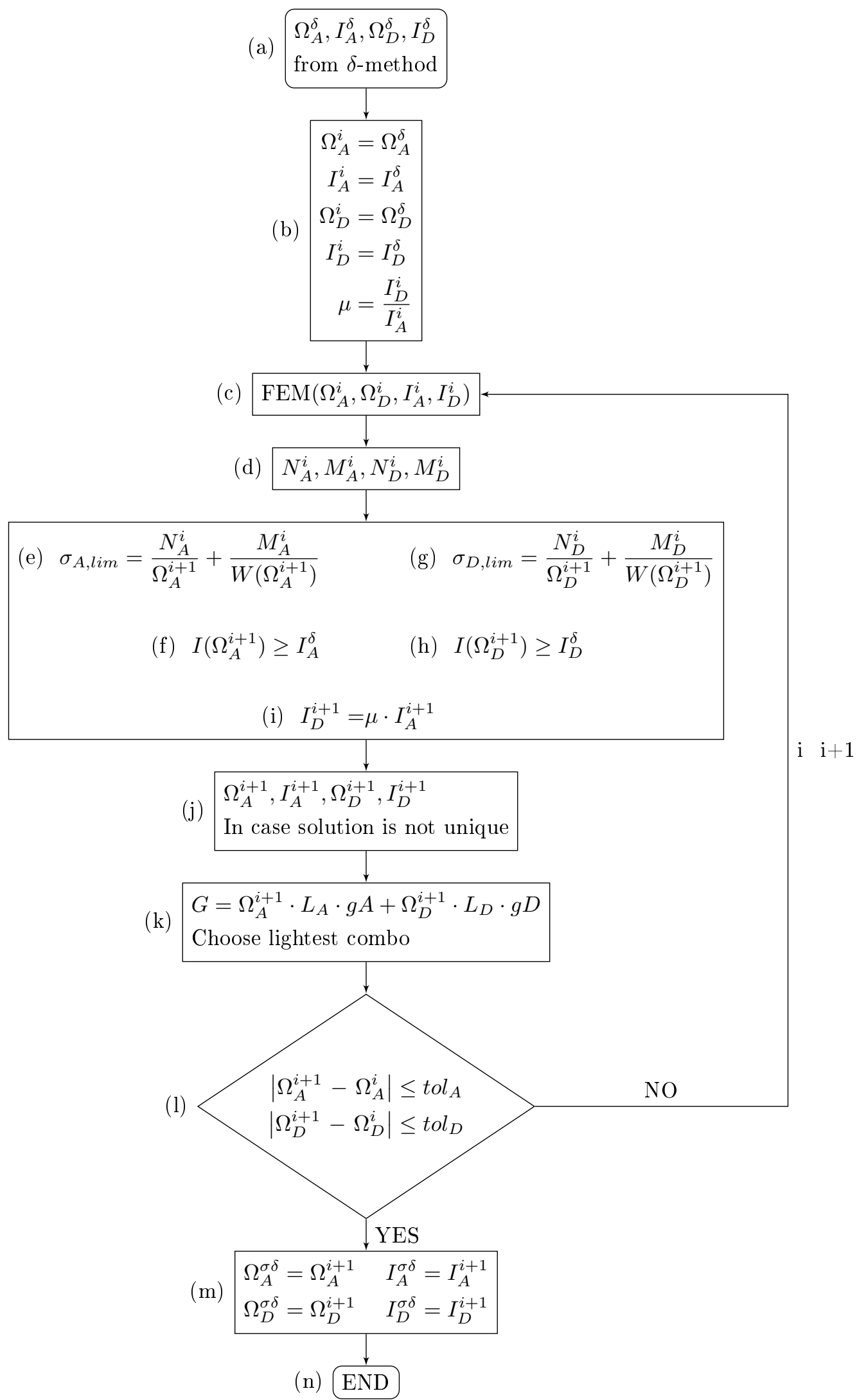

Figura 4.16: Diagrama de flujo para el $\sigma+\delta$-method. 


\section{CAPÍTULO 4. DIMENSIONAMIENTO DE SECCIONES EN EL PLANO}

\begin{tabular}{|c|c|c|c|c|}
\hline \multirow{2}{*}{$\begin{array}{l}\text { Flowchart } \\
\text { step } \\
\text { (Fig. 4.16) }\end{array}$} & \multicolumn{4}{|c|}{ - (a), (b) } \\
\hline & Iterations & 0 & 1 & 2 \\
\hline \multirow{3}{*}{ (j) } & $\Omega_{A}\left[\mathrm{~cm}^{2}\right]$ & $\Omega_{A}^{\delta} 392.6$ & 398.4 & $3985 \Omega_{A}^{\sigma \delta}$ \\
\hline & $I_{A}\left[\mathrm{~m}^{4}\right]$ & $I_{A}^{\delta} \quad 0.0145$ & 0.0145 & $0.0145 I_{A}^{\sigma \delta}$ \\
\hline & $\Omega_{D}\left[\mathrm{~cm}^{2}\right]$ & $\Omega_{D}^{\delta} 489.7$ & 489.7 & $489.7 \Omega_{D}^{\sigma \delta}$ \\
\hline \multirow[t]{4}{*}{ 才 } & $I_{D}\left[\mathrm{~m}^{4}\right]$ & $I_{D}^{\delta} \quad 0.0337$ & 0.0337 & $0.0337 I_{D}^{\sigma \delta}$ \\
\hline & $\sigma_{A}[\mathrm{MPa}]$ & 158 & 150 & $150^{(\mathrm{m})}$ \\
\hline & $\sigma_{D}[\mathrm{MPa}]$ & 172 & 172 & 172 \\
\hline & $\delta_{D}[\mathrm{~mm}]$ & -40.0 & -40.0 & -40.0 \\
\hline (b) & $C_{A}$ & 0.3 & 0.3 & 03 \\
\hline (k) & $G$ & 723 & 728 & 728 \\
\hline
\end{tabular}
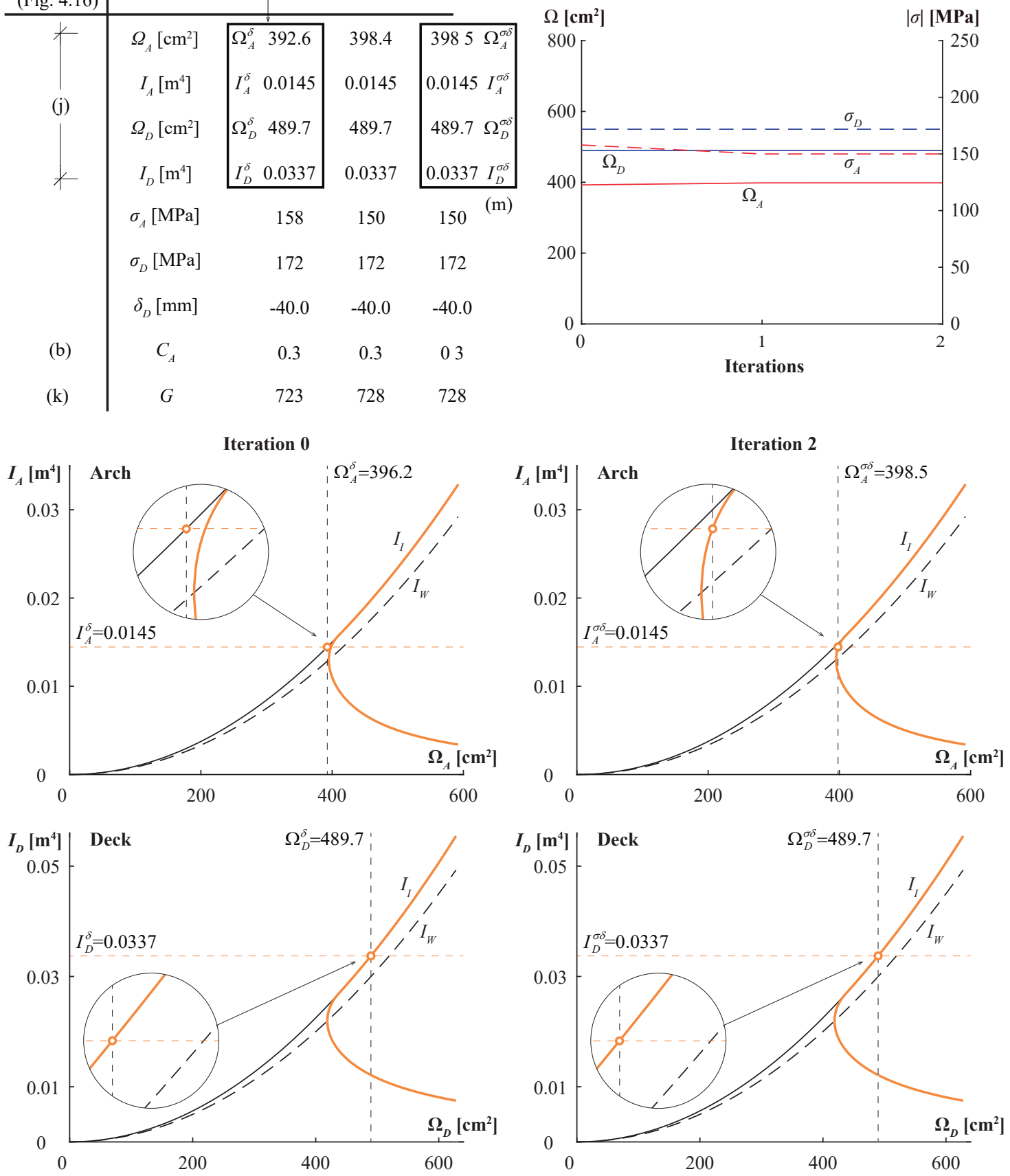

Figura 4.17: Ejemplo de aplicación del $\sigma+\delta$-method, para el puente definido en las figuras 4.12 y 4.13 . 


\subsection{Ejemplos de aplicación}

\subsubsection{Arco atirantado}

Para ilustrar las posibilidades del método, el arco atirantado usado como ejemplo en los puntos 4.4 y 4.5 se desarrolla ahora por completo. La definición del puente se puede encontrar en la figura 4.12 , y los resultados para un conjunto de valores de $C_{A}$ entre 0.02 y 0.98 se muestran en la figura 4.18.

Los resultados incluyen la salida para el $\delta$-method y el $\sigma+\delta$-method, respectivamente, en línea discontinua y continua. Dos líneas verticales dividen los resultados en tres zonas: en la zona central el puente es del tipo $\delta$-controlled, coincidiendo los resultados para el $\delta$-method y el $\sigma+\delta$-method, ya que la sección transversal del puente permanece inalterada después de la aplicación del $\sigma+\delta$-method. En la zona izquierda y en la zona derecha de la figura, se puede ver como la sección transversal tiene que ser aumentada para verificar la limitación de tensiones, con lo que el peso $G$ y la altura del alma $z$ crecen. 


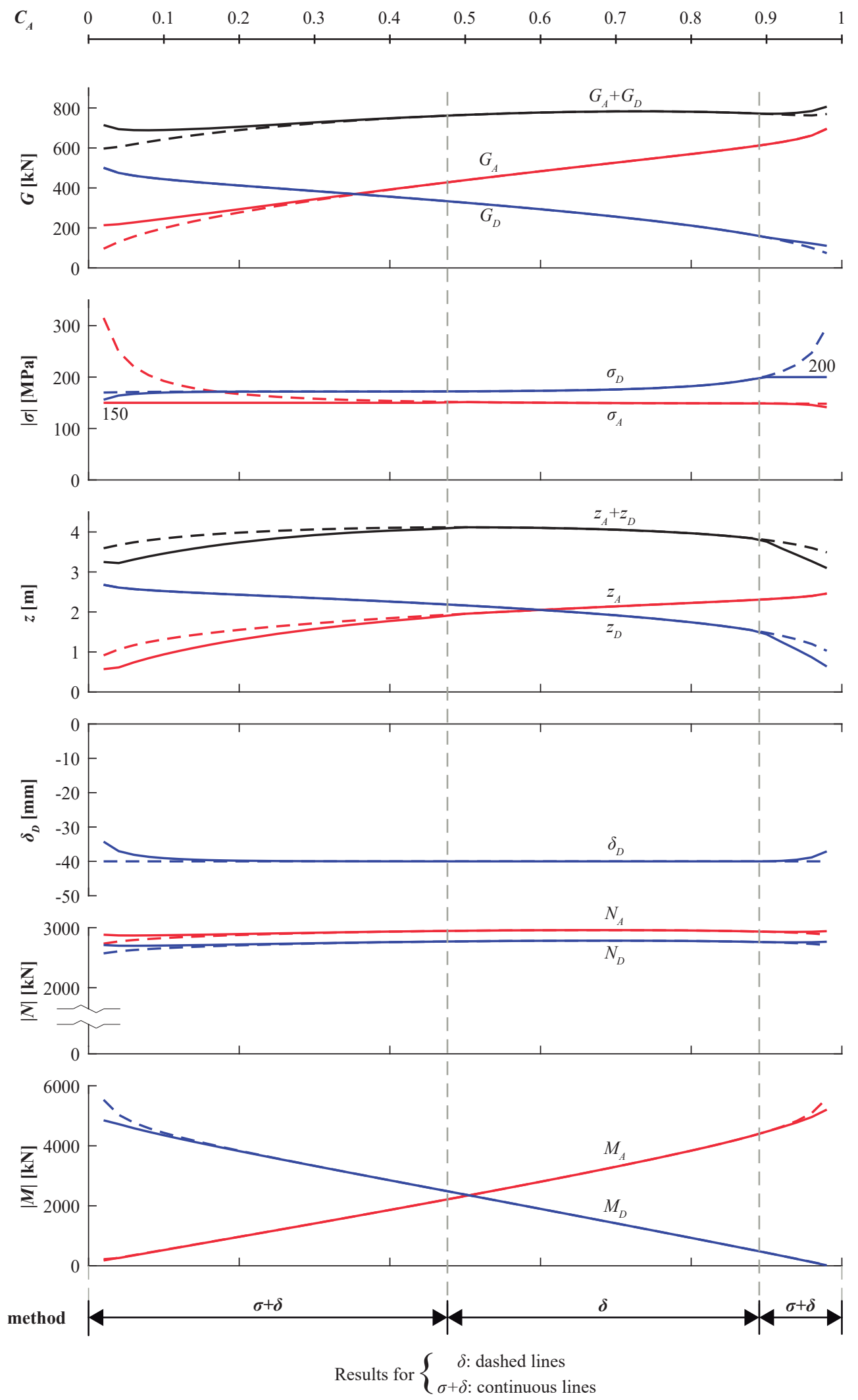

Figura 4.18: Ejemplo de aplicación para el puente definido en las figura 4.12. 


\subsubsection{Puente arco de tablero superior}

En este caso, se ha analizado un puente arco de tablero superior, con una luz de $54 \mathrm{~m}$ (véase la figura 4.19). Los resultados se muestran en la figura 4.20. Se puede observar como el puente, probablemente debido a los valores altos de $\sigma_{A, l i m}$ y $\sigma_{D, l i m}$, es $\delta$-controlled, y solo una pequeña porción de la parte izquierda de la figura necesita ser redefinida usando el $\sigma+\delta$-method. Está claro que en este caso la solución, para estos valores de $\beta_{A}, \beta_{D}$, $\sigma_{A, l i m}$ y $\sigma_{D, l i m}$, tiende a arcos laminares (véase Billington [18]), es decir, un tablero rígido sustentado por un arco delgado.

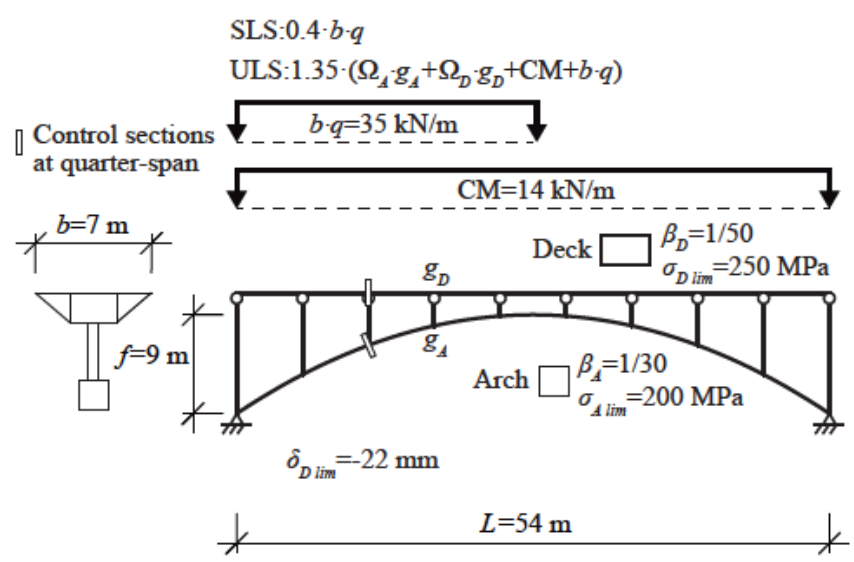

Figura 4.19: Definición del puente arco de tablero superior usado para el ejemplo. 


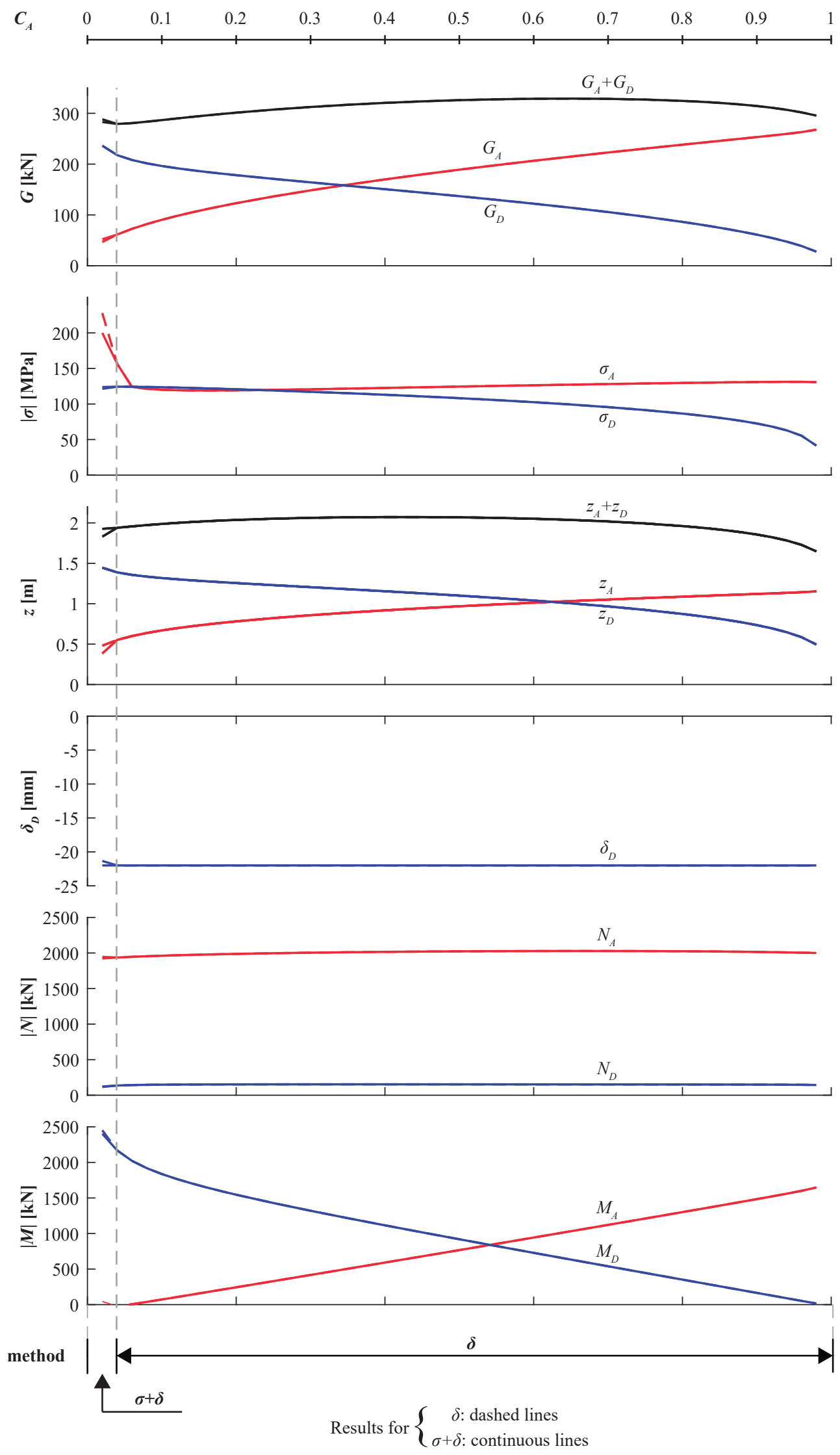

Figura 4.20: Ejemplo de aplicación para el puente definido en la figura 4.19. 


\subsubsection{Puente arco con atirantamiento tipo Nielsen-Löhse}

En este caso el puente arco y sus resultados están definidos en las figuras 4.21 y 4.22. El puente del ejemplo es $\sigma+\delta$-controlled, ya que las curvas del $\delta$-method y del $\sigma+$ $\delta$-method están claramente separadas, lo que significa que los resultados del $\delta$-method deben ser redefinidos para cumplir con la limitación a tensiones. El mínimo peso no se obtiene claramente, puesto que la curva $C_{A}-G$ es muy plana para los valores centrales de $C_{A}$. En este caso, el peso global del puente no es el factor determinante, y otras consideraciones como los requerimientos funcionales o la facilidad de ejecución del puente, son más relevantes.

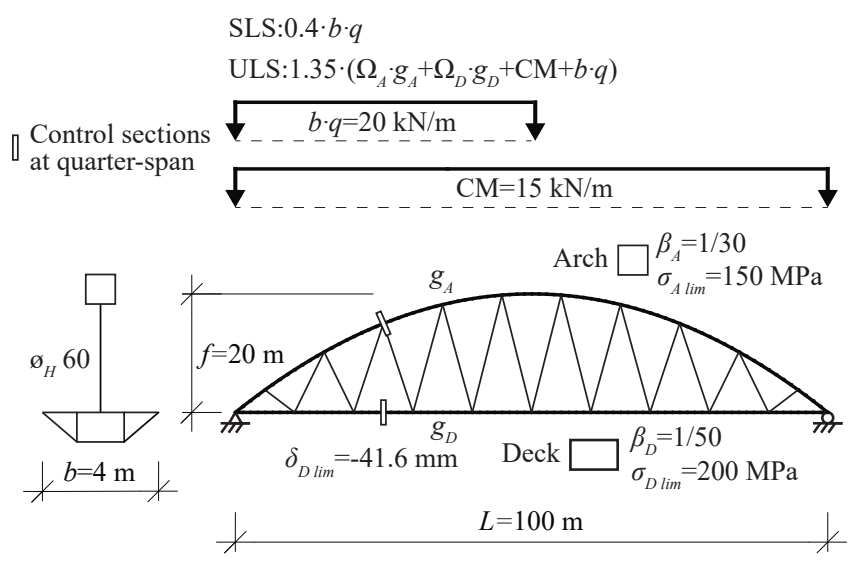

Figura 4.21: Definición del puente arco con atirantamiento tipo Nielsen-Löhse usado para el ejemplo. 

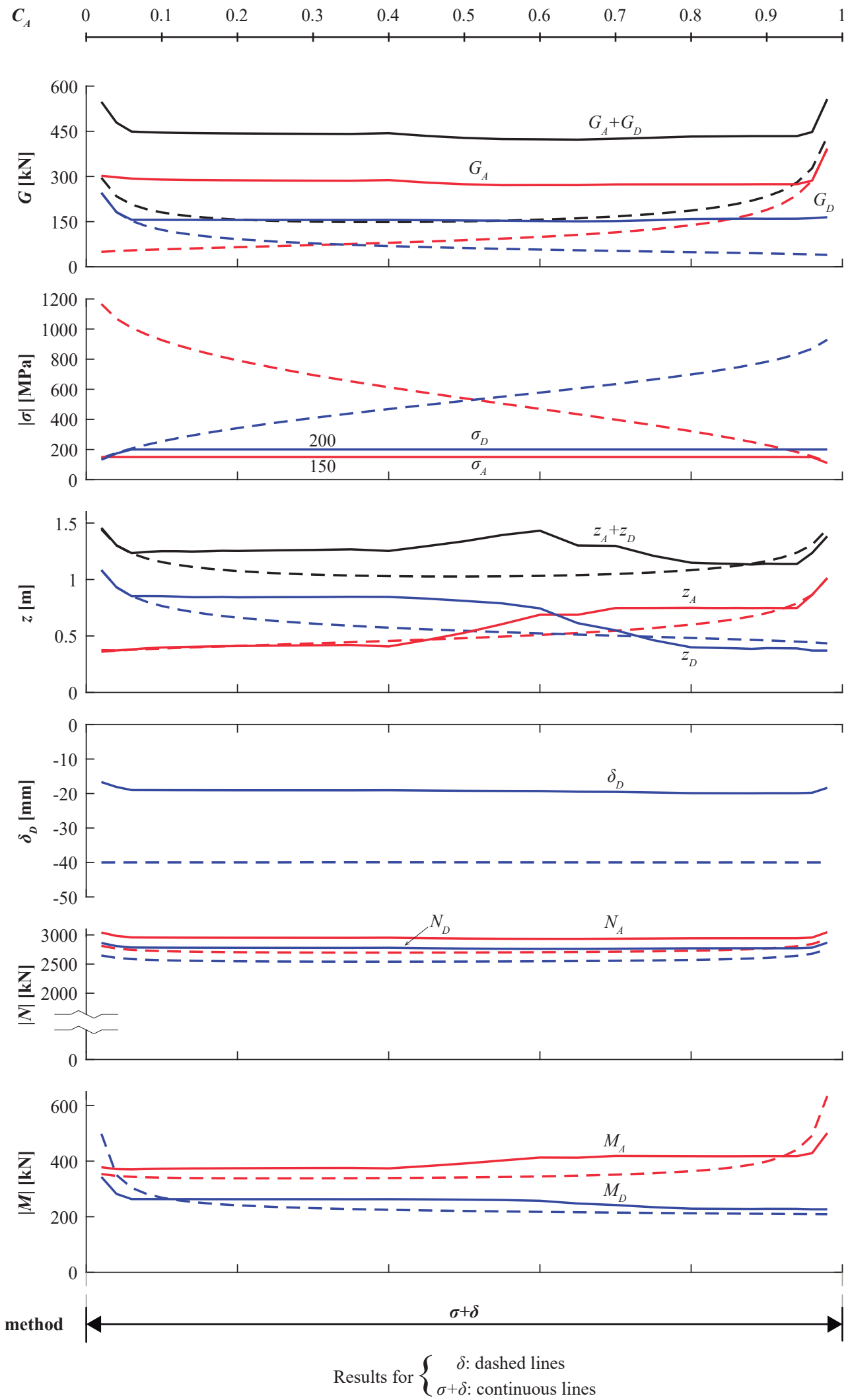

Figura 4.22: Ejemplo de aplicación para el puente definido en la figura 4.21. 


\subsection{Efecto de los parámetros de diseño en el diseño preliminar}

Como se ha visto en el punto 4.2, el número de parámetros relevantes en el diseño preliminar ha sido reducido notablemente. Este hecho hace que el proceso de diseño sea más fácil, sin embargo tiene la desventaja de que cada parámetro usado cobra importancia. Para ilustrar la importancia de algunos de estos parámetros, se han realizado dos estudios para el puente definido en la figura 4.12. El primer estudio analiza la influencia de las esbelteces de las almas, $\beta_{A}$ y $\beta_{D}$, en el peso global del puente, mientras que el segundo estudio analiza la influencia de los límites de tensión establecidos, $\sigma_{A, l i m}$ y $\sigma_{D, l i m}$. Los valores de las esbelteces y de los límites de tensión se han escogido deliberadamente para resaltar sus efectos en el estudio.

El efecto de $\beta_{A}$ y $\beta_{D}$ se muestra en la figura 4.23-a. Se puede observar como el peso global del puente decrece para valores bajos de $\beta$, es decir, para almas esbeltas. Esto ocurre porque el material de ambas secciones se distribuye de tal forma que incremente el brazo de la sección para un área dada. El peso del arco y del tablero depende principalmente de dos factores. En primer lugar, cuanto mayor es $C_{A}$, más pesado es el arco y más ligero el tablero, ya que se necesitan secciones transversales más pesadas para proporcionar la rigidez global requerida para valores altos de $C_{A}$. En segundo lugar, cuanto mayor es la esbeltez, más ligero es la sección transversal, puesto que los valores requeridos de inercia pueden lograrse con menos material.

La figura 4.23-b muestra la relevancia de $\sigma_{A, l i m}$ y $\sigma_{D, \text { lim }}$ para $\beta_{A}=\beta_{D}=1 / 30$. En términos generales, siempre que la tensión longitudinal admisible de un elemento decrece, su peso se incrementa. Cuando ambos límites $\sigma_{A, l i m}$ y $\sigma_{D, l i m}$, se incrementan, las secciones del arco y del tablero se hacen más ligeras. Este análisis muestra lo importante que es el criterio ingenieril cuando se está estimando el valor de los límites de tensiones.

\subsection{Consideraciones generales sobre los métodos pro- puestos}

Este capítulo describe un novedoso método iterativo que permite llevar a cabo el diseño preliminar en el plano de puentes arco cuyo comportamiento se asume contenido dentro del plano vertical. Este método puede ser aplicado satisfactoriamente a diferentes tipologías, como arcos laminares, o puentes arco con atirantamientos tipo Nielsen-Löhse o Network.

En el capítulo se recomienda una formulación simplificada y compacta, que reduce enormemente el número de parámetros relevantes para las propiedades mecánicas de la secciones transversales, proporcionando la suficiente precisión para el dimensionamiento preliminar.

Además, se proporciona un método simplificado para estimar la flecha de un puente arco, compuesto por un arco y un tablero vinculados con péndolas verticales.

La principal contribución de este capítulo, es proporcionar un método que puede ser aplicado para obtener las dimensiones de las secciones transversales del arco y del tablero que constituyen la configuración de mínimo peso del puente. El método se basa en con- 

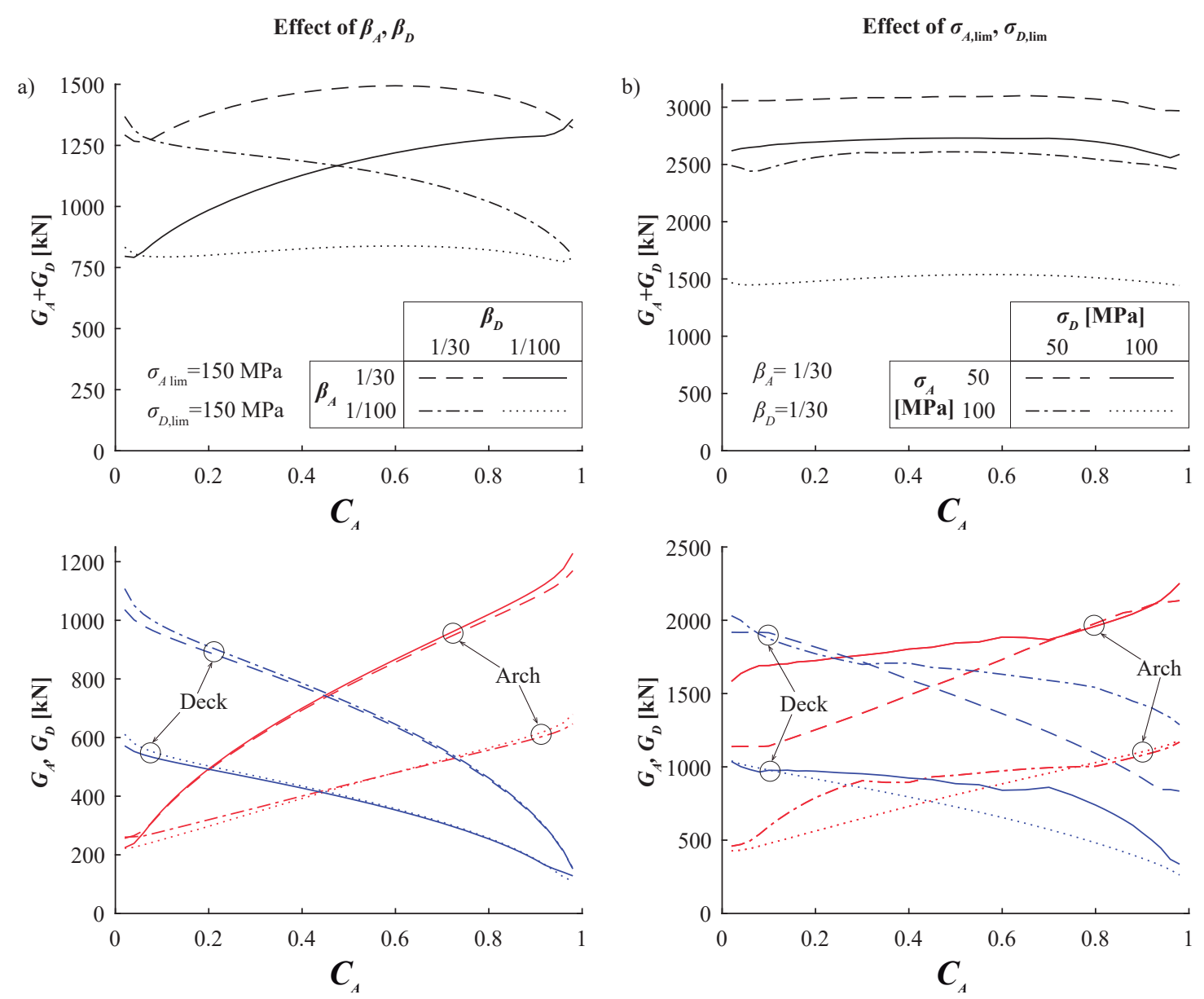

Figura 4.23: Efecto de la esbeltez del alma y de la tensión longitudinal admisible en el peso del puente de la figura 4.12 .

sideraciones puramente estructurales, siendo libre el proyectista de incorporar, durante la fase de diseño, cualquier criterio constructivo o de diseño que desee, o incluso adaptar iterativamente la topología de la estructura.

El método resalta la relevancia de la contribución del arco a la rigidez a flexión global del puente, definida por el parámetro $C_{A}$. Además, es la primera vez, desde el punto de vista de la literatura técnica relacionada con esta temática, que se muestra como el criterio determinante de diseño del arco puede ser diferente del de tablero. Se puede ver también como, por ejemplo, el arco puede estar diseñado para cumplir con el criterio de tensiones, mientras que el tablero se dimensiona siguiendo un requerimiento de rigidez.

Reduciendo el número de parámetros relevantes, el capítulo enfatiza como de crítico puede llegar a ser el buen criterio ingenieril en las etapas tempranas del diseño conceptual. Particularmente, se ha mostrado la importancia de ambas esbelteces de las almas, el significado de definir límites realistas de las flechas en servicio, y la influencia de la máxima tensión longitudinal permitida en el peso del puente. 


\section{Capítulo 5}

\section{Péndolas rigidizadas longitudinalmente}

Este capítulo, basado en un artículo realizado durante el periodo de tesis (véase [33]), muestra unas conclusiones que pueden ser muy útiles para ingenieros estructurales, principalmente en fases tempranas del diseño de puentes arco.

En el proceso de diseño de un puente arco, el proyectista puede decidir rigidizar las péndolas, vinculando el arco y el tablero, generalmente con el fin de reducir los esfuerzos internos o las flechas. En este capítulo, se estudia el efecto de las péndolas rígidas en el comportamiento longitudinal (en el plano) de los puentes arco. Además, se muestra el efecto de la rigidez de las péndolas y la relevancia de la rigidez relativa arco-tablero.

En este capítulo se describe también como las péndolas rígidas con una articulación (en el extremo superior o inferior) ofrecen una eficiencia estructural muy alta así como una gran facilidad de construcción. Todo esto se menciona una vez que se han comentado las desventajas de las péndolas rígidas, así como un posible inconveniente. El problema que puede surgir para péndolas rígidas, es que el momento flector cerca de los estribos del tablero puede llegar a ser peor para cargas simétricas que para cargas asimétricas, como normalmente ocurre en puentes arco. Para abordar este problema, se sugiere en este capítulo una solución novedosa, que consiste en la combinación de péndolas articuladas y empotradas, algo que puede llegar a ser tan eficiente como una configuración donde todas las péndolas están empotradas, mientras simultáneamente reduce el momento flector en los extremos del tablero.

\subsection{Introducción}

Un puente arco se compone principalmente de dos elementos: el tablero, que proporciona una superficie para el tráfico, y el arco, que es el elemento portante. El arco puede estar sobre el tablero o debajo de él. Independientemente, la localización de los extremos del arco, conocidos como arranques, tienden a separarse cuando el tablero se carga.

Es muy importante resaltar que, para comportarse como un arco, el movimiento horizontal de los arranques debe ser contenido, por ejemplo, con las cimentaciones localizadas en los dos estribos del puente. Así, cuando los puntos de arranques se fijan eficientemente, el arco se encuentra comprimido, lo que constituye la forma principal de soportar cargas de 


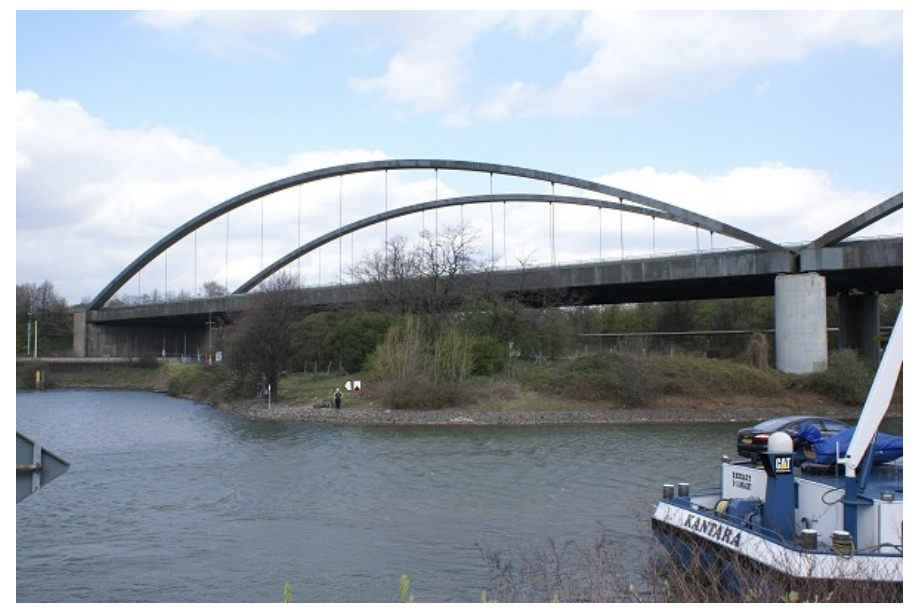

Figura 5.1: Puente de la Autobahn A 42 sobre el Canal Rhine-Herne. Fotografía: Nicolas Janberg (structurae.net), 2008

un arco (véase por ejemplo Lacidogna et al. [53]). El arco se encontrará completamente comprimido cuando toda la línea de presiones del arco esté contenida en el tercio medio de la sección del arco. De lo contrario, se deben tener en cuenta tensiones de tracción (véase Accornero et al. [1] o Block et al. [19]).

En el llamado arco bow-string (o arco atirantado), que se estudia en este capítulo, el arco se sitúa sobre el tablero, que ata los puntos de arranque del arco el uno al otro. En consecuencia, los movimientos horizontales de los arranques del arco son coartados por el tablero. Por lo tanto, en un arco atirantado, el arco está comprimido, mientras que el tablero se encuentra traccionado. Una descripción general del comportamiento de los arcos puede encontrarse en Karnowsky [50].

Un ejemplo de puente arco atirantado, entre los muchos que hay, es el puente de la Autobahn A 42 sobre el Canal Rhine-Herne (véase la figura 5.1)

En las primeras fases del proceso de diseño de un puente arco, la carga más desfavorable es normalmente una sobrecarga que actúa sobre la mitad del tablero, lo que causa momentos flectores en el arco y el tablero.

En este capítulo se mostrará que cuando las péndolas están articuladas en ambos extremos, se puede asumir de una manera precisa, que la cantidad de momento flector soportado por el arco es proporcional al ratio $E \cdot I_{A} /\left(E \cdot I_{A}+E \cdot I_{D}\right)$, es decir, al ratio entre la rigidez a flexión de la sección del arco con respecto a la rigidez a flexión del arco y del tablero (donde $E$ es el módulo de Young del acero, e $I_{A}$ e $I_{D}$ son, respectivamente, los momentos de inercia del arco y del tablero), definido en la ecuación 4.1 como $C_{A}$. Por lo tanto, durante el proceso de diseño, puede suceder que las dimensiones de las secciones transversales no puedan evitar el fallo del puente. De forma similar, puede ocurrir que la flecha del tablero esté más allá de los valores permitidos. Llegados a este punto, el proyectista decide normalmente rediseñar la sección transversal del arco, la del tablero, o ambas, de acuerdo a su experiencia profesional. Sin embargo, y como una alternativa, el proyectista puede decidir rigidizar las péndolas, vinculando el arco y el tablero, generalmente con el fin de reducir los esfuerzos internos o las flechas; tal decisión es el objeto de este capítulo de la tesis. 
Se mostrará en este capítulo, el efecto de las péndolas rígidas en el comportamiento longitudinal (en el plano) de los puentes arco. El estudio se ha llevado a cabo para un puente arco atirantado de referencia, que se ha considerado representativo de su clase. En las siguientes páginas se muestra el efecto de las péndolas rígidas y la relevancia de la rigidez relativa arco-tablero. En el capítulo se describe también como las péndolas rígidas con una articulación, en el extremo superior o en el inferior, combinan una alta eficiencia estructural con una fácil construcción. Ya que el pandeo en el plano del arco es raramente la causa de fallo en los puentes arco, como se describe en Palkowski [73], este efecto no se considera en este estudio.

Una de las conclusiones más relevantes de este capítulo es resaltar un posible inconveniente de las péndolas rígidas. El problema surge ya que, para péndolas rígidas, el momento flector cerca de los extremos del tablero puede ser más grande para cargas simétricas que para distribuciones de carga asimétricas, como normalmente ocurre en los puentes arco. Para abordar este problema, se sugiere en este capítulo una solución novedosa, que consiste en el diseño de una combinación de péndolas empotradas y articuladas, algo que puede ser tan eficiente como una configuración donde todas las péndolas están empotradas, y simultáneamente reduce el momento flector en las zonas próximas a los extremos del tablero. Así, esta solución combina eficiencia estructural y facilidad de ejecución.

\subsection{Modelo de referencia y cargas usadas en el estudio}

Todos los puentes estudiados en este capítulo están basados en el puente arco de referencia descrito en el capítulo 3, aunque con algunas variaciones (véase la figura 5.2). Ya que el estudio es principalmente cualitativo, el puente de referencia es considerado como representativo de su clase. Este modelo de referencia está compuesto por un tablero recto soportado por un arco plano vertical. El puente pertenece a la tipología conocida como bow-string (o arco atirantado), ya que los arranques del arco están sujetos por el tablero traccionado. El arco y el tablero están unidos por una familia de péndolas verticales ancladas al eje del tablero. En el modelo de referencia, las péndolas se modelizan como cables que están articulados en ambos extremos. Este capítulo se centra en los efectos de rigidizar esas péndolas. 


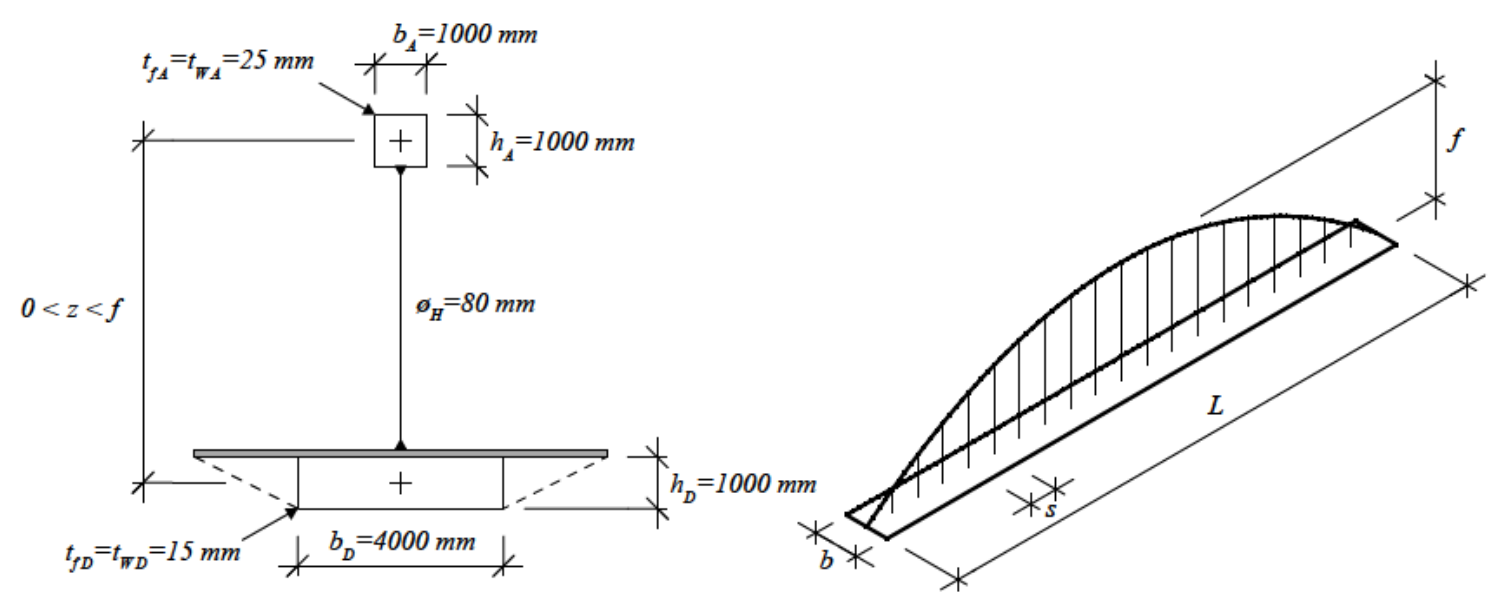

Figura 5.2: Definición geométrica del puente arco de referencia usado en este capítulo.

El modelo de estudio tiene una luz $L=100 \mathrm{~m}$, y una flecha del arco $f=20 \mathrm{~m}$. La distancia entre péndolas medida sobre el tablero es $s=5 \mathrm{~m}$. El ancho cargado del tablero se ha modificado con respecto al modelo de referencia mostrado en el capítulo 3 con el fin de amplificar el efecto a estudiar, teniendo ahora un valor $b=8 \mathrm{~m}$ (véase la figura 5.2). Estas dimensiones están inspiradas por puentes arco reales, y relativamente comunes (véase por ejemplo Leonhardt [56], o Lebet y Hirt [55]). Todos los puentes estudiados han sido diseñados de acuerdo al Eurocódigo 3 [12].

Un resumen de las dimensiones de las secciones del puente, las cuales son también usuales en puentes de este tipo, se puede observar en la tabla 5.1.

Solo han sido consideradas cargas estáticas. Para cargas dinámicas, unas referencias a tener en cuenta son Jong-Dar [44] y Roeder et al. [90]. Los casos de carga considerados en este estudio son:

- El peso propio (PP), evaluado para un peso específico de $78.5 \mathrm{kN} / \mathrm{m}^{3}$, y la carga muerta $(\mathrm{CM})$, con un valor de $\left(3.75 \mathrm{kN} / \mathrm{m}^{2}\right)$. Ambas cargas están definidas en el capítulo 3 .

- Para este estudio, no es necesario considerar todos los posibles casos de carga que pueden aparecer en el diseño de un puente. Por lo tanto, solo se van a considerar cargas peatonales, ya que ilustran con la suficiente precisión, el efecto en el comportamiento longitudinal que tienen las péndolas cuando son rigidizadas. Estas sobrecargas de uso son $q_{3}, q_{4}$ y $q_{5}$, las cuales también están definidas en el capítulo 3. Las sobrecargas (véanse las zonas de carga en la figura 3.4), son de tipo peatonal, y se corresponden con una carga distribuida de $5 \mathrm{kN} / \mathrm{m}^{2}$ (véase la IAP [27] o el Eurocódigo $1[10]$ ), para el ancho de tablero antes mencionado $b=8 \mathrm{~m}$. 


\begin{tabular}{|cccc|}
\hline Elemento & Sección transversal & Dimensiones & $\begin{array}{c}\text { Módulo de Young } \\
\mathbf{E}\left(\mathbf{N} / \mathbf{m m}^{2}\right)\end{array}$ \\
\hline Arco & Cuadrada hueca & $\begin{array}{c}1000 \times 1000 \mathrm{~mm}, \\
t_{f, A}=t_{w, A}=25 \mathrm{~mm} \\
\phi 80 \mathrm{~mm}\end{array}$ & $2.0 \times 10^{5}$ \\
Péndolas & Circular maciza & $\begin{array}{c}4000 \times 1000 \mathrm{~mm}, \\
t_{f, D}=t_{w, D}=15 \mathrm{~mm}\end{array}$ & $2.0 \times 10^{5}$ \\
Tablero & Rectangular hueca & 1.65 \\
\hline
\end{tabular}

Tabla 5.1: Materiales y dimensiones de las secciones del puente usado en el estudio de este capítulo.

\subsection{Péndolas rígidas longitudinalmente}

En algunos casos, principalmente por razones estructurales, las péndolas están rigidizadas. En estos casos, los cables se sustituyen por secciones doble T o secciones cajón huecas. En las secciones doble $\mathrm{T}$, la orientación de la péndola determina la dirección de flexión donde el efecto de la péndola es más relevante. Dos ejemplos de Santiago Calatrava ilustran este hecho. En el primer ejemplo, el puente de La Devesa (véase la figura 5.3) construido en Ripoll, en el norte de España, la orientación de sus péndolas doble T está definida para disponer de rigidez con la que soportar la flexión fuera del plano. En el puente de la Alameda de Valencia, las péndolas están completamente empotradas al arco (véase la figura 5.4), lo que permite proporcionar rigidez longitudinal al puente.

Cuando las péndolas están rigidizadas, se modifica el comportamiento estructural del arco y del tablero, ya que las péndolas rígidas introducen momentos flectores concentrados en sus extremos. Estos contrarrestan parcialmente los momentos flectores que aparecen en el arco y el tablero de un puente con péndolas articuladas o cables.

Como los momentos flectores se reducen, las flechas del arco se reducen en consecuencia.

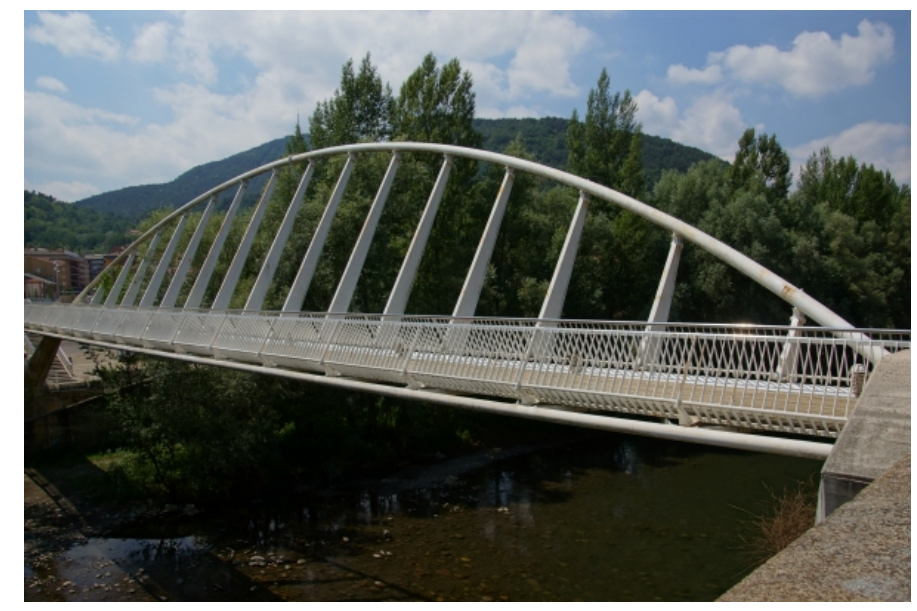

Figura 5.3: Puente de La Devesa (véanse Tzonis [118] y Jorquera Lucerga [47]). Fotografía: Nicolas Janberg (structurae.net), 2011. 
El comportamiento estructural sería similar al de una celosía tipo Vierendeel, es decir, una celosía sin elementos diagonales, con huecos rectangulares. A diferencia de las celosías tradicionales, esta celosía tiene que resistir momentos flectores importantes.

En la figura 5.5, se muestra el Town Centre Link Bridge, en Stratford, cerca de Londres (Reino Unido), el cual es un ejemplo de un puente donde una celosía tipo Vierendeel constituye el elemento estructural principal. En este puente, el cordón superior es recto, como suele ocurrir en las celosías tipo Vierendeel, mientras que en un puente arco el cordón superior es curvo, como se muestra en las figuras 5.3 y 5.4.

Por lo tanto, ya que las péndolas rígidas son una manera eficiente de reducir los esfuerzos internos y las flechas en el arco y el tablero, estas pueden ser consideradas como una herramienta para el proyectista, quien puede decidir usarlas dentro de un proceso de diseño más general.

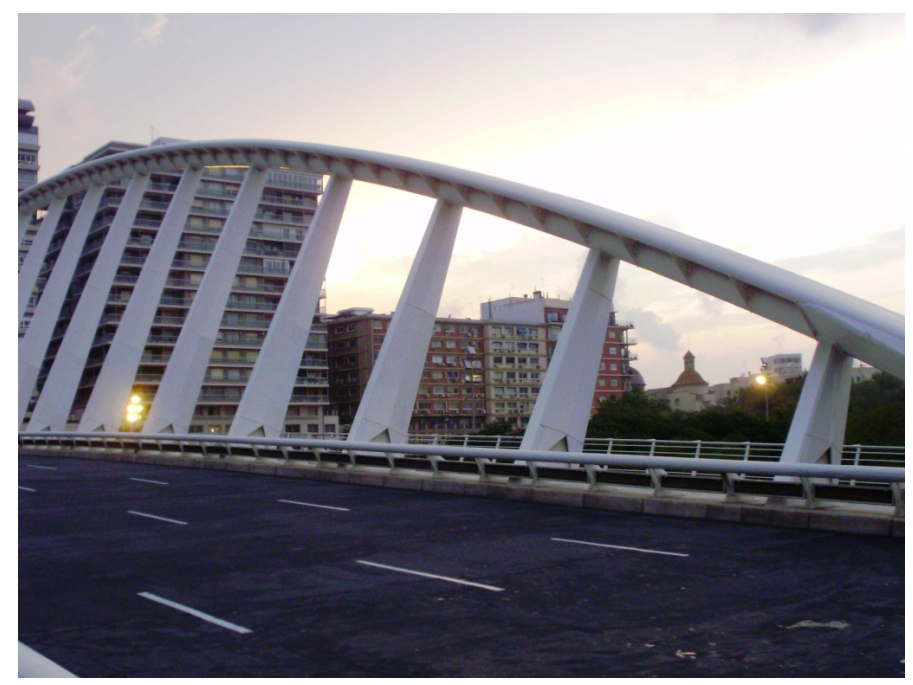

Figura 5.4: Puente de La Alameda (véanse Tzonis [118], Jorquera Lucerga [47] y Jodidio [42]). Fotografía: Juan José Jorquera Lucerga.

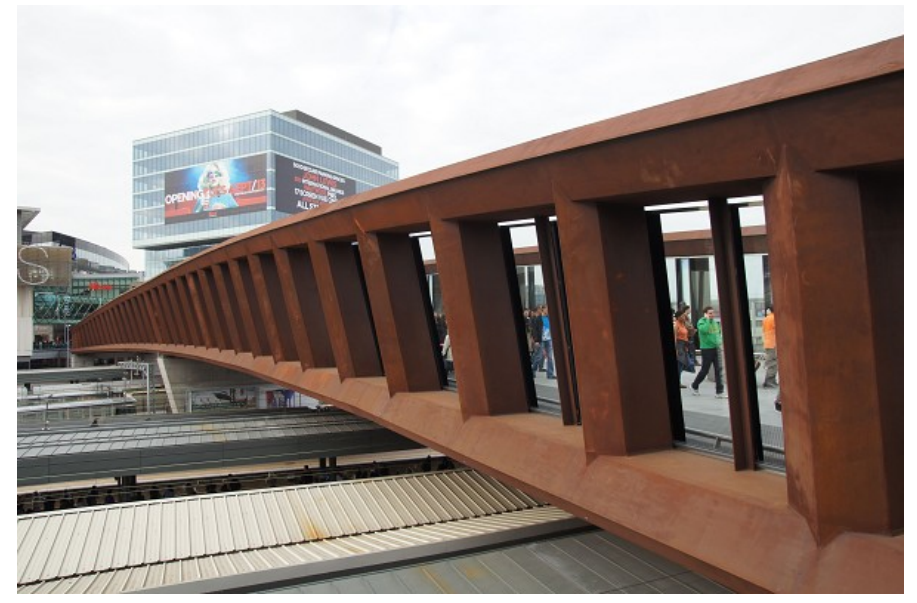

Figura 5.5: Town Centre Link Bridge en Stratford (Reino Unido). Fotografía: Nicolas Janberg (structurae.net), 2011. 
En la figura 5.6 se muestra el efecto de rigidizar las péndolas en el puente de referencia descrito para este capítulo, para la sobrecarga de uso en medio tablero $\left(q_{3}\right)$ y en el tablero completo $\left(q_{5}\right)$. Con independencia del caso de carga, se puede ver como los momentos flectores son siempre más pequeños para el puente con péndolas rígidas. Todos los diagramas de esfuerzos y flechas mostrados en este capítulo han sido obtenidos con el programa de elementos finitos SAP2000 (véase Computers and Structures, Inc. [24]).

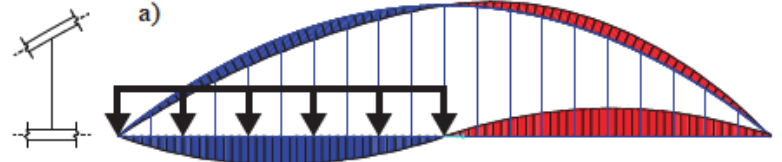

Pinned
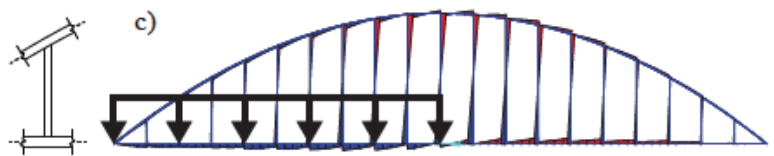

SHB $800 \times 800 \times 20$ $\mathrm{x} 1$

$\mathrm{x} 1$

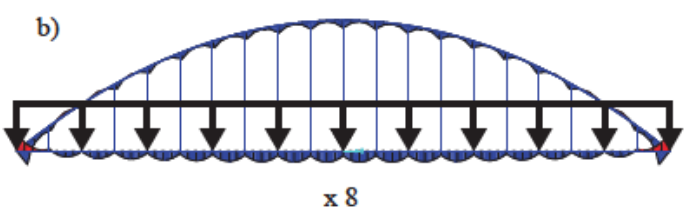

d)

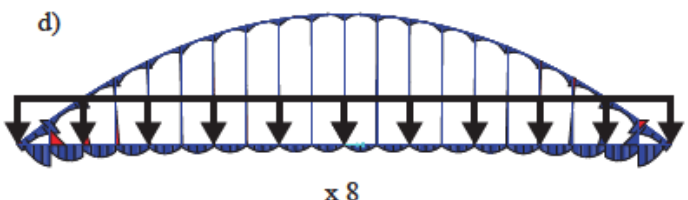

Figura 5.6: Diagramas de momentos flectores para péndolas rígidas $(800 \times 800 \times 20 \mathrm{~mm})$ y articuladas. Sobrecarga de uso en medio tablero, $q_{3}$ (a y c), y en el tablero completo, $q_{5}$ (c y d), para cables (a y b) y péndolas rígidas (c y d).

\subsubsection{Comparación de péndolas articuladas y rígidas}

En algunos casos, no es estrictamente necesario que las péndolas rígidas estén completamente fijas en ambos extremos. La rotación en el extremo superior o en el inferior puede ser liberada, una decisión tomada por el proyectista como una fase del proceso de diseño.

La figura 5.7 compara 4 configuraciones distintas de péndolas: péndolas rígidas empotradas en ambos extremos, péndolas rígidas articuladas en el extremo superior, en el extremo inferior, o en ambos extremos (compuestas por cables). La sección transversal considerada para las péndolas rígidas es una sección de acero rectangular hueca, con unas dimensiones de $800 \times 800 \times 20 \mathrm{~mm}$. 

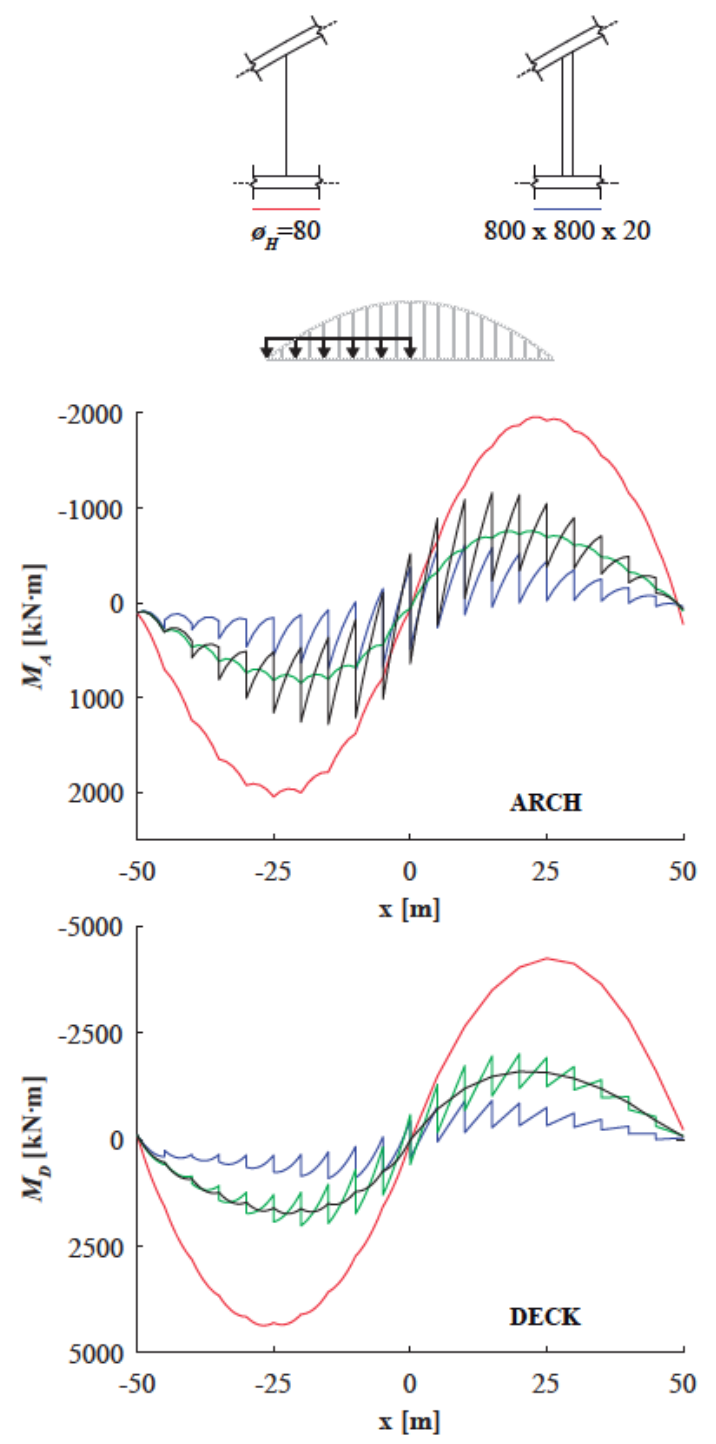
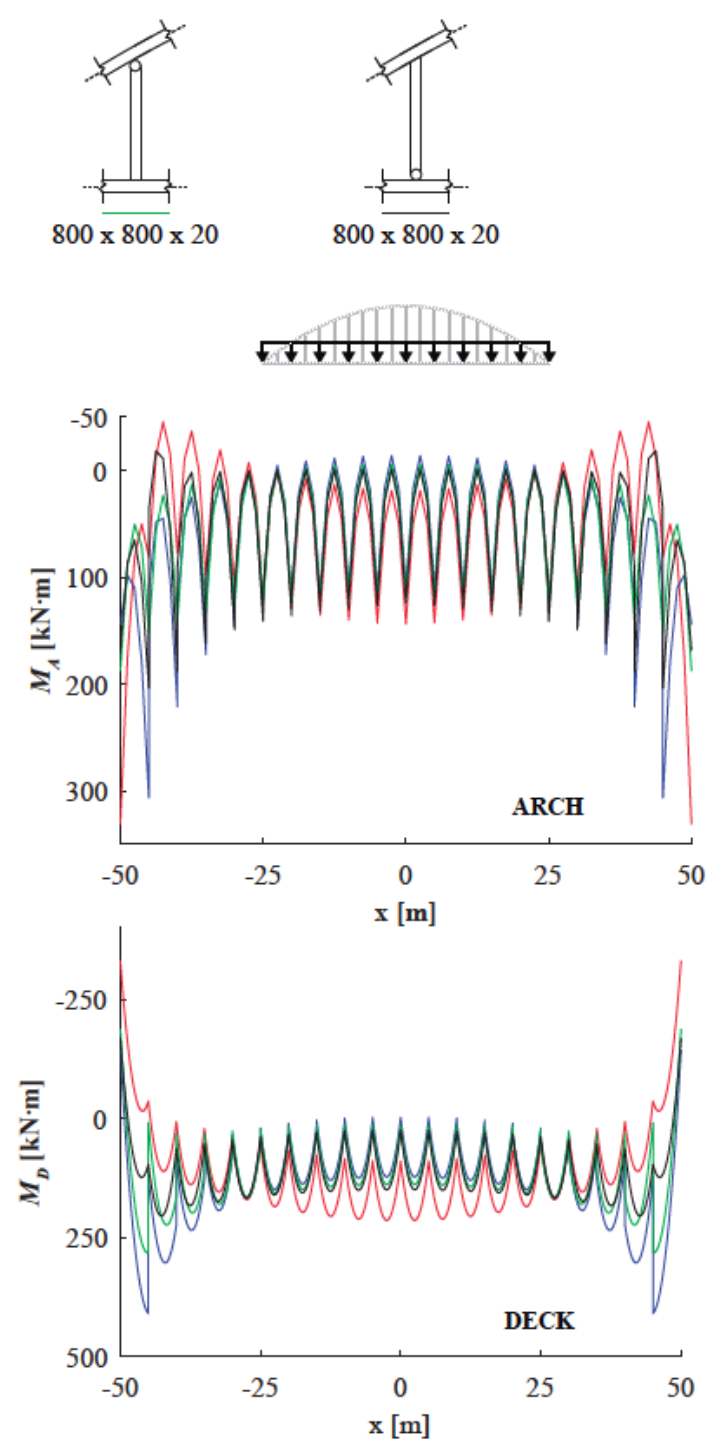

Figura 5.7: Comparación de péndolas rígidas y articuladas: momentos flectores en el arco y el tablero.

Para la combinación de carga más desfavorable $\left(q_{3}\right)$, se puede observar fácilmente que cuando las mitad del tablero es cargado, los momentos flectores en el arco y en el tablero pueden ser reducidos rigidizando las péndolas. De hecho, los mínimos momentos flectores se logran siempre para péndolas rígidas con ambos extremos fijos. Las péndolas con un solo extremo articulado no son tan eficientes como las péndolas rígidas sin articulaciones. Por ejemplo, cuando las péndolas se articulan en el extremo unido al arco, se puede ver como el diagrama de momentos flectores es más suave para el arco, mientras que el diagrama de flectores del tablero tiene forma de dientes de sierra, y viceversa. Esto se debe a la introducción de momentos flectores concentrados en el extremo fijo (el que está en la parte inferior) de las péndolas.

Sin embargo, para la sobrecarga $q_{5}$, que actúa sobre el tablero completo, los momentos positivos cerca de los arranques son mayores para las péndolas rígidas sin ninguna articulación. Este efecto se explica debido al comportamiento estructural de las celosías tipo 
Vierendeel. Este hecho es un posible inconveniente de las péndolas rígidas, el cual debe tenerse en cuenta durante el proceso de diseño de la estructura.

Las péndolas rígidas son también una manera muy eficiente de reducir las flechas del tablero. La figura 5.8 muestra el efecto de las péndolas rígidas en las flechas del tablero para las cargas $q_{3}$ y $q_{5}$. La máxima reducción se alcanza siempre para péndolas rígidas fijas en ambos extremos. Además, para la misma configuración de péndola (es decir, para articulaciones localizadas en la parte superior o inferior), una péndola de $800 \mathrm{x} 800 \mathrm{x} 20$, con una rigidez a flexión mayor, es más eficiente para reducir flexiones que una péndola de 400 x 400 x 20, con menor rigidez a flexión.
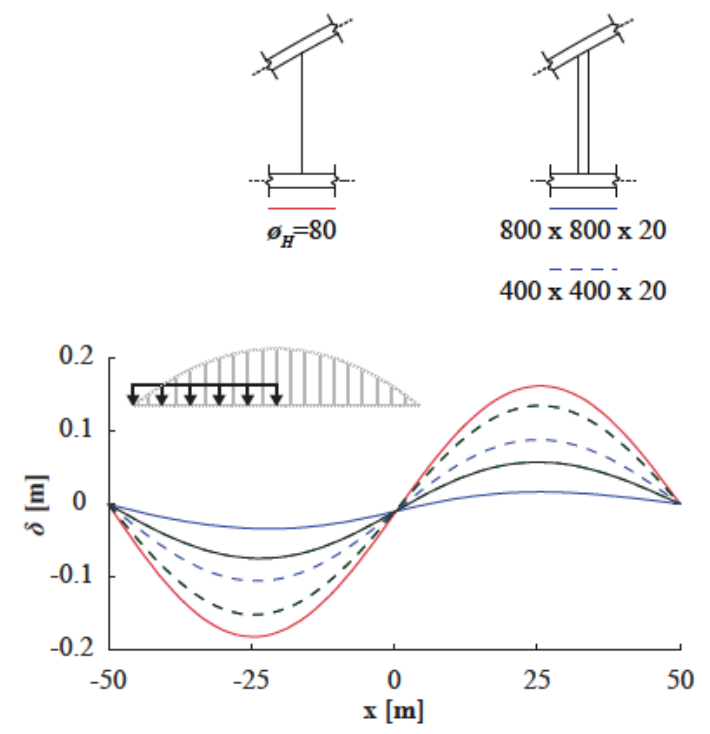
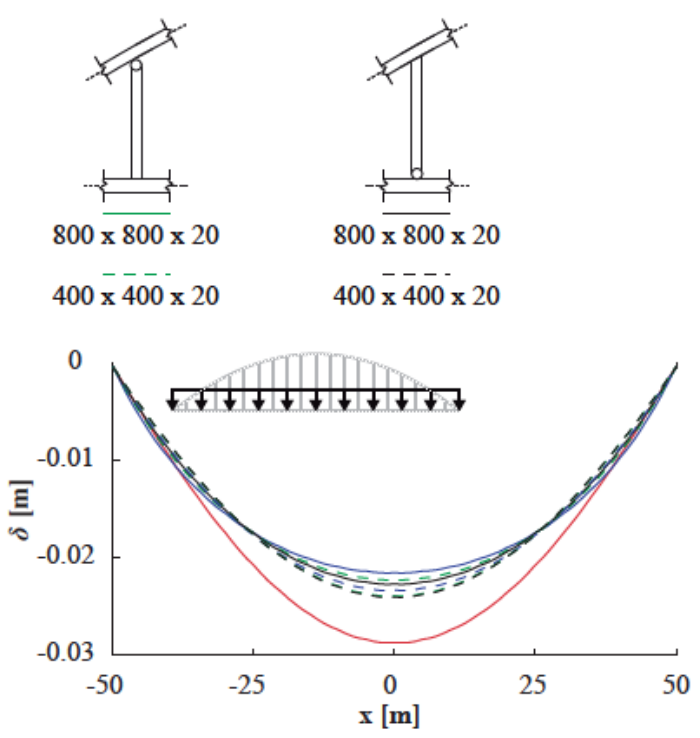

Figura 5.8: Flechas para péndolas rígidas.

\subsubsection{Efecto de la rigidez de las péndolas}

La rigidez de las péndolas es el factor más importante que gobierna su efectividad, en términos de reducción de esfuerzos y flechas. En la figura 5.9, se han dibujado los momentos flectores del arco y del tablero para dos secciones transversales de las péndolas: la primera sección es un perfil rectangular hueco de 800 x 800 x 20, y la segunda es también un perfil rectangular hueco pero con unas dimensiones de 400 x 400 x $20 \mathrm{~mm}$.

Se puede observar como la sección transversal más rígida es siempre más eficiente. En el caso mostrado en este ejemplo, la sección de 400 x 400 es menos eficiente que la de 800 x 800, incluso cuando la péndola está completamente fija en ambos extremos y tiene solo una articulación.

Sin embargo, los esfuerzos internos en las péndolas aumentan conforme se vuelven más efectivas. La figura 5.10 muestra los esfuerzos para las dos secciones transversales de las péndolas y para las dos cargas consideradas. Se puede ver como la de 800 x 800 es la sección más efectiva, aun a expensas de soportar momentos flectores más altos para cada caso de carga. 

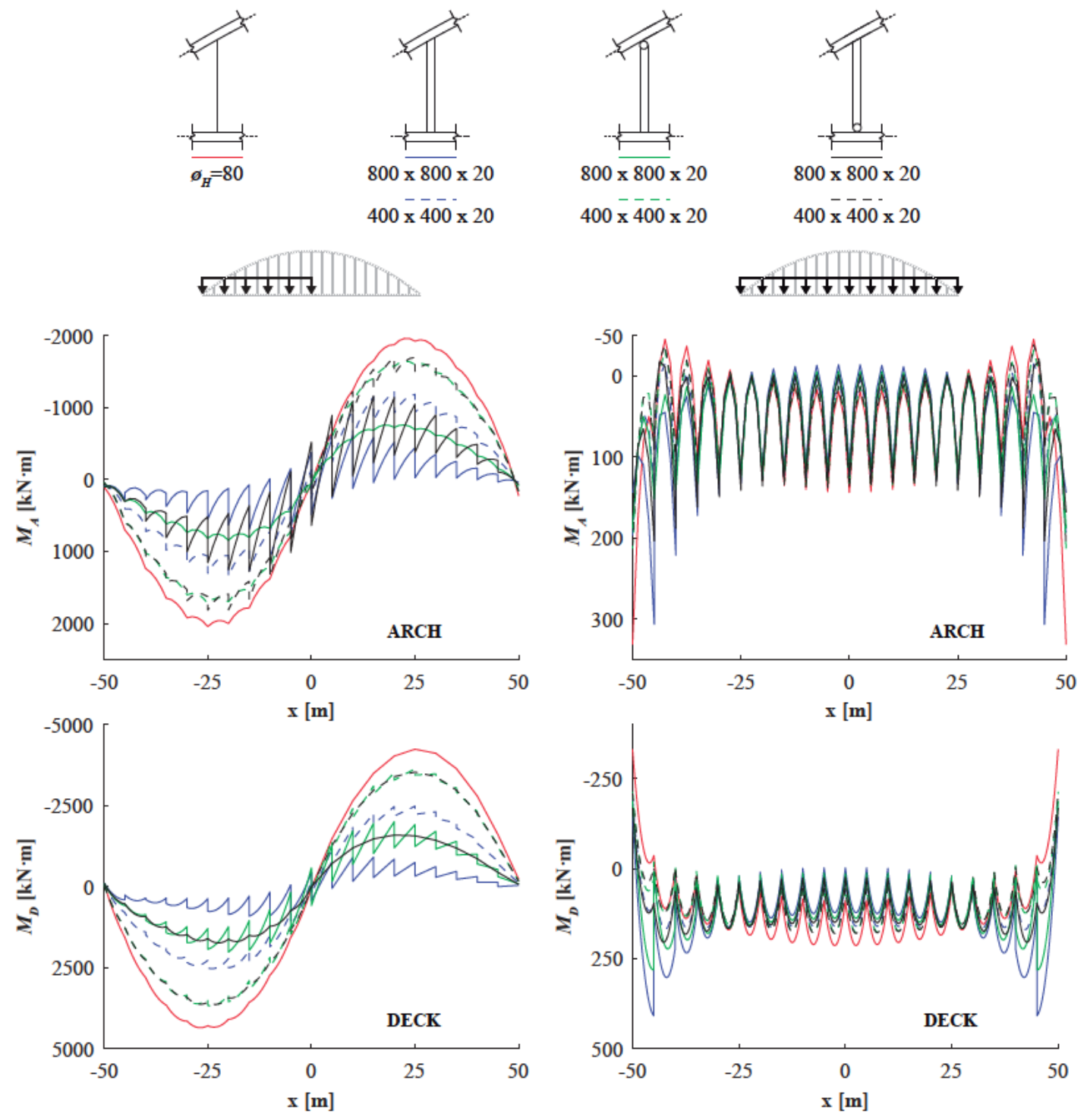

Figura 5.9: Efecto de la rigidez de la péndola en la distribución del momento flector del arco y del tablero.

\subsubsection{Efecto de la rigidez de las péndolas y del tablero}

En un puente arco, la rigidez relativa entre el arco y el tablero, (es decir, la contribución del arco o del tablero a la rigidez global a flexión) es un factor de gran importancia cuando se determina la respuesta estructural. En el diseño conceptual de puentes arco, las ecuaciones 4.1, 5.1 y 5.2 (que pueden encontrarse, por ejemplo en Menn [65] y Manterola [60]) se consideran lo suficientemente precisas para estimar los momentos flectores en el arco y en el tablero, $M_{A}$ y $M_{D}$ respectivamente, en un puente similar al puente de referencia usado en este capítulo:

$$
M_{A}=M \cdot C_{A}
$$




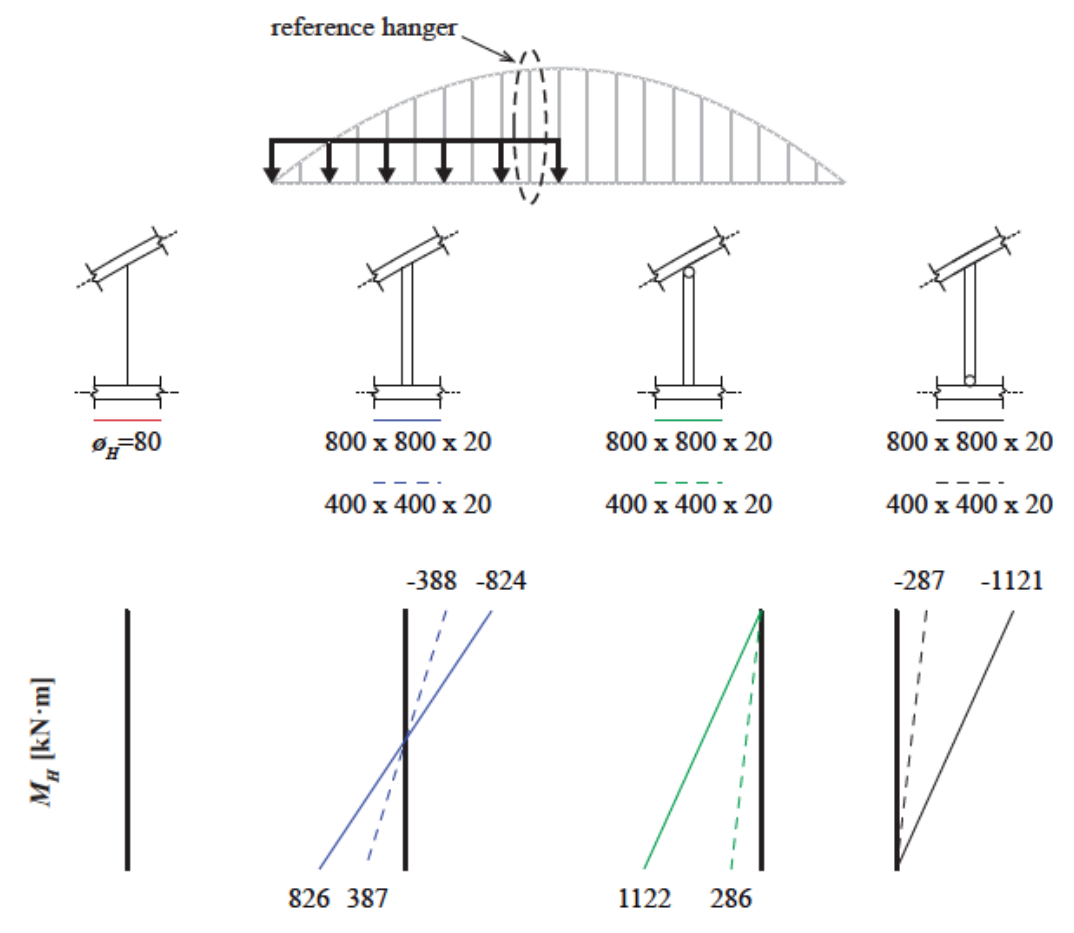

Figura 5.10: Comparación de péndolas rígidas y articuladas: distribución de momento flector en una péndola.

$$
M_{D}=M \cdot\left(1-C_{A}\right)
$$

donde $M$ representa el momento flector global, y $C_{A}$ representa la contribución del arco a la rigidez a flexión global del sistema estructural arco-tablero, definida en la ecuación 4.1 .

Por lo tanto, la rigidez a flexión de las péndolas debe ser estudiada detalladamente, de acuerdo a la rigidez global del sistema estructural arco-tablero y a su rigidez relativa, con el fin de maximizar su eficiencia. La figura 5.11 muestra como la distribución de momentos flectores se modifica por el efecto de las péndolas rígidas, para diferentes valores de $C_{A}=0.20,0.33$ (puente de referencia) y 0.50 .

\subsection{Combinación de péndolas rígidas y articuladas}

En el punto 5.3.1 se mostró que para la sobrecarga de uso actuando sobre el tablero completo, es decir, para cargas simétricas, los máximos momentos flectores positivos aparecen al lado de los arranques del arco para péndolas rígidas empotradas en ambos extremos. En ciertos casos, estos momentos flectores pueden llegar a convertirse en la combinación de cargas más adversa y, en consecuencia, determinar las dimensiones de la sección transversal situada cerca de los arranques. Para hacer frente a este inconveniente de las péndolas rígidas, la distribución de momentos flectores puede ser optimizada en estas zonas, rigidizando solo las péndolas situadas en el centro del puente. Obviamente, el número exacto de 

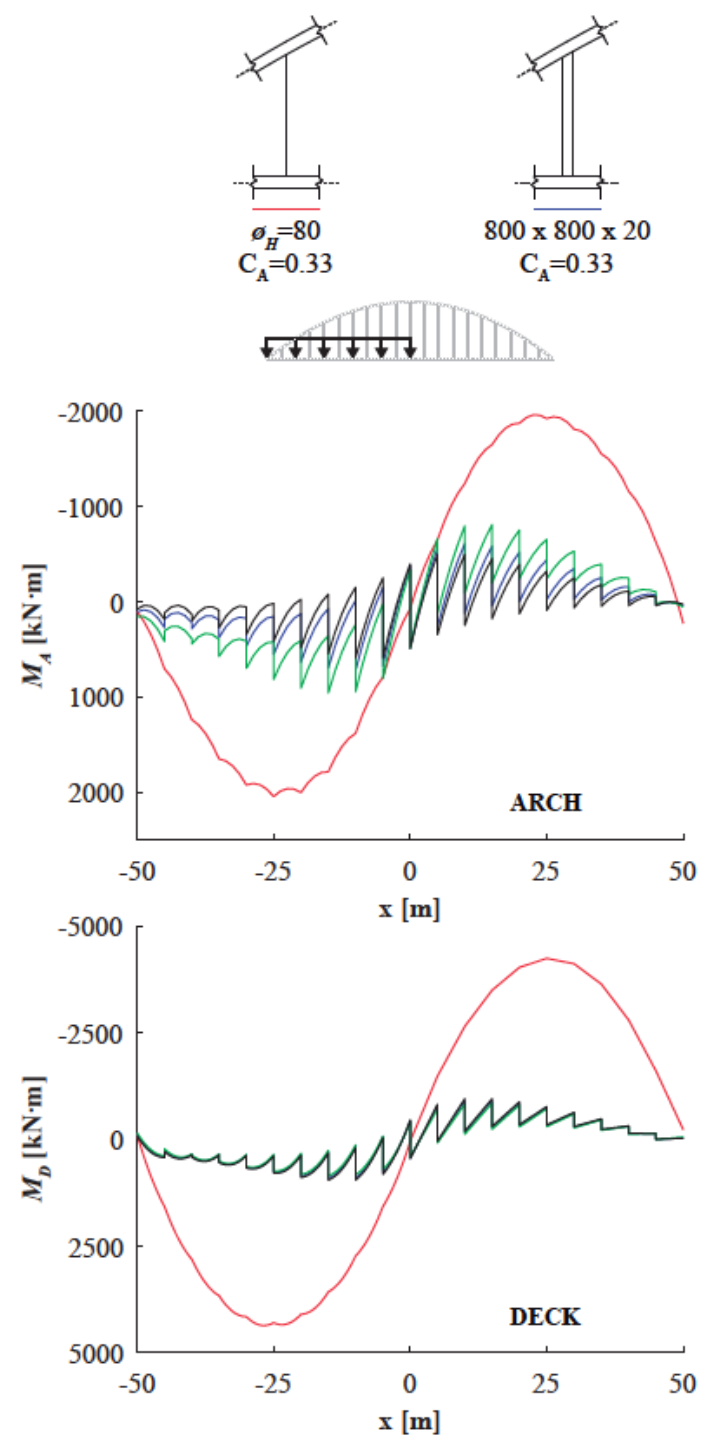
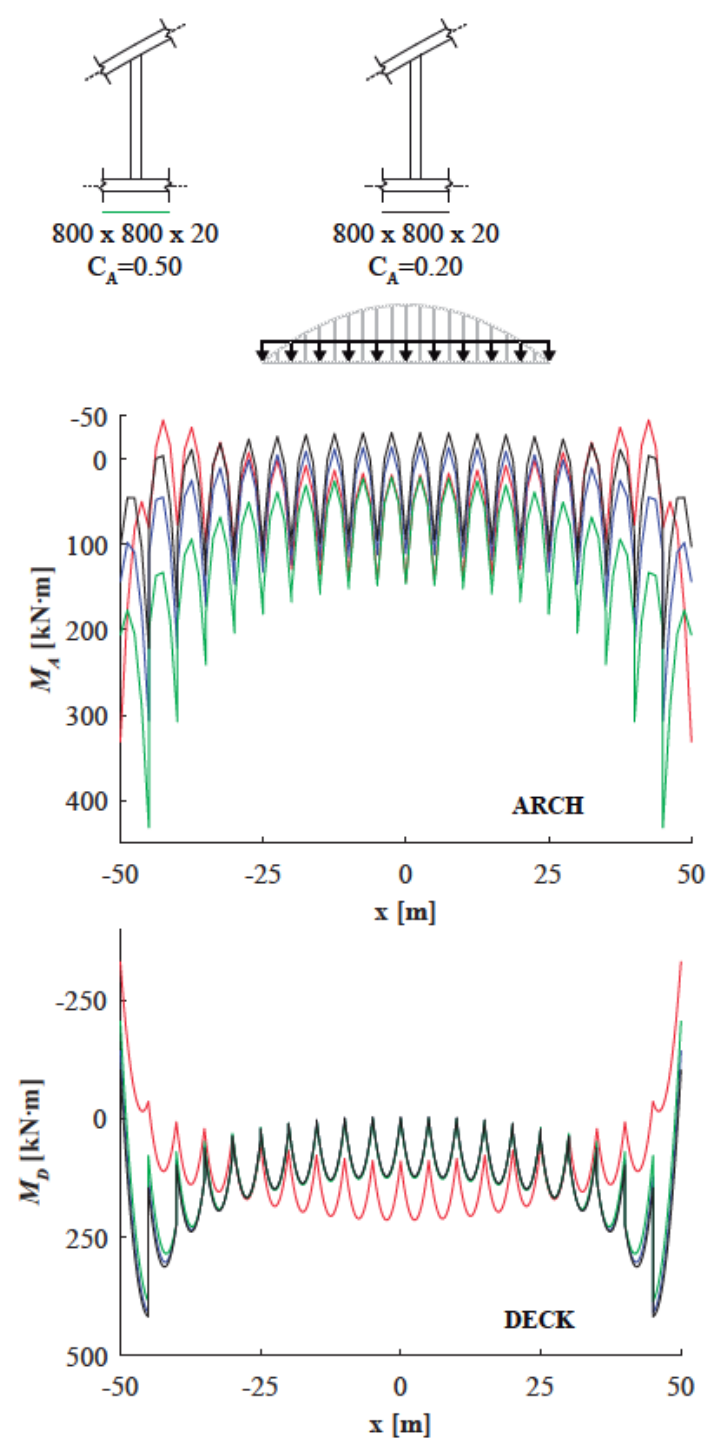

Figura 5.11: Efecto de una péndola rígida con una sección rectangular hueca de 800 x 800 x $20 \mathrm{~mm}$, para un $C_{A}=0.20,0.33$ (puente de referencia) y 0.50 .

péndolas donde las rotaciones son liberadas y la localización de las articulaciones, deben ser estudiadas meticulosamente para cada caso particular de puente. Con esta solución tipológica, el momento flector para $q_{5}$ puede ser reducido en los extremos del tablero (véase la figura 5.12).

En la figura 5.12, se puede observar como la configuración propuesta, donde las péndolas rígidas y articuladas se combinan en el mismo puente, es casi tan eficiente como la configuración donde todas las péndolas están fijas en ambos extremos. Los momentos flectores son muy parecidos. Además, los momentos flectores se reducen en las zonas próximas a los extremos del tablero para cargas simétricas, que es lo que se persigue. Además, se muestra el efecto de liberar la rotación de las péndolas en el extremo superior y en el inferior.

La figura 5.13 muestra como para el puente de referencia, los momentos flectores cercanos a los extremos del tablero (rodeados por un línea roja discontinua) son más pequeños para 
una carga $q_{5}$ que para una carga $q_{3}$ cuando todas las péndolas están fijas. Este hecho no cambia cuando las tres últimas péndolas de los extremos del tablero están articuladas, y $q_{3}$ continua siendo la carga más adversa, como es normal en el diseño de puentes arco. Por el contrario, cuando se considera una sección transversal alternativa de 1000 x 1000 x 20 para las péndolas usadas, $q_{5}$ se convierte en la combinación de cargas más adversa para esta zona. En este caso, una combinación de péndolas rígidas fijas y articuladas se puede considerar para corregir este hecho.
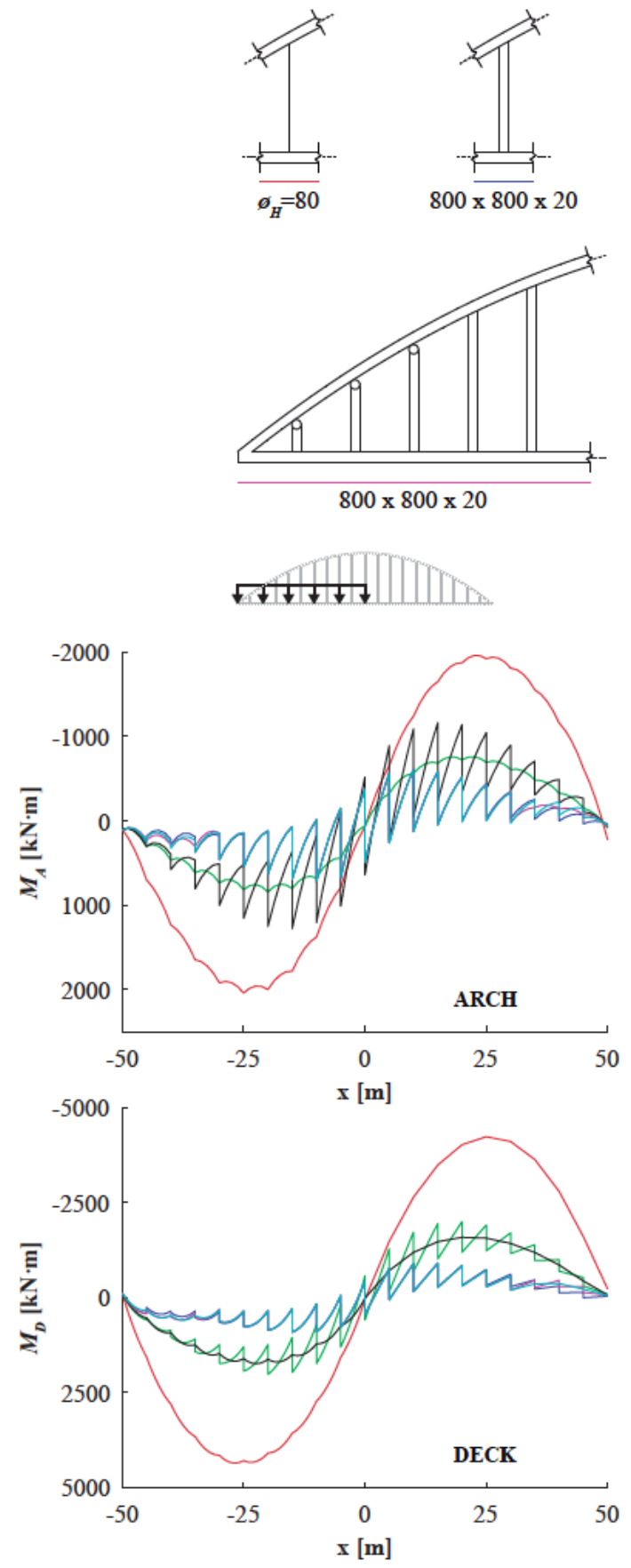
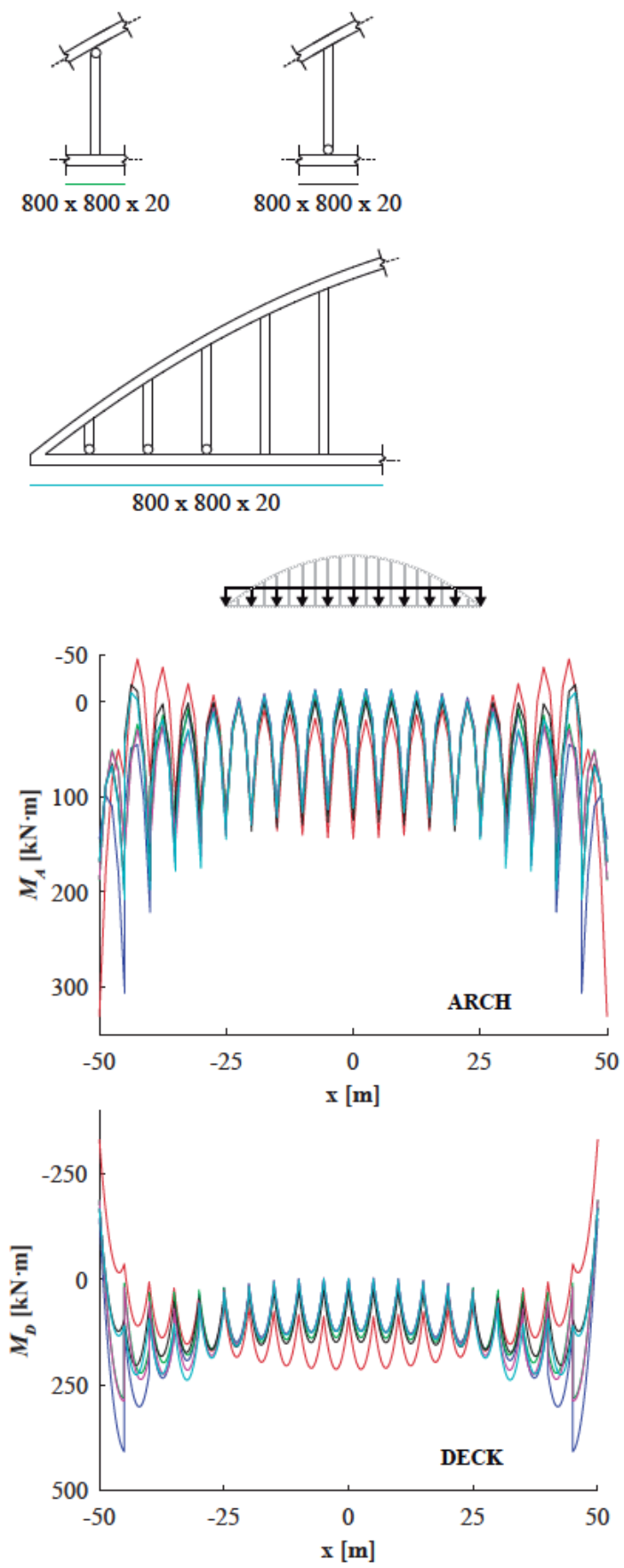

Figura 5.12: Momentos flectores para una distribución de péndolas rígidas y articuladas. 


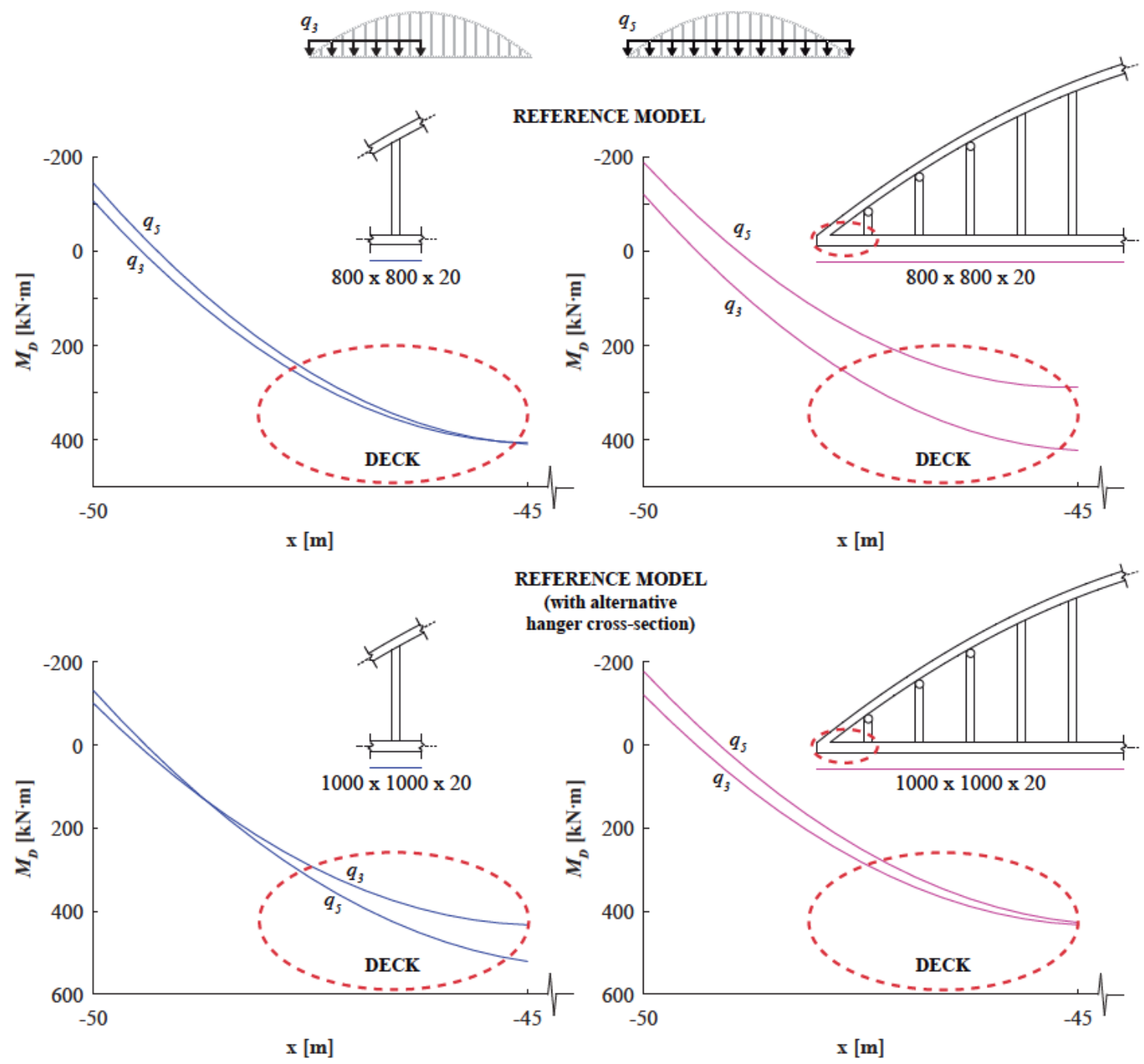

Figura 5.13: Efecto de la configuración mixta de péndolas rígidas y articuladas en la reducción de los momentos flectores para una carga $q_{5}$.

\subsection{Consideraciones generales sobre las péndolas rígi- das y articuladas longitudinalmente}

En este capítulo de la tesis se ha estudiado el efecto de rigidizar las péndolas en el comportamiento longitudinal (en el plano). También se ha mostrado el efecto de la rigidez de las péndolas, la relevancia de la rigidez del arco y del tablero, y las consecuencias de colocar articulaciones en el extremo superior e inferior de las péndolas.

De manera general, las péndolas rígidas son una forma eficiente de reducir los momentos flectores en el arco y el tablero, y de reducir las flechas para las sobrecargas. La rigidez de la péndolas es el factor más relevante que gobierna su eficiencia.

Las péndolas articuladas en uno de sus extremos ofrecen una eficiencia intermedia, si se comparan con las péndolas fijas en ambos extremos. En algunos casos, estas péndolas pueden ser una alternativa ventajosa, ya que la conexión arco-péndola o tablero-péndola 
puede ser más simple cuando no hay que transmitir ningún momento flector.

Con el fin de maximizar su eficiencia, la rigidez de las péndolas debe ser estudiada cuidadosamente de acuerdo a la rigidez relativa del arco y del tablero, y de acuerdo a la rigidez a flexión global del puente.

La combinación de carga más desfavorable tiene lugar normalmente en puentes arco, cuando se carga la mitad del tablero. Sin embargo, cuando las péndolas están fijas, y para cargas simétricas, los valores de los momentos flectores cerca de los extremos del tablero pueden ser más grandes que para distribuciones de cargas asimétricas. Para resolver este problema, en este capítulo se ha propuesto una combinación de péndolas rígidas y articuladas, detalladamente estudiada para un puente dado, combinación que puede ser casi tan eficiente como una configuración donde todas las péndolas están fijas y no tienen ninguna articulación. 



\section{Capítulo 6}

\section{Pandeo en el plano}

\subsection{Introducción}

Un arco es principalmente una estructura sometida a compresión, con lo que en consecuencia es una estructura susceptible de sufrir pandeo. Este pandeo puede producirse dentro del plano que contiene el arco, o fuera de él.

El pandeo en el plano del arco es un efecto de segundo orden muy presente en arcos actuales, dada la esbeltez de muchas de estas estructuras.

Determinar la carga crítica de pandeo es complicado, sobre todo a la hora de determinar la longitud de pandeo. La cantidad de factores que intervienen, hace que las formulaciones desarrolladas por diversos autores para calcular el axil crítico de pandeo $\left(N_{c r}\right)$ sean del tipo:

$$
N_{c r}=C_{1} \cdot \frac{E \cdot I_{A}}{L^{2}}
$$

Donde $E$ es el módulo de Young del material, $I_{A}$ es la inercia longitudinal de la sección del arco, $L$ es la luz del arco, y $C_{1}$ es un coeficiente que depende de numerosos factores, como los apoyos del arco, la variación de la sección, la relación flecha/luz, etc.

Valores para $C_{1}$ pueden encontrarse, por ejemplo, en el Manual of Bridge Engineering del ICE (véanse [75] y O'Connor [71]) para arcos parabólicos con péndolas bajo una carga uniformemente distribuida y diferentes condiciones de contorno.

\subsection{Pandeo en el plano de arcos vinculados al tablero con péndolas}

En un puente arco tipo bow-string, la longitud de pandeo tiene que ser asimilada mediante una viga curva sometida a compresión y flexión, la cual se encuentra atada al tablero mediante péndolas. La estabilidad del arco al completo tiene que ser comprobada para el pandeo dentro y fuera de su plano, así como para los segmentos de arco entre péndolas. 


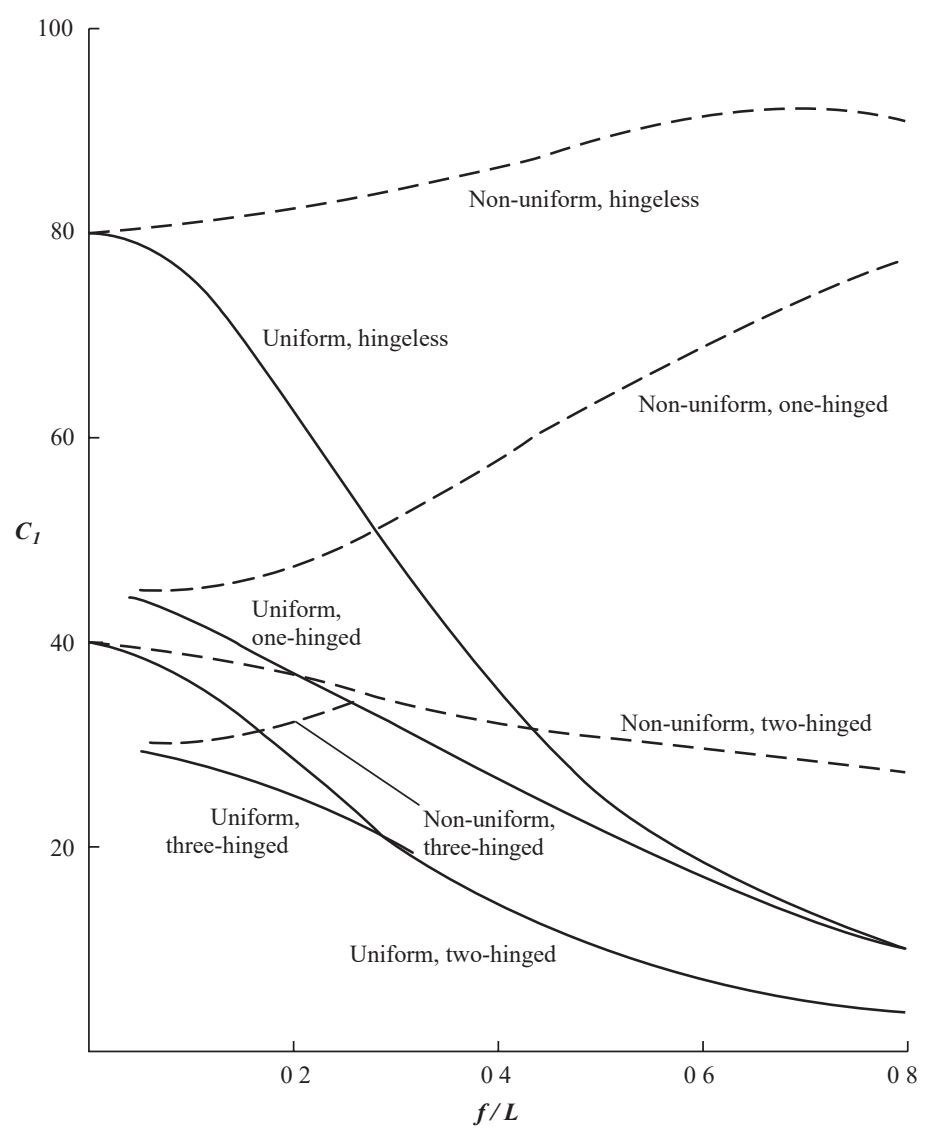

Figura 6.1: Coeficientes de pandeo en el plano para arcos parabólicos exentos. Figura extraída de [75] con notación adaptada a la de esta tesis.

Mientras que en un arco exento los parámetros que rigen la carga crítica de pandeo son entre otros la inercia de la sección y las condiciones de contorno del arco, en el caso de los arcos bow-string se suman además como elementos clave las péndolas y el tablero.

Así, diversos autores (véase por ejemplo Lebet y Hirt [55]) establecen que el pandeo dentro del plano depende entre otros factores de:

- Las condiciones de contorno de los apoyos. Como ocurre en una columna, un arco que está empotrado en ambos arranques tiene una longitud de pandeo más corta que un arco que está articulado en ambos extremos, es decir, si el arco está empotrado en apoyos el axil crítico de pandeo es mayor que cuando está articulado.

- La flecha del arco. Para una luz dada, el axil crítico de pandeo es mayor cuanto mayor es la flecha del arco, algo que es debido a que el axil en el arco para una carga dada se reduce cuando aumenta la flecha, $N=q \cdot L^{2} /(8 \cdot f)$.

- El momento de inercia longitudinal de la sección. Cuanto mayor es la inercia, mayor es la resistencia del arco al pandeo.

- La rigidez y el número de péndolas. Cuanto mayor es el número de péndolas y su diámetro, mayor es el axil crítico de pandeo. 
- La rigidez a flexión del tablero. Puesto que las péndolas se anclan al tablero, cuanto más rígido sea este, mayor será el axil crítico de pandeo.

No hay una formulación única para estimar el axil crítico de pandeo en arcos tipo bowstring, pues diversos autores han propuesto fórmulas y tablas para preveer el pandeo, siendo Kollár [51] una referencia bibliográfica que expone estos diferentes métodos y aproximaciones de la carga crítica de pandeo.

Una de estas aproximaciones para calcular el axil crítico de pandeo, y con la cual se obtienen unos valores bastante realistas, es la obtenida con los gráficos de la figura 6.2 (véanse Lebet y Hirt [55] y Petersen [76]).

\subsection{Estudio de pandeo en el plano con arcos de sección variable}

Para completar la información existente en diversas referencias acerca del pandeo dentro del plano del arco en puentes arco atirantados, en esta tesis se ha realizado un estudio sobre la variación del axil crítico de pandeo en secciones de arco variables.

Para estudiar la variación del axil crítico de pandeo en puentes arco, el modelo de referencia expuesto en el capítulo 3 ha sido modificado variando la sección del arco, así como el ancho cargado sobre el tablero, que pasar a ser $b=8 \mathrm{~m}$, con el fin de aumentar el efecto a estudiar.

Así, se ha aumentado el canto o el ancho de la sección de manera constante (Planta 0, figura 6.3), y se han hecho secciones variables con arranques más anchos que claves (Planta 1, figura 6.3) o con claves más anchas que arranques (Planta 2, figura 6.3). Por último también se ha estudiado el pandeo en arcos con arranques bifurcados (Planta 3, figura $6.3)$.

Para determinar el coeficiente de pandeo, en los modelos se ha considerado la imperfección geométrica correspondiente, considerándose para este estudio, los valores del punto 22.3.4.1. de la Instrucción de Acero Estructural (véase [23]).

Para estimar la carga crítica de pandeo se han analizado todos los modelos en SAP2000 bajo la combinación de cargas de la ecuación 6.2 :

$$
1,35 \cdot(P P+C M)+0,6 \cdot 1,5 \cdot V T O+\lambda_{u} \cdot q_{3}
$$

Donde $\lambda_{u}$ es el coeficiente de pandeo, expresado como el número de veces que hay que aumentar la sobrecarga de uso $^{1} q_{3}$ para que se produzca el pandeo (véase Manterola [60]).

Los resultados de todos los casos analizados se muestran en la figura 6.3, donde se puede ver la planta del arco, las secciones del mismo, y el valor $\lambda_{u}$ que multiplica a la sobrecarga de uso en el momento del pandeo.

\footnotetext{
${ }^{1}$ Se ha considerado la sobrecarga $q_{3}$, al ser la que produce una mayor deformada y la que se obtienen valores de pandeo más bajo, pues el resto de sobrecargas, si bien se han considerado, arrojan valores de pandeo más elevados.
} 


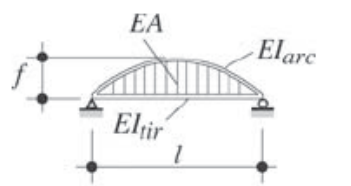

$m$ : number of hangers
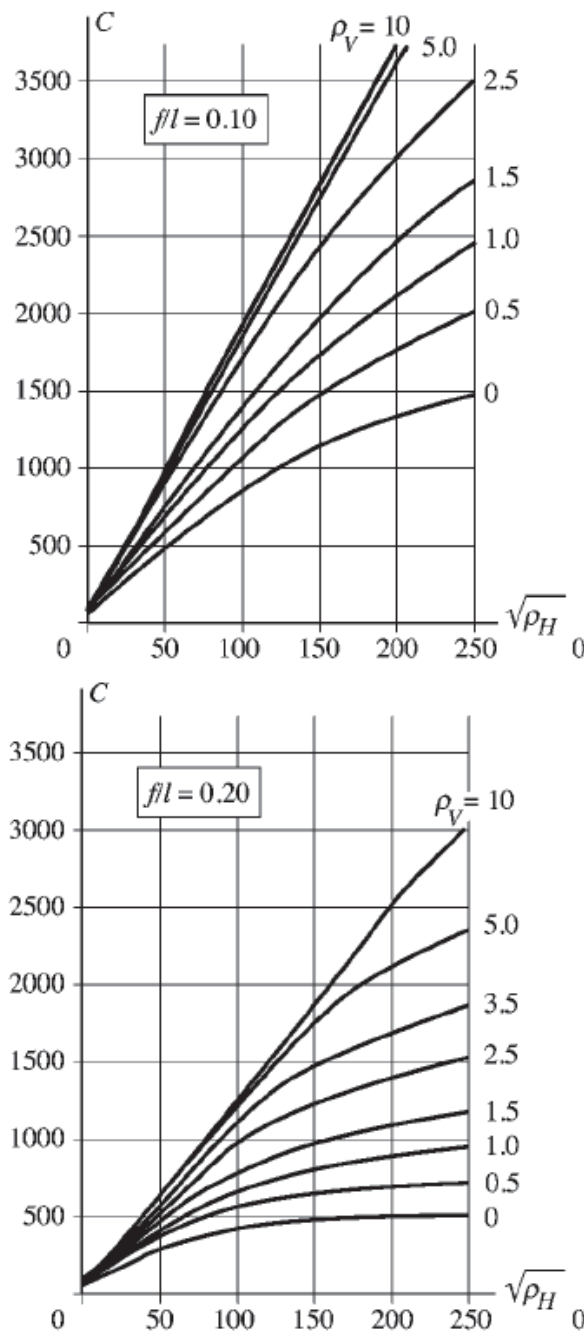

$$
\rho_{V}=\frac{E I_{\text {tir }}}{E I_{\text {arc }}}
$$$$
\rho_{H}=\frac{(m+1) l^{2}}{8} \cdot \frac{E A}{E I_{\text {arc }}}
$$$$
N_{c r}=C \cdot \frac{E I_{a r c}}{l^{2}}
$$
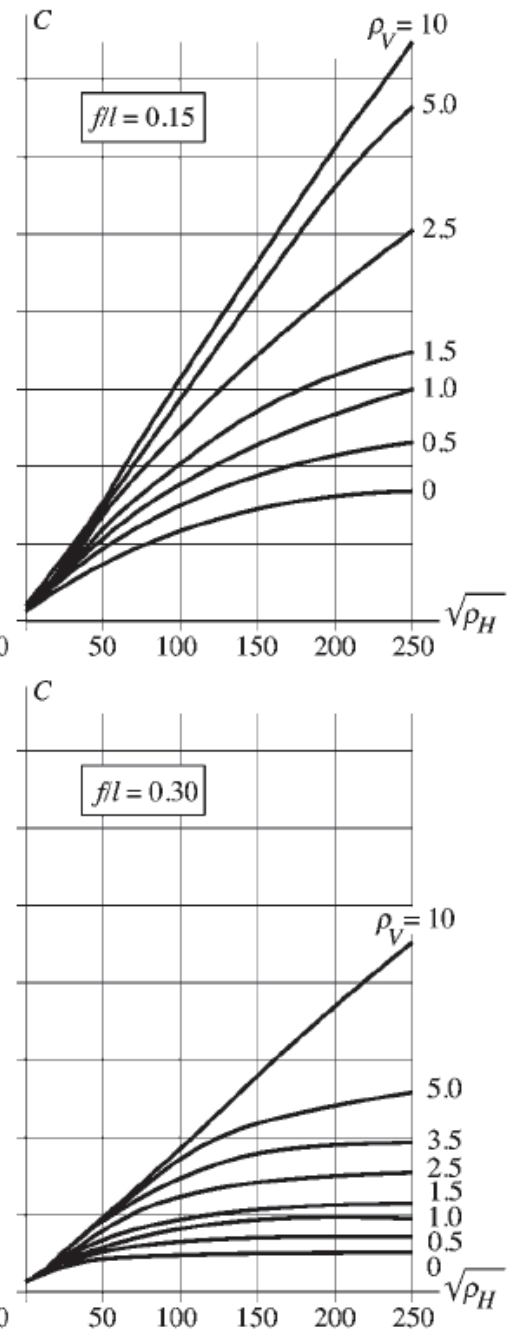

Figura 6.2: Coeficientes de pandeo en el plano para arco parabólico vinculado al tablero con péndolas. Figura extraída de Lebet y Hirt [55].

Como se puede ver en la figura 6.3, el pandeo dentro del plano del arco no es relevante en ninguno de los casos analizados, pues todos los modelos dan un coeficiente de pandeo superior como mínimo a 50 veces la sobrecarga de uso. Aun así, se puede ver como algunos de los modelos tienen un coeficiente de pandeo mayor o menor al obtenido con el modelo de referencia, que se fija en $\lambda_{u}=65$.

Estos valores elevados de pandeo dentro del plano se explican en gran medida por la ayuda de las péndolas, que arriostran el arco vinculándolo al tablero, evitando así que el arco pandee. 
En el caso de secciones constantes (Planta 0, según la figura 6.3), aumentar el canto, aun manteniendo el área del modelo inicial, hace que el coeficiente de pandeo dentro del plano aumente, lo que es debido a una mayor inercia longitudinal.

El área de material también podría mantenerse con una sección variable, apareciendo dos posibilidades. La primera es hacer una sección de arco con más ancho que canto en arranques y con más canto que ancho en la clave (Planta I, figura 6.3). La segunda posibilidad es hacer una sección de arco con más canto que ancho en arranques y con más ancho que canto en la clave (Planta II, figura 6.3). En estas secciones variables donde se mantiene el área de la sección del modelo de referencia, el coeficiente de pandeo se ve incrementado al colocar en los arranques secciones con más canto que ancho y en la clave secciones con más ancho que canto.

Como último caso analizado para modificar el coeficiente de pandeo, se ha considerado un arco bifurcado en arranques (Planta III, figura 6.3). Este modelo tiene unas secciones iguales al modelo de referencia, incluso en las bifurcaciones de los arranques. El hecho de considerar los arranques bifurcados disminuye, aunque no sensiblemente, el coeficiente de pandeo dentro del plano, algo que está relacionado con que el modelo de arranques bifurcados tiene un menor número de péndolas.

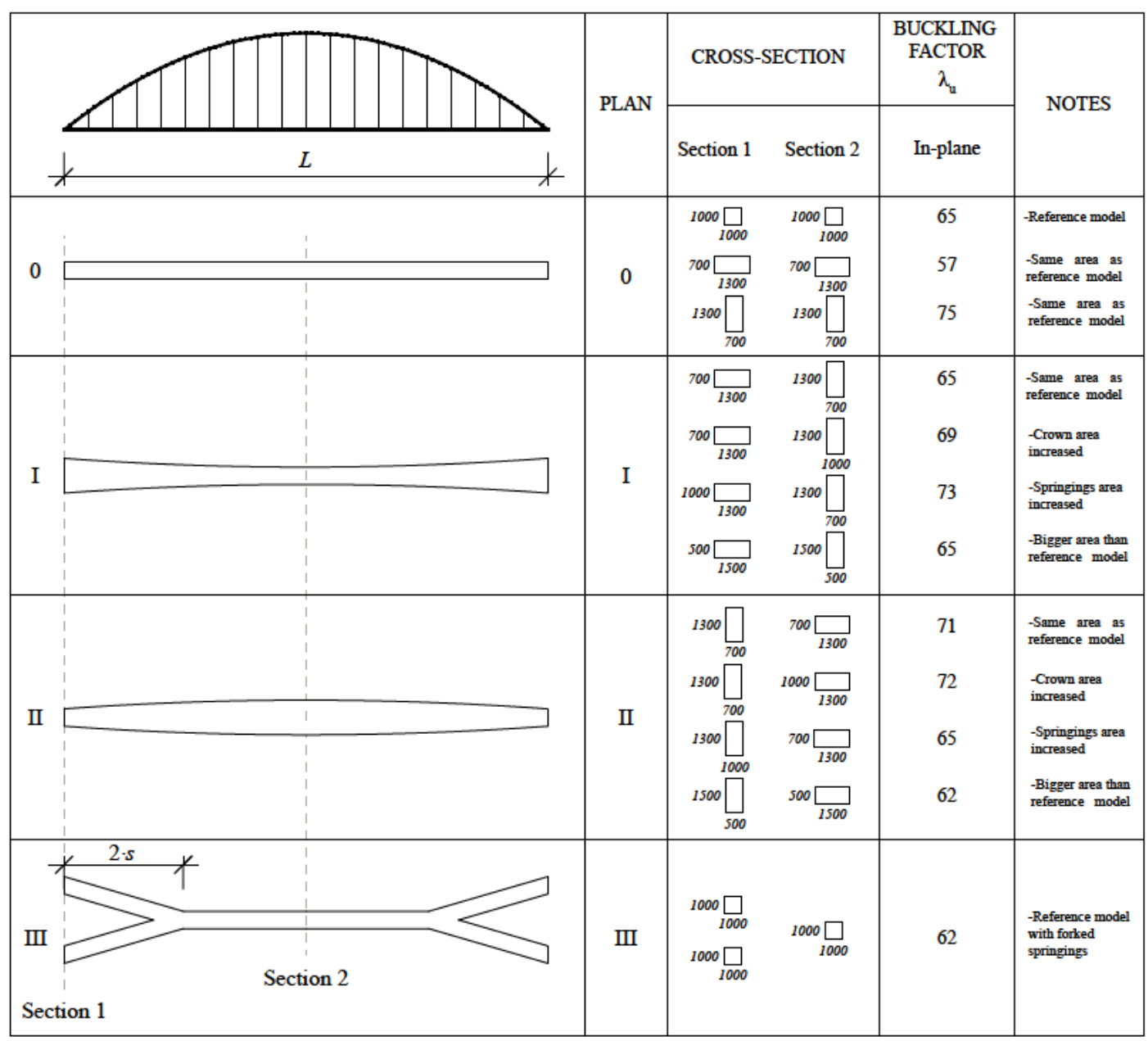

Figura 6.3: Coeficientes de pandeo dentro del plano del arco estimados para diferentes secciones. 



\section{Parte III}

\section{Diseño fuera del plano}





\section{Capítulo 7}

\section{Esfuerzos fuera del plano}

\subsection{Flexión transversal}

Cuando el tablero del modelo se somete a una carga transversal como el viento, su comportamiento se asemeja al de una viga biapoyada, sencilla de calcular. El caso del arco es más complejo, ya que su directriz es parabólica.

El arco, al estar sometido a cargas transversales como el viento, se comporta como una viga balcón, donde la flexión transversal y la torsión se encuentran acopladas (véase Manterola [60]).

Con el fin de obtener unos valores de los flectores transversales en el arco, que puedan ser usados para un predimensionamiento de la sección, se ha realizado un estudio para obtener una formulación aproximada.

Se ha usado el modelo de referencia descrito en el capítulo 3, modificándose la flecha del arco para obtener diferentes relaciones $f / L$, así como las secciones de arco con el fin de usar distintas relaciones $E I / G J$, donde $G=E /(2 \cdot(1+\nu))$. Para los estudios, se ha considerado siempre una carga transversal $q_{y}=10 \mathrm{kN} / \mathrm{m}$.

\subsubsection{Flexión negativa en los arranques del arco}

$\mathrm{Al}$ estar el arco empotrado en los arranques, para una carga transversal como la de viento, los mayores momentos se producen en la clave del arco $\left(M^{+}\right.$en la figura 7.1) y en los arranques $\left(M^{-}\right.$en la figura 7.1$)$.

Si se asimila el arco a una viga recta empotrada en ambos extremos, los momentos flectores transversales de los arranques se podrían calcular como:

$$
M^{-}=\frac{q_{y} \cdot L^{2}}{\xi}
$$

donde $\xi$ se corresponde con un coeficiente que tendría un valor de 12 para una viga recta con los dos extremos empotrados.

En el estudio llevado a cabo en este apartado, se han obtenido los momentos transver- 


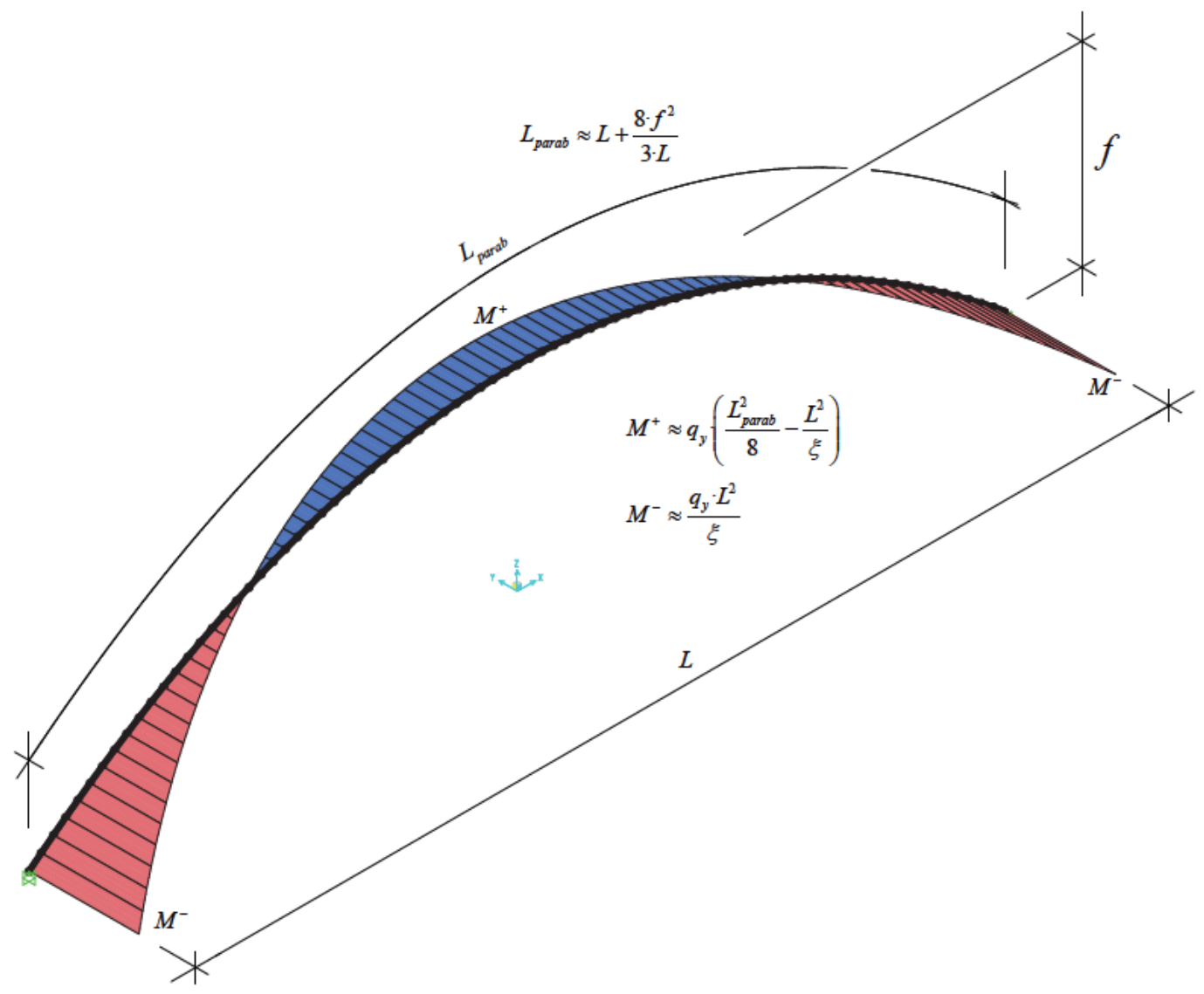

Figura 7.1: Flexión del arco para una carga transversal, y expresiones aproximadas. Véase el coeficiente $\xi$ en la tabla 7.1.

sales en los arranques del arco para una carga transversal $q_{y}=10 \mathrm{kN} / \mathrm{m}$, calculándose el coeficiente $\xi$ como si el arco se tratase de una viga recta con una luz $L=100 \mathrm{~m}$.

En la figura 7.2 se muestra el valor del coeficiente $\xi$ para diferentes relaciones de $f / L$ y $E I / G J$ de la sección del arco, estando los valores tabulados en la tabla 7.1. Como se puede observar tanto en la figura como en la tabla, los valores de $\xi$ no son muy sensibles a la variación del valor de $E I / G J$ para una misma relación $f / L$, siendo los valores bastante similares. Donde se obtienen valores de $\xi$ más diferentes es al variar la relación $f / L$, que hace cambiar $\xi$ desde un valor de 12 para $f / L=0$ hasta aproximadamente 5 en el caso de $f / L=0.4$.

\subsubsection{Flexión positiva en la clave del arco}

El momento transversal en la clave del arco no se ha podido asimilar a una viga empotrada de longitud $L$, lo que si ha ofrecido resultados con un nivel de precisión elevado ha sido el cálculo de la suma en valor absoluto del momento transversal en arranques y del momento transversal en la clave. Esta suma de términos en valor absoluto se ha podido aproximar a la ecuación 7.2, que coincide con el máximo momento flector de una viga biapoyada bajo una carga uniforme en toda su longitud, con la salvedad de que la luz de la viga no es $L$ 

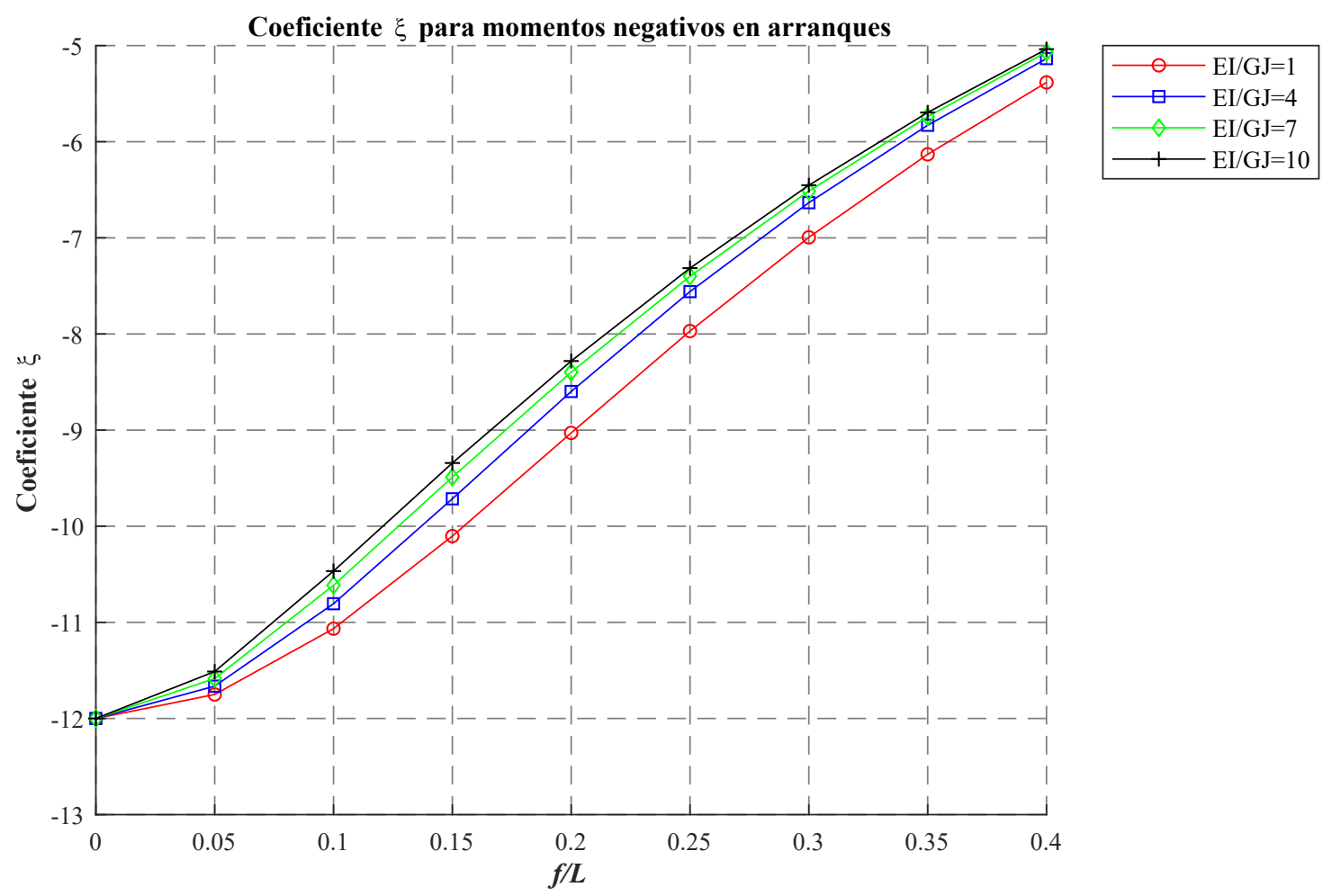

Figura 7.2: Coeficiente $\xi$ para el cálculo de los momentos transversales en los arranques del arco (ver tabla 7.1).

\begin{tabular}{|c|cccc|}
\hline$\xi$ & \multicolumn{4}{|c|}{$E I / G J$} \\
\hline$f / L$ & 1 & 4 & 7 & 10 \\
\hline 0.00 & 12 & 12 & 12 & 12 \\
0.05 & 11.75 & 11.66 & 11.58 & 11.51 \\
0.10 & 11.07 & 10.81 & 10.61 & 10.47 \\
0.15 & 10.10 & 9.72 & 9.49 & 9.34 \\
0.20 & 9.03 & 8.60 & 8.40 & 8.23 \\
0.25 & 7.97 & 7.56 & 7.40 & 7.32 \\
0.30 & 7.00 & 6.63 & 6.51 & 6.45 \\
0.35 & 6.13 & 5.83 & 5.74 & 5.70 \\
0.40 & 5.38 & 5.14 & 5.07 & 5.04 \\
\hline
\end{tabular}

Tabla 7.1: Coeficientes $\xi$ para estimar los momentos transversales en los arranques del arco (véase la figura 7.2).

sino $L_{\text {parab }}$, la longitud desarrollada de la parábola del arco (véase la figura 7.1).

$$
\left|M^{+}\right|+\left|M^{-}\right|=\frac{q_{y} \cdot L_{\text {parab }}^{2}}{8}
$$

En el estudio llevado a cabo en este apartado, se han vuelto a obtener los momentos transversales en los arranques y en la clave del arco para una carga transversal $q_{y}=10 \mathrm{kN} / \mathrm{m}$. El 
momento flector calculado como si fuese una viga biapoyada ha sido divido por la suma de los valores absolutos en el arranque y la clave (véase la ecuación 7.3), comprobándose como el valor se aproxima mucho a 1 (véase la figura 7.3). Los resultados de la gráfica anterior permiten deducir que la diferencia entre el valor teórico y el experimental es inferior a un $2 \%$ hasta una relación $f / L=0.25$.

$$
\frac{q_{y} \cdot L_{\text {parab }}^{2}}{8 \cdot\left(\left|M^{+}\right|+\left|M^{-}\right|\right)} \approx 1
$$

El momento en la clave del arco se puede calcular simplemente sustrayendo al valor de la suma de los flectores en valor absoluto del arranque y la clave, el valor del momento en el arranque calculado con la expresión 7.1.

$$
M^{+}=q_{y} \cdot\left(\frac{L_{\text {parab }}^{2}}{8}-\frac{L^{2}}{\xi}\right)
$$

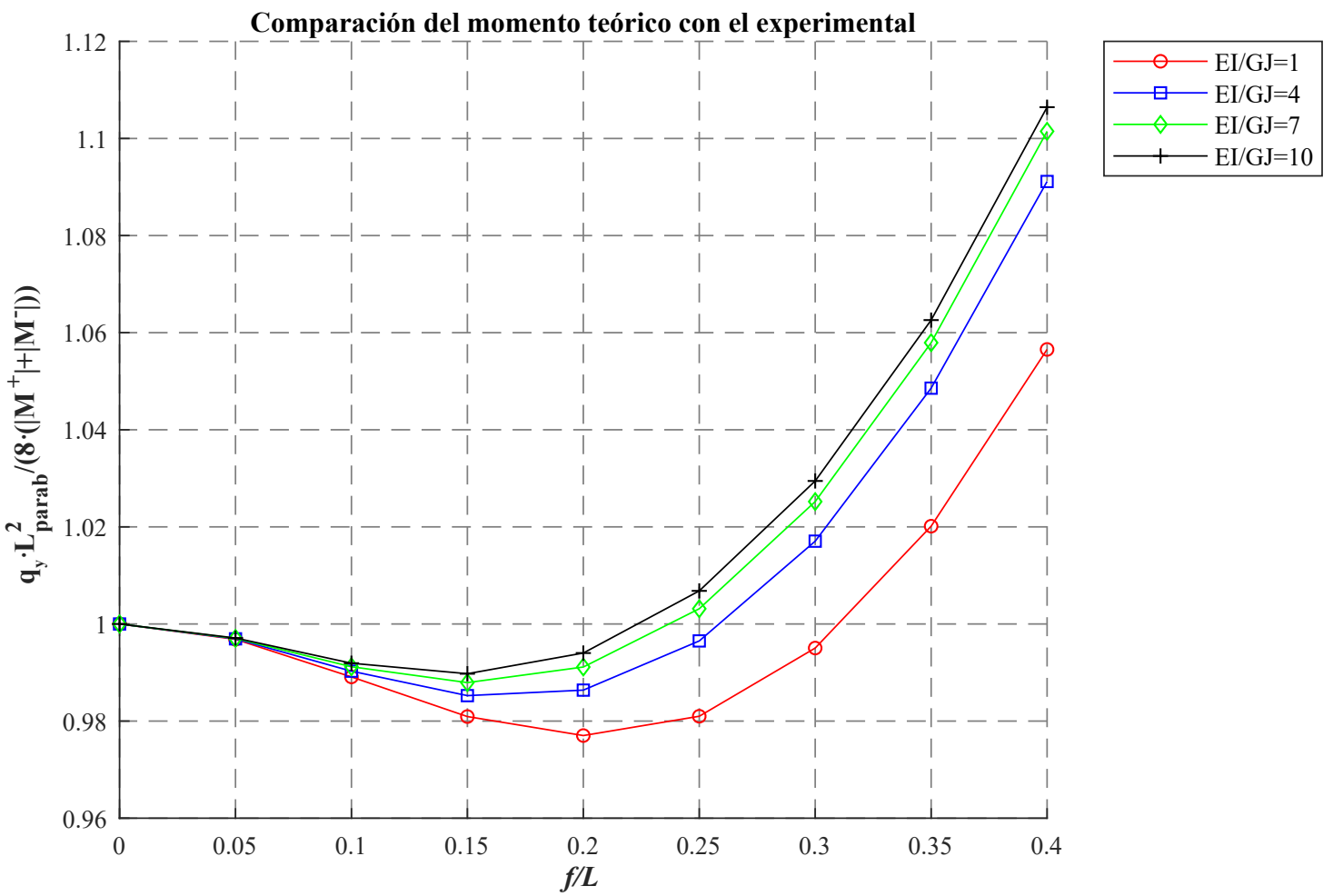

Figura 7.3: Error en tanto por 1 del momento teórico respecto al momento experimental.

\subsection{Pandeo fuera del plano}

\subsubsection{Introducción}

Como se mencionó en el punto 6.1, un arco es principalmente una estructura sometida a compresión, con lo que en consecuencia es una estructura susceptible de sufrir pandeo. 
El pandeo fuera del plano del arco es un efecto de segundo orden susceptible de ocurrir en arcos de reciente construcción, dada la esbeltez de las secciones, y la espacialidad de los arcos, que hace que estos estén sometidos a esfuerzos transversales considerables.

$\mathrm{Al}$ igual que pasaba en el pandeo dentro del plano, determinar la carga crítica de pandeo fuera del plano es complejo, pues intervienen diversos factores que hacen que las formulaciones desarrolladas por diversos autores para calcular el axil crítico de pandeo $\left(N_{c r}\right)$ sean del tipo:

$$
N_{c r}=C_{2} \cdot \frac{E \cdot I_{A, Z}}{L^{2}}
$$

Donde $E$ es el módulo de Young del material, $I_{A, Z}$ es la inercia a flexión transversal de la sección del arco, $L$ es la luz del arco, y $C_{2}$ es un coeficiente que depende de numerosos factores, como los apoyos del arco, la rigidez torsional $J$, el módulo de elasticidad transversal $G$, la variación de la sección, la relación flecha/luz, etc.

Valores para $C_{2}$ pueden encontrarse por ejemplo en Kollár [51].

\subsection{Pandeo fuera del plano en arcos vinculados al ta- blero con péndolas articuladas}

En puentes arco de tablero inferior, la carga crítica de pandeo fuera del plano es incrementada por la inclinación en los tirantes. Para arcos tipo bow-string, el coeficiente de pandeo fuera del plano suele ser menor que para dentro del plano. Si bien las péndolas arriostran el arco evitando que salga fuera del plano, el efecto que estas tienen dentro del plano es mucho mayor.

Al igual que ocurre con el pandeo dentro del plano, no hay una formulación única para estimar el axil crítico de pandeo en puentes arco atirantados. Existen investigaciones con modelos experimentales como las de Godden (véanse [34] y [35]), y la de Shukla y Ojalvo [100]. Estos estudios permiten estimar un coeficiente de pandeo fuera del plano para arcos vinculados con péndolas al tablero, bajo una carga uniformemente distribuida y diferentes condiciones de contorno, si bien los resultados tienen cierto error ${ }^{1}$.

En la figura 7.4 y en la tabla 7.2 , se puede observar el valor del coeficiente $C_{2}$ propuesto por Godden y por Shukla y Ojalvo respectivamente, para diferentes condiciones de contorno.

\subsection{Estudio de pandeo fuera del plano con arcos de sección variable}

Para centrar la información existente en diversas referencias acerca del pandeo fuera del plano del arco en puentes arco atirantados, en esta tesis se ha realizado un pequeño estudio

\footnotetext{
${ }^{1}$ En los diversos estudios realizados en esta tesis se comprobó que los valores obtenidos con las fórmulas y gráficas de Godden quedan del lado de la seguridad, mientras que las tablas de Shukla y Ojalvo quedan del lado de la inseguridad
} 


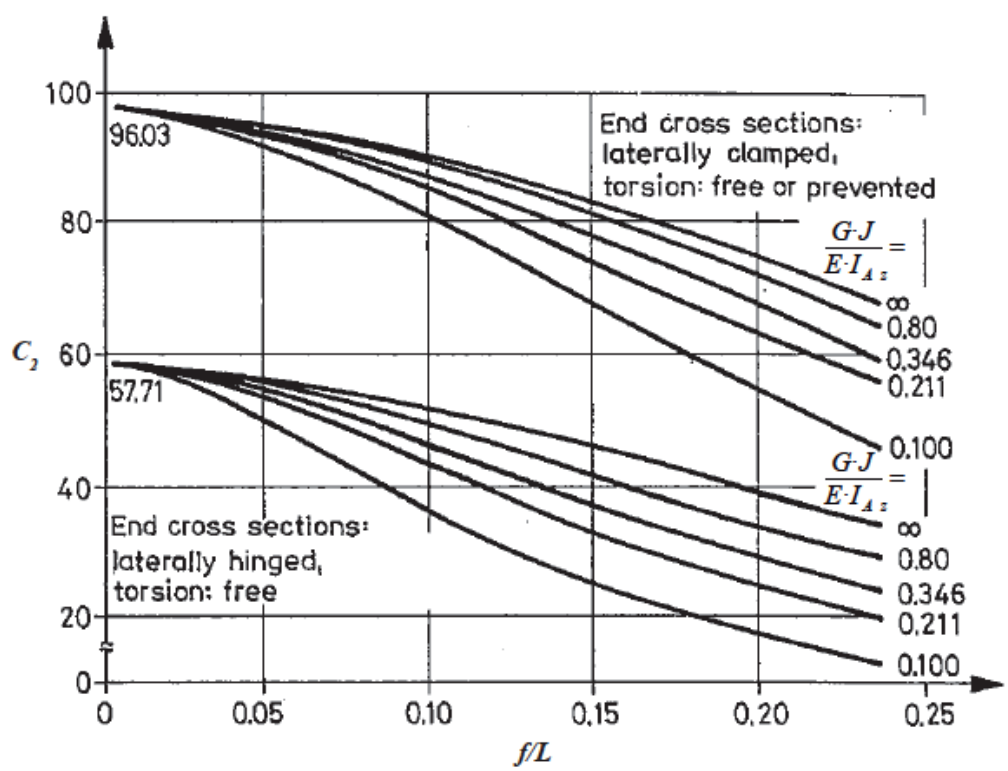

Figura 7.4: Coeficientes de pandeo $C_{2}$ fuera del plano dados por Godden para arco parabólico vinculado al tablero con péndolas. Figura extraída de Kollár [51] con notación adaptada a la de esta tesis.

\begin{tabular}{|c|c|c|c|c|c|c|c|}
\hline$G \cdot J$ & \multicolumn{7}{|c|}{$f / L$} \\
\cline { 3 - 8 }$E \cdot I_{A, Z}$ & 0.10 & 0.15 & 0.20 & 0.25 & 0.30 & 0.40 & 0.60 \\
\hline 0.01 & 49.2 & 32.1 & 21.8 & 15.7 & 11.9 & 7.5 & $(3.31)$ \\
0.02 & $62 . I$ & 45.0 & 32.9 & 24.6 & 19.0 & 12.3 & $(5.75)$ \\
0.2 & 84.5 & 74.0 & 62.7 & 52.1 & 42.7 & 28.6 & 13.7 \\
0.8 & 88.0 & 80.2 & 70.6 & 60.5 & 50.7 & 34.3 & 15.8 \\
1.2 & 88.5 & 81.2 & 71.9 & 62.0 & 52.2 & 35.6 & 16.5 \\
1.6 & 88.7 & 81.7 & 72.6 & 628 & 53.2 & 36.5 & 16.9 \\
\hline
\end{tabular}

Tabla 7.2: Coeficientes de pandeo $C_{2}$ fuera del plano dados por Shukla y Ojalvo para arco parabólico vinculado al tablero con péndolas. Figura extraída de Kollár [51] con notación adaptada a la de esta tesis.

sobre la variación del axil crítico de pandeo en secciones de arco variables.

Para estudiar la variación del axil crítico de pandeo en puentes arco, el modelo de referencia expuesto en el capítulo 3 ha sido modificado variando la sección del arco, así como el ancho cargado sobre el tablero, que pasar a ser $b=8 \mathrm{~m}$, con el fin de aumentar el efecto a estudiar.

Así, se ha aumentado el canto o el ancho de la sección de manera constante (Planta 0, figura 7.5), y se han hecho secciones variables con arranques más anchos que claves (Planta 1, figura 7.5) o con claves más anchas que arranques (Planta 2, figura 7.5). Por último también se ha estudiado el pandeo en arcos con arranques bifurcados (Planta 3, figura $7.5)$.

Para determinar el coeficiente de pandeo, en los modelos se ha considerado la imperfección geométrica correspondiente, considerándose para este estudio, los valores del punto 
22.3.4.2. de la Instrucción de Acero Estructural (véase [23]).

Para estimar la carga crítica de pandeo se han analizado todos los modelos en SAP2000 bajo la combinación de cargas de la ecuación 7.6:

$$
1,35 \cdot(P P+C M)+0,6 \cdot 1,5 \cdot V T O+\lambda_{u} \cdot q_{5}
$$

Donde $\lambda_{u}$ es el coeficiente de pandeo, expresado como el número de veces que hay que aumentar la sobrecarga de uso $^{2} q_{5}$ para que se produzca el pandeo (véase Manterola [60]).

Los resultados de todos los casos analizados se muestran en la figura 7.5, donde se pueden ver las diferentes plantas del arco, las secciones del mismo, y el valor $\lambda_{u}$ que multiplica a la sobrecarga de uso en el momento del pandeo.

Todos los casos analizados en la figura 7.5 presentan coeficientes de pandeo fuera del plano mucho más pequeños que los obtenidos en la figura 6.3 para pandeo dentro del plano. Así, a la hora de dimensionar un arco atirantado, el pandeo fuera del plano debe ser considerado un factor a tener en cuenta, antes que el pandeo dentro del plano.

En el caso de secciones constantes (Planta 0, figura 7.5), si se aumenta el ancho, se aumenta la inercia transversal, incrementado el coeficiente de pandeo fuera del plano. Al querer conservar el área inicial de la sección, aumentar el canto supondrá reducir el ancho y viceversa. Para igual área de material, intentar obtener un coeficiente de pandeo superior (sea fuera o dentro del plano), conllevará reducir el restante coeficiente de pandeo.

En el caso de secciones variables (Planta I y II, figura 7.5), el coeficiente de pandeo fuera del plano ha sido similar, pues la diferencia de inercia de la sección es muy pequeña. Si se exageran los valores, cambiando $700 \mathrm{~mm}$ por $500 \mathrm{~mm}$, y $1300 \mathrm{~mm}$ por $1500 \mathrm{~mm}$, se pueden observar diferencias en los coeficientes de pandeo. La Planta II presenta un coeficiente de pandeo fuera del plano superior, mientras que en la Planta I ocurre todo lo contrario. Las secciones variables mejoran el coeficiente a pandeo fuera del plano si la sección tiene una mayor inercia transversal en la clave del arco (más ancho). Si por el contrario tienen una mayor inercia longitudinal (más canto) mejoran el coeficiente a pandeo dentro del plano.

Un caso especial de secciones variables son las que tienen un área igual en los arranques o en la clave al modelo de referencia, y esta área aumenta hacia la clave o los arranques. En estos casos singulares de secciones variables, aumentar el área en la clave mejora también el pandeo fuera del plano.

Como último caso analizado para modificar el coeficiente de pandeo, se ha considerado un arco bifurcado en arranques (Planta III, figura 7.5). Este modelo tiene unas secciones iguales al modelo de referencia, incluso en las bifurcaciones de los arranques. El hecho de considerar los arranques bifurcados mantiene un coeficiente de pandeo fuera del plano igual al del modelo de referencia.

\footnotetext{
${ }^{2}$ Se ha considerado la sobrecarga $q_{5}$, al ser con la que se obtienen valores de pandeo más bajos, pues el resto de sobrecargas, si bien se han considerado, arrojan valores de pandeo más elevados.
} 


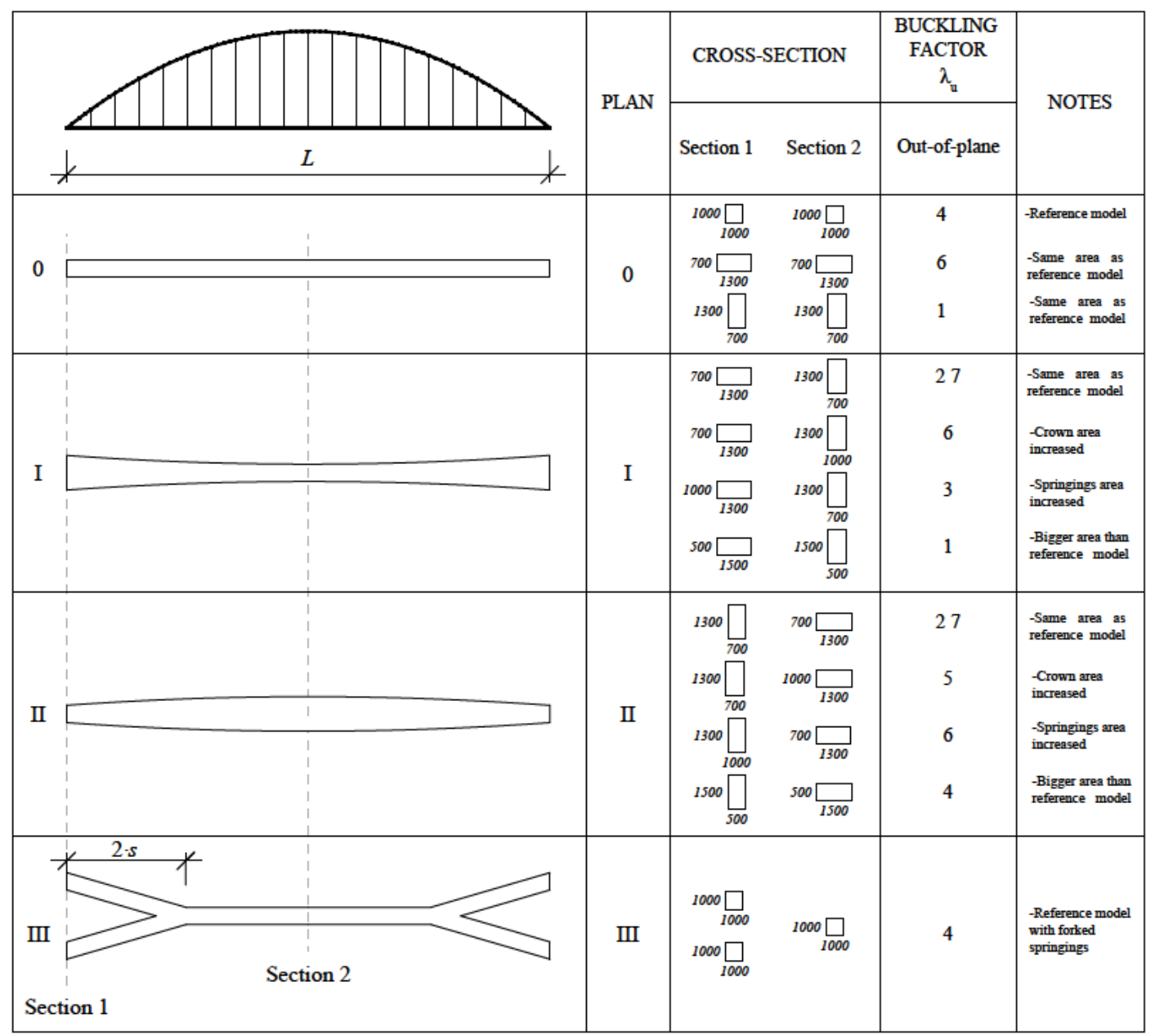

Figura 7.5: Coeficientes de pandeo fuera del plano del arco estimados para diferentes secciones. 


\section{Capítulo 8}

\section{Péndolas rigidizadas transversalmente}

\subsection{Introducción}

En puentes arco, la forma en la que el arco y el tablero se vinculan puede resultar crucial. Esta conexión define, por ejemplo, la forma en la que los esfuerzos se distribuyen entre el arco y el tablero, o cuán efectivo es el puente para reducir las flechas del tablero bajo cargas de servicio. Cuando el tablero se suspende del arco, las péndolas están habitualmente compuestas de cables de acero (véanse EC-3 [13] y Pfeifer [77]), elementos que son relativamente baratos y fáciles de construir (véase la figura 8.1). En términos prácticos, puede suponerse que los cables no tienen rigidez a flexión y, en consecuencia, sólo pueden resistir cargas axiales.

La disposición de cables en el plano puede ser modificada, por ejemplo, para reducir los momentos flectores en el puente. Con esta intención, las péndolas verticales pueden ser sustituidas por péndolas inclinadas, como ocurre en la configuración llamada NielsenLöhse, de la que el puente de Castelmoron, sobre el río Lot (véase la figura 8.2) es pionera.

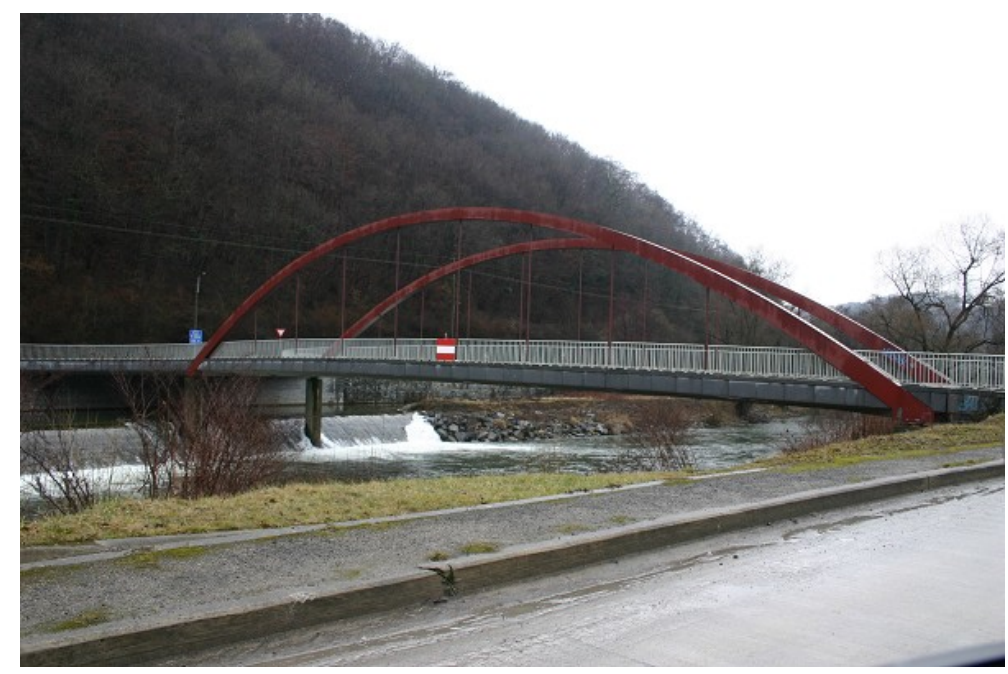

Figura 8.1: Ejemplo de péndolas articuladas. Chanxe Bridge. Fotografía: René Beideler (structurae.net). 


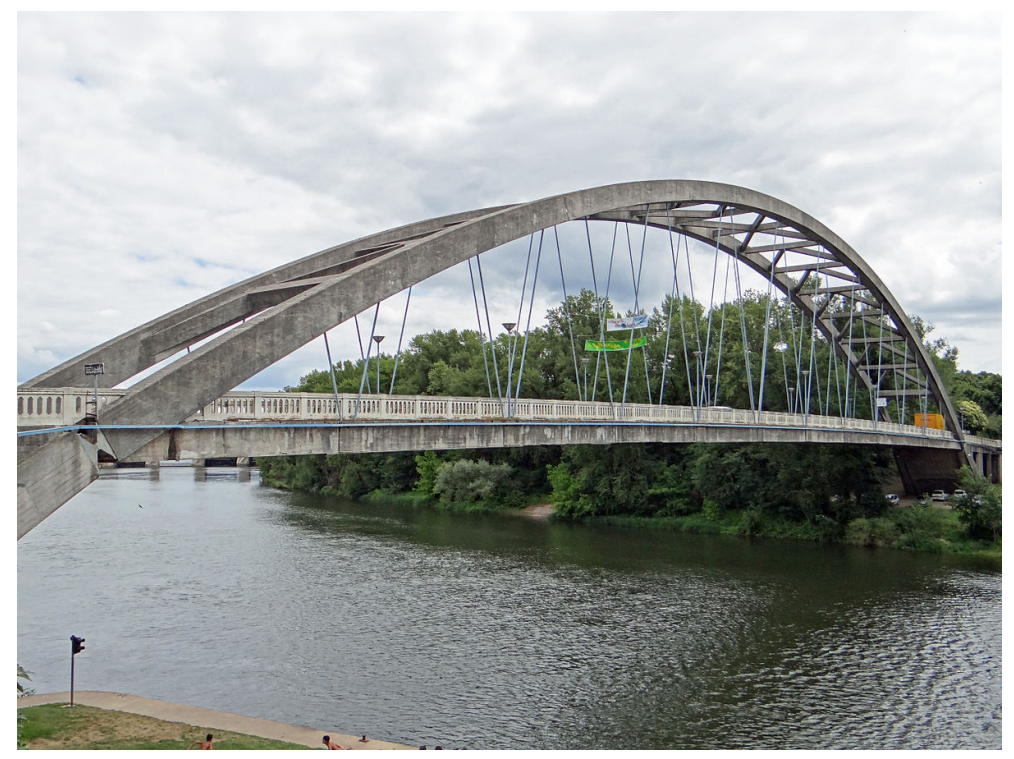

Figura 8.2: Puente de Castelmoron sobre el río Lot, Francia. Fotografía: MOSSOT (Wikimedia Commons).

En esta tipología debe mencionarse que, debido a su inclinación, los cables están sujetos a altas oscilaciones tensionales, lo que puede llevar a daños debidos a la fatiga.

Una reducción aún mayor de momentos flectores, tanto en el arco como en el tablero, puede ser obtenida mediante el puente tipo Network, una evolución del Nielsen-Löhse, donde las péndolas se cruzan al menos dos veces entre sí, y que lleva a arcos muy esbeltos. Esta tipología fue propuesta por primera vez por P. Tveit en 1959 (véase [117]). Quizá el ejemplo más famoso de esta tipología sea el puente de Fehrmandsund (véase la figura 8.3). La eficiencia relativa de estas tres configuraciones de cables (vertical, Nielsen-Löhse y Network) descritas hasta ahora se comparan en la figura 8.4 para una carga uniformemente distribuida actuando sobre un semitablero.

Sin embargo, en algunos casos, el diseñador decide que, para asegurar un correcto comportamiento estructural global, las péndolas deben resistir, además de fuerzas axiales, esfuerzos de cortante y flexión. Por lo tanto, las péndolas deben tener secciones transversales con capacidad a flexión, como las secciones en doble T o secciones huecas tubulares, es decir, las péndolas deben ser rigidizadas.

Cuando se utilizan secciones en doble $\mathrm{T}$, la orientación de las péndolas determina la dirección de la flexión donde el efecto de la rigidización de la péndola es efectivo, como en la pasarela de La Devesa (véase la figura 8.5) o en el Merchants Bridge (véase la figura 8.6). La orientación de las péndolas en doble $\mathrm{T}$, por lo tanto, se define para proporcionar bien rigidez longitudinal (para resistir flexiones en el plano) o bien rigidez transversal (para resistir torsiones en el tablero o flexión transversal en el arco). Cuando se utilizan secciones huecas cerradas, habitualmente están empotradas en ambos extremos, lo que proporciona simultáneamente rigidez longitudinal y transversal, es decir, en el plano y fuera de este, como ocurre (véase la figura 8.7) en el Puente de la Alameda en Valencia.

Merece la pena destacar que, tanto en el Puente de la Devesa, como en el Merchants Bridge, aunque las secciones doble T están orientadas transversalmente, no están empotradas 


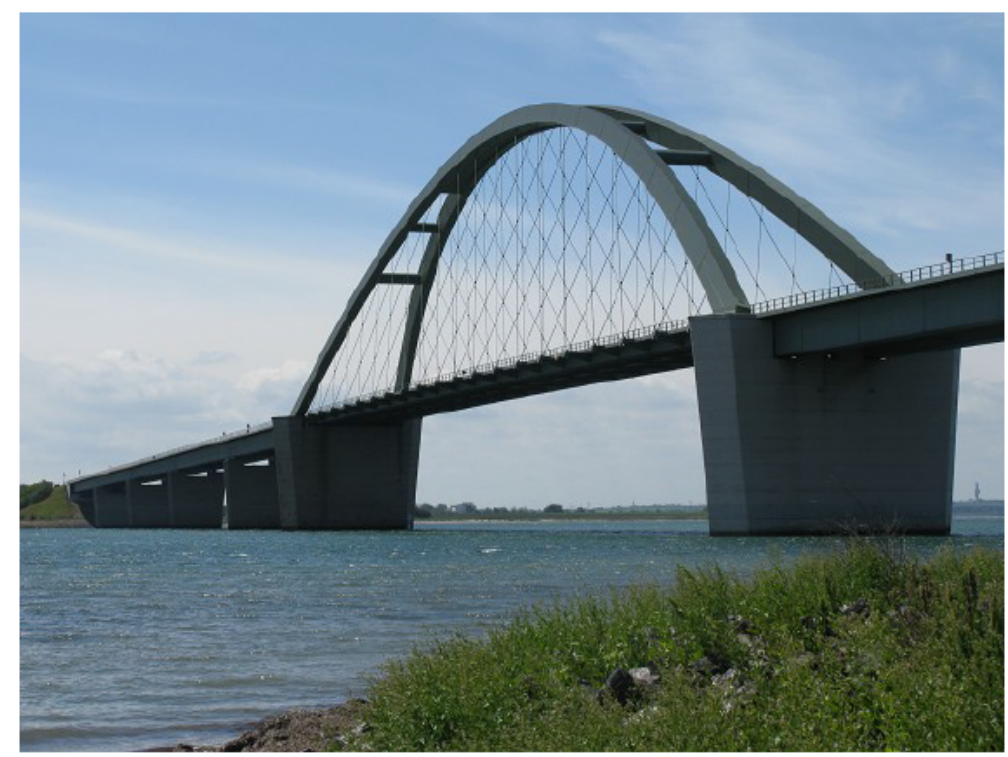

Figura 8.3: Puente de Fehmarnsund. Fotografía: Herrad Elisabeth Taubenheim (structurae.net)
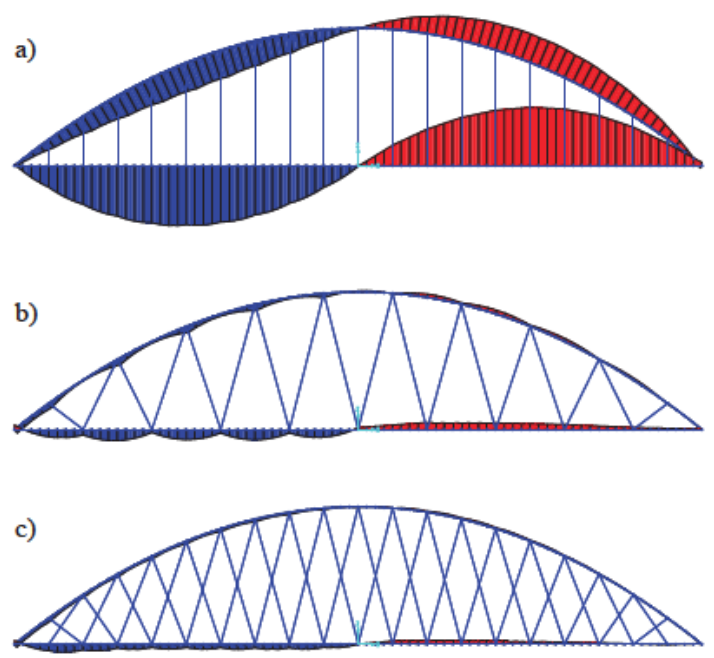

Figura 8.4: Comparación de momentos flectores para diferentes configuraciones de atirantamiento, dibujadas a la misma escala, para una carga uniforme en un semitablero: a) péndolas verticales, b) Nielsen-Löhse, c) Network.

en el arco en la dirección transversal. Como se muestra en Jorquera Lucerga y Manterola [45], en este y en otros muchos casos, una péndola con su extremo superior articulado es casi tan eficiente como una péndola totalmente empotrada mientras que resulta más fácil de construir. Sin embargo, hasta donde los autores conocen, el efecto de la posición de la articulación de la péndola sobre la respuesta estructural del puente no se ha estudiado todavía.

La forma en la que el arco y el tablero se conectan también tiene su importancia a la hora de analizar la sensibilidad del arco a pandeo. En general, las péndolas rígidas son más 


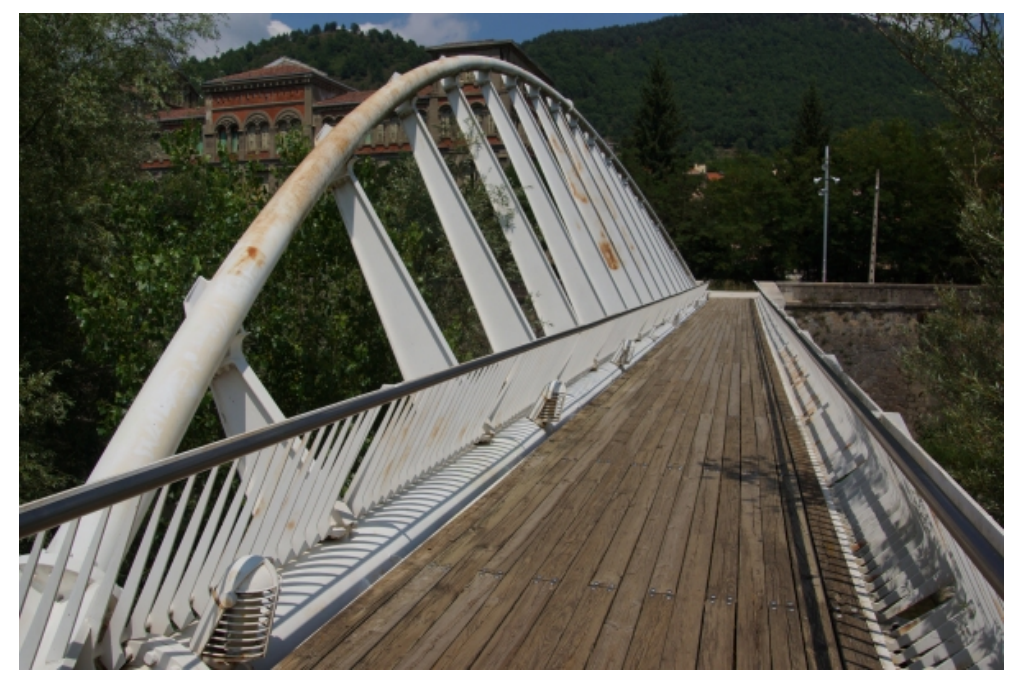

Figura 8.5: Pasarela de La Devesa. Fotografía: Nicolas Janberg (structurae.net)

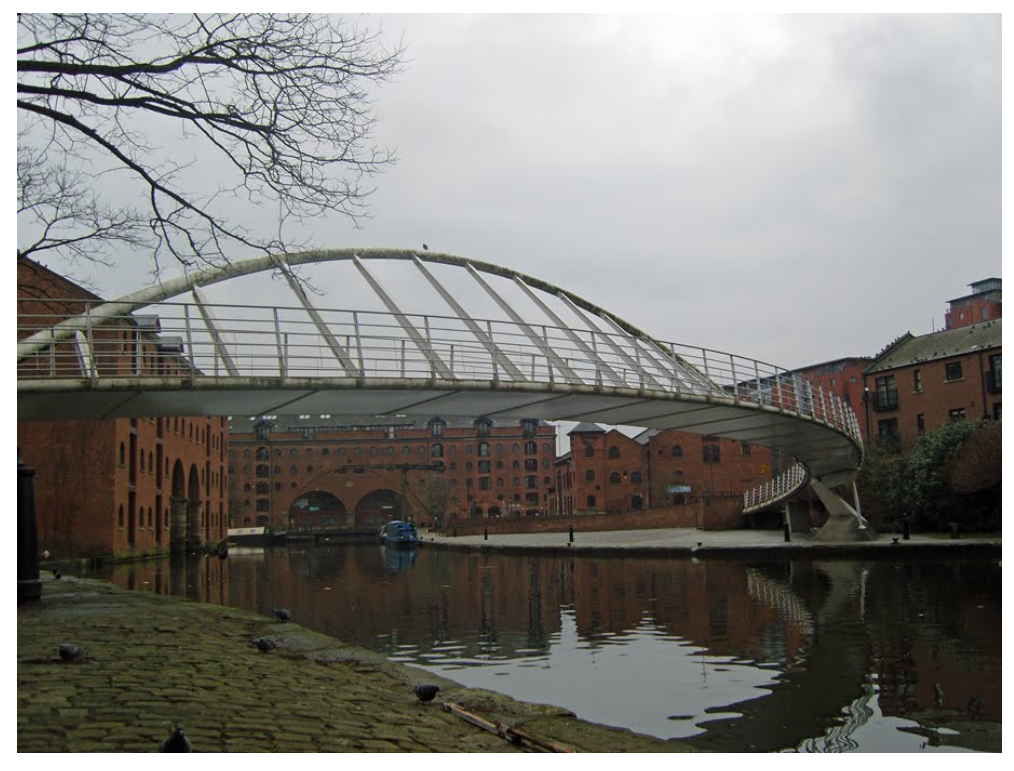

Figura 8.6: Merchants Bridge. Fotografía: The Happy Pontist.

eficientes que los cables para impedir el pandeo del arco, y, obviamente, la propia rigidez de la péndola se convierte en un factor de importancia primordial, como se muestra, por ejemplo, en Palkowski [73]. Por lo tanto, rigidizar las péndolas se convierte así en una opción tipológica disponible para el diseñador en las fases iniciales del proyecto, en la que la carga crítica del arco se puede incrementar con sólo rigidizar las péndolas, es decir, sin modificar la sección transversal de arco. Este parece ser el caso del Destructor Bridge (véase la figura 8.8) en Bath (Reino Unido), donde las péndolas rigidizadas transversalmente son simplemente chapas planas de acero del mismo ancho que el arco, que arriostran a pandeo un arco muy esbelto de sólo $200 \mathrm{~mm}$ de espesor.

Las péndolas articuladas y rigidizadas raramente se combinan en el mismo puente, y es una decisión basada habitualmente más en criterios estéticos que en consideraciones estructurales. Un ejemplo famoso es el puente de Ondarroa, en el norte de España (véase 


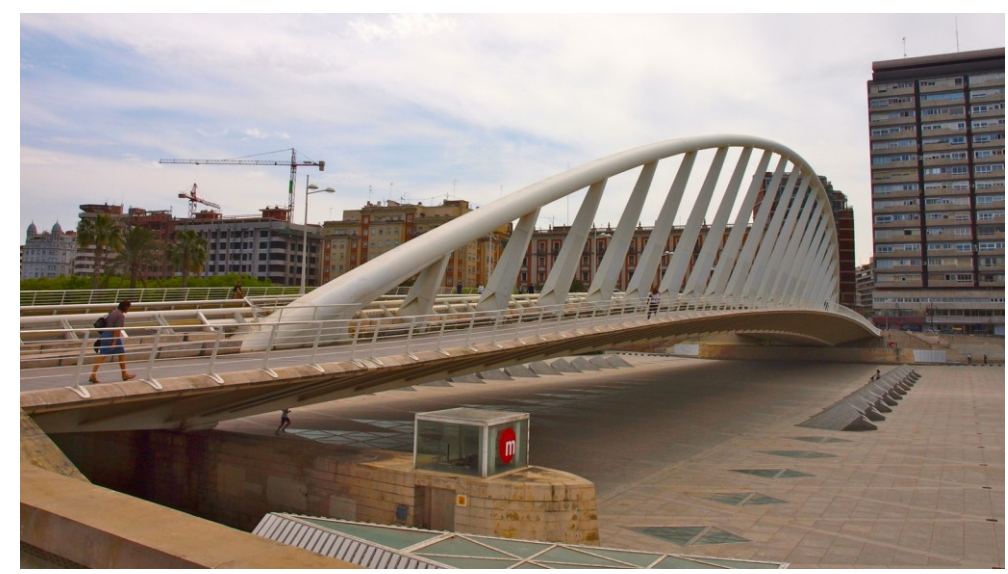

Figura 8.7: Ejemplo de péndolas rígidas. Puente de La Alameda (Valencia). Fotografía: Pedro Plasencia (puentemania.com).

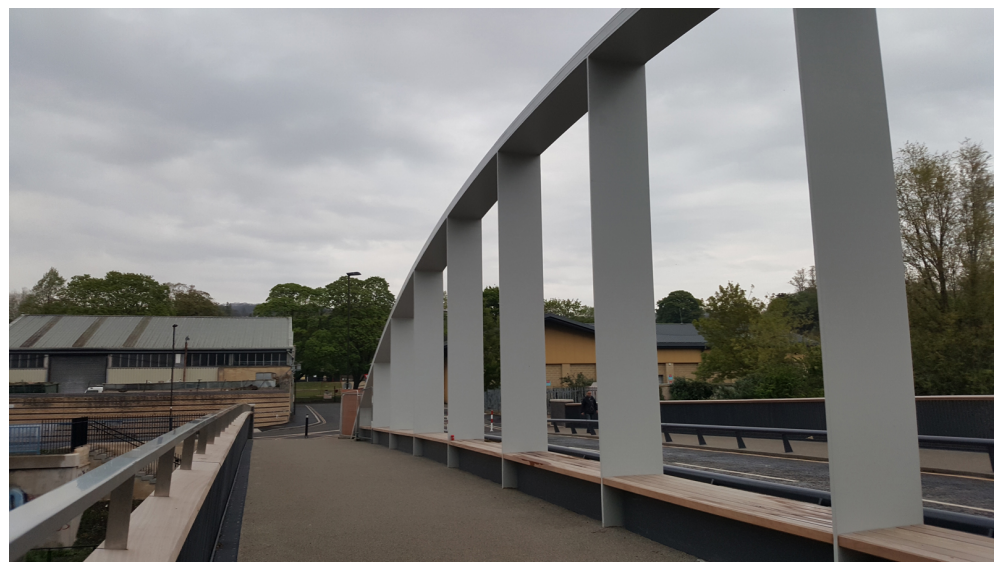

Figura 8.8: Destructor Bridge, Bath (Reino Unido). Fotografía: The Happy Pontist.

la figura 8.9), diseñado por Calatrava (véanse Calatrava [22], Tzonis [118], o Jodidio [42]). Este puente tiene dos tableros separados: un tablero curvo para peatones sujeto por péndolas rígidas, y otro recto para vehículos sostenido por cables.

Las péndolas articuladas también se pueden utilizar en disposiciones tridimensionales o espaciales. El puente sobre el río Galindo (véase la figura 8.10), en el norte de España, diseñado en 1997, es un puente donde la planta del arco coincide con el eje del tablero inferior curvo, lo que provoca que el arco tenga una geometría alabeada, es decir, no contenida dentro de un plano. El tablero se une al arco mediante dos juegos de cables. El primero se compone de péndolas verticales que tienen la misma función que en los arcos planos, transfiriendo las cargas verticales del tablero al arco. El segundo juego se compone de cables activos pseudo-horizontales anclados al arco y a elementos rígidos en voladizo empotrados en el borde interior del tablero. Estos cables introducen fuerzas horizontales en el arco que pretenden conseguir una configuración antifunicular contenida dentro de la geometría del arco (véase Jorquera Lucerga [46]).

Resulta interesante también detenerse en las alternativas no construidas del puente sobre el río Galindo. La figura 8.11 muestras dos de ellas (extraídas de Aguiló et al. [2]). En la 


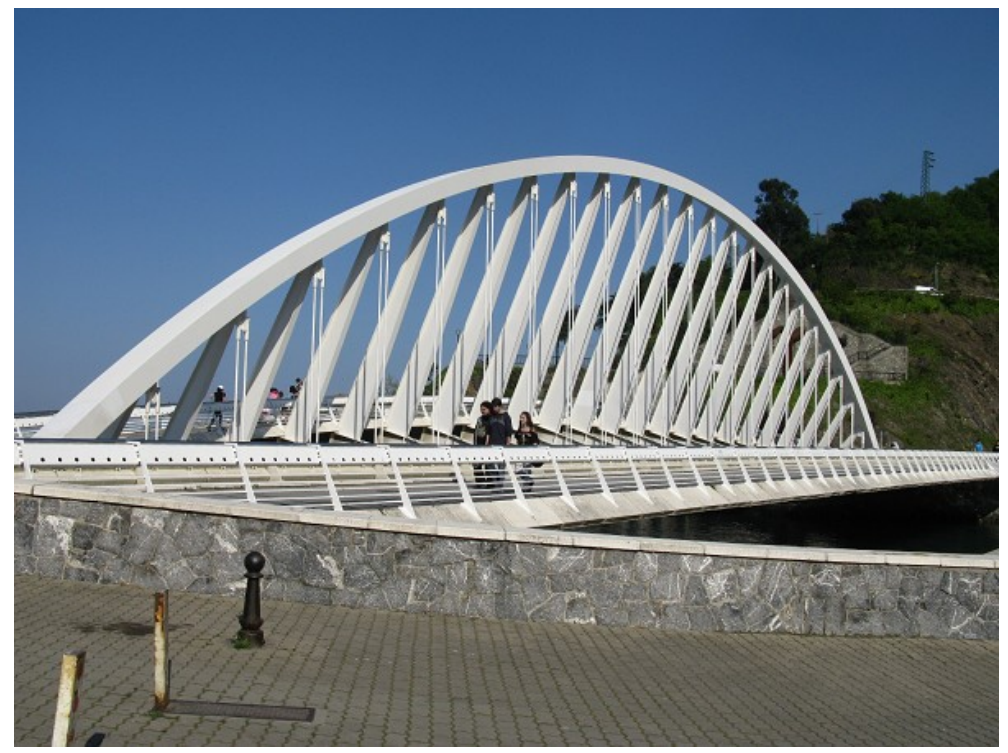

Figura 8.9: Puente de Ondarroa. Fotografía: Herrad Elisabeth Taubenheim (structurae.net).

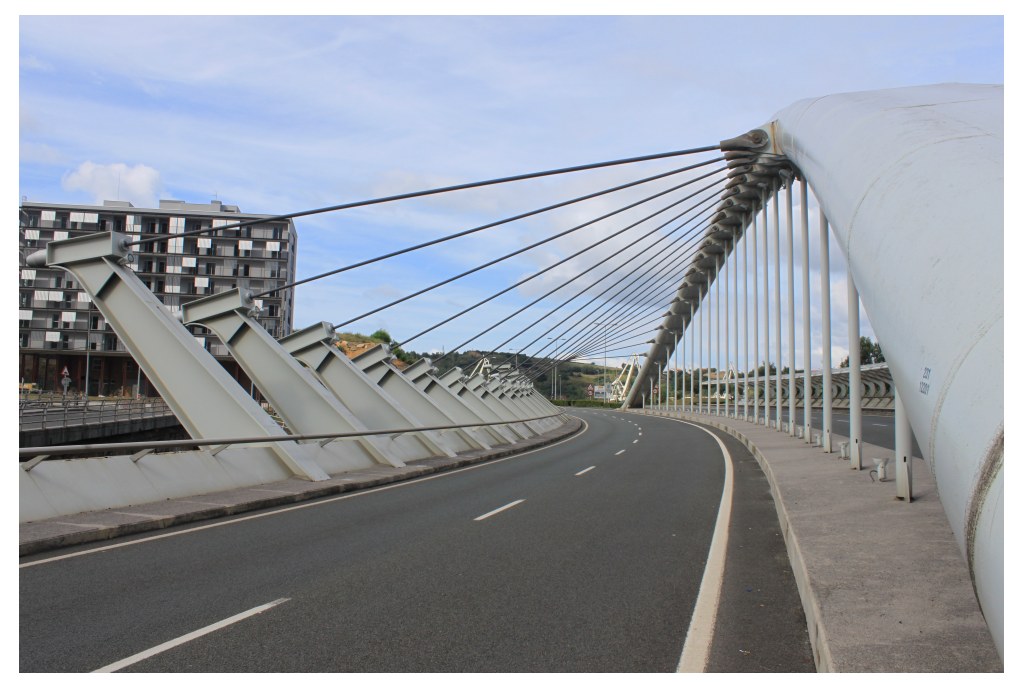

Figura 8.10: Puente sobre el río Galindo. Fotografía del autor.

primera (figura 8.11-a) las fuerzas horizontales de desvío no compensadas que aparecen en el arco debido a su curvatura en planta son resistidas gracias al incremento de su rigidez transversal, pues el arco se transforma en una celosía horizontal. Además se duplican las péndolas, una decisión que, al inclinarlas ligeramente, les otorga cierta capacidad para resistir acciones radiales.

Para nuestra investigación, la segunda alternativa no construida, mostrada en la figura 8.11-b, es más interesante: la compleja disposición espacial de cables de la solución construida se sustituye en esta alternativa por un conjunto de péndolas rigidizadas transversalmente, es decir, radialmente. Aunque quizá las grandes fuerzas horizontales de desvío que aparecen en el arco no habrían podido ser resistidas solamente por péndolas rígidas, esta alternativa ha inspirado nuestra investigación: las péndolas rígidas y las péndolas 
compuestas de más de un cable quizá puedan ser intercambiables.

Un problema parecido, aunque de menor entidad debido a la menor curvatura, aparece en el puente de Endarlatsa (Navarra, España), otro arco alabeado construido en fechas similares por el mismo diseñador (véase la figura 8.12). En este caso el problema se resolvió utilizando péndolas rígidas entre el arco inferior y el tablero curvo.

El objetivo de este capítulo es expandir las posibilidades estructurales tanto de las péndolas rígidas como articuladas para proporcionar a los diseñadores herramientas útiles en las fases iniciales del diseño. Para péndolas rígidas se analizará la posición de las articulaciones tanto en la dirección longitudinal como transversal. Para péndolas formadas por cables se estudiarán diferentes combinaciones, con el objetivo de encontrar disposiciones de péndolas que proporcionen un punto intermedio entre la eficacia estructural de las péndolas rígidas y la facilidad constructiva de las péndolas de cables.

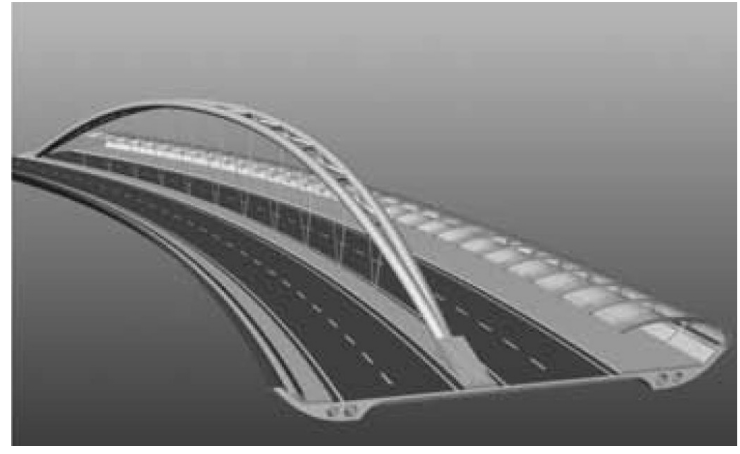

(a)

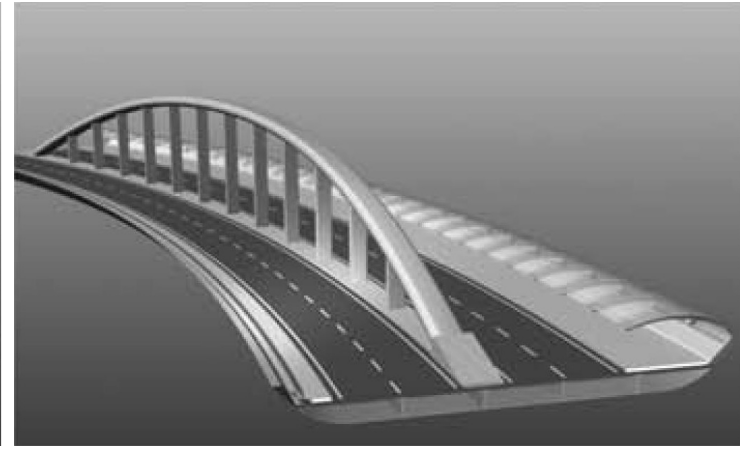

(b)

Figura 8.11: Alternativas no construidas para el río Galindo. (a) Arco en celosía. (b) Péndolas rigidizadas transversalemente. Fotografía: extraídas de Aguiló et al. [2].

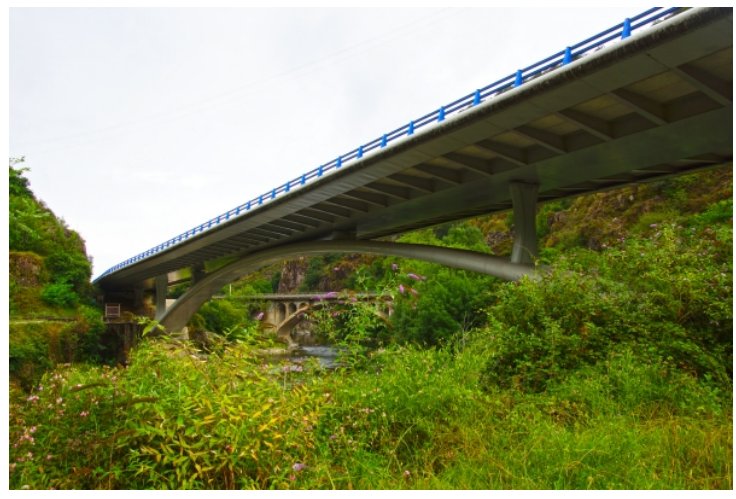

(a)

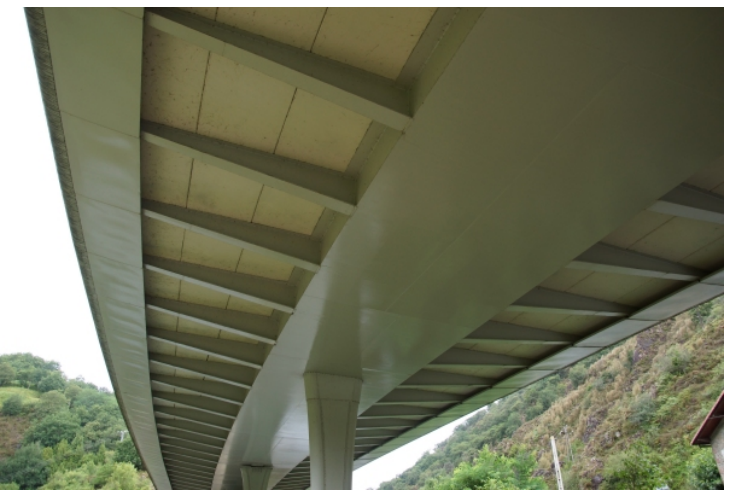

(b)

Figura 8.12: Puente de Endarlatsa. a) Vista general. b) Montantes rígidos entre el arco y el tablero. Fotografía: Nicolas Janberg (structurae.net). 


\subsubsection{Modelo de referencia y acciones usadas en el estudio}

Todos los puentes estudiados en este capítulo están basados en el puente arco de referencia descrito en el capítulo 3, aunque con algunas variaciones (véase la figura 5.2). Ya que el estudio es principalmente cualitativo, el puente de referencia es considerado como representativo de su clase. Este modelo de referencia está compuesto por un tablero recto soportado por un arco plano vertical. El puente pertenece a la tipología conocida como bow-string (o arco atirantado), ya que los arranques del arco están sujetos por el tablero traccionado. El arco y el tablero están unidos por una familia de péndolas verticales ancladas al eje del tablero. En el modelo de referencia, las péndolas se modelizan como cables que están articulados en ambos extremos. Este capítulo se centra en los efectos de rigidizar esas péndolas.

El modelo de estudio tiene una luz $L=100 \mathrm{~m}$, y una flecha del arco $f=20 \mathrm{~m}$. La distancia entre péndolas medida sobre el tablero es $s=5 \mathrm{~m}$. El ancho cargado del tablero se ha modificado con respecto al modelo de referencia mostrado en el capítulo 3 con el fin de amplificar el efecto a estudiar, teniendo ahora un valor $b=8 \mathrm{~m}$ (véase la figura 5.2). Estas dimensiones están inspiradas por puentes arco reales, y relativamente comunes (véase por ejemplo Leonhardt [56], o Lebet y Hirt [55]). Todos los puentes estudiados han sido diseñados de acuerdo al Eurocódigo 3 [12].

Un resumen de las dimensiones de las secciones del puente, las cuales son también usuales en puentes de este tipo, se puede observar en la tabla 8.1.

Solo han sido consideradas cargas estáticas. Para cargas dinámicas, unas referencias a tener en cuenta son Jong-Dar [44] y Roeder et al. [90]. Los casos de carga considerados en este estudio son:

- El peso propio (PP), evaluado para un peso específico de $78.5 \mathrm{kN} / \mathrm{m}^{3}$, y la carga muerta $(\mathrm{CM})$, con un valor de $\left(3.75 \mathrm{kN} / \mathrm{m}^{2}\right)$. Ambas cargas están definidas en el capítulo 3.

- Para este estudio, no es necesario considerar todos los posibles casos de carga que pueden aparecer en el diseño de un puente. Por lo tanto, solo se van a considerar cargas peatonales, ya que ilustran con la suficiente precisión, el efecto en el comportamiento que tienen las péndolas cuando son rigidizadas. Estas sobrecargas de uso son $q_{3}, q_{4}$ y $q_{5}$, las cuales también están definidas en el capítulo 3. Las sobrecargas (véanse las zonas de carga en la figura 3.4), son de tipo peatonal, y se corresponden con una carga distribuida de $5 \mathrm{kN} / \mathrm{m}^{2}$ (véase la IAP [27] o el Eurocódigo 1 [10]), para el ancho de tablero antes mencionado $b=8 \mathrm{~m}$. 


\begin{tabular}{|c|c|c|c|}
\hline Elemento & Sección transversal & Dimensiones & $\begin{array}{l}\text { Módulo de Young } \\
\mathrm{E}\left(\mathrm{N} / \mathrm{mm}^{2}\right)\end{array}$ \\
\hline Arco & Cuadrada hueca & $\begin{array}{l}1250 \times 1250 \mathrm{~mm}, \\
t_{f, A}=t_{w, A}=30 \mathrm{~mm}\end{array}$ & $2.0 \times 10^{5}$ \\
\hline Péndolas & Circular maciza & $\phi 80 \mathrm{~mm}$ & $1.6 \times 10^{5}$ \\
\hline Tablero & Rectangular hueca & $\begin{array}{c}5000 \times 1000 \mathrm{~mm}, \\
t_{f, D}=t_{w, D}=20 \mathrm{~mm}\end{array}$ & $2.0 \times 10^{5}$ \\
\hline
\end{tabular}

Tabla 8.1: Materiales y dimensiones de las secciones del puente usado en el estudio del capítulo 8.

\subsubsection{Desacoplamiento de los sistemas estructurales dentro y fue- ra del plano}

Se supone que la sección transversal del arco tiene doble simetría, una configuración muy común en puentes arco. Esto significa que el comportamiento del arco se puede descomponer en dos sistemas estructurales desacoplados: en primer lugar, el comportamiento en el plano, que corresponde a un arco en flexocompresion, en segundo lugar, el comportamiento fuera del plano, en el que el arco se comporta como una viga curva, donde la flexión fuera del plano y los momentos torsores están acoplados (véase Jorquera Lucerga [46]). Las respuestas dentro y fuera del plano son debidas, respectivamente, a cargas contenidas en el plano y a cargas fuera del plano o momentos torsores.

Sólo por mencionar una consecuencia de este comportamiento desacoplado, si se coloca una articulación en un punto dado de una péndola rígida, se permitirá una rotación en una dirección sin afectar al comportamiento en la dirección perpendicular. De la misma manera, la rigidez de las péndolas puede ser ajustada para proporcionar inercias mayores en la dirección deseada, como ocurre en secciones doble T. Una importante consecuencia desde el punto de vista de esta investigación es que el análisis del efecto de las articulaciones en el plano y en el plano perpendicular puede acometerse independientemente, como se realiza a continuación.

\subsection{Comportamiento en el plano: péndolas rígidas y articuladas longitudinalmente}

Las péndolas rígidas pueden ser utilizadas para reducir los esfuerzos y las deformaciones globales del puente. Para ilustrar la eficiencia de las péndolas rígidas con respecto a los cables, en la figura 8.13 se comparan los momentos flectores para péndolas formadas por cables con los momentos flectores cuando las péndolas tienen secciones huecas cuadradas (SHB, 400x400x20 mm y 800x800x20mm) y están empotradas en ambos extremos, bajo las cargas $q_{3}$ y $q_{5}$ para el puente de referencia.

Puede verse como para los dos casos de carga considerados los momentos son menores cuanto más rígidas son las péndolas. Los momentos más altos siempre se obtienen en las 


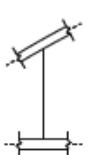

a)

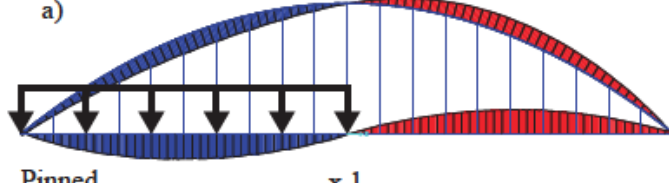

$\prod_{1}^{x}$

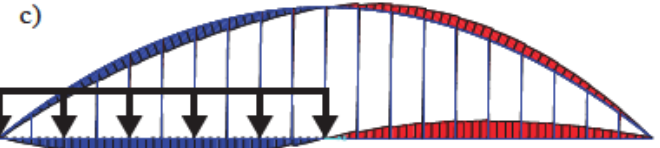

SHB $400 \times 400 \times 20$

$\mathrm{x} 1$
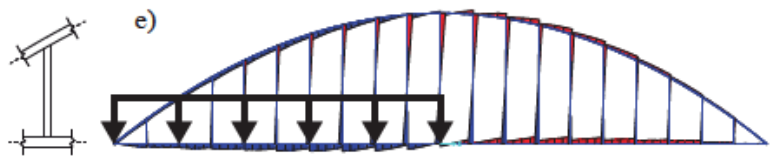

SHB $800 \times 800 \times 20$

$\mathrm{x} 1$
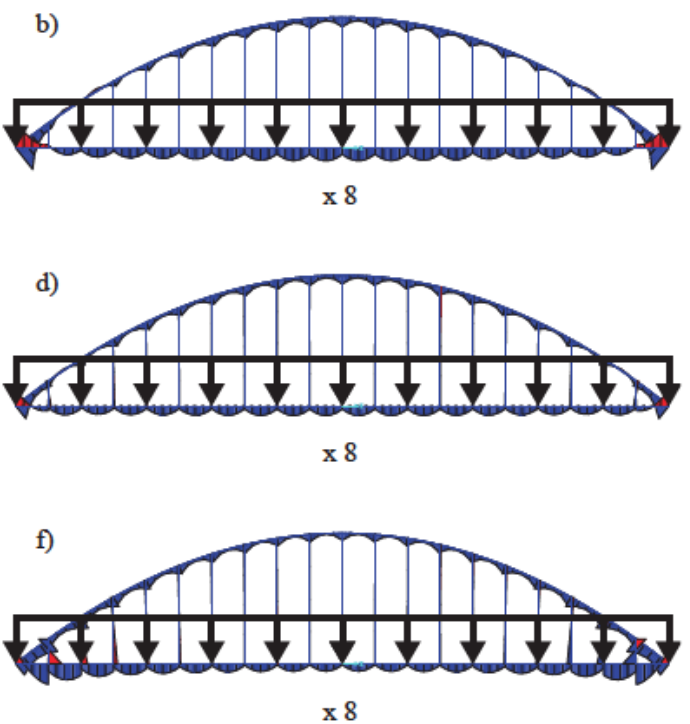

Figura 8.13: Momentos flectores para el puente de referencia $(\mathrm{a}, \mathrm{b})$, péndolas rígidas SHB 400x400x20mm (c, d) y SHB 800x800x20mm (e, f), bajo cargas $q_{3}(\mathrm{a}, \mathrm{c}, \mathrm{e})$ y $q_{5}(\mathrm{~b}, \mathrm{~d}, \mathrm{f})$.

secciones de riñones $(x= \pm L / 4)$ para una carga actuando sobre el semitablero, $q_{3}$, que se convierte así en el caso de carga más desfavorable como es habitual en arcos (véase Menn [65] y Manterola [60]).

\subsubsection{Estudio de la posición de la articulación (flexion longitudi- nal)}

Para estudiar el efecto de la posición de la articulación en la péndola, se ha añadido una articulación en sentido longitudinal a todas las péndolas de un puente de referencia, en el que todas las péndolas son rígidas (SHB $800 \times 800 \times 20 \mathrm{~mm}$ ). La posición relativa de la articulación es $\alpha \cdot h$, donde $h$ corresponde a la longitud de cada péndola, y $\alpha$ varía desde 0 en el extremo superior en el arco hasta 1 en el extremo inferior en el tablero. En este estudio se ha supuesto que la posición relativa de la articulación, es decir, $\alpha \cdot h$, es la misma para todas las péndolas, aunque, obviamente, en un diseño real, las péndolas formadas por cables o con secciones transversales rígidas, con o sin articulaciones, pueden ser combinadas libremente.

La figura 8.14 muestra la distribución de momentos flectores en el arco (a) y en el tablero (b) para las diferentes posiciones de las articulaciones. Además, la figura 8.14 también muestra los valores para el puente de referencia, tanto para péndolas formadas por cables $\left(\phi_{H}=80 \mathrm{~mm}\right)$ como para péndolas rígidas (SHB 800x800x20mm) sin articulaciones. En la figura 8.14-d, los valores de los momentos en el arco y en el tablero se muestran en riñones, que corresponde con la localización de los esfuerzos máximos. Es de destacar que los momentos máximos siempre corresponden a péndolas formadas por cables, mientras que los momentos mínimos siempre corresponden a péndolas rígidas empotradas. Resulta muy interesante confirmar que, en lo que se refiere a la reducción de momentos flectores (véase la figura 8.14-d), las péndolas articuladas son tan efectivas como las péndolas rígidas 

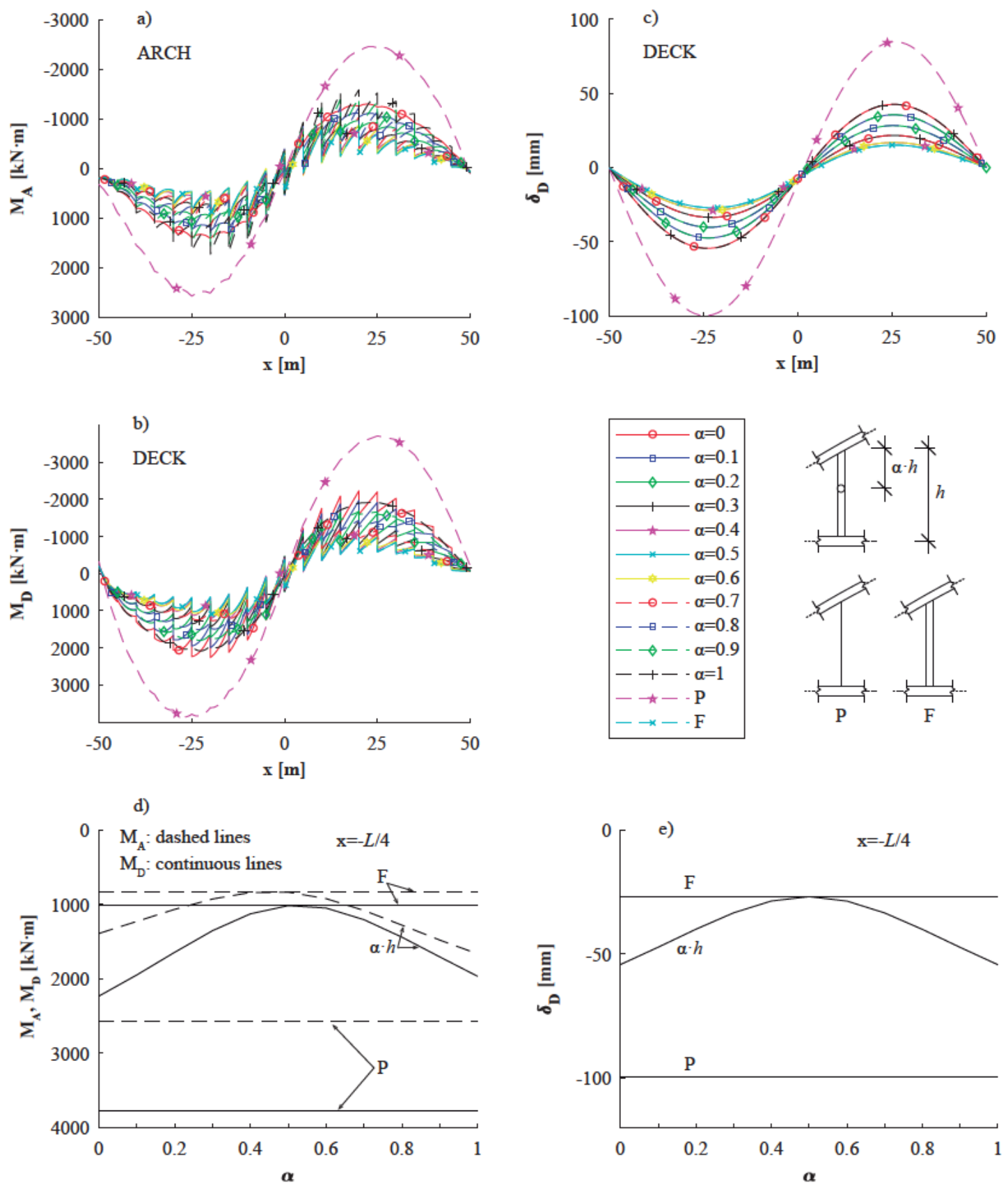

Figura 8.14: Diagramas longitudinales de momentos flectores en a) arco y b) tablero vs. rigidez de péndolas y localización de las articulaciones. c) deformación vertical del tablero. d) detalle de momentos flectores en la sección de riñones. e) detalle de flechas en la sección de riñones.

empotradas cuando tienen sus articulaciones en $\alpha=0.5$. Esto ocurre tanto para el arco como para el tablero. Además las posiciones relativas de las péndolas (aproximadamente $\alpha=0.5$ ) donde se alcanza la mayor eficiencia de las mismas no parece depender ni de la rigidez relativa de las secciones transversales del arco o del tablero ni de sus valores absolutos (véase la figura 8.15). 

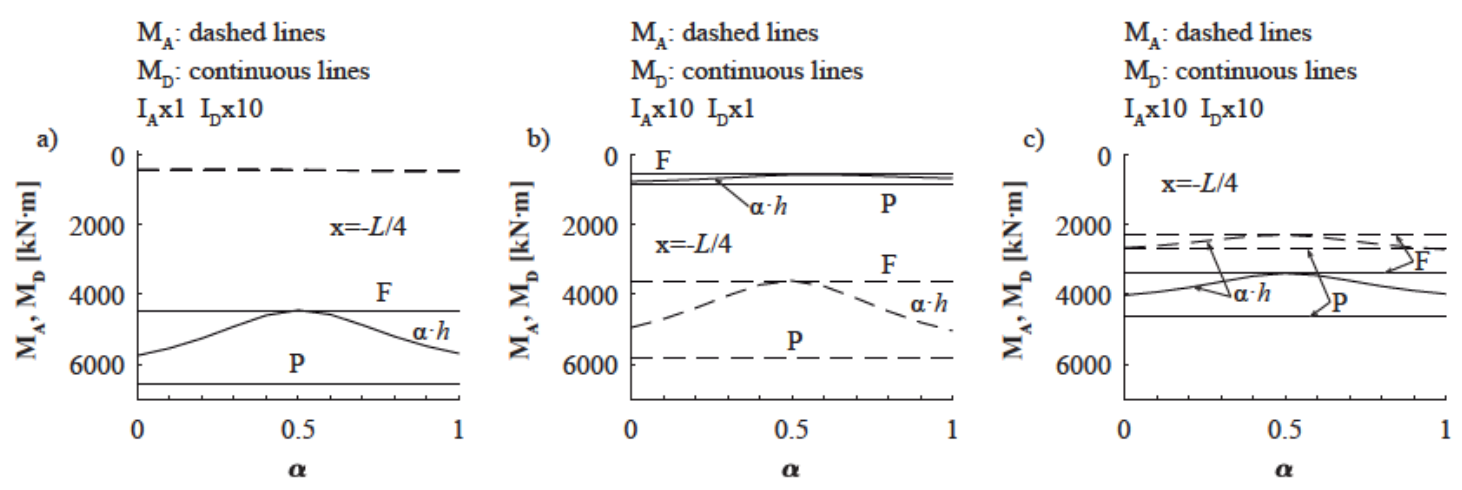

Figura 8.15: Flexión longitudinal vs. rigidez. Rigideces en el plano del arco y del tablero ponderadas, respectivamente, por $k_{A}$ y $k_{D}$. a) $k_{A}=1, k_{D}=10$, b) $k_{A}=10, k_{D}=1$, c) $k_{A}=10$, $k_{D}=10$.

De la misma manera, las figuras 8.14-c y 8.14-e muestran las deformaciones en el tablero para las diferentes posiciones de las articulaciones y para los dos puentes de referencia, con cables y con péndolas rígidas empotradas. De una forma similar a los resultados ya descritos, las péndolas formadas por cables siempre producen mayores deformaciones, mientras que los valores de $\alpha$ cercanos a 0.5 son tan efectivos como las péndolas empotradas en términos de reducción de la deformación.

\subsection{Comportamiento fuera del plano: péndolas rigidi- zadas transversalmente}

En esta sección se estudia el efecto de rigidizar las péndolas sobre la respuesta fuera del plano del arco. Los efectos de las articulaciones transversales y sus posiciones se analizan en un estudio parecido al recién realizado. Sin embargo en esta sección, la respuesta de la estructura será analizada para las cargas $q_{1}$ o $q_{2}$ (véase la figura 3.4), es decir, cargas uniformemente distribuidas longitudinalmente sobre el vano completo y sobre su semiancho. De esta manera aparecen momentos torsores en el tablero, como muestra la figura 8.16, y las deformaciones verticales son diferentes entre el eje y el borde (puntos $\mathrm{C}$ y E, figura 8.16-b) de su sección transversal. La deformación vertical $\delta_{E}$ en el borde del tablero puede evaluarse como:

$$
\delta_{E}=\delta_{C}+\theta_{C} \cdot \frac{b}{2}
$$

donde $\theta_{C}$ es el giro longitudinal debido a la torsión en el centro del tablero.

\subsubsection{Efecto de la posición de las articulaciones}

Para estudiar el efecto de la posición de las articulaciones, se ha añadido una articulación transversal a todas las péndolas de un puente de referencia con péndolas empotradas (SHB 

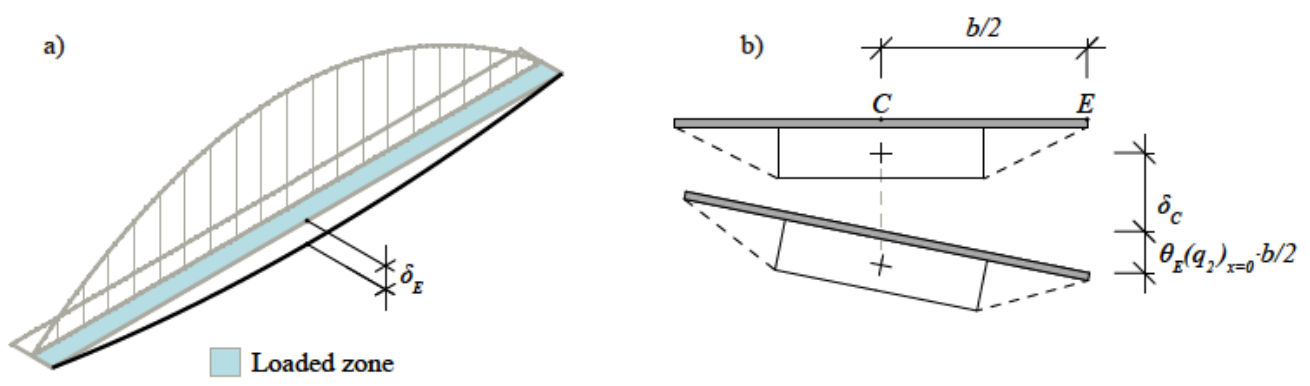

Figura 8.16: a) deformada del puente para $q_{2}$. b) deformada de la sección transversal del tablero.

$800 \times 800 \times 20 \mathrm{~mm})$. La posición relativa de la articulación es $\alpha \cdot h$, donde $h$ corresponde a la longitud de cada péndola y $\alpha$ varía desde 0 en el extremo superior en el arco y 1 en el extremo inferior en el tablero. En este estudio se ha considerado que la posición relativa de la péndola, $\alpha \cdot h$, es la misma para todas aunque, obviamente, en un diseño real, se pueden combinar péndolas de diferentes tipos con o sin articulaciones. En el estudio se han analizado los momentos fuera del plano del arco y los momentos de eje vertical del tablero para la carga $q_{2}$ (véase la figura 8.17), así como los momentos torsionales tanto para el arco como para el tablero (véase la figura 8.18). Para la misma carga, se han obtenido las deformaciones verticales en el borde del tablero, así como las deformaciones transversales en la clave del arco (véase la figura 8.19).

Como se muestra en la figura 8.19-c, la deformación transversal en la clave desciende con $\alpha$, mientras que la deformación vertical en el eje del tablero aumenta. Este hecho es coherente con el diagrama de torsores que se muestra en la figura 8.18-b: a medida que $\alpha$ crece, el momento torsional el tablero decrece, porque la torsión está recogida parcialmente por el sistema estructural arco-péndola, reduciendo consecuentemente el giro del tablero y la deformación vertical de su eje. Merece la pena mencionar que la mínima deformación se obtiene para $\alpha=0$ (articulaciones en el arco), y este valor permanece prácticamente inalterable para péndolas fijas, por lo que el efecto de empotrar o no las péndolas en el arco es prácticamente irrelevante.

\subsubsection{Sistemas estructurales}

El efecto de las cargas $q_{1} \circ q_{2}$ puede descomponerse en dos cargas uniformemente distribuidas, una vertical $p=q \cdot b / 2$ y un momento torsor $m_{t}=q \cdot b^{2} / 8$ actuando en el eje del tablero. La forma en la que $p$ y $m$ son soportadas conjuntamente por parte del tablero se explica en la figura 8.20. En primer lugar, en lo que respecta a la carga vertical, se puede suponer que cada péndola soporta aproximadamente la carga tributaria $P$ que le corresponde, $P=p \cdot s$, donde $s$ es la separación entre péndolas.

Cuando el arco se vincula al tablero por medio de péndolas articuladas en su base (véase la figura 8.20-c), la totalidad del momento torsor $m_{t}$ debido a la carga excéntrica es soportada por la sección transversal del tablero y transferida enteramente a los estribos (véase la figura 8.18-b). Sin embargo cuando el arco está vinculado al tablero por péndolas rigidizadas transversalmente (véase la figura 8.20-a), una fracción del momento torsor en 

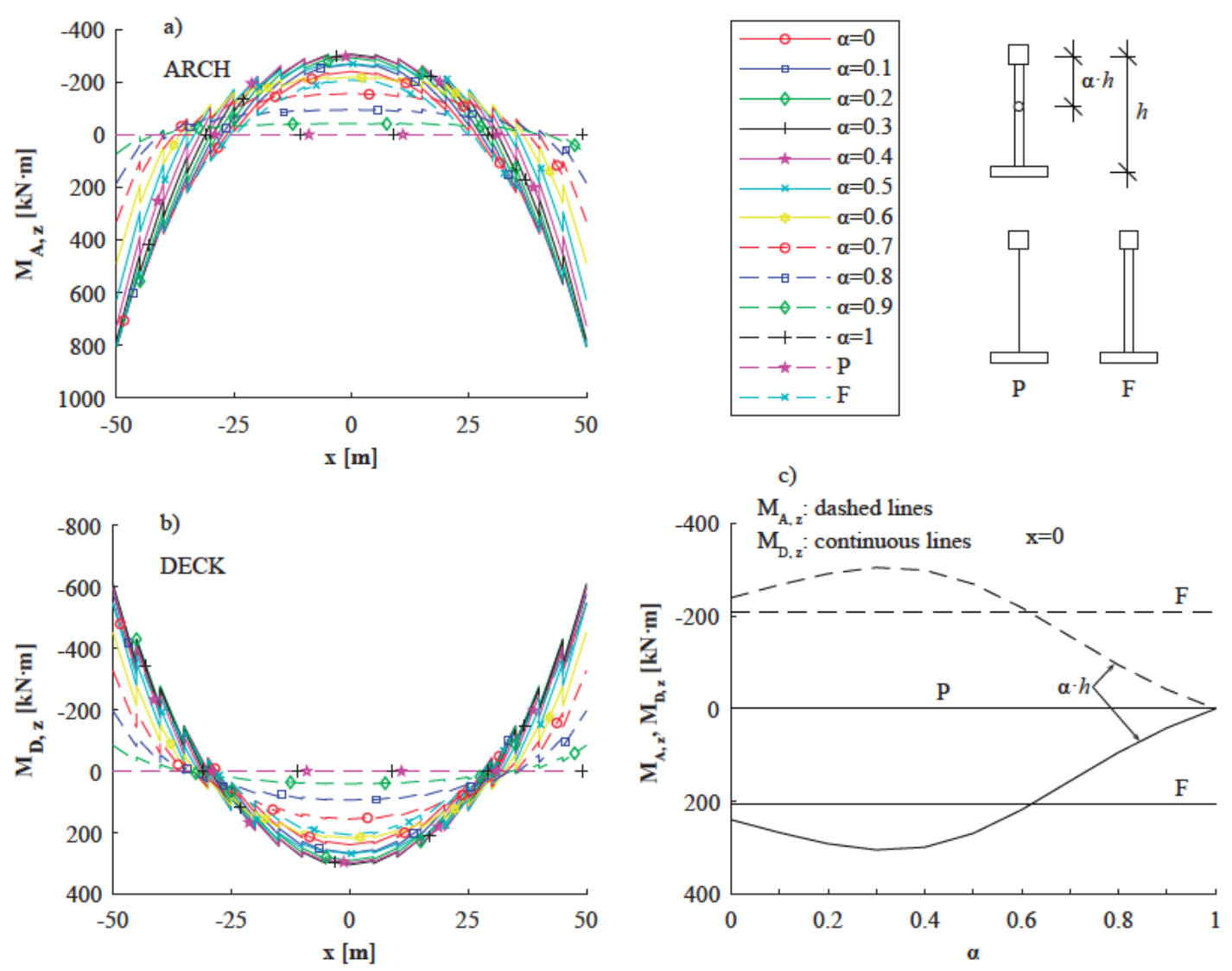

Figura 8.17: Momento transversal del arco (a) y del tablero (b) para una carga $q_{2}$ en función de la altura de la articulación.

el tablero, tributario de una péndola, $M_{t}=m_{t} \cdot s$ se transfiere como un momento flector transversal concentrado en la base inferior de la péndola, $M_{i}$. Por supuesto siempre ocurre que $M_{t} \geq M_{i} . M_{s}$ es el momento flector puntual que aparece en la cabeza de la péndola y se transfiere al arco.

Dado que el cortante $\mathrm{V}$ es el mismo a ambos lados de la articulación, la relación $M_{s} / M_{i}$ se puede expresar, para péndolas con una articulación, como:

$$
\frac{M_{s}}{M_{i}}=\frac{\alpha}{1-\alpha}
$$

El cortante horizontal $V$ actúa en ambos extremos de la péndola, y su valor depende de la posición de la articulación (véase la figura 8.20-a). En el tablero genera flexión de eje vertical (véase la figura 8.17-b), que muy raramente será el caso de carga más desfavorable pues la anchura del tablero viene dada habitualmente por requerimientos funcionales y suele ser muy alta. En el arco, $V$ es una carga concentrada actuando fuera del plano que hace que el arco se comporte como una viga curva donde la flexion (véase la figura 8.17-a) y la torsion (véase la figura 8.18-a) están acopladas (véase Jorquera Lucerga [46] y [47]). 

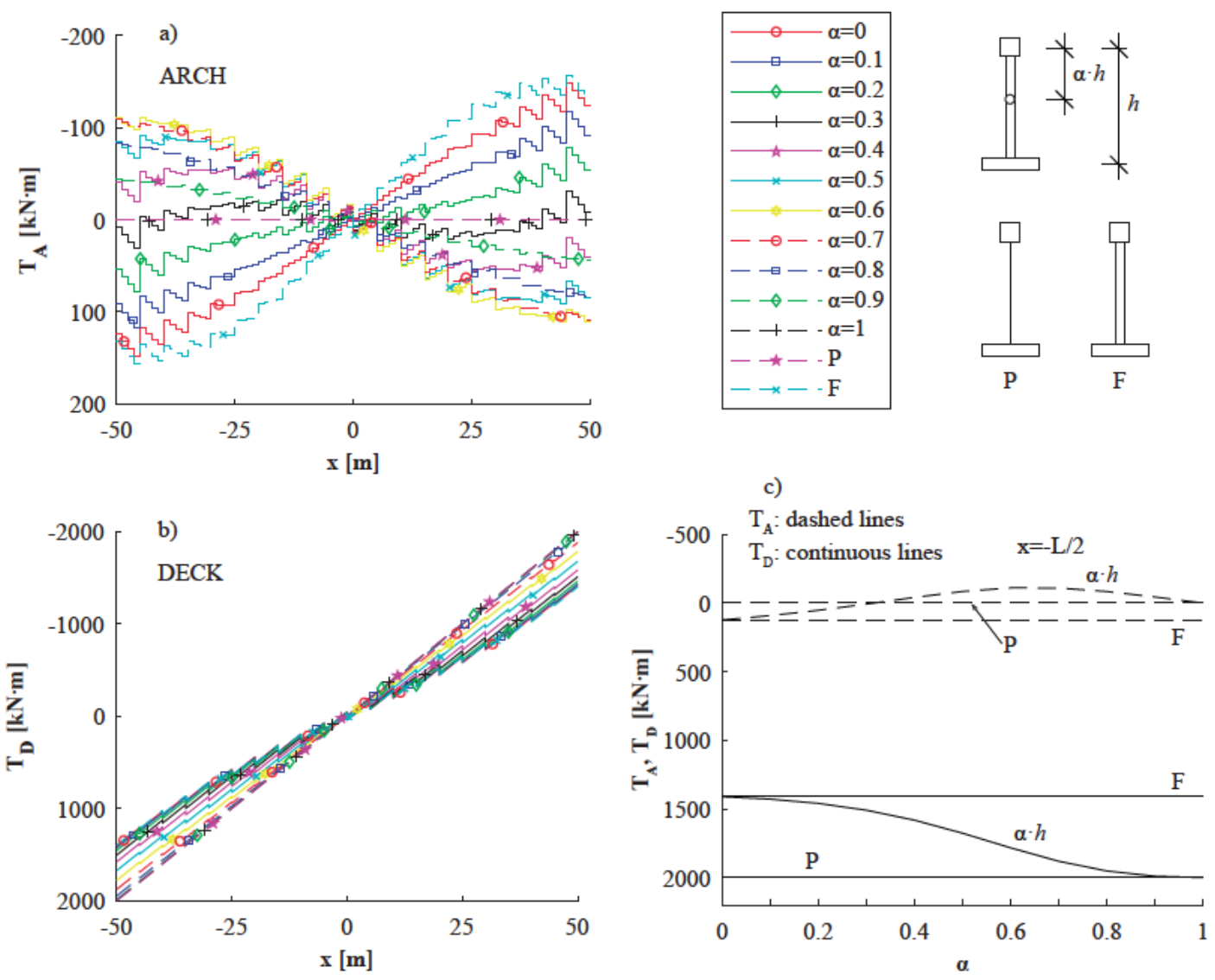

Figura 8.18: Torsión para $q_{2}$ en el arco (a) y el tablero (b) vs. posición de la articulación. c) detalle de resultados en arranques y estribos.

\subsubsection{Efectos de la rigidez transversal del arco y la péndola}

La eficacia transversal de las péndolas rígidas puede ser estimada, por ejemplo, por el procedimiento de comparar para la longitud tributaria $s$ de tablero para cada péndola, el momento flector transversal soportado en la base de la péndola $M_{i}$ (véase la figura 8.20), con respecto al torsor producido por la excentricidad de la carga $q_{2}$ actuando sobre el tablero, $M_{t}$. Para los casos mostrados anteriormente, la eficiencia de las péndolas puede expresarse por el coeficiente $e_{H}=M_{i} / M_{t}$. La figura 8.21-a muestra cómo $e_{H}$ es mayor para las péndolas totalmente empotradas, mientras que para las péndolas con una articulación la posición más efectiva es $\alpha=0$. La eficacia se incrementa hacia el centro de vano, alcanzándose valores máximos de en torno al $40 \%$.

La rigidez transversal de las péndolas es un parámetro de importancia fundamental para definir su eficacia. Sin embargo, tiene un límite superior: si la rigidez transversal de la péndola se mayora por 100 (un valor poco realista pero muy ilustrativo), la eficacia de las péndolas alcanza valores máximos en torno al $55 \%$ (véase la figura 8.21-b). Si se mayoran por ese mismo factor de 100 las inercias transversal y torsional del arco, mientras se mantiene la rigidez de la péndola (véase la figura 8.21-c), la eficacia alcanza valores en torno al $75 \%$. Es necesario mayorar, simultáneamente, tanto la rigidez fuera del plano del 

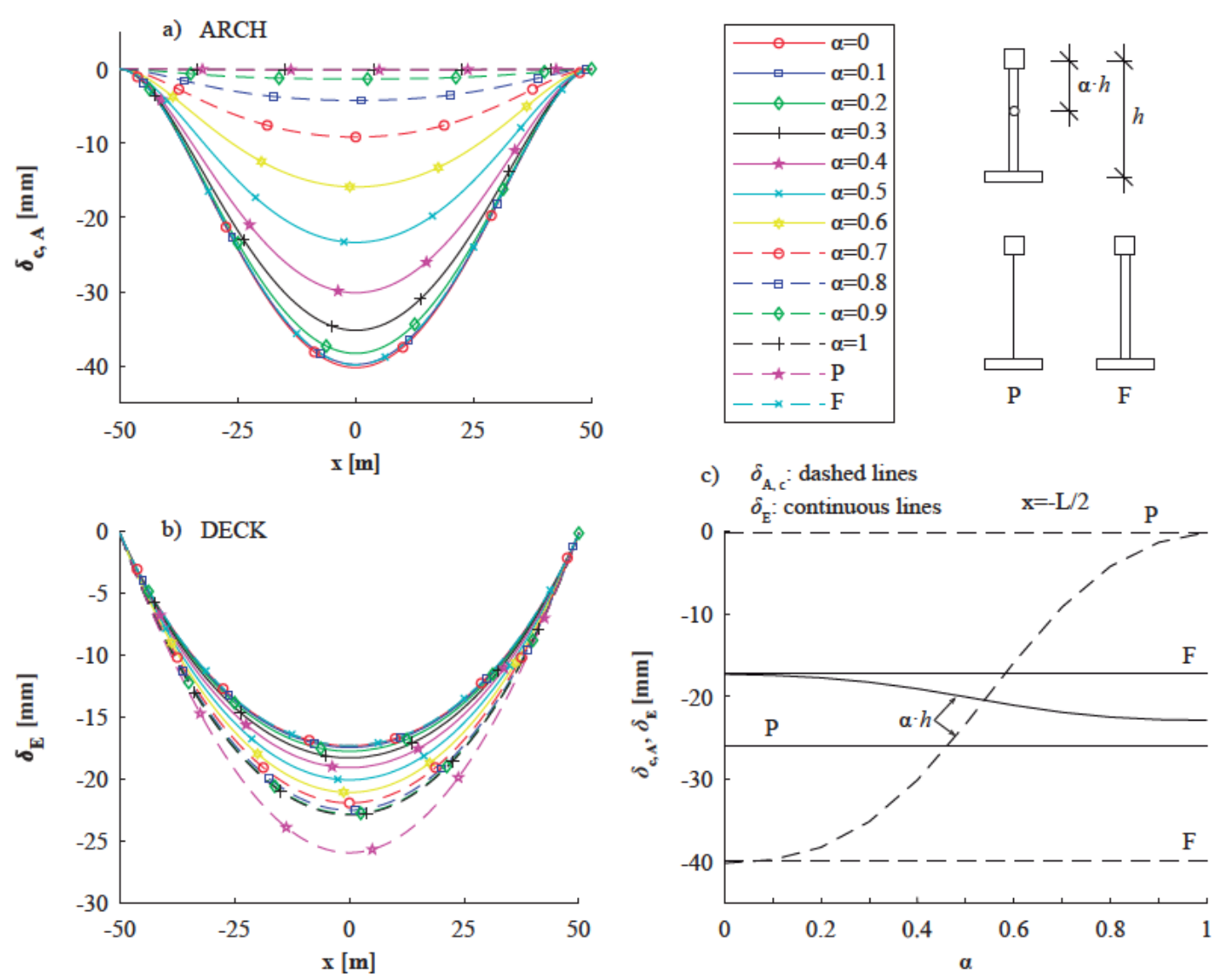

Figura 8.19: a) Deformación transversal en la clave para $q_{2}$. b) Deformación vertical en el borde del tablero para $q_{2}$. c) Detalle de resultados en el centro de la luz.

arco (inercias transversales y torsional, que definen conjuntamente su comportamiento como viga curva) como la rigidez transversal de la péndola por factores muy altos (por 100 en la figura 8.21-d) para alcanzar valores de eficacia cercanos al $100 \%$. En resumen, la capacidad de las péndolas para transformar parte del momento torsor del tablero $M_{t}$ en un momento flector en la base de las péndolas $M_{i}$ viene definida por la rigidez transversal combinada arco-péndolas. Es de destacar que la eficacia más alta siempre se obtiene en todos los casos (véase la figura 8.21) para las péndolas biempotradas. La configuración más eficaz, para las péndolas con una articulación, aparece para valores muy bajos de $\alpha$, es decir, para articulaciones muy cercanas al arco.

\subsubsection{Comparación de péndolas rígidas frente a péndolas con una articulación}

En las secciones anteriores se acaba de mostrar cómo las péndolas rígidas transversalmente pueden utilizarse para reducir los momentos torsores del tablero y, en consecuencia, las deflexiones en su borde. Sin embargo, sería deseable que la eficiencia del sistema arcopéndola no se consiguiera a costa de inducir esfuerzos elevados en el arco. Así es preferible, para soportar un momento dado $M_{i}$, reducir $M_{s}$ al mínimo. Con ese objetivo, se estudiarán 

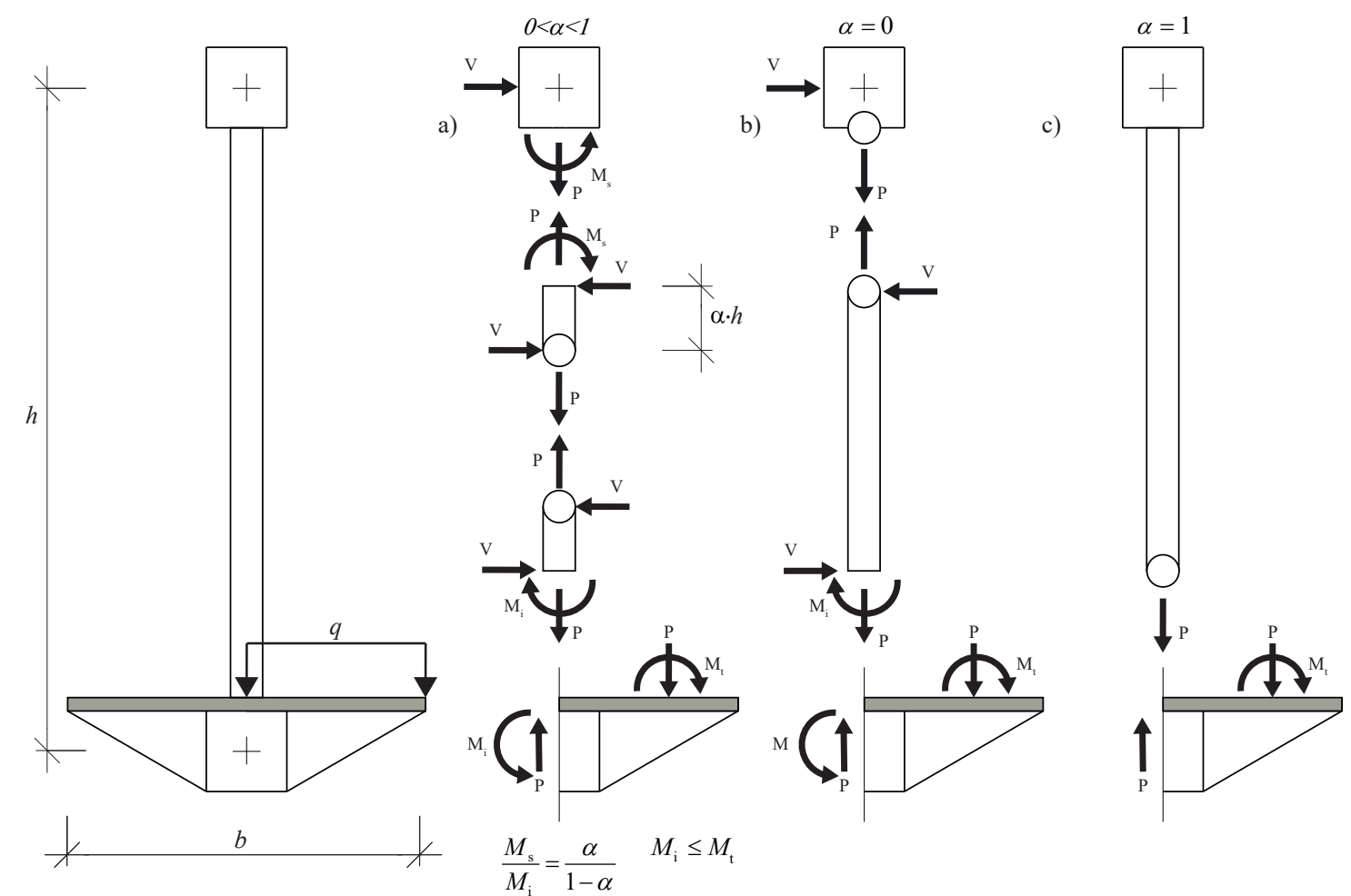

Figura 8.20: Transferencia de cargas de un tablero cargado asimétricamente hacia el mecanismo resistente compuesto por un arco y una péndola con una articulación.

las configuraciones de la figura 8.22.

A primera vista, podría parecer que el comportamiento de las péndolas rigidizadas transversalmente se describe adecuadamente en las figuras 8.22-a y 8.22-c, es decir, que la suposición de que el giro del tablero está totalmente restringido puede considerarse válida. Así, el arco funcionaría como un empotramiento para la cabeza de la péndola.

Supongamos que el criterio para seleccionar entre diferentes péndolas viene dado por minimizar la relación $M_{s} / M_{i}$. Para el caso (a), $M_{i}$ viene definido por la ecuación 8.2, es decir, $M_{s}=\alpha /(1-\alpha) \cdot M_{i}$, mientras que, para el caso (c) siempre se verifica que $M_{s}=0,5 \cdot M_{i}$. Así, la péndola con una articulación siempre resultaría más eficaz que una péndola empotrada para $M_{s}<0,5 \cdot M_{i}$, es decir, para $0<\alpha<1 / 3$.

Sin embargo, esta suposición no es válida, porque el arco se comporta como un apoyo elástico para la péndola, cuyo comportamiento se define según las figuras 8.22-b y 8.22d. Así, la conexión entre el arco y la péndola puede ser modelizada, simplificadamente, como dos muelles, uno rotacional y otro traslacional, que permiten parcialmente tanto el desplazamiento fuera del plano como el giro del arco, y, consecuentemente, también en la cabeza de la péndola. Las rigideces de estos muelles se han representado por $k_{\delta} \mathrm{y}$ $k_{\theta}$ en las figuras 8.22-b y 8.22-d. Por lo tanto, para la péndola empotrada $M_{s}$ sufre una importante reducción. Por el contrario, para la péndola con una articulación (caso b), $M_{s}$ sigue siendo definido por la ecuación 8.2, independientemente del valor de $\alpha$. Este hecho es crucial y puede comprobarse en la figura 8.23, que muestra la relación $M_{s} / M_{i}$ para el puente de referencia. Es de destacar que las líneas de la figura 8.23 son horizontales 

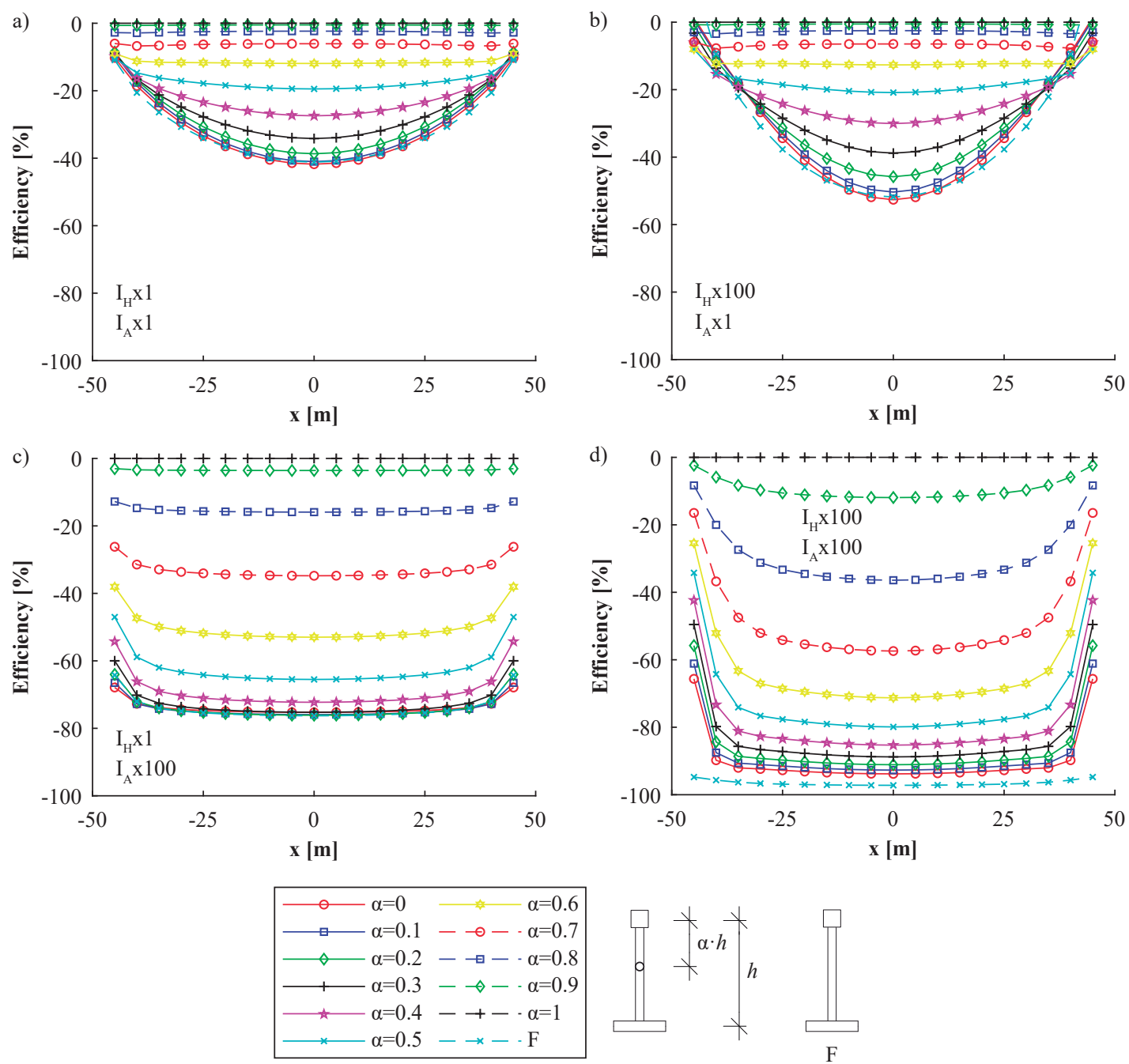

Figura 8.21: Eficacia $e_{H}=M_{i} / M_{t}$ vs rigidez. Rigidez transversal de péndolas ponderada por $k_{H}$, rigidez transversal y torsional del arco ponderada por $k_{A}$. (a) $k_{H}=k_{A}=1$, (b) $k_{H}=100, k_{A}=1$, (c) $k_{H}=1, k_{A}=100$, (d) $k_{H}=k_{A}=100$.

para péndolas con una articulación, lo que significa que $M_{s}$ depende de la localización de la articulación dentro de la péndola (véase la figura 8.22-e) y no de la posición de la péndola en el puente. Como puede verse, $M_{s} / M_{i}$ cae por debajo del $1 \%$ para péndolas empotradas, valores estos muy similares a los obtenidos para péndolas con articulaciones en el extremo superior, es decir en $\alpha=0$.

Por lo tanto, como conclusión general, puede deducirse que las péndolas con articulaciones transversales no son tan efectivas como las péndolas totalmente empotradas, excepto para configuraciones no realistas en las cuales la rigidez transversal del arco puede ser considerada prácticamente infinita. Sin embargo las péndolas con una articulación en su extremo superior $(\alpha=0)$ son prácticamente tan eficaces como las péndolas totalmente empotradas, porque en estas últimas el momento $M_{s}$ tiende a desaparecer debido a la flexibilidad rotacional del arco. 

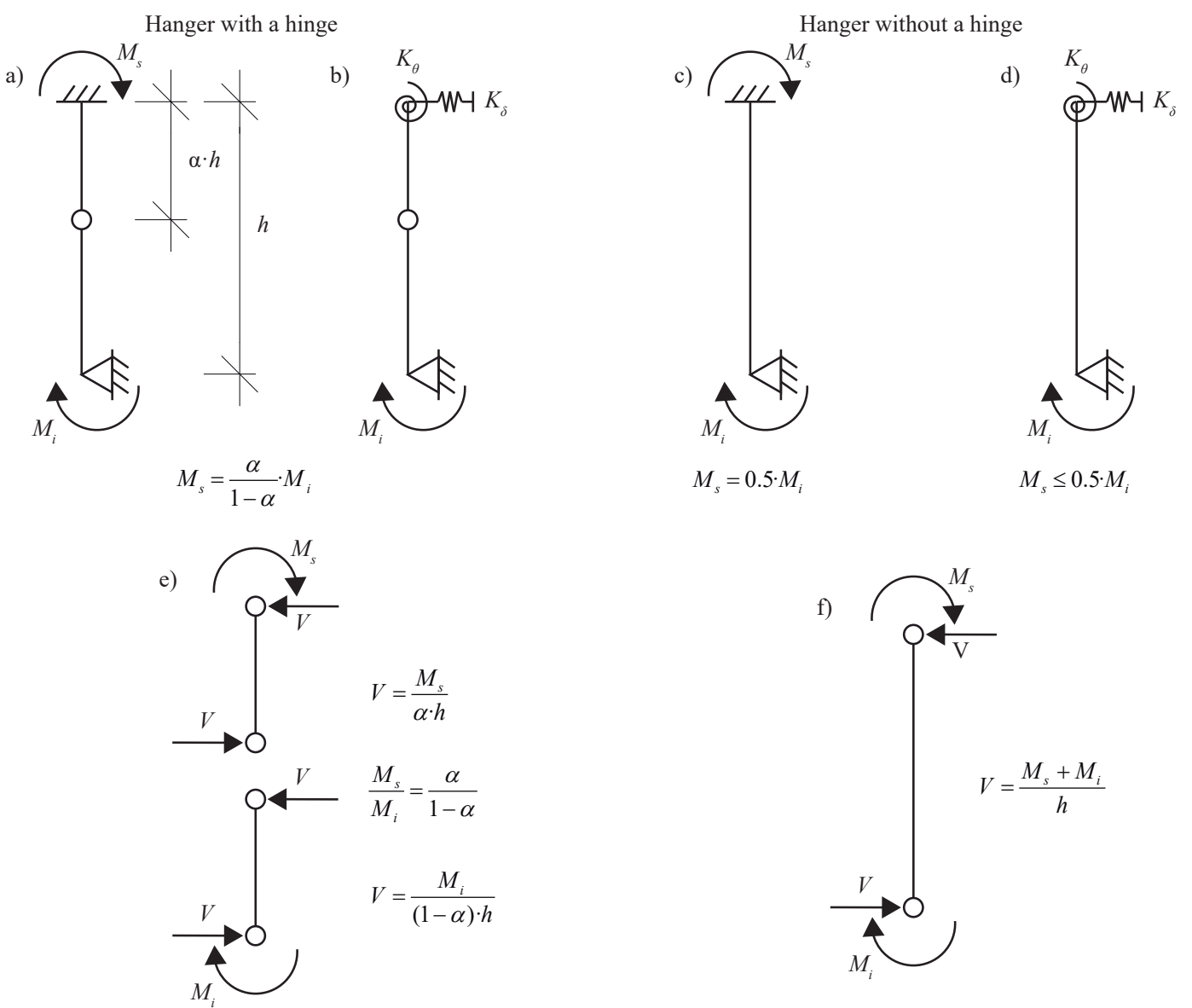

Figura 8.22: Mecanismos resistentes en péndolas con y sin articulaciones.
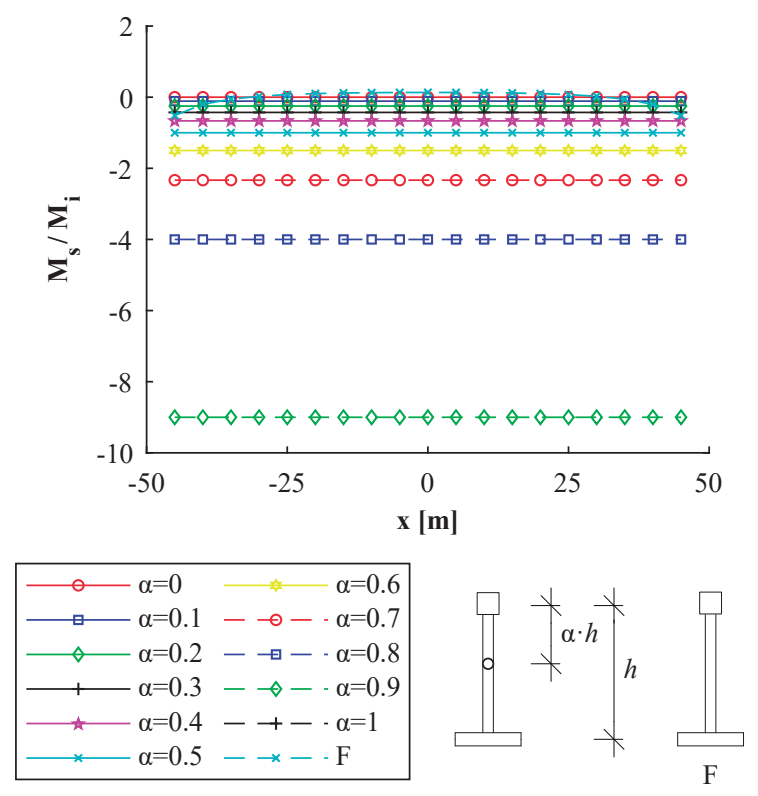

Figura 8.23: $M_{s} / M_{i}$ para $q_{2}$. Puente de referencia. 


\subsubsection{Pandeo fuera del plano}

La rigidización transversal de péndolas también puede ser utilizada para reducir la sensibilidad al pandeo transversal del arco. Para el puente de referencia se ha obtenido una carga crítica de pandeo para la combinación simplificada de cargas $1,35 \cdot(P P+C M)+0,6$. $1,5 \cdot V T O+\lambda \cdot q_{5}$, donde PP se corresponde con el peso propio, CM con la carga muerta, VTO con una carga de viento transversal de $2 \mathrm{kN} / \mathrm{m}^{2}$, y el coeficiente $\lambda$ se incrementa gradualmente hasta que $\lambda=\lambda_{u}$, situación que correspondería al colapso (véase la figura 8.24). Como puede verse, lo que se corresponde con la intuición, las péndolas empotradas son las más eficaces a la hora de impedir el pandeo del arco.
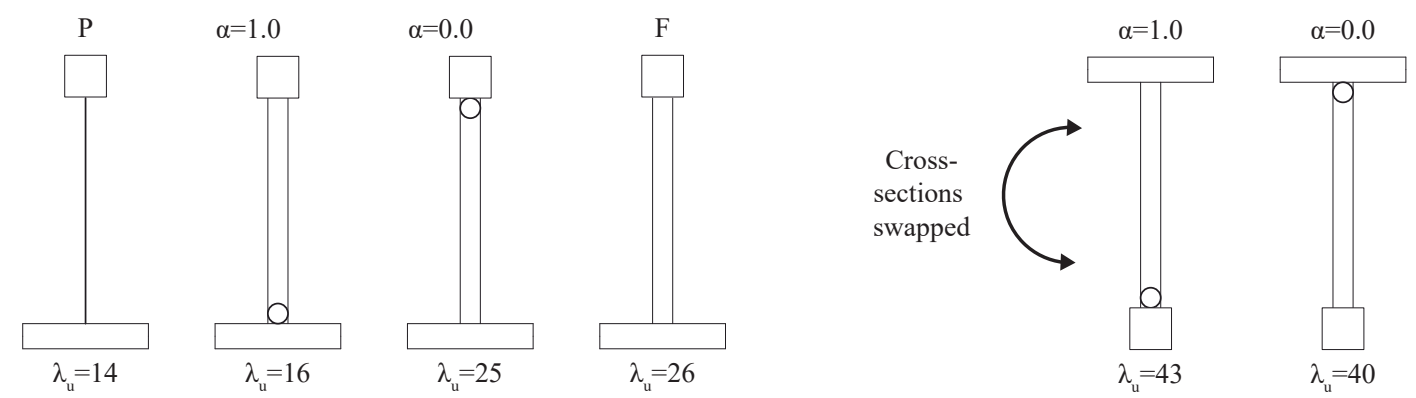

Figura 8.24: Puente de referencia: Coeficiente $\lambda_{u}$ para diferentes configuraciones de péndolas, para la hipótesis de carga $1,35 \cdot(P P+C M)+0,6 \cdot 1,5 \cdot V T O+\lambda \cdot q_{5}$.

\subsubsection{Péndolas rígidas de sección variable frente a constante}

Como se ha visto anteriormente, las péndolas rígidas con una articulación en uno de sus extremos son prácticamente tan efectivas como las péndolas totalmente empotradas. El hecho de no necesitar capacidad a flexión en un extremo facilita la ejecución de este, como por ejemplo en los casos ya mostrados del Merchants Bridge y la pasarela de La Devesa.

En esta sección, una péndola rígida de sección transversal constante (RHS 500x400x20), articulada en uno de sus extremos se compara con una péndola de sección transversal variable entre una RHS 800x400x20 y una RHS 200x400x20. Esta distribución de material a lo largo de las péndolas se ha definido de tal manera que la cantidad de acero consumida por ambas péndolas sea igual. Como la sección transversal más pequeña tiene una rigidez asociada también muy pequeña, en términos prácticos se comporta como si estuviera articulada en ese extremo (véase la figura 8.25).

La figura 8.26-a muestra como el valor más pequeño de la deformación vertical en el borde del tablero corresponde a la péndola de sección variable, aunque los valores se distinguen poco debido a la elevada rigidez torsional del tablero. La figura 8.26-b muestra los resultados para un puente en el que la rigidez torsional anterior se ha ponderado por un factor de 0.02 , poco realista pero ilustrativo, lo que evidencia las diferencias entre los diferentes tipos de péndolas. Como el caso anterior, la péndola más eficaz es la de sección variable. 


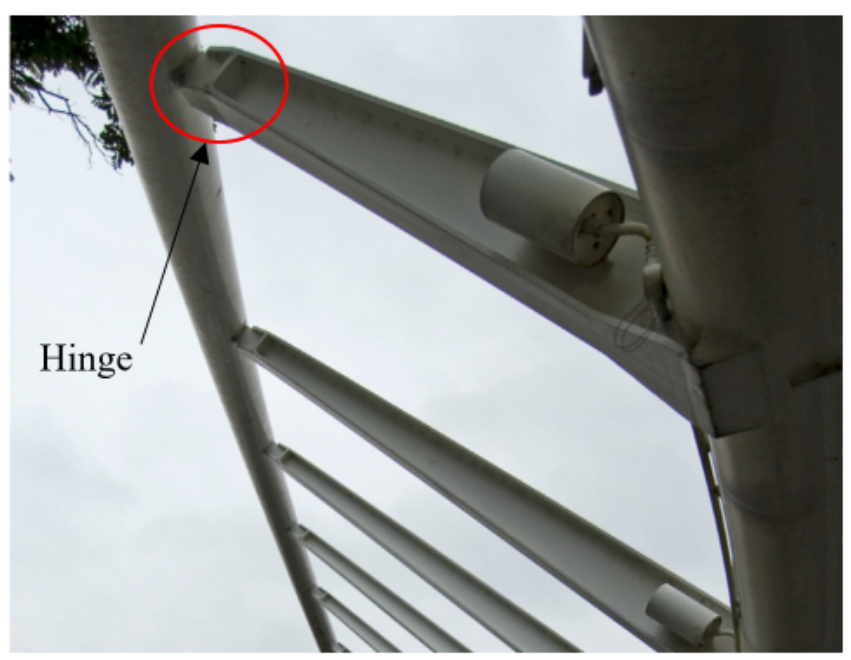

Figura 8.25: Extremo articulado conseguido mediante una sección de muy baja rigidez en el extremo. Merchants Bridge, Manchester.
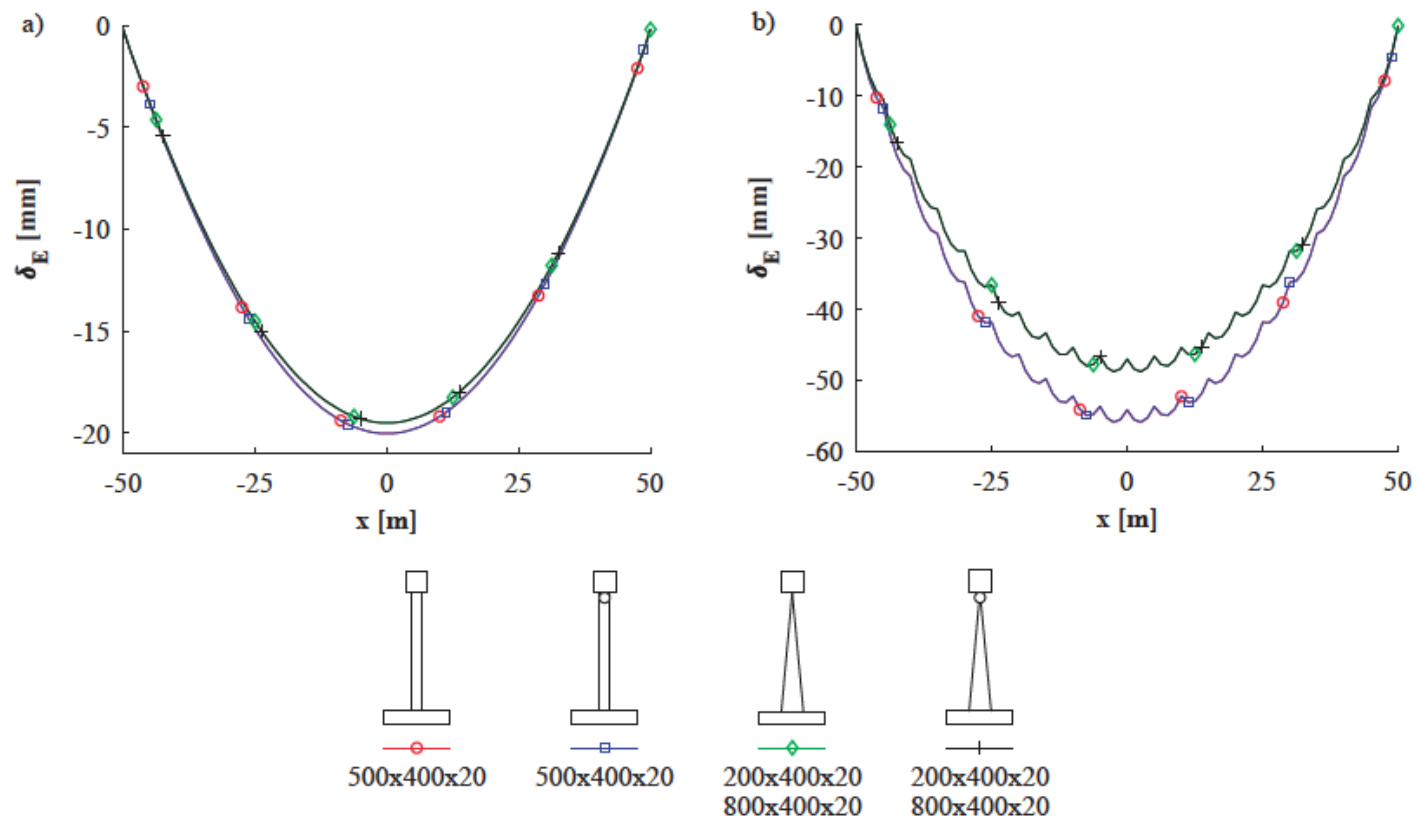

Figura 8.26: Deformación del borde del tablero para $q_{2}$, (a) Puente de referencia, (b) rigidez torsional del puente de referencia ponderada por 0.02 .

\subsection{Configuraciones de cables con rigidez a flexión}

En general, vincular el arco y el tablero por medio de cables conduce a un coste global menor en el puente, dado que los cables son también más fáciles de construir que las péndolas rígidas. Sin embargo las péndolas rígidas son más eficaces, desde el punto de vista estructural, a la hora de reducir flectores y deformaciones, como se ha mostrado en los capítulos anteriores.

Por lo tanto en esta sección se llevará a cabo un estudio para encontrar una configuración 
de cables cuyo efecto en la respuesta de la estructura sea comparable al de una péndola rígida, en un intento de combinar la eficacia estructural de las péndolas rígidas y la facilidad de ejecución de los cables. Como las respuestas dentro y fuera del plano están desacopladas, las configuraciones se han estudiado separadamente, como ya se hizo para las péndolas rígidas.

La figura 8.27 muestra las configuraciones estudiadas de péndolas contenidas en el plano del arco: A, V y X, así como dobles paralelas verticales (D). Todas se comparan con un cable único $(\mathrm{P})$ y una péndola totalmente empotrada $(\mathrm{F})$. La péndola rígida con una articulación en el arco no se ha considerado porque su efecto es muy similar al de la péndola biempotrada. La separación entre los cables es de $800 \mathrm{~mm}$, que es igual al canto de la péndola rígida.

Configuraciones similares se han estudiado para el comportamiento fuera del plano (véase la figura 8.28), que se han obtenido rotando 90 grados las configuraciones longitudinales mostradas en la figura 8.27.

La figura 8.29 muestra los momentos flectores y las deformaciones en el eje del tablero para $q_{3}$, para las diferentes configuraciones mostradas en la figura 8.27. Como era de esperar, la péndola con la configuración más eficaz es la totalmente empotrada. De las formadas por cables, la menos eficaz es la de un cable aislado y la más eficaz es la configuración en $\mathrm{X}$.

La figura 8.30 muestra, nuevamente, como la péndola totalmente empotrada es la más eficaz en lo que respecta al comportamiento transversal. Para las péndolas compuestas exclusivamente de cables, la péndola en A es la más eficaz.

Por lo tanto, parece claro que la eficiencia de la péndola totalmente empotrada no se
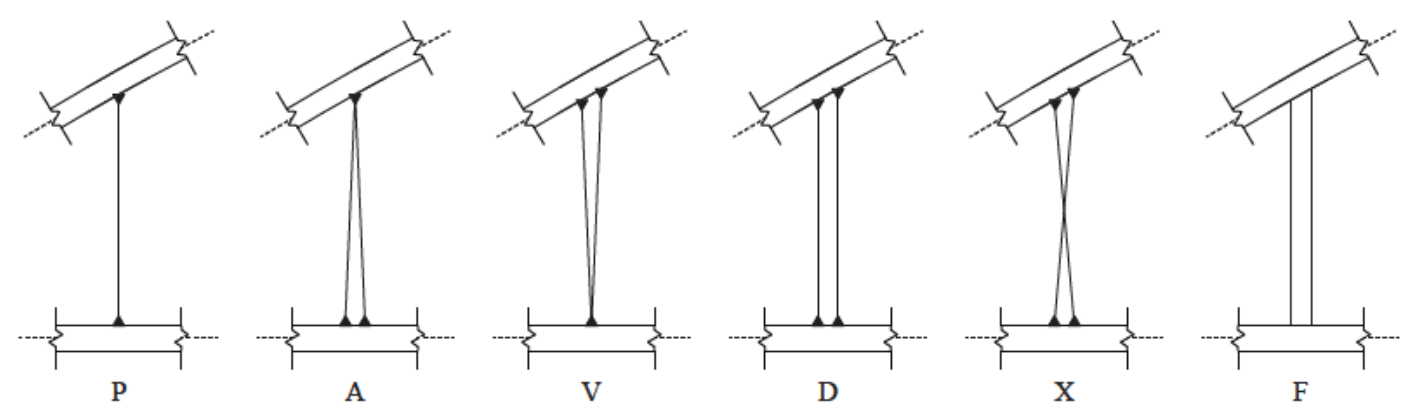

Figura 8.27: Configuraciones de cables contenidas en el plano del arco.
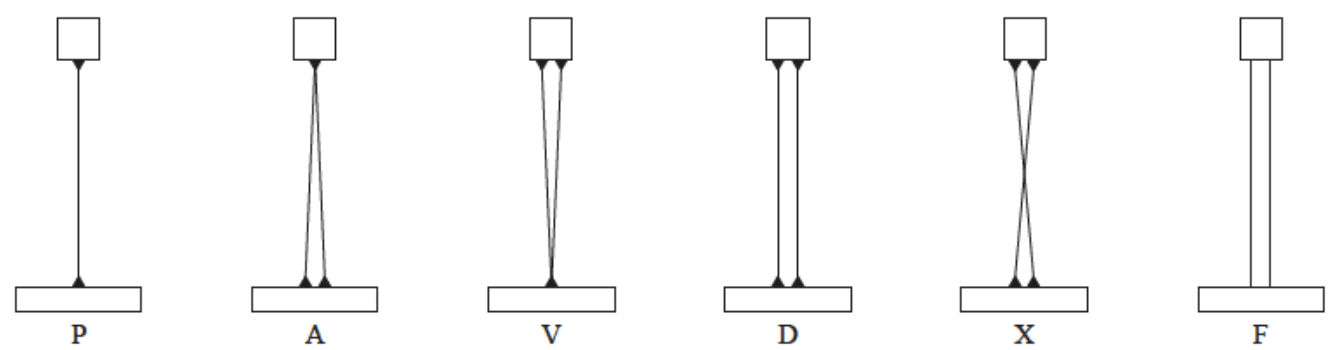

Figura 8.28: Configuraciones de cables contenidas en el plano perpendicular al del arco. 
puede conseguir usando las configuraciones de cables definidas en las figuras 8.27 y 8.28. Sin embargo una solución a medio camino entre la eficacia y el coste se puede conseguir combinando, en una configuración espacial, las más efectivas obtenidas dentro y fuera del plano, como se muestra en la figura 8.31.
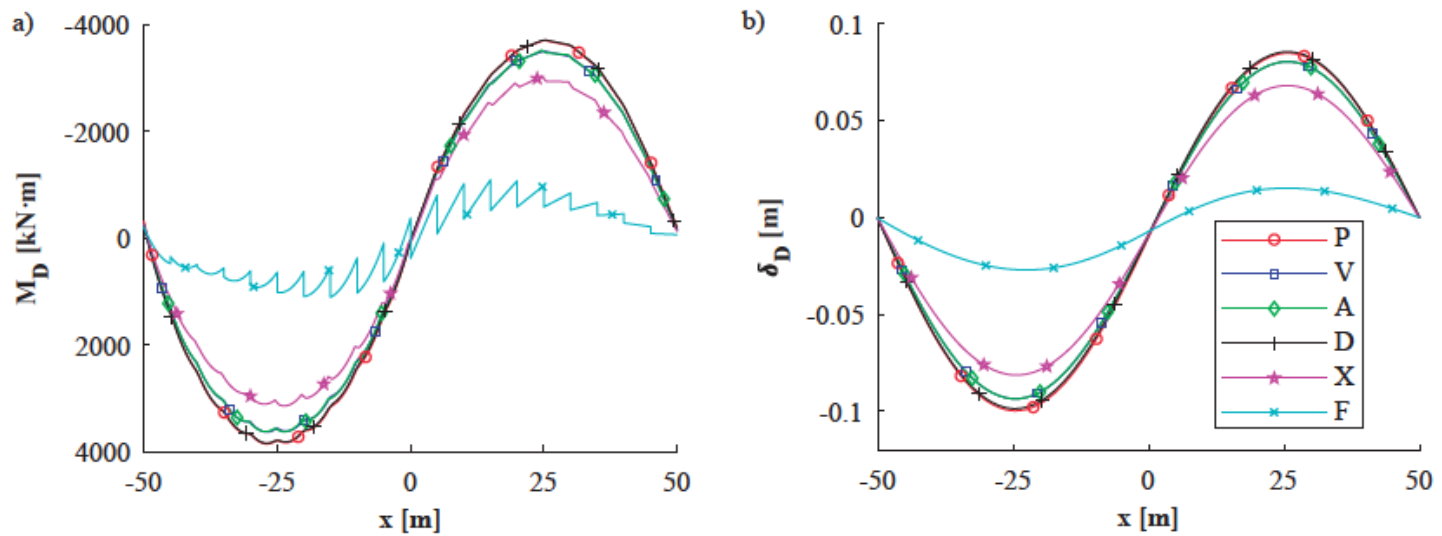

Figura 8.29: Tablero para $q_{3}$. a) flectores, b) deformaciones verticales en el eje.
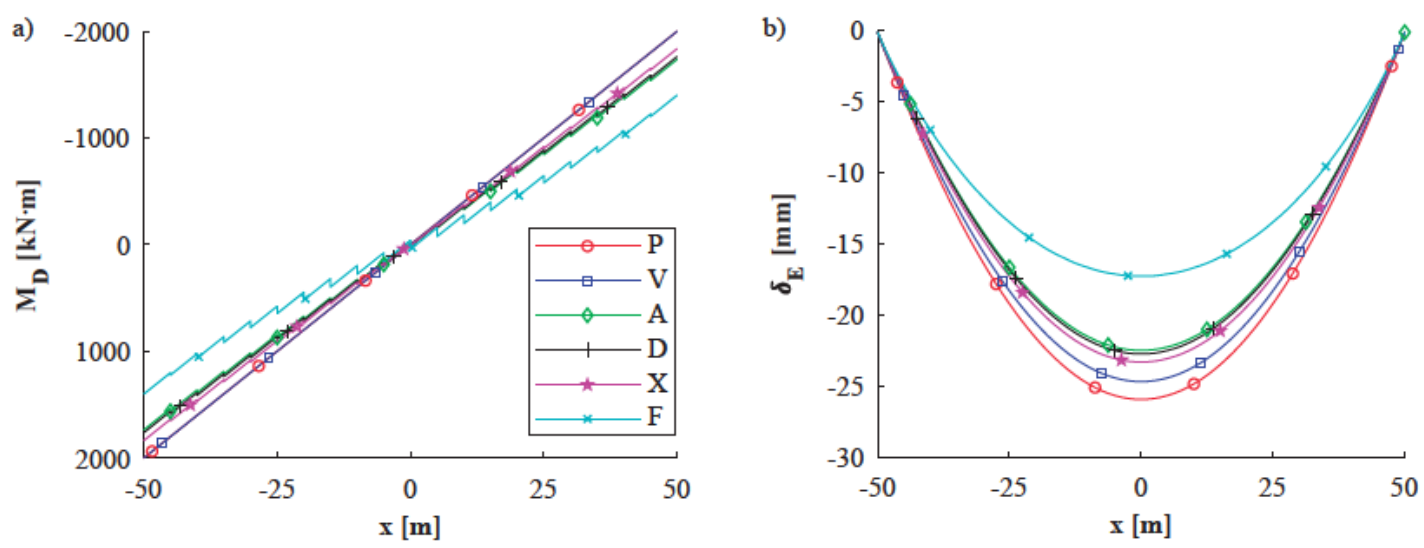

Figura 8.30: Tablero para $q_{2}$. a) torsores, b) deformaciones verticales en el borde.

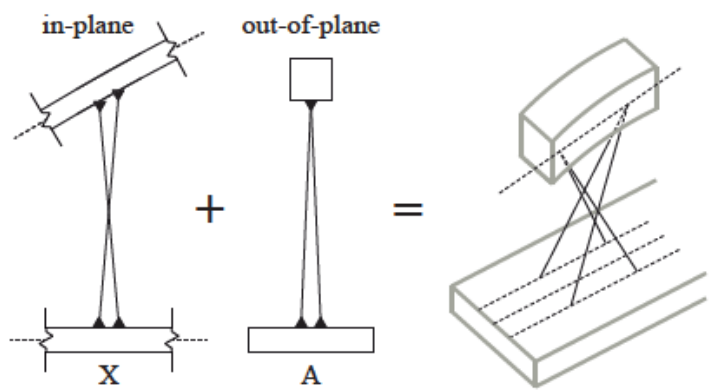

Figura 8.31: Configuración tridimensional de cables obtenida por combinación de configuraciones planas. 


\subsection{Consideraciones acerca de las péndolas rigidizadas transversalmente}

En puentes arco, la forma en la que el tablero y el arco se conectan puede resultar crucial. Si la tipología de la conexión arco tablero está adecuadamente elegida, tanto los momentos como las deformaciones pueden ser reducidos sensiblemente. De esta forma, la disposición de péndolas se convierte en una herramienta a disposición del diseñador, principalmente en las fases iniciales del diseño conceptual.

Dado que, debido a la simetría longitudinal de la estructura, las respuestas en el plano y fuera de este están desacopladas, el efecto de las péndolas puede ser considerado independientemente para ambos planos. Por ejemplo, la orientación de las péndolas en doble $\mathrm{T}$ puede ser definida para proporcionar rigidez longitudinal, para soportar flexión en el plano, o alternativamente, rigidez transversal, para resistir esfuerzos torsores en el tablero o esfuerzos fuera del plano en el arco.

La eficacia de las péndolas no solo depende de su rigidez, sino de la rigidez del arco y del tablero. Por ejemplo, la reducción de la deformación en el borde del tablero viene gobernada por la rigidez transversal arco-péndola.

Los estudios realizados muestran que en términos prácticos, los extremos de las péndolas son las únicas posiciones posibles para las articulaciones que no llevan a una pérdida significativa de eficacia resistente.

Si la péndola está articulada en uno de sus extremos, la péndola conserva una gran parte de la eficacia de las péndolas empotradas. La pérdida de eficacia es menor si la péndola está empotrada en el elemento más rígido, bien sea el arco o el tablero. Dado que la conexión en el extremo articulado no necesita capacidad ni a cortante ni a flexión, la péndola articulada es más fácil de construir y supone un ahorro en términos generales.

El material de la péndola se puede distribuir de manera que sea más rígida en el extremo empotrado. Esta distribución incrementa la eficacia de la péndola al coste de tener que usar secciones variables.

La eficiencia de la péndola totalmente empotrada (o soluciones similares) no se puede conseguir usando las configuraciones de cables estudiadas. Sin embargo soluciones a medio camino pueden conseguirse combinando la configuración en X en el plano longitudinal con la solución en A en el plano perpendicular. 


\section{Parte IV}

La espacialidad como evolución del diseño conceptual en puentes arco simétricos 



\section{Capítulo 9}

\section{Atirantamiento a ambos bordes}

El objetivo de este capítulo de la tesis es comprender como un arco plano clásico puede evolucionar hasta convertirse en un arco espacial atirantado a ambos bordes, con el fin de resolver un problema en el tablero. Se establece también como objetivo secundario, comprobar si una configuración de péndolas tipo Nielsen, muy efectiva en la reducción de esfuerzos y deformaciones de puentes arcos clásicos, sigue manteniendo su gran efectividad en arcos espaciales simétricos como el de este capítulo.

Un ejemplo muy ilustrativo es el puente de Wittenberg sobre el río Elba (véase la figura 9.1). Este puente está formado por dos arcos, uno de ellos vinculado al centro del tablero mediante un atirantamiento simple, y el otro, que sustenta una línea de ferrocarril, está unido al tablero mediante dos juegos de cables atados a los bordes del tablero.

Puesto que los puentes arco espaciales tienen un comportamiento complejo, el estudio es una progresión gradual de distintas disposiciones de arco y tablero. Las secciones transversales que se estudian en el capítulo se muestran en la figura 9.2. En esta figura se puede observar un puente arco clásico con un atirantamiento simple, compuesto por un solo juego de péndolas atadas al centro de tablero (figura 9.2-a), y un puente arco con un atirantamiento doble, que está formado por dos juegos de péndolas atadas a los bordes del tablero (figura 9.2-b).

\subsection{Modelo de referencia y acciones consideradas}

La totalidad de los puentes estudiados en este capítulo, están basados en el puente arco de referencia descrito en el capítulo 3, aunque con algunas variaciones. Ya que el estudio es principalmente cualitativo, el puente de referencia es considerado como representativo de su clase. Este modelo de referencia está compuesto por un tablero recto soportado por un arco plano vertical. El puente pertenece a la tipología conocida como bow-string (o arco atirantado), ya que los arranques del arco están sujetos por el tablero traccionado. El arco y el tablero están unidos por una familia de péndolas verticales ancladas al eje del tablero. En el modelo de referencia, las péndolas se modelizan como cables que están articulados en ambos extremos. Este capítulo se centra en los efectos de vincular el arco mediante cables sujetos a ambos bordes del tablero (véase la figura 9.2-b). 


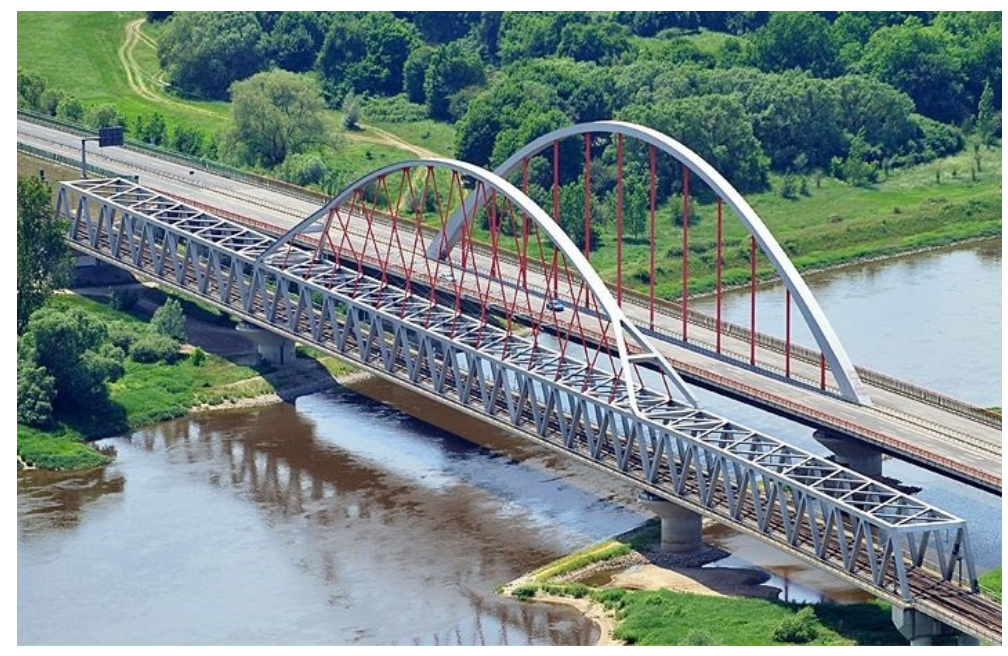

Figura 9.1: Puente de Wittenberg sobre el río Elba. Fotografía: Schüßler-Plan (schuesslerplan.de)
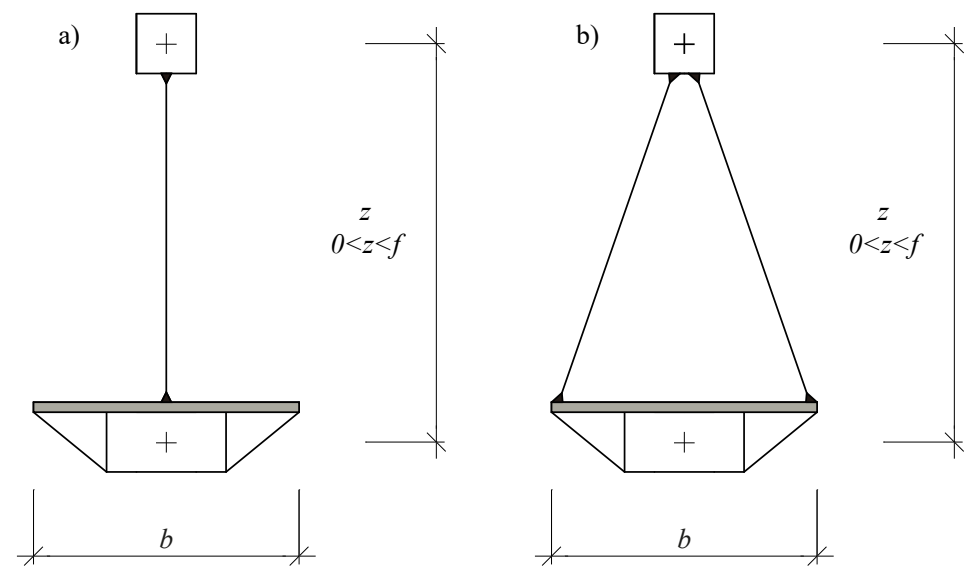

Figura 9.2: a) arco recto al centro con atirantamiento simple , b) arco recto al centro con atirantamiento doble.

El modelo de estudio tiene una luz $L=100 \mathrm{~m}$, y una flecha del arco $f=20 \mathrm{~m}$. La distancia entre péndolas medida sobre el tablero es $s=5 \mathrm{~m}$. El ancho cargado del tablero se ha modificado con respecto al modelo de referencia mostrado en el capítulo 3 con el fin de amplificar el efecto a estudiar, teniendo ahora un valor $b=8 \mathrm{~m}$. Estas dimensiones están inspiradas por puentes arco reales, y relativamente comunes (véase por ejemplo Leonhardt [56], o Lebet y Hirt [55]). Todos los puentes estudiados han sido diseñados de acuerdo al Eurocódigo 3 [12].

Las dimensiones de las secciones del modelo de referencia del capítulo 3 se han modificado para que se sigan cumpliendo las limitaciones de flechas y tensiones, pues el ancho cargado es el doble del especificado en el modelo de referencia del capítulo 3. En los casos donde se colocan cables en ambos bordes, la sección de los mismos se mantiene igual a la de los cables de los modelos con cables anclados solo al centro del tablero. Un resumen de las dimensiones de las secciones del puente, las cuales son también usuales en puentes de este tipo, se puede observar en la tabla 9.1. 


\begin{tabular}{|cccc|}
\hline Elemento & Sección transversal & Dimensiones & $\begin{array}{c}\text { Módulo de Young } \\
\mathbf{E}\left(\mathbf{N} / \mathbf{m m}^{2}\right)\end{array}$ \\
\hline \multirow{2}{*}{ Arco } & Cuadrada hueca & $\begin{array}{c}1250 \times 1250 \mathrm{~mm}, \\
t_{f, A}=t_{w, A}=30 \mathrm{~mm} \\
\phi 80 \mathrm{~mm}\end{array}$ & $2.0 \times 10^{5}$ \\
Péndolas & Circular maciza & $\begin{array}{c}5000 \times 1000 \mathrm{~mm}, \\
t_{f, D}=t_{w, D}=20 \mathrm{~mm}\end{array}$ & $2.0 \times 10^{5}$ \\
Tablero & Rectangular hueca & $2.0 \times 10^{5}$ \\
\hline
\end{tabular}

Tabla 9.1: Materiales y dimensiones de las secciones del puente usado en el estudio del capítulo 9 .

En este capítulo solo han sido consideradas cargas estáticas, siendo las usadas en este estudio:

- El peso propio (PP), evaluado para un peso específico de $78.5 \mathrm{kN} / \mathrm{m}^{3}$, y la carga muerta $(\mathrm{CM})$, con un valor de $\left(3.75 \mathrm{kN} / \mathrm{m}^{2}\right)$. Ambas cargas están definidas en el capítulo 3.

- Para este estudio, no es necesario considerar todos los posibles casos de carga que pueden aparecer en el diseño de un puente. Por lo tanto, solo se van a considerar cargas peatonales y de viento, ya que ilustran con la suficiente precisión, el efecto en el comportamiento longitudinal que tienen las péndolas ancladas a ambos bordes del tablero. Las sobrecargas de uso son $q_{1}, q_{2}, q_{3}, q_{4}$ y $q_{5}$, también definidas en el capítulo 3. Las sobrecargas (véanse las zonas de carga en la figura 3.4), son de tipo peatonal, y se corresponden con una carga distribuida de $5 \mathrm{kN} / \mathrm{m}^{2}$ (véase la IAP [27] o el Eurocódigo 1 [10]), para el ancho de tablero antes mencionado $b=8 \mathrm{~m}$. En cuanto al viento, la carga considerada es VTO, con un valor de de $2 \mathrm{kN} / \mathrm{m}^{2}$.

\subsection{Puentes arco con atirantamiento simple}

En este punto se comparan dos puentes con un arco centrado sobre el tablero y un solo juego de péndolas atadas al eje del tablero, pero con disposiciones de péndolas verticales (modelo V1) y tipo Nielsen (modelo N1). Estos modelos no son arcos espaciales (véase la figura 9.3), pero sirven para observar el problema inicial de exceso de flecha en el borde del tablero. El hecho de considerar dos tipos de atirantamiento, vertical y Nielsen, responde como se comentó anteriormente, a un segundo objetivo de demostrar si el atirantamiento tipo Nielsen sigue manifestándose igual de útil en arcos con doble atirantamiento.

En la figura 9.4 se puede observar como para una carga asimétrica $q_{3}$ el modelo N1 presenta una deformación mucho menor del eje del tablero que el modelo V1. Para comparar numéricamente la flecha de uno y otro modelo, se considera un punto en los riñones de ambos puentes $(x=-L / 4)$. En este punto la flecha para N1 es de $28 \mathrm{~mm}$, y para V1 de $100 \mathrm{~mm}$. La diferencia de flecha entre uno y otro modelo es de $72 \mathrm{~mm}$, con lo que la disposición de péndolas tipo Nielsen logra reducir la flecha del modelo de péndolas verticales en un $72 \%$. 


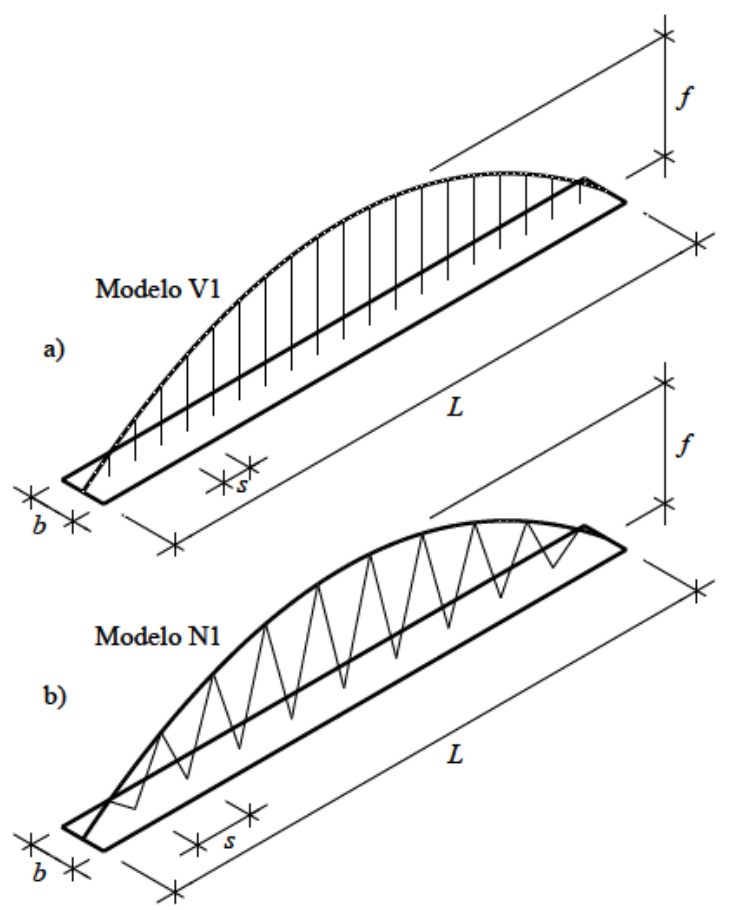

Figura 9.3: Definición de los modelos con un juego de (a) cables verticales (V1) y (b) tipo Nielsen (N1), anclados al eje del tablero.

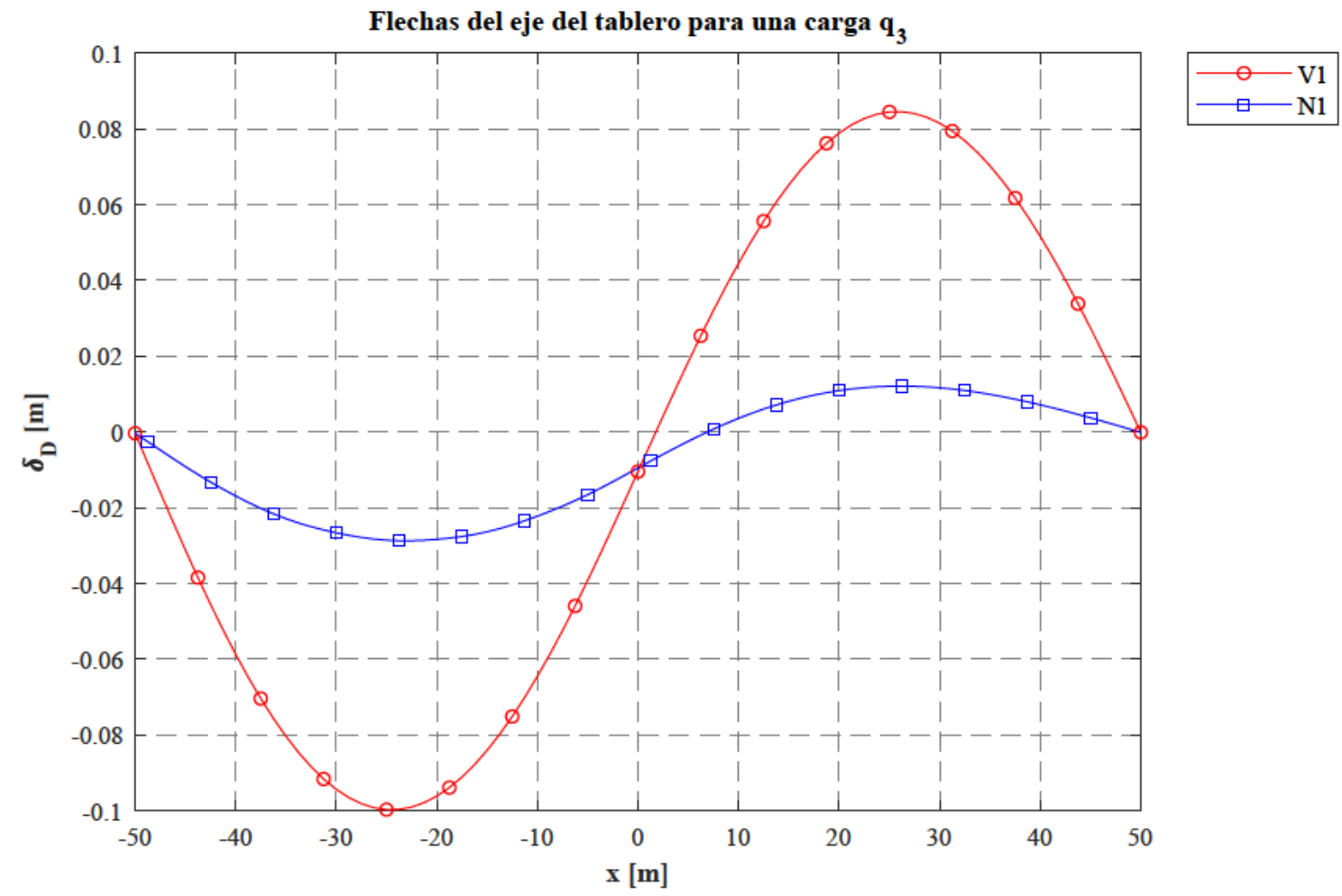

Figura 9.4: Flechas del eje del tablero para modelos con un solo juego de péndolas verticales (V1) o Nielsen (N1) ancladas al eje del tablero. 
Si se considera ahora la figura 9.5, se puede ver como ambas disposiciones de péndolas no son capaces de reducir la flecha del borde del tablero, ya que ambas configuraciones de péndolas están ancladas al eje del tablero, con lo que es este último el que tiene que resistir por si solo la torsión producida por la carga $q_{2}$, no participando en ningún momento la resistencia del arco.

Las carga $q_{2}$ introduce un momento torsor sobre el tablero. Este momento torsor (véase la figura 9.6) debe ser resistido únicamente por el tablero, pues no puede transmitirse al arco con un solo juego de péndolas. La carga $q_{2}$ produce la misma flexión longitudinal que si estuviese centrada en el tablero, pero introduce un giro que produce grandes flechas en el borde del tablero. Para el modelo V1 la carga $q_{2}$ produce en el borde del tablero donde se aplica la carga, y para el punto de riñones $(x=-L / 4)$, una flecha de $26 \mathrm{~mm}$, frente a los $10 \mathrm{~mm}$ del centro de tablero en riñones. La flecha en el borde es 2.6 veces superior a la del centro de tablero. En el arco N1 la carga $q_{2}$ produce en el borde del tablero donde se aplica la carga, y para el punto de riñones, una flecha de $25 \mathrm{~mm}$, frente a los $9 \mathrm{~mm}$ del eje de tablero en riñones. La flecha en el borde es 2.8 veces superior a la del centro de tablero. Se puede concluir así, que, como era de esperar, el atirantamiento simple al eje del tablero no permite reducir la flecha de borde.

En cuanto a la flexión longitudinal del arco (véase la figura 9.7), en el punto de riñones el flector para el modelo V1 es de $2579 \mathrm{kN} \cdot \mathrm{m}$ mientras que para el modelo $\mathrm{N} 1$ es de $747.5 \mathrm{kN} \cdot \mathrm{m}$, con lo que este último modelo logra reducir la flexión en el arco un $71 \%$. En el tablero ocurre algo similar (véase la figura 9.8), pues el flector en la sección de

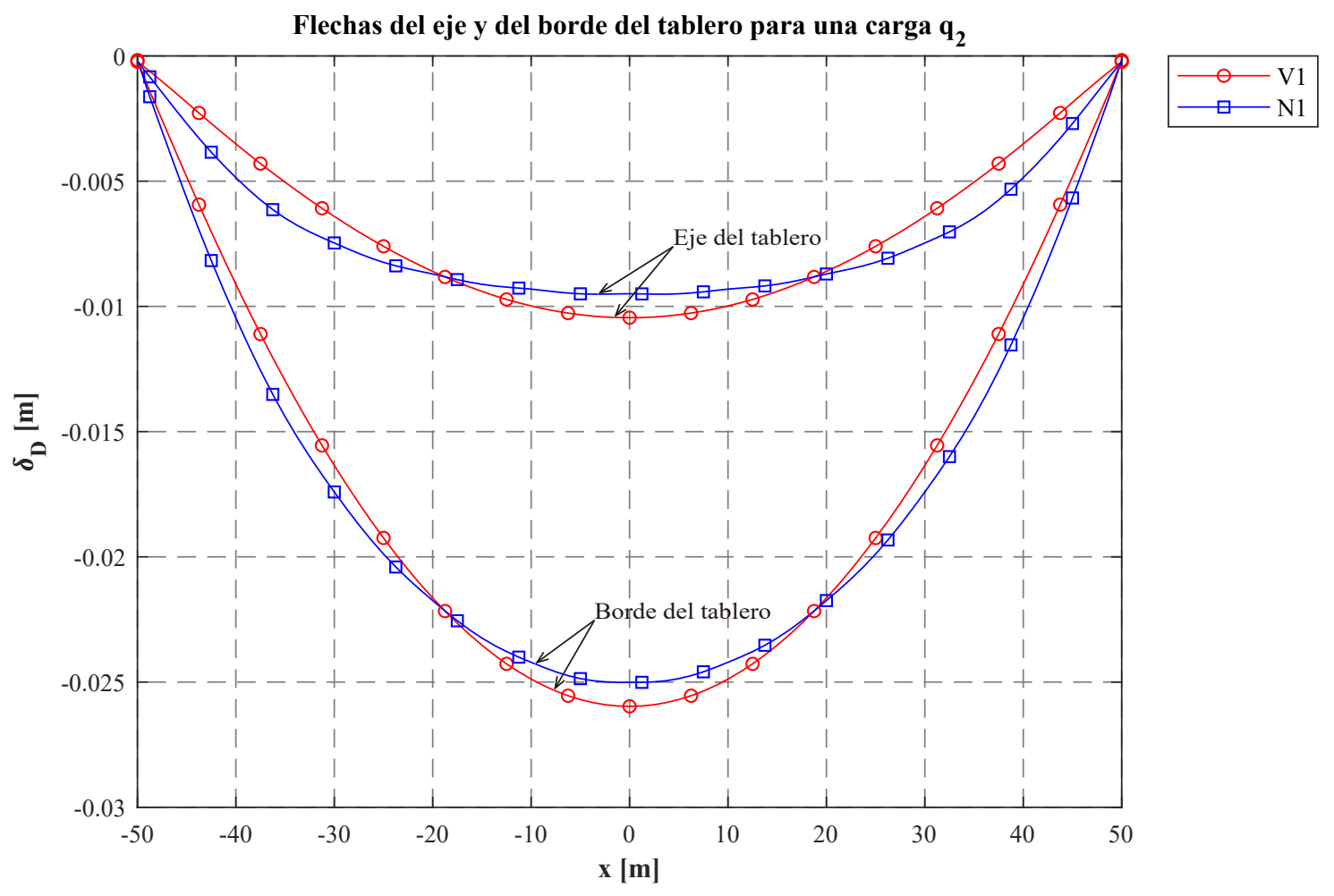

Figura 9.5: Flechas del eje y del borde del tablero para modelos con un solo juego de péndolas verticales (V1) o Nielsen (N1) ancladas al eje del tablero. 
riñones es de $3784 \mathrm{kN} \cdot \mathrm{m}$ para el modelo $\mathrm{V} 1$ y de $1009 \mathrm{kN} \cdot \mathrm{m}$ para el modelo $\mathrm{N} 1$, con lo que el atirantamiento Nielsen al eje del tablero logra reducir la flexión en este elemento estructural un $73 \%$.

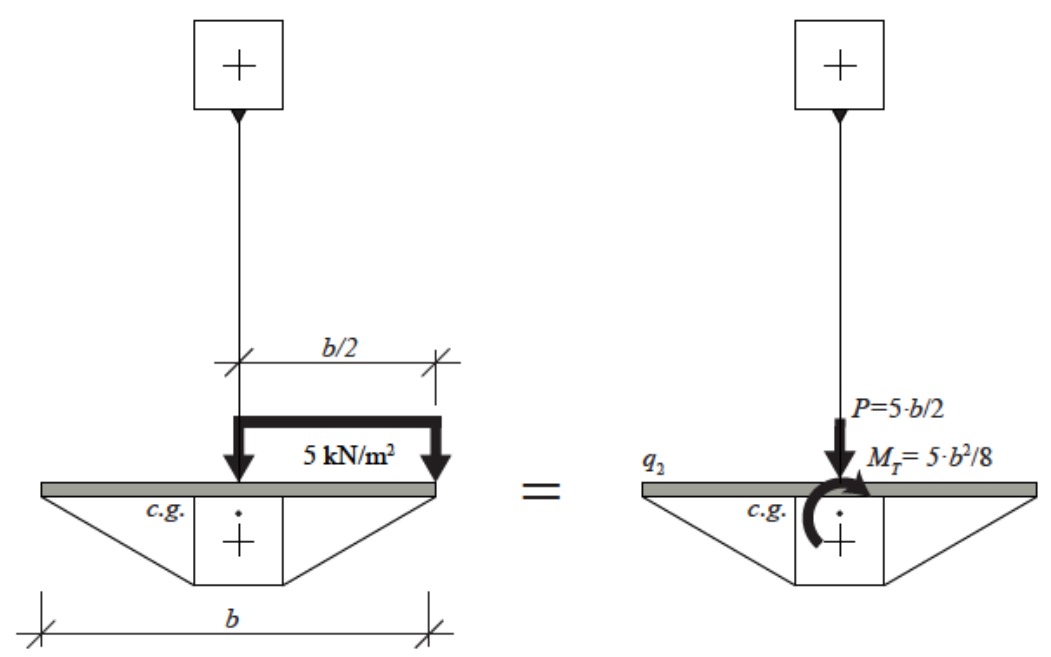

Figura 9.6: Cargas equivalentes para modelos con un solo juego de péndolas verticales (V1) o Nielsen (N1) ancladas al eje del tablero.

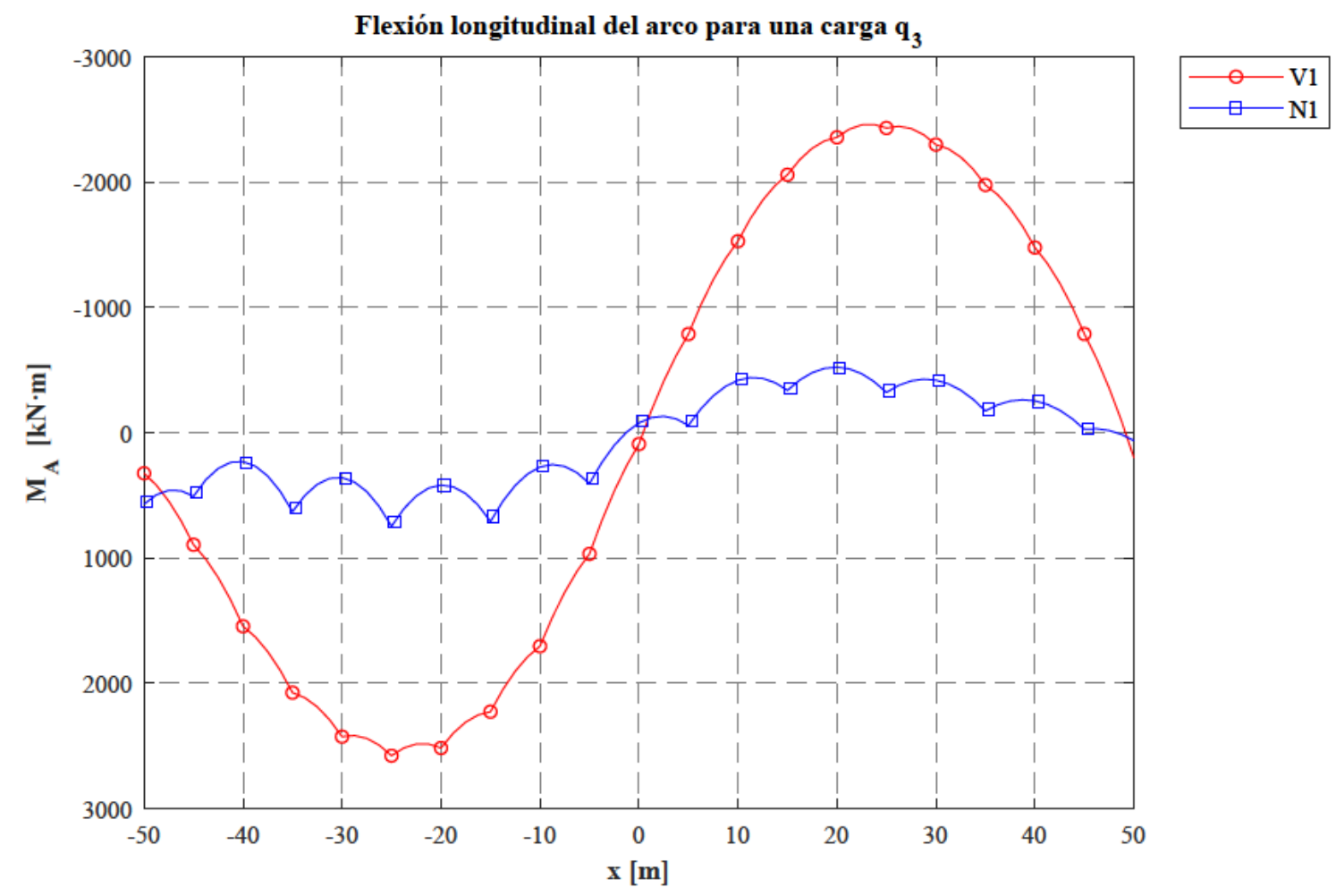

Figura 9.7: Flexión longitudinal del arco para modelos con un solo juego de péndolas verticales (V1) o Nielsen (N1) ancladas al eje del tablero. 


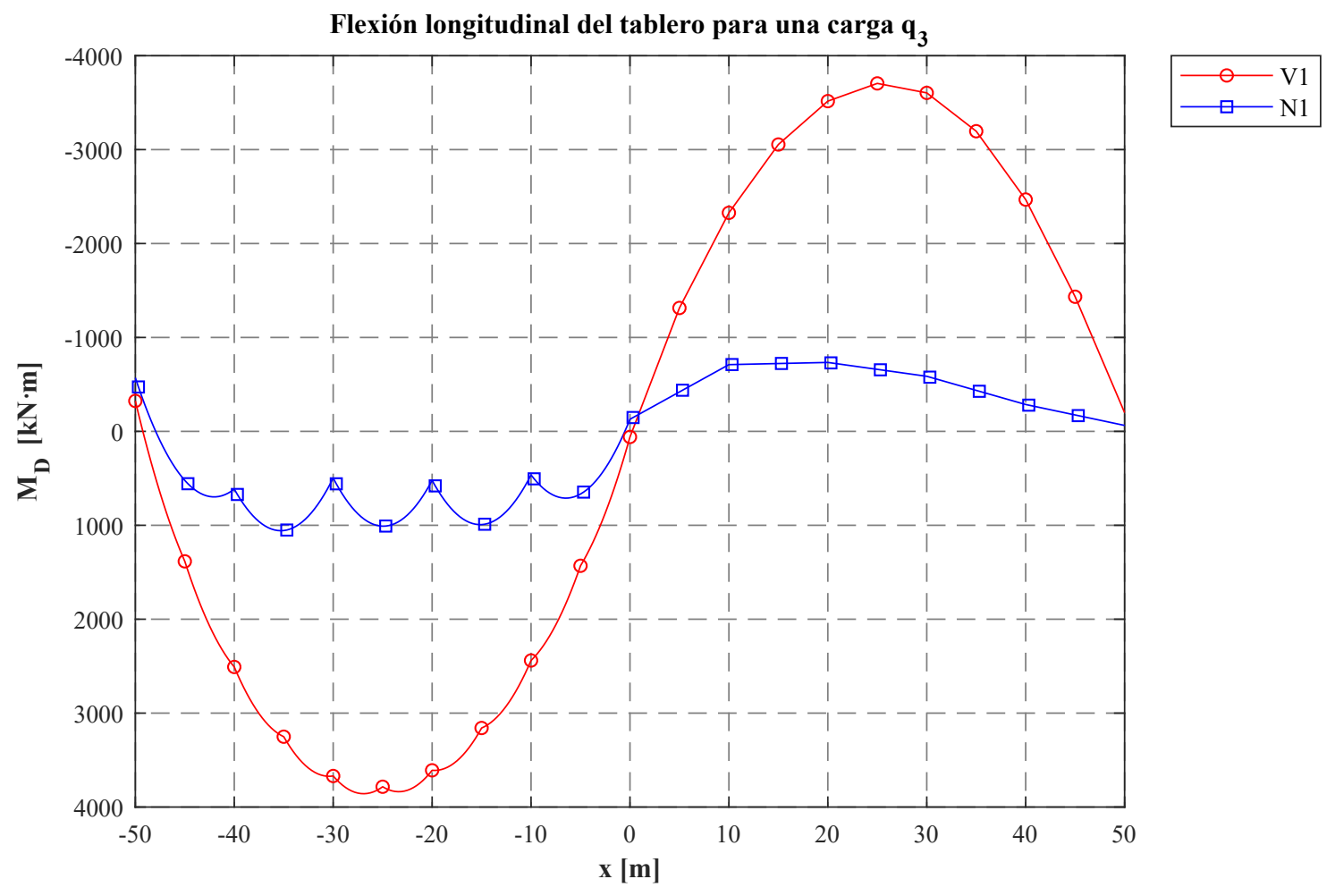

Figura 9.8: Flexión longitudinal del tablero para modelos con un solo juego de péndolas verticales (V1) o Nielsen (N1) ancladas al eje del tablero.

\subsection{Puentes arco con atirantamiento doble}

Si se modifica el atirantamiento de los puentes mostrados en el punto anterior, pasando ahora a vincularse el arco y el tablero mediante dos familias de cables que parten del arco y se anclan a ambos bordes del tablero (véase la figura 9.9), el resultado son unos arcos espaciales con atirantamiento mediante cables verticales (modelo V2), y mediante una disposición tipo Nielsen (modelo N2).

Estos nuevos modelos son arcos espaciales, mientras que los modelos anteriores eran arcos planos, siendo la condición de arco espacial dada por tener dos juegos de péndolas atadas a los bordes del tablero, que hacen que el trabajo del arco no se limite sólo al llevado a cabo en el plano en el que está contenido.

En la figura 9.10 se analizan ahora las flechas del eje del tablero de estos nuevos puentes (V2 y N2), pudiéndose observar que para una carga asimétrica $q_{3}$ la deformación es prácticamente igual para los modelos V1 y V2, y muy parecida para los modelos N1 y N2. En los puentes con doble atirantamiento vertical y tipo Nielsen, la flecha es sensiblemente diferente debido a que no se moviliza todo el efecto cortina que se estudió en el punto 3.8.3.4, y debido también a que la sección de la péndola del atirantamiento simple no es equivalente al trabajo conjunto de los dos cables del atirantamiento doble.

Si se tiene en cuenta ahora la flecha del borde del tablero para una carga $q_{2}$, que en el caso de los puentes con atirantamiento simple al eje del tablero resultaba excesiva, puede 


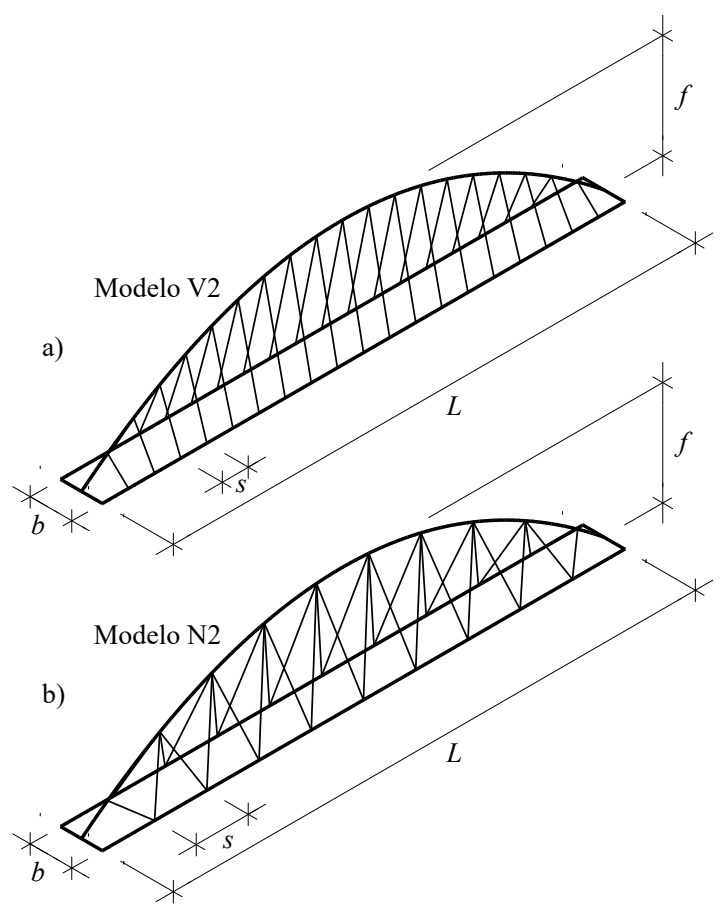

Figura 9.9: Definición de los modelos con dos juegos de cables, (a) verticales (V2) y (b) tipo Nielsen (N2), anclados a ambos bordes del tablero.

observarse en la figura 9.11 que esta se reduce en torno a la mitad para los modelos con atirantamiento a ambos bordes del tablero. Esto se debe a que la carga $q_{2}$ introduce un torsor que en los modelos con atirantamiento simple era soportado en su totalidad por el tablero, mientras que ahora el doble atirantamiento hace que el arco colabore para resistir este torsor, movilizando su resistencia transversal. Es de destacar que el atirantamiento tipo Nielsen a ambos bordes del tablero sigue manteniendo su efectividad a la hora de reducir flechas, resultando mucho más eficaz que el doble atirantamiento con cables verticales.

Otro de los aspectos a tener en cuenta es el viento, mientras que en los modelos con atirantamiento simple el arco y el tablero se comportan como una viga balcón en el primer caso, y como una viga recta sujeta en ambos extremos en el segundo, en los modelos con doble atirantamiento este comportamiento es diferente. Ahora el arco ya no se comporta como una simple viga balcón porque ahora está sujeto con péndolas a ambos bordes del tablero, lo que da lugar a una mayor rigidez transversal. El tablero por su parte también podría considerarse sujeto al arco, pero por ser este último el elemento con menos rigidez, se considera que es el arco el que se beneficia de la mayor rigidez transversal del tablero, y no al revés. Si fuese el arco el elemento de mayor rigidez y al tablero el de menor, se podría dar el caso en el que es el tablero el que se ayuda del arco. Si se observa la figura 9.12, el momento transversal del arco para la carga de viento se reduce a la mitad cuando el arco y el tablero se vinculan con péndolas dobles, sean verticales o tipo Nielsen. En el tablero ocurre lo contrario, aumentando la flexión transversal, pues es este elemento el que ayuda al arco por su mayor rigidez transversal (véase la figura 9.13).

La flexión longitudinal del arco y del tablero de los modelos con doble atirantamiento a 
los bordes se mantiene prácticamente igual que en los modelos con atirantamiento simple para una carga asimétrica $q_{3}$ (véanse las figuras 9.14 y 9.15). Los esfuerzos que varían son las flexiones transversales del arco y el tablero, así como la torsión en ambos elementos. Mientras que en los modelos con atirantamiento simple solo aparece flexión longitudinal para la carga $q_{2}$, en los modelos con doble atirantamiento aparece una flexión transversal en el arco y el tablero (véanse las figuras 9.16 y 9.17).

En los arcos con atirantamiento simple, era el tablero el único elemento sometido a torsión bajo una carga $q_{2}$, no existiendo además ningún elemento, arco o tablero, que estuviese sometido a flexión transversal. Al estar el arco y el tablero vinculados con dos juegos de cables, la torsión del tablero pasa a ser recogida en parte por el arco en forma de flexión transversal (véase la figura 9.16), reduciéndose así esta torsión en el tablero (véase la figura 9.19). Esta flexión transversal del arco implica un comportamiento como viga balcón, lo que unido a la directriz parabólica del arco, hacen que aparezca una torsión acoplada a la flexión transversal del arco (véase la figura 9.18). La diferencia de axiles en los cables situados en una misma sección transversal hace que el tablero esté sometido a flexión transversal.

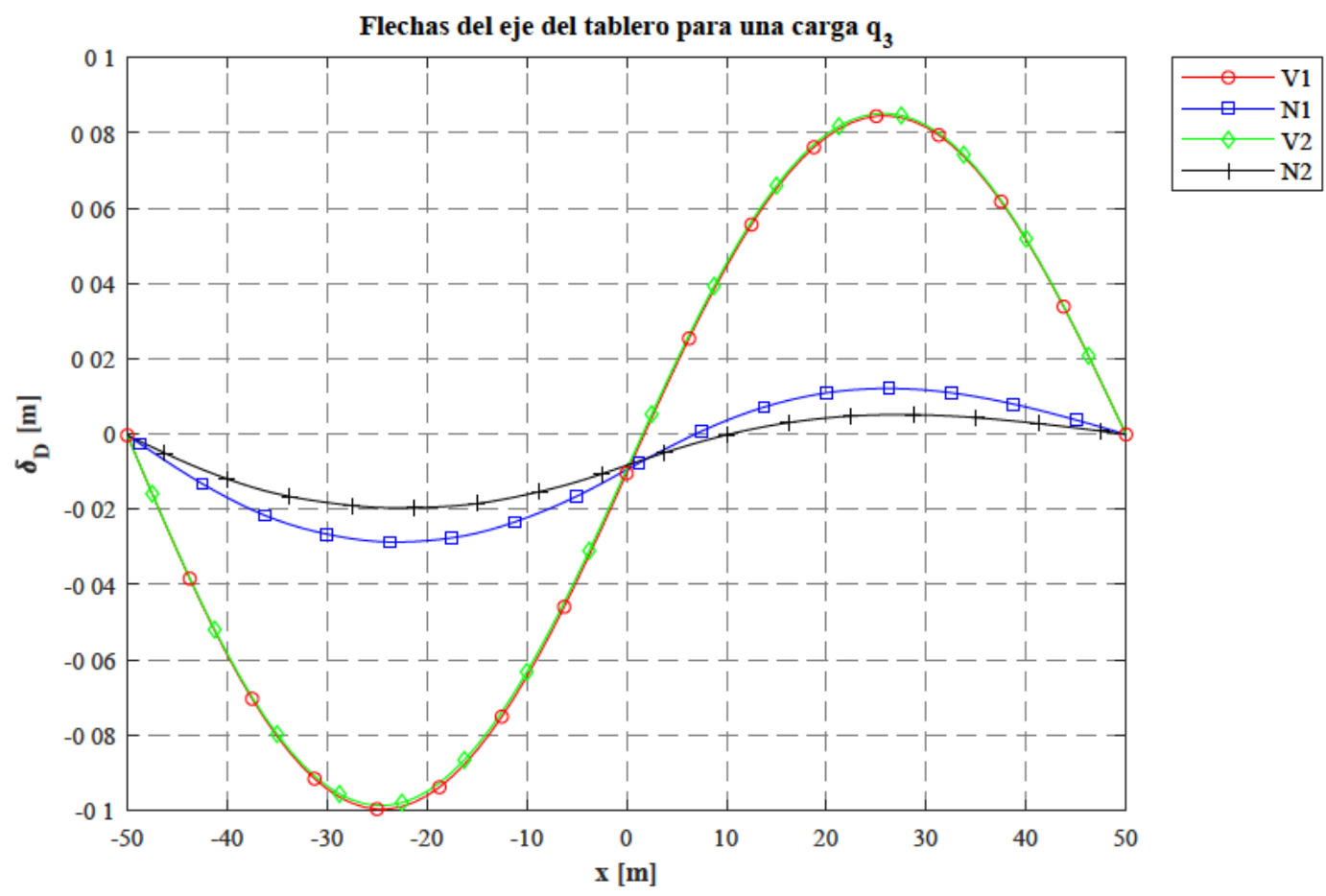

Figura 9.10: Flechas del eje del tablero para modelos con un solo juego de péndolas verticales (V1) o Nielsen (N1), y para modelos con dos juegos de péndolas verticales (V2) o Nielsen (N2). 


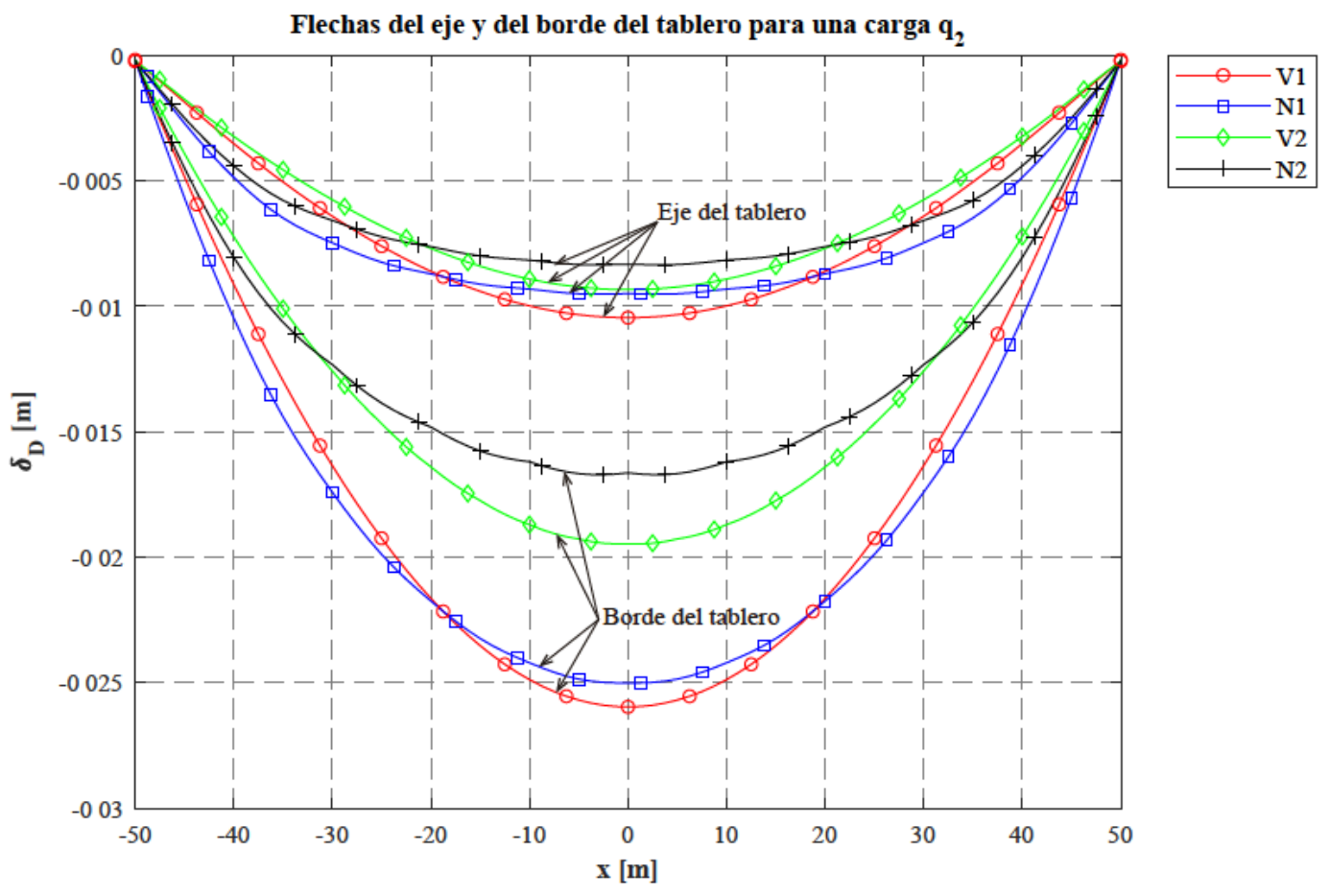

Figura 9.11: Flechas del eje y del borde del tablero para modelos con un solo juego de péndolas verticales (V1) o Nielsen (N1), y para modelos con dos juegos de péndolas verticales (V2) o Nielsen (N2).

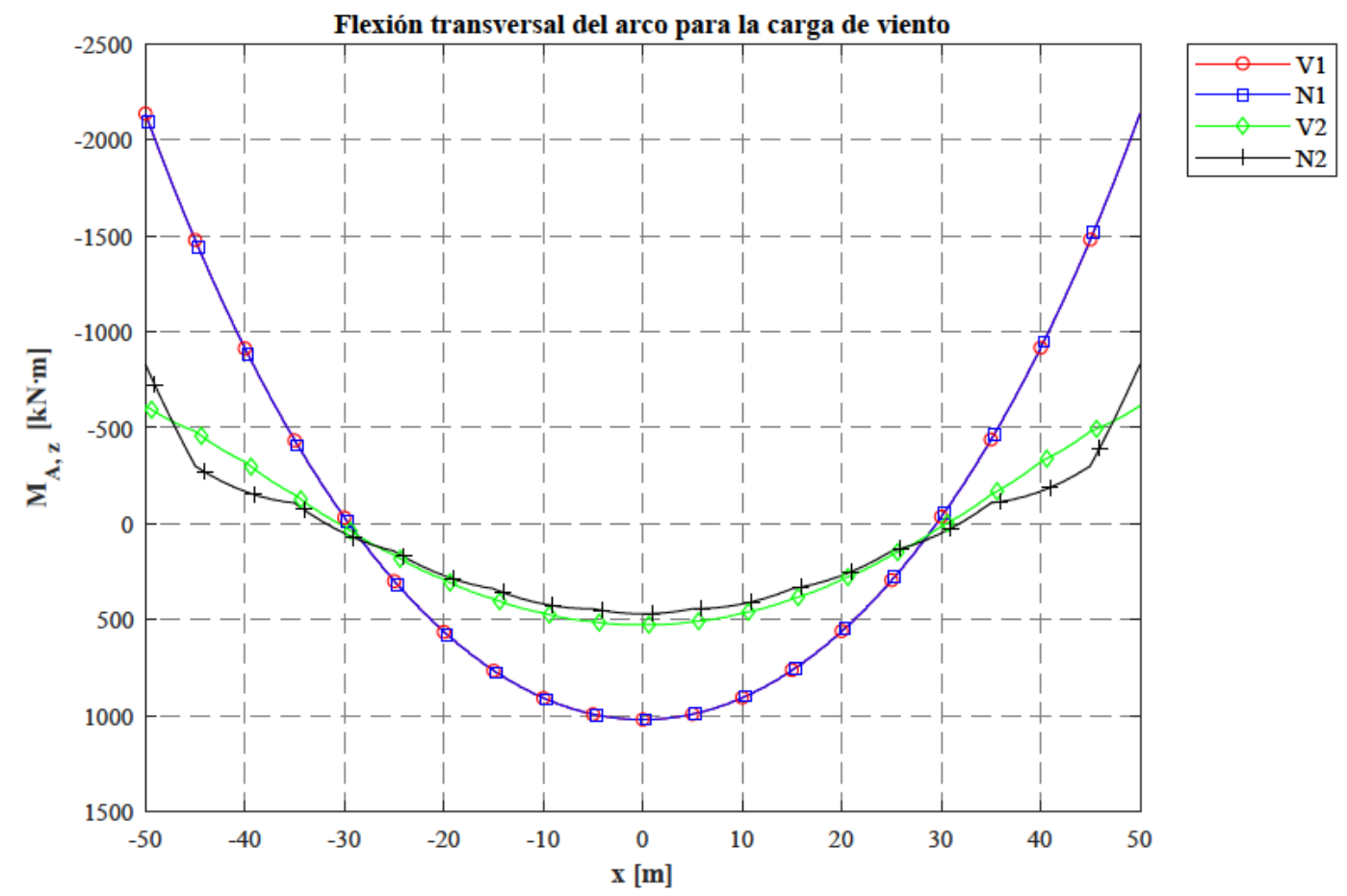

Figura 9.12: Flexión transversal del arco para modelos con un solo juego de péndolas verticales (V1) o Nielsen (N1) ancladas al eje del tablero, y para modelos con dos juegos de péndolas verticales (V2) o Nielsen (N2), para la carga de viento. 


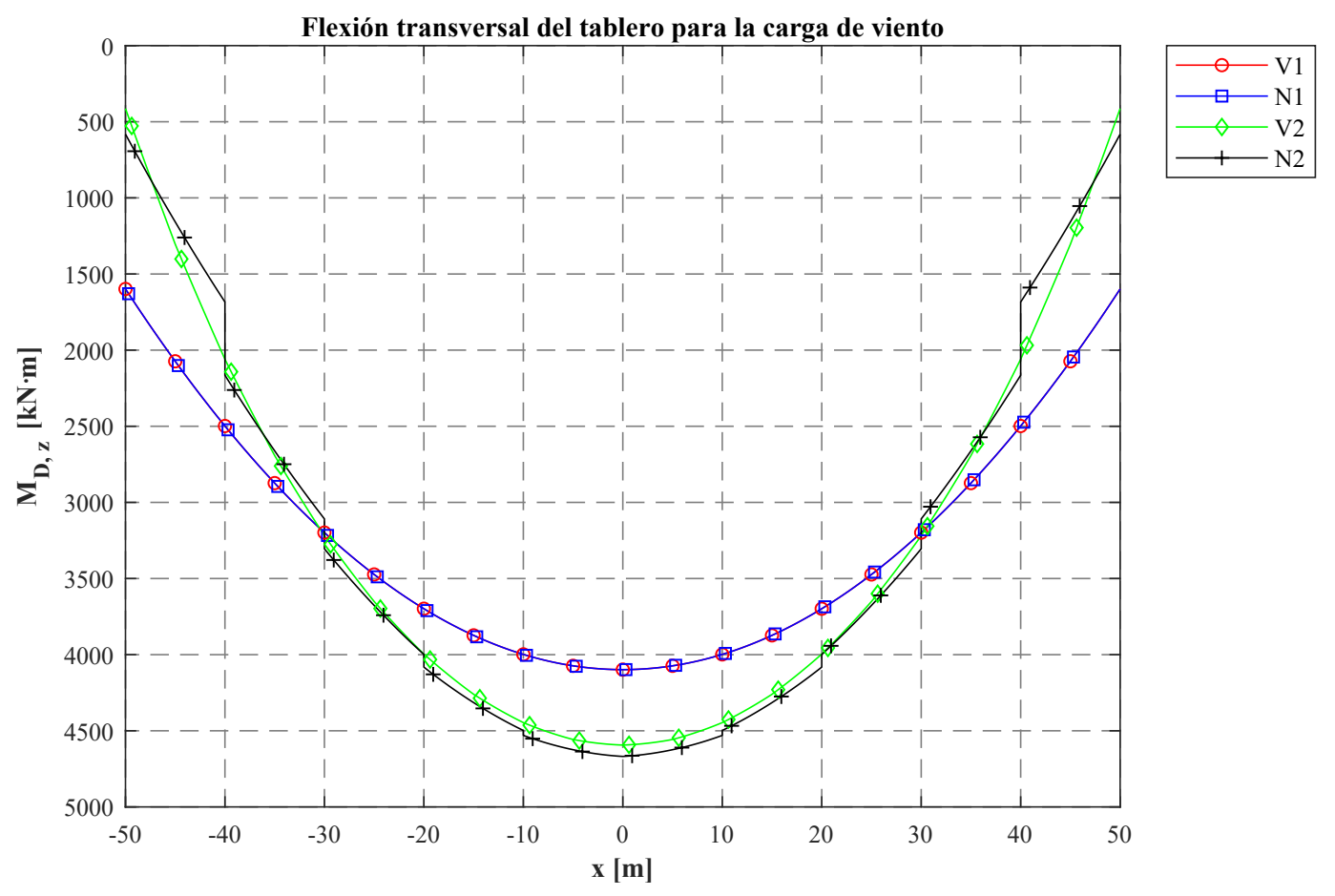

Figura 9.13: Flexión transversal del tablero para modelos con un solo juego de péndolas verticales (V1) o Nielsen (N1) ancladas al eje del tablero, y para modelos con dos juegos de péndolas verticales (V2) o Nielsen (N2), para la carga de viento.

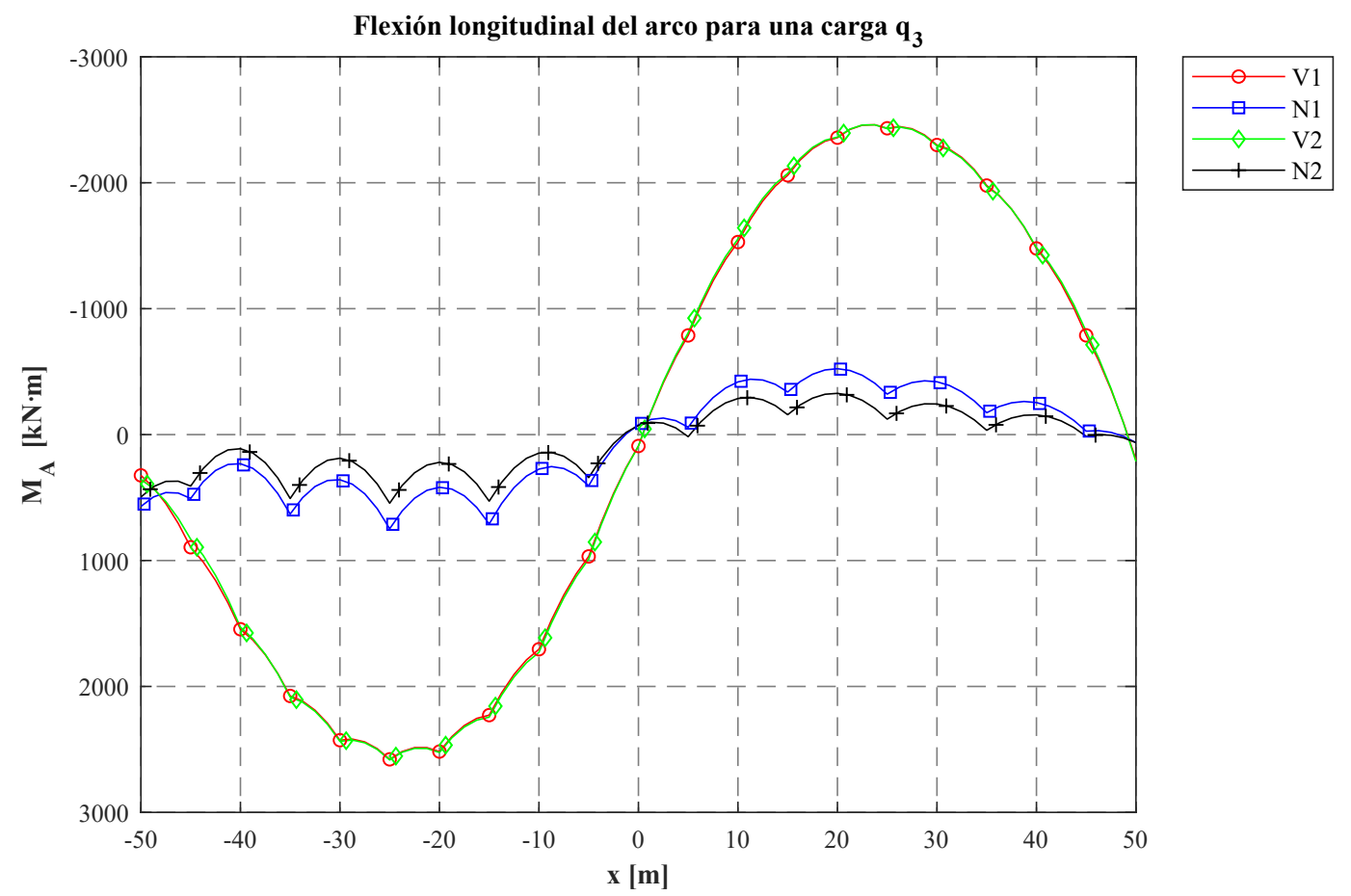

Figura 9.14: Flexión longitudinal del arco para modelos con un solo juego de péndolas verticales (V1) o Nielsen (N1) ancladas al eje del tablero, y para modelos con dos juegos de péndolas verticales (V2) o Nielsen (N2). 


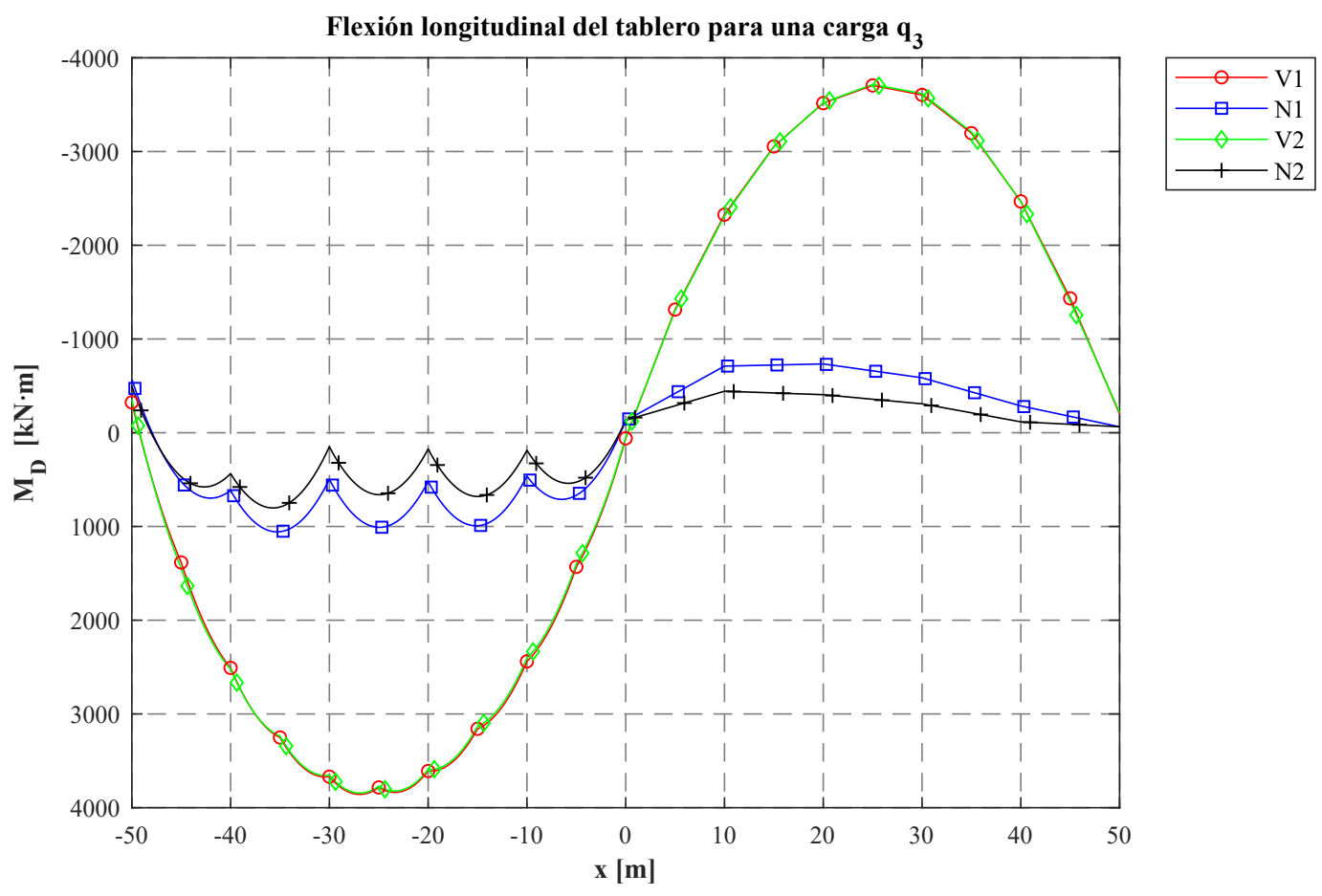

Figura 9.15: Flexión longitudinal del tablero para modelos con un solo juego de péndolas verticales (V1) o Nielsen (N1) ancladas al eje del tablero, y para modelos con dos juegos de péndolas verticales (V2) o Nielsen (N2).

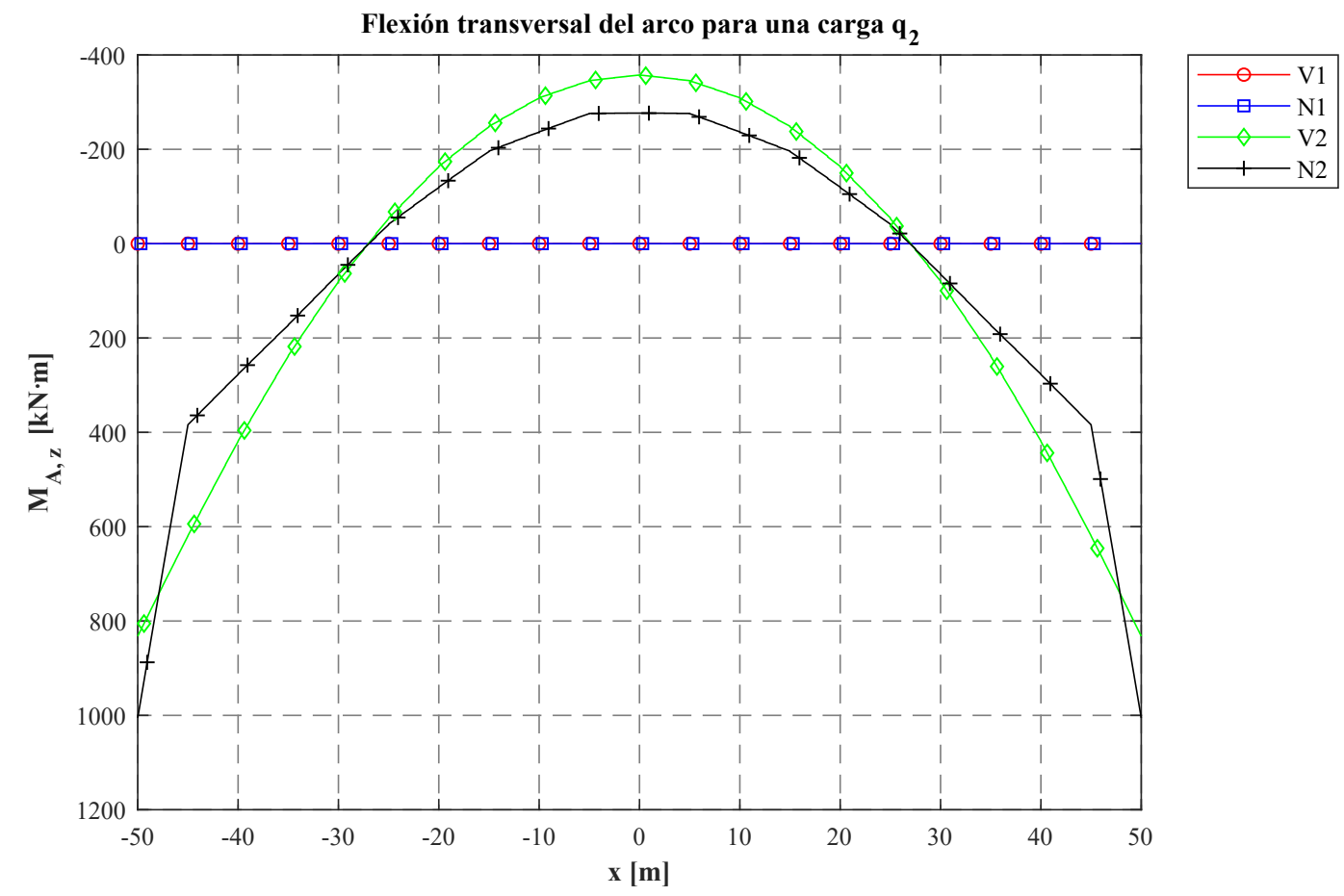

Figura 9.16: Flexión transversal del arco para modelos con un solo juego de péndolas verticales (V1) o Nielsen (N1) ancladas al eje del tablero, y para modelos con dos juegos de péndolas verticales (V2) o Nielsen (N2). 


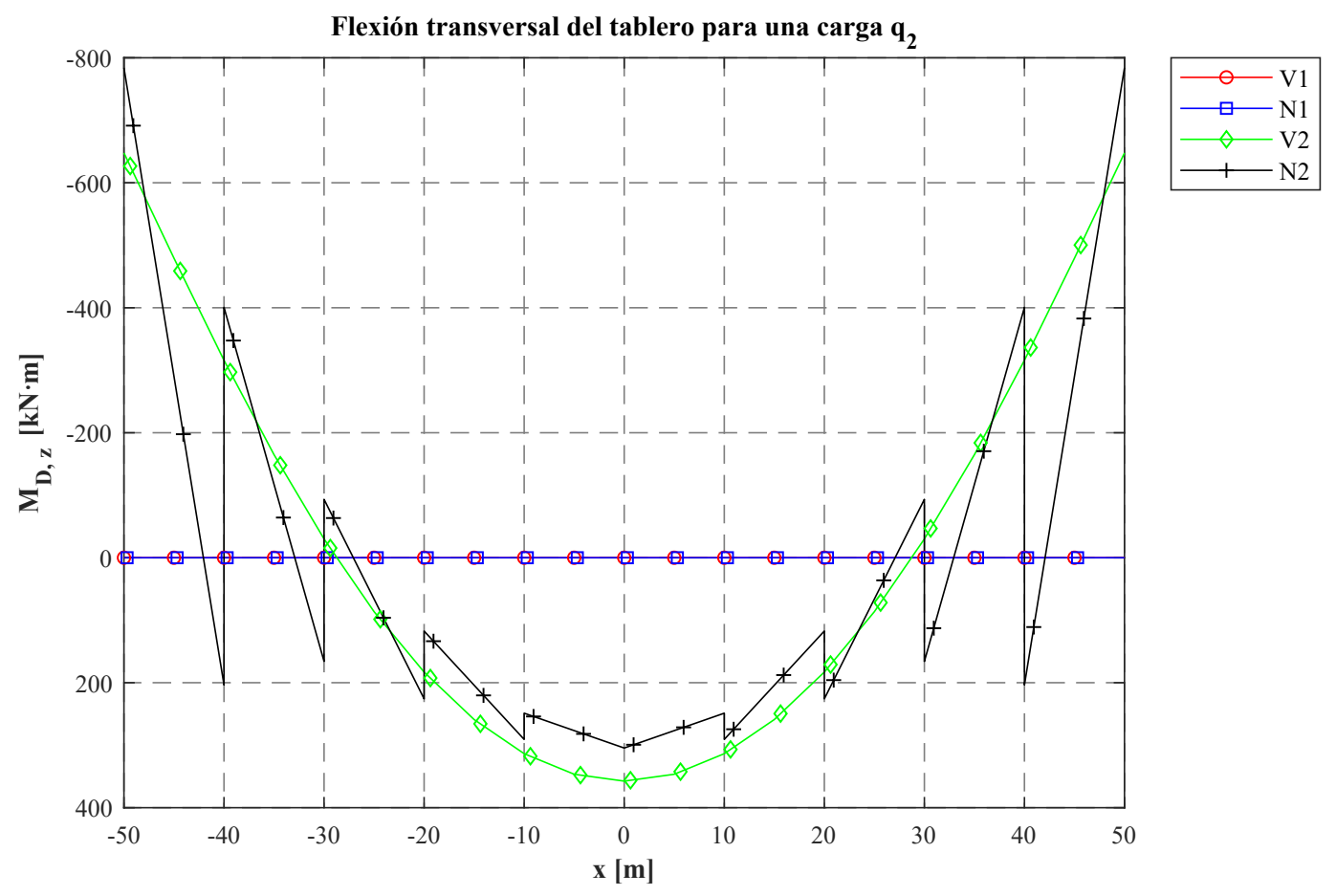

Figura 9.17: Flexión transversal del tablero para modelos con un solo juego de péndolas verticales (V1) o Nielsen (N1) ancladas al eje del tablero, y para modelos con dos juegos de péndolas verticales (V2) o Nielsen (N2).

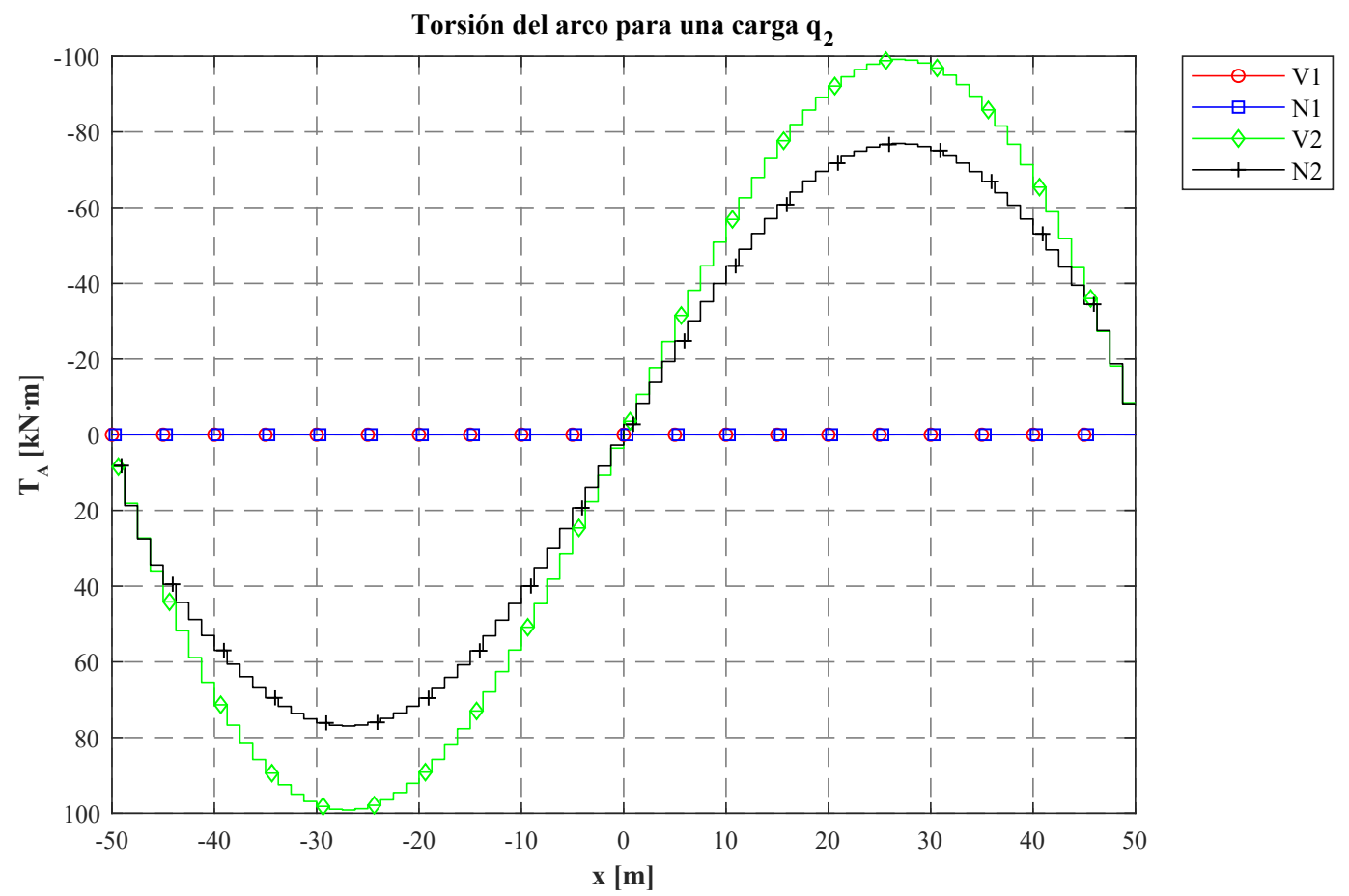

Figura 9.18: Torsión del arco para modelos con un solo juego de péndolas verticales (V1) o Nielsen (N1) ancladas al eje del tablero, y para modelos con dos juegos de péndolas verticales (V2) o Nielsen (N2). 


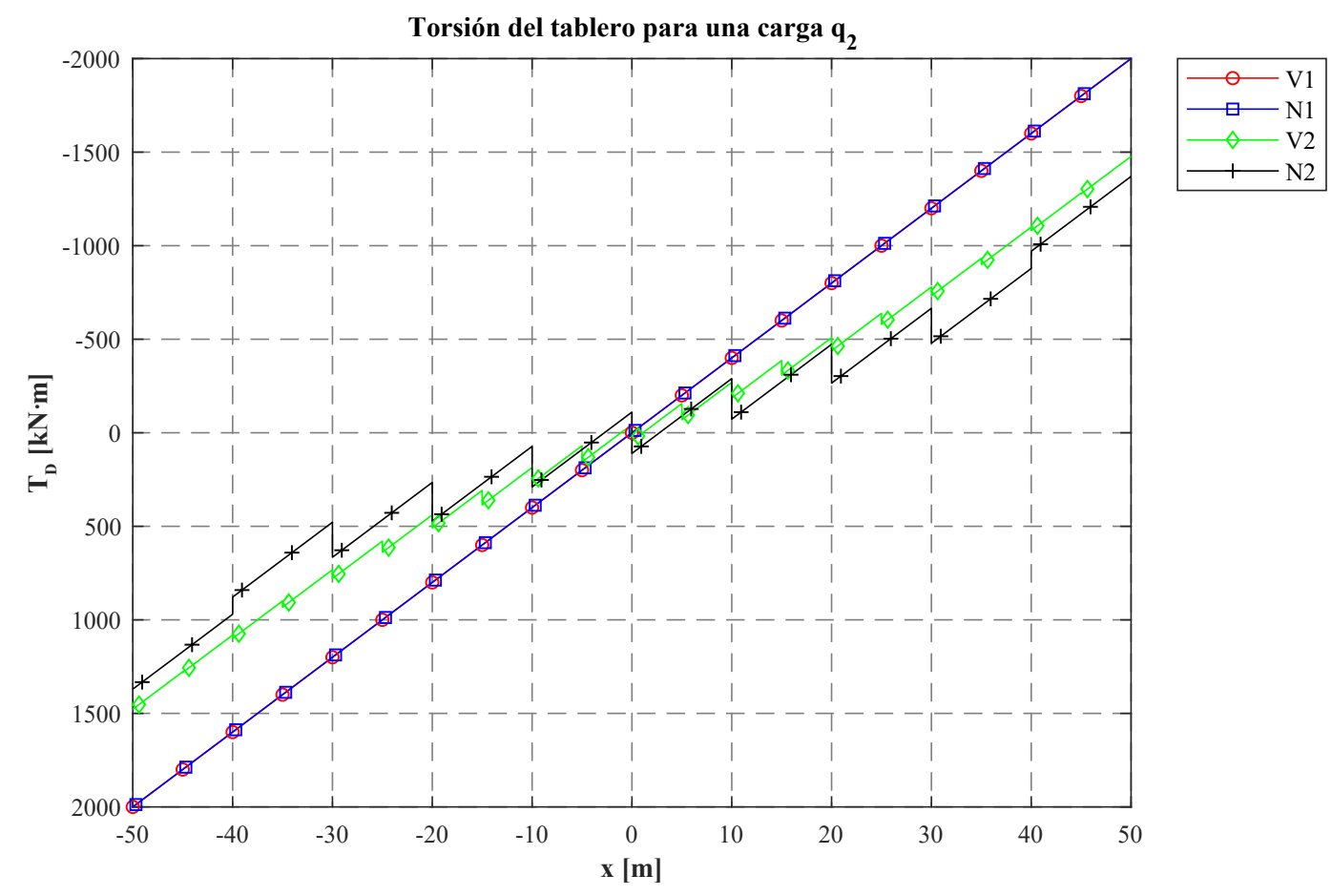

Figura 9.19: Torsión del tablero para modelos con un solo juego de péndolas verticales (V1) o Nielsen (N1) ancladas al eje del tablero, y para modelos con dos juegos de péndolas verticales (V2) o Nielsen (N2).

\subsection{Comportamiento resistente de puentes arco con atirantamiento doble}

En el diseño de un puente arco, es generalmente asumido que su respuesta estructural puede ser descompuesta en dos comportamiento estructurales (dentro del plano y fuera del plano), que se encuentran desacoplados (véase Jorquera Lucerga [46] y [47]). Este comportamiento desacoplado de los puentes arco hace que en caso de que dispongan de un atirantamiento doble a ambos bordes, estos puentes pueden ser considerados como celosías espaciales.

Atendiendo al comportamiento como celosía espacial, el arco espacial con doble atirantamiento vertical se comporta como una viga Vierendeel (véase la figura 9.20-a) tanto en alzado como en planta, ya que carece de diagonales. Sin embargo, en la celosía en planta hay que considerar un cordón horizontal intermedio en toda su longitud, que se corresponde con el arco.

El cuanto al arco espacial con doble atirantamiento tipo Nielsen, su comportamiento se asimila al de una celosía Warren en alzado (véase la figura 9.20-b), y una celosía en rombo a la que también hay que añadirle un cordón horizontal intermedio en toda su longitud, que se corresponde con el arco.

El mecanismo resistente de la celosía en alzado es bien conocido, mientras que en el caso de la celosía en planta, interviene como nuevo elemento resistente la rigidez transversal 


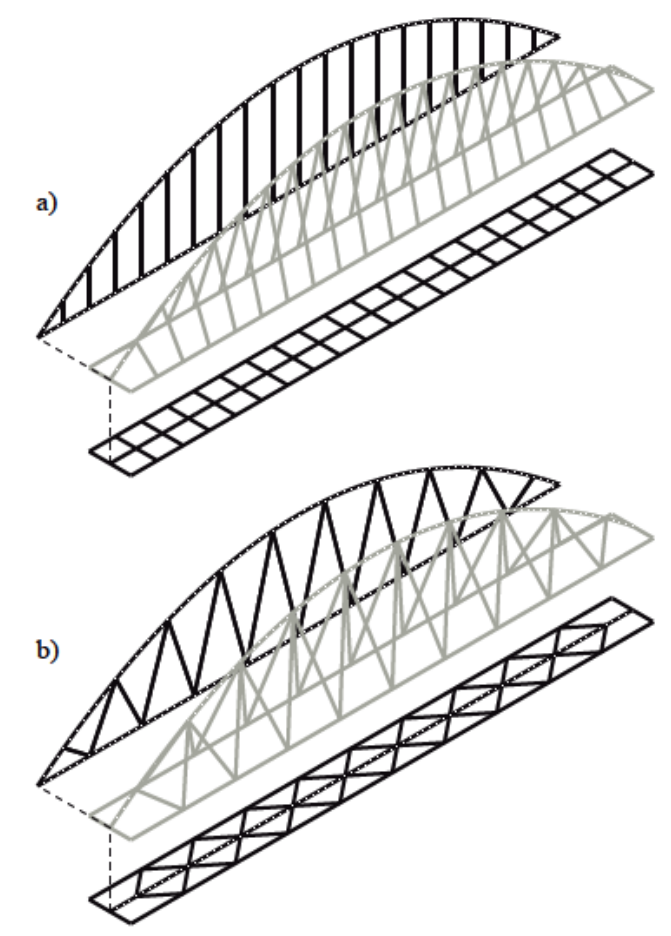

Figura 9.20: Proyección de los elementos del puente que conforman las celosía vertical y en planta, para un arco con doble atirantamiento vertical (a) y tipo Nielsen (b).

del arco, que actúa como un cordón de la celosía. La rigidez transversal del arco es determinante a la hora de establecer el movimiento lateral en el caso de cargas asimétricas respecto al eje longitudinal del tablero.

Para explicar el mecanismo resistente de la torsión, hay que considerar los esquemas de fuerzas representados en las figuras 9.21 y 9.22 .

El esquema de fuerzas y momentos expuesto en las imágenes anteriores, da lugar a tres casos de funcionamiento en función de la rigidez transversal del arco (véase la figura 9.23).

En el primer caso (figura 9.23-a), la inercia transversal del arco es 0. El resto de secciones mantienen sus inercias. Al ser la inercia transversal del arco 0, este no puede resistir cargas transversales, así que ante una carga en el borde del tablero (flecha hueca en la figura 9.23) las péndolas deben de tener el mismo axil para que el sistema esté en equilibrio, bajando el borde donde se aplica la carga, y subiendo el contrario.

En el segundo caso (figura 9.23-b), la inercia transversal del arco es infinita, con lo que este no se puede desplazar transversalmente. La incapacidad de desplazamiento transversal hace que al aplicar la carga en el borde la péndola amarrada al borde donde se aplica la carga quede traccionada, mientras que la otra no se encuentra cargada, produciéndose un desequilibrio de fuerzas en el sistema que produce el movimiento transversal del tablero.

Por último, en el tercer caso (figura 9.23-c), la inercia transversal del arco adquiere el valor propio de la sección rectangular. Este valor de inercia transversal hace que el arco se pueda desplazar transversalmente, con lo que al aplicar la carga en el borde la péndola amarrada al borde de la carga se tracciona, y la otra péndola adquiere un axil de tracción 
que queda controlado por la rigidez del arco, y que en todo caso será menor que el axil de la péndola vinculada al borde de la carga.

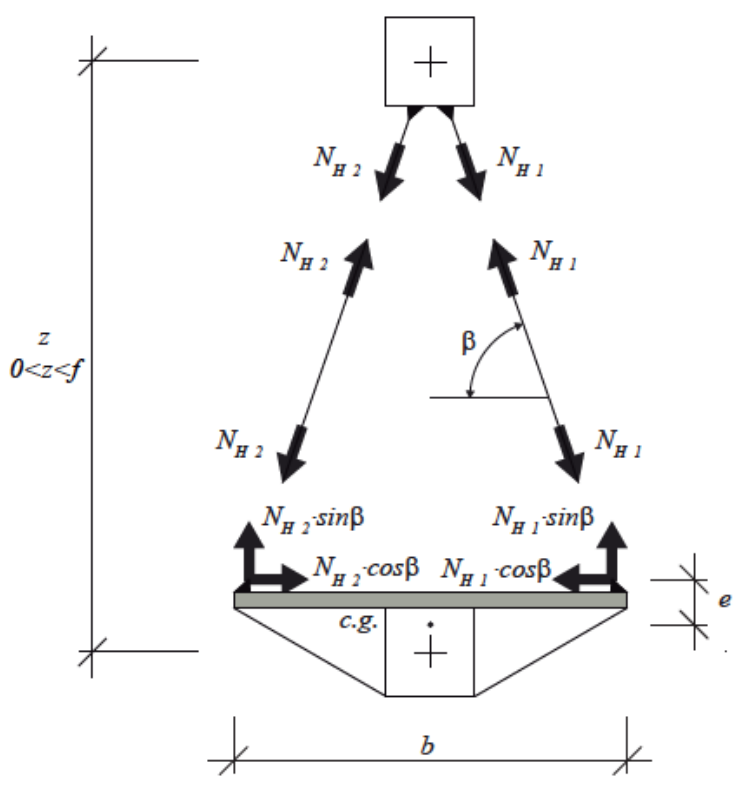

Figura 9.21: Descomposición de fuerzas actuantes en la sección transversal del puente arco con doble atirantamiento.

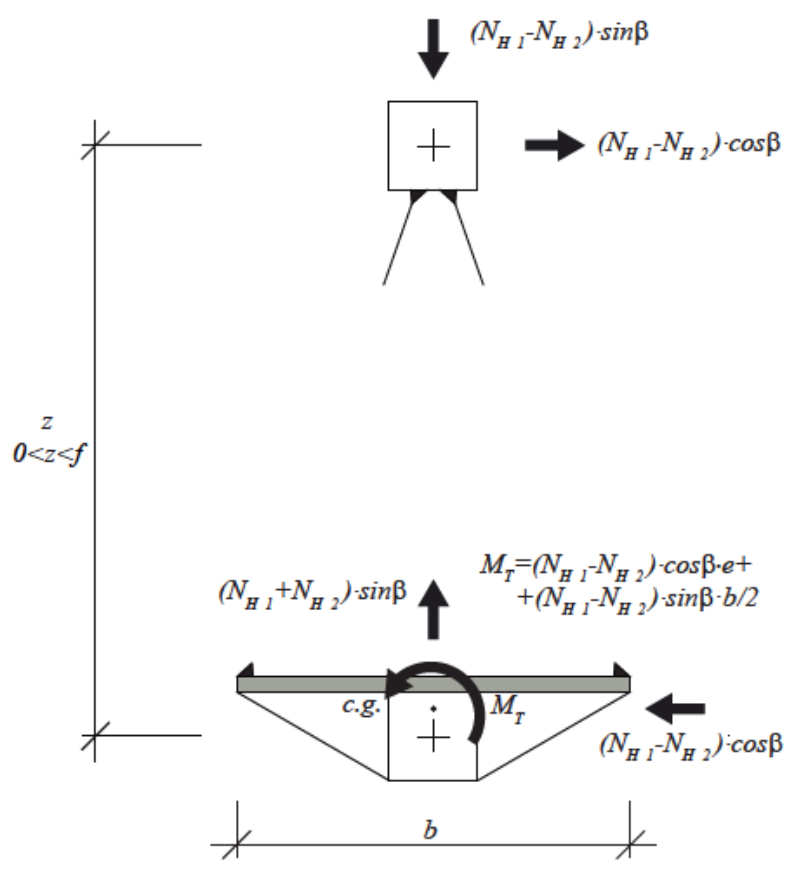

Figura 9.22: Descomposición de fuerzas actuantes en la sección transversal del puente arco con doble atirantamiento, supuesta $N_{H, 1}>N_{H, 2}$. 

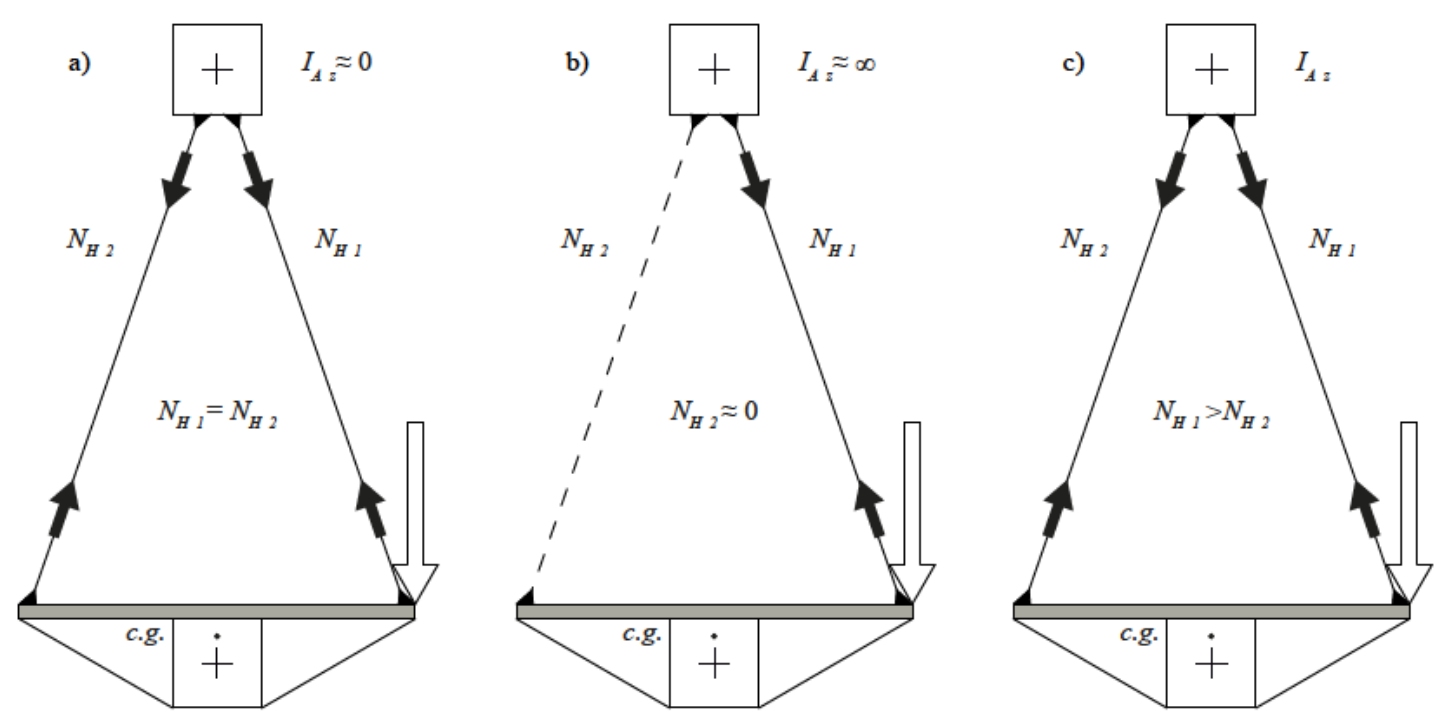

Figura 9.23: Comportamiento de la sección transversal del puente para una carga de borde (flecha hueca). a) arco con inercia transversal igual a 0. b) arco con inercia transversal infinita. c) arco con su inercia transversal.

\subsubsection{Trabajo de la celosía en alzado}

En el caso de arcos espaciales con doble atirantamiento, el comportamiento estructural se divide en dos trabajos desacoplados, planta y alzado. El trabajo en alzado es el de una celosía (véase la figura 9.20), donde las diagonales son las péndolas abatidas sobre el plano del arco, y el cordón superior e inferior se corresponde con el arco y el tablero respectivamente. La celosía en alzado, es equivalente al modelo de arco con un solo juego de péndolas, si bien el diámetro de las péndolas no es el mismo. Este diámetro se ha calculado atendiendo a lo explicado por Ortiz Berrocal en [72], obteniéndose un modelo plano con $\phi_{H}$ variable, que presenta los mismos axiles en alzado que el modelo con dos juegos de péndolas.

$\mathrm{Al}$ colocar unas péndolas de sección equivalente, la suma de las proyecciones de los axiles de las péndolas sobre el plano del arco, es igual al axil de la péndola correspondiente en el modelo con un juego de péndolas (figura 9.24).

\subsubsection{Trabajo de la celosía en planta}

Como se ha comentado en el punto anterior, los arcos espaciales con doble atirantamiento se comportan como una celosía en alzado y en planta. La celosía en planta tiene al arco como cordón intermedio (véase la figura 9.20), siendo las diagonales las péndolas que amarran el tablero al arco. La inercia transversal del arco pasa a tener un papel importante, pues se encuentra en el centro de la celosía y controla las deformaciones transversales del arco. 


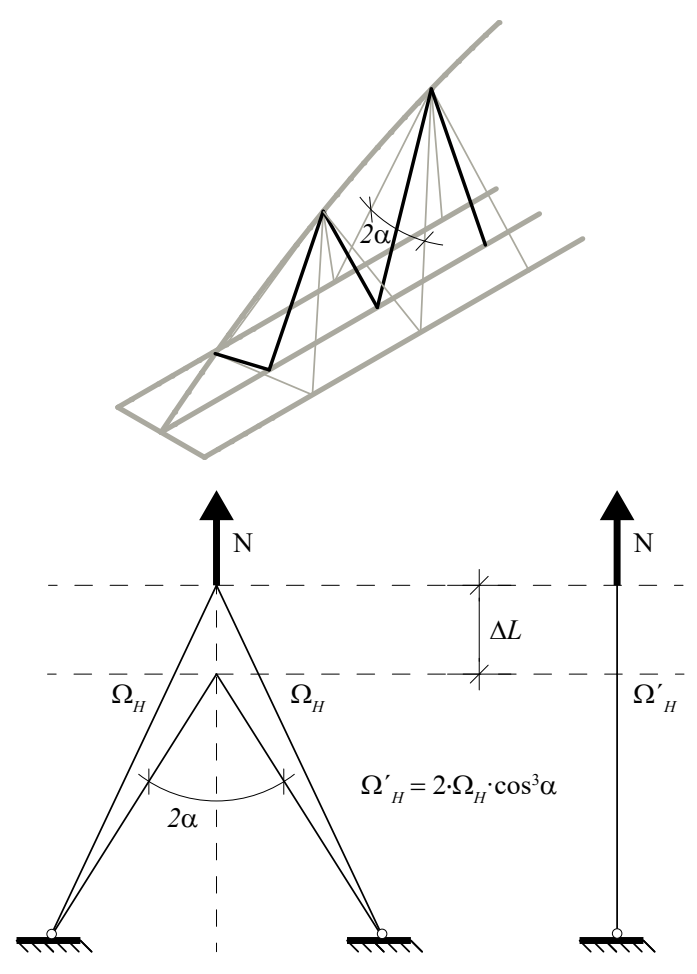

Figura 9.24: Esquemas para el cálculo de una sección equivalente de péndolas.

$\mathrm{Al}$ estar sometido el arco a torsión (está acoplada a la flexión transversal, véase Manterola [60]), este elemento se intenta empotrar con la planta del tablero, lo que produce un aumento de la flexión transversal del tablero. Así, la celosía en planta debe soportar un momento en el plano de la celosía, provocado por la torsión del arco, la cual se transmite por los arranques al tablero.

En el caso del arco con péndolas Nielsen, se puede observar en la figura 9.20-b, que las péndolas extremas no se atan a los estribos, lo que hace que haya un tramo de celosía incompleta. Esta celosía incompleta hace que en las péndolas extremas haya un desplazamiento relativo arco-tablero menor, produciéndose en algunas ocasiones la compresión de las primeras péndolas.

En algunos modelos, al comparar el arco con una celosía, tanto vertical como en planta, se obtenían valores similares de axiles en todas las péndolas, salvo en los pares de péndolas situados más cerca de los apoyos. En estos pares de péndolas situados en los apoyos, se registran valores de compresión (véase la figura 9.25, donde los axiles de las péndolas tipo Nielsen se han representado en el punto medio de cada péndola) que hacen que los axiles de las péndolas sean distintos a los que se obtienen al comparar el modelo espacial con la celosía. El axil en estas péndolas extremas varía por la aparición en planta del momento de empotramiento, que provoca que en las péndolas extremas haya un desplazamiento relativo arco-tablero menor, produciéndose la compresión de las primeras péndolas. 

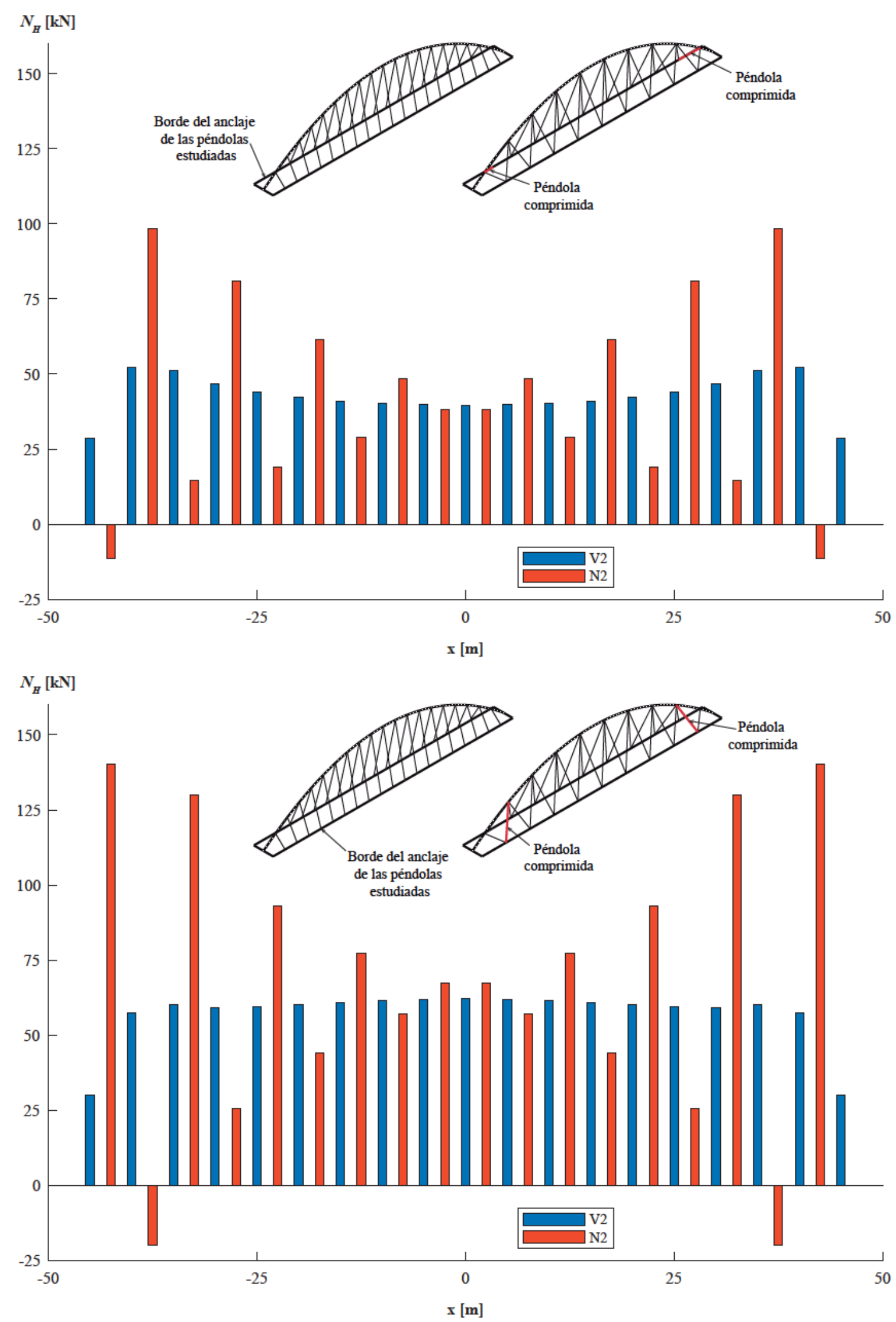

Figura 9.25: Axiles en las péndolas (fig. superior/inferior: péndolas del semitablero descargado/cargado) para los modelos V2 y N2 bajo una carga $q_{2}$. 


\subsubsection{Arco bifurcado en arranques}

Los puentes con doble atirantamiento tienen un problema con el gálibo, pues la V invertida que forman los cables si se considera la sección transversal (véase la figura 9.2) puede interferir sensiblemente con el gálibo del puente, sobre todo en los extremos, donde el anclaje superior de las péndolas es más bajo. Otro de los posibles inconvenientes del doble atirantamiento es la posibilidad de que haya péndolas que se compriman en los extremos, como consecuencia del momento en planta mencionado en el punto anterior.

En estos casos es muy usual bifurcar el arco en los arranques, lo que evita colocar péndolas en los extremos del puente, evitando la compresión de péndolas y problemas con el gálibo (véase la figura 9.26). Algunos ejemplos de realizaciones de arcos bifurcados son el puente del Tercer Milenio (véase el punto 2.7.2.2)), con un atirantamiento vertical a ambos bordes del tablero, o el puente de Montigny-lès-Cormeilles (véase el punto 2.7.2.5), con un atirantamiento doble tipo Nielsen.

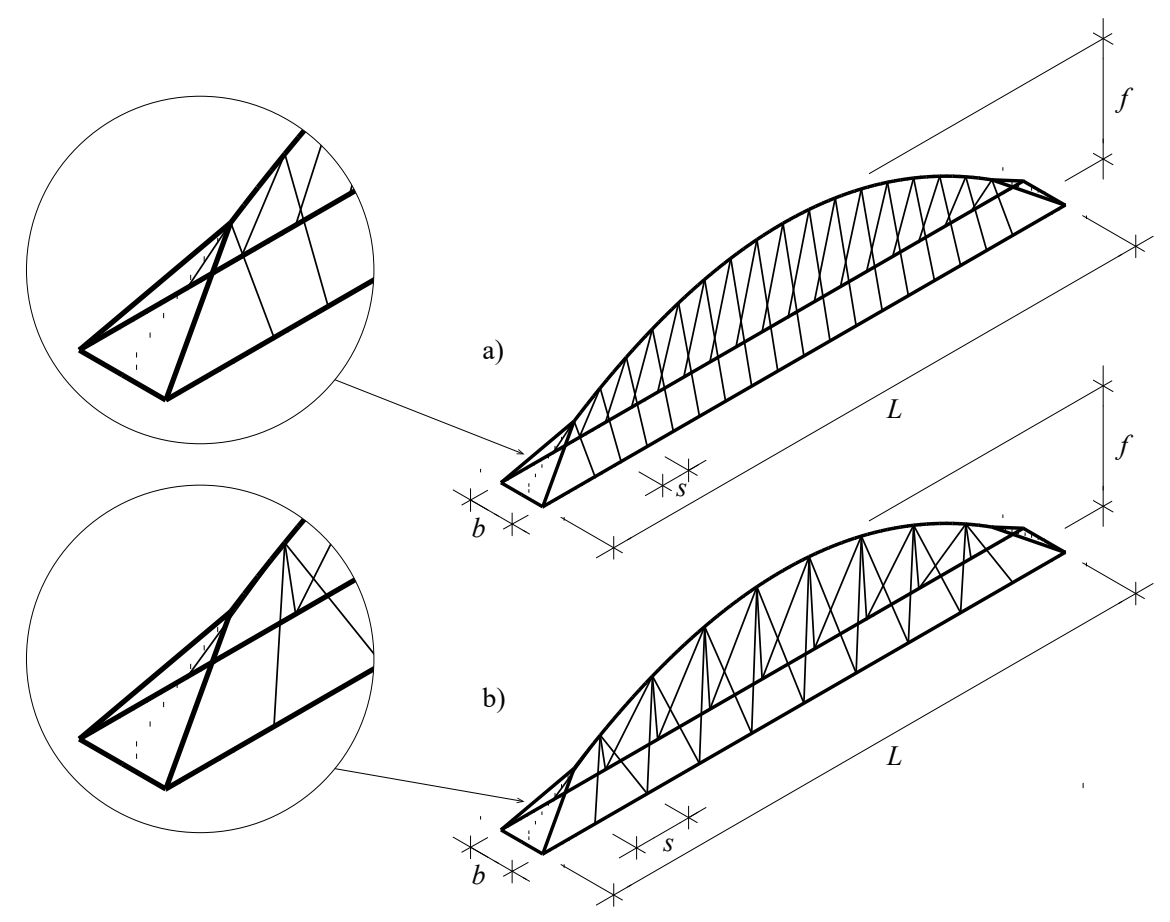

Figura 9.26: Bifurcación del arco en los arranques. a) arco con doble atirantamiento vertical. b) arco con doble atirantamiento tipo Nielsen.

\subsubsection{Pandeo}

En este capítulo se han analizado hasta el momento esfuerzos y flechas del arco y el tablero para puentes con atirantamiento simple y doble, y con disposiciones de cables verticales o tipo Nielsen. En este apartado se va a intentar establecer si el atirantamiento doble tiene algún efecto sobre el axil crítico de pandeo en la sección del arco. Como en puntos anteriores, el estudio se va a realizar para configuraciones de cables verticales y tipo Nielsen. 
Para estudiar la variación del axil crítico de pandeo en puentes arco se ha considerado el modelo de referencia usado en este capítulo.

Para determinar el coeficiente de pandeo, en los modelos se ha considerado la imperfección geométrica correspondiente, considerándose para este estudio, los valores del punto 22.3.4.2. de la Instrucción de Acero Estructural (véase [23]).

Para estimar la carga crítica de pandeo se han analizado todos los modelos en el programa SAP2000 bajo la combinación de cargas de la ecuación 9.1:

$$
1,35 \cdot(P P+C M)+0,6 \cdot 1,5 \cdot V T O+\lambda \cdot q_{5}
$$

El coeficiente $\lambda$ se incrementa hasta alcanzar $\lambda_{u}$, que es el coeficiente de pandeo, expresado como el número de veces que hay que aumentar la sobrecarga de uso $^{1} q_{5}$ para que se produzca el pandeo (véase Manterola [60]).

Los resultados de todos los casos analizados se muestran en la tabla 9.2, donde se puede ver el valor $\lambda_{u}$ que multiplica a la sobrecarga de uso en el momento del pandeo.

Todos los casos analizados presentan coeficientes de pandeo fuera del plano mucho más pequeños que los obtenidos para pandeo dentro del plano, con lo que en la práctica solo se han considerado los valores de $\lambda_{u}$ para el pandeo fuera del plano.

\begin{tabular}{|c|c|}
\hline Modelo & $\begin{array}{c}\text { Coeficiente de pandeo } \\
\text { Out-of-plane }\end{array}$ \\
\hline V1 & 13 \\
N1 & 13 \\
V2 & 26 \\
N2 & 30 \\
\hline
\end{tabular}

Tabla 9.2: Coeficientes de pandeo fuera del plano para arcos con atirantamiento simple al eje del tablero, y para modelos con doble atirantamiento a los bordes del tablero.

Como se puede observar en la tabla 9.2, los modelos con atirantamiento simple al eje del tablero presentan los coeficientes de pandeo más bajos, no existiendo diferencia entre un atirantamiento tipo Nielsen y otro con cables verticales. En el caso de los modelos con doble atirantamiento a los bordes del tablero, el coeficiente de pandeo se incrementa notablemente, pasando a ser como poco el doble que en el caso de los modelos de atirantamiento simple. En este caso si existe una pequeña diferencia entre el coeficiente de pandeo de un modelo con atirantamiento doble mediante cables verticales y otro con cables tipo Nielsen, siendo en este último caso el coeficiente algo mayor, lo que se puede atribuir a la mayor rigidez en planta de su celosía equivalente.

A la vista de los resultados anteriores, se puede concluir que vincular el arco y el tablero mediante cables a ambos bordes aumenta el axil crítico de pandeo fuera del plano del arco, siendo incluso mayor cuando la configuración doble de cables es tipo Nielsen.

\footnotetext{
${ }^{1}$ Se ha considerado la sobrecarga $q_{5}$, al ser con la que se obtienen valores de pandeo más bajo, pues el resto de sobrecargas, si bien se han considerado, arrojan valores de pandeo más elevados.
} 


\subsection{Consideraciones funcionales}

Las configuraciones de péndolas a ambos bordes del tablero mostradas en puntos anteriores mejoran los esfuerzos y deformaciones con respecto a los arcos con un solo juego de péndolas atado al eje del tablero. Sin embargo, estas configuraciones de cables dobles pueden ocasionar diferentes problemas con el gálibo de la estructura.

En el caso de los puentes con atirantamiento simple (V1 y N1), el gálibo se divide en dos debido a las péndolas que se vinculan al eje del tablero. Estas dos partes en las que se divide el gálibo de la pasarela tienen un ancho $b / 2$ y una altura $h$ (véase la figura 9.27).

Para los arcos con doble atirantamiento, el gálibo tiene una sola sección, de base $b$. Si se quiere alcanzar la misma altura $h$ de gálibo de los puentes con un solo juego de cables, se deben disponer unas costillas auxiliares que aumenten el ángulo de las péndolas con respecto al plano del arco (véase la figura 9.28). Estas costillas serán más largas en ambos extremos del puente, decreciendo su longitud conforme se acercan a la mitad del puente, es decir, a la clave del arco (véase la figura 9.29). Cuanto más largas sean las costillas, mayor será la inclinación de las péndolas, y por lo tanto mayor será el comportamiento como viga balcón del arco.

Cabe mencionar, que en los modelos con arcos bifurcados en arranques habría que modificar los apoyos, de manera que los arcos no arrancasen en los bordes del tablero, y si a una distancia adecuada para salvar el gálibo.

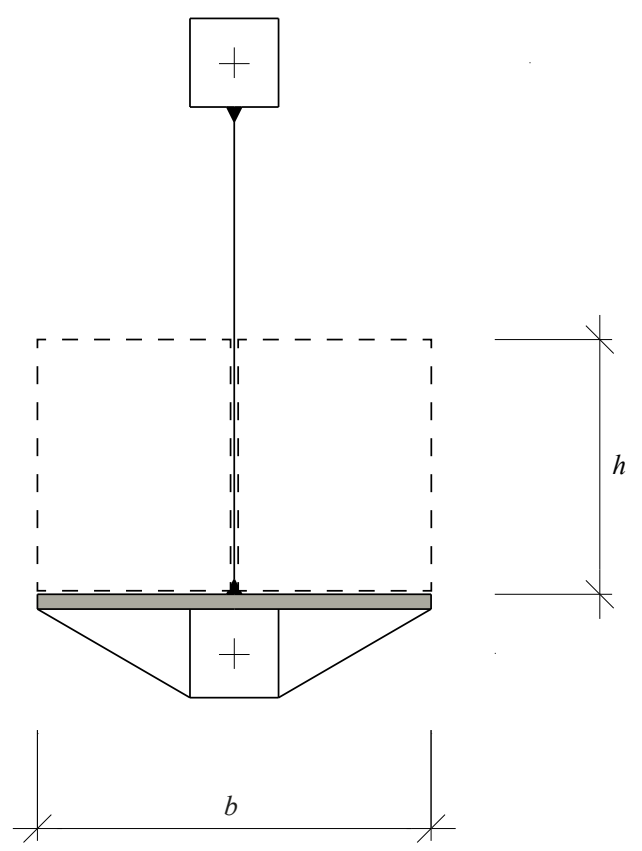

Figura 9.27: Gálibo para puentes arco con un solo juego de cables anclados al eje del tablero. 


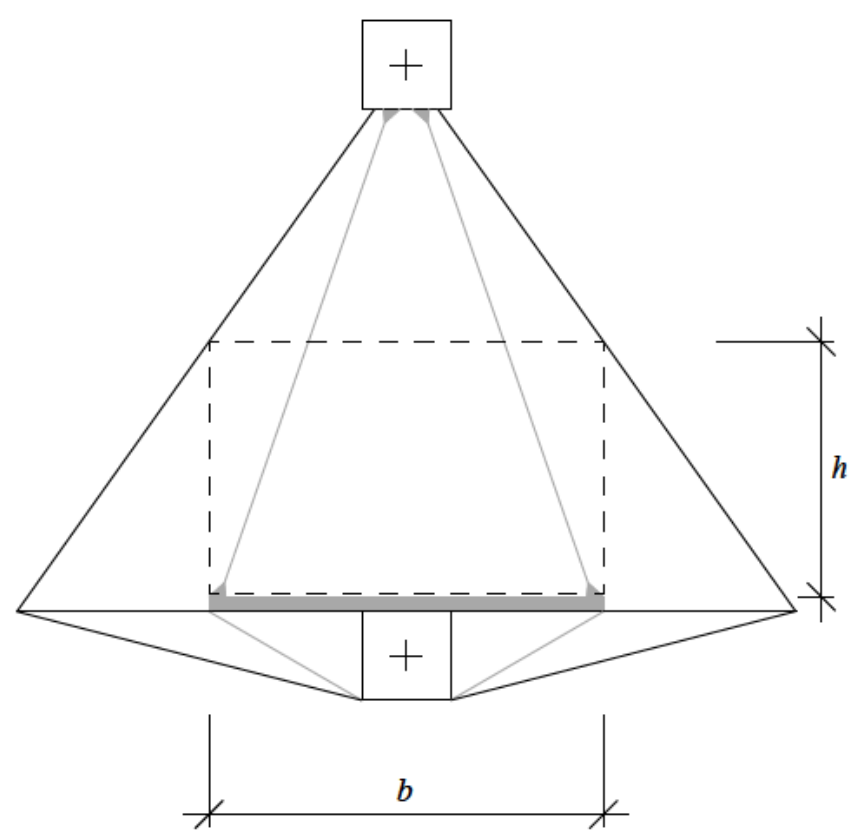

Figura 9.28: Gálibo para puentes arco con dos juegos de cables anclados a ambos bordes del tablero. En gris claro se representa la sección inicial del puente, antes de añadir las costillas para mantener el gálibo.
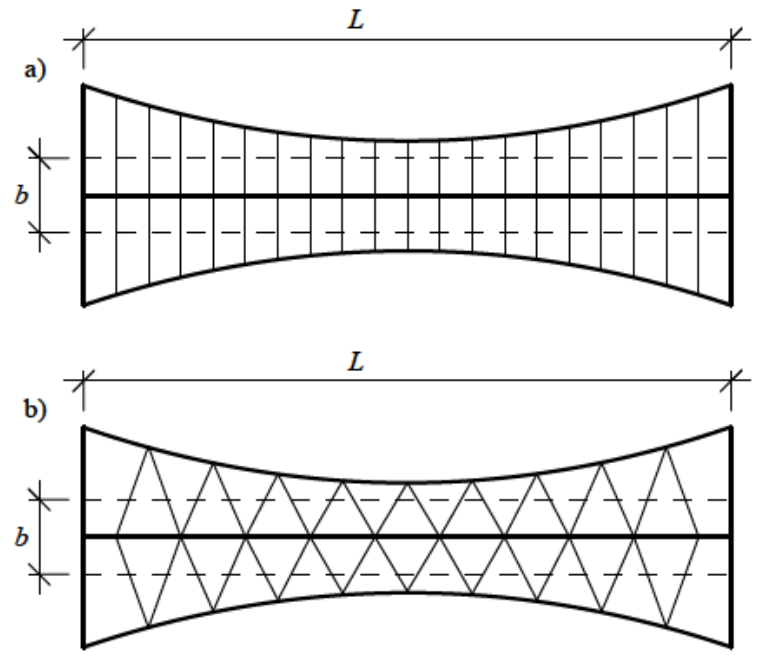

Figura 9.29: Vista en planta de los sobreanchos necesarios para mantener el gálibo. a) planta del modelo V2 con péndolas verticales, b) planta del modelo N2 con péndolas tipo Nielsen. 



\section{Parte V}

Conclusiones y futuras líneas de estudio 



\section{Capítulo 10}

\section{Conclusiones y futuras líneas de estudio}

\subsection{Conclusiones}

La presente tesis muestra, como se estableció en el capítulo 1, que el puente arco espacial simétrico supone una evolución tipológica con respecto al puente arco plano clásico, que permite verificar los condicionantes tensodeformacionales que determinan la validez de la estructura, tanto en rotura como en servicio.

Como se mencionaba a la hora de establecer los objetivos de esta tesis, el puente arco espacial simétrico se origina así, desde un punto de vista estructural, de manera ortodoxa. Según el enfoque de esta tesis, los elementos definitorios del puente arco espacial simétrico, como las péndolas rigidizadas transversalmente, los atirantamientos al borde del tablero, la duplicación de arcos o los arcos inclinados convergentes, tienen un origen que trasciende la justificación estética, pues son la consecuencia de la decisión de un diseñador que recurre a ellos como estrategia de índole puramente estructural.

A continuación se describen, muy brevemente, las principales contribuciones fruto de los estudios realizados en esta tesis.

\subsubsection{Diseño en el plano}

\subsubsection{Dimensionamiento de secciones}

En lo referente al diseño en el plano de los puentes arco, una de las contribuciones más relevantes de esta tesis es el desarrollo de un método iterativo que permite el diseño preliminar de secciones transversales para puentes arco cuyo comportamiento se pueda considerar contenido en el plano vertical.

El método es aplicable, con resultados satisfactorios, a diferentes tipologías de arco, como arcos laminares o arcos atirantados, así como a diferentes configuraciones de péndolas, como las formadas por péndolas verticales, péndolas tipo Nielsen-Löhse y péndolas tipo Network.

Es aplicable a aquellos casos en los que la deformación vertical del tablero o la tensión longitudinal en las secciones críticas de arco y tablero gobiernan, en condiciones de ser- 
vicio o de rotura, el dimensionamiento del puente. Para cada uno de estos casos, se han desarrollado, respectivamente, los llamados $\delta$-method y $\sigma+\delta$-method.

El método es válido, además, para puentes de sección variable, siempre que el puente quede definido totalmente si se concreta su sección de control. Asimismo, el método es aplicable a puentes arco donde los arcos estén inclinados, sólo con tener en cuenta unas mínimas consideraciones a la hora de definir los modelos de cálculo.

Se basa además en una formulación simplificada, precisa y compacta, que permite obtener las características mecánicas de las secciones del arco y del tablero con una drástica reducción de los parámetros de diseño. Esta notación resulta de utilidad por sí misma, y es también de aplicación en el dimensionamiento de elementos con una sola sección de control, como ocurre en las vigas.

En contraste con el dimensionamiento de secciones basado en algoritmos de optimización, el método se basa en consideraciones puramente estructurales, de carácter muy intuitivo, lo que permite al diseñador añadir, durante la fase de diseño, cualquier criterio adicional constructivo o topológico.

Una de las conclusiones más importantes derivadas de este método, es cómo, con el fin de obtener la distribución de secciones de peso mínimo, los criterios de diseño (fallo por tensiones o fallo por rigidez insuficiente) pueden ser diferentes en el arco y en el tablero.

Dado que en un puente arco espacial, el comportamiento en el arco puede descomponerse en el plano que contiene al arco y su plano perpendicular, este método resulta muy útil a la hora de optimizar las secciones resistentes de puentes arco espaciales en el plano del arco.

\subsubsection{Péndolas rigidizadas longitudinalmente}

Las péndolas rigidizadas longitudinalmente son una herramienta a disposición del diseñador para disminuir las flexiones tanto en arco como en tablero, además de las deformaciones generales del puente. En esta tesis se ha estudiado el efecto de la rigidez de las péndolas, que se ha mostrado como el factor más importante a la hora de definir su influencia en el comportamiento global de la estructura. Si bien las péndolas empotradas en ambos extremos son las más eficaces en los estudios realizados, las péndolas articuladas en cabeza han arrojado una eficacia muy similar. Por lo tanto, articular las péndolas en cabeza es un modo de conseguir una eficacia muy alta sin los inconvenientes de tener que empotrar y transmitir flexión entre uno de los extremos y el arco o el tablero.

Los estudios relativos a colocar rótulas internas dentro de las péndolas, no arrojan resultados concluyentes respecto de su eficacia. Las únicas secciones que parecen minimizar la pérdida de eficacia al articular son las secciones situadas en los extremos de la péndola. En particular, en las péndolas rigidizadas longitudinalmente, la colocación de una articulación a mitad de la altura ofrece prácticamente los mismos resultados que la péndola empotrada.

Las péndolas biempotradas, las rigidizadas con una articulación y las formadas por cables pueden combinarse libremente por el diseñador para conseguir matizar los esfuerzos en la estructura en función de sus necesidades. 
A pesar de que el pandeo en el plano no es la forma más frecuente de colapso en puentes arco, las péndolas rigidizadas longitudinalmente incrementan sensiblemente el axil crítico de pandeo.

\subsubsection{Configuraciones de atirantamiento}

Como resulta bien conocido, configuraciones del atirantamiento con cables inclinados, como los puentes tipo Nielsen-Löhse o, más modernamente, el tipo Network, resultan muy efectivas a la hora de disminuir tanto los esfuerzos como las deformaciones en el plano. Aunque dependen de cada caso en concreto, en los estudios realizados se han obtenido reducciones de deformaciones en el eje del tablero de alrededor del $70 \%$, lo que nos da una idea de la eficacia de estas configuraciones de atirantamiento.

\subsubsection{Diseño fuera del plano}

\subsubsection{Esfuerzos fuera del plano}

En esta tesis, y siempre con el objeto de simplificar las fases iniciales del diseño, se proporcionan unas fórmulas sencillas para estimar la flexión transversal del arco frente a cargas transversales, que recogen la influencia del rebajamiento del arco $(f / L)$ y de la relación entre las rigideces a flexión y torsional.

Asimismo se comprueba cómo prácticamente manteniendo constante la cantidad de material del arco, existen distribuciones de secciones variables que reducen significativamente la sensibilidad del arco a pandeo transversal.

Soluciones como los arcos bifurcados, los arcos de rigidez transversal creciente hacia arranques, o los arcos de canto creciente y ancho decreciente hacia arranques mejoran, en lo que se refiere a pandeo, el comportamiento del arco de sección constante.

En particular la sección de canto creciente y ancho decreciente hacia arranques tiene la ventaja de minimizar el sobreancho necesario para acomodar el arco en las secciones de cruce arco-tablero, lo que minimiza el ancho de la plataforma, y, consecuentemente el coste de la solución.

\subsubsection{Péndolas rigidizadas transversalmente}

Como ocurre con las péndolas rigidizadas longitudinalmente, las péndolas rigidizadas transversalmente son una herramienta a disposición del proyectista para reducir los esfuerzos y deformaciones globales del puente.

Es interesante destacar a este respecto, que, dado que las respuestas en el plano y fuera de éste están desacopladas, el efecto de las péndolas puede ser considerado independientemente para ambos planos. Por ejemplo, el diseñador puede decidir la orientación de las péndolas en doble $\mathrm{T}$ en función del plano que desee rigidizar. La rigidez longitudinal puede ser empleada para soportar flexión en el plano o, alternativamente, la rigidez transversal puede ser empleada para ayudar a resistir esfuerzos torsores en el tablero o esfuerzos fuera del plano del arco. 
La eficacia de las péndolas transversales depende fundamentalmente de su rigidez, pero también de la rigidez del arco y del tablero. A la hora de reducir las deformaciones transversales, es crucial la rigidez conjunta del sistema estructural arco péndola.

Como ocurre con las péndolas rigidizadas longitudinalmente, los estudios muestran que, en términos prácticos, las únicas posiciones razonables para las articulaciones son los extremos de las péndolas, pues no llevan a una pérdida significativa de eficacia resistente.

En los estudios realizados, las péndolas articuladas en uno de sus extremos conservan gran parte de la eficacia de las péndolas empotradas, puesto que al estar la péndola vinculada elásticamente al arco o al tablero, el momento de empotramiento se relaja notablemente. Dado que la conexión no necesita resistir a flexión y cortante, la péndola articulada es, en general, más fácil de construir y supone un ahorro en términos generales.

Se consigue una mayor eficacia de la péndola articulada en cabeza si el material de la péndola se distribuye de manera que sea más rígida en el extremo empotrado, es decir, si la péndola es de sección variable.

La eficacia de la péndola totalmente empotrada no se puede conseguir mediante combinaciones tridimensionales de cables articulados, por lo menos en los estudios realizados. Sin embargo, solicitaciones a medio camino entre la eficacia resistente y la facilidad constructiva pueden conseguirse combinando péndolas en $\mathrm{X}$ en el plano longitudinal con soluciones en A en el plano perpendicular.

\subsubsection{Atirantamiento a los bordes}

De modo similar a los casos anteriores, el atirantamiento a los bordes también constituye una posibilidad tipológica a la que el diseñador puede recurrir para ayudar a que la respuesta de la estructura se mantenga por debajo de ciertos umbrales límite que definen la bondad de su comportamiento.

El hecho de atirantar a los bordes moviliza la rigidez transversal del arco (es decir, su comportamiento como viga balcón) y la rigidez transversal del tablero (como viga trabajando en planta) tan pronto como los axiles de las dos péndolas ancladas en el mismo punto del arco sean diferentes. Las péndolas por lo tanto, ayudan a resistir la torsión del tablero, y reducen la flecha vertical en su borde. Asimismo, las péndolas inclinadas resultan muy eficaces a la hora de disminuir los esfuerzos y deformaciones en el arco, como los debidos, por ejemplo, al viento.

\subsubsection{La espacialidad como estrategia de diseño}

Por lo tanto, como conclusión general de esta tesis, puede establecerse que el diseño de puentes arco basado en la verificación de los estados límite y de servicio acepta diversas estrategias por parte del diseñador, las cuales conducen a la espacialidad, de un modo natural, como una manera de resolver determinados problemas tensodeformacionales de la estructura.

En lo que respecta al diseño en el plano, la primera estrategia (veáse la primera columna de la figura 10.1) y más evidente es la redefinición de las secciones transversales tanto de 


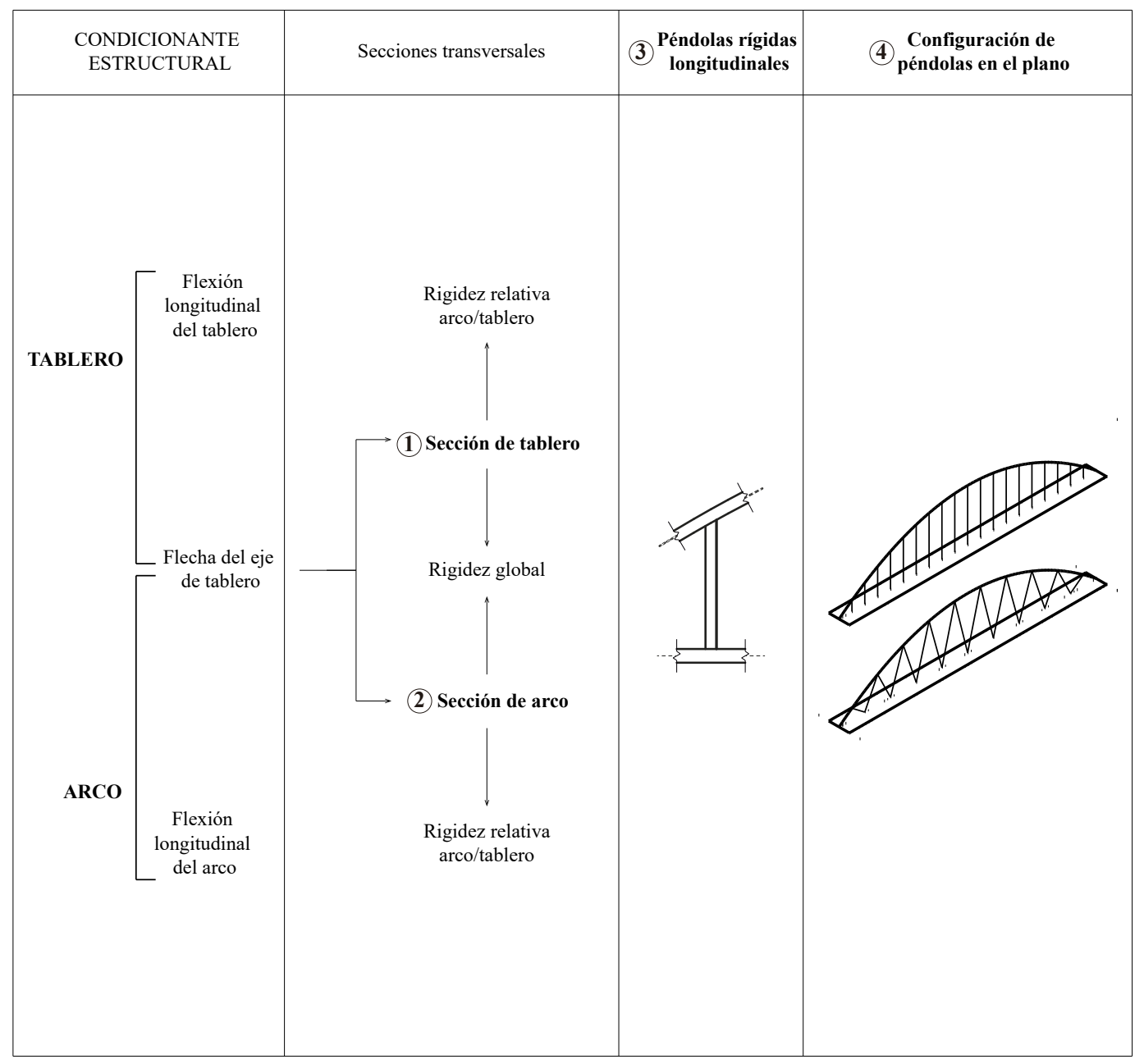

Figura 10.1: Resumen de estrategias a seguir para el diseño en el plano.

arco como de tablero. Si el problema no es tensional, sino de flecha vertical en el eje del tablero, habrá que aumentar la rigidez global de la estructura.

Si el problema es de flexión en el de tablero, la estrategia puede ser tanto reforzar la sección de tablero para hacer frente a los esfuerzos, como aumentar la contribución de la rigidez del arco a la rigidez global arco-tablero, con el objeto de reducir los esfuerzos que llegan al tablero. El mismo problema a la inversa puede plantearse para el arco.

El método desarrollado en el capítulo 4 resuelve perfectamente estos casos.

Esta estrategia se puede combinar con la rigidización longitudinal de las péndolas, descrita en los apartados anteriores.

Alternativamente a la rigidización de las péndolas, se puede recurrir a configuraciones de atirantamiento más eficaces como las ya mencionadas Nielsen-Löhse y Network.

En relación al diseño fuera del plano, los principales problemas que se plantean en el tablero suelen ser por torsión excesiva o por un exceso de deformación debida a la torsión en el borde del tablero. Para ambos casos la solución más inmediata es aumentar la rigidez 
torsional de la sección del tablero.

También puede plantearse un problema por flexión transversal del tablero, pero dado que el ancho del tablero viene dado por necesidades funcionales, este problema no suele ser crítico a efectos resistentes.

En el arco, los problemas más habituales que se plantean suelen ser de flexión transversal o de pandeo fuera del plano. En ambos casos la mejor solución es rigidizar el comportamiento como viga balcón del arco. Para ello se puede directamente reforzar la sección del arco, o, si el predimensionamiento falla por poco, puede distribuirse el material del arco de una manera más eficaz. Soluciones como las mostradas en el apartado 2 de la figura 10.2 resultan muy adecuadas para ello. Destacar que la solución en la que el ancho crece hacia los arranques necesita de un sobreancho del tablero, que puede encarecer la solución. Lo contrario ocurre si el ancho en los arranques es menor que en clave.

El comportamiento transversal del puente mejora sensiblemente si las péndolas se rigidizan transversalmente. Se puede recurrir, como se ha descrito anteriormente, a péndolas de ancho variable y empotradas en el elemento más rígido.

Como estrategia alternativa a rigidizar las péndolas transversalmente, pueden duplicarse las péndolas y atirantar los bordes del tablero. Esto de por sí moviliza mecanismos resistentes que permanecen inactivos en el arco plano, como las rigideces transversales del arco y del tablero. Puede utilizarse un atirantamiento con péndolas verticales, con péndolas tipo Nielsen-Löhse o tipo Network.

Por supuesto, los problemas de esfuerzos fuera del plano pueden resolverse duplicando el arco, y disponiendo un arco en cada borde del tablero. Los arcos pueden ser verticales o convergentes, apoyados entre sí. Si están arriostrados entre sí, la rigidez conjunta transversal de los arcos aumenta notablemente, hasta el punto de poder reducir notablemente su sección en la dimensión horizontal.

De modo similar puede duplicarse el tablero, y dividirse aproximadamente en dos semi secciones, dispuesta cada una en un borde. La torsión es ahora resistida por un mecanismo de carga y descarga vertical de ambos semitableros, en lugar de ser resistida por una única sección situada en el centro.

Como puede apreciarse en la figura 10.2, las soluciones más eficaces a los problemas tensodeformacionales del puente arco tienen un carácter espacial, como el atirantamiento a los bordes, o la duplicación de arcos y tableros.

\subsection{Futuras líneas de estudio}

\subsubsection{Posibilidades formales de los puentes arco espaciales}

Evidentemente, esta tesis no agota las posibilidades tipológicas de los puentes arco espaciales, ni siquiera de los simétricos.

En la misma línea de esta tesis pueden realizarse estudios en los que se analice como muchos tipos de puentes arco espaciales aparecen como una consecuencia de la resolución de los distintos problemas en rotura y servicio que presentan los puentes arco clásicos. 


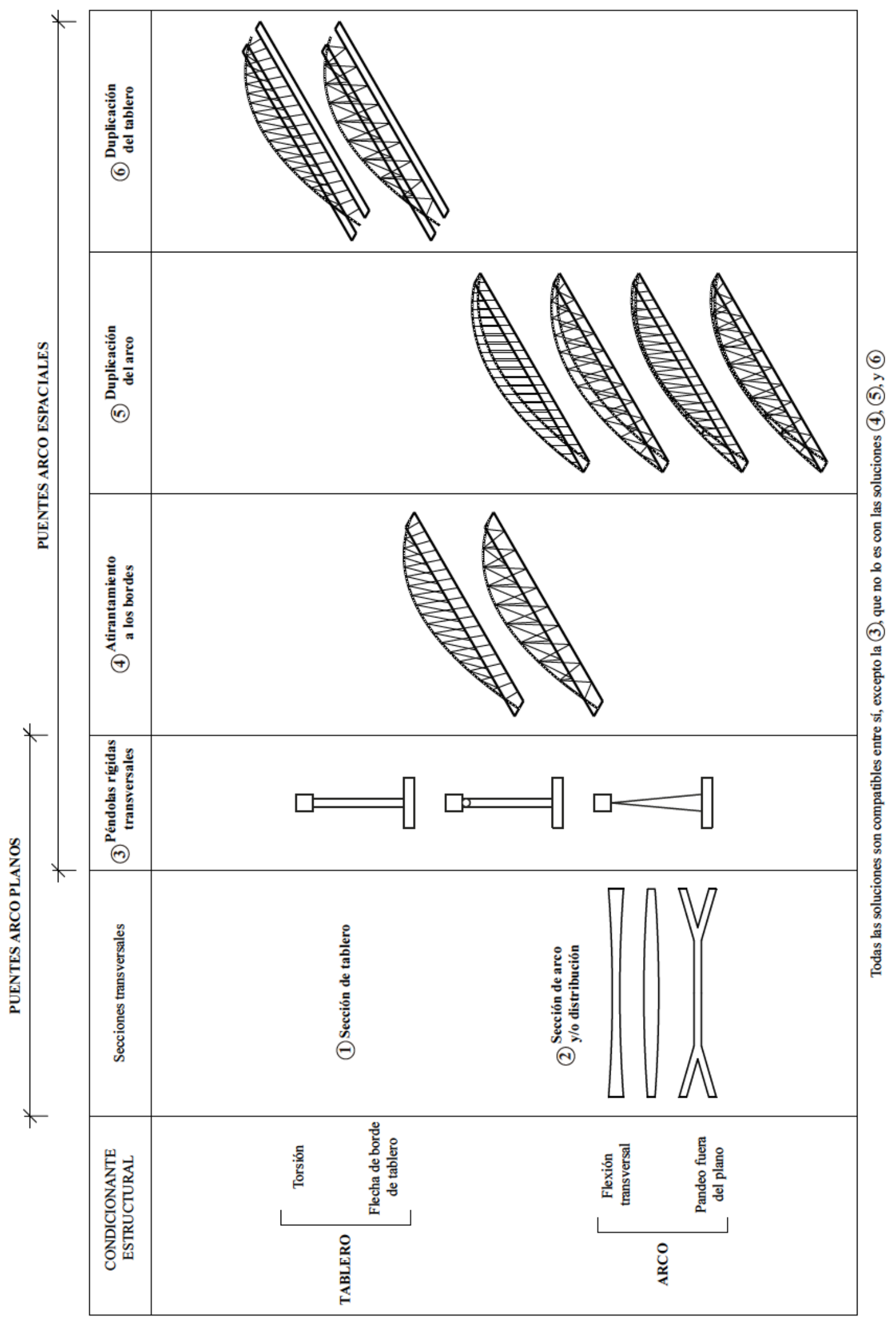

Figura 10.2: Resumen de estrategias a seguir para el diseño fuera del plano. 
Por ejemplo, en la figura 10.3 aparecen una serie de puentes con tableros curvos dobles. Estos tableros se suspenden de arcos tanto únicos como duplicados. Estos últimos en forma de arcos paralelos, convergentes o divergentes. También se muestran girados perpendicularmente al eje del puente. La mayoría de las configuraciones mostradas en la figura 10.3 no han sido construidas todavía, lo que nos da una idea breve, pero ilustrativa, de todas las posibilidades tipológicas y formales que ofrecen los puentes arco espaciales, aún sin salir de las soluciones longitudinalmente simétricas.

\subsubsection{Asimetría longitudinal}

De la misma manera, en la figura 10.4 se muestran soluciones con asimetría longitudinal. En este caso, claramente, no se obtienen por evolución tipológica de los puentes arco clásicos, pues éstos son todos por definición simétricos.

La asimetría longitudinal hay que buscarla, desde un punto de vista más ortodoxo, en los condicionantes funcionales, fundamentalmente por la presencia de un tablero curvo en planta, como ocurre en la pasarela de Ripshorst, el puente sobre el río Galindo y el puente de Endarlatsa. Estos tres casos son ejemplos en los que la originalidad surge a posteriori, como una consecuencia del proceso de diseño, y no como una premisa anterior al mismo.

Sin embargo, hoy en día, la mayoría de puentes arco espaciales asimétricos lo son debido a una deliberada intención estética. Esto nos hace cuestionarnos si, como ingenieros estructurales, para los que el correcto comportamiento resistente de las estructuras debe ser un objetivo irrenunciable, este tipo de estructuras debe o no proyectarse. En cualquier caso, aun a sabiendas de que el comportamiento estructural en estos puentes puede no ser el óptimo, sí encontramos no sólo lícito, sino plenamente justificado, tratar de explotar las posibilidades estructurales todavía inexploradas, en un afán de conjugar novedad formal con eficacia resistente. 


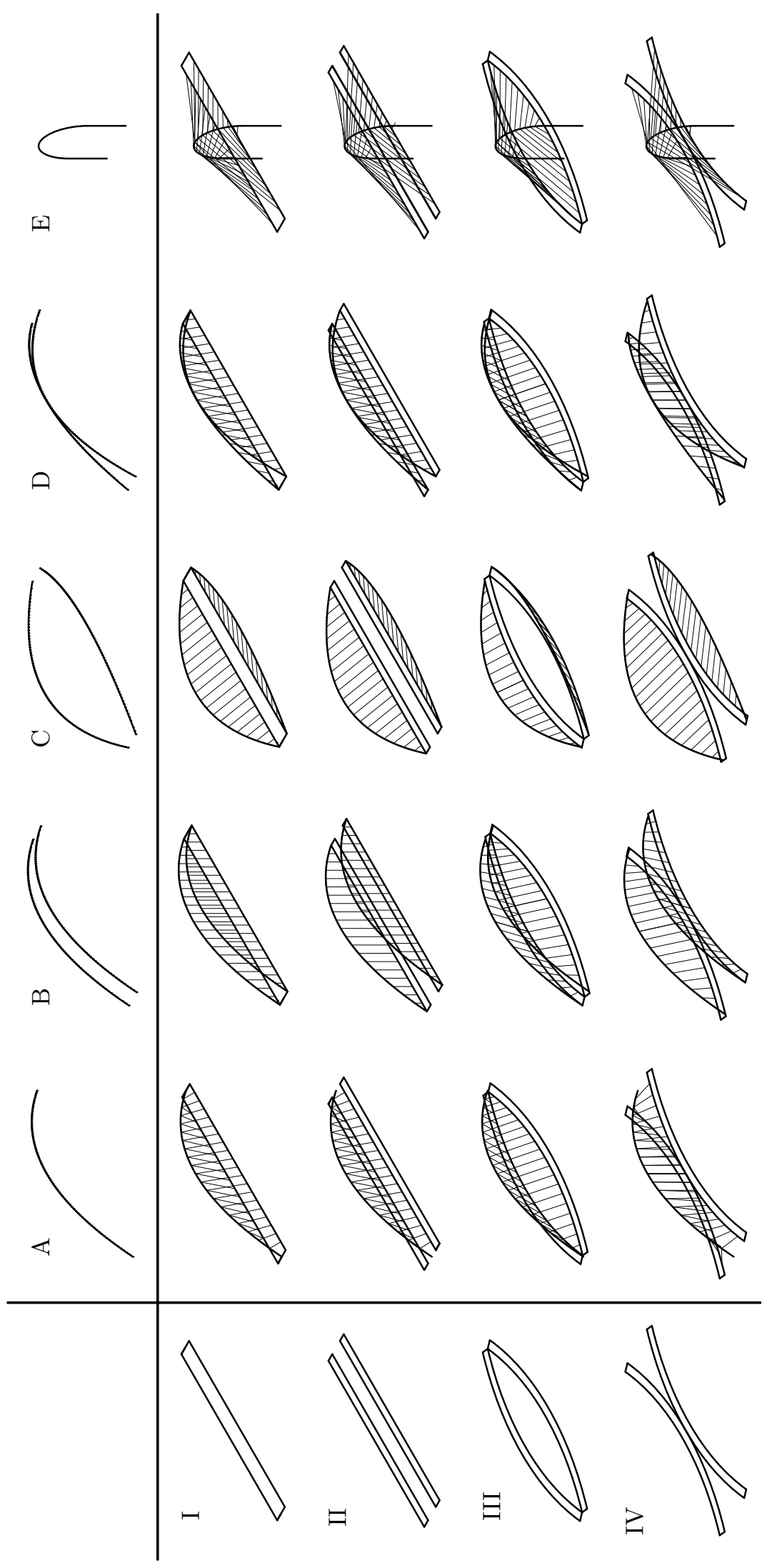

Figura 10.3: Obtención de puentes arco espaciales simétricos por combinación de arcos y tableros. 


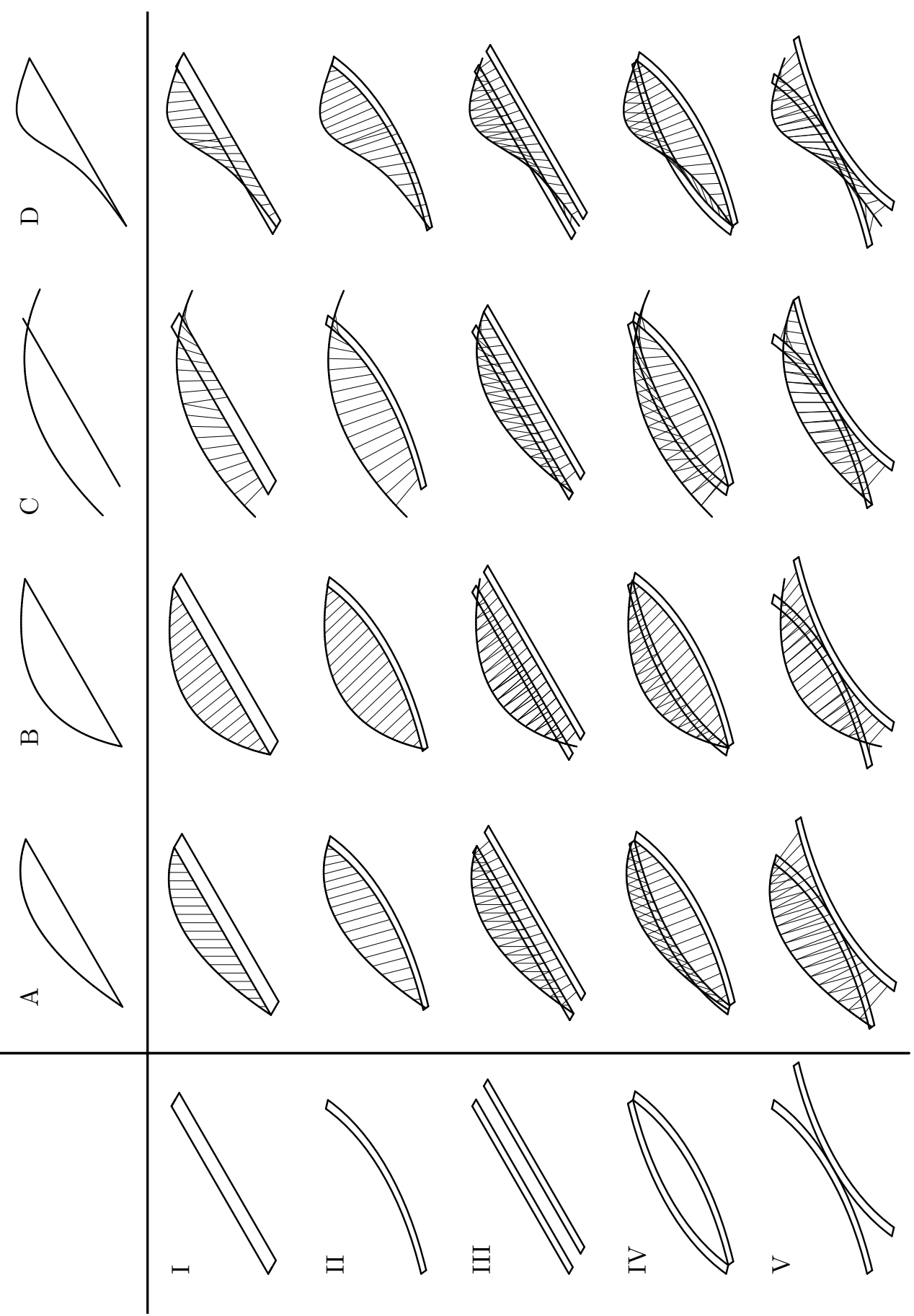

Figura 10.4: Obtención de puentes arco espaciales asimétricos por combinación de arcos y tableros. 


\section{Bibliografía}

[1] Accornero, F., Lacidogna, G., y Carpinteri, A. Evolutionary fracture analysis of masonry arches: Effects of shallowness ratio and size scale. Comptes Rendus Mécanique 344, 9 (Septiembre 2016), 623-630.

[2] Aguiló, M., Manterola, J., Onzain, M., y Rui-Wamba, J. Javier Manterola Armisén - Pensamiento y Obra. Fundación ESTEYCO, Madrid, 2004.

[3] Anderson, W. V., Y Mccall, J. Design and Construction of Urban Footbridges in Canada. En Footbridge, 4th International Conference (Wroclaw, Julio 2011).

[4] Arenas de Pablo, J. J., Capellán Miguel, G., Beade Pereda, H., y MarTínez ApARicio, J. El puente del Tercer Milenio: retos en el diseño de puentes desde la perspectiva de la ingeniería creativa. (I) Génesis de formas. En Comunicaciones al IV congreso ACHE de puentes y estructuras (Valencia, Noviembre 2008).

[5] Arenas de Pablo, J. J., Capellán Miguel, G., Beade Pereda, H., Ortega Arias, A., Y Martínez Aparicio, J. El puente del Tercer Milenio: retos en el diseño de puentes desde la perspectiva de la ingeniería creativa. (II) Desarrollo. En Comunicaciones al IV congreso ACHE de puentes y estructuras (Valencia, Noviembre 2008).

[6] Arenas de Pablo, J. J., Capellán Miguel, G., Martínez Aparicio, J., Y Beade Pereda, H. El puente del Tercer Milenio: retos en el diseño de puentes desde la perspectiva de la ingeniería creativa. (III) Comportamiento y cálculo. En Comunicaciones al IV congreso ACHE de puentes y estructuras (Valencia, Noviembre 2008).

[7] Arenas de Pablo, J. J., y Pantaleón Prieto, M. J. El puente de la Barqueta, sobre el viejo cauce del río Guadalquivir, en Sevilla. Revista de Obras Públicas. Monográfico, Puentes arco (I), Historia de los puentes arco., 3311 (Junio 1992), $47-63$.

[8] Arenas de Pablo, J. J., y Pantaleón, M. J. Barqueta Bridge, Sevilla, Spain. Structural Engineering International 2, 4 (Noviembre 1992), 251-252.

[9] Argüelles Álvarez, R. Estructuras de acero: Cálculo. Bellisco, Ediciones Técnicas y Científicas, Madrid, 2005. 
[10] Asociación Española de Normalización y Certificación. Eurocódigo 1: Acciones en estructuras. Parte 2: Cargas de tráfico en puentes. Eurocodigos. Norma europea experimental. AENOR, 2004.

[11] Asociación Española de Normalización y Certificación. Eurocódigo 3: Proyecto de estructuras de acero. Parte 1-1: Reglas generales y reglas para edificios. Eurocodigos. Norma europea experimental. AENOR, 2013.

[12] Asociación Española de Normalización y Certificación. Eurocódigo 3: Proyecto de estructuras de acero. Parte 2: Puentes. Eurocodigos. Norma europea experimental. AENOR, 2013.

[13] Asociación Española de Normalización y Certificación. Eurocódigo 3: Proyecto de estructuras de acero. Parte 1-11: Cables y tirantes. Eurocodigos. Norma europea experimental. AENOR, 2015.

[14] Baus, U., y Schlaich, M. Footbridges. Birkhäuser Architecture, 2007.

[15] Beghini, A., Beghini, L. L., Schultz, J. A., Carrion, J., Y Baker, W. F. Rankine's theorem for the design of cable structures. Structural and Multidisciplinary Optimization 48, 5 (Junio 2013), 877-892.

[16] Bögle, A., Schmal, P. C., Y Flagge, I. Leicht Weit/Light Structures: Jörg Schlaich - Rudolf Bergermann. Prestel Pub, 2004.

[17] Billington, D. P. The Tower and the Bridge: The New Art of Structural Engineering. Princeton University Press, 1985.

[18] Billington, D. P. Robert Maillart's Bridges: The Art of Engineering. Princeton University Press, 1989.

[19] Block, P., DeJong, M., y Ochsendorf, J. As Hangs the Flexible Line: Equilibrium of Masonry Arches. Nexus Network Journal 8, 2 (Octubre 2006), 13-24.

[20] Buchiold , H. A. An Introduction to Cable Roof Structures, 2nd Edition. Thomas Telford, Londres, 1999.

[21] Burnton, P., Birmingham, N., y Buxton, S. Elizabeth Quay Pedestrian Bridge, Perth - The Jewel of the Quay. En Footbridge 2017 Berlin - Tell A Story: Conference Proceedings 6-8.9.2017 TU-Berlin (Septiembre 2017), Chair of Conceptual and Structural Design, Fachgebiet Entwerfen und Konstruieren - Massivbau, Technische Universität Berlin.

[22] Calatrava, S. Santiago Calatrava: Conversations with Students - The MIT Lectures. Princeton Architectural Press, 2002.

[23] Comisión Permanente de Estructuras de Acero. Instrucción de Acero Estructural (EAE). serie normativas. Ministerio de Fomento, Secretaría General Técnica, Centro de Publicaciones, Madrid, 2017. 
[24] Computers and Structures, Inc. Analysis Reference Manual for SAP2000® $v$ 16, Septiembre 2013.

[25] Corbal, J., Meijide, A. G., Y Antón, A. Innovative solutions for urban footbridges. En Footbridge, 2nd International Conference (Venecia, Diciembre 2005).

[26] Curran, P. Bridging an urban renaissance. En Footbridge, 2nd International Conference (Venecia, Diciembre 2005).

[27] Dirección General DE CARRETERAS. Instrucción sobre las acciones a considerar en el proyecto de puentes de carretera, IAP-11, $2^{\mathrm{a}}$ ed. Ministerio de Fomento, Secretaría General Técnica, Centro de Publicaciones, Madrid, Mayo 2012.

[28] Dutton, H. Architecture of footbridges. 4 projects by Hugh Dutton Associates. En Footbridge, 3rd International Conference (Oporto, Julio 2008).

[29] Dutton, H., Porrone, I., Tarditi, S., Bucci, P., y Soldani, P. 2006 Olympic Footbridge, Turin. En Footbridge, 2nd International Conference (Venecia, Diciembre 2005).

[30] Fernández Troyano, L. Tierra sobre el agua: Vision Histórica universal de los puentes, $1^{\mathrm{a}}$ ed., vol. (Coleccion de Ciencias, Humanidades e Ingeniería). Colegio de Ingenieros de Caminos Canales y Puertos, Madrid, 1999.

[31] Flaga, K., Y Januszkiewicz, K. On the Aesthetics and Technical Efficiency of Current Arched Footbridges. En Footbridge, 4th International Conference (Wroclaw, Julio 2011).

[32] Fu, F. Advanced Modelling Techniques in Structural Design. Wiley-Blackwell, 2015.

[33] García Guerrero, J. M., y Jorquera Lucerga, J. J. Effect of stiff hangers on the longitudinal structural behavior of tied-arch bridges. Applied Sciences 8, 2 (2018), 258.

[34] Godden, W. G. The Lateral Buckling of Tied Arches. Proceedings of the Institution of Civil Engineers 3, 4 (Julio 1954), 496-514.

[35] Godden, W. G., Y Thompson, J. C. An experimental study of a model tiedarch bridge. Proceedings of the Institution of Civil Engineers 14, 4 (Diciembre 1959), 383-394.

[36] Greenwold, D. J. Dynamic analysis of Calatrava's la Devesa footbridge. Master's thesis, Massachusetts Institute of Technology, Department of Civil and Environmental Engineering, 1999.

[37] Hague, S., Y Hutton, H. The New Main Street Bridge, Columbus, Ohio A Signature Single-Rib Tied Arch. IABSE Congress Report 17, 5 (Enero 2008), 406407.

[38] Hines, E. M., Buonopane, S. G., Garlock, M. E. M., Y Billington, D. Festschrift Billington, 2012: Essays in Honor of David P. Billington. International Network for Structural Art, 2012. 
[39] Hudecek, M. Structural Behaviour of Spatial Arch Bridges. Tesis doctoral, University of Calgary, Mayo 2017.

[40] Hussain, N., Y Wilson, I. The Hulme Arch Bridge, Manchester. Proceedings of the Institution of Civil Engineers - Civil Engineering 132, 1 (Febrero 1999), 2-13.

[41] Idelberger, K. The World of Footbridges: From the Utilitarian to the Spectacular. Ernst \& Sohn, 2011.

[42] Jodidio, P. Santiago Calatrava. Taschen, Colonia, 1998.

[43] Johnson, J., Y Curran, P. Gateshead Millennium Bridge-an eye-opener for engineering. Proceedings of the Institution of Civil Engineers - Civil Engineering 156, 1 (Febrero 2003), 16-24.

[44] JONG-DAR, Y. Vibration of parabolic tied-arch beams due to moving loads. International Journal of Structural Stability and Dynamics 06, 02 (Junio 2006), 193-214.

[45] Jorquera Lucerga, J. J.; Manterola Armisén, J. An iterative form-finding method for antifunicular shapes in spatial arch bridges. Computers \& Structures 108 (2012), $42-60$.

[46] Jorquera LuCERGA, J. J. Estudio del comportamiento resistente de los puentes arco espaciales. Tesis doctoral, Universidad Politécnica de Madrid, Escuela Técnica Superior de Ingenieros de Caminos, Canales y Puertos, Noviembre 2007.

[47] Jorquera LuCERGA, J. J. Understanding Calatrava's bridges: A conceptual approach to the 'La Devesa-type' footbridges. Engineering Structures 56 (Noviembre 2013), 2083-2097.

[48] Jorquera Lucerga, J. J., Lozano Galant, J. A., y Turmo, J. Structural behavior of non-symmetrical steel cable-stayed bridges. Steel and Composite Structures 20, 2 (2016), 447-468.

[49] Jorquera Lucerga, J. J., Y Manterola Armisén, J. Galindo-type arch bridges: a conceptual approach. En 5th Annual Symposium of IABSE - 52nd Annual Symposium of IASS (Londres, Septiembre 2011).

[50] Karnovsky, I. A. Theory of Arched Structures. Springer New York, Berlín/Heidelberg, 2012.

[51] Kollár, L. Structural Stability in Engineering Practice. E \& FN SPON, 1999.

[52] LaChaUeR, L. Interactive Equilibrium Modelling - A new approach to the computeraided exploration of structures in architecture. Tesis doctoral, June 2015.

[53] Lacidogna, G., Y ACCornero, F. Elastic, plastic, fracture analysis of masonry arches: A multi-span bridge case study. Curved and Layered Structures 5, 1 (Enero 2018), 1-9.

[54] Laffranchi, M.; Marti, P. Robert Maillart's Curved Concrete Arch Bridges. Journal of Structural Engineering 123, 10 (Octubre 1997), 1280-1286. 
[55] Lebet, Jean Paul; Hirt, M. A. Steel bridges: Conceptual and Structural Design of Steel and Steel-Concrete Composite Bridges. EPFL Press, 2013.

[56] Leonhardt, F. Bridges, Brücken. The Architectural Press, Londres, 1982.

[57] MAIRs, D. York Millennium Bridge - A Footbridge with an Inclined Arch, UK. Structural Engineering International 11, 3 (Agosto 2001), 172-174.

[58] Manterola Armisén, J. Puentes arco con tablero inferior. Revista de Obras Públicas, 3436 (Septiembre 2003), 7-30.

[59] Manterola Armisén, J. Cuarto puente sobre el río Ebro en Logroño. En Comunicaciones al III congreso ACHE de puentes y estructuras (Zaragoza, 2005).

[60] Manterola Armisén, J. Puentes: apuntes para su diseño, cálculo y construcción. Colección Escuelas. Colegio de Ingenieros de Caminos, Canales y Puertos, 2006.

[61] Manterola Armisén, J., Gil, M. A., y Muñoz-Rojas, J. Spatial Arch Bridges Over the Galindo and Bidasoa Rivers. Structural Engineering International 21, 1 (Febrero 2011), 114-121.

[62] Manterola Armisén, J., y Gil Ginés, M. A. Puente sobre el río Galindo en Baracaldo. En Comunicaciones al IV congreso ACHE de puentes y estructuras (Valencia, Noviembre 2008).

[63] Manterola Armisén, J., y Muñoz-Rojas Fernández, J. Nuevo puente sobre el río Bidasoa Endarlatsa. En Comunicaciones al IV congreso ACHE de puentes y estructuras (Valencia, Noviembre 2008).

[64] Manterola Armisén, J., Muñoz-Rojas Fernández, J., López Padilla, A., Y Fernández Revenga, J. Actuación sobre el río Guadalentín y espacio urbano del barrio de San Cristóbal en la ciudad de Lorca. En Comunicaciones al III congreso ACHE de puentes y estructuras (Zaragoza, 2005).

[65] Menn, C. Prestressed concrete bridges. Birkhäuser Verlag, 2012.

[66] Menéndez-Pidal, G., Tarquis Alfonso, F., y González, J. The Arch Loading of the Third Millennium Bridge at Zaragoza, Spain. Structural Engineering International 21, 4 (Noviembre 2011), 456-461.

[67] Millanes Mato, F., y Carnerero Ruiz, A. Puente arco sobre el río Deba. En Comunicaciones al IV congreso ACHE de puentes y estructuras (Valencia, Noviembre 2008).

[68] Millanes Mato, F., Ortega Cornejo, M., y Carnerero Ruiz, A. Puente arco sobre el río Guadalquivir en Palma del Río. En Comunicaciones al IV congreso ACHE de puentes y estructuras (Valencia, Noviembre 2008).

[69] Montminy, S.; Anderson, W. V., y CrabB, J. Trends in ethics and aesthetics in footbridge design in Canada. En Footbridge, 2nd International Conference (Venecia, Diciembre 2005). 
[70] Nettleton, Douglas A.; Torkelson, J. S. Arch bridges. Structural engineering series. Bridge Division, Office of Engineering, Federal Highway Administration, U.S. Dept. of Transportation, Washington, D.C., 1977.

[71] O’Connor, C. Design of Bridge Superstructures. Wiley, Chichester, 1971.

[72] Ortiz Berrocal, L. Resistencia de Materiales. McGraw-Hill, 1990.

[73] Palkowski, S. Buckling of parabolic arches with hangers and tie. Engineering Structures 44 (Noviembre 2012), 128-132.

[74] Pantaleón Prieto, M. J., y Ramos Gutiérrez, O. R. Los puentes arco metálicos modernos. Revista de Obras Públicas. Monográfico, Puentes arco (I), Historia de los puentes arco. (2015).

[75] Park, G.; Hewson, N. ICE Manual of Bridge Engineering, 2a ed. Thomas Telford, Noviembre 2008.

[76] Petersen, C. Statik und Stabilität der Baukonstruktionen, 2a ed. Vieweg, Brunswick, 1982.

[77] PFEIFER. PFEIFER Tension Members, Octubre 2015.

[78] PÁgina Web. Arenas \& Asociados. http://www.arenasing.com/.

[79] PÁGINA WEB. FCK consultoría estructural. http://www.fckestructural.com/.

[80] PÁGina WeB. Ney \& Partners. http://www.ney.be/.

[81] PÁGIna WEB. Ramboll UK. http://www.ramboll.co.uk/.

[82] PÁGInA WeB. Richard Meier \& Partners Architects LLP. http://www . richardmeier. com/.

[83] PÁGInA WeB. Santiago Calatrava, Architects and Engineers. https: //calatrava . $\mathrm{com} /$.

[84] PÁgina Web. The Happy Pontist. http://happypontist.blogspot.com.es/.

[85] PÁGina WeB. Zwarts \& Jansma Architects. http://www.zja.nl/.

[86] Pollalis, S. N. What is a Bridge? Bridge Design as a Strategic Element in Urban and Regional Development. En 3rd International Conference on Current \& Future Trends in Bridge Design (Shanghai, Septiembre 2003).

[87] Rasmussen, M. B., Saberi, M., Døssing, J., Y Von Scholten, C. Arched Footbridge - Architectural Elegance and Engineering Challenges. En Footbridge, 3rd International Conference (Oporto, Julio 2008).

[88] ReyHer, B. Difficult roots and happy ends - how to master the design process. En Footbridge 2017 Berlin - Tell A Story: Conference Proceedings 6-8.9.2017 TUBerlin (Septiembre 2017), Chair of Conceptual and Structural Design, Fachgebiet Entwerfen und Konstruieren - Massivbau, Technische Universität Berlin. 
[89] Robertson, L. E., See, S.-T., y Sesil, D. A. The Miho Museum Bridge. ShigaRaki, Japan. A post-tensioned steel space-frame. En Comunicaciones al World Steel Bridge Symposium (Chicago, Septiembre 1998).

[90] Roeder, C. W., Macrae, G., Crocker, P., Arima, K., Y Wong, S. Dynamic Response and Fatigue of Steel Tied-Arch Bridge. Journal of Bridge Engineering 5, 1 (Febrero 2000), 14-21.

[91] RomeiJn, A., Y Bouras, C. Investigation of the arch in-plane buckling behaviour in arch bridges. Journal of Constructional Steel Research 64, 12 (Diciembre 2008), $1349-1356$.

[92] Salonga, J., Y Gauvreau, P. Comparative Study of the Proportions, Form, and Efficiency of Concrete Arch Bridges. Journal of Bridge Engineering 19, 3 (Marzo 2014).

[93] Sarmiento Comesías, M. Structural behaviour and design criteria of spatial arch bridges. Tesis doctoral, Universidad Politécnica de Cataluña, Departamento de Ingeniería de la Construcción, Septiembre 2015.

[94] Sarmiento Comesías, M., Ruiz Teran, A. M., y Aparicio, A. C. State-ofthe-art of spatial arch bridges. Proceedings of the Institution of Civil Engineers Bridge Engineering 166, 3 (Septiembre 2013), 163-176.

[95] Schlaich, J. Tendencias en el diseño de puentes / Trends in Bridge Design. Grupo español IABSE, Madrid, 2000, cap. Diversidad en el diseño de puentes / Variety in Bridge Design, pp. 67-100.

[96] Schlaich, J. Urban footbridges. En Comunicaciones al $16 .^{\circ}$ Congreso de IABSE (Lucerna, 2000).

[97] Schlaich, J., Y MoschneR, T. Die Ripshorster Brücke über den Rhein-HerneKanal, Oberhausen. Bautechnik 76, 6 (Junio 1999), 459-462.

[98] Schlaich, M., Bleicher, A., Y Nier, M. Die Weinbergbrücke in Rathenow. Bauingenieur 91, 2 (Febrero 2016), 71-80.

[99] Serna García-Conde, J.; Rui-Wamba, J. Los puentes del Tren. Fundación ESTEYCO, Madrid, 2006.

[100] Shukla, S. N., Y OJalvo, M. Lateral Buckling of Parabolic Arches. Journal of the Structural Division 97, 6 (1971), 1763-1773.

[101] Siegrist Fernández, C. Curso de doctorado de puentes arco de hormigón. Publicaciones de la E.T.S.I.C.C.P. Madrid.

[102] Siotor, I. G., Hermeking, T., y Schloegl, C. State of the Art new Products and Methods for Cable Bridges Small and Big. En Footbridge 2017 Berlin - Tell A Story: Conference Proceedings 6-8.9.2017 TU-Berlin (Septiembre 2017), Chair of Conceptual and Structural Design, Fachgebiet Entwerfen und Konstruieren Massivbau, Technische Universität Berlin. 
[103] Siviero, E., Y Attolico, L. Rari Nantes Footbridge in Padua. En Footbridge, 4 th International Conference (Wroclaw, Julio 2011).

[104] Siviero, E., Y Attolico, L. Transformation of the City of Padua for the Benefit of "Weak" Users: Footbridge Over San Gregorio Channel (Padua, Italy). En Footbridge, 4 th International Conference (Wroclaw, Julio 2011).

[105] Siwowski, T., Zóltowski, P., Zóltowski, K., Y Biliszczuk, J. The New Arch Footbridge over Vistula River in Cracow. En Footbridge, 4th International Conference (Wroclaw, Julio 2011).

[106] Smith, E. M. A critical analysis of the Campo Volantín footbridge, Bilbao, Spain. En Bridge Engineering 2 Conference, University of Bath (2011).

[107] Sánchez de León, R., y Bernal Pérez, C. Desdoblamiento del puente de la Peraleda en Toledo y pasarelas adosadas. En Comunicaciones al $V$ congreso ACHE de puentes y estructuras (Barcelona, Octubre 2011).

[108] Strasky, J. New structural concepts for footbridges. En Footbridge, 1st International Conference (Paris, Noviembre 2002).

[109] Strasky, J. Stress Ribbon and Cable-supported Pedestrian Bridges, second edition. Thomas Telford, Londres, 2011.

[110] Strasky, J., Formanek, M., Kocourek, P., Y Necas, R. Integral arch footbridges. En Footbridge, 5th International Conference (Londres, Julio 2014).

[111] Strasky, J., Y Necas, R. Footbridges with Prestressed Concrete Decks. En Footbridge 2017 Berlin - Tell A Story: Conference Proceedings 6-8.9.2017 TU-Berlin (Berlín, Septiembre 2017), Chair of Conceptual and Structural Design, Fachgebiet Entwerfen und Konstruieren - Massivbau, Technische Universität Berlin.

[112] Tarquis Alfonso, F., y Hue Ibargüen, P. Puente juscelino kubitschek. En Comunicaciones al III congreso ACHE de puentes y estructuras (Zaragoza, 2005).

[113] The Mathworks Inc. Matlab (R2014).

[114] Torres Arcila, M. Puentes - Ponti - Pontes. Atrium Internacional, 2002.

[115] Trojaborg, S. S., Jensen, P. O., Y Henriksen, J. B. Rethinking cities. En Footbridge 2017 Berlin - Tell A Story: Conference Proceedings 6-8.9.2017 TU-Berlin (Berlín, Septiembre 2017), Chair of Conceptual and Structural Design, Fachgebiet Entwerfen und Konstruieren - Massivbau, Technische Universität Berlin.

[116] Tveit, P. Considerations for Design of Network Arches. Journal of Structural Engineering 113, 10 (Octubre 1987), 2189-2207.

[117] Tveit, P. About the Network Arch. Serie de articulos dipsonibles en la web Information on the Network Arch (Enero 2011).

[118] Tzonis, A. Santiago Calatrava: obra completa. Ediciones Polígrafa, 2007. 
[119] Varios Autores. Monografía Santiago Calatrava. No. 38. El croquis, Madrid, 1989.

[120] Varios Autores. Pont de l'Observatorie. Freyssinet magazine, 209 (Octubre 2000), 12.

[121] Varios Autores. 33 puentes singulares de España. Revista del Ministerio de Fomento, 531 (Julio 2004).

[122] Varios Autores. Tailor Made Concrete Structures: New Solutions for our Society. CRC Press, 2008.

[123] Varios Autores. Handbook of International Bridge Engineering. CRC Press, 2013.

[124] Varios Autores. Footbridges-Small is beautiful. European Council of Civil Engineers, 2014.

[125] Warren, L. B. A critical analysis of the Hulme Arch Bridge, Manchester. En Bridge Engineering 2 Conference, University of Bath (2009).

[126] Wells, M. Puentes. Laurence King Publishing Ltd. (Edición española de Editorial H Kliczkowski), Londres, 2002.

[127] Wittfont, H. Puentes. Ejemplos internacionales. Gustavo Gili, Barcelona, 1975.

[128] Zóltowski, K., Y Kozakiewicz, A. The New Footbridge in City of Cracow Dynamic Design and Final Verification in Test Loading. En Footbridge, 4th International Conference (Wroclaw, Julio 2011). 